SANDRA SAYURI SATO

SIMULAÇÃO MULTIFÍSICA UTILIZANDO MÉTODO DOS ELEMENTOS FINITOS AUXILIANDO ITERATIVAMENTE A FABRICAÇÃO DE MODULADORES ELETRO-ÓPTICOS EM SUBSTRATOS DE $\mathrm{Bi}_{4} \mathrm{Ge}_{3} \mathrm{O}_{12}$ 
SANDRA SAYURI SATO

SIMULAÇÃO MULTIFÍSICA UTILIZANDO MÉTODO DOS ELEMENTOS FINITOS AUXILIANDO ITERATIVAMENTE A FABRICAÇÃO DE MODULADORES ELETRO-ÓPTICOS EM SUBSTRATOS DE $\mathrm{Bi}_{4} \mathrm{Ge}_{3} \mathrm{O}_{12}$

Tese apresentada à Escola Politécnica da Universidade de São Paulo para obtenção do título de Doutor em Ciências 


\title{
SIMULAÇÃO MULTIFÍSICA UTILIZANDO MÉTODO DOS ELEMENTOS FINITOS AUXILIANDO ITERATIVAMENTE A FABRICAÇÃO DE MODULADORES ELETRO-ÓPTICOS EM SUBSTRATOS DE $\mathrm{BI}_{4} \mathrm{GE}_{3} \mathrm{O}_{12}$
}

\author{
Tese apresentada à Escola Politécnica da \\ Universidade de São Paulo para obtenção do \\ título de Doutor em Ciências
}

Área de Concentração: Sistemas de Potência

Orientador: Prof. Dr. Josemir Coelho Santos

São Paulo 
Este exemplar foi revisado e corrigido em relação à versão original, sob responsabilidade única do autor e com a anuência de seu orientador.

São Paulo, de de

Assinatura do autor:

Assinatura do orientador:

Catalogação-na-publicação

Sato, Sandra Sayuri

Simulação multifísica utilizando método dos elementos finitos auxiliando iterativamente a fabricação de moduladores eletro-ópticos em substratos de Bi4Ge3O12 / S. S. Sato -- versão corr. -- São Paulo, 2015.

$250 \mathrm{p}$.

Tese (Doutorado) - Escola Politécnica da Universidade de São Paulo. Departamento de Engenharia de Energia e Automação Elétricas.

1.Simulação (Fabricação) 2.Métodos dos elementos finitos I.Universidade de São Paulo. Escola Politécnica. Departamento de Engenharia de Energia e Automação Elétricas II.t. 


\section{AGRADECIMENTOS}

À DEUS, pelas pessoas maravilhosas e oportunidades que foram colocadas em meu caminho para realização deste trabalho.

Ao orientador e amigo, Prof. Dr. Josemir Coelho Santos, os meus sinceros reconhecimento e gratidão por ter-me acolhido em seu laboratório, ajudando-me a realizar este trabalho de pesquisa na área de Sensores a Fibra Óptica. Muito obrigada pela confiança depositada em mim, pelas orientações nas minhas atividades científicas ao longo desses anos, pela disposição e empenho em ajudar a solucionar problemas que apareceram em minha vida durante o processo acadêmico, sua intervenção foi fundamental para a realização deste trabalho. Agradeço, também, pelos incentivos e conselhos que me fizeram escolher o melhor caminho a ser percorrido.

Ao Prof. Dr. Luiz Claudio Ribeiro Galvão, pela confiança e auxílio da bolsa do departamento que me foi concedida para término deste trabalho.

A minha verdadeira amiga, Madalena Gião, por apresentar-me as pessoas maravilhosas que conheci nos laboratórios do IEAv e pelas nossas conversas divertidas.

Ao meu grande amigo Jonas Rubini Junior, pela sua valorosa amizade, pelas longas conversas que tivemos e pelo auxílio na execução deste trabalho.

A minha grande amiga Carmem Lucia Barbosa, por, apresentar-me ao Prof. Dr. Josemir Coelho Santos e pela sua preciosa amizade.

Ao Prof. Nicolau André Silveira Rodrigues, pela confiança, pela ajuda e pela sua valiosa amizade.

Aos amigos Ana Maria, cabo Ferraz, Lavras e Gilson, pela sua amizade e pela ajuda técnica nos laboratórios da Fotônica do IEAV.

Ao Prof. Marcos Antonio Ruggieri Franco, pela ajuda nas simulações numéricas, pela compreensão nos momentos difíceis e pela sua amizade. 
Ao Prof. Dr. Nilton Itiro Morimoto, pela confiança ao acesso na utilização do Laboratório de Sistemas Integráveis, EPUSP.

Ao Prof. Dr. Acácio Luiz Siarkowski, pela amizade, pelo auxílio nos processos de fabricação dos moduladores eletro-ópticos baseados em guias de ondas ópticos integrados no LSI/EPUSP.

Aos amigos Adelino, Edson e Marcos, sempre prestativos.

Aos amigos, Thiago, Raul e Shigueru, pela ajuda nas leituras do meu texto dissertativo e pelas conversas divertidas.

Aos amigos e companheiros de laboratório, Domingos, Gleison, Helton, Luiz Pinheiro, Marcia, Ricardo, por toda ajuda.

Ao meu amigo Luiz Augusto da Silva Faria, pela sincera e singela amizade, pelas conversas divertidas que tivemos em pouquíssimo tempo e pelos novos ensinamentos.

Ao Departamento de Engenharia e Automação - PEA-USP, por dar condições para realização deste trabalho.

Às secretárias do PEA: Diná, Valquíria, Solange, Rosangela, Beta e Patrícia.

À amiga Sra. Eníria (Tia) pelos cafés, pelos chás e pelos conselhos e pelas longas conversas.

À Fundação Universidade de São Paulo - FUSP, por, através da bolsa de doutoramento que me foi concedida, tornou possível à dedicação em tempo integral ao trabalho científico.

À minha amiga Sra. Ana Maria de Castro Badiali pela sua valiosa amizade, pelo auxílio na formatação da minha tese e pelas conversas divertidas que tivemos em pouquíssimo tempo.

À minha amada filha, Paola Sakura Sato Moreno, pela sua paciência, doçura, companheirismo, dedicação, generosidade, compreensão e muito amor.

Aos meus amados pais, por terem me acolhido nas horas mais difíceis da minha vida, com notável paciência e generosa compreensão destes momentos, durante todo o processo de aprendizagem. 
Aos meus queridos irmãos e cunhados, pelo acolhimento e proteção à minha filha amada.

A todas as pessoas que direta ou indiretamente colaboraram na realização deste trabalho.

MUITO OBRIGADA, POR TUDO. 


\section{LISTA DE ABREVIATURAS}

\begin{tabular}{|c|c|}
\hline $\mathrm{Al}$ & Alumínio \\
\hline $\mathrm{Al}_{2} \mathrm{O}_{3}$ & Óxido de Alumínio \\
\hline $\mathrm{Bi}_{4} \mathrm{Ge}_{3} \mathrm{O}_{12}$ & Germanato de Bismuto \\
\hline $\mathrm{Bi}_{12} \mathrm{GeO}_{20}$ & Óxido de Germânio e Bismuto \\
\hline $\mathrm{Bi}_{4} \mathrm{Si}_{3} \mathrm{O}_{12}$ & Silicato de Bismuto \\
\hline $\mathrm{Bi}_{12} \mathrm{SiO}_{20}$ & Óxido de Silício e Bismuto \\
\hline $\mathrm{Bi}_{12} \mathrm{TiO}_{20}$ & Óxido de Titânio e Bismuto \\
\hline CAD & Computer Aided Design \\
\hline CCS/UNICAMP & Centro de Componentes Semicondutores da Universidade de Campinas \\
\hline CVD & Deposição química a vapor (Chemical Vapor Deposition) \\
\hline DAD322 & Nome da máquina de corte \\
\hline DI & Água deionizada \\
\hline DEQ/IFGW & Departamento de Eletrônica Quântica da UNICAMP \\
\hline EFA & Divisão de Física Aplicada \\
\hline EFA-E & Subdivisão de Eletromagnetismo Aplicado \\
\hline EFO & Divisão de Fotônica \\
\hline EFO-O & Laboratório de Subdivisão de Óptica Aplicada \\
\hline EM & Eletromagnetismo \\
\hline FLX -2410 & Modelo do stress meter \\
\hline FOLCI & $\begin{array}{l}\text { Interferometria de Baixa Coerência a Fibra Óptica (Fiber Optic Low } \\
\text { Coherence Interferometry) }\end{array}$ \\
\hline IEC & International Electrotecnical Comission \\
\hline IEAv-DCTA & $\begin{array}{l}\text { Instituto de Estudos Avançados - Departamento de Ciência e } \\
\text { Tecnologia Aeroespacial }\end{array}$ \\
\hline ISS & (Induced Static Strain) \\
\hline ITO & Óxido de Estanho e Índio \\
\hline $\mathrm{LiNbO}_{3}$ & Niobato de Lítio \\
\hline $\mathrm{LiTaO}_{3}$ & Tantalato de Lítio \\
\hline LME-EPUSP & $\begin{array}{l}\text { Laboratório de Micro-elerônica da Escola Politécnica da Universidade } \\
\text { de São Paulo }\end{array}$ \\
\hline LPCVD & Deposição química a vapor a baixa pressão \\
\hline LSI/EPUSP & $\begin{array}{l}\text { Laboratório de Sistemas Integráveis da Escola Politécnica da } \\
\text { Universidade de São Paulo }\end{array}$ \\
\hline LSO/PEA/EPUSP & $\begin{array}{l}\text { Laboratório de Sensores Ópticos do Departamento de Engenharia e } \\
\text { Automação da Escola Politécnica da Universidade de São Paulo }\end{array}$ \\
\hline LTCC & Low-Temperature Co-fire Ceramic ou Green Tape \\
\hline MEF & Método dos Elementos Finitos \\
\hline MEMS & $\begin{array}{l}\text { Estruturas de microssistemas integrados (Micro-Electro-Mechanical } \\
\text { Systems) }\end{array}$ \\
\hline PAC & Projeto Assistido por Computador \\
\hline PECVD & $\begin{array}{l}\text { Deposição química a vapor e aprimorados por exposição a plasma em } \\
\text { baixas temperaturas (Plasma Enhanced Chemical Vapor Deposition) }\end{array}$ \\
\hline PMR/EPUSP & $\begin{array}{l}\text { Laboratório de Sensores e Atuadores da Engenharia Mecatrônica e de } \\
\text { Sistemas Mecânicos da Escola Politécnica da Universidade de São } \\
\text { Paulo }\end{array}$ \\
\hline PVD & Deposição física a vapor (Physical Vapor Deposition) \\
\hline OI & Óptica Integrada \\
\hline OPD & Diferença de Caminhos Ópticos (Optical Path Difference) \\
\hline RF & Rádio frequência \\
\hline RPM & Rotação por minuto \\
\hline SEP & Sistemas Elétricos de Potência \\
\hline
\end{tabular}


sccm

$\mathrm{SF}_{6}$

$\mathrm{Si}$

$\mathrm{SiH}_{2} \mathrm{Cl}_{2}$

$\mathrm{NH}_{3}$

$\mathrm{SiO}_{2}$

$\mathrm{Si}_{3} \mathrm{~N}_{4}$

TEOS

$\mathrm{Ti}$

TC

TE

TEM

TM

TI

TIO

TP

TPO

WLI
Standard flow, Standard Cubic Centimeters per Minute

Hexafluoreto de enxofre

Silício

Diclorosilano

Amônio

Óxido de Silício

Nitreto de Silício

Tetraetilortossilicato

Titânio

Transformador de Corrente

Ondas elétricas transversais

Ondas eletromagnéticas transversais

Ondas magnéticas transversais

Transformadores para Instrumentos

Transformador para Instrumento Óptico

Transformador de Potencial

Transformador de Potencial Óptico

Interferometria de Luz Branca (White Ligth Interferometry) 


\section{RESUMO}

Este trabalho apresenta um método desenvolvido pela autora para, através de simulações multifísicas pelo Método dos Elementos Finitos (MEF), servir como ferramenta de apoio ao projeto e fabricação de guias de onda e moduladores eletro-ópticos em óptica integrada, além de possibilitar a análise da performance de moduladores eletro-ópticos.

A técnica adotada para a fabricação dos guias de onda ópticos foi a de tensão mecânica. Os parâmetros de geometria (espessura do filme e larguras das trincheiras) e de temperatura de deposição do filme são definidos nas simulações e utilizados no processo de fabricação de guias de ondas em óptica integrada, que servem de base para a fabricação de moduladores eletro-ópticos em substrato cristalino de retículo cúbico. As trincheiras dos guias de onda do tipo canal são construídas em Germanato de Bismuto (BGO - $\mathrm{Bi}_{4} \mathrm{Ge}_{3} \mathrm{O}_{12}$ ), a partir da deposição sobre o substrato de um filme fino indutor de tensão mecânica (stress) Nitreto de Silício $\left(\mathrm{Si}_{3} \mathrm{~N}_{4}\right)$ e definidas pelos processos de litografia óptica e corrosão seletiva por plasma. Os moduladores são obtidos através da deposição dos eletrodos de alumínio sobre o filme, seguida de $\mathrm{Si}_{3} \mathrm{~N}_{4}$ dos processos de litografia óptica e corrosão, obtendo-se eletrodos.

O processo iterativo proposto inicia-se com os resultados das simulações, em que são definidos os parâmetros de fabricação do filme, da trincheira e dos eletrodos. Após a fabricação desses elementos, o componente é caracterizado e são medidos os parâmetros reais do filme e do substrato. Esses valores são realimentados nas simulações para refinar o projeto do componente.

O trabalho, além de apresentar todos os passos do processo interativo de simulações, projeto, fabricação e caracterização do componente desejado, indica as dificuldades encontradas na implementação do processo $\mathrm{e}$ as atividades futuras a serem desenvolvidas para o aperfeiçoamento do mesmo.

Palavras chaves: Guias de onda ópticos. LPCVD. Estresse residual induzido termicamente. Germanato de Bismuto $\left(\mathrm{Bi}_{4} \mathrm{Ge}_{3} \mathrm{O}_{12}\right)$. Nitreto de Silício $\left(\mathrm{Si}_{3} \mathrm{~N}_{4}\right)$. Óptica integrada. Modulador eletro-óptico. Simulação baseada no método dos elementos finitos. 


\begin{abstract}
This work presents a method developed by the author to support the project and fabrication of integrated optic waveguides and electro-optic modulators by means of Finite Element Method (FEM) multiphysics simulations, also enabling the electro-optic modulators performance analysis.

The technique used for fabricating the optical waveguides was the thermally induced residual stress (ISS). The geometry parameters (film thicknesses and trenches widths) and the film deposition temperature are obtained in the simulations and subsequently used in the integrated optical waveguides fabrication process, which serve as a basic building block for the electrooptic modulators on crystalline cubic lattice substrate. The channel waveguide trenches are built on Bismuth Germanate $\left(\mathrm{BGO}-\mathrm{Bi}_{4} \mathrm{Ge}_{3} \mathrm{O}_{12}\right)$ by depositing a Silicon Nitride $\left(\mathrm{Si}_{3} \mathrm{~N}_{4}\right)$ Stress-inducing thin film, being later defined by optical lithography and plasma etching process. Modulators are obtained depositing aluminum on the $\mathrm{Si}_{3} \mathrm{~N}_{4}$ film followed by the optical lithography and corrosion process, defining electrodes.

The proposed iterative process starts with the simulation results that define the fabrication parameters of the film, trench and electrodes. After the fabrication of these elements, the device is characterized and the actual parameters of the film and substrate are measured. These values are fed back into the simulations to refine the component design.

The work besides presenting all the simulation-design-fabrication-characterization iterative process for obtaining the devised device also highlights the difficulties encountered in the implementation process along with suggestions of future activities aiming at improving it.
\end{abstract}

Key words: Optical waveguides. LPCVD. ISS. Bismuth Germanate $\left(\mathrm{Bi}_{4} \mathrm{Ge}_{3} \mathrm{O}_{12}\right)$. Silicon Nitride $\left(\mathrm{Si}_{3} \mathrm{~N}_{4}\right)$. Plasma etching. Integrated optic. Electro-optic modulator. FEM simulation. 


\section{LISTA DE SÍMBOLOS}

\begin{tabular}{|c|c|}
\hline alfa & Ângulos da equação do índice de refração no COMSOL \\
\hline alpha & Coeficiente de expansão térmica no COMSOL \\
\hline B & Densidade de fluxo magnético \\
\hline beta & Ângulos da equação do índice de refração no COMSOL \\
\hline$c$ & Velocidade da luz no vácuo \\
\hline$C$ & Capacitância por unidade de comprimento do guia de onda elétrica \\
\hline D & Densidade de fluxo elétrico \\
\hline$D$ & Matriz de elasticidade \\
\hline $\mathrm{e}$ & Eletrodos \\
\hline $\mathbf{E}$ & Campo elétrico \\
\hline$E_{e l}$ & Campo elétrico da onda TEM (modos quase-estáticos) \\
\hline$E_{o p}$ & Campo elétrico da onda óptica \\
\hline epsr & Constante dielétrica relativa \\
\hline $\mathrm{E}_{\mathrm{s}}$ & Módulo de Young no COMSOL \\
\hline$E_{S} / 1-v_{S}$ & Módulo de elasticidade do substrato no stress meter \\
\hline$E_{x}$ & Campo elétrico externo modulante \\
\hline$E^{x}$ & Modo propagado \\
\hline$F$ & Componentes da matriz \\
\hline$f_{i j k l}$ & Coeficientes eletro-ópticos lineares \\
\hline G & Largura do canal \\
\hline$g_{i j k}$ & Coeficientes eletro-ópticos quadráticos \\
\hline $\mathbf{H}$ & Campo magnético \\
\hline$h_{S}$ & Espessura do substrato no stress meter \\
\hline $\boldsymbol{J}$ & Densidade de corrente elétrica \\
\hline$K$ & Constante de propagação \\
\hline $\mathrm{K}^{-1}$ & Temperatura em Kelvin \\
\hline $\mathrm{K} / \mathrm{m}^{3}$ & Kilometro por metro ao cubo \\
\hline$L$ & Comprimento do componente (modulador) \\
\hline Lamb & Comprimento de onda no COMSOL \\
\hline $\mathrm{m} / \mathrm{V}$ & Metro por volt \\
\hline $\mathrm{n}$ & Índice de refração \\
\hline $\mathrm{N}$ & Îndice de refração no COMSOL \\
\hline nBGO & Fórmula de dispersão do BGO no COMSOL \\
\hline$n_{b e}$ & Îndice de refração do substrato \\
\hline $\mathrm{nm}$ & Nanômetro \\
\hline $\mathrm{N} / \mathrm{m}^{2}$ & Newton por metro ao quadrado \\
\hline$N_{\text {eff }}$ & Índice efetivo \\
\hline nu & Razão de Poisson no COMSOL \\
\hline$n_{x}$ & Índice de refração \\
\hline $\boldsymbol{P}$ & Vetor de campo de polarização \\
\hline$p_{i j k l}$ & Coeficientes do tensor elasto-óptico (strain-optic tensor) \\
\hline$p_{11}$ & Coeficientes elasto-óptico do cristal \\
\hline$R$ & Raio efetivo da curvatura no stress meter \\
\hline $\mathrm{R}_{1}$ & Raio de curvatura do substrato antes da deposição do filme \\
\hline $\mathrm{R}_{2}$ & Raio de curvatura do substrato com o filme depositado \\
\hline$R_{l}$ & Representação do retângulo 1 no COMSOL \\
\hline rho & Densidade no COMSOL \\
\hline$r_{l k}$ & Coeficientes eletro-ópticos lineares \\
\hline$r_{41}$ & Coeficiente eletro-óptico relevante \\
\hline$r_{i j k}$ & Coeficientes eletro-ópticos lineares \\
\hline$s$ & Versor na direção da propagação \\
\hline
\end{tabular}


Tensão_esq

Tensão_dir

$\mathrm{T}_{1}-\mathrm{T}_{0}$

$\mathrm{T}_{1}$

$\mathrm{T}_{0}$

$U_{e}$

$\mathrm{V}$

V

$\mathrm{V}_{\pi}$

$Z_{c}$

$\alpha$

$\alpha$

$\alpha_{f}$

$\alpha_{s}$

$\alpha \alpha$

$\beta$

$\beta \beta$

$\delta_{x}$

$\varepsilon$

$\varepsilon_{x}$

$\phi(x, y)$

$\eta_{i j}$

$\eta_{r}$

$\lambda_{0}$

$\mu$

$\mu_{r}$

$\xi_{1}$

$\rho$

$\sigma$

$\sigma_{i}$

$\sigma_{t}$

$\sigma_{t h}$

$\chi_{1}$

$\varphi$

$\omega$

$\nabla_{t}^{2}$

$\Delta T$

$\Delta \eta_{i j}$

$\Gamma$

$\Delta f$

$\Omega$

$\{N\}$

\{\}

\{\}$^{-1}$

[F]
Deformação (strain)

Coeficientes eletro-ópticos quadráticos

Tensor de deformação

Esforço (stress)

Espessura do filme no stress meter

Espessura do filme

Espessura dos eletrodos de alumínio

Tensão esquerdo

Tensão direito

Diferença de temperatura usado no processo de fabricação

Temperatura Ambiente no COMSOL

Temperatura de deposição de trabalho no COMSOL

Densidade de energia elétrica

Tensão entre os eletrodos

Autovetores

Tensão de meia onda

Impedância característica

Coeficiente de expansão térmica

Constante de atenuação

Coeficientes de expansão linear térmica do filme

Coeficientes de expansão linear térmica do substrato

Ângulo de rotação

Constante de fase

Ângulo de rotação

Variáveis

Permissividade

Constante dielétrica principal

Função escalar

Tensor de impermeabilidade

Tensor de impermeabilidade relativa

Comprimento de onda

Permeabilidade

Permeabilidade relativa

Coordenadas de um ponto arbitrário de um novo sistema de coordenadas

Densidade de carga elétrica

Esforço

Tensão intrínseca

Tensão total média do filme no stress meter

Tensão térmica

Autovalor

Ângulo de rotação

Frequência angular

Operador Laplaciano transversal

Variação de temperatura

Mudança na impermeabilidade dielétrica

Integral de sobreposição (overlap integrated)

Largura de banda

Domínio

Conjunto completo de funções de base em cada elemento finito usado

Matriz linha

Matriz transposta

Matriz 


\begin{tabular}{ll}
{$[\bar{F}]$} & Matriz \\
{$[\mathrm{M}]$} & Matriz \\
{$[\bar{M}]$} & Matriz \\
$2 \mathrm{D}$ & \\
alfa & Duas dimensões \\
alpha & Ângulos da equação do índice de refração no COMSOL \\
$\mathbf{B}$ & Coeficiente de expansão térmica no COMSOL \\
beta & Densidade de fluxo magnético \\
$c$ & Ângulos da equação do índice de refração no COMSOL \\
$C$ & Velocidade da luz no vácuo \\
$\mathbf{D}$ & Capacitância por unidade de comprimento do guia de onda elétrica \\
$D$ & Densidade de fluxo elétrico \\
$\mathrm{e}$ & Matriz de elasticidade \\
$\mathbf{E}$ & Eletrodos \\
$E_{e l}$ & Campo elétrico \\
$E_{o p}$ & Campo elétrico da onda TEM (modos quase-estáticos) \\
epsr & Campo elétrico da onda óptica \\
$\mathrm{E}_{\mathrm{s}}$ & Constante dielétrica relativa \\
$E_{S} / 1-v_{S}$ & Módulo de Young no COMSOL \\
$E_{x}$ & Módulo de elasticidade do substrato no stress meter \\
$E^{x}$ & Campo elétrico externo modulante \\
$F$ & Modo propagado \\
$f_{i j k l}$ & Componentes da matriz \\
$\mathrm{G}$ & Coeficientes eletro-ópticos lineares \\
$g_{i j k}$ & Largura do canal \\
$\mathbf{H}$ & Coeficientes eletro-ópticos quadráticos \\
$h_{S}$ & Campo magnético \\
$\boldsymbol{J}$ & Espessura do substrato no stress meter \\
$K$ & Densidade de corrente elétrica \\
$\mathrm{K}^{-1}$ & Constante de propagação \\
& Temperatura em Kelvin \\
\hline
\end{tabular}




\section{LISTA DE FIGURAS}

Figura 1- Diagrama de blocos de um transformador eletrônico genérico, conforme a norma IEC 60044-7

Figura 2- Diagrama de blocos de um transformador óptico genérico ....

Figura 3- Padrão de intensidade de saída teórico de um interferômetro iluminado com luz branca

Figura 4- Diagrama de blocos de um sistema de sensoriamento a WLI típico 31

Figura 5- Padrão de intensidade de saída teórico de um sistema WLI com dois interferômetros em série

Figura 6- Interferômetro recuperador baseado em modulador eletro-óptico de birrefringência em OI

Figura 7- Esquema simplificado das condições, necessárias, mas não suficientes, para formação de um guia de onda óptico.

Figura 8- Formação de guia de onda óptico pela técnica de dopagem por difusão térmica.....42

Figura 9- Distribuição do campo E e $\mathrm{H}$ em ondas eletromagnéticas a cada instante.

Figura 10- Elipsoide de índice e elipse definida pela interseção do mesmo com o plano normal a uma direção de propagação arbitrária s

Figura 11- Estruturas básicas de moduladores eletro-ópticos; a) volumétrica; b) guia de onda planar; c) guia de onda do tipo canal.

Figura 12- Modulador eletro-óptico volumétrico típico em configuração transversal. 60

Figura 13- Representação do modulador eletro-óptico baseado em guia de onda do tipo canal em OI

Figura 14- Campo elétrico no modulador eletro-óptico baseado em guias de onda do tipo canal em OI.

Figura 15- Desenho esquemático de um modulador eletro-óptico baseado em guias de onda do tipo canal.

Figura 16- Modulador eletro-óptico em OI, considerando a seção de corte no plano transversal xy

Figura 17- Modulador eletro-óptico em OI, considerando a seção de análise no plano ( $\overline{1} 10)$ paralelo ao campo de deformação aplicado

Figura 18- Definição das constantes do substrato de BGO e do filme de $\mathrm{Si}_{3} \mathrm{~N}_{4}$.

Figura 19- Inserção no COMSOL das equações dos efeitos elasto-óptico e eletro-óptico e da fórmula de dispersão do índice de refração do substrato de $\mathrm{BGO}$, do filme de $\mathrm{Si}_{3} \mathrm{~N}_{4}$

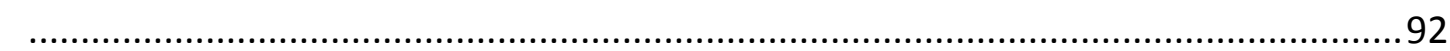

Figura 20- Definição das linhas do Potencial Elétrico

Figura 21- Esquema da deposição do filme de $\mathrm{Si}_{3} \mathrm{~N}_{4}$ por LPCVD sobre o substrato de $\mathrm{Bi}_{4} \mathrm{Ge}_{3} \mathrm{O}_{12}$

Figura 22- Esquema da fotogravação das trincheiras (largura do canal) sobre o filme de $\mathrm{Si}_{3} \mathrm{~N}_{4}$

Figura 23- Esquema da definição das trincheiras sobre o substrato de $\mathrm{Bi}_{4} \mathrm{Ge}_{3} \mathrm{O}_{12}$, obtido pela corrosão 
Figura 24- Esquema do resultado final da limpeza e remoção do fotorresiste (photo-resist -

PR positivo - AZ1518).

Figura 25- Esquema da deposição de Al por meio de uma evaporação térmica sobre o filme de

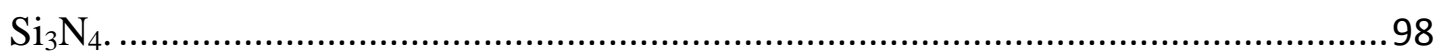

Figura 26- Esquema da fotogravação dos eletrodos sobre o filme de $\mathrm{Al}$................................99

Figura 27- Esquema da definição dos eletrodos sobre as trincheiras .....................................100

Figura 28- Esquema do resultado da limpeza e remoção do fotorresiste (photo-resist - PR

positivo - AZ1518) ...................................................................................100

Figura 29- Foto da Máquina de Corte Automática - Disco DAD322 ....................................101

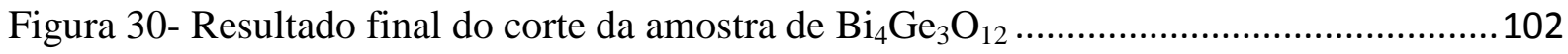

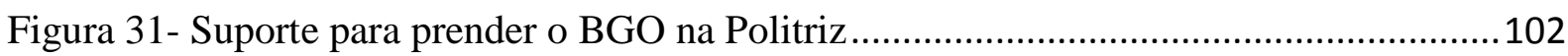

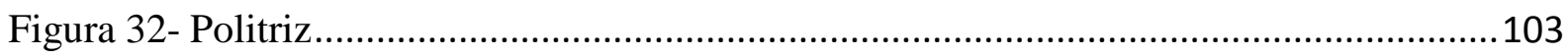

Figura 33- Lixas usadas no processo de polimento óptico de quina e borda ..........................104

Figura 34- Modulador eletro-óptico em $\mathrm{Bi}_{12} \mathrm{GeO}_{20}$ com camada de filme indutor de tensão mecânica de $\mathrm{SiO}_{2}$ e dois eletrodos metálicos ........................................................111

Figura 35- Perfis de deformação induzida na região do guia óptico do tipo canal. (a)

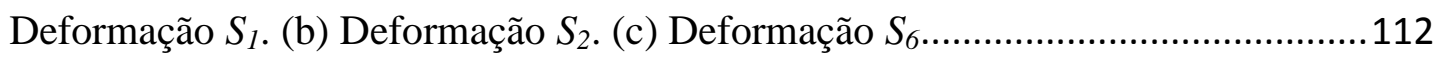

Figura 36- Isolinhas de potencial elétrica e campo elétrico (vetores locais) da onda TEM.

Vista da região da trincheira (gap) ...................................................................113

Figura 37- Perfil do campo óptico modal. (a) modo $E^{x}$. (b) modo $E^{y}$..................................114

Figura 38- $n_{\text {eff }}$ dos modos fundamentais ópticos guiados em função da largura do canal

(trincheira), $G$, pela espessura do filme de $\mathrm{SiO}_{2}, t$, (passo a passo de $0,1 \mu \mathrm{m}$ ) .........115

Figura 39- $Z_{c}$ e Neff da onda elétrica em função da largura do canal, $G$, e do filme de $\mathrm{SiO}_{2} .116$

Figura 40- $Z_{c}$ e Neff da onda elétrica em função da espessura do eletrodo, com $G=5 \mu \mathrm{m}$ e $t=$

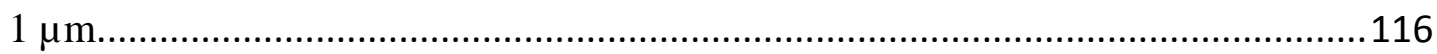

Figura $41-Z_{c}$ e Neff da onda elétrica em função da espessura do filme fino $\mathrm{SiO}_{2}$ para $G=5$

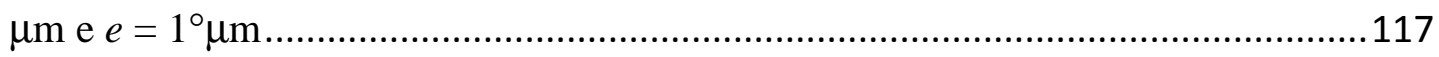

Figura 42- $\Delta V$ e $\Delta$ neffy em função da largura do canal $e=1 \mu \mathrm{m}$ e $t=1 \mu \mathrm{m}$..........................118

Figura 43- Modulador eletro-óptico em $\mathrm{Bi}_{12} \mathrm{GeO}_{20} \mathrm{com}$ filme indutor de tensão mecânica de

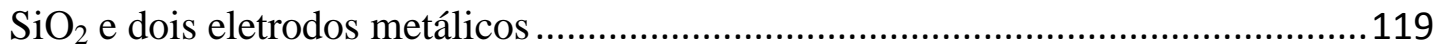

Figura 44- Perfil do campo modal óptico. (a) Modo $E^{x}$. (b) Modo $E^{y}$...................................120

Figura 45- neff do monomodo guiado em função largura do canal, $G$, e da espessura do filme de $\mathrm{SiO}_{2}, t$, (passo a passo de $0,1 \mu \mathrm{m}$ ). (a) Temperatura de $900^{\circ} \mathrm{C}$. (b) Temperatura de $1000^{\circ} \mathrm{C}$

Figura 46- (a) $Z_{c}$ e $N e f f$ da onda elétrica em função da espessura do filme de $\mathrm{SiO}_{2}$. As espessuras dos eletrodos e do filme são de $1 \mu \mathrm{m}$. (b) $Z_{c}$ e $N$ eff da onda elétrica em função da espessura dos eletrodos, $\operatorname{com} G=5 \mu \mathrm{m}$ e $t=1 \mu \mathrm{m}$. (c) $Z_{c}$ e Neff da onda elétrica em função da espessura do filme de $\mathrm{SiO}_{2}, \operatorname{com} G=5 \mu \mathrm{m}$ e $e=1 \mu \mathrm{m}$........123

Figura 47- Modulador eletro-óptico em $\mathrm{Bi}_{12} \mathrm{GeO}_{20}$ com uma camada de filme indutor de tensão mecânica de $\mathrm{Si}_{3} \mathrm{~N}_{4}$ e dois eletrodos metálicos.

Figura 48- Perfil do campo óptico modal. (a) Modo $E^{x}$. (b) Modo $E^{y}$

Figura 49- neffxe neffy em função da variação da largura do canal, $G$. 
Figura 50- Modulador eletro-óptico em substrato de $\mathrm{Bi}_{4} \mathrm{Ge}_{3} \mathrm{O}_{12}$ com camada de filme indutor de tensão mecânica de $\mathrm{Si}_{3} \mathrm{~N}_{4}$ e dois eletrodos metálicos

Figura 51-Perfis de deformação induzida na região do guia. (a) Deformação $S_{1}$. (b)

Deformação $S_{2}$. (c) Deformação $S_{6}$

Figura 52- Perfis dos campos ópticos modais com comprimento de onda $\lambda=1,550 \mu m$. (a)

Modo $E^{x}$. (b) Modo $E^{y}$

Figura 53- neff do modo fundamental guiado em função da largura do canal, G. (a) $\lambda=0,633$

$\mu \mathrm{m}$. (b) $\lambda=0,950 \mu \mathrm{m}$. (c) $\lambda=1,310 \mu \mathrm{m}$. (d) $\lambda=1,55 \mu \mathrm{m}$.

Figura 54- Neff e $Z_{c}$ da onda elétrica em função da largura do canal do guia, G, considerandose espessura dos eletrodos metálicos de $500 \mathrm{~nm}$.

Figura 55- $\Gamma$ em função da variação da largura do canal. (घ) $\lambda=0,633 \mu \mathrm{m}$. (•) $\lambda=1,310 \mu \mathrm{m}$.

$(\mathbf{\Delta}) \lambda=1,550 \mu \mathrm{m}$.

Figura 56- Guia de onda do tipo canal em substrato de $\mathrm{Bi}_{4} \mathrm{Ge}_{3} \mathrm{O}_{12}$

133

Figura 57- Perfil do campo óptico modal considerando-se temperatura de $740^{\circ} \mathrm{C}$ (no forno de deposição). (a) Modo $E^{x}$. (b) Modo $E^{y}$. 135

Figura 58- Perfil do campo óptico modal considerando-se temperatura de $720^{\circ} \mathrm{C}$ (no forno de deposição). (a) Modo $E^{x}$. (b) Modo $E^{y}$.

Figura 59- $n_{\text {eff }}$ do modo fundamental guiado em função da largura do canal, $G$. (a) $\lambda=0,633$ $\mu \mathrm{m}$. (b) $\lambda=1,310 \mu \mathrm{m}$. (c) $\lambda=1,55 \mu \mathrm{m}$.....

Figura 60- Perfil do campo óptico modal considerando-se $\lambda$ de 1,55 $\mu \mathrm{m}$ e temperatura de $720^{\circ} \mathrm{C}$ do forno de deposição. (a) Modo $E^{x}$. (b) Modo $E^{y}$. 139

Figura 61- neff em função da variação da largura do canal. (a) $\lambda=0,633 \mu \mathrm{m}$. (b) $\lambda=1,31 \mu \mathrm{m}$. (c) $\lambda=1,55 \mu \mathrm{m}$.

Figura 62- neff em função da largura do canal. (a) $\lambda=0,633 \mu \mathrm{m}$. (b) $\lambda=1,31 \mu \mathrm{m}$. (c) $\lambda=1,55 \mu \mathrm{m}$.

Figura 63- Neff e $Z_{c}$ da onda elétrica em função da largura do canal do guia, G, no filme de $\mathrm{Si}_{3} \mathrm{~N}_{4}$, considerando-se espessura dos eletrodos metálicos de 500nm. (a) espessura de $\mathrm{t}=50 \mathrm{~nm}$ e $=500 \mathrm{~nm}$. (b) espessura de $\mathrm{t}=50 \mathrm{~nm}$, e $=500 \mathrm{~nm} \mathrm{com}$ deslocamento de $1000 \mathrm{~nm}$ entre o eletrodo e o canal de cada lado. (c) espessura de $\mathrm{t}=50 \mathrm{~nm}$ e $=1000 \mathrm{~nm}$. (d) espessura de $\mathrm{t}=50 \mathrm{~nm}, \mathrm{e}=1000 \mathrm{~nm}$ com deslocamento de $1000 \mathrm{~nm}$ entre o eletrodo e o canal de cada lado. 145

Figura 64- $V \pi$ em função da largura do canal. (a) Espessura dos eletrodos de $500 \mathrm{~nm}$. (b) Espessura dos eletrodos de $1000 \mathrm{~nm}$.... 146

Figura 65- Máscara de padrões dos guias de onda do tipo canal 147

Figura 66- Máscara de padrões das trincheiras dos eletrodos e os PADs 148

Figura 67- Definição dos padrões de linhas para guias de onda ópticos usando a técnica da corrosão por via úmida do filme de $\mathrm{Si}_{3} \mathrm{~N}_{4}$ 150

Figura 68- Padrões de guias de onda transferidos 151

Figura 69- Teste da máscara dos padrões de tricheiras existente no LSI para fabricação de guias de onda do tipo canal.

Figura 70- $\mathrm{O}$ filme de $\mathrm{Si}_{3} \mathrm{~N}_{4}$ depositado por LPCVD sobre o substrato de $\mathrm{Bi}_{4} \mathrm{Ge}_{3} \mathrm{O}_{12} \ldots \ldots \ldots . .152$

Figura 71- Trincheiras no filme de $\mathrm{Si}_{3} \mathrm{~N}_{4}$ sobre o substrato de $\mathrm{Bi}_{4} \mathrm{Ge}_{3} \mathrm{O}_{12}$ com face rugosa .153 
Figura 72- Guiamento de feixes de luz no guia de ondas em substrato de $\mathrm{Bi}_{4} \mathrm{Ge}_{3} \mathrm{O}_{12}$ com face rugosa.....

Figura 73- Resultado da deposição do filme de $\mathrm{Si}_{3} \mathrm{~N}_{4}$ com espessura de $465 \mathrm{~nm}$ sobre o $\mathrm{Bi}_{4} \mathrm{Ge}_{3} \mathrm{O}_{12}$. Neste filme apareceram vários tipos de defeitos 156

Figura 74- Resultado da deposição do filme de $\mathrm{Si}_{3} \mathrm{~N}_{4}$ com espessura menor que $100 \mathrm{~nm}$ sobre o $\mathrm{Bi}_{4} \mathrm{Ge}_{3} \mathrm{O}_{12}$..... 158

Figura 75- Guias de ondas em substrato de $\mathrm{Bi}_{4} \mathrm{Ge}_{3} \mathrm{O}_{12}$ .158

Figura 76- Guiamento de luz em guia de onda formado por ISS em substrato de $\mathrm{Bi}_{4} \mathrm{Ge}_{3} \mathrm{O}_{12}$ com filme de $\mathrm{Si}_{3} \mathrm{~N}_{4}$ de espessura pouco inferior a $100 \mathrm{~nm}$... 159

Figura 77- Filme de $\mathrm{Si}_{3} \mathrm{~N}_{4}$ depositado por LPCVD exibindo dois tipos de defeitos. (a) Ilha. (b) Trincas. 161

Figura 78- Fotogravação das trincheiras por litografia óptica (a) Detalhe da trincheira de $80 \mu \mathrm{m}$. (b) Trincheiras de $80 \mu \mathrm{m}, 10 \mu \mathrm{m}$ e de $7 \mu \mathrm{m}$. 162

Figura 79- (c) Efeito de borda nas trincheiras de $80 \mu \mathrm{m}$ e de $10 \mu \mathrm{m}$ a $8 \mu \mathrm{m}$ (fotorresiste nas bordas da lâmina). (d) Efeito de borda nas trincheiras de $80 \mu \mathrm{m}$ e de $1 \mu \mathrm{m}$ a $5 \mu \mathrm{m}$ (fotorresiste nas bordas da lâmina) 163

Figura 80- Definição das trincheiras dos guias de onda do tipo canal. (a) Trincheiras de 1, 2 e $3 \mu \mathrm{m}$. (b) Imagem da borda do substrato de $\mathrm{Bi}_{4} \mathrm{Ge}_{3} \mathrm{O}_{12}$. (c) Trincheiras de $6 \mu \mathrm{m}$ a $10 \mu \mathrm{m}$ e de $80 \mu \mathrm{m}$ 165

Figura 81- Definição dos eletrodos e pads de Al dos moduladores eletro-ópticos, antes da corrosão via úmida deles. (a) Detalhes dos moduladores eletro-ópticos com trincheiras de 8,9 e $10 \mu \mathrm{m}$. (b) Detalhe do modulador eletro-óptico com trincheira de $80 \mu \mathrm{m}$. 166

Figura 82- Definição dos eletrodos e pads de Al dos moduladores eletro-ópticos, depois da corrosão via úmida deles. (a) Detalhes dos moduladores eletro-ópticos com trincheiras de 8, 9 e $10 \mu \mathrm{m}$. (b) Detalhe do modulador eletro-óptico com trincheira de $80 \mu \mathrm{m}$.

Figura 83- Lâmina de $\mathrm{Bi}_{4} \mathrm{Ge}_{3} \mathrm{O}_{12}$ (lâmina de teste). (a) Corte realizado com rotação de $30000^{\circ} \mathrm{RPM}$, avanço de $3^{\circ} \mathrm{mm} / \mathrm{min}$., profundidade de corte passante de $1,10 \mathrm{~mm}$. (b) Corte realizado com rotação de $45000 \mathrm{RPM}$, avanço de $0.5 \mathrm{~mm} / \mathrm{min}$, profundidade de corte de passante $1,10^{\circ} \mathrm{mm}$. 169

Figura 84- (a) Corte realizado com rotação de $45000 \mathrm{RPM}$, avanço de $0.05 \mathrm{~mm} / \mathrm{min}$, profundidade de corte de passante $1,10 \mathrm{~mm}$. (b) Corte realizado com rotação de 45000 RPM, avanço de $0.05 \mathrm{~mm} / \mathrm{min}$, profundidade de corte em vários passos, - $\mathrm{n}$ $=1,2,3,4,5$ e 6 cortes com incrementos de profundidade $1^{\circ} \mathrm{mm} / \mathrm{n}$.

Figura 85- Segundo teste de corte para separação dos moduladores eletro-ópticos da lâmina de $\mathrm{Bi}_{4} \mathrm{Ge}_{3} \mathrm{O}_{12}$. (a) Imagem da trincheira de $80 \mu \mathrm{m}$. (b) Imagem da cobertura removida durante o processo de corte pelo refrigerante do spindle (água)

Figura 86- (a) Corte realizado com rotação de $45000^{\circ} \mathrm{RPM}$, avanço de $2 \mathrm{~mm} / \mathrm{min}$, Vazão frontal (bucal) de $1 \mathrm{~L} / \mathrm{min}$, Vazão chuveiro (lateral) de $0,5^{\circ} \mathrm{L} / \mathrm{min}$, Disco com espessura de $80 \mu \mathrm{m}$, tamanho de diamante $12 \mu \mathrm{m}$. (b) corte a "seco": Rotação de 45000,00 RPM, avanço de $2 \mathrm{~mm} / \mathrm{min}$, Vazão frontal (bucal) de $2 \mathrm{~L} / \mathrm{min}$, Vazão 
chuveiro (lateral) de 0,02L/min, Disco com espessura de $80 \mu \mathrm{m}$, tamanho de

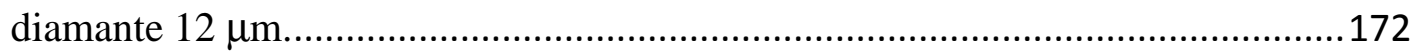

Figura 87- Corte a "seco": Rotação de 45000 RPM, avanço de 0,2 mm/min, Vazão frontal (bucal) de $0,02^{\circ} \mathrm{L} / \mathrm{min}$, Vazão chuveiro (lateral) de $0,5 \mathrm{~L} / \mathrm{min}$, Disco com espessura

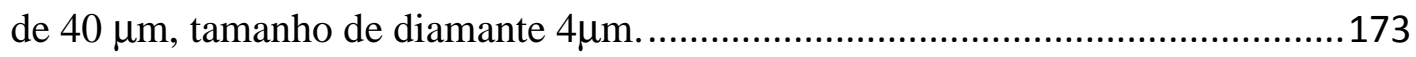

Figura 88- Rotação dos ângulos $\alpha \alpha$ e $\beta \beta$ nos eixos de coordenadas $x, y$ e $z$........................190

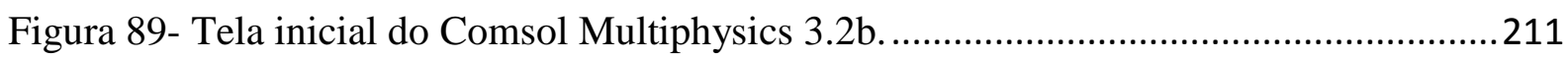

Figura 90- Escolha do Modo Estrutural Mecânico...................................................................212

Figura 91- Escolha do Modo Eletromagnetismo - ondas perpendiculares - ondas de modo híbrido

Figura 92- Escolha do Modo MEMS (microelectromechanical systems - sistema microeletromecânico) - microfluídico - eletrostático.

Figura 93- Definição das grades ( rid) e das dimensões do projeto de modulador baseado em guia de onda do tipo canal.

Figura 94- Geometria de um projeto de modulador baseado em guia de onda do tipo canal.217 Figura 95- Definição das constantes do substrato de $\mathrm{BGO}$ e do filme de $\mathrm{Si}_{3} \mathrm{~N}_{4}$. 218

Figura 96- Inserção no COMSOL das equações dos efeitos elasto-óptico e eletro-óptico e da fórmula de dispersão do índice de refração do substrato de $\mathrm{BGO}$, do filme de $\mathrm{Si}_{3} \mathrm{~N}_{4}$.

Figura 97- Definições das condições de contorno do subdomínio para a deformação plana.

(a) Inicialização da definição, (b) Definição das condições para o substrato,

Figura 98- (a) Definição das condições para o filme e (b) Definição das condições para o ar.

Figura 99- Definições das condições de contorno do subdomínio para ondas de modo híbrido.

(a) Inicialização da definição, (b) Definição das condições para o substrato

Figura 100- (a) Definição das condições para o filme e (b) Definição das condições para o ar.

Figura 101- Definições das condições de contorno do subdomínio para eletrostática. (a) Inicialização da definição, (b) Definição das condições para o substrato.

Figura 102- (a) Definição das condições para o filme e (b) Definição das condições para o ar

Figura 103- Definições das condições de contorno da fronteira para deformação plana. (a) Inicialização da definição, (b) Definição das condições para o substrato,

Figura 104- Definição das condições para o filme e o ar.

Figura 105- Definições das condições de contorno da fronteira para ondas de modo híbrido. (a) Inicialização da definição, (b) Definição das condições no substrato e no filme como condutor magnético perfeito.

Figura 106- Definição das condições como continuidade para os eletrodos e as fronteiras externas do problema.

Figura 107- Definições das condições de contorno da fronteira para eletrostática. Inicialização da definição. 
Figura 108 (a) Definição das condições como continuidade para o filme, (b) Definição das condições como potencial flutuante para as fronteiras externas do problema.....230

Figura 109- (a) Definição das condições como potencial elétrico, nesse caso, tensão do eletrodo esquerdo. (b) Definição das condições como potencial elétrico, nesse caso, tensão do eletrodo direito.

Figura 110- Definições das condições de contorno dos pontos do modulador proposto. ......232

Figura 111- Definição da malha de triângulos para o projeto do modulador. (a) Definição dos pontos nodais Global. (b) Definição dos pontos nodais no Subdomain para o subdomínio 1 e 4

Figura 112- (a) Definição dos pontos nodais no Subdomain para o subdomínio 2, 4 e 11. (b) Definição dos pontos nodais no Subdomain para o subdomínio 3.

Figura 113- (a) Definição dos pontos nodais no Subdomain para o subdomínio 6 e 9. (b) Definição dos pontos nodais no Subdomain para o subdomínio 7.

Figura 114- (a) Definição dos pontos nodais no Subdomain para o subdomínio 8. (b) Definição dos pontos nodais no Subdomain para o subdomínio 3, 5 e 10.

Figura 115Malha definida para o projeto do modulador...................................................237

Figura 116- Definição da simulação do Plane Strain............................................................238

Figura 117- Definição do Solver Parameters..................................................................238

Figura 118- Definição do Solver Manager para o modo estrutural mecânico. (a) Definição do valor inicial. (b) Definição para entrada da solução. ..........................................2239

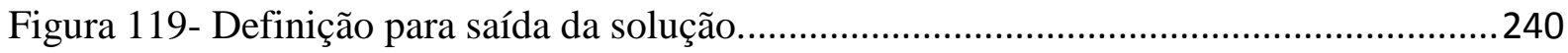

Figura 120- Definição do Solver Manager para o modo eletrostático. (a) Definição do valor inicial. (b) Definição para entrada da solução. .................................................241

Figura 121- Definição para saída da solução.....................................................................242

Figura 122- Definição do Solver Parameters para os autovalores .....................................243

Figura 123- Definição do Solver Manager. (a) Definição para entrada da solução. (b) Definição para saída da solução. ...................................................................244

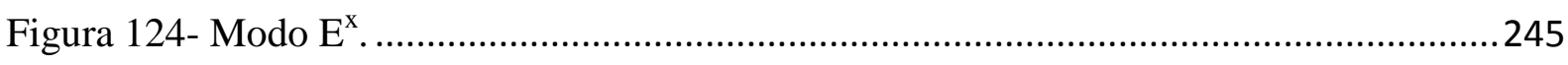

Figura 125- Definição das linhas do Potencial Elétrico ........................................................246

Figura 126- Definição das representações do vetor de um Campo Elétrico Local ................247 


\section{LISTA DE TABELAS}

Tabela 1- Algumas das propriedades: mecânicas, térmicas, eletro-ópticas e óptica dos

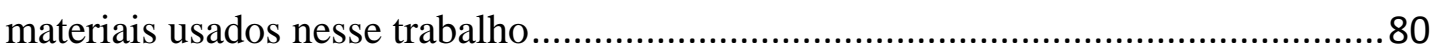

Tabela 2- Parâmetros de deposição do $\mathrm{Si}_{3} \mathrm{~N}_{4}$ por PLCVD ....................................................94

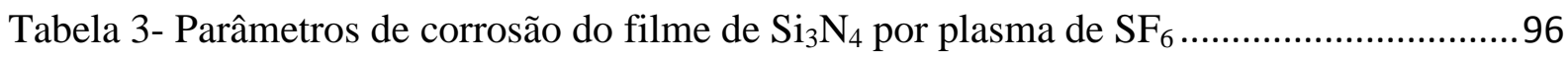

Tabela 4- Parâmetros de deposição do Al por meio de uma evaporação térmica convencional

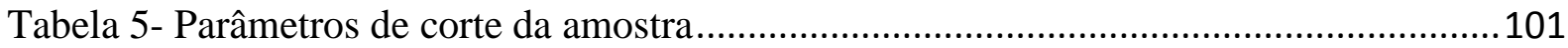

Tabela 6- Parâmetros de polimento de quina no modulador eletro-óptico...............................103 


\section{SUMÁRIO}

1 INTRODUÇÃO ....................................................................................................................23

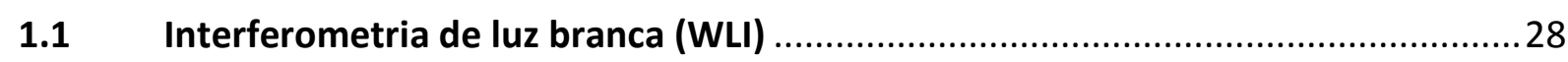

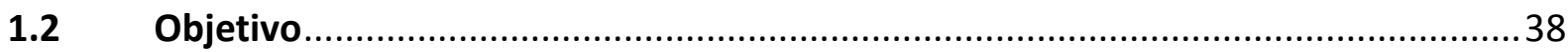

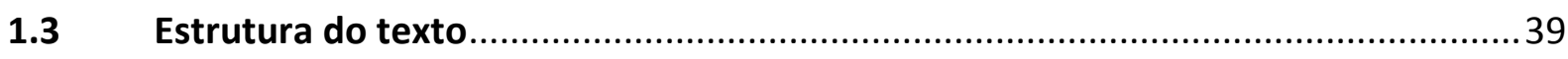

2 DISPOSITIVOS ÓPTICOS INTEGRADOS ........................................................41

2.1 Técnicas de fabricação de guias de onda do tipo canal .......................................44

2.2 Propagação de luz em guias de onda................................................................ 45

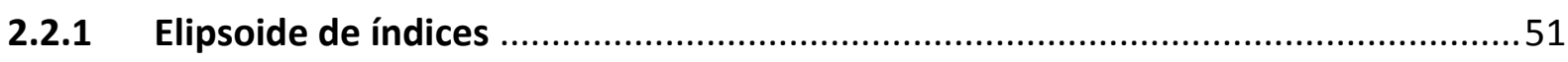

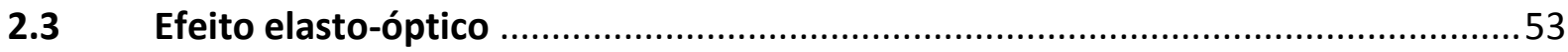

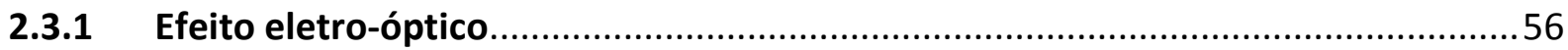

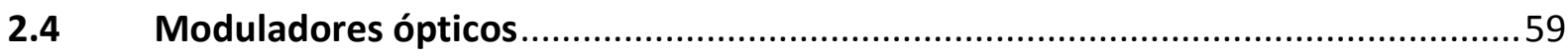

2.4.1 Tensão de meia onda $\left(V_{\pi}\right)$ de moduladores eletro-ópticos ...............................61

2.5 Moduladores eletro-ópticos baseados em guias de onda do tipo canal em óptica

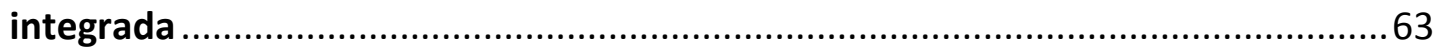

2.6 Formulação das equações de onda para os modos em método de elementos

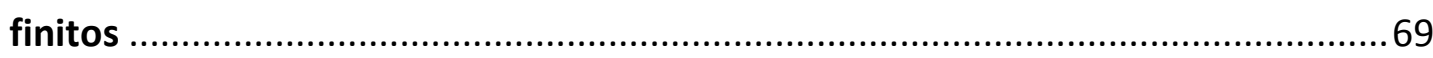

3 MATERIAIS E MÉTODOS.......................................................................................... 73

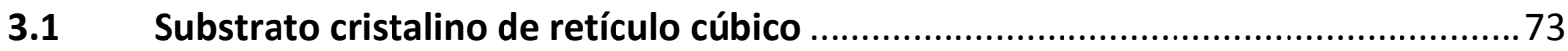

3.2 Filmes finos indutores de tensão mecânica......................................................... 74

3.3 Técnicas de fabricação de moduladores eletro-ópticos baseados em guias de onda

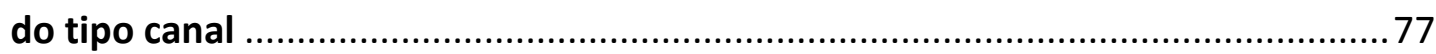

3.3.1 Técnica de fabricação de guias de onda do tipo canal ........................................77

3.3.2 Técnica de fabricação de moduladores eletro-ópticos ........................................78

3.4 Simulação e modelamento do guia e do modulador ............................................79

3.4.1 Equação do índice de refração dos materiais.......................................................79

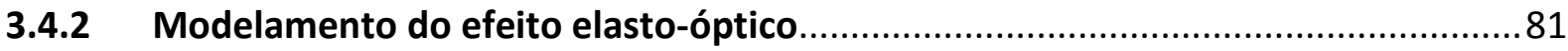

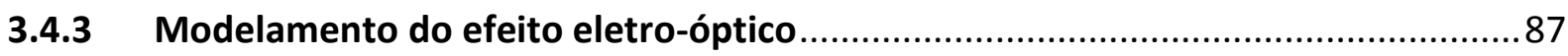

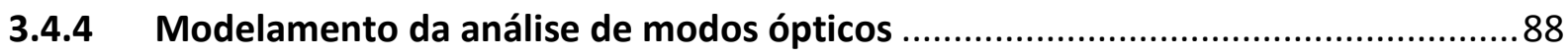

3.5 O programa computacional - como ferramenta de simulação ...............................89 


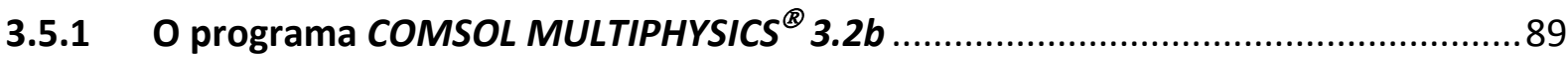

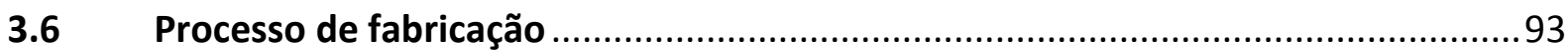

3.6.1 Etapas de fabricação de guias ópticos do tipo canal...........................................93

3.6.2 Etapas de fabricação de moduladores eletro-ópticos............................................97

3.7 Etapa 10: corte dos componentes (moduladores eletro-ópticos) ........................101

3.8 Etapas 11: polimento de quina no componente ............................................102

3.9 Medidas realizadas pelo stress meter (modelo flx - 2410) .................................104

3.10 Simulação auxiliando iterativamente o processo de fabricação de dispositivos em

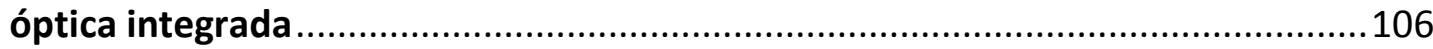

4 RESULTADOS E DISCUSSÕES ..................................................................................109

4.1 Resultados das simulações numéricas e discussões ..........................................109

4.1.1 Primeiro grupo: rotações dos eixos do elipsoide de índice do substrato de $\mathrm{Bi}_{12} \mathrm{GeO}_{12}$ e as condições de contorno do problema

4.1.2 Segundo grupo: usando a segunda orientação do cristal dos $\mathrm{BGOs}\left(\mathrm{Bi}_{12} \mathrm{GeO}_{20} \mathrm{E}\right.$ $\mathrm{Bi}_{4} \mathrm{Ge}_{3} \mathrm{O}_{12}$ ) e condições de contorno

4.1.3 Terceiro grupo: simulações de guias de onda óptico do tipo canal para encontrar o melhor grupo de geometria desses guias.

4.1.4 Quarto grupo: moduladores eletro-ópticos baseados em guias de onda do tipo canal

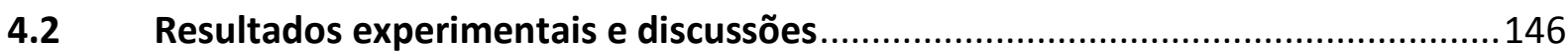

4.2.1 Testes realizados com as máscaras existentes no LSI/EPUSP .............................149

4.2.2 Procedimento 1: substrato de $\mathrm{Bi}_{4} \mathrm{Ge}_{3} \mathrm{O}_{12}$ rugoso

4.2.3 Procedimento 2: substrato de $\mathrm{Bi}_{4} \mathrm{Ge}_{3} \mathrm{O}_{12}$ polido com espessura aproximadamente de $500 \mathrm{~nm}$ do filme indutor de $\mathrm{Si}_{3} \mathrm{~N}_{4}$

4.2.4 Procedimento 3: substrato polido de $\mathrm{Bi}_{4} \mathrm{Ge}_{3} \mathrm{O}_{12}$ com filme fino de $\mathrm{Si}_{3} \mathrm{~N}_{4}$

4.2.5 Procedimento 4: fabricação do modulador eletro-óptico ...................................159

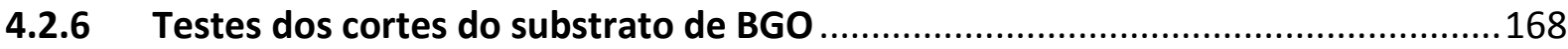

4.2.7 Resultados do cálculo da tensão total a partir de medições feitas por stress meter

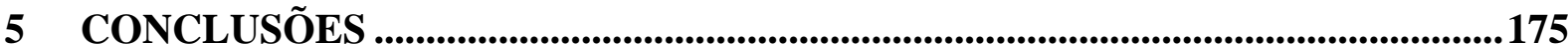

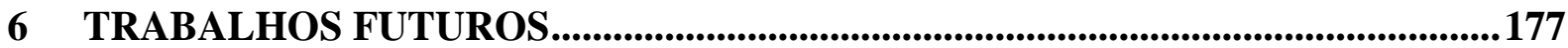

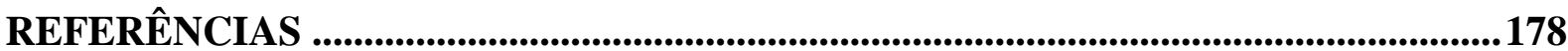




\section{INTRODUÇÃ̃O}

Os sensores a fibra óptica apresentam inúmeras vantagens em relação aos sensores convencionais, dentre os quais podem se destacar o fato de serem constituídos e conectados por fibras ópticas, que podem ser fabricadas exclusivamente com materiais eletricamente isolantes, tornando-se imunes a interferências eletromagnéticas radiadas ou conduzidas na comunicação de sinais. Este fato propicia a aplicação desses sensores em dispositivos de medição de altas tensões, pois, além disso, exibem outras características interessantes, tais como: pequenas dimensões, leveza, grande sensibilidade e ampla faixa de resposta em frequência $[1,2]$.

Aplicações de sensores ópticos em automação foram estabelecidas antes da década de 70, utilizando métodos ópticos de monitoração e controle que já eram bem conhecidos pela comunidade científica [2-5]. Estes sensores analisavam uma grande variedade de mecanismos, utilizando desde simples interruptores ópticos baseados na interrupção de feixe de luz até técnicas complexas de interferometria óptica. Uma característica geral da maioria destes instrumentos ópticos baseados em propagação não guiada de luz é o fato de serem delicados, no sentido que o desempenho do dispositivo se degrada quando o alinhamento óptico é perturbado. Consequentemente, embora possuíssem elevado desempenho, poucas propostas de sensores deste tipo passavam da fase de desenvolvimento. [4, 5].

\footnotetext{
De acordo com Pinheiro, observa-se que as áreas da instrumentação e da medição, no que diz respeito ao desenvolvimento de sensores, estão entre as que mais rapidamente têm se expandido. Em especial, atualmente, tem-se evidenciado a necessidade de integração de sensores de elevada qualidade nos mais sofisticados sistemas de medição e controle. Em paralelo com o desenvolvimento acelerado de sensores baseados em tecnologia microeletrônica, outros sensores baseados em técnicas ópticas têm também progredido significativamente durante os últimos anos, em particular desde o aparecimento das fibras ópticas [1].
}

Os sensores a fibra óptica têm sido instalados em ambientes que utilizam altas tensões, entre eles os Sistemas Elétricos de Potência (SEP), que apresentam elevadas intensidades de campos elétricos e magnéticos. $\mathrm{O}$ interesse em sua instalação se deve principalmente a suas características particulares, citadas anteriormente [6].

Para realizar a automação dos SEPs há necessidade de sensoriar diversas grandezas que caracterizam os processos de geração, transmissão e distribuição de energia elétrica. Dentre as grandezas de interesse, encontram-se as químicas (presença de contaminantes no óleo de 
isolamento de transformadores, etc) e as físicas (temperatura, força, deformação, vibração, tensão, corrente, campos eletromagnéticos, etc) [4, 5].

As medições das grandezas de interesse para automação dos SEPs são feitas por meio de sistemas de instrumentação, que são compostos por sensores (ou transdutores), enlaces de comunicação, processadores de sinais e processadores de medidas (que podem incluir indicadores diretos).

Conhecendo a severidade do ambiente de medição a que os sensores ou transdutores são submetidos nos SEPs, onde há presença de intensas interferências eletromagnéticas, a utilização dos sensores a fibra óptica torna-se interessante [6]. Dessa maneira, a instrumentação baseada em sensores a fibra óptica vem conquistando maior espaço no setor elétrico em consequência das vantagens de sua tecnologia, a qual, entre outras coisas, possibilita a fabricação de sistemas de medição que, em muitos casos, são praticamente imunes às interferências eletromagnéticas que afetam as medições no setor elétrico.

Em se tratando das medições de grandezas elétricas em SEPs, os equipamentos normalmente utilizados são os transformadores para instrumentos (TI), divididos em transformadores de potencial (TPs) e transformadores de corrente (TCs), que como Lima [7] menciona são equipamentos essenciais para a realização das funções de medição e de proteção nos SEPs, pois são responsáveis por gerar sinais proporcionais aos valores de correntes e tensões presentes nos sistemas de alta tensão e oferecê-los para os dispositivos de medição, proteção, monitoração e controle. Assim, os TIs são usados, por exemplo, em conjunto tanto com medidores de energia, quanto com relés de proteção, como também com circuitos de controle de tensão de geradores.

$\mathrm{Na}$ automação dos SEPs existe a necessidade de se monitorarem as tensões e correntes elétricas nos condutores das linhas de transmissão e também nos barramentos de subestações.

Por muitos anos, os TIs com enrolamentos de cobre e núcleos de ferro, os chamados TI's convencionais, têm sido usados nas medições de tensão e corrente nos SEPs [8]. Com a crescente demanda por aumento de capacidade dos SEPs e com o aumento das tensões de transmissão impõem-se aumentos de tamanho, peso e preço aos TIs convencionais [8]. Mais atualmente, além dos TIs convencionais, começaram a ser usados os TIs baseados em tecnologia óptica, os chamados TIs ópticos (TIOs), para medição de valores de correntes e 
tensões nos sistemas elétricos de alta, extra alta e ultra alta tensão. Os exemplos de uso de sensores ópticos para medições de tensão e campo elétrico em sistemas de alta tensão foram citados nos trabalhos de Santos [9, 10].

Assim, com vistas a atender às novas exigências de qualidade e desempenho nos sistemas de potência, e também diante de algumas características vantajosas anteriormente mencionadas, o emprego de sensores ópticos na medição de grandezas elétricas apresenta-se atualmente como uma alternativa promissora.

Os TIOs, pertencentes à categoria dos transformadores não convencionais, possuem características aprimoradas em termos de exatidão, segurança, interferência eletromagnética, faixa dinâmica e resposta em frequência em relação ao TIs convencionais.

Os transformadores não convencionais são descritos como transformadores eletrônicos nas normas 60044-7 e 60044-8 da International Electrotecnical Comission (IEC), em que foram classificados como: transformadores eletrônicos para instrumentos, transformadores eletrônicos de tensão e transformadores eletrônicos de corrente. A descrição na forma de diagrama de blocos dos componentes de um transformador eletrônico genérico é apresentada na Figura 1, a seguir.

Figura 1- Diagrama de blocos de um transformador eletrônico genérico, conforme a norma IEC 60044-7

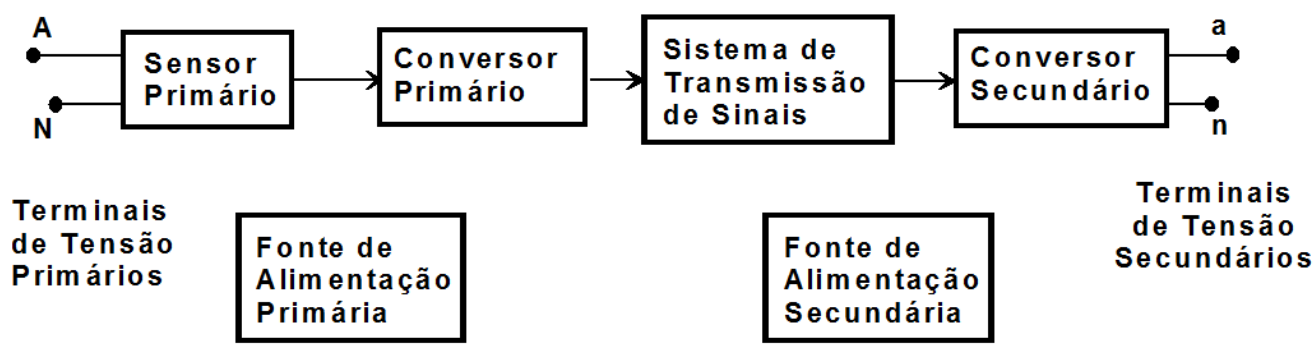

Fonte: [11]

Os componentes indicados na Figura 1 foram detalhados no trabalho de livre docência de Santos [11], que descreve transformadores ópticos como transformadores eletrônicos.

Os transformadores ópticos para instrumentos são transformadores eletrônicos que empregam sensores ópticos como sensores primários. Existem várias formas de se implementar sensores ópticos para medição de tensão e corrente em altas tensões. Os sensores ópticos passivos (que não necessitam alimentação elétrica para funcionar) são chamados de moduladores ópticos e 
podem modular as características da luz que os atravessa de quatro formas diferentes: em amplitude, em fase, em polarização e em espectro. Portanto, os sensores primários ópticos entregam em sua saída sinais ópticos que traduzem a informação da grandeza elétrica medida na forma de um feixe de luz modulado de uma dessas quatro maneiras.

As definições de transformadores ópticos de potencial e de corrente foram transcritos por Santos [11] como:

Transformador Óptico de Potencial: É o transformador óptico para instrumentos no qual a tensão secundária, em condições normais de uso, é substancialmente proporcional à tensão primária e difere em fase desta por um ângulo que é aproximadamente zero para uma "polaridade" apropriada de conexões.

Transformador Óptico de Corrente: É o transformador eletrônico para instrumentos no qual a tensão secundária, em condições normais de uso, é substancialmente proporcional à corrente primária e difere em fase desta por um ângulo que é aproximadamente zero para uma "polaridade" apropriada de conexões.

A partir das informações coletadas do trabalho [11], pode-se fazer um diagrama de blocos de um transformador óptico genérico que é apresentado na Figura 2.

Figura 2- Diagrama de blocos de um transformador óptico genérico

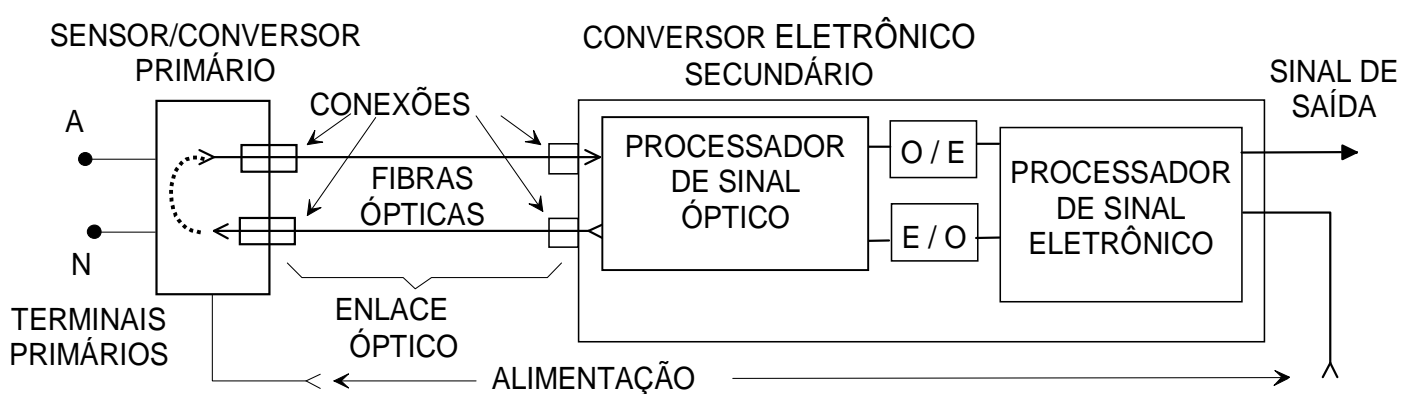

Fonte: Modificado [11].

O conversor eletrônico secundário, ilustrado na Figura 2, pode desempenhar diversas funções. Se o conversor primário for um modulador, ele atuará como um processador de sinal óptico, cujo papel é traduzir o sinal recebido do sensor primário (quando este é modulado em espectro, polarização ou fase) para modulação em intensidade, isto porque os dispositivos fotodetectores só são sensíveis à intensidade óptica, transformando esta informação em sinal elétrico (fotocorrente), o qual é transmitido ao processador de sinal eletrônico.

Observa-se que o bloco denominado "Sensor/Converso Primário" no diagrama da Figura 2 pode ser a descrição de um transformador eletrônico para instrumentos que emprega sensores 
eletromagnéticos associados a conversores optoeletrônicos, por exemplo, um transformador convencional de potencial (TP) ou de corrente (TC) associado a um circuito eletrônico que aciona um emissor de luz (LED - Light Emitting Diode ou Laser - Light Amplification Stimulated Emission of Radiation) que entrega a uma fibra óptica um sinal luminoso cuja intensidade é proporcional à grandeza medica (tensão ou corrente). A Figura 2 também é adequada para descrever um transformador eletrônico para instrumentos em que o sensor primário é um modulador óptico passivo, o qual modula um sinal de luz recebido de uma fonte de referência por meio do enlace óptico. Esse enlace também transmite o sinal modulado ao conversor secundário. O conversor secundário processa a informação recebida e fornece em sua saída uma tensão proporcional à grandeza primária para alimentar instrumentos de medição, leitura e dispositivos de controle e proteção.

Os moduladores de potência óptica podem agir de duas maneiras: na amplitude do campo elétrico (e, portanto, na intensidade) de uma onda óptica ou na distribuição espacial de intensidade óptica (formato) de um feixe [12]. Este tipo de modulador é o único que pode ser conectado diretamente aos fotodetectores, pois estes traduzem diretamente a potência óptica recebida para sinais de corrente elétrica (fotocorrente) [13].

Os moduladores de fase atuam modificando a fase de uma onda óptica de referência. Esta modificação pode ser obtida através de mudanças do caminho óptico (no comprimento e/ou no índice de refração do meio). Para medir o atraso de fase induzido por este tipo de modulador utilizam-se técnicas de interferometria [14], que convertem a diferença de fase em modulação de intensidade.

Os moduladores de polarização modificam o padrão de polarização de uma onda óptica de referência. Para construir este tipo de modulador utilizam-se materiais birrefringentes ou que se tornam birrefringentes pela ação da grandeza física que se quer medir, ou seja, que apresentam o índice de refração dependente da direção de polarização da luz que os atravessam. Nesse caso, também, a modificação do padrão de polarização da luz incidente pode ser obtida alterando-se o caminho óptico, modificando-se seu comprimento ou a birrefringência do meio por ações externas acopladas via certos efeitos, tais como o eletroóptico e o elasto-óptico, entre outros. Para identificar o padrão de polarização na saída do modulador utilizam-se técnicas de polarimetria, que traduzem a informação contida no estado de polarização para modulação de intensidade [15]. 
Os moduladores de espectro óptico atuam na distribuição espectral de energia de uma onda óptica de referência [16]. Há várias formas de obter-se este tipo de modulação, incluindo filtros ópticos sintonizados, efeitos ópticos não lineares, superposição de duas ou mais ondas ópticas de espectro largo, etc. Esta modulação pode ser analisada por meio de técnicas de espectrometria, que traduzem a informação contida em algum parâmetro específico do espectro para modulação de intensidade. No caso específico de superposição de duas ou mais ondas de espectro largo pode-se utilizar técnicas de interferometria para recuperar a informação contida no espectro modulado.

Entre as técnicas citadas para construção de sensores ópticos figura a de interferometria de luz branca, em inglês, White Ligth Interferometry (WLI). Nos casos em que utilizam-se fibras ópticas para comunicação de sinais na construção de sistemas de sensoriamento, essa técnica também pode ser chamada de interferometria de baixa coerência a fibra óptica, em inglês, Fiber Optic Low Coherence Interferometry (FOLCI) [1].

Como este trabalho destina-se a tratar do desenvolvimento de sistemas de sensoriamento óptico que empregam a técnica WLI, a seguir são apresentados os conceitos básicos a respeito desta técnica e, posteriormente, dos princípios de funcionamento de um sistema baseado na técnica FOLCI.

\subsection{Interferometria de luz branca (WLI)}

Antes de apresentar a técnica WLI é conveniente fazer uma introdução aos conceitos básicos de interferometria.

Normalmente, quando se superpõem dois feixes ópticos, espera-se que a intensidade resultante seja igual à soma das intensidades de cada feixe. Em alguns casos, pode-se observar que a intensidade resultante em cada ponto da região onde se superpõem os feixes é diferente da soma algébrica das intensidades de cada feixe. Nesses casos a observação da diferença existente entre a intensidade resultante em cada ponto e a soma das intensidades de cada feixe é decorrente de interferência óptica entre os dois feixes. 
Para que se observe este fenômeno é necessário que os dois feixes ópticos tenham o mesmo conteúdo espectral, a mesma direção e sentido de propagação, o mesmo padrão de polarização e sejam coerentes.

\footnotetext{
De acordo com Peatross e Ware [17], teoria da coerência é um estudo estatístico da correlação existente entre partes diferentes do campo do feixe óptico. Na teoria da coerência temporal focam-se as correlações entre os campos em diferentes tempos. $\mathrm{Na}$ teoria da coerência espacial focam-se as correlações entre os campos em diferentes localizações espaciais.
}

No interferômetro de dois feixes separados por divisão de amplitude, os feixes ópticos são divididos e propagados em caminhos ópticos diferentes, denominados de braços do interferômetro. Durante a propagação é introduzida uma diferença de fase proporcional à diferença de caminhos ópticos (Optical Path Difference - OPD) e, ao final dos caminhos ópticos, os feixes são recombinados. Se a polarização desses feixes for preservada, após a recombinação, aparecerá um padrão de franjas de interferência com regiões de intensidades de luz máximas e mínimas.

Os lasers, geralmente, são usados em sensores interferométricos comuns como fonte de luz por produzirem radiação altamente monocromática, o que resulta em intensidades máximas e mínimas das franjas de interferências adjacentes praticamente iguais. Caso utilize-se um interferômetro como instrumento de medição, para medir a diferença de fase ou de caminho óptico, como todas as franjas exibem a mesma amplitude, na saída do interferômetro vai aparecer uma ambiguidade na medida sempre que a diferença de fase variar por múltiplos de $2 \pi$, ou o caminho óptico variar por múltiplo do comprimento de onda [18]. Pode-se definir a visibilidade de um padrão de interferência como sendo a diferença entre os valores das intensidades máxima e mínima de uma franja dividida pela soma destes dois valores. Portanto, o padrão de interferência de um interferômetro iluminado por uma fonte monocromática exibe uma visibilidade constante.

Por outro lado, fontes de luz com espectros de bandas mais largas que as dos lasers, como, por exemplo, LEDs e diodos superluminescentes (SLDs - Superluminescent Diodes), são utilizadas na técnica de interferometria de luz branca. Neste caso, ao se usar um interferômetro como instrumento de medição, no padrão de interferência obtido em sua saída (interferograma) as franjas não exibem a mesma amplitude, ou seja, a visibilidade do padrão 
de interferência varia com a OPD, ou com a diferença de fase. De modo geral, a visibilidade diminui com o aumento da OPD, como ilustra a Figura 3.

Figura 3- Padrão de intensidade de saída teórico de um interferômetro iluminado com luz branca

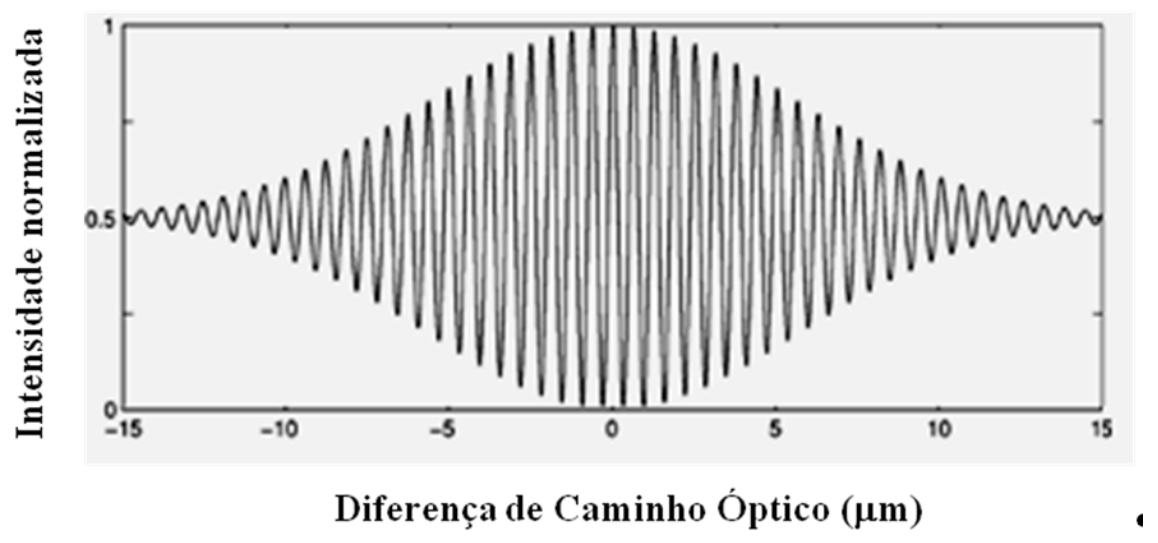

Fonte: [10].

Assim, esta técnica oferece a capacidade de identificar a ordem da franja de interferência no padrão de franjas, tornando possível evitar a ambiguidade na medida sempre que a diferença de fase variar por múltiplos de $2 \pi$, ou o caminho óptico variar por múltiplos do comprimento de onda [19].

No entanto, quando o valor em módulo da OPD se torna muito grande, a visibilidade tende a zero, como mostrado na Figura 3. Assim, a intensidade na saída do interferômetro, mesmo variando a OPD, tende a ficar constante, tornando impossível identificar diretamente o valor da grandeza que se deseja medir. Isso limita o valor máximo da grandeza que se consegue medir através de um sensor interferométrico por WLI. Por exemplo, considerando que a Figura 3 representa um medidor interferométrico de distância, para valores acima de $15 \mu \mathrm{m}$ não se observam mais variações significativas de intensidade de luz na saída do interferômetro. Nesta circunstância (quando a visibilidade se aproxima de zero), as informações sobre a grandeza medida não estão perdidas, elas se encontram moduladas no espectro da luz [19]. Então, uma alternativa para analisar a luz na saída do interferômetro e recuperar a medida seria utilizar um espectrômetro. Entretanto, estes dispositivos são caros e relativamente lentos.

Uma outra alternativa, menos cara e potencialmente mais rápida, para recuperar o valor medido é a utilização de um segundo interferômetro ligado em série com o primeiro. A luz emitida pela fonte de banda larga percorre o primeiro trecho do enlace óptico até o 
interferômetro sensor, que divide a luz em dois feixes e introduz entre eles uma OPD e os interferem. Após passar pelo interferômetro sensor, a luz percorre o segundo trecho do enlace óptico até o interferômetro recuperador. Neste ponto, a informação pode ser recuperada por meio de um sistema de demodulação temporal ou espacial [20], como ilustrado na Figura 4, a seguir. Neste caso trata-se de um sistema FOLCI, pois toda comunicação entre os dispositivos é feita por fibras ópticas.

Figura 4- Diagrama de blocos de um sistema de sensoriamento a WLI típico

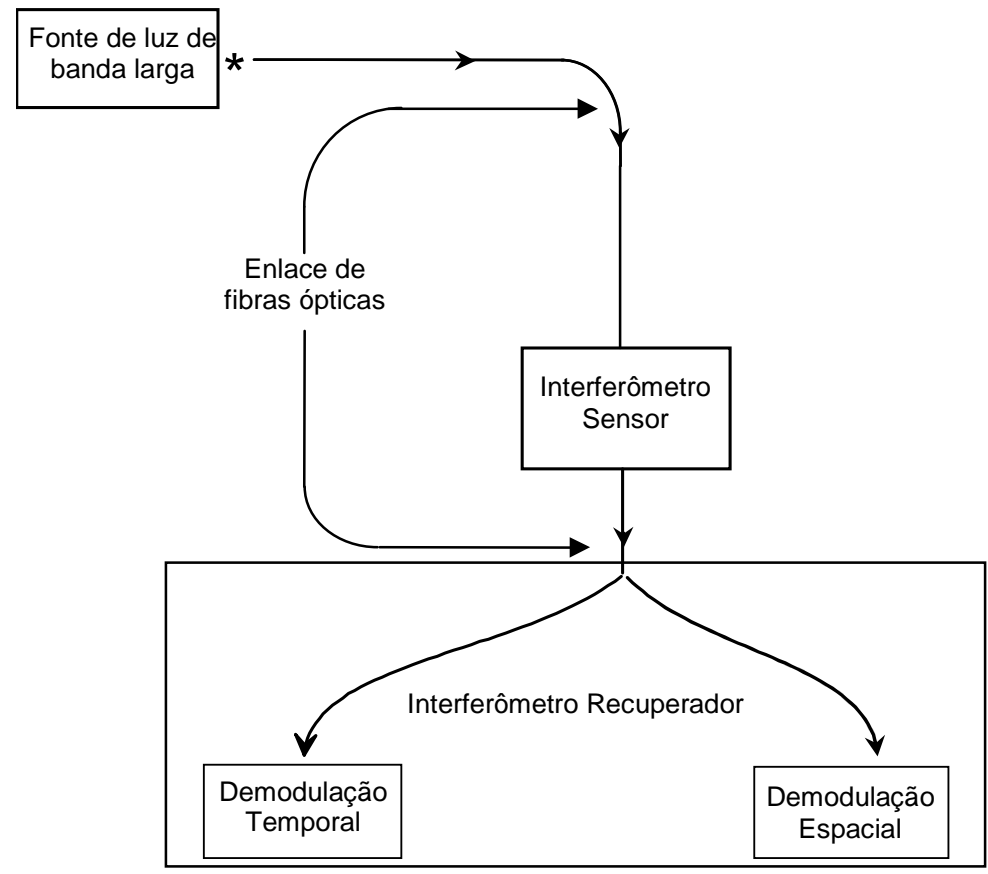

Fonte: Autora.

Existem diversos sistemas de interrogação de sensores por WLI. No trabalho de Santos [10] foram citados e comparados alguns desses sistemas que recuperam informações de grandeza medida.

Em um sistema de sensoriamento por WLI com demodulação temporal típico, a saída do interferômetro recuperador é conectada diretamente a um fotodetector. Nesse tipo de sistema, a luz emitida pela fonte percorre o primeiro trecho do enlace até o interferômetro sensor, que a divide em duas partes e introduz entre elas uma OPD e as interferem, dando origem a um novo feixe, no qual as duas partes caminham superpostas. Neste novo feixe, se a OPD for igual ao comprimento de coerência da fonte (Lc), definido como sendo o inverso da largura de banda espectral da fonte, pode-se demonstrar que a intensidade de luz na saída do 
interferômetro cai a 1/e de seu valor máximo [21]. Caso a OPD seja muito maior que o Lc a visibilidade da interferência cai a zero, ou seja, não é mais possível observar diretamente a interferência. Porém, pode-se considerar que as energias provenientes das duas partes estão se propagando superpostas nesse feixe, o qual percorre o segundo trecho do enlace até o interferômetro recuperador. Neste interferômetro a luz é novamente divida em duas partes, entre as quais é inserida uma nova OPD. Na saída do interferômetro recuperador, ao serem interferidas as duas partes da luz, forma-se um feixe óptico composto por quatro componentes superpostas viajando simultaneamente até o fotodetector. A intensidade da luz neste ponto é, portanto, formada pelas interferências mútuas entre as quatro componentes. Se o valor médio da OPD introduzida pelo recuperador for igual ao valor médio da OPD introduzida pelo interferômetro sensor, duas dessas quatro componentes voltarão a se interferir na região de visibilidade máxima, enquanto que as outras duas permanecerão a na região da visibilidade nula, ou seja, contribuirão apenas para o valor médio da intensidade de luz do feixe, como ilustrado na Figura 5 [10].

\section{Figura 5- Padrão de intensidade de saída teórico de um sistema WLI com dois interferômetros em série}

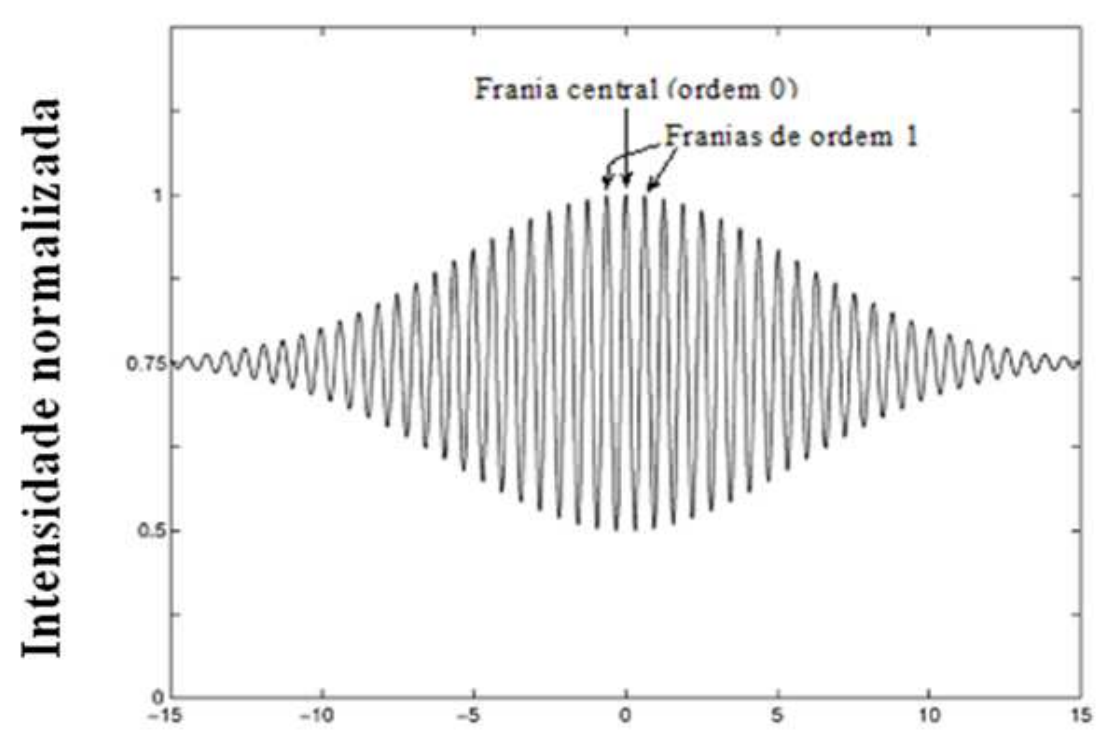

\section{Diferença de Caminho Óptico $(\mu \mathrm{m})$}

Fonte: [11].

Em 1997, Santos [10] propõe e descreve teoricamente a construção de um sistema de sensoriamento por WLI genérico, utilizando dois interferômetros compostos por moduladores eletro-ópticos de birrefringência ligados em série por um enlace de fibras ópticas (portanto um FOLCI). Em 1999 [22] foram apresentados os princípios desse método numa conferência 
internacional. Nesse trabalho o interferômetro recuperador proposto é formado por um modulador birrefringente polarimétrico, no caso uma célula Pockels, projetado para introduzir uma OPD igual à gerada pelo interferômetro sensor.

Em outro trabalho [23] apresenta-se uma variação mais simples da aplicação dessa técnica WLI em um sistema de medição de tensão a fibras ópticas. Essa abordagem utiliza um interferômetro recuperador fixo que introduz uma OPD igual ao valor médio daquela inserida pelo interferômetro sensor, com isso o sinal óptico na saída do interferômetro recuperador apresenta uma intensidade proporcional à grandeza medida.

O objetivo do autor daquele trabalho foi criar um sistema que fosse capaz de compensar flutuações lentas na potência óptica média obtida na saída do sistema, advindas de perdas nos interferômetros e no enlace a fibras ópticas, tais como: de acoplamento, de transmissão, de envelhecimento de componentes, etc. Um protótipo desse sistema foi construído e testado, demonstrando eficiência para atender os objetivos citados. Apesar disso, o protótipo apresentou outros tipos de problemas, como sensibilidade a ruídos e à deriva térmica dos componentes, que não puderam ser compensadas naquela abordagem.

Buscando eliminar, ou pelo menos minimizar, os problemas citados acima, construiu-se um protótipo de interferômetro recuperador volumétrico, baseado num modulador eletro-óptico Pockels polarimétrico, que foi aplicado ao sistema de sensoriamento descrito anteriormente [25].

Outros grupos de pesquisa vêm desenvolvendo trabalhos na área de transformadores ópticos para sistemas de alta e extra-alta tensão [26-28]. Contudo esta parte deste trabalho não se aprofundará no estudo destas outras abordagens, pois visa apenas apresentar o cenário que justifica a execução desta pesquisa no âmbito do LSO/PEA. Outros pesquisadores do grupo se dedicam a estudar outras propostas de desenvolvimento [2, 29] e compara-las às abordagens adotadas no LSO.

Prosseguindo com o desenvolvimento de TPOs, foi apresentada uma nova versão de processador de sinal opto-eletrônico aplicado na demodulação do sinal de saída do protótipo anteriormente citado [29]. Essa versão é baseada na detecção precisa dos picos e vales presentes no sinal de saída do interferômetro recuperador. Este sinal contém a informação inserida pela alta tensão aplicada na célula Pockels usada como interferômetro sensor. Nos 
testes realizados com esse protótipo foram obtidas, além da redução da dependência da tensão medida na saída do TPO com a intensidade de luz no enlace óptico, melhoria na relação sinalruído, aumento da faixa dinâmica de medição e capacidade de compensação da deriva térmica da resposta do sistema.

Embora moduladores volumétricos demonstrem um bom desempenho como interferômetros recuperadores para sistemas WLI, eles também apresentam características inadequadas, tais como: elevados valores de tensão de meia onda $\left(\mathrm{V}_{\pi}\right)$, sensibilidade a vibrações mecânicas, baixa imunidade eletromagnética, dificuldade de conectorização, sensibilidade à variação da temperatura relativamente elevada, montagem volumosa e delicada, necessidade de alinhamentos axial e angular precisos entre os componentes ópticos, etc. Algumas dessas características dificultam o seu manuseio durante o processo de montagem e comprometem a performance desse tipo de sistema.

Toda a explanação precedente visa apresentar o cenário dos problemas que justificam o interesse do LSO/PEA em novos desenvolvimentos de interferômetros recuperadores baseados em moduladores eletro-ópticos que não apresentem as características inadequadas citadas acima.

Desde então, Santos e o grupo de pesquisadores do LSO/EPUSP vem avançando nos desenvolvimentos: dos sistemas sensores eletro-ópticos [6], do processamento de sinais ópticos e eletrônicos dos sensores [30-32], do uso de ferramentas de cálculos numéricos para auxílio ao projeto de moduladores eletro-ópticos para medição de altas tensões [29, 33, 34], do desenvolvimento de componentes em óptica integrada (OI) $[35,36]$ e dos estudos de viabilidade técnica e econômica da aplicação de TPOs em SEPs [7, 9].

No trabalho de doutorado de Pinheiro [1] foi identificado que os moduladores eletro-ópticos em OI são os mais promissores para realização da função do interferômetro recuperador, pois eles apresentam características como: pequenas dimensões, baixo peso, resposta rápida, baixas perdas por inserção, montagem mecanicamente estável, facilidade de conectorização, excelente imunidade eletromagnética e estabilidade térmica melhor do que a dos volumétricos. 
No trabalho de Pinheiro utilizou-se um componente comercial modificado para demonstrar a viabilidade da aplicação desta tecnologia em interferômetros recuperadores de sistemas de sensoriamento baseados em WLI, como os TPOs.

No entanto, ainda não se encontram disponíveis no mercado internacional componentes em OI perfeitamente adequados para a aplicação específica de moduladores eletro-ópticos como interferômetros recuperadores em sistema WLI, como o TPO em desenvolvimento no LSO, que necessitam apresentar: birrefringência natural nula, baixo valor de tensão de meia onda, insensibilidade a vibrações mecânicas, elevada imunidade eletromagnética, baixa sensibilidade à variação da temperatura, montagem compacta e robusta, etc.

Neste contexto, faz-se necessário o desenvolvimento de moduladores eletro-ópticos em OI que apresentem as características desejadas citadas acima.

Uma possibilidade para construir moduladores em materiais que apresentem efeito eletroóptico com a utilização de OI, que operem com tensões de meia onda mais baixas e não apresentem vários dos inconvenientes citados, é obtida pela deposição de eletrodos próximos a um guia de onda óptico do tipo canal. Tais eletrodos permitem a aplicação de campos elétricos intensos na região do guia a partir de baixas tensões aplicadas. Esses campos alteram o índice de refração do substrato cristalino via efeito eletro-óptico. Este efeito será detalhado na seção 2.4.1 no capítulo 2, dedicado aos materiais e métodos.

Com a escolha adequada de materiais e de orientações (tais como: corte do cristal, direção de propagação da luz e de aplicação do campo elétrico) é possível construir um modulador eletro-óptico de birrefringência com as características desejadas.

Um interferômetro recuperador baseado neste tipo de modulador em OI pode ser descrito como ilustra a Figura 6. 
Figura 6- Interferômetro recuperador baseado em modulador eletro-óptico de birrefringência em OI

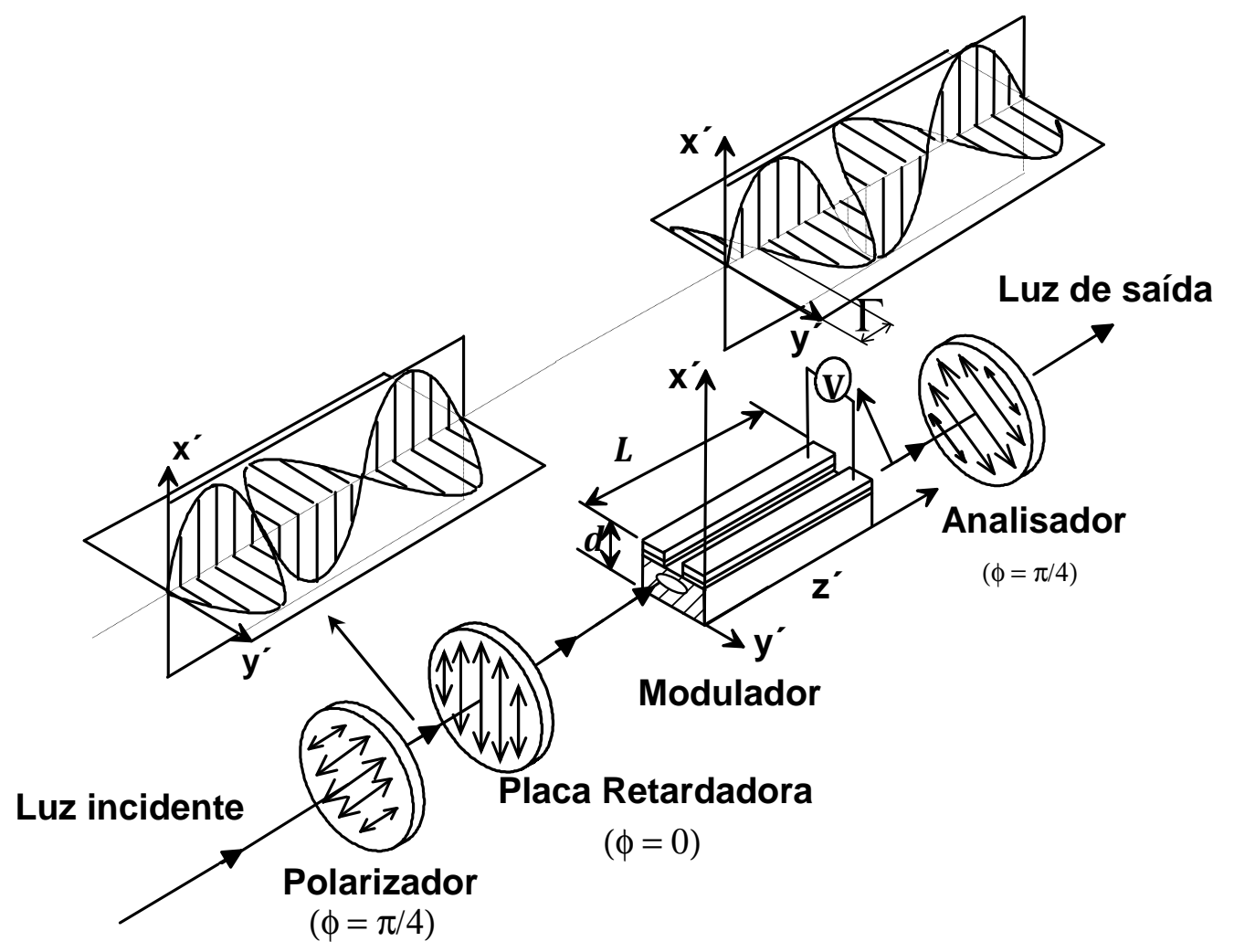

Fonte: [10].

Na Figura 6 não foi incluída a parte de focalização e acoplamento da luz no guia óptico para simplificar a representação. Na verdade considera-se nesta figura que o feixe de entrada seja colimado e tenha dimensões compatíveis com o modo guiado do modulador. As partes de focalização e de acoplamento da luz no guia são muito importantes, pois interferem diretamente na maneira que é realizada a montagem e no desempenho de todo sistema.

Na representação da Figura 6, o interferômetro recuperador é composto por um polarizador, uma placa retardadora, um modulador eletro-óptico baseado em guia de onda do tipo canal e um polarizador analisador. Um feixe de luz incidente passa pelo polarizador (que seleciona uma direção de polarização para a luz transmitida) e pela placa retardadora (que por ser birrefringente cria a partir da luz incidente duas componentes de polarização ortogonais entre si, as quais podem ser consideradas como dois feixes ópticos distintos, e introduz uma diferença de fase óptica entre eles). Esses feixes são modulados, ao longo do caminho óptico pela tensão aplicada nos eletrodos do modulador eletro-óptico. No entanto, por exibirem as 
direções de polarização cruzadas, eles não interferem entre si. Quando eles passam pelo polarizador analisador é realizada a sua recombinação.

Esse interferômetro, mostrado na Figura 6, por ser baseado em modulador eletro-óptico de birrefringência em OI apresenta uma tensão de meia onda $\left(\mathrm{V}_{\pi}\right)$ baixa, mas exibe outros problemas, tais como os outros componentes continuam sendo discretos (volumétricos) e dependem de posicionamento e alinhamento precisos, o que faz com o que a montagem seja delicada, sensível a vibrações e de grandes dimensões.

Para amenizar esses problemas, muitas vezes utilizam-se componentes fabricados a fibras ópticas, tais como, polarizador e lâmina retardadora, buscando melhorias nesse sistema. $\mathrm{O}$ objetivo de se obter componentes desse tipo é a facilidade de acoplamento entre os mesmos e o modulador, desde que eles disponham de uma conexão direta a um trecho fibra óptica (pigtail). Isso faz com que aumente a robustez e a estabilidade mecânica da montagem do sistema óptico, possibilitando as reduções da sensibilidade às vibrações, da deriva térmica, etc.

A questão do acoplamento do modulador à fibra óptica gera um requisito muito importante para este trabalho, pois o tamanho do modo guiado tem que ser compatível com o modo da fibra utilizada no sistema. Para obter o tamanho adequado deste modo será realizado um estudo para o projeto do guia de onda do tipo canal que servirá de base para o modulador. Este estudo definirá um conjunto de larguras do canal do guia a serem simuladas numericamente, o programa que será utilizado nas simulações numéricas e o processo de fabricação desses guias (juntamente com seus parâmetros de interesse).

Como já foi dito anteriormente, não se encontram componentes comercialmente disponíveis, como o modulador retratado na Figura 6, que sejam plenamente adequados à aplicação pretendida. Em vista disto, o desenvolvimento de um modulador eletro-óptico de birrefringência baseado em guia de onda do tipo canal é o foco deste trabalho. Para isso é necessário definir uma técnica de fabricação do componente para orientar o projeto do mesmo. Após a definição da técnica de fabricação a ser empregada, é essencial contar com uma técnica de simulação computacional para apoio ao projeto. A mesma técnica de simulação pode ser usada para apoio interativo ao processo de fabricação, desde que ela tenha capacidade de levar em consideração os parâmetros desse processo. 
As escolhas dos materiais e das orientações relativas (mecânicas, ópticas e elétricas) do componente, assim como as definições e o domínio da aplicação das ferramentas e das técnicas citadas acima, fazem parte dos objetivos desse trabalho que serão apresentados no item a seguir.

A originalidade deste trabalho apresenta-se não só nas características do componente desenvolvido como também no método da aplicação das técnicas de simulação no apoio ao projeto e à fabricação desse componente, como será visto adiante.

É importante ressaltar que este trabalho apresenta características originais, frutos de contribuições da autora. Primeiramente, a autora propõe nesse trabalho um projeto que desenvolve e fabrica moduladores eletro-ópticos adequados para serem usados nas atividades de pesquisas ligadas aos sensores que utilizam a técnica WLI. Também, está sendo proposta uma nova metodologia que define: tipos de materiais a serem usados nesse trabalho, uso de técnicas de simulação multifísicas avançadas, baseadas no Método dos Elementos Finitos (MEF), para a recaracterização dos materiais e definição da espessura dos eletrodos e dimensões dos canais do guia. Outra característica original do trabalho envolve utilizar interativamente a simulação com o processo de fabricação de guias de onda e moduladores eletro-ópticos. Os detalhes dessas partes do trabalho serão apresentados nos capítulos dedicados às descrições dos materiais e métodos e dos resultados experimentais.

\subsection{Objetivo}

Este trabalho tem como objetivo global apresentar o estudo de moduladores em óptica integrada com baixa birrefringência natural através de simulações multifísicas por MEF de guias de onda obtidos a partir de métodos de fabricação como o de estresse residual termicamente induzido, conhecido nos artigos e revistas internacionais do assunto como Induced Static Strain (ISS), utilizando como substrato materiais eletro-ópticos de retículo cúbico, especialmente o BGO.

Dessa forma, os objetivos específicos deste trabalho são:

1. Estudar o estado da arte de guias de onda do tipo canal e moduladores eletro-ópticos. 
2. Definir os materiais e a técnica a ser utilizada no estudo (simulação, projeto e fabricação do componente óptico).

3. Definir o programa de simulação numérica que resolva problemas multifísicos.

4. Simular numericamente moduladores eletro-ópticos baseados em guias de onda do tipo canal.

5. Fabricar e testar os guias de onda do tipo canal.

Como resultado, pretende-se aprimorar os conhecimentos do uso de modelagem, simulações multifísicas como ferramentas de auxílio interativo ao projeto de fabricação de guias ópticos, a serem aplicados na obtenção de moduladores eletro-óptico em óptica integrada com baixa tensão de modulação e livres de birrefringência natural.

Nesse sentido, em trabalhos futuros a serem realizados após a conclusão deste trabalho, pretende-se dar continuidade às atividades aqui descritas procurando alcançar os seguintes objetivos:

6. Caracterizar os guias de onda do tipo canal fabricados;

7. Utilizar iterativamente a simulação como ferramenta de apoio ao projeto e a fabricação dos guias de onda e do modulador;

8. Comparar as características dos guias de onda obtidos através dos resultados experimentais com os simulados.

\subsection{Estrutura do texto}

O trabalho é organizado nas seguintes etapas:

O capítulo 1 apresenta uma introdução ao panorama geral dos sistemas de sensoriamento óptico por WLI que estão sendo desenvolvidos pelo grupo de pesquisadores do qual a pesquisadora faz parte, ligado ao Laboratório de Sensores Ópticos (LSO) do Departamento de Engenharia e Energia e Automação Elétricas (PEA) da Escola Politécnica da Universidade de São Paulo (EPUSP), onde seu trabalho está inserido. Esta introdução pretende mostrar a motivação do interesse desse Departamento em apoiar este trabalho. 
O capítulo 2 apresenta uma revisão bibliográfica com o levantamento de técnicas e de desenvolvimentos que são usadas nas simulações numéricas e nos processos de fabricação de guias de onda do tipo canal e de moduladores eletro-ópticos em OI.

O capítulo 3 apresenta a metodologia aplicada neste trabalho: escolha dos materiais, definição das técnicas de fabricação dos componentes em OI, a escolha de um programa de simulação numérica apropriada para auxiliar o processo de fabricação.

O capítulo 4 apresenta as análises dos resultados simulados e dos experimentais.

O capítulo 5 apresenta as conclusões do trabalho e propostas de trabalhos futuros. 


\section{DISPOSITIVOS ÓPTICOS INTEGRADOS}

No início da década de 60, os lasers foram desenvolvidos para serem utilizados em várias aplicações científicas e também como fonte de luz estável e coerente em transmissão e processamento de sinais. Os feixes de luz emitidos pelos lasers podem ser transmitidos através do ar, mas suas características são alteradas por influências ambientais. Eles também podem ser usados em sistemas de processamento de sinais ópticos, porém, nesses casos, são necessários outros componentes ópticos, tais como, prismas, lentes, espelhos, moduladores ópticos, detectores, etc. A montagem desses sistemas, geralmente, acontece em ambientes de laboratórios, gerando arranjos delicados, volumosos, sensíveis a vibrações e a outras influências ambientais, o que dificulta o manuseio desses sistemas em lugares abertos e tornando-os não muito práticos [37]. No final daquela década surgiu o conceito de óptica integrada que está relacionado às tecnologias de filmes finos e de microfabricação de componentes eletrônicos integrados para caracterização e desenvolvimento de sistemas de guias de onda ópticos em pequenas dimensões [38]. A aplicação desse conceito veio possibilitar a miniaturização dos sistemas de processamentos de sinais ópticos, inclusive permitindo que esses sistemas pudessem executar funções de processamento mais complexas, o que torna viável a substituição de circuitos eletrônicos convencionais por circuitos ópticos integrados de pequenas dimensões [37] em aplicações ligadas à fotônica.

Em vários centros de pesquisa ao redor do mundo têm sido realizados desenvolvimentos envolvendo guias de onda em óptica integrada utilizando diferentes processos de fabricação tais como: wet etching [39], troca protônica [40, 41], litografia leve microfluídico assistida à vácuo [42], troca iônica [43].

Os guias são obtidos pela modificação de uma região pré-determinada do substrato onde se formará o guia, como mostra a Figura 7, ou seja, é alterado o índice de refração desta região para induzir o confinamento da luz. O material, as dimensões e a diferença de índices entre as regiões envolvidas são características muito importantes para um guia.

As técnicas de difusão de íons, implantação de íon e dopagem por difusão térmica são técnicas conhecidas como difusão de dopantes. As técnicas de migração de íons e de troca de íons são baseadas na migração de íons eletricamente induzida [37]. A técnica ISS [44, 45] será mencionada e detalhada no capítulo 2. As técnicas citadas acima, exceto a técnica ISS, 
são as mais conhecidas e muito utilizadas na fabricação de guias de onda ópticos em materiais monocristalinos.

Figura 7- Esquema simplificado das condições, necessárias, mas não suficientes, para formação de um guia de onda óptico.

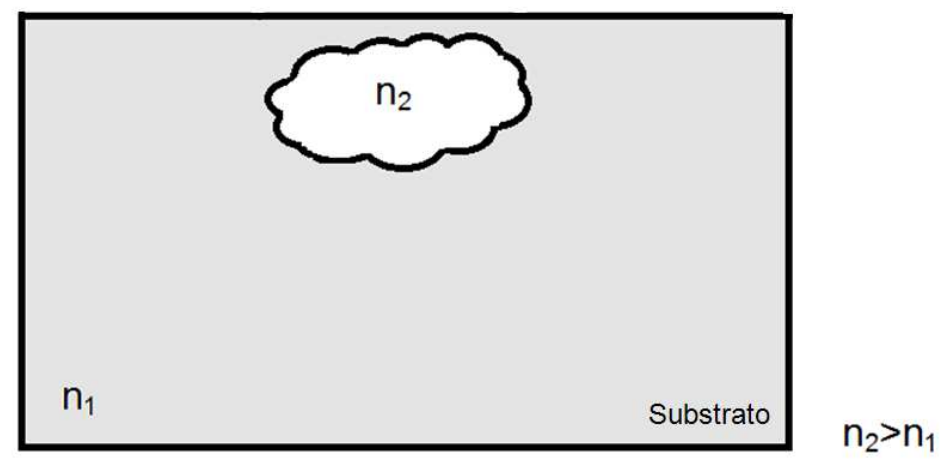

Fonte: Autora

A técnica de dopagem por difusão térmica, muito utilizada na fabricação de guias de ondas óptico em materiais monocristalinos, pode ser dividida em dois grupos: dopagem de materiais (difusão de um material em outro) e remoção de material do substrato. A Figura 8 ilustra a difusão térmica, como por exemplo, a que ocorre no caso do Titânio (Ti) em substrato de $\mathrm{LiNbO}_{3}$, originando um guia de onda do tipo canal que é formado pela diferença de índices de refração.

Figura 8- Formação de guia de onda óptico pela técnica de dopagem por difusão térmica
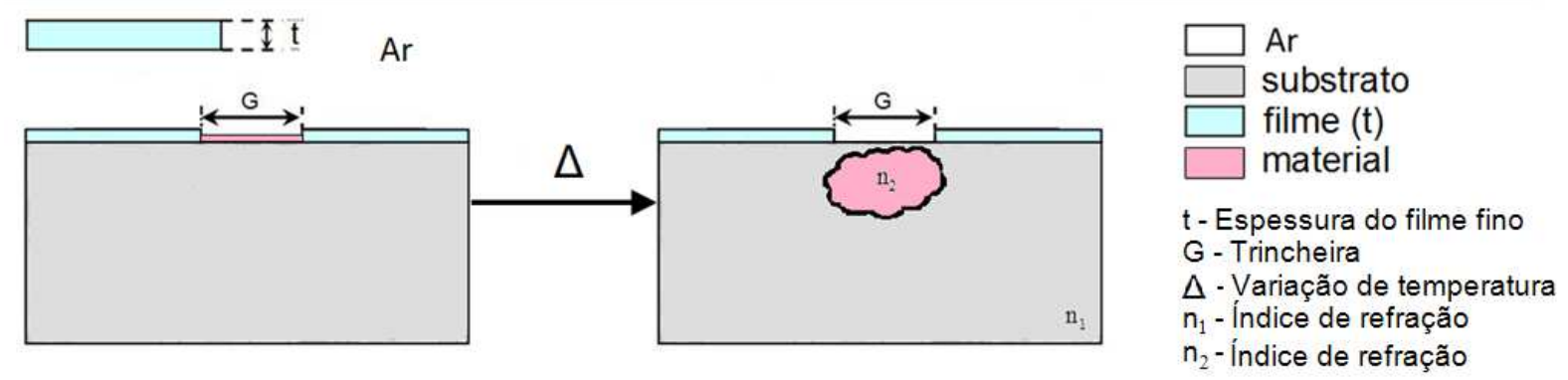

Fonte: Autora

As técnicas de deposição física a vapor (Physical Vapor Deposition - PVD) [46] e deposição química a vapor "Chemical Vapor Deposition" (CVD) [47] depositam camadas de filmes finos, que podem expandir-se ou contrair-se sobre o substrato dependendo da diferença entre as temperaturas de deposição e de utilização e da diferença dos coeficientes de expansão térmicas do filme e do substrato. 
A indústria de microeletrônica tem grande interesse em filmes finos de $\mathrm{SiO}_{2}$ de qualidade obtidos através da técnica de deposição química a vapor e aprimorados por exposição a plasma em baixas temperaturas [48, 49] (Plasma Enhanced Chemical Vapor Deposition PECVD). A técnica PECVD usa o tetraetilortossilicato (TEOS) como fonte de Si na fabricação de componentes microeletrônicos. Os filmes depositados por esta técnica apresentam boa aderência e uniformidade [50] e baixo teor tóxico [51].

Em 2002, Gonçalves usou a técnica ISS [35, 36] para fabricar guias de onda ópticos utilizando filmes de $\mathrm{SiO}_{2}$ depositados sobre substratos de $\mathrm{LiNbO}_{3}$. Essa técnica depende da diferença dos coeficientes de expansão térmica do substrato e do filme, que depende da diferença entre a temperatura de deposição e a temperatura de uso do componente $\left(\mathrm{T}_{1}-\mathrm{T}_{0}\right)$. Em geral, essa última é igual à temperatura ambiente. Foi demonstrado na literatura [52] que a aplicação dessa técnica apresentou bons resultados nas fabricações de guias e moduladores de luz integrados em vários tipos de substratos, incluindo materiais que exibem coeficientes eletro-ópticos elevadíssimos, tais como os Tetragonal Tungsten Bronze (TTN) [53].

No estudo de Gonçalves [54] foi relatado que os filmes de $\mathrm{SiO}_{2}$ apresentavam grande histerese na tensão mecânica em ciclos térmicos usando temperaturas até $400^{\circ} \mathrm{C}$, o que inviabiliza seu uso na fabricação de sensores de temperatura. Na sequência desse trabalho, obtiveram-se camadas bastante tensionadas a temperaturas relativamente baixas $\left(\mathrm{T}=360^{\circ} \mathrm{C}\right)$.

Porém, além do problema citado acima, o processo de deposição do filme $\mathrm{SiO}_{2}$ era considerado muito longo, em alguns caso levando até quinze horas [54]. Em vista disso ocorrem riscos elevados de interrupção durante o processo, o que dificulta a fabricação do componente.

Devido a esse problema, no início desse trabalho, foi realizada uma investigação das características de outros filmes candidatos a serem usados como camadas indutoras de tensão mecânica na fabricação de guias de onda sobre substratos de retículo cúbico, notadamente os BGOs, tais como o GreenTape, conhecido também como Low-Temperature Co-fired Ceramic (LTCC), e Óxido de Estanho e Índio (ITO). Detalhes desta investigação que levou à escolhas dos materiais empregados neste trabalho são relatados no capítulo 3, dedicado aos Materiais e Métodos. 


\subsection{Técnicas de fabricação de guias de onda do tipo canal}

Os guias de onda do tipo canal são muito usados na construção de componentes ópticos (acopladores direcionais, moduladores ópticos, interferômetros, etc.) que são adequados para compor sistemas de processamento de sinais ópticos, como os necessários em sistemas de sensoriamento a fibras ópticas.

Alguns exemplos de aplicações de guias de onda são:

- Modulação de características de feixes luminosos [4];

- Conexão entre componentes ópticos, que podem ser utilizados em circuitos integrados fotônicos [37];

- Separação e combinação de feixes de luz, que podem ser empregados, por exemplo, em interferômetros ópticos integrados [19].

Há várias técnicas para fabricação desses guias de onda, tais como: difusão de íons, implantação de íons, troca iônica, bombardeamento de prótons, crescimento epitaxial, ISS, etc. Essas técnicas tem demonstrado eficiência na fabricação de guias de onda em vários substratos. A escolha de uma técnica específica irá determinar o processo de fabricação e quais os recursos necessários, que deverão estar disponíveis no laboratório em que deseja-se realizá-la.

As técnicas de substituição introduzem átomos dopantes na estrutura do substrato, modificando seu o índice de refração. As técnicas desse tipo são: difusão de íons, implantação iônica, dopagem por difusão térmica, troca e migração iônica [33] e ISS [44, 45]. Já a técnica ISS está relacionada com a tensão mecânica, que deforma a estrutura cristalina dos materiais e modifica o índice de refração dos mesmos. Essa relação pode ser denominada de efeito elastoóptico, o qual é utilizado para criar a região de índice de refração aumentado que irá guiar a luz.

A escolha do substrato é muito importante, pois esta indicará qual a técnica mais apropriada para fabricação de guias de onda, como foi mencionado acima.

Como há dificuldade na fabricação de guias de ondas em materiais de retículo cúbico utilizando-se técnicas como a troca iônica e dopagem por difusão térmica [37], há tempos tem sido estudada pelos pesquisadores ligados ao LSO a técnica ISS [44, 45], que se mostra 
promissora para superar as dificuldades na fabricação de guias de ondas nesses materiais e, além disso, utiliza recursos de fabricação de componentes de microeletrônicos em Silício ( $\mathrm{Si}$ ), os quais são disponíveis no Laboratório de Sistemas Integráveis da Escola Politécnica da USP (LSI/EPUSP) que é parceiro do LSO em suas pesquisas. Esta é a técnica escolhida para fabricação dos componentes neste trabalho e será melhor detalhada no capítulo de materiais e métodos.

\subsection{Propagação de luz em guias de onda}

A propagação de ondas eletromagnéticas, em um dado meio, é descrita pelos vetores campo elétrico $(\mathbf{E})$ e campo magnético $(\mathbf{H})$, pela densidade de fluxo elétrico $(\mathbf{D})$ e pela densidade de fluxo magnético (B). Uma onda eletromagnética é usualmente representada de forma gráfica apenas pelos campos $E$ e $H$, que variam no tempo e no espaço perpendicularmente um ao outro, como ilustra a Figura 9 [4].

Figura 9- Distribuição do campo E e H em ondas eletromagnéticas a cada instante

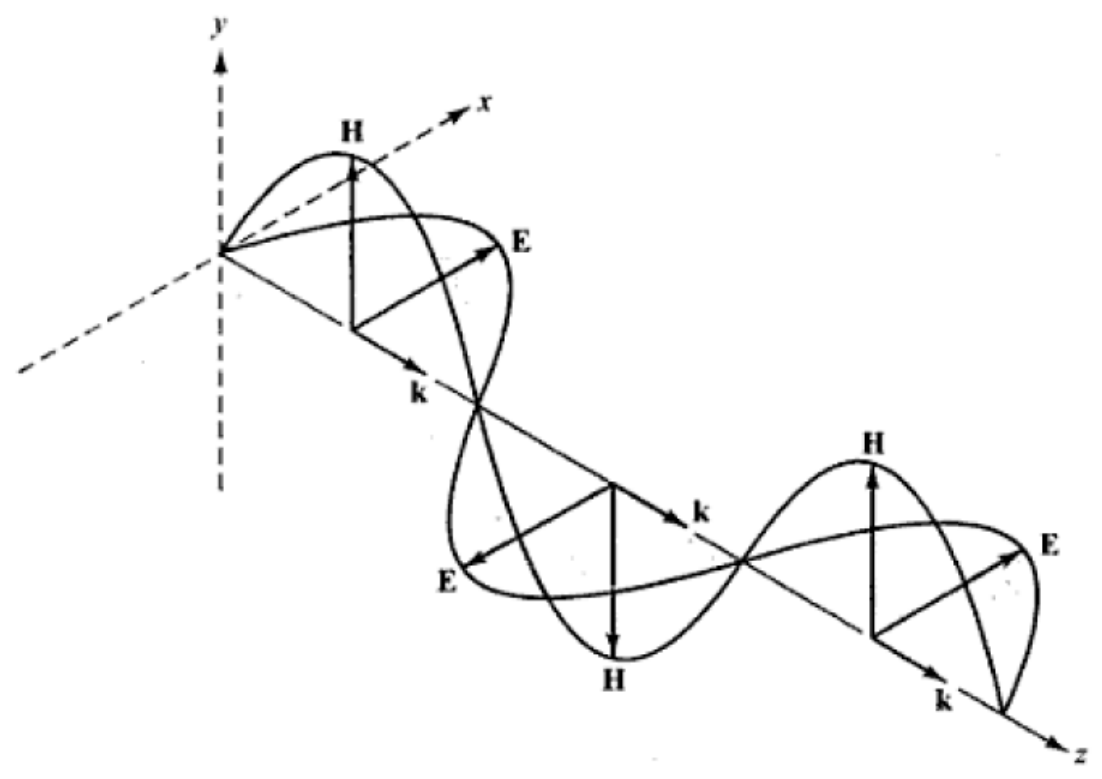

Fonte: [55]

No caso de uma onda óptica propagando-se na direção $z$ com seu vetor do campo elétrico $\boldsymbol{E}$ contido no plano perpendicular ao eixo $z$, pode-se considerar que o mesmo pode ser decomposto em duas componentes independentes da mesma frequência contidas no plano $x y$, uma paralela ao eixo $x$ e a outra paralela ao eixo $y$. Como pode-se demonstrar que duas ondas 
eletromagnéticas propagando-se na mesma direção com vetores de campo elétrico vibrando na mesma frequência em direções perpendiculares não se interferem [14], o estado de polarização de uma onda óptica composta por duas componentes ortogonais entre si pode ser definido pela adição vetorial dos campos elétricos dessas duas componentes. No caso mais genérico, a forma geométrica descrita pela ponta do vetor de campo $\boldsymbol{E}$ ao passar por um plano fixo perpendicular à direção de propagação é uma elipse. Num caso particular, supondo que as duas componentes do vetor de campo $\boldsymbol{E}$ sejam ortogonais e estejam em fase, a soma vetorial das amplitudes recairá em qualquer instante sobre um dado segmento de reta. Este estado de polarização é denominado linear. Noutro caso particular, supondo que as duas componentes do vetor de campo $\boldsymbol{E}$ sejam ortogonais, tenham amplitudes iguais e a diferença de fase entre elas seja um múltiplo de $\pi / 4$ radianos, a ponta do vetor resultante da soma das componentes percorrerá sempre um círculo. Neste caso o estado de polarização é denominado circular.[56, 57].

A aplicação da teoria eletromagnética de Maxwell que trata da propagação de ondas eletromagnéticas em meios guiados começou na área de micro-ondas, onde as paredes do guia são condutoras. Quando uma configuração espacial de campo é obtida a partir da solução das equações de Maxwell, satisfazendo as condições de contorno impostas pelo guia, é caracterizado um modo de propagação.

Segundo Pissolato Filho [55], a análise dos guias é feita utilizando-se as equações de Maxwell escritas no sistema de coordenadas adequado à forma geométrica da seção transversal dos guias de onda em estudo e impondo-se as condições de contorno fornecidas pelas paredes do guia.

As equações de Maxwell com variação temporal para os campos são definidas como:

$$
\begin{array}{cl}
\nabla \times \boldsymbol{E}+\frac{\partial \boldsymbol{B}}{\partial t}=0 & \text { (Lei de Faraday) } \\
\nabla \times \boldsymbol{H}-\frac{\partial \boldsymbol{D}}{\partial t}=\boldsymbol{J} & \text { (Lei de Ampere) } \\
\nabla . \boldsymbol{D}=\rho & \text { (Lei de Gauss para o campo elétrico) } \\
\nabla . \boldsymbol{B}=0 & \text { (Lei de Gauss para o campo magnético) }
\end{array}
$$


onde:

$\boldsymbol{E}$ é a intensidade de campo elétrico $(\mathrm{V} / \mathrm{m})$,

$\boldsymbol{D}$ é a densidade de fluxo elétrico $(\mathrm{C} / \mathrm{m})$,

$\boldsymbol{H}$ é a intensidade de campo magnético $(\mathrm{A} / \mathrm{m})$,

$\boldsymbol{B}$ é a densidade de fluxo magnético $\left(\mathrm{Wb} / \mathrm{m}^{2}\right)$,

$J$ é a densidade de corrente elétrica $\left(\mathrm{A} / \mathrm{m}^{2}\right)$,

$\rho$ é a densidade de carga elétrica $\left(\mathrm{C} / \mathrm{m}^{3}\right)$.

Como dito anteriormente, a onda eletromagnética é representada pelos campos elétricos e magnéticos que são perpendiculares entre si. Escolhendo um sistema cartesiano para representar as direções dos campos e supondo que a direção de propagação seja ao longo do eixo $\mathrm{z}$, as ondas chamadas transversais eletromagnéticas (TEM) apresentam $E_{z}=H_{z}=0$. Nesse caso, o campo elétrico pode ser encontrado através do gradiente transversal de uma função escalar $\Phi(x, y)$, que é dependente das coordenadas transversais e é solução da equação de Laplace em duas dimensões [58]:

$$
\nabla(\varepsilon \nabla \Phi)=0
$$

No caso das ondas transversais elétricas (TE), que apresentam $E_{z}=0$, mas $H_{z} \neq 0$, todas as componentes podem ser derivadas da componente axial do campo magnético. Para o caso, das ondas transversais magnéticas (TM), que têm $H_{z}=0$ mas $E_{z} \neq 0$, todas as componentes podem ser obtidas através da componente axial do campo elétrico.

Assumindo a propagação da luz ao longo do eixo z, a equação da onda para os modos transversais (TE e TM) é obtida através das equações de Maxwell livres de fontes de cargas e correntes internas, como descrito em [59]:

$$
\begin{gathered}
H_{i}=|H| e^{j(\omega t-\beta z)} \quad i=x, y, z \\
E_{i}=|E| e^{j(\omega t-\beta z)} \quad i=x, y, z \\
\nabla \times \boldsymbol{E}=-j \omega \mu \boldsymbol{H} \\
\nabla \times \boldsymbol{H}=j \omega \varepsilon \boldsymbol{E} \\
\nabla . \boldsymbol{H}=0 \\
\nabla \cdot(\varepsilon \boldsymbol{E})=0
\end{gathered}
$$


onde:

$\omega$ é a frequência angular, $\boldsymbol{E}$ e $\boldsymbol{H}$ são os campos elétrico e magnético, $\varepsilon$ e $\mu$ são a permissividade e a permeabilidade e $\beta$ é a constante de fase.

Substituindo as equações 2.6 e 2.7 nas equações $2.8,2.9,2.10$ e 2.11 , eliminado o fator $e^{j(\omega t-\beta z}$ e recombinando-as. As componentes do campo elétrico e magnético podem ser escritos como:

$$
\begin{aligned}
& H_{x}= \frac{j\left(\omega \varepsilon \frac{\partial E_{z}}{\partial y}-\beta \frac{\partial H_{z}}{\partial x}\right)}{\left(k^{2}-\beta^{2}\right)} \\
& H_{y}= \frac{-j\left(\omega \varepsilon \frac{\partial E_{z}}{\partial x}+\beta \frac{\partial H_{z}}{\partial y}\right)}{\left(k^{2}-\beta^{2}\right)} \\
& E_{x}=-j\left(\beta \frac{\partial E_{z}}{\partial x}+\omega \mu \frac{\partial H_{z}}{\partial y}\right) \\
& E_{y}= j\left(-\beta \frac{\partial E_{z}}{\partial y}+\omega \mu \frac{\partial H_{z}}{\partial x}\right) \\
&\left(k^{2}-\beta^{2}\right)
\end{aligned}
$$

onde $k^{2}=\omega^{2} \mu \varepsilon$.

As demais componentes são calculadas a partir das equações 2.12 a 2.15, e, portanto, considerando-se uma onda TE $\left(E_{z}=0\right)$, a equação de onda é obtida através de manipulações das equações anteriores, resultando em [58]:

$$
\left(\frac{\partial^{2}}{\partial x^{2}}+\frac{\partial^{2}}{\partial y^{2}}\right) H_{z}+\left(\omega^{2} \mu \varepsilon-\beta^{2}\right) H_{z}=0
$$

Realizando o mesmo procedimento de cálculo para obter a equação de onda para ondas TM $\left(H_{z}=0\right)$, resulta em: 


$$
\left(\frac{\partial^{2}}{\partial x^{2}}+\frac{\partial^{2}}{\partial y^{2}}\right) E_{z}+\left(\omega^{2} \mu \varepsilon-\beta^{2}\right) E_{z}=0
$$

As diversas configurações de campos eletromagnéticos dos modos TE, TM e, se existirem, TEM, além dos modos de radiação (radiation modes), modos híbridos e modos espúrios, constituem um conjunto de campos que pode descrever qualquer perturbação eletromagnética em um guia ou cavidade preenchido homogeneamente com material dielétrico [59].

Os modos TE e TM puros aparecem apenas em guias metálicos onde a guiagem é forte, ou seja, os campos elétricos e magnéticos da onda óptica diminuem rapidamente e praticamente não penetram nas regiões externas ao núcleo do guia. Nos guias ópticos dielétricos, formados por diferenças pequenas de índices de refração entre o núcleo o meio envolvente, transmitindo luz em comprimentos de onda curtos em relação às dimensões transversais do guia, a guiagem é fraca e há grande penetração dos campos guiados na região externa, sendo chamados de campos evanescentes. Nestas condições, é possível escolher a orientação do sistema de coordenadas de modo que o campo elétrico transverso seja primariamente paralelo a um dos eixos transversais [60]. No caso do campo elétrico ser paralelo ao eixo y os modos são denominados $E_{m n}^{y}$ e no caso do campo elétrico ser paralelo ao eixo $x$ os modos são denominados $E_{m n}^{x}$, onde os subscritos $m n$ são o número de máximos observados na amplitude do campo ao longo das direções de $x$ e $y$, respectivamente.

Koshiba [61] notou que os modos $E^{x}$ podem ser bem aproximados pelos modos quase-TE (para os quais $E_{y} \equiv 0$ ) e que os modos $E^{y}$ podem ser bem aproximados pelos modos quase-TM (para os quais $H_{y} \equiv 0$ ). Assim sendo, a equação de Helmholtz pode ser derivada pelas equações de Maxwell [62, 63].

Para chegar à equação de onda escalar, pode-se considerar o caso de uma onda propagando-se harmonicamente ao longo do eixo z num meio que obedece as seguintes condições:

- dielétrico e anisotrópico;

- meio não homogêneo e sem perdas;

- com permeabilidade magnética relativa $\mu_{r}=\mu_{0}$.

- tensor de permissividade relativa definido por: 


$$
\varepsilon_{r}=\left[\begin{array}{ccc}
n_{x}^{2}(x, y) & 0 & 0 \\
0 & n_{y}^{2}(x, y) & 0 \\
0 & 0 & n_{z}^{2}(x, y)
\end{array}\right]
$$

onde: $n_{x}, n_{y}$ e $n_{z}$ são os índices de refração nas direções cartesianas $x, y$ e $z$, na devida ordem.

Isolando $H_{y}, E_{z}$ e $H_{z}$ das equações de Maxwell para determinar equação de onda para os modos $E^{x}$ e realizar as substituições necessárias nos cálculos que resulta em:

$$
\frac{\partial}{\partial y}\left(\frac{\partial E_{y}}{\partial x}\right)-\frac{\partial^{2} E_{x}}{\partial y^{2}}-\frac{\partial}{\partial x}\left(\frac{1}{n_{z}^{2}} \frac{\partial\left(n_{x}^{2} E_{x}\right)}{\partial x}+\frac{1}{n_{z}^{2}} \frac{\partial\left(n_{y}^{2} E_{y}\right)}{\partial y}\right)=-\beta^{2} E_{x}+\omega^{2} \mu_{0} \varepsilon_{0} n_{x}^{2} E_{x}
$$

Desenvolvendo a equação 2.19 e usando a aproximação para modos quase-TE, é possível escrever a equação de onda escalar, a seguir:

$$
n_{z}^{2} \frac{\partial}{\partial x}\left(\frac{1}{n_{z}^{2}}\right) \frac{\partial\left(n_{x}^{2} E_{x}\right)}{\partial x}+\frac{\partial^{2}\left(n_{x}^{2} E_{x}\right)}{\partial x^{2}}+n_{z}^{2} \frac{\partial^{2} E_{x}}{\partial y^{2}}=n_{z}^{2} \beta^{2} E_{x}-k_{0}^{2} n_{x}^{2} n_{z}^{2} E_{x}
$$

onde:

$$
k_{0}^{2}=\omega^{2} \mu_{0} \varepsilon_{0}
$$

Isolando $\mathrm{E}_{y}, E_{z}$ e $H_{z}$ das equações de Maxwell para determinar equação de onda para os modos $E^{y}$ e realizar as substituições necessárias nos cálculos que resulta em:

$$
\frac{\partial^{2} H_{x}}{\partial x^{2}}+n_{y}^{2} \frac{\partial}{\partial y}\left(\frac{1}{n_{z}^{2}} \frac{\partial H_{x}}{\partial y}\right)-\beta^{2} H_{x}+n_{y}^{2} k_{0}^{2} H_{x}=0
$$

Para um caso ideal de guia de onda (geometria simples, como por exemplo, regiões do substrato, filme e a trincheira são representados por retângulos, e considerando as paredes externas do guia perfeitamente condutoras), os modos $E^{x}$ e $E^{y}$ são calculados de forma analítica através das equações 2.20 e 2.21. Para os casos em que os guias de ondas apresentam geometria complexa, várias características físicas e paredes do guia não perfeitamente condutoras, a melhor opção é usar os métodos numéricos para obtenção dos modos, como por exemplo, o Método dos Elementos Finitos (MEF) que será apresentado mais adiante. 


\subsubsection{Elipsoide de índices}

O efeito elasto-óptico em materiais acopla a deformação mecânica ao índice de refração óptico. Da mesma forma o efeito eletro-óptico acopla a influência de um campo elétrico externo ao índice de refração óptico. Ambos os efeitos podem ser descritos usando o conceito de elipsoide de índices.

O índice de refração $(n)$ que afeta uma luz incidente propagando em um meio anisotrópico, como por exemplo, em um cristal, dependerá tanto da polarização quanto da direção de propagação da luz. O índice de refração do cristal depende do tensor de impermeabilidade dielétrica $\left(\eta_{i j}\right)$, definido em função da permissividade $\left(\varepsilon_{i j}\right)$ como:

$$
\eta_{i j}=\varepsilon_{0}\left(\varepsilon^{-1}\right)_{i j}
$$

onde $\varepsilon_{0}$ é a permissividade do vácuo.

Como a polarização não é necessariamente paralela ao campo elétrico aplicado pela onda óptica $(\boldsymbol{E})$ e a suscetibilidade é um tensor, a equação que define a densidade de energia elétrica $\left(U_{e}\right)$, para um meio anisotrópico, sem perdas e homogêneo, é dada por [56, 57]:

$$
U_{e}=\frac{\varepsilon_{0}}{2} \sum_{i j} \eta_{i j}^{2} E_{i} E_{j}=\frac{1}{2} \sum_{i j} E_{i} \varepsilon_{i j} E_{j}=\frac{1}{2} \boldsymbol{E} . \boldsymbol{D}
$$

onde no termo à direita da equação aparece o vetor deslocamento elétrico $(\boldsymbol{D})$, cujas componentes são iguais às da polarização somadas às do campo elétrico afetadas pela permissividade, ou seja, $\boldsymbol{D}=\varepsilon_{0} \boldsymbol{E}+\boldsymbol{P}=\varepsilon_{i j} \boldsymbol{E}$.

Ao longo dos eixos principais do material, ou seja, as direções nas quais os campos $\boldsymbol{E}$ e $\boldsymbol{D}$ são paralelos, pode-se demonstrar que o tensor dielétrico é dado por:

$$
\varepsilon=\left[\begin{array}{ccc}
\varepsilon_{x} & 0 & 0 \\
0 & \varepsilon_{y} & 0 \\
0 & 0 & \varepsilon_{z}
\end{array}\right\rfloor
$$

onde: 


$$
\varepsilon_{x}, \varepsilon_{y} \text { e } \varepsilon_{z} \text { são as constantes dielétricas principais. }
$$

Num sistema de coordenadas cartesiano cujos eixos sejam paralelos aos eixos principais do cristal, uma superfície de densidade de energia constante no espaço $\boldsymbol{D}$ pode ser descrita como [57]:

$$
2 U_{e}=\frac{D_{x}^{2}}{\varepsilon_{x}}+\frac{D_{y}^{2}}{\varepsilon_{y}}+\frac{D_{z}^{2}}{\varepsilon_{z}}
$$

Como sobre a superfície definida por (2.25) $U_{e}$ é uma constante, o vetor posição de qualquer ponto sobre esta superfície é dado por: $\boldsymbol{r}=\boldsymbol{D} / \sqrt{2 \varepsilon_{0} U_{e}}$.

Definindo os índices de refração principais $n_{x}, n_{y}$ e $n_{z}$ por $n_{i}^{2}=\varepsilon_{i} / \varepsilon_{0}(i=x, y$ e $z)$, pode-se reescrever a equação (2.25) como sendo:

$$
\frac{x^{2}}{n_{x}^{2}}+\frac{y^{2}}{n_{y}^{2}}+\frac{z^{2}}{n_{z}^{2}}=1 .
$$

A equação 2.26 é denominada como elipsoide de índice não perturbado descrita num sistema de coordenadas cartesiano. A Figura 10 ilustra um elipsoide de índice genérico [56]. Esse elipsoide é utilizado para calcular os dois índices de refração e as duas direções de $\boldsymbol{D}\left(D_{1}\right.$ e $D_{2}$ ) associadas às duas ondas planas independentes que podem propagar-se ao longo de uma direção arbitrária $s$ de um cristal.

Figura 10- Elipsoide de índice e elipse definida pela interseção do mesmo com o plano normal a uma direção de propagação arbitrária $s$

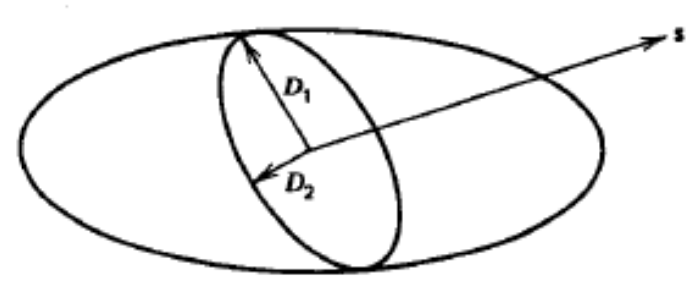

Fonte: [56]

Demonstra-se que [56] num sistema de coordenadas genérico, em que as componentes de um ponto arbitrário são $\xi_{1}, \xi_{2}, \xi_{3}$, o elipsoide de índice pode ser expresso por: 


$$
\sum_{\alpha, \beta=1}^{3} \eta_{\alpha \beta} \xi_{\alpha} \xi_{\beta}=1
$$

Utilizando a equação (2.27) o elipsoide de índice não perturbado, num sistema de coordenadas cartesianas, pode ser descrito como:

$$
\sum_{i . j=1}^{3} \eta_{i j} x_{i} x_{j}=1
$$

\subsection{Efeito elasto-óptico}

O efeito elasto-óptico em materiais acopla a deformação mecânica ao índice de refração óptico e esse efeito pode ser descrito usando o conceito de elipsoide de índices.

No caso da presença da perturbação mecânica, ou seja, um campo de deformação (S), o elipsoide de índice perturbado pode ser descrito através da mudança do tensor da impermeabilidade dielétrica, usando a notação de índices contraídos por [56]:

$$
\eta_{i j}(S)-\eta_{i j}(0) \equiv \Delta \eta_{i j}=p_{i j k l} \boldsymbol{S}_{k l}
$$

sendo:

$$
i, j, k, l=1,2, \ldots, 6 \text {. }
$$

onde:

- $\eta_{i j}$ é o tensor de impermeabilidade dielétrica

- $\Delta \eta_{i j}$ é a mudança na impermeabilidade dielétrica,

- $S_{k l}$ é o tensor de deformação,

- $p_{i j k l}$ são os coeficientes do tensor elasto-óptico (strain-optic tensor).

Ao longo dos eixos principais do material a equação acima, resulta em:

$$
\Delta \eta_{i j}=\Delta\left(\frac{1}{n^{2}}\right)_{i j}=p_{i j k l} S_{k l}
$$


Na equação 2.29, os termos de ordem mais elevada do tensor de deformação são desprezados, porque os mesmos são usualmente pequenos comparados com os termos lineares $\left(S_{k l} \sim\right.$ tipicamente $10^{-5}$ ).

Isolando-se o na equação (2.29) e substituindo-o na equação (2.28), o elipsoide de índices de um cristal afetado por um campo de deformações é dado por:

$$
\sum_{i, j=1}^{3}\left(\eta_{i j}(0)+p_{i j k l} S_{k l}\right) x_{i} x_{j}=1 .
$$

Quando o tensor de deformação é nulo $\left(S_{k l}=0\right)$, o índice de refração se reduz na equação 2.31. Desde que ambos os tensores $S_{k l}$ e $\eta_{i j}$ sejam simétricos, os índices $i$ e $j$, como também $k$ e $l$, da equação 2.30 podem ser permutados. A permutação simétrica do tensor, $p_{i j k l}$, é idêntica à utilizada no caso do tensor eletro-óptico quadrático $\left(S_{i j k l}\right)$ [56]. É, portanto, conveniente usar a forma contraída dos índices para abreviar a notação.

Nesse caso, equação 2.31 pode ser reescrita como:

$$
\Delta\left(\frac{1}{n^{2}}\right)_{i}=p_{i j} S_{j}
$$

onde:

$i, j=1,2, \ldots, 6$ e $S_{j}$ são as componentes de deformação. A equação do elipsoide de índices afetado por um campo de deformações pode ser descrita como:

$$
\begin{aligned}
& x^{2}\left(\frac{1}{n_{x}^{2}}+p_{11} S_{1}+p_{12} S_{2}+p_{13} S_{3}+p_{14} S_{4}+p_{15} S_{5}+p_{16} S_{6}\right) \\
& +y^{2}\left(\frac{1}{n_{y}^{2}}+p_{21} S_{1}+p_{22} S_{2}+p_{23} S_{3}+p_{24} S_{4}+p_{25} S_{5}+p_{26} S_{6}\right) \\
& +z^{2}\left(\frac{1}{n_{z}^{2}}+p_{31} S_{1}+p_{32} S_{2}+p_{33} S_{3}+p_{34} S_{4}+p_{35} S_{5}+p_{36} S_{6}\right) \\
& +2 y z\left(p_{41} S_{1}+p_{42} S_{2}+p_{43} S_{3}+p_{44} S_{4}+p_{45} S_{5}+p_{46} S_{6}\right) \\
& +2 z x\left(p_{51} S_{1}+p_{52} S_{2}+p_{53} S_{3}+p_{54} S_{4}+p_{55} S_{5}+p_{56} S_{6}\right) \\
& +2 x y\left(p_{61} S_{1}+p_{62} S_{2}+p_{63} S_{3}+p_{64} S_{4}+p_{65} S_{5}+p_{66} S_{6}\right)=1
\end{aligned}
$$


onde:

$n_{x}, n_{y}$ e $n_{z}$ são os índices de refração principais. Os coeficientes elasto-opticos, $p_{i j}$, são usualmente definidos no sistema de coordenadas principais do elipsoide de índices na presença do campo de deformação.

O novo elipsoide de índices afetado pelo campo de deformações é, em geral, diferente do elipsoide de índices na ausência do campo. O campo de deformações muda as dimensões e também as orientações da equação do elipsoide de índices. Essa mudança é dependente da aplicação do campo de deformações e dos coeficientes elasto-opticos, $p_{i j}$, de acordo com a equação 2.33. A forma, mas não a magnitude, dos coeficientes elasto-opticos, $p_{i j}$, pode ser derivada a partir de considerações de simetria do cristal. Essa simetria de grupo de ponto determina quais dos 36 coeficientes são nulos e as relações que possam existir entre os coeficientes não nulos. As formas dos coeficientes elasto-óptico em notação contraída para os cristais de simetria cúbica são apresentadas a seguir, [56].

Cristal cúbico, classe $23, \mathrm{~m} 3$

$$
\left[\begin{array}{cccccc}
p_{11} & p_{12} & p_{21} & 0 & 0 & 0 \\
p_{21} & p_{11} & p_{12} & 0 & 0 & 0 \\
p_{12} & p_{21} & p_{11} & 0 & 0 & 0 \\
0 & 0 & 0 & p_{44} & 0 & 0 \\
0 & 0 & 0 & 0 & p_{44} & 0 \\
0 & 0 & 0 & 0 & 0 & p_{44}
\end{array}\right]
$$

Cristal cúbico, classe $\overline{4} 3 \mathrm{~m}, 432, \mathrm{~m} 3 \mathrm{~m}$

$$
\left[\begin{array}{cccccc}
p_{11} & p_{12} & p_{12} & 0 & 0 & 0 \\
p_{12} & p_{11} & p_{12} & 0 & 0 & 0 \\
p_{12} & p_{12} & p_{11} & 0 & 0 & 0 \\
0 & 0 & 0 & p_{44} & 0 & 0 \\
0 & 0 & 0 & 0 & p_{44} & 0 \\
0 & 0 & 0 & 0 & 0 & p_{44}
\end{array}\right]
$$

onde:

$p_{11}, p_{21}, p_{12}$ e $p_{44}$ são os coeficientes elasto-óptico do cristal.

A relação entre tensão-deformação (stress-strain) em materiais isotrópicos, sem estresse inicial, é dada por [45]: 


$$
\boldsymbol{T}=\boldsymbol{D}(\boldsymbol{S}-\alpha \cdot \Delta T)
$$

onde:

- $\boldsymbol{T}$ é a tensão mecânica (stress),

- $\boldsymbol{D}$ é a matriz de elasticidade,

- $\boldsymbol{S}$ é a deformação (strain),

- $\alpha$ é o coeficiente de expansão térmica,

- $\Delta T$ é a variação de temperatura.

Dependendo do deslocamento global, a deformação pode ser representada na forma de deformação normal (normal strain) para os índices (1, 2 e 3) e na forma de tensor de cisalhamento (shear tensor) para os índices (4, 5 e 6$)$.

As componentes de deformação normal e os componentes do tensor de cisalhamento vêm do deslocamento global $(u, v, w)$, definido em um sistema de coordenadas cartesianas $X, Y$ e $Z$ como:

$$
\begin{gathered}
\text { Deformação normal }\left\{S_{1}=\frac{\partial u}{\partial x}, \quad S_{2}=\frac{\partial v}{\partial y} \quad \text { e } \quad S_{3}=\frac{\partial w}{\partial z}\right. \\
\text { Tensor de cisalhamento: } \\
\left\{S_{4}=\frac{1}{2}\left(\frac{\partial v}{\partial z}+\frac{\partial w}{\partial y}\right), \quad S_{5}=\frac{1}{2}\left(\frac{\partial u}{\partial z}+\frac{\partial w}{\partial x}\right) \quad \text { e } \quad S_{6}=\frac{1}{2}\left(\frac{\partial u}{\partial y}+\frac{\partial v}{\partial x}\right)\right.
\end{gathered}
$$

A condição de deformação plana prevalece em geometrias cuja extensão é grande numa direções, por exemplo, $z$, comparada com as dimensões nas outras direções, por exemplo, $x \mathrm{e}$ $y$. Na deformação plana assume-se que $S_{3}, S_{4}$ e $S_{5}$ são nulos.

No capítulo de materiais e métodos será apresentado o uso da teoria do efeito elasto-óptico nas modelagens do elipsoide de índices desses cristais e serão implementadas em um programa computacional numérico.

\subsubsection{Efeito eletro-óptico}

A equação 2.22 define o tensor de impermeabilidade dielétrica $\eta_{i j}$, como já apresentado na seção sobre elipsoide de índice, sem perturbação. Considerando o efeito eletro-óptico, que se 
manifesta nos materiais em que a presença de um campo elétrico externo $\boldsymbol{E}$ provoca uma perturbação do tensor de impermeabilidade dielétrica $\eta_{i j}$, a equação 2.22 pode ser redefinida como:

$$
\eta_{i j}(\boldsymbol{E})-\eta_{i j}(0) \equiv \Delta \eta_{i j}=r_{i j k} \boldsymbol{E}_{k}+s_{i j k l} \boldsymbol{E}_{k} \boldsymbol{E}_{l}=f_{i j k} \boldsymbol{P}_{k}+g_{i j k l} \boldsymbol{P}_{k l}
$$

onde

$\boldsymbol{E}$ é o campo elétrico aplicado e $\boldsymbol{P}$ é o vetor de campo de polarização elétrica. As constantes $r_{i j k}$ e $f_{i j k}$ são os coeficientes eletro-ópticos lineares e $s_{i j k l}$ e $g_{i j k l}$ são os coeficientes eletro-ópticos quadráticos [56].

Nesse trabalho serão usados apenas materiais que apresentam efeito eletro-óptico linear. Nesse caso, os coeficientes eletro-ópticos quadráticos são desprezados.

\subsubsection{Efeito eletro-óptico linear}

O efeito eletro-óptico linear é representado partindo-se da equação 2.39, na qual o termo linear, que envolve os coeficientes $r_{i j k}$, relaciona o campo $\boldsymbol{E}$ com o tensor de impermeabilidade $\left(\eta_{i j}\right)$, e desprezando-se os termos quadráticos. Este efeito é também conhecido como efeito Pockels. Na maioria das aplicações o termo quadrático é desprezado, pois o mesmo é muito pequeno comparado ao termo linear.

Partindo-se da equação 2.28 e considerando-se o efeito eletro-óptico linear, o elipsoide de índices de um cristal afetado pelo campo elétrico aplicado é dado por:

$$
\sum_{i, j=1}^{3} \eta_{i j}(\boldsymbol{E}) x_{i} x_{j}=1
$$

Caso o meio tenha poucas perdas e não exiba atividade óptica, o tensor dielétrico $\varepsilon_{i j}$ pode ser descrito por um tensor simétrico e, portanto, o $\eta_{i j}$ também é descrito como um tensor simétrico [56]. Logo, os índices $i$ e $j$ da equação 2.39 podem ser permutados. Usando a notação de índices contraídos na forma reduzida pela permutação simétrica é possível obter os seguintes coeficientes eletro-ópticos lineares: 


$$
\begin{aligned}
& r_{1 k}=r_{11 k}, \\
& r_{2 k}=r_{22 k}, \\
& r_{3 k}=r_{33 k}, \\
& r_{4 k}=r_{23 k}=r_{32 k}, \\
& r_{5 k}=r_{13 k}=r_{31 k}, \\
& r_{6 k}=r_{12 l k}=r_{21 k} .
\end{aligned}
$$

onde

$$
k=1,2,3 .
$$

Isolando-se o $\eta_{i j}(\boldsymbol{E})$ na equação (2.39) e substituindo-o na equação (2.40), o elipsoide de índices de um cristal eletro-óptico afetado por um campo elétrico externo é dado por:

$$
\sum_{i, j=1}^{3}\left(\eta_{i j}(0)+r_{i j k} E_{k}\right) x_{i} x_{j}=1
$$

Expandindo a equação 2.42 e utilizando a notação contraída, a equação do elipsoide de índice afetado por um campo elétrico externo resulta em:

$$
\left(\frac{1}{n_{x}^{2}}+r_{1 k} E_{k}\right) x^{2}+\left(\frac{1}{n_{y}^{2}}+r_{2 k} E_{k}\right) y^{2}+\left(\frac{1}{n_{z}^{2}}+r_{3 k} E_{k}\right) z^{2}+2 y z r_{4 k} E_{k}+2 z x r_{5 k} E_{k}+2 x y r_{6 k} E_{k}=1 .
$$

onde

$E_{k}(k=1,2$ e 3$)$ são as componentes do campo elétrico aplicado; 1, 2 e 3 são os índices correspondentes aos eixos principais do dielétrico $x, y$ e $z$; e $n_{x}, n_{y}$ e $n_{z}$ são os índices de refração.

A dimensão e a orientação do elipsoide de índices são dependentes do módulo da direção do campo aplicado e também dos elementos da matriz do tensor eletro-óptico do material. Essa matriz pode possuir elementos (ou coeficientes) nulos e não nulos, dependendo de condições fixadas pela simetria do retículo cristalino do material [65].

A forma dessa matriz, em notação contraída, para os cristais cúbicos é apresentada como [56]: 


\section{$\overline{4} 3 m, 23$}

$$
\left(\begin{array}{ccc}
0 & 0 & 0 \\
0 & 0 & 0 \\
0 & 0 & 0 \\
r_{41} & 0 & 0 \\
0 & r_{41} & 0 \\
0 & 0 & r_{41}
\end{array}\right)
$$

onde

$r_{41}$ é o coeficiente eletro-óptico relevante do cristal.

No capítulo de materiais e métodos será apresentado o uso da teoria do efeito eletro-óptico na modelagem do elipsoide de índice desse cristal implementada em um programa computacional de simulação numérica.

\subsection{Moduladores ópticos}

Os moduladores ópticos são dispositivos que permitem alterar uma propriedade detectável do feixe de luz em resposta de um sinal aplicado. Essas propriedades são: intensidade (amplitude), fase, polarização, frequência [51] e o espectro óptico [52]. Os moduladores podem ser classificados de acordo com a natureza do sinal aplicado, existindo vários tipos deles, tais como, acusto-ópticos, eletro-ópticos, magneto-ópticos, etc.

Os moduladores eletro-óptico podem ser baseados em dois tipos de efeitos eletro-ópticos, o linear e o quadrático, sendo que ambos podem ser definidos como alterações nas propriedades ópticas de um material induzidas por um campo elétrico aplicado externamente [66]. O quadrático é conhecido como efeito Kerr, no qual a variação do índice de refração do material é proporcional ao quadrado do campo elétrico aplicado [57]. O linear é conhecido como efeito Pockels, no qual a variação do índice de refração é diretamente proporcional ao campo elétrico externo [57]. Nye explica que esse efeito é observado exclusivamente em sólidos cristalinos que não sejam centro simétricos [67].

As estruturas básicas dos moduladores podem ser classificadas em três tipos como sendo, volumétrica, guia de onda planar e guia de onda do tipo canal, como mostra a Figura 11 [37]. 
Figura 11- Estruturas básicas de moduladores eletro-ópticos; a) volumétrica; b) guia de onda planar; c) guia de onda do tipo canal.

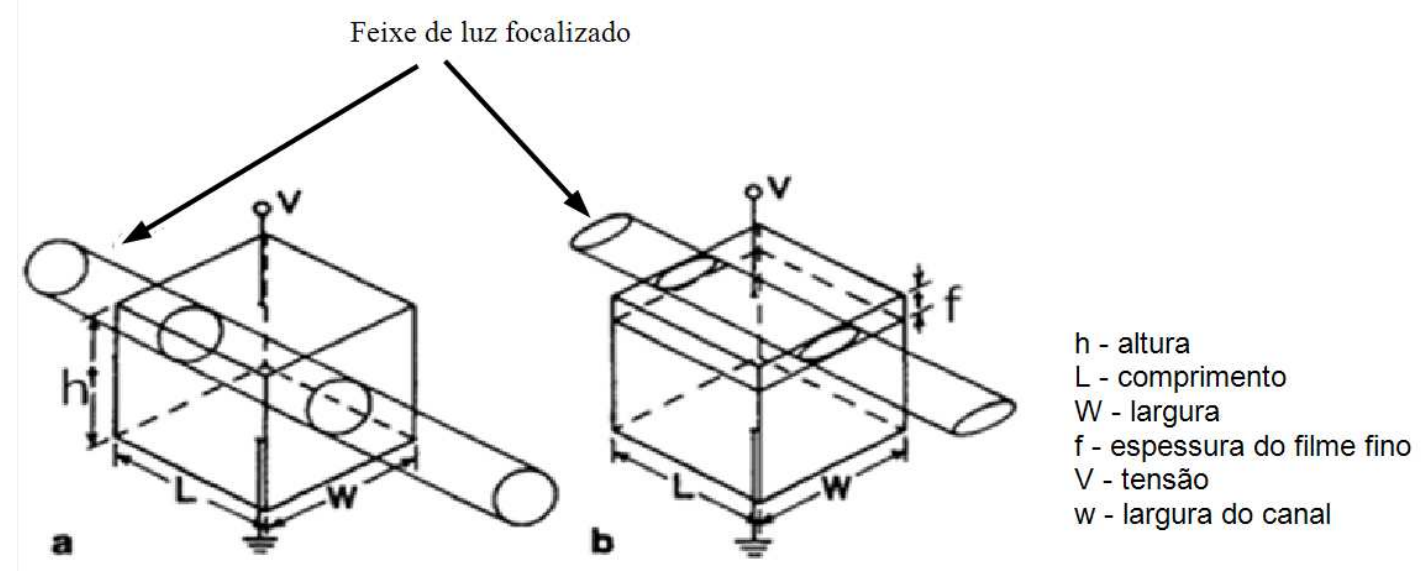

Fonte: Baseado e modificado em [37]]

A Figura 12, a seguir, mostra os moduladores eletro-ópticos volumétricos em configuração transversal que podem ser usados como moduladores de polarização ou de fase. Um material normalmente usado nesses moduladores é o cristal de $\mathrm{LiNbO}_{3}$ [66].

Figura 12- Modulador eletro-óptico volumétrico típico em configuração transversal.

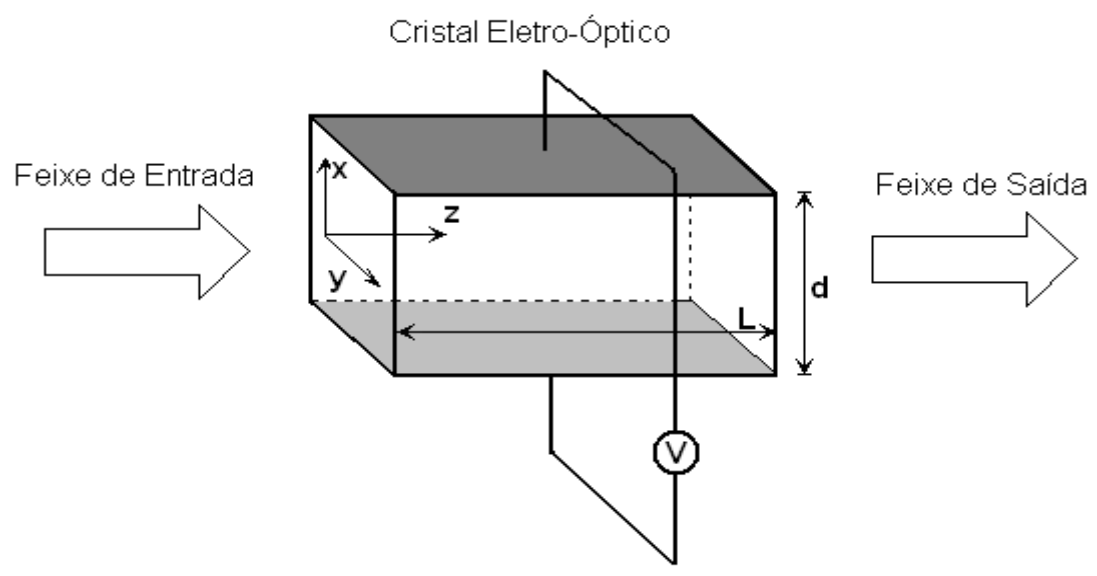

Fonte: Baseado em [2].

Quando os eletrodos, mostrados na Figura 12, são submetidos a uma tensão modulante, geram um campo elétrico que penetra na região do campo óptico, modificando a permissividade elétrica do material. Esta interação afeta as características de propagação da onda óptica e permite a sua modulação [68-70]. 
Frequentemente são usados materiais com efeito óptico linear (efeito Pockels) pronunciado na fabricação de moduladores eletro-ópticos, tais como, cristais de $\mathrm{LiNbO}_{3}$ e de Tantalato de Lítio $\left(\mathrm{LiTaO}_{3}\right)$.

\subsubsection{Tensão de meia onda $\left(V_{\pi}\right)$ de moduladores eletro-ópticos}

A Figura 12 apresenta um esquema de um modulador eletro-óptico volumétrico em configuração transversal, na qual ocorre uma interação da luz com um campo elétrico aplicado ao longo de uma direção perpendicular à da sua propagação. Considerando somente o efeito eletro-óptico linear, a mudança do índice de refração induzido pelo campo elétrico é proporcional ao campo elétrico.

Nesse trabalho foram escolhidos materiais eletro-ópticos cristalinos de retículo cúbico, os quais são opticamente isotrópicos (não apresentam birrefringência) e, portanto, tem um grande campo de aplicação em muitos sistemas ópticos [56]. Eles apresentam eixos de simetria nas direções: $\langle 100\rangle,\langle 010\rangle$ e $\langle 001\rangle$ e eixos de simetria nas direções: $\langle 111\rangle,\langle\overline{1} 11\rangle$, $\langle 1 \overline{1} 1\rangle,\langle 11 \overline{1}\rangle$.

Para o cristal de $\mathrm{Bi}_{4} \mathrm{Ge}_{3} \mathrm{O}_{12}$, aplicando a matriz 2.44 na equação 2.43, o elipsoide de índices perturbado é apresentado como:

$$
\frac{x^{2}+y^{2}+z^{2}}{n^{2}}+2 r_{41}\left(y z E_{x}+z x E_{y}+x y E_{z}\right)=1
$$

onde

$E_{x}, E_{y}$ e $E_{z}$ são as componentes do campo elétrico ao longo dos eixos do cristal e $r_{41}$ é o coeficiente eletro-óptico relevante.

Nesse caso, as variáveis $\mathrm{x}, \mathrm{y}, \mathrm{e} \mathrm{z}$ são acopladas, pois existem termos cruzados. A equação 2.45, na sua forma diagonal, é obtida através dos seguintes autovalores: 


$$
\left(\begin{array}{ccc}
\frac{1}{n^{2}} & r_{41} E_{z} & r_{41} E_{y} \\
r_{41} E_{z} & \frac{1}{n^{2}} & r_{41} E_{x} \\
r_{41} E_{y} & r_{41} E_{x} & \frac{1}{n^{2}}
\end{array}\right) \boldsymbol{V}=\frac{1}{n^{\prime 2}} \boldsymbol{V}
$$

Adotando os autovetores $\boldsymbol{V}$ como novos eixos principais e os autovalores $n^{\prime}$ como novos índices de refração principais, escolhendo o campo elétrico na direção $\langle 110\rangle$, admitindo $E$ como intensidade do campo e substituindo os componentes na equação 2.46 , resulta em:

$$
\left(\begin{array}{ccc}
\frac{1}{n^{2}}-\frac{1}{n^{\prime 2}} & 0 & \frac{1}{\sqrt{2}} r_{41} E_{y} \\
0 & \frac{1}{n^{2}}-\frac{1}{n^{\prime 2}} & \frac{1}{\sqrt{2}} r_{41} E_{x} \\
\frac{1}{\sqrt{2}} r_{41} E_{y} & \frac{1}{\sqrt{2}} r_{41} E_{x} & \frac{1}{n^{2}}-\frac{1}{n^{\prime 2}}
\end{array}\right)=0
$$

A solução dessa equação são os índices de refração principais, dados por:

$$
\begin{aligned}
& n_{x^{\prime}}=n+\frac{1}{2} n^{3} r_{41} E, \\
& n_{y^{\prime}}=n-\frac{1}{2} n^{3} r_{41} E, \\
& n_{z^{\prime}}=n .
\end{aligned}
$$

O atraso de fase $\Gamma_{o p}$ é definido por:

$$
\Gamma_{o p}=\frac{2 \pi}{\lambda} n^{3} r_{41}\left(\frac{L}{d}\right) V .
$$

Impondo o atraso de fase $\Gamma_{o p}=\pi$ na equação 2.49 , a tensão de meia onda $V_{\pi}$ é escrita como:

$$
V_{\pi}=\frac{d}{L} \cdot \frac{\lambda}{2 n^{3} r_{41}} .
$$

A tensão de meia onda $V_{\pi}$ é um índice de mérito usado para caracterizar moduladores eletroópticos quanto à sua sensibilidade ao campo elétrico aplicado. Como nesse trabalho, pretende- 
se usar esse tipo de modulador como interferômetro recuperador em sistemas WLI, é interessante que o valor de $V_{\pi}$ seja o menor possível.

\subsection{Moduladores eletro-ópticos baseados em guias de onda do tipo canal em óptica integrada}

Moduladores baseados em guias de ondas do tipo canal podem ser utilizados como componentes fundamentais em sistemas de telecomunicações ópticas de alto desempenho [58], em interferômetros sensores [10] e interferômetros recuperadores [1].

No Brasil, alguns grupos de pesquisadores têm utilizado moduladores em OI baseados em $\mathrm{LiNbO}_{3}$ em suas pesquisas. O Departamento de Eletrônica Quântica da UNICAMP (DEQ/IFGW) [71] foi um dos grupos que se destacou no estudo de fenômenos ópticos com tempo de duração ultra-curto em telecomunicação ou receptores ópticos com taxa elevada de transmissão.

O grupo de sensores ópticos no IEAv-DCTA (Instituto de Estudos Avançados - Departamento de Ciência e Tecnologia Aeroespacial) [72] sobressaiu-se usando os moduladores eletroópticos integrados comerciais como componente de sistemas de sensores para giroscópios a fibra óptica. Nesse caso, o interesse estava concentrado na largura de faixa disponível, baixa deriva térmica, tamanho reduzido, robustez e a confiabilidade de moduladores eletro-ópticos integrados, comparados aos moduladores ópticos de fase tradicionais, baseados em fibras ópticas enroladas em cilindros de materiais piezo-elétricos [73].

Desde a década de 90, o grupo do Laboratório de Micro-elerônica da Escola Politécnica da Universidade de São Paulo (LME-EPUSP) vem desenvolvendo técnicas de fabricação e implementação de moduladores eletro-ópticos para aplicações em sistemas de comunicação óptica. Esse grupo enfatizou a técnica de difusão de titânio na fabricação de guias ópticos e o grupo de sensores do IEAv/DCTA desenvolveu pesquisas na fabricação de moduladores usando a técnica de troca de prótons [74].

O grupo LSI/EPUSP tem usado a técnica de deposição química a vapor a baixa pressão (LPCVD) para depositar filmes finos de Nitreto de Silício $\left(\mathrm{Si}_{3} \mathrm{~N}_{4}\right)$ [75] e pela técnica de crescimento térmico (Plasma-enhanced chemical vapor deposition - PECVD) para depositar 
filmes de $\mathrm{SiO}_{2}$. A definição das trincheiras dos guias é realizada pelos processos convencionais de litografia e corrosão.

Assim como ocorre com os guias de onda, pesquisas ligadas ao desenvolvimento de moduladores elétro-opticos em OI tem sido realizadas por diversos grupos de pesquisa ao redor do mundo. Entre estes desenvolvimentos podem ser citados vários casos de interesse, como por exemplo: Toney, J. E., et al., relata o projeto, a fabricação e os testes de moduladores eletro-ópticos em Niobato de Lítio, para uma faixa de frequência de 40 a 60 Ghz.[76], Kim, J.W., et al, apresentaram uma abordagem de controladores de polarização ópticos integrados que são formados por três moduladores de birrefringência [77], Chmielak B., et al. demonstrou pela primeira vez que os Moduladores eletro-ópticos baseados em guias de onda do tipo rib deformados [78]; entre outros.

O grupo LSO/EPUSP está interessado em moduladores baseados em substratos eletro-ópticos que idealmente não exibem birrefringência natural, pois necessitam de moduladores para compor os interferômetros recuperadores de sistemas de sensoriamento baseados em WLI. Materiais desse tipo tem simetria cristalina cúbica, tais como, $\mathrm{Bi}_{4} \mathrm{Ge}_{3} \mathrm{O}_{12}, \mathrm{Bi}_{12} \mathrm{GeO}_{20}$, Silicato de Bismuto ( $\left.\mathrm{Bi}_{4} \mathrm{Si}_{3} \mathrm{O}_{12}\right)$, Óxido de Silício e Bismuto $\left(\mathrm{Bi}_{12} \mathrm{SiO}_{20}\right)$ e Óxido de Titânio e Bismuto $\left(\mathrm{Bi}_{12} \mathrm{TiO}_{20}\right)$.

A fabricação desses moduladores pode ser realizada usando uma das técnicas de deposição de eletrodos paralelos a guias de onda obtidos através da técnica ISS, como foi mencionado anteriormente. O processo de fabricação desses moduladores é detalhado no capítulo de materiais e métodos.

O modulador eletro-óptico volumétrico utilizado como interferômetro recuperador no trabalho de Pinheiro [1] apresentava características inadequadas, tais como: elevados valores de $V_{\pi}$, sensibilidade a vibrações mecânicas, baixa imunidade eletromagnética, dificuldade de conectorização, alta sensibilidade à variação da temperatura, montagem volumétrica e delicada, necessidade de alinhamento axial e angular precisos entre os componentes ópticos, etc.

As vantagens de usar um modulador em OI como interferômetro recuperador no sistema WLI são: melhor desempenho, menores perdas globais de intensidade óptica, menores dimensões, menor peso, montagem mecanicamente mais estável, maior facilidade de conectorização, 
maiores imunidade eletromagnética e melhor estabilidade térmica. Pinheiro [1] destacou em seu trabalho algumas alternativas para a implementação do interferômetro recuperador com baixa tensão de meia onda. Entre essas alternativas foram encontradas as topologias que empregam a construção de moduladores eletro-ópticos baseados em OI. Pinheiro optou por construir um interferômetro de Michelson a partir de um dispositivo modulador eletro-óptico em OI composto por uma junção em Y com trechos de fibras ópticas instalados em seus acessos (rabichos, ou em inglês pigtails).

Um dos interesses, nesse trabalho, está ligado às necessidades levantadas por Pinheiro [1] de eliminar ou minimizar o elevado valor de $V_{\pi}$ do modulador, uma vez que esse parâmetro dificulta a implementação da unidade de processamento eletrônico de sinais, que trabalha conectada ao interferômetro recuperador.

O dispositivo modulador de fase eletro-óptico comercial em OI escolhido por Pinheiro [1], foi modificado para operar como um interferômetro de Michelson de braços desbalanceados. Ele encontrou dificuldades na realização da montagem do interferômetro recuperador e, também, no processo de sua modificação do componente, pois a montagem continua sendo delicada, tendo perdas de inserção consideráveis, apresentando sensibilidade à temperatura comparável à das montagens volumétricas e sensibilidade a vibrações mecânicas consideráveis. Além das dificuldades apresentadas acima, esse componente, que foi modificado, não é um produto nacional. Isso implica em sua indisponibilidade nesse mercado, o que acarreta em custos mais elevados associados à importação.

O modulador proposto por Pinheiro [1], não é um modulador eletro-óptico birrefringente e continua com problemas de sensibilidade à temperatura e às vibrações mecânicas; sendo que ele não atende às necessidades da pesquisa de sistemas de processamento de sinais ópticos realizada pelo LSO/PEA/EPUSP. Por estes motivos justifica-se, nesse trabalho, a importância de desenvolver e fabricar um modulador eletro-óptico de birrefringência do tipo canal em OI que tenha as seguintes características: resposta rápida, baixas perdas por inserção, pequenas dimensões, baixo peso, montagem mecanicamente estável, facilidade de conectorização, imunidade eletromagnética, estabilidade térmica.

Com um protótipo desse modulador pronto (um componente), será possível testá-lo e implementá-lo no interferômetro recuperador de sistemas de sensoriamento baseados em WLI. Após esses testes realizados no LSO, afim de transformar esse componente em um 
produto disponível no mercado nacional, será de grande importância encontrar uma empresa brasileira que esteja disposta a participar um processo de transferência de tecnologia, investir na fabricação do mesmo e comercializá-lo a preços acessíveis.

A fabricação de um modulador eletro-óptico focada nas características desejáveis, citadas acima, para aplicação no protótipo de TPO para medição de altas tensões em desenvolvimento no LSO, levou a uma análise de técnicas de fabricação de componentes em OI e à procura de parceros para fabricá-los.

Baseando-se nessas características, fixou-se o objetivo de fabricar moduladores eletro-ópticos baseados em guias de onda do tipo canal em OI, como mostra a Figura 13 a seguir.

\section{Figura 13- Representação do modulador eletro-óptico baseado em guia de onda do tipo canal em OI}
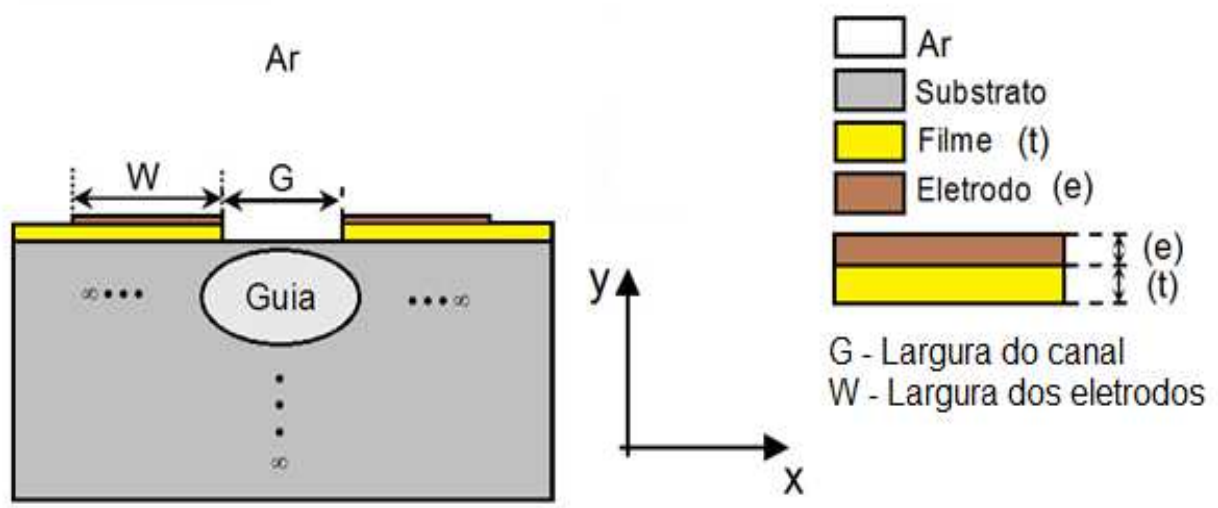

\section{Fonte: Autora}

Numa estrutura como apresentada a Figura 13, quando se aplica uma tensão nos eletrodos aparece um campo elétrico que irá produzir modulação do índice de refração do material do substrato pelo efeito eletro-óptico. Fazendo-se uma simulação computacional pode-se mapear o campo elétrico presente nessa estrutura. Na Figura 14 são observadas as representações do vetor de um campo elétrico local perpendicular a direção de propagação do campo óptico que caracteriza um modulador eletro-óptico transversal baseado em guias de onda do tipo canal. 
Figura 14- Campo elétrico no modulador eletro-óptico baseado em guias de onda do tipo canal em OI.

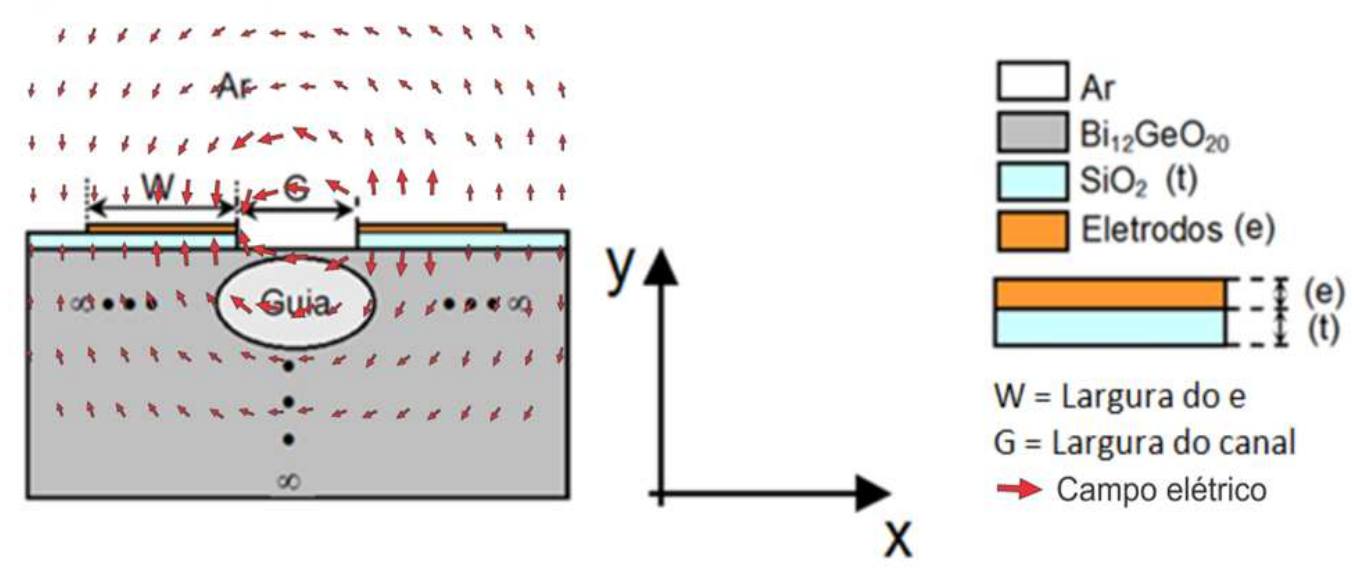

Fonte: Autora

É possível definir uma grandeza $V_{\pi}$ para os moduladores eletro-ópticos em OI de forma similar à definida para moduladores volumétricos, como apresentada anteriormente. Nesse caso, porém, como o campo elétrico e os campos ópticos não são uniformes, torna-se necessário calcular o fator integral de sobreposição $\left(\Gamma_{s o b}\right)$ do campo elétrico com o campo óptico. Essa integral é conhecida como integral de overlap e é definida por [79-82]:

$$
\Gamma_{s o b}=\frac{G}{V} \frac{\iint E_{o p}^{2}(x, y) E_{e l}(x, y) d x d y}{\iint E_{o p}^{2}(x, y) d x d y},
$$

Como não é possível resolver analiticamente a integral de sobreposição, a mesma será calculada usando um método numérico, como por exemplo, o MEF.

Moduladores deste tipo podem ser utilizados como componentes em sistemas de sensoriamento óptico, que é a aplicação de interesse deste trabalho. Eles também podem ser usados como moduladores em telecomunicações, caso em que são características importantes: largura de banda, impedância característica, tensão de meia onda, coeficientes de perdas, entre outras. Nas aplicações em que se exige grande velocidade de resposta (ou largura de banda de modulação elevada) e baixa tensão de meia onda, é usual construírem-se moduladores longos e formados com eletrodos paralelos ao guia. Tais moduladores são conhecidos como "a onda caminhante", pois o campo elétrico é produzido por uma tensão de modulação aplicada numa extremidade dos eletrodos que dá origem a uma onda elétrica que se propaga (caminha) ao 
longo do guia, paralelamente à onda óptica. A caracterização elétrica desses moduladores será efetuada pelos seguintes parâmetros: impedância característica $\left(Z_{c}\right)$, índice efetivo do modo elétrico $\left(N_{\text {eff }}\right)$, largura de banda $(\Delta f)$ e $V_{\pi}$, considerando-se uma onda elétrica de variação senoidal [59]. Esses parâmetros [79-82] são definidos por:

$$
\begin{gathered}
Z_{c}=\frac{1}{c} \frac{1}{\sqrt{C C_{1}}}, \\
N_{e f f}=\sqrt{\varepsilon_{e f f}}=\sqrt{\frac{C}{C_{1}}}, \\
\Delta f L=\frac{1.4 c}{\pi\left|\sqrt{N_{e f f}-n_{e f f}}\right|}, \\
V_{\pi} \cdot L=\frac{\lambda_{0} \cdot G}{2 n_{b e}^{3} \cdot r_{41}(|\Gamma|)},
\end{gathered}
$$

onde:

- $C$ é a capacitância por unidade de comprimento do guia de onda elétrica (material dielétrico),

- $C_{1}$ é a capacitância por unidade de comprimento do guia de onda elétrica (no vácuo),

- $c$ é a velocidade da luz no vácuo,

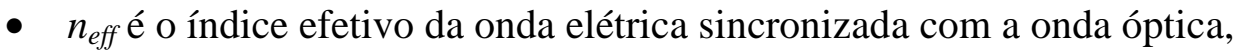

- $\quad V$ é a tensão entre os eletrodos,

- $E_{o p}$ é o campo elétrico da onda óptica,

- $E_{e l}$ é o campo elétrico da onda TEM (modos quase-estáticos),

- L é o comprimento do componente (modulador),

- $\lambda_{0}$ é o comprimento de onda,

- $n_{b e}$ é o índice de refração do substrato,

- $\quad r_{41}$ é o coeficiente eletro-óptico do substrato.

No capítulo de materiais e métodos serão apresentados: o cálculo da integral de superposição, a fabricação dos guias de onda usando a técnica ISS e o processo de deposição dos eletrodos metálicos para obtenção dos moduladores. 


\subsection{Formulação das equações de onda para os modos em método de elementos finitos}

Este trabalho usa o MEF [83, 84] como ferramenta, pois ele tem se mostrado adequado para resolver problemas como os que são objetos deste estudo. Este método é usado na solução de problemas físicos macroscópicos envolvendo grandezas mecânicas, térmicas, eletromagnéticas, ópticas, etc., sendo que vários programas usam esse método como base para seus cálculos.

Desde o fim da década de 60 vem crescendo o número de publicações de aplicações do MEF em problemas que envolvem eletromagnetismo (EM) [84]. Diversas universidades e indústrias vêm usando programas com tecnologia Computer Aided Design (CAD) (ou Projeto Assistido por Computador - PAC) baseados em MEF, na intenção de reduzir os custos de desenvolvimento de novos componentes e produtos. Com esse tipo de abordagem é possível reduzir o tempo necessário das etapas do projeto e permite antever o desempenho dos produtos antes de sua fabricação, o que pode diminuir o número necessário de protótipos e o investimento total no desenvolvimento.

A caracterização dos modos de propagação de onda em estudos de guias de ondas do tipo canal, geralmente é obtida através da solução das equações de Maxwell [55]. No entanto, a solução da equação da onda é muito complicada porque a geometria do guia não é totalmente simétrica, resultando modos não exatamente simétricos. Nesses guias, a solução de propagação de onda pode ser tratada pela análise de Marcatili [85] ou pode ser analisada usando o MEF. Em ambos os casos a análise continua sendo muito complicada. Cada um dos métodos citados tem as suas vantagens e desvantagens na obtenção da caracterização desses guias [37] e o uso de programas de simulação numérica [86, 87] ou analítica [88] ajuda a solucionar esse problema.

A aplicação do MEF é feita subdividindo-se a geometria em pequenas partes e podem ser utilizados modelos geométricos em uma dimensão (1D), duas dimensões (2D) ou três dimensões (3 D). Esta subdivisão é denominada de malha. Nesse trabalho é utilizado o modelo 2D e a malha é formada por triângulos, sendo que os vértices dos mesmos são chamados de nós da malha. Por meio dela é construído um sistema de equações que representa o fenômeno estudado e cuja solução oferece um cálculo do efeito a ser observado. 
Os primeiros estudos numéricos de propagação de ondas em guias fechados, preenchidos com materiais homogêneos e isotrópicos foram apresentados por Arlett e Silvester [89-91].

Franco [58] apresentou um estudo a respeito da aplicação do MEF à resolução de problemas envolvendo propagação de ondas em componentes baseados em guias de onda do tipo canal e fibras ópticas. Neste trabalho, assim como naquele, uma onda transversal eletromagnética (TEM) propaga-se na direção $z$, ou seja, ela apresenta componentes transversais nulas $\left(E_{z}=H_{z}\right.$ $=0)$ [83]. Nesse caso, o campo elétrico pode ser obtido através do gradiente transversal de uma função escalar $\phi(x, y)$, que depende das coordenadas transversais e é solução da equação de Laplace em duas dimensões:

$$
\nabla \cdot(\varepsilon \nabla \phi)=0
$$

Por outro lado, se considerarmos $E_{z}=0$ e $H_{z} \neq 0$, podem-se obter as ondas TE a partir da componente axial $H_{z}$ do campo magnético e se considerarmos $H_{z}=0$ e $E_{z} \neq 0$, podem-se obter as ondas TM através do campo elétrico $E_{z}$.

A partir das equações de ondas, já demonstradas nesse capítulo, aplicando o método dos resíduos ponderados na equação 2.20 , a formulação da equação de onda para modos $E^{x}$ pode ser escrita como [92]:

$$
[F]\left\{E_{x}\right\}^{T}=n_{e f f}^{2}[M]\left\{E_{x}\right\}^{T}
$$

onde

e $n_{\text {eff }}=\beta / k_{0}$ é o índice de refração efetivo.

As matrizes $[\mathrm{F}]$ e $[\mathrm{M}]$ são:

$$
\begin{gathered}
{[M]=k_{0}^{2} \int_{\Omega} n_{z}^{2}\{N\}^{T}\{N\} d x d y,} \\
{[F]=\left[F_{1}\right]-\left[F_{2}\right]-\left[F_{3}\right]-\left[F_{4}\right]-\left[F_{5}\right]+\left[F_{6}\right],}
\end{gathered}
$$

onde

$\Omega$ é o domínio [58], $\{N\}$ representa o conjunto completo de funções de base em cada elemento finito usado, \{\} representa uma matriz linha e \{\}$^{-1}$ é a matriz transposta.

As componentes das matrizes $F$ são: 


$$
\begin{gathered}
{\left[F_{1}\right]=k_{0}^{2} \int_{\Omega} n_{x}^{2} n_{z}^{2}\{N\}^{T}\{N\} d x d y} \\
{\left[F_{2}\right]=\delta_{x} \int_{\Omega} \frac{n_{x}^{2}}{\partial x} \frac{\partial\{N\}^{T}}{\partial x}\{N\} d x d y} \\
{\left[F_{3}\right]=\int_{\Omega} n_{x}^{2} \frac{\partial\{N\}^{T}}{\partial x} \frac{\partial\{N\}}{\partial x} d x d y,} \\
{\left[F_{4}\right]=\int_{\Omega} n_{z}^{2} \frac{\partial\{N\}^{T}}{\partial y} \frac{\partial\{N\}}{\partial y} d x d y,} \\
{\left[F_{5}\right]=\delta_{z} \int_{\Omega} \frac{\partial n_{z}^{2}}{\partial y}\{N\}^{T} \frac{\partial\{N\}}{\partial y} d x d y,} \\
{\left[F_{6}\right]=\delta_{z} \int_{\Omega}\{N\}^{T} n_{z}^{2} \frac{\partial g_{z}^{2}}{\partial x}\left(\delta_{x} \frac{\partial n_{x}^{2}}{\partial x}\{N\}+n_{x}^{2} \frac{\partial\{N\}}{\partial x}\right) d x d y,}
\end{gathered}
$$

onde

$$
g_{z}^{2}=1 / n_{z}^{2}
$$

Em $\left[F_{2}\right],\left[F_{5}\right]$ e $\left[F_{6}\right]$ as variáveis $\delta_{x}$ e $\delta_{z}$ assumem valor unitário nos casos em que os meios apresentarem índices de refração $n_{x}$ e $n_{z}$ não homogêneos ou zero nos casos em os meios forem homogêneos [58].

Para modos $E^{y}$, aplicando o método dos resíduos ponderados associado à técnica de Galerkin na equação 2.21 , resulta em:

$$
[\bar{F}]\left\{H_{x}\right\}^{T}=n_{e f f}^{2}[\bar{M}]\left\{H_{x}\right\}^{T} .
$$

As matrizes $[\bar{M}]$ e $[\bar{F}]$ são:

$$
\begin{gathered}
{[\bar{M}]=k_{0}^{2} \int_{\Omega}\{N\}^{T}\{N\} d x d y,} \\
{[\bar{F}]=\left[\bar{F}_{1}\right]-\left[\bar{F}_{2}\right]-\left[\bar{F}_{3}\right]+\left[\bar{F}_{4}\right]+\left[\bar{F}_{5}\right]+\left[\bar{F}_{6}\right],}
\end{gathered}
$$

onde:

$$
\begin{gathered}
{\left[\bar{F}_{1}\right]=k_{0}^{2} \int_{\Omega} n_{y}^{2}\{N\}^{T}\{N\} d x d y,} \\
{\left[\bar{F}_{2}\right]=\int_{\Omega} \frac{\partial\{N\}^{T}}{\partial x} \frac{\{N\}}{\partial x} d x d y,}
\end{gathered}
$$




$$
\begin{gathered}
{\left[\bar{F}_{3}\right]=\int_{\Omega} n_{y}^{2} g_{z}^{2} \frac{\partial\{N\}^{T}}{\partial y} \frac{\partial\{N\}}{\partial y} d x d y,} \\
{\left[\bar{F}_{4}\right]=\delta_{y} \int_{\Omega} g_{z}^{2} \frac{\partial n_{y}^{2}}{\partial y}\{N\}^{T} \frac{\partial\{N\}}{\partial y} d x d y,} \\
{\left[\bar{F}_{5}\right]=\delta_{z} \int_{\Omega} n_{y}^{2} \frac{\partial g_{z}^{2}}{\partial y}\{N\}^{T} \frac{\partial\{N\}}{\partial y} d x d y,} \\
{\left[\bar{F}_{6}\right]=\delta_{z} \int_{\Omega} n_{y}^{2} g_{z}^{4} \frac{\partial n_{z}^{2}}{\partial y}\{N\}^{T} \frac{\partial\{N\}}{\partial y} d x d y,}
\end{gathered}
$$

Assumindo as expansões a seguir nas equações 2.66 a 2.74 para cada elemento finito.

$$
\begin{gathered}
H_{x}=\{N\}\left\{H_{x}\right\}^{T}, \\
n_{y}^{2}=\{N\}\left\{n_{y}^{2}\right\}^{T}, \\
n_{z}^{2}=\{N\}\left\{n_{z}^{2}\right\}^{T}, \\
\frac{1}{n_{z}^{2}}=g_{z}^{2}=\{N\}\left\{g_{z}^{2}\right\}^{T},
\end{gathered}
$$

$\operatorname{Em}\left[\overline{F_{4}}\right],\left[\overline{F_{5}}\right]$ e $\left[\overline{F_{6}}\right]$ as variáveis $\delta_{y}$ e $\delta_{z}$ assumem valor unitário nos casos em que os meios apresentarem índices de refração $n_{y}$ e $n_{z}$ não homogêneos ou zero nos casos em os meios forem homogêneos.

Koshiba adotou a mesma abordagem para guias ópticos canais isotrópicos [93] e para guias planares anisotrópicos [94], porém não utiliza derivadas parciais dos índices de refração. Considerando uma região homogênea com anisotropia, a equação 2.66 é reduzida às equações apresentadas em [63], e nas regiões homogêneas e isotrópicas se reduzem às apresentadas em [64]. As matrizes $\left[F_{2}\right],\left[F_{5}\right]$ e $\left[F_{6}\right]$ são esparsas e não são simétricos pela influência dos termos com $d n^{2} / d x$ ou $d n^{2} / d y$.

No capítulo de materiais e métodos são definidos: os materiais (substrato e filme), a técnica de fabricação do componente desejado (modulador baseado em guia de onda do tipo canal), o modelamento numérico para o guia de onda e para o modulador eletro-óptico, a simulação numérica desse componente, o processo de fabricação desse componente e o processo iterativo entre a simulação e a fabricação desse componente. 


\section{MATERIAIS E MÉTODOS}

A escolha dos materiais é muito importante, como foi mencionado no capítulo 2, pois define a técnica adequada de fabricação dos componentes em OI. Além disso, também é importante a escolha de um programa de simulação numérica apropriado para auxiliar o projeto do componente desejado. Nesse capítulo são apresentados, além dos materiais, da técnica de fabricação, o processo de fabricação adotado e a proposta de um procedimento completo que utiliza a simulação auxiliando interativamente esse processo.

\subsection{Substrato cristalino de retículo cúbico}

Um dos principais materiais citados em fabricações de moduladores em $\mathrm{OI}$ é o $\mathrm{LiNbO}_{3}$, pois esse material apresenta excelente combinação de propriedades ópticas, tais como, transparência na faixa do espectro de luz do interesse em comunicações ópticas e sensores [95], coeficientes eletro-ópticos, acusto-ópticos e piezo-elétricos elevados, facilidade de receber dopagens químicas para fabricação de guias de ondas, etc. Entretanto, por apresentar simetria trigonal (3m) [96] exibe birrefringência própria, que na maioria dos casos dificulta a obtenção de moduladores transversais de birrefringência do tipo desejável nesse trabalho. Pelo mesmo motivo, outros materiais que apresentam coeficientes eletro-ópticos até mais elevados que o $\mathrm{LiNbO}_{3}$, como por exemplo os do tipo TTN, também não são adequados para a aplicação em vista neste trabalho por apresentarem birrefringência própriamuito elevada.

Em vista disso, os materiais de interesse neste trabalho são os substratos cristalinos de retículo cúbico, pois eles exibem uma birrefringência natural desprezível. Alguns exemplos desses substratos são: $\mathrm{Bi}_{4} \mathrm{Ge}_{3} \mathrm{O}_{12}, \mathrm{Bi}_{4} \mathrm{Si}_{3} \mathrm{O}_{12}, \mathrm{Bi}_{12} \mathrm{GeO}_{20}, \mathrm{Bi}_{12} \mathrm{SiO}_{20}$ e $\mathrm{Bi}_{12} \mathrm{TiO}_{20}$.

$\mathrm{O}$ cristal de $\mathrm{Bi}_{12} \mathrm{GeO}_{20}$ apresenta vários atrativos, tais como:

- efeito eletro-óptico pronunciado,

- alta resistividade elétrica,

- birrefringência natural desprezível, como foi mencionado acima.

Outro candidato é o $\mathrm{Bi}_{4} \mathrm{Ge}_{3} \mathrm{O}_{12}$, porque exibe características parecidas ao $\mathrm{Bi}_{12} \mathrm{GeO}_{20}$, mas não tem atividade óptica, que é uma característica indesejável, pois contribui para diminuir a 
eficiência da modulação óptica obtida. Ambas as formas químicas são conhecidas como BGOs.

Os cristais de BGOs têm sido usados no LSO/PEA/EPUSP por mais de quinze anos em desenvolvimento de protótipos de sensores eletro-ópticos. Estes são materiais bem conhecidos pelos pesquisadores do LSO/PEA/EPUSP e existem fornecedores internacionais identificados que oferecem esses cristais em dimensões adequadas para seu uso, na quantidade necessária e por preços acessíveis. Em vista desses motivos, optou-se no LSO por indicar esses materiais para serem empregados nesse trabalho.

\subsection{Filmes finos indutores de tensão mecânica}

Como foi mencionada anteriormente, a escolha da técnica ISS que será apresentada mais adiante, implica no uso de filmes indutores de tensão mecânica e realização dos processos de litografia com corrosão no intuito de obter guias de onda do tipo canal.

Filmes finos desempenham um papel muito importante nos componentes e dispositivos integrados. Geralmente são usados: em conexões das regiões ativas, em comunicação entre componentes, em isolamento de camadas condutoras, em proteção as superfícies do ambiente externo, como elementos estruturais, etc. Esses filmes podem ser condutores, semicondutores ou isolantes. De modo geral, eles são crescidos termicamente ou depositados a vapor [97].

Os filmes finos usados, nesse trabalho, devem apresentar características controladas, isto é, a espessura deve ser uniforme, a estrutura atômica com baixa densidade de defeitos e a composição química com mínima contaminação por partículas.

Segundo Tatsch [97] Os processos de formação dos filmes podem ser divididos em dois grupos fundamentais:

a) crescimento dos filmes pela reação da superfície do substrato com as substâncias presentes no ambiente de processo;

b) crescimento dos filmes por deposição sem reação com substrato. 
O segundo grupo pode ser subdividido em três subgrupos [97]:

I. deposição química a vapor, denominado CVD (Chemical Vapor Deposition): nesse processo, os filmes são formados por reação química de espécies convenientes na superfície do substrato;

II. deposição física a vapor: nesse processo as espécies do filme são arrancadas fisicamente de uma fonte, por temperatura (nesse caso, o material é evaporado) ou por impacto de íons (denominado Sputtering) e, como vapor, se desloca até o substrato onde se condensam na forma de um filme. O ambiente desse processo é mantido em baixa pressão.

III. deposição a partir de líquidos: nesse processo a espécie (em forma líquida) é gotejado e centrifugado sobre o substrato (também chamado de Spinner).

Nesse trabalho utilizaram-se as técnicas do segundo grupo na fabricação do componente. $\mathrm{O}$ subgrupo I foi usado para deposição do filme indutor de tensão mecânica e o subgrupo III, na fase de deposição de fotoresiste para o processo de litografia óptica.

As propriedades mecânicas de interesse de um filme fino depositado sobre a superfície de uma amostra são: aderência e tensão. Estas duas propriedades são importantes no processo de fabricação do componente proposto nesse trabalho.

A aderência do filme deve ser adequada, porque se for muito forte pode acarretar o seu trincamento e alívio do estresse e se for muito fraca, o filme irá se descolar da amostra. Essa aderência depende muito dos processos de limpeza e da rugosidade da superfície da amostra. A rugosidade contribui na adesão do filme, entretanto se ela for excessiva pode acarretar um efeito contrário, prejudicando a adesão do filme [97] e afetando a propagação da luz no guia.

Tatsch diz [97]: A tensão interna de um filme pode ser de compressão ou de expansão. Filmes com tensões de compressão tendem a expandir paralelamente à superfície do substrato (amostra). Em casos extremos podem formar protuberâncias nas superfícies. Filmes com tensões de expansão tendem a se contrair paralelamente ao substrato (amostra), podendo apresentar fissuras ao exceder seu coeficiente de elasticidade. Normalmente, as tensões em um filme variam entre $10^{8}$ a $10^{10}$ dinas $/ \mathrm{cm}^{2}$." É importante perceber que essa afirmação de Tatsch se refere a uma situação em que ocorre uma variação negativa da temperatura, ou seja, o filme é depositado a uma temperatura elevada e depois resfriado até a temperatura ambiente. 
A tensão total de um filme resulta de vários fatores [97], tais como:

a) Tensão térmica, resultante da diferença dos coeficientes de expansão térmica do filme e da amostra;

b) Tensões externas, que pode ser, por exemplo, gerada pelo outro filme;

c) Tensão intrínseca, relacionada com a estrutura do filme e, portanto, dependente de parâmetros como: temperatura de deposição, espessura, taxa de deposição, pressão de processo e tipo de amostra.

Em trabalhos anteriores do grupo LSO/PEA/EPUSP [48, 49], o filme de Óxido de Silício $\left(\mathrm{SiO}_{2}\right)$ foi estudado para aplicação em estruturas de microssistemas integrados (MicroElectro-Mechanical Systems - MEMS) e sensores.

Como foi citado no capitulo 2, no início desse trabalho, foi realizada uma investigação das características de filmes candidatos a serem usados como camadas indutoras de tensão mecânica na fabricação de guias de onda sobre substratos de retículo cúbico, notadamente os BGOs, tais como o GreenTape, conhecido também como Low-Temperature Co-fired Ceramic (LTCC), e Óxido de Estanho e Índio (ITO).

Nesse estudo chamou a atenção o fato de os valores dos coeficientes de expansão térmica tanto dos filmes de ITO quanto do LTCC serem muito próximos aos dos coeficientes dos substratos, nesse caso os BGOs. Isto fez com que se descartassem esses materiais, porque eles não gerariam camadas indutoras de tensão mecânica suficientemente intensa, tornando impossível fabricar guias de onda do tipo canal usando a técnica ISS sobre substrato de BGOs.

Sem opções de materiais para serem usados como filme indutor de tensão mecânica, a autora procurou a equipe do LSI/EPUSP para verificar a possibilidade de usar o filme de $\mathrm{SiO}_{2}$ na fabricação de guias de onda do tipo canal pela técnica ISS sobre substratos de BGOs. Entretanto, aqueles pesquisadores sugeriram usar o filme de Nitreto de Silício $\left(\mathrm{Si}_{3} \mathrm{~N}_{4}\right)$ em vez de usar o $\mathrm{SiO}_{2}$. O filme indutor de tensão mecânica de $\mathrm{Si}_{3} \mathrm{~N}_{4}$ apresenta característica significativa e uniformidade [98], tornando-se muito promissor para a fabricação de guias de onda do tipo canal. Um grupo do LSI/EPUSP vem usando-o na fabricação de sensores químicos ópticos baseados no interferômetro Mach-Zehnder [75]. Além das características 
citadas acima, esse filme apresenta: alta resistência à temperatura, alta resistividade elétrica, baixa taxa de oxidação e boa resistência a choque térmico [99].

Na seção 3.3.1, desse capítulo é apresentada a técnica escolhida para deposição do filme de $\mathrm{Si}_{3} \mathrm{~N}_{4}$, como filme indutor de tensão mecânica na intenção de obter guias de onda do tipo canal.

\subsection{Técnicas de fabricação de moduladores eletro-ópticos baseados em guias de onda do tipo canal}

\subsubsection{Técnica de fabricação de guias de onda do tipo canal}

A técnica de Deposição Química a Vapor a Baixa Pressão (Low Pressure Chemical Vapor Deposition - LPCVD) [98] é uma das linhas de pesquisas do LSI/EPUSP, que desenvolve e caracteriza filmes de $\mathrm{Si}_{3} \mathrm{~N}_{4}$ para fabricação de guias de ondas e componentes ópticos [100$102]$.

Qualquer que seja a técnica de deposição de filmes finos, ela deposita uma camada fina de indutor de tensão mecânica sobre substrato. Após o filme depositado, é realizado o processo de litografia para definir as trincheiras do guia, sendo que o processo de corrosão remove partes pré-determinadas do filme para formação das trincheiras [75].

A técnica ISS [44, 45] inicia-se aquecendo o substrato em que será depositado o material isolante. Após a deposição, o substrato resfria-se até a temperatura ambiente. Devido à diferença entre os coeficientes de expansão térmica desse material e do substrato, surgirá entre eles uma tensão mecânica. Depois desse processo, são realizados os de litografia e de corrosão, como foi explicado acima. Sob a área em que o filme foi retirado é formada uma região pré-determinada com índice de refração alterado pela influência do efeito elasto-óptico. Os passos dessa técnica estão apresentados na seção 3.4.2 desse capítulo.

Os guias de onda fabricados pela técnica ISS têm a vantagem de manter inalterada a composição do substrato e, consequentemente, as perdas de propagação podem ser minimizadas. Entre muitos materiais disponíveis como candidatos para compor o substrato, o BGO foi escolhido para fabricação de guias de onda em OI por apresentar características que 
o fazem adequado para a aplicação alvo do componente a ser desenvolvido por meio deste trabalho, como será apresentado na seção 3.41 deste capítulo.

\subsubsection{Técnica de fabricação de moduladores eletro-ópticos}

Moduladores eletro-ópticos em OI são compostos por um guia de onda em substrato eletroóptico provido de eletrodos para aplicação de uma tensão externa. Dessa forma impõem-se o a voltagem externo ao material eletro-óptico. Estes eletrodos podem ser construídos por placas metálicas na forma de filmes finos metálicos, os quais são depositados, como por exemplo, pela técnica de evaporação ou, até mesmo, pintados usando tintas condutoras.

Arranjos desse tipo são semelhantes a células Pockels volumétricas descritas anteriormente. Dependendo da disposição dos eletrodos em uma célula Pockels podem ocorrer dois tipos de configurações: transversal ou longitudinal; caso a direção do campo elétrico esteja perpendicular ou paralela á direção de propagação do feixe óptico, respectivamente.

A Figura 15 mostra um desenho esquemático da estrutura básica de um modulador eletroóptico em OI, que foi utilizado nesse trabalho $\mathrm{O}$ substrato, nesse caso, foram utilizados dois tipos de substratos $\left(\mathrm{Bi}_{4} \mathrm{Ge}_{3} \mathrm{O}_{12}\right.$ e $\left.\mathrm{Bi}_{12} \mathrm{GeO}_{20}\right)$ e foram também usados dois tipos de filme $\left(\mathrm{SiO}_{2}\right.$ e $\mathrm{Si}_{3} \mathrm{~N}_{4}$ ) depositado por PECVD e LPCVD, respectivamente e depositado dois eletrodos simétricos metálicos $(\mathrm{Al})$.

Figura 15- Desenho esquemático de um modulador eletro-óptico baseado em guias de onda do tipo canal.

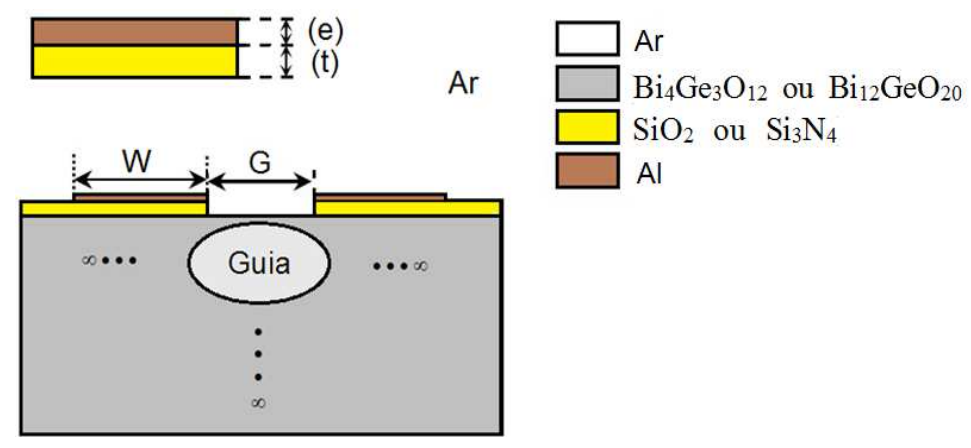

Fonte: Autora

Vários metais são utilizados na deposição de eletrodos em componentes microeletrônicos, tais como, ouro, alumínio, titânio, etc. Entre estes optou-se pelo Alumínio pela disponibilidade no 
LSI/EPUSP e pela experiência dos pesquisadores desse laboratório em depositar eletrodos desse tipo sobre diversos substratos, incluindo filmes de $\mathrm{Si}_{3} \mathrm{~N}_{4}$. A espessura desse filme usada nas simulações, neste estudo, varia de $30 \mathrm{~nm}$ até $100 \mathrm{~nm}$, em passos de $10 \mathrm{~nm}$. Além dessas espessuras, foram também simuladas as de $250 \mathrm{~nm}$ e $500 \mathrm{~nm}$.

A deposição do alumínio (Al) é um processo convencional e foi realizada uma deposição de $1 \mu \mathrm{m}$ de $\mathrm{Al}$ por meio de evaporação térmica [103].

$\mathrm{Na}$ evaporadora é colocado um filamento de $275 \mathrm{mg}$ de Al. A massa do Al é calculada para

$1 \mu \mathrm{m}$ de espessura para uma amostra a $9 \mathrm{~cm}$ de distância do filamento. É realizado o vácuo na câmara com uma pressão de até $10 \times 10^{-5}$ mTorr e o aquecimento do filamento é obtido por meio da passagem de corrente de até $60 \mathrm{~A}$. A evaporação total do filamento de $\mathrm{Al}$ acontece em 1 minuto, isso é suficiente para evaporá-lo [103].

\subsection{Simulação e modelamento do guia e do modulador}

Nesta seção serão apresentadas: as características dos materiais e as modelagens matemáticas do efeito elasto-óptico e do efeito eletro-óptico, que são implementadas em um programa de simulação numérica. O detalhamento do tutorial da simulação do modulador eletro-óptico baseado em guia de onda óptico do tipo canal em substrato cristalino de retículo cúbico é apresentado no anexo C.

\subsubsection{Equação do índice de refração dos materiais}

As fórmulas da dispersão do índice de refração são implementadas e as propriedades dos materiais, citadas na Tabela 1 serão usadas como dados de entrada do programa de simulação numérica. 
Tabela 1- Algumas das propriedades: mecânicas, térmicas, eletro-ópticas e óptica dos materiais usados nesse trabalho

\begin{tabular}{|c|c|c|c|c|}
\hline Material & $\mathrm{Bi}_{12} \mathrm{GeO}_{20}$ & $\mathrm{Bi}_{4} \mathrm{Ge}_{3} \mathrm{O}_{12}$ & $\mathrm{Si}_{3} \mathrm{~N}_{4}$ & $\mathrm{SiO}_{2}$ \\
\hline Índice de refração & 2.55 & 2.09 & ---- & --- \\
\hline $\begin{array}{c}\text { Classe do cristal e } \\
\text { grupo de interesse [104] }\end{array}$ & Cúbico, (I23) & $\begin{array}{l}\text { Cúbico, } \\
\text { (I43d) }\end{array}$ & amorfo & amorfo \\
\hline $\begin{array}{l}\text { Coeficiente de expansão } \\
\text { térmica }\left(\mathrm{K}^{-1}\right)[104]\end{array}$ & $16.8 \times 10^{-6}$ & $6.310^{-6}$ & $2.80 \times 10^{-6}$ & $6.0 \times 10^{-7}$ \\
\hline $\begin{array}{l}\text { Módulo de Young }\left(\mathrm{N} / \mathrm{m}^{2}\right) \\
{[104]}\end{array}$ & $82 \times 10^{9}$ & $10.5610^{10}$ & $1.5 \times 10^{17}$ & $7.0 \times 10^{10}$ \\
\hline Razão de Poisson [104] & 0.28 & 0.26 & 0.24 & 0.17 \\
\hline Densidade $\left(\mathrm{kg} / \mathrm{m}^{3}\right)$ [104] & 9231 & 7130 & 324 & 2201 \\
\hline $\begin{array}{l}\text { Índice de refração } \\
\text { @ } 633 \text { nm [104] }\end{array}$ & 2.55 & 2.09 & ---- & --- \\
\hline Coeficiente de elasto-óptico & $\begin{array}{c}p_{11}=0.12 \\
p_{12}=p_{21}=0.095 \\
p_{44}=0.01 \\
{[105]}\end{array}$ & $\begin{array}{c}p_{11}=0.11, \\
p_{12}=0.083, \\
p_{44}=-0.0595 \\
{[106]}\end{array}$ & --- & --- \\
\hline $\begin{array}{l}\text { Coeficiente dielétrico relativo } \\
\qquad\left(\varepsilon_{\mathrm{r}}\right)[104]\end{array}$ & 40 & 16 & $6-7$ & \\
\hline $\begin{array}{l}\text { Coeficiente eletro-óptico } \\
(\mathrm{m} / \mathrm{V})\end{array}$ & $\begin{array}{c}r_{41}=3.6710^{-12} \\
{[104]}\end{array}$ & $\begin{array}{c}r_{41}=1,1110^{-12} \\
{[106]}\end{array}$ & --- & --- \\
\hline
\end{tabular}

Fontes citadas dentro da tabela

As fórmulas da dispersão do índice de refração, em temperatura ambiente, dos materiais escolhidos nesse estudo são [104]:

$\mathrm{Bi}_{12} \mathrm{GeO}_{20}$

$$
n^{2}=\frac{1+4,601 \lambda^{2}}{\lambda^{2}-(0,242)^{2}}
$$

$\mathrm{Bi}_{4} \mathrm{Ge}_{3} \mathrm{O}_{12}$

$$
n^{2}=\frac{1+3,08959 \lambda^{2}}{\lambda^{2}-0,01337}
$$

$\mathrm{SiO}_{2}$

$$
n^{2}=\frac{1+0.6961663 \lambda^{2}}{\left[\lambda^{2}-(0.0684043)^{2}\right]}+\frac{0.4079426 \lambda^{2}}{\left[\lambda^{2}-(0.1162414)^{2}\right]}+\frac{0.8974794 \lambda^{2}}{\left[\lambda^{2}-(9.896161)^{2}\right]}
$$

$\mathrm{Si}_{3} \mathrm{~N}_{4}$

$$
n^{2}=\frac{1+2,8939 \lambda^{2}}{\lambda^{2}-\left(139,67 \cdot 10^{-3}\right)^{2}}
$$

onde:

$\lambda$ é o comprimento de onda inserido, dado em $\mu \mathrm{m}$. 


\subsubsection{Modelamento do efeito elasto-óptico}

\subsubsection{Tensão mecânica e deformação planas}

A tensão mecânica (stress), $\sigma$, é definido como a intensidade de força em um ponto. Em mecânica, um material é dito estar em esforço plano, se o vetor esforço é zero sobre uma superfície em particular. Quando esta situação ocorre ao longo da estrutura, geralmente acontece em superfícies finas, a análise de esforço é considerada simplificada [107].

No caso especial da deformação plana (plane strain), a tensão mecânica e a deformação são tensores tridimensionais (3D), mas a geometria do corpo é específica, no sentido em que o comprimento da estrutura é muito maior do que as outras duas dimensões.

No caso particular, a deformação associada com o comprimento é de contração nas extremidades do material e é pequena em comparação com a deformação na seção perpendicular ao comprimento, portanto a deformação plana torna-se uma aproximação aceitável. Considerando essas informações, o tensor de tensão mecânica pode ser escrito como [107]:

$$
\bar{\sigma}=\left[\begin{array}{ccc}
\sigma_{11} & \sigma_{12} & 0 \\
\sigma_{21} & \sigma_{22} & 0 \\
0 & 0 & \sigma_{33}
\end{array}\right]
$$

e o tensor de deformação dado por:

$$
\bar{S}=\left[\begin{array}{ccc}
S_{1} & S_{2} & 0 \\
S_{2} & S_{6} & 0 \\
0 & 0 & 0
\end{array}\right] .
$$

Para efeito de simulação, o tipo de material escolhido como substrato dos moduladores em OI (BGOs) foi considerado macroscopicamente isotrópico. Apesar dos materiais na verdade serem cristais, como a versão do programa de simulações numérica baseada em MEF havia limitações associadas à programação da implementação do trabalho, foi adotada a simplificação de considerar os materiais como macroscopicamente isotrópicos na etapa da simulação mecânica, uma vez que, por ser tratar de materiais de retículo cúbico, esse é o caso 
mais próximo dos materiais isotrópicos, em que as influências das direções dos esforços nas deformações possam ser consideradas simétricas em torno dos eixos principais dos cristais.

Com essa aproximação, esperava-se que a simulação fosse capaz de identificar a região de formação dos modos de guiagem, o que foi comprovado conforme apresentado na seção 4.1.1 do capítulo dos resultados e discussões.

\subsubsection{Definição das possíveis orientações do cristal e das direções de propagação}

A escolha das possíveis orientações do cristal e das direções de propagação define a resolução de problemas como propagação de luz em guias de onda, pois existem diferentes combinações de seções de corte e de direções de propagação, tais como os que se pretende usar nesse trabalho: seção de corte no plano $x y$ e propagação em $z$ e seção de corte no plano (110)e propagação paralela ao eixo $z$. Os motivos dessas escolhas ficarão claros na apresentação feita a seguir sobre as características de cada uma dessas configurações.

\subsection{Seção de corte no plano $x y$ e propagação paralela ao eixo $z$}

Nesse trabalho foi considerado um guia de onda óptico em OI, que usa a técnica ISS, adotouse inicialmente uma orientação que simplifica a resolução do problema da propagação de modos na guia, nesse caso, a seção de corte no plano transversal $x y$. Assumindo que a estrutura é uniforme ao longo da direção de propagação em z, a mesma pode ser ilustrada como na Figura 16. 
Figura 16- Modulador eletro-óptico em OI, considerando a seção de corte no plano transversal $x y$
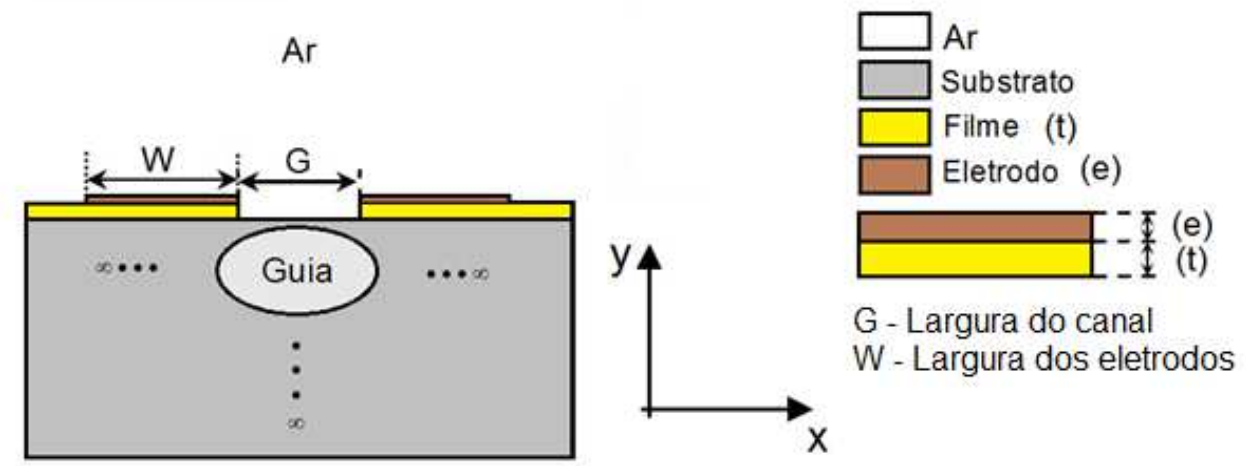

Fonte: $[108]$

Aplicando a teoria do efeito elasto-óptico (apresentado na seção 2.3 do capítulo 2) na equação 2.31 e fazendo uso do caso particular, citado acima, essa equação pode ser expressa como [56]:

$$
\left[\begin{array}{c}
\Delta \frac{1}{n_{x x}^{2}} \\
\Delta \frac{1}{n_{y y}^{2}} \\
0 \\
0 \\
0 \\
\Delta \frac{1}{n_{x y}^{2}}
\end{array}\right]=\left[\begin{array}{cccccc}
p_{11} & p_{12} & p_{21} & 0 & 0 & 0 \\
p_{21} & p_{11} & p_{12} & 0 & 0 & 0 \\
0 & 0 & 0 & 0 & 0 & 0 \\
0 & 0 & 0 & 0 & 0 & 0 \\
0 & 0 & 0 & 0 & 0 & 0 \\
0 & 0 & 0 & 0 & 0 & p_{44}
\end{array}\right] \cdot\left[\begin{array}{c}
S_{1} \\
S_{2} \\
0 \\
0 \\
0 \\
S_{6}
\end{array}\right]
$$

A nova equação do elipsoide de índice afetado pela deformação pode ser reescrita como:

$$
x^{2}\left(\frac{1}{n_{B G O}^{2}}+p_{11} S_{1}+p_{12} S_{2}\right)+y^{2}\left(\frac{1}{n_{B G O}^{2}}+p_{21} S_{1}+p_{11} S_{2}\right)+2 x y\left(p_{44} S_{6}\right)=1
$$

Como único termo cruzado é em $x y$, a nova diagonal dos eixos principais é obtida pela rotação do antigo eixo principal em torno do eixo $z$. O índice de refração principal $n_{z}$ não muda, enquanto os índices de refração $n_{x}$ e $n_{y}$ são dados por:

$$
n_{B G O x}^{\prime}=n_{B G O}-\frac{1}{2} n_{B G O x}^{3}\left(p_{11}+p_{21}\right) S_{1}-\frac{1}{2} n_{B G O x}^{3}\left(p_{21}+p_{11}\right) S_{2}-\frac{1}{2} n_{B G O x}^{3} p_{44} S_{6} \tan 2 \theta
$$




$$
\begin{gathered}
n_{B G O y}^{\prime}=n_{B G O}-\frac{1}{2} n_{B G O y}^{3}\left(p_{11}+p_{21}\right) S_{1}-\frac{1}{2} n_{B G O y}^{3}\left(p_{21}+p_{11}\right) S_{2}+\frac{1}{2} n_{B G O y}^{3} p_{44} S_{6} \tan 2 \theta, \\
n_{B G O z}^{\prime}=n_{B G O z},
\end{gathered}
$$

sendo que a tangente do ângulo é dada por:

$$
\tan 2 \theta=\frac{2 p_{44} S_{6}}{\left(p_{11}-p_{21}\right) S_{1}+\left(p_{21}-p_{11}\right) S_{2}}
$$

\subsection{Seção de corte no plano $(\overline{1} 10)$ e propagação paralela ao eixo $z$}

Considerando o caso anterior, com a seção de corte paralela ao plano $x y$ e a direção de propagação paralela ao eixo $z$, como será apresentado posteriormente na seção 2.4.1 relativa ao efeito eletro-óptico, ao aplicar o campo elétrico ao cristal de retículo cúbico paralelamente ao eixo $x$, ocorre uma rotação dos eixos principais $y$ e $z$ em torno do eixo $x$, o que dificulta o cálculo da birrefringência induzida eletricamente. Em vista disso, optou-se por usar uma outra orientação para continuar obtendo, após aplicação do campo elétrico, a propagação ao longo no novo eixo óptico $z$ ' desse cristal. A orientação de corte do cristal escolhida foi paralela ao plano (001). O objetivo disso, é assegurar que a birrefringência induzida eletricamente apresentada pelo cristal tenha a forma mais simples possível e com isso facilitar o modelamento do efeito eletro-óptico para simulação pelo MEF e posterior implementação no programas de simulação numérica.

Seguindo o raciocínio aplicado no caso anterior (plano transversal $x y$ ), no caso atual é considerado um guia de onda óptico, usando a técnica ISS, com a seção de análise no plano ( 110$)$, paralelo ao campo de deformação aplicado e assumindo a direção de propagação em z’ [56], como ilustra a Figura 17.

Partindo da equação 2.22, considerando a seção de análise no plano ( $\overline{1} 10$ ) paralelo ao campo de deformação aplicado, o novo sistema de coordenadas $x^{\prime}, y^{\prime}$ e $z^{\prime}$ é obtido como:

$$
\frac{x^{\prime 2}}{n_{x}^{\prime 2}}+\frac{y^{\prime 2}}{n_{y}^{\prime 2}}+\frac{z^{\prime 2}}{n_{z}^{\prime 2}}=1
$$


Figura 17- Modulador eletro-óptico em OI, considerando a seção de análise no plano ( $\overline{1} 10$ ) paralelo ao campo de deformação aplicado

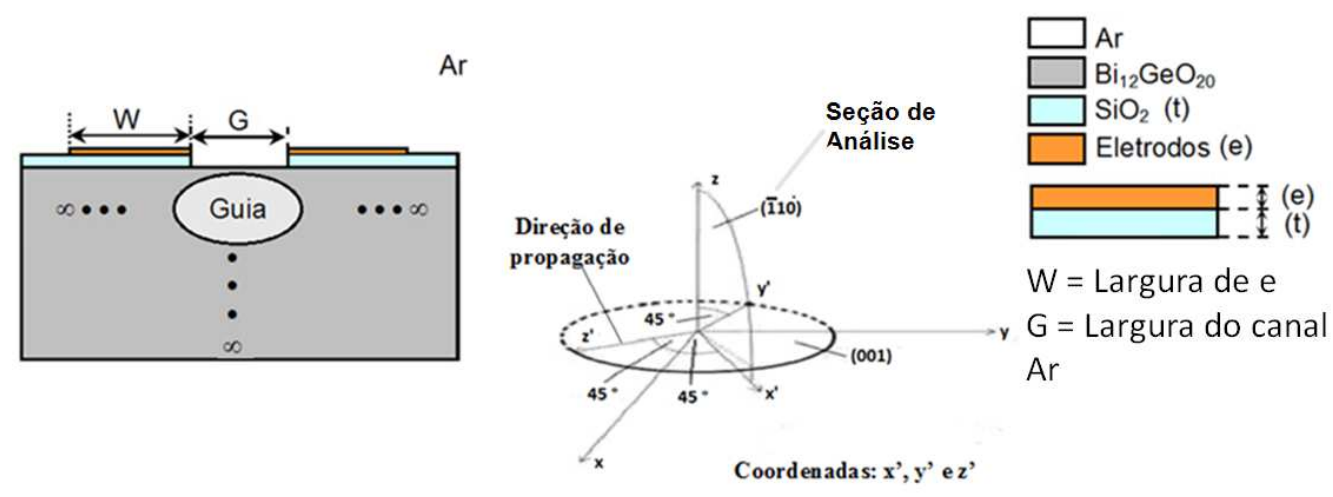

Fonte: [109]

Usando as transformações: primeira rotação do ângulo $\alpha \alpha$ e segunda rotação ângulo $\beta \beta$ nos eixos de coordenadas $x, y$ e $z$ e realizando o cálculo no programa mathematica [109] para obter a nova equação do elipsoide de índices. Essa equação pode ser reescrita nos eixos $x^{\prime}, y^{\prime}$ e $z^{\prime}$ (ver o desenvolvimento no anexo A) Os índices de refração principais são dados por:

$$
\begin{aligned}
& n_{x}^{\prime}=\left\{n-\frac{1}{2} n^{3}\left[\cos ^{2} \beta \beta\left(p_{11} S_{1} \cos ^{2} \alpha \alpha+p_{12} S_{1} \sin ^{2} \alpha \alpha\right)\right.\right. \\
& -\frac{1}{2} n^{3}\left(p_{21} S_{1}+p_{12} S_{3}+p_{11} S_{2}\right) \sin ^{2} \beta \beta-\frac{1}{2} n^{3}\left(p_{11} S_{3}+p_{21} S_{2}\right) \cos ^{2} \beta \beta \sin ^{2} \alpha \alpha \\
& -\frac{1}{2} n^{3} p_{12} p_{21} S_{2} S_{3} \cos ^{2} \alpha \alpha \cos ^{2} \beta \beta+\frac{1}{2} n^{3} 2 p_{44} S_{5} \cos \alpha \alpha \cos ^{2} \beta \beta \sin \alpha \alpha \\
& \left.\left.+\frac{1}{2} n^{3} 2 p_{44} S_{6} \cos \alpha \cos \beta \sin \beta\right]\right\}^{-\frac{1}{2}} \\
& n_{y}^{\prime}=\left\{n-\frac{1}{2} n^{3}\left[\sin ^{2} \beta \beta\left(p_{11} S_{1} \cos ^{2} \alpha \alpha+p_{12} S_{1} \sin ^{2} \alpha \alpha\right)\right.\right. \\
& -\frac{1}{2} n^{3}\left(p_{21} S_{1}+p_{11} S_{2}+p_{12} S_{3}\right) \cos ^{2} \beta \beta \\
& -\frac{1}{2} n^{3}\left(p_{21} S_{2}+p_{11} S_{3}\right) \sin ^{2} \alpha \alpha \sin ^{2} \beta \beta \\
& -\frac{1}{2} n^{3}\left(p_{44} S_{4} \sin \alpha \alpha+p_{44} S_{6} \cos \alpha \alpha\right) \sin 2 \beta \beta \\
& \left.\left.-\frac{1}{2} n^{3}\left(p_{12} p_{21} S_{2} S_{3} \cos ^{2} \alpha \alpha-p_{44} S_{5} \sin 2 \alpha \alpha\right) \sin ^{2} \beta \beta\right]\right\}^{-\frac{1}{2}}
\end{aligned}
$$




$$
\begin{aligned}
n_{z}^{\prime}= & \left\{n-\frac{1}{2} n^{3}\left[\left(p_{12} S_{1}+p_{21} S_{2}+p_{11} S_{3}\right) \cos ^{2} \alpha \alpha\right.\right. \\
& \left.\left.-\frac{1}{2} n^{3}\left(p_{11} S_{1}+p_{12} p_{21} S_{2} S_{3}\right) \sin ^{2} \alpha \alpha-\frac{1}{2} n^{3} p_{44} S_{5} \sin 2 \alpha \alpha\right]\right\}^{-\frac{1}{2}}
\end{aligned}
$$

Como será apresentada a partir da seção 4.1.1.2 com resultados das simulações pelo programa que utiliza o MEF, na região logo abaixo da trincheira, onde se espera que haja formação do guia, o campo de deformação gerado será paralelo à direção (110) do cristal, ou seja, intermediária entre as orientações dos eixos $x$ e $y$, podendo ser descrito como:

$$
S=\frac{1}{\sqrt{2}} S(\hat{x}+\hat{y})
$$

Nesse caso, a equação do elipsoide de índice afetado pela deformação (2.35) pode ser reescrita como:

$$
\frac{x^{2}+y^{2}}{n_{B G O}^{2}}+\left(p_{11}+p_{12}\right) \frac{S}{\sqrt{2}} x^{2}+\left(p_{21}+p_{11}\right) \frac{S}{\sqrt{2}} y^{2}+2 p_{44} \frac{S}{\sqrt{2}}(z y+z x)=1
$$

A nova diagonal dos eixos principais é obtida pela rotação dos antigos eixos principais $x y$ em torno do eixo $z$. Os índices de refração são dados por:

$$
\begin{aligned}
n_{B G O x}^{\prime}= & n_{B G O x}-\frac{\sqrt{2}}{2} n_{B G O x}^{3}\left(p_{11}+p_{12}\right) S \cos ^{2} \beta \beta-\frac{\sqrt{2}}{2} n_{B G O x}^{3}\left(p_{12}+p_{21}\right) S \cos ^{2} \alpha \alpha \sin ^{2} \beta \beta \\
& -\frac{\sqrt{2}}{2} n_{B G O x}^{3}\left(p_{12}+p_{11}\right) S \sin ^{2} \alpha \alpha \sin ^{2} \beta \beta+\frac{\sqrt{2}}{2} n_{B G O x}^{3} p_{44} S \sin (2 \beta \beta) \cos ^{2} \alpha \alpha \\
& -\frac{\sqrt{2}}{2} n_{B G O x}^{3} p_{44} S \sin (2 \alpha \alpha) \sin ^{2} \beta \beta, \\
n_{B G O y}^{\prime}= & n_{B G O y}-\frac{\sqrt{2}}{2} n_{B G O y}^{3}\left(p_{11}+p_{21}\right) S \cos ^{2} \alpha \alpha-\frac{\sqrt{2}}{2} n_{B G O y}^{3}\left(p_{12}+p_{21}\right) S \sin ^{2} \alpha \alpha \\
& -\frac{\sqrt{2}}{2} n_{B G O y}^{3} p_{44} S \sin (2 \alpha \alpha),
\end{aligned}
$$




$$
\begin{aligned}
n_{B G O z}^{\prime}= & n_{B G O z}-\frac{\sqrt{2}}{2} n_{B G O z}^{3}\left(p_{11}+p_{12}\right) S \sin ^{2} \beta \beta-\frac{\sqrt{2}}{2} n_{B G O z}^{3}\left(p_{12}+p_{21}\right) S \cos ^{2} \alpha \alpha \cos ^{2} \beta \beta \\
& -\frac{\sqrt{2}}{2} n_{B G O z}^{3}\left(p_{11}+p_{21}\right) S \sin ^{2} \alpha \alpha \cos ^{2} \beta \beta-\frac{\sqrt{2}}{2} n_{B G O z}^{3} p_{44} S \cos \alpha \alpha \sin (2 \beta \beta) \\
& +\frac{\sqrt{2}}{2} n_{B G O z}^{3} p_{44} S \sin (2 \alpha \alpha) \cos ^{2} \beta \beta,
\end{aligned}
$$

onde: $\alpha \alpha=\beta \beta=\frac{\pi}{4}$.

Portanto, implementar uma simulação com a formulação descrita acima seria equivalente, na região do guia, à implementação com a formulação completa descrita anteriormente, porém seria computacionalmente mais simples e mais rápido.

\subsubsection{Modelamento do efeito eletro-óptico}

Buscando aplicar a teoria apresentada no capítulo 2 sobre efeito eletro-óptico aos moduladores baseados em guias de onda do tipo canal, usando as equações 2.44 e 2.45, obtem-se a modelagem do elipsoide de índices na presença de campo elétrico externo modulante $\left(E_{x}, E_{y}, E_{z}\right)$. No caso do substrato cristalino de retículo cúbico isotrópico $\left(n_{x}=n_{y}=n_{z}=n_{o}\right)$, como é o caso do $\mathrm{Bi}_{4} \mathrm{Ge}_{3} \mathrm{O}_{12}$, a aplicação da equação 2.45 na 2.44 leva ao seguinte elipsoide de índices:

$$
\frac{x^{2}}{n_{o}^{2}}+\frac{y^{2}}{n_{o}^{2}}+\frac{z^{2}}{n_{o}^{2}}+2 r_{41} E_{x} y z+2 r_{41} E_{y} x z+2 r_{41} E_{z} x y=1 .
$$

No caso do substrato cristalino de retículo cúbico submetido a uma deformação como é o caso descrito nesse capítulo, o substrato torna-se anisotrópico uniaxial. Nesse caso, $n_{x}{ }_{x}, n_{y}^{\prime}$ e $n_{z}^{\prime}$ são calculados conforme apresentado naquela seção. Nesse caso, a equação anterior passa a ser:

$$
\frac{x^{2}}{n_{x}^{\prime 2}}+\frac{y^{2}}{n_{y}^{\prime 2}}+\frac{z^{2}}{n_{z}^{\prime 2}}+2 r_{41} E_{x} y z+2 r_{41} E_{y} x z+2 r_{41} E_{z} x y=1
$$


Para calcular o resultado do efeito eletro-óptico no caso do modulador eletro-óptico em OI, seria necessário implementar a equação 3.23 no programa de simulação numérica, como existem três termos cruzados naquela equação, haveria a necessidade de três rotações do sistema de coordenadas para representar o novo elipsoide de índices, e essas rotações teriam que ser aplicadas nos cálculos de cada nó da malha porque, sendo o campo elétrico não uniforme sua direção varia ponto-a-ponto e, portanto, também suas componentes $E_{x}, E_{y}$ e $E_{z}$.

Em vista disso, para simplificar o cálculo, e reduzir o tempo e a carga computacional da simulação, decidiu-se adotar uma orientação específica do campo elétrico que, como é apresentado na seção 4.1 do capítulo de resultados e discussões, é a que predomina na região do substrato em que deve formar-se o modo guiado. A região em questão situa-se logo abaixo do centro da trincheira e nela o campo elétrico é paralelo à direção do corte do cristal (110) e perpendicular a direção de propagação (001), ou seja, $E_{x}=E_{y}=E / \sqrt{ } 2$ e $E_{z}=0$. A equação 2.44, nesse caso, pode ser representada como:

$$
\frac{x^{2}}{n_{x}^{\prime 2}}+\frac{y^{2}}{n_{y}^{\prime 2}}+\frac{z^{2}}{n_{z}^{\prime 2}}+2 r_{41} E_{x} y z+2 r_{41} E_{z} x z=1
$$

Usando a rotação nos eixos do elipsoide de índices do substrato de $\mathrm{Bi}_{4} \mathrm{Ge}_{3} \mathrm{O}_{12}$, separando-a por eixos e resolvendo-os. Os novos eixos do elipsoide podem ser reescrito como:

$$
\begin{gathered}
n_{x}^{\prime \prime} \cong n_{x}^{\prime} \\
n_{y}^{\prime \prime} \cong n_{y}^{\prime}-\frac{1}{2} E_{x} r_{41} n_{y}^{\prime 3} \\
n_{z}^{\prime \prime} \cong n_{z}^{\prime}-\frac{1}{2} E_{x} r_{41} n_{z}^{\prime 3}
\end{gathered}
$$

\subsubsection{Modelamento da análise de modos ópticos}

O estresse residual induzido termicamente formado nos substratos cristalinos de retículo cúbicos permite fabricar guias de onda do tipo canal integrado pela técnica ISS que suportam modos com baixas perdas de transmissão. Considerando as somas dos efeitos elasto-óptico, 
eletro-óptico e índice de refração de substratos cristalinos de retículo cúbico, a equação abaixo representa a soma de todos os efeitos considerada neste trabalho:

$$
n^{\prime \prime \prime}=n^{\text {bulk }}+\Delta n_{\text {strain }}^{\prime}+\Delta n_{\text {Pockels }}^{\prime \prime}
$$

O programa de simulação numérica calcula o $n$ "”, conforme a equação acima e utiliza-o para determinar os modos de propagação, como por exemplo, do cristal de $\mathrm{Bi}_{4} \mathrm{Ge}_{3} \mathrm{O}_{12}$ para $\lambda$ de 1,55 $\mu \mathrm{m}$ são: índice de refração é de 2.09, a diferença do índice de refração do efeito elastoóptico é de $8,9 \times 10^{-4}$ e a diferença do índice efetivo do efeito eletro-óptico é de 2.815, conforme é apresentado a seguir.

\subsection{O programa computacional - como ferramenta de simulação}

Nesse trabalho, a autora optou usar um programa de simulação numérica multifísicas comercial, denominado de COMSOL MULTIPHYSICS ${ }^{\circledR}$ versão 3.2b, 2006 [87], porque esse programa é um simulador de alto desempenho para modelagem de componentes, como por exemplo, em duas dimensões (2D) capaz de resolver matematicamente diversos problemas eletromagnéticos.

Esse programa é baseado no MEF, que permite o usuário desenhar a geometria do projeto, especificar a física por trás da mesma, analisar cada resultado obtido. A interface do programa é muito amigável, isso, faz com o que, o usuário não necessite de um profundo conhecimento de programação computacional para realizar essas simulações.

\subsubsection{O programa COMSOL MULTIPHYSICS ${ }^{\circledR} 3.2 b$}

O programa é capaz de resolver matematicamente várias situações comuns em aplicações da física e da engenharia; sua especialidade são os fenômenos acoplados e múltiplos modelos físicos que combinam diversos efeitos diferentes, trabalhando com interfaces de diversas áreas da física e da engenharia de modo distinto, o que faz dele uma ferramenta muito poderosa aplicável a diversos problemas de eletromagnetismo. 
As simulações nesse programa utilizam o MEF que, por sua vez, é uma técnica numérica capaz de encontrar soluções aproximadas para equações diferenciais parciais. O MEF é uma opção muito utilizada para resolver equações diferenciais parciais em domínios complicados [111], como é o caso desse trabalho que estuda moduladores eletro-ópticos baseados em guias de onda do tipo canal.

Considerando as modelagens das seções 3.4.2.2.2 e 3.4.3 desse capítulo, torna-se possível a modelagem de moduladores eletro-ópticos baseados em guias ópticos do tipo canal em substratos de BGOs, que é o tema desse trabalho. Esse componente é considerado importante, pois ele faz parte de um dispositivo (interferômetro recuperador) que compõem um sistema sensor em desenvolvimento no LSO, conforme apresentado no capítulo de introdução.

Nesse trabalho é apresentado o acoplamento de diversos fenômenos, tais como: tensão mecânica-residual (mecânico), térmico, elasto-óptico, eletro-óptico e elétrico. Esses fenômenos foram denominados de variáveis que foram inseridas diretamente nos domínios, fronteiras, bordas e em pontos nodais.

A exatidão das soluções dependerá do refino de malha, isto é, quanto mais discretizada for a malha aplicada à geometria envolvida, melhor será a resolução dos cálculos e mais refinada será à apresentação dos resultados. Isso significa que, como os pontos existentes no domínio serão utilizados nas soluções de equações diferenciais parciais no módulo solver desse programa, refinar a malha leva ao aumento da exatidão das soluções e, portanto, aumenta o esforço computacional.

O detalhamento do tutorial da simulação desse componente é apresentado no anexo C, no qual podem ser destacados os cálculos dos seguintes modos do programa COMSOL:

- Modo eletromagnetismo - ondas perpendiculares - ondas de modo híbrido;

- Modo estrutural mecânico - deformação plana (plane strain);

- Modo MEMS (microelectromechanical systems - sistema microeletromecânico) microfluídico - eletrostática.

Existem outros modos do programa, mas foge ao escopo deste trabalho detalhá-los. A simulação e a construção dos moduladores citados são abordadas nesta seção. 
Inicia-se o procedimento adicionando os modulos (estrutural mecânico), (eletromagnetismo) e (MEMS). Seleciona-se a aba desenhar (draw) desenha-se o modulador e o guia de onda, usando-se vários retângulos. A Figura 18 mostra como são inseridos no programa COMSOL os parâmetros dos materiais $\mathrm{Bi}_{4} \mathrm{Ge}_{3} \mathrm{O}_{12}$ e $\mathrm{Si}_{3} \mathrm{~N}_{4}$ contidos na tabela 1. Já a Figura 19 mostra como são inseridas as equações 3.2 e 3.4 (fórmula de dispersão); 3.19, 3.20 e 3.21 (efeito elasto-óptico) e 3.25, 3.26 e 3.27 (efeito eletro-óptico).

Após definir as condições de contorno dos modos selecionados e discretizar a malha de triângulos, conforme descrito no Anexo C, inicia-se a simulação pelo item Plain Strain modulo estrutural mecânico (que simula o efeito elasto-óptico). Logo após depois simula-se o efeito eletro-óptico através do item ondas hibridas perpendiculares, contidas modulo eletromagnetismo. Por último, utiliza-se o modulo MEMS para simular a distribuição do campo elétrico imposto pelos eletrodos, como mostra a Figura 20.

Figura 18- Definição das constantes do substrato de BGO e do filme de $\mathrm{Si}_{3} \mathrm{~N}_{4}$

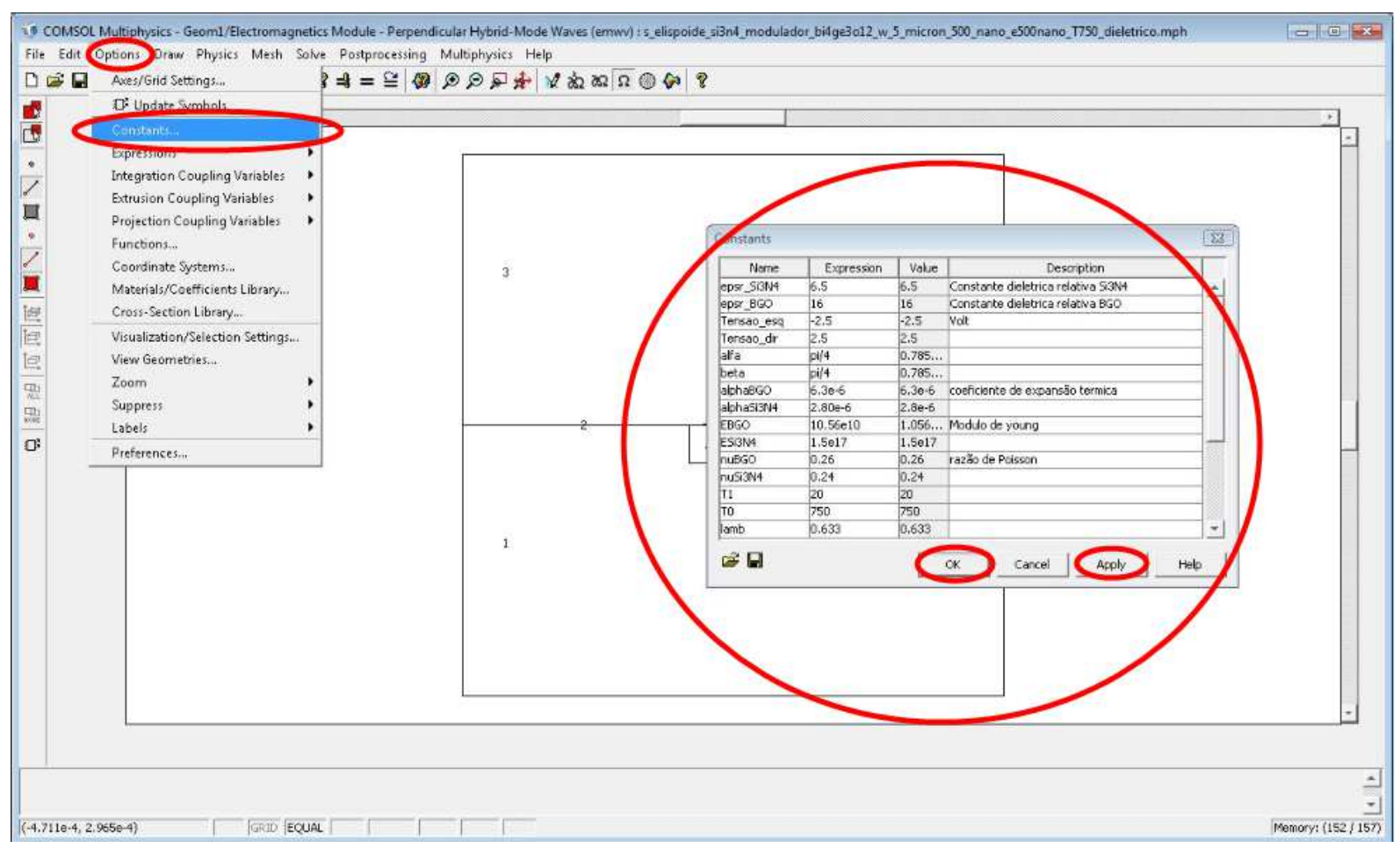

Fonte: Autora 
Figura 19- Inserção no COMSOL das equações dos efeitos elasto-óptico e eletro-óptico e da fórmula de dispersão do índice de refração do substrato de $\mathrm{BGO}$, do filme de $\mathrm{Si}_{3} \mathrm{~N}_{4}$

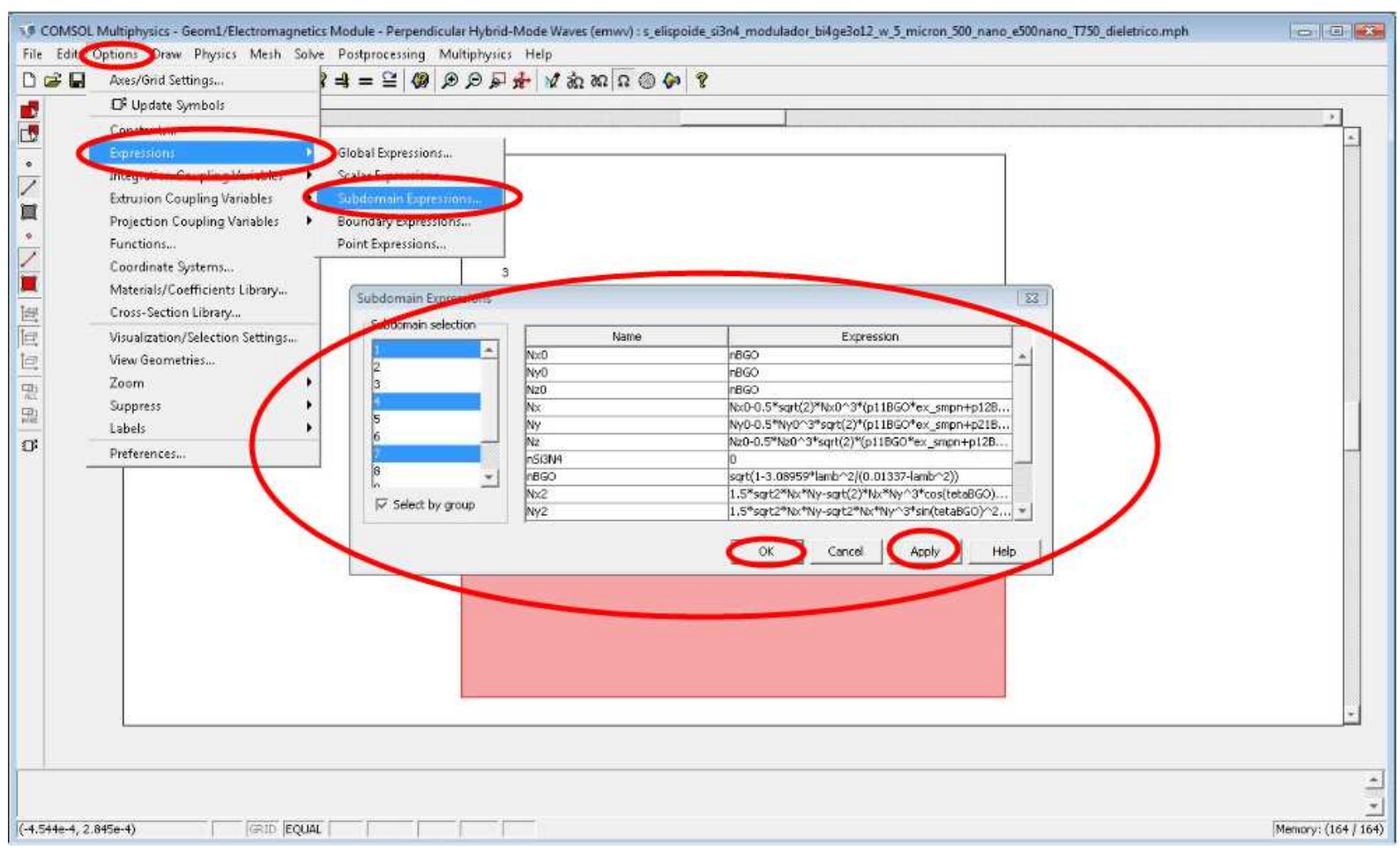

Fonte: Autora

Figura 20- Definição das linhas do Potencial Elétrico

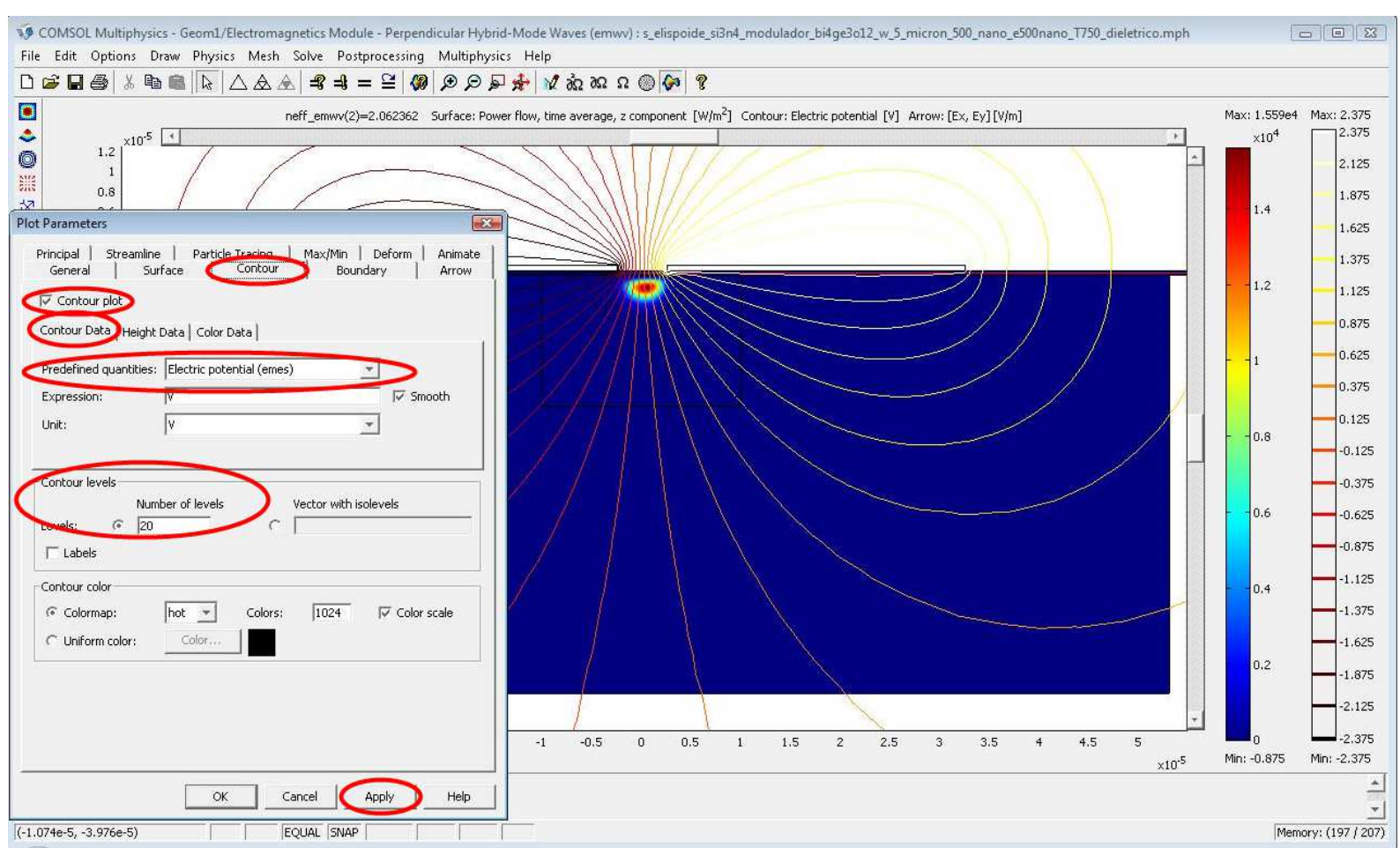




\subsection{Processo de fabricação}

Neste capítulo são detalhadas as etapas de fabricação de guias ópticos do tipo canal (ver o seção 3.3.1 deste capítulo) e as etapas de fabricação de moduladores eletro-ópticos.

\subsubsection{Etapas de fabricação de guias ópticos do tipo canal}

\subsubsection{Etapa 1: Limpeza de lâminas}

Foram utilizadas lâminas de $\mathrm{Bi}_{4} \mathrm{Ge}_{3} \mathrm{O}_{12}$ [111], como substratos, orientação cristalográfica (110) e as lâminas de Si foram usadas como substratos teste nas realizações de todo processo de fabricação do componente.

A fabricação dos guias de onda do tipo canal iniciou-se com uma limpeza de álcool isopropílico aquecido a temperatura de $80^{\circ} \mathrm{C}$ por 10 minutos numa capela (classe 10), que consiste na remoção de impurezas das superfícies das lâminas.

A limpeza com álcool isopropílico consiste na imersão das lâminas em solução deste álcool aquecido $[112,113]$ :

1) Lavagem em água deionizada (DI) por 5 minutos para remoção de particulados;

2) Imersão em álcool isopropílico aquecido a temperatura de $80^{\circ} \mathrm{C}$ por 10 minutos. Nesta solução são removidas outras partículas existentes sobre a superfície;

3) Lavagem em água DI por 5 minutos para neutralização da solução anterior;

4) Após passar pelos itens 1, 2 e 3. As lâminas foram secadas com jatos de ar.

\subsubsection{Etapa 2: Deposição do filme de $\mathrm{Si}_{3} \mathrm{~N}_{4}$ por LPCVD}

Os filmes de $\mathrm{Si}_{3} \mathrm{~N}_{4}$ foram depositados pelo reator LPCVD a partir da reação do gás diclorosilano $\left(\mathrm{SiH}_{2} \mathrm{Cl}_{2}\right)$ e amônio $\left(\mathrm{NH}_{3}\right)[98,114]$ :

$$
3 \mathrm{SiH}_{2} \mathrm{Cl}_{2}(\mathrm{~g})+4 \mathrm{NH}_{3}(\mathrm{~g}) \rightarrow \mathrm{Si}_{3} \mathrm{~N}_{4}(\mathrm{~s})+6 \mathrm{HCl}(\mathrm{g})+6 \mathrm{H}_{2}(\mathrm{~g})\left(650 \mathrm{a} 750^{\circ} \mathrm{C}\right)
$$

Os parâmetros de deposição são mostrados na Tabela 2. 
Tabela 2- Parâmetros de deposição do $\mathrm{Si}_{3} \mathrm{~N}_{4}$ por PLCVD

\begin{tabular}{|l|l|}
\hline Fluxo de $\mathrm{SiH}_{2} \mathrm{Cl}_{2}(\mathrm{sccm})$ & 20 \\
\hline Fluxo de $\mathrm{NH}_{3}(\mathrm{sccm})$ & 320 \\
\hline Temperatura $\left({ }^{\circ} \mathrm{C}\right)$ & 720 a 800 \\
\hline Pressão (Torr) & $500 \mathrm{~m}$ \\
\hline
\end{tabular}

Fonte: [98]

A Figura 21 mostra um esquema da deposição do filme de $\mathrm{Si}_{3} \mathrm{~N}_{4}$ sobre em uma das faces do substrato de $\mathrm{Bi}_{4} \mathrm{Ge}_{3} \mathrm{O}_{12}$. No processo de deposição da técnica de LPCVD é obtida uma alta mobilidade gasosa, resultando em alta uniformidade em espessura e baixa rugosidade superficial no filme, possibilitando a implementação de guias ópticos fracamente guiados e de alta qualidade. Foram utilizados nesse trabalho filmes de $\mathrm{Si}_{3} \mathrm{~N}_{4}$ com espessuras de $\sim 500 \mathrm{~nm}$, de $\sim 100 \mathrm{~nm}$ e de $\sim 50 \mathrm{~nm}$. No entanto, o filme com a espessura de $\sim 500^{\circ} \mathrm{nm}$ ficou todo craqueado e descolado sobre o substrato. Foi aventada a hipótese de que este efeito foi causado pela tensão mecânica excessiva, a qual poderia estar diretamente relacionada à espessura do filme. Portanto, a partir de estudos realizados com o auxílio da simulação numérica [102, 115-118] foi decidida a diminuição da espessura do filme depositado.

Figura 21- Esquema da deposição do filme de $\mathrm{Si}_{3} \mathrm{~N}_{4}$ por $\mathrm{LPCVD}$ sobre o substrato de $\mathrm{Bi}_{4} \mathrm{Ge}_{3} \mathrm{O}_{12}$
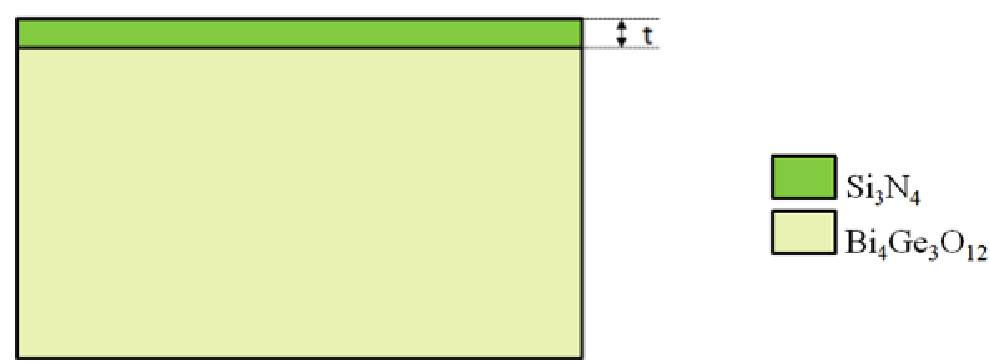

Fonte: Autora

\subsubsection{Etapa 3: Fotogravação de trincheiras por litografia óptica}

O fotorresiste (photo-resist - PR positivo - AZ1518) é pingado sobre o conjunto (substrato mais filme) depositado e fixado a vácuo no equipamento denominado spinner. Ele é espalhado sobre o filme, usando uma velocidade de 3500 RPM. Após, o conjunto é levado a um prato quente (hot plate) para ser realizado o processo térmico de pré-cura (soft bake) à temperatura de $105^{\circ} \mathrm{C}$ por 90 segundos, assim são definidas as trincheiras sobre o filme. 
O processo litográfico óptico convencional com máscara é realizado no LSI/EPUSP [114]. Essa máscara litográfica é fixada por vácuo no primeiro suporte e o conjunto é fixado a vácuo no segundo suporte, ambos são alinhados. O conjunto é exposto ao ultra-violeta do equipamento convencional de litografia com lâmpadas de mercúrio (comprimento de onda de $400 \mathrm{~nm}$ ), que inicialmente é usada as 3 linhas - $436 \mathrm{~nm}$ (“g-line”), $405 \mathrm{~nm}$ (“h-line”) e 365 nm ("i-line), por 17 segundos e em seguida é mergulhado no revelador (AZ MIF 300), agitando-se constantemente, por 50 segundos. Depois, é mergulhado na água deionizada (DI) para ser limpo, após o que é seco a jatos de nitrogênio e submetido ao processo de pós-cura (hard bake) à temperatura de $135^{\circ} \mathrm{C}$ por 5 minutos.

A Figura 22 mostra um esquema da fotogravação dos canais no filme de $\mathrm{Si}_{3} \mathrm{~N}_{4}$.

Figura 22- Esquema da fotogravação das trincheiras (largura do canal) sobre o filme de $\mathrm{Si}_{3} \mathrm{~N}_{4}$

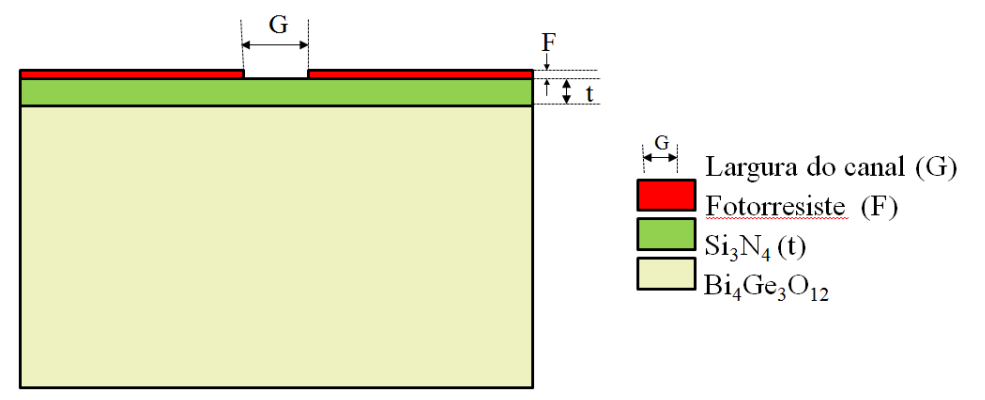

Fonte: Autora

\subsubsection{Etapa 4: Obtenção das trincheiras por corrosão do filme de nitreto de silício}

Os guias do tipo canal foram obtidos pela corrosão total do filme de $\mathrm{Si}_{3} \mathrm{~N}_{4}$ nas regiões do guia induzido. Após a definição das marcas de alinhamento pelo processo de litografia óptica sobre o filme de $\mathrm{Si}_{3} \mathrm{~N}_{4}$, é necessária a corrosão dos filmes até o substrato de $\mathrm{Bi}_{4} \mathrm{Ge}_{3} \mathrm{O}_{12}$. Pode-se usar dois tipos de processo de corrosão: por via úmida e por plasma $\mathrm{SF}_{6}(\mathrm{~g})$ utilizando gás hexafluoreto de enxofre.

Após a litografia óptica, o processo de corrosão via úmida é realizada da seguinte forma: o conjunto é mergulhado em uma solução de limpeza (ácido fosfórico mais ácido nítrico) por 15 minutos. Em seguida, ele é enxaguado em água DI por 5 minutos e o fotorresiste (photo-resist 
- PR positivo - AZ1518) é removido mergulhando-o em uma solução (acetona aquecida) por 30 minutos.

A corrosão por plasma $\mathrm{SF}_{6}$ é realizada no filme de $\mathrm{Si}_{3} \mathrm{~N}_{4}$, utilizando os parâmetros apresentados na Tabela 3, a seguir.

Tabela 3- Parâmetros de corrosão do filme de $\mathrm{Si}_{3} \mathrm{~N}_{4}$ por plasma de $\mathrm{SF}_{6}$

\begin{tabular}{|c|c|}
\hline Fluxo de $\mathrm{SF}_{6}(\mathrm{sccm})$ & 20 \\
\hline Pressão (Torr) & 0,15 \\
\hline Temperatura $\left({ }^{\circ} \mathrm{C}\right)$ & 20 \\
\hline Potência de RF $(\mathrm{W})$ & 50 \\
\hline Tempo (min) & 4 \\
\hline
\end{tabular}

Fonte: [98]

A Figura 23 mostra um esquema da definição das trincheiras sobre o substrato de $\mathrm{Bi}_{4} \mathrm{Ge}_{3} \mathrm{O}_{12}$, obtido pelo processo de corrosão deste filme em lugares pré-determinados.

Figura 23- Esquema da definição das trincheiras sobre o substrato de $\mathrm{Bi}_{4} \mathrm{Ge}_{3} \mathrm{O}_{12}$, obtido pela corrosão

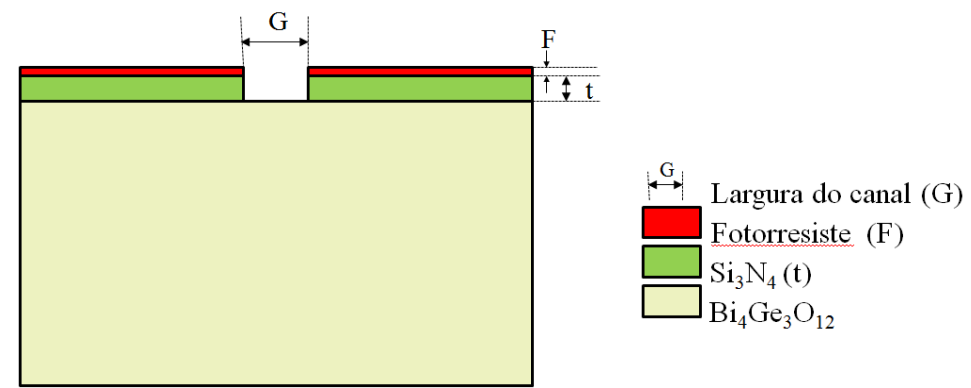

Fonte: Autora

\subsubsection{Etapa 5: Limpeza e remoção das camadas de fotorresiste (photo-resist - PR positivo - AZ1518)}

Na etapa de limpeza e remoção de fotorresiste (photo-resist - PR positivo - AZ1518) foi utilizada a seguinte sequência de processos:

1) Imersão por 10 minutos em acetona aquecida a $80^{\circ} \mathrm{C}$;

2) Lavagem em DI por 5 minutos; 
3) Imersão por 10 minutos em álcool isopropílico aquecido a $80^{\circ} \mathrm{C}$;

4) Lavagem em água DI por 5 minutos;

5) Secagem com jato de nitrogênio.

Seguindo o procedimento que usarão estes reagentes para atacar os compostos orgânicos e mantendo-se o filme de $\mathrm{Si}_{3} \mathrm{~N}_{4}$ intacto. A Figura 24 mostra um esquema do resultado final da etapa de limpeza e remoção do fotorresiste.

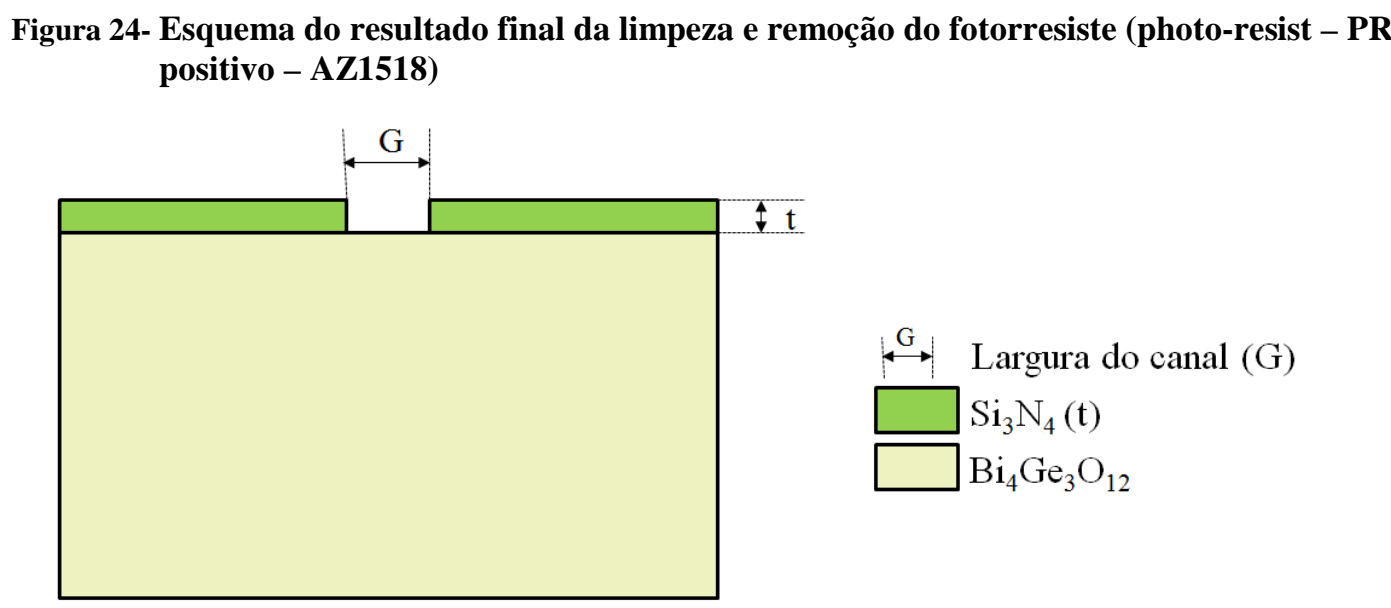

Fonte: Autora

\subsubsection{Etapas de fabricação de moduladores eletro-ópticos}

A etapa de fabricação dos moduladores eletro-ópticos é iniciada após a obtenção dos guias de onda do tipo canal em OI.

\subsubsection{Etapa 6: Deposição de eletrodos de Al por meio de uma evaporação térmica convencional}

Os eletrodos são depositados por um processo convencional em que, a partir de um filamento de Al, é realizada uma deposição por meio de uma evaporação térmica.

Os parâmetros de deposição são apresentados na Tabela 4 
Tabela 4- Parâmetros de deposição do Al por meio de uma evaporação térmica convencional

\begin{tabular}{|l|l|}
\hline Filamento de $\mathrm{Al}$ & $275 \mathrm{mg}$ \\
\hline Pressão (Torr) & $10 \mathrm{e}-5 \mathrm{~m}$ \\
\hline Corrente & $60 \mathrm{~A}$ \\
\hline
\end{tabular}

Fonte: 75

A Figura 25 mostra um esquema da deposição de Al (eletrodos) por meio de uma evaporação térmica sobre o filme $\left(\mathrm{Si}_{3} \mathrm{~N}_{4}\right)$. Nesse processo é obtida uma camada de $\mathrm{Al}$ aproximadamente de $1 \mu \mathrm{m}$.

Figura 25- Esquema da deposição de Al por meio de uma evaporação térmica sobre o filme de $\mathrm{Si}_{3} \mathbf{N}_{4}$.

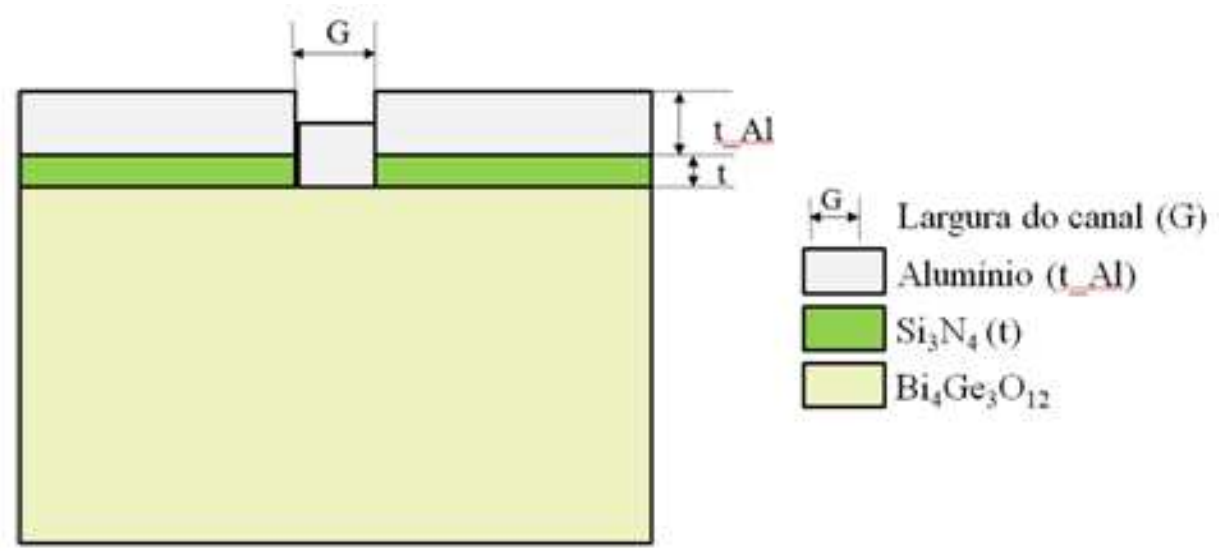

Fonte: Autora

\subsubsection{Etapa 7: fotogravação dos eletrodos por litografia óptica}

A definição dos eletrodos sobre o $\mathrm{Al}$ foi realizada pelo processo litográfico óptico convencional [114] no LSI/EPUSP. A Figura 26 mostra um esquema da fotogravação dos eletrodos por litografia óptica. 
Figura 26- Esquema da fotogravação dos eletrodos sobre o filme de Al

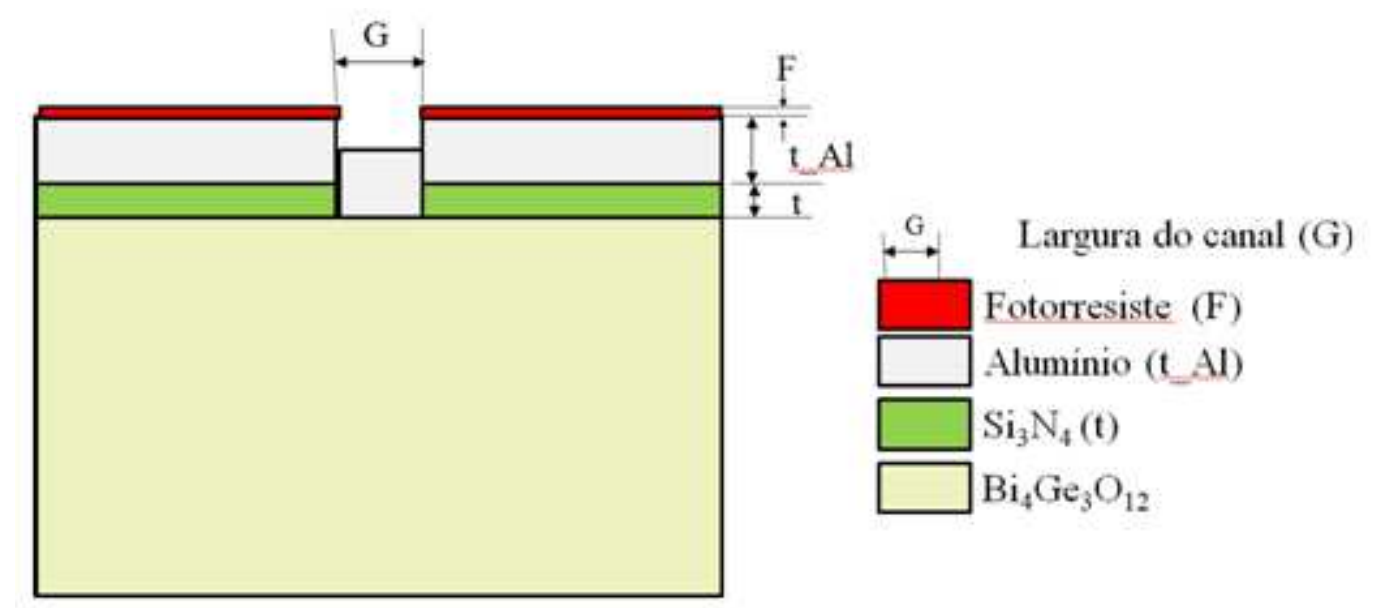

Fonte: Autora

\subsubsection{Etapa 8: Definição dos eletrodos por corrosão do alumínio}

O processo de corrosão via úmida do Al foi usado uma solução de ácido sulfúrico mais ácido nítrico na definição dos eletrodos nas larguras de trincheiras de 3 a $12 \mu \mathrm{m}$ de passos $1 \mu \mathrm{m}$ e dos PADs maiores que a ponta do equipamento (que realiza os testes de modulação do componente fabricado). Os eletrodos foram obtidos pela corrosão total do Al nas regiões sobre a trincheira e nas laterais destas, formando uma pequena tira fina de Al de cada lado da trincheira. Após as definições das marcas de alinhamento pelo processo de litografia óptico sobre o $\mathrm{Al}$ é necessária à corrosão do $\mathrm{Al}$ até atingir o filme de $\mathrm{Si}_{3} \mathrm{~N}_{4}$ (no caso das laterais da trincheira) ou o substrato de $\mathrm{Bi}_{4} \mathrm{Ge}_{3} \mathrm{O}_{12}$ (no caso da região sobre a trincheira).

A Figura 27 mostra um esquema da definição dos eletrodos sobre os guias de onda do tipo canal usando a técnica ISS, obtida pelo processo de corrosão. 
Figura 27- Esquema da definição dos eletrodos sobre as trincheiras

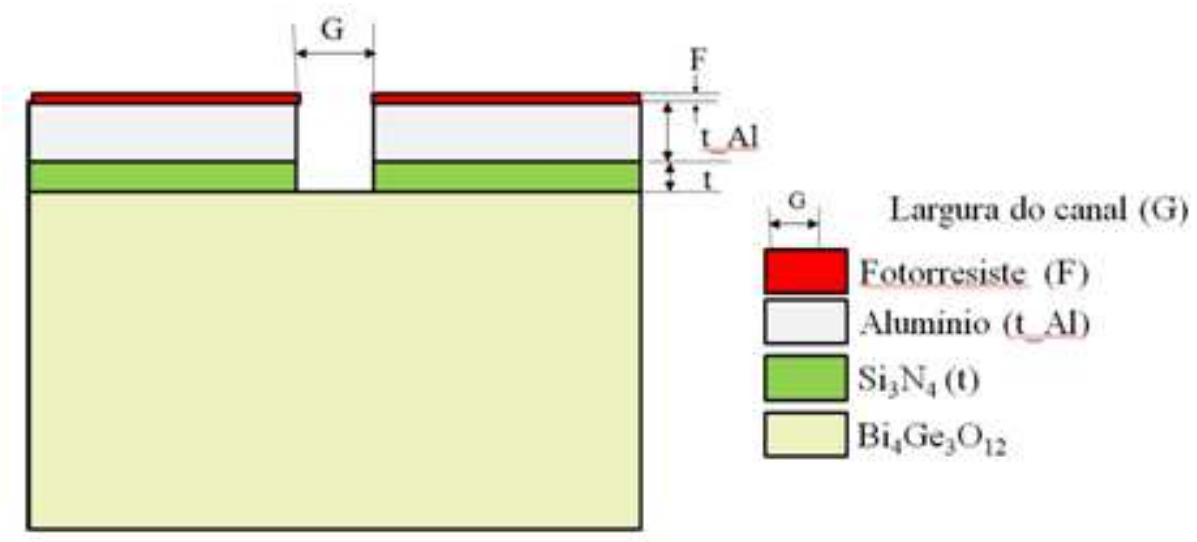

Fonte: Autora

3.6.2.4 Etapa 9: limpeza e remoção das camadas de fotoresiste (photo-resist - PR positivo - AZ1518)

Na etapa de limpeza e remoção de fotorresiste (photo-resist - PR positivo - AZ1518) foi utilizado o mesmo procedimento realizado na etapa 5 deste processo. A Figura 28 mostra um esquema do resultado final da etapa de limpeza e remoção do fotorresiste (photo-resist - PR positivo - AZ1518).

Figura 28- Esquema do resultado da limpeza e remoção do fotorresiste (photo-resist - PR positivo AZ1518)

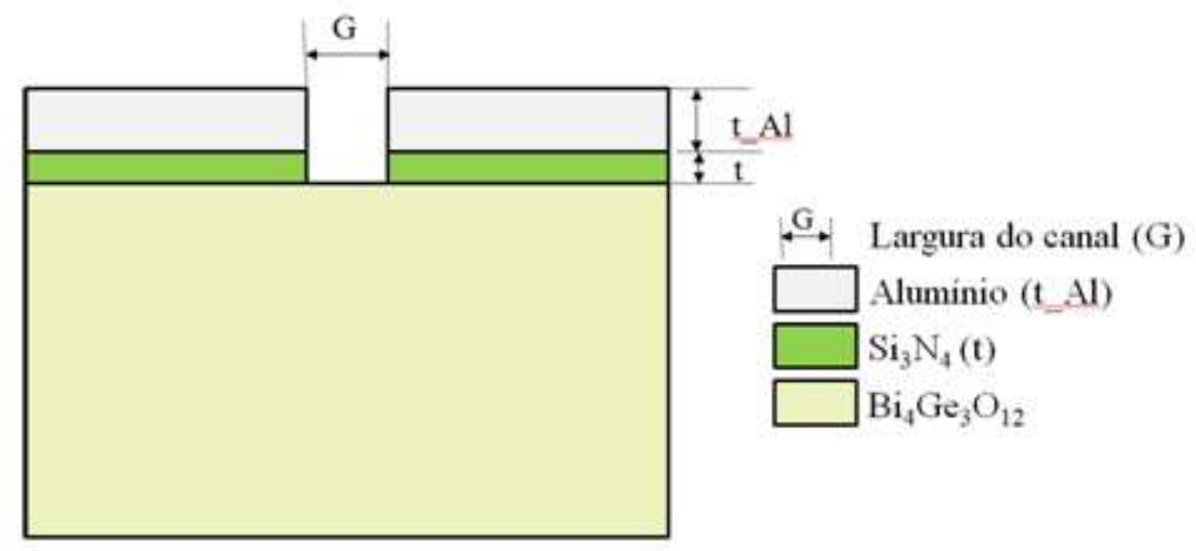

Fonte: Autora 


\subsection{Etapa 10: corte dos componentes (moduladores eletro-ópticos)}

A etapa de corte dos componentes (moduladores eletro-ópticos em $\mathrm{Bi}_{4} \mathrm{Ge}_{3} \mathrm{O}_{12}$ ) foi realizada com uma máquina de corte automática modelo Disco DAD322 do fabricante Machine Manufacture - Disco Corporation, serra circular, usando lubrificantes nos cortes, como mostra a Figura 29.

Figura 29- Foto da Máquina de Corte Automática - Disco DAD322

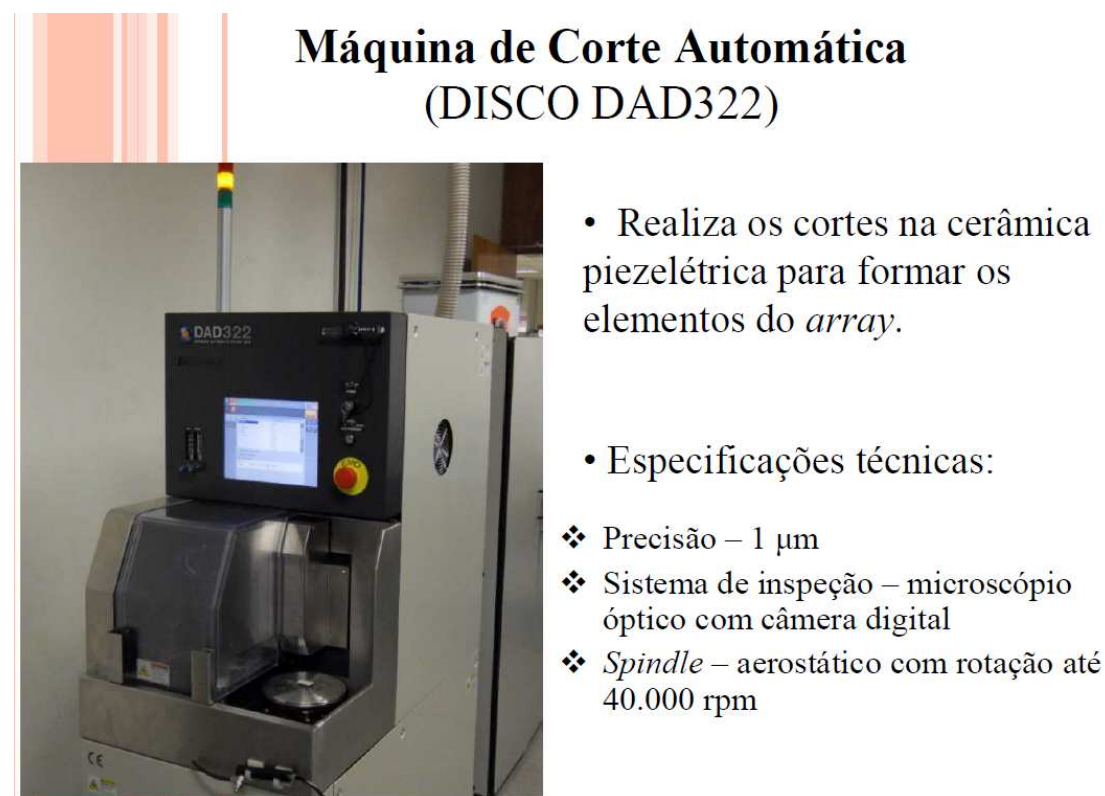

Fonte: Autora

Os parâmetros de corte no componente são apresentados na Tabela 5

Tabela 5- Parâmetros de corte da amostra

\begin{tabular}{|l|l|}
\hline Rotação & $45000 \mathrm{RPM}$ \\
\hline Avanço & $2 \mathrm{~mm} / \mathrm{min}$ \\
\hline Vazão Frontal (bucal) & $1 \mathrm{~L} / \mathrm{min}$ \\
\hline Vazão Chuveiro (lateral) & $0,5 \mathrm{~L} / \mathrm{min}$ \\
\hline Disco (espessura e tamanho diamante) & $40 \mu \mathrm{m} \mathrm{e} 4 \mu \mathrm{m}$ \\
\hline
\end{tabular}

Fonte: Autora

A Figura 30 mostra o corte realizado pela máquina de corte automática na parte superior da amostra de $\mathrm{Bi}_{4} \mathrm{Ge}_{3} \mathrm{O}_{12}$. 
Figura 30- Resultado final do corte da amostra de $\mathrm{Bi}_{4} \mathrm{Ge}_{3} \mathrm{O}_{12}$

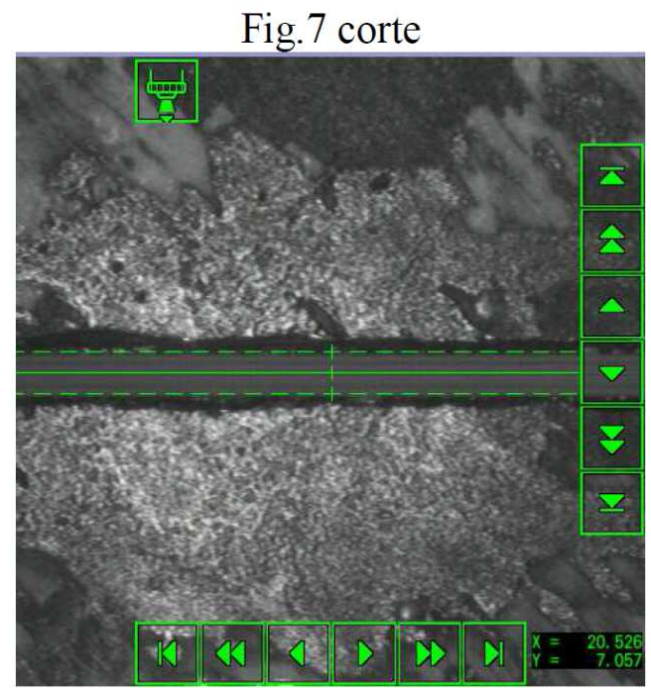

Fonte: Autora

\subsection{Etapas 11: polimento de quina no componente}

$\mathrm{Na}$ etapa de polimento óptico de quina no componente, nesse caso, no modulador eletroóptico foi utilizada a sequência de lixas com granulações diferentes apresentada na Tabela 6. No processo de polimento foi usado um suporte mostrado na Figura 31, que é fixado no equipamento de polir fibras ópticas do Laboratório de Subdivisão de Óptica Aplicada (EFOO) da Divisão de Fotônica (EFO) do IEAv/DCTA, como ilustra a Figura 32.

Figura 31- Suporte para prender o BGO na Politriz

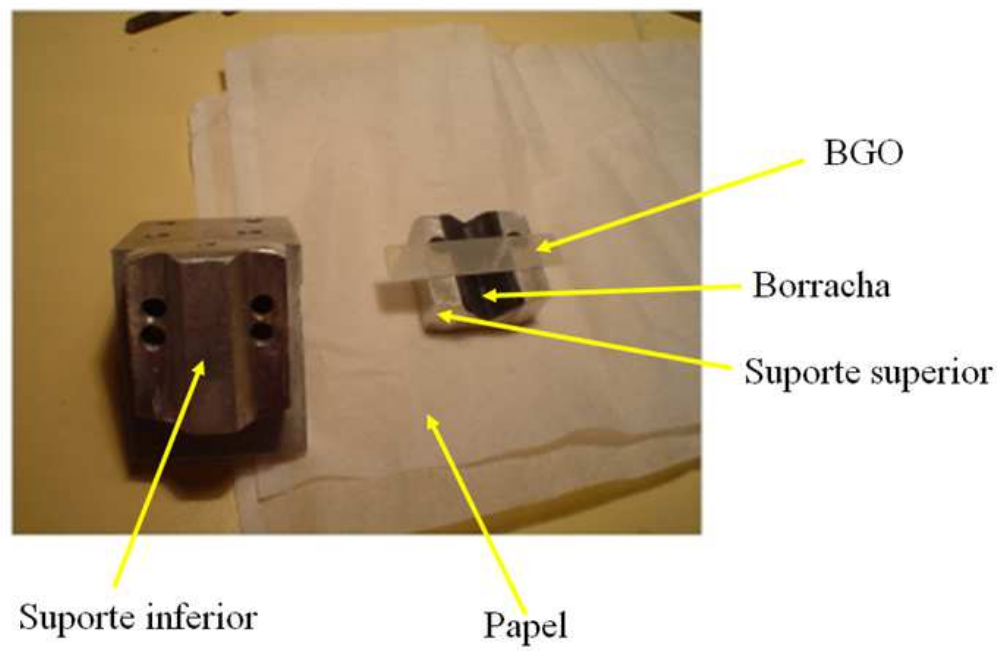

Fonte: Autora 
Figura 32- Politriz

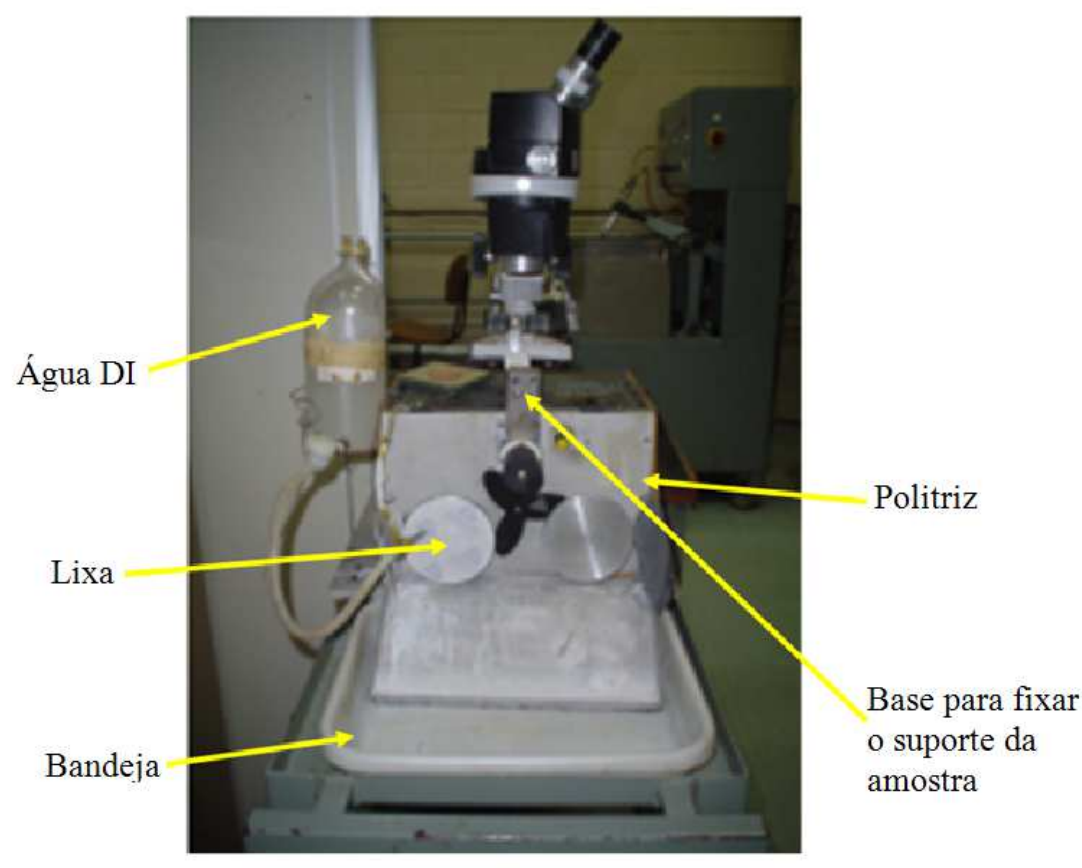

Fonte: Autora

A Figura 33 ilustra as lixas que foram usadas nesse procedimento de polimento.

Tabela 6- Parâmetros de polimento de quina no modulador eletro-óptico

\begin{tabular}{|l|c|}
\hline LIXA (GRANULAÇÃO - MICRO) & TEMPO DE POLIMENTO (min) \\
\hline Amarela - 12 (Óxido de Alumínio $\left.-\mathrm{Al}_{2} \mathrm{O}_{3}\right)$ & 10 \\
\hline Azul - $9\left(\mathrm{Al}_{2} \mathrm{O}_{3}\right)$ & 10 \\
\hline Cinza $-3($ Silicon Carbide) & 10 \\
\hline Lilás $-1\left(\mathrm{Al}_{2} \mathrm{O}_{3}\right)$ & 15 \\
\hline Branca $-0,3\left(\mathrm{Al}_{2} \mathrm{O}_{3}\right)$ & 10 \\
\hline
\end{tabular}

Fonte: Autora 
Figura 33- Lixas usadas no processo de polimento óptico de quina e borda

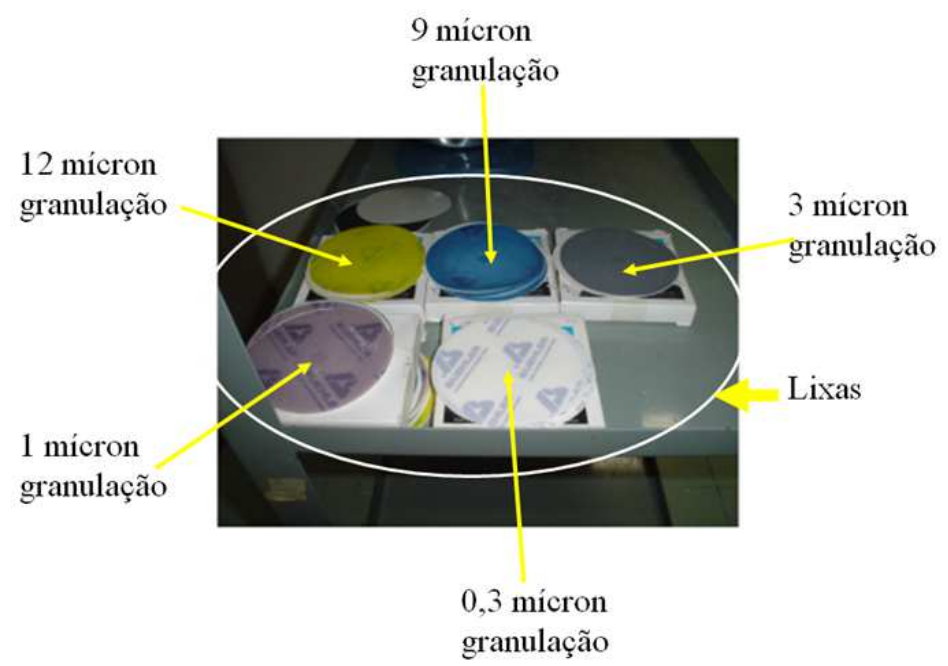

Fonte: Autora

Seguindo a ordem da granulação das lixas, apresentada acima, é possível obter um polimento óptico de quina e borda.

\subsection{Medidas realizadas pelo stress meter (modelo flx - 2410)}

A tensão total extraída com o uso do medidor de tensão total FLX - 2410 é calculada utilizando-se a equação [119, 120] abaixo:

$$
\sigma_{t}=\frac{E_{S}-h_{S}^{2}}{\left(1-v_{S}\right) \cdot 6 \cdot R \cdot t}
$$

onde

$E_{S} / 1-v_{S}$ é o módulo de elasticidade do substrato, $h_{S}$ é a espessura do substrato, $t$ é a espessura do filme, $R$ é o raio efetivo da curvatura e $\sigma_{t}$ é a tensão total média do filme.

R é calculado por:

$$
R=\frac{R_{1} \cdot R_{2}}{\left(R_{1}-R_{2}\right)}
$$


$\mathrm{R}_{1}$ é o raio de curvatura do substrato antes da deposição do filme, $\mathrm{R}_{2}$ é o raio de curvatura do substrato com o filme depositado.

Neste trabalho, os valores dos raios de curvatura das superfícies dos substratos de Si e de $\mathrm{Bi}_{4} \mathrm{Ge}_{3} \mathrm{O}_{12}$ foram extraídas do equipamento Flextrace FLX-2410, da Tencor Instruments [121], cujo princípio de funcionamento baseia-se em varrer "perpendicularmente" a superfície dos substratos com um feixe de luz, como por exemplo, um feixe de $L A S E R$, o qual é refletido de volta a um detector óptico que determina a posição do spot de luz. Conhecendo-se a geometria do equipamento, obtêm-se a variação da posição do spot durante a medida e o seu resultado é convertido em raio de curvatura da superfície do substrato.

A etapa de medição é iniciada pelo substrato de Si, pois esse substrato é bem conhecido pelos pesquisadores e está documentado na literatura. Antes de realizar a deposição do filme de $\mathrm{Si}_{3} \mathrm{~N}_{4}$, é feita uma medição do raio de curvatura do substrato de $\mathrm{Si}$. Os valores extraídos pelo stress meter são armazenados em seus dados e depois de realizar a deposição do filme, é feita uma nova medição do raio de curvatura do conjunto (substrato + filme). Com isso obtém-se o valor da tensão do filme depositado. Foi realizado o mesmo processo descrito acima com o substrato de $\mathrm{Bi}_{4} \mathrm{Ge}_{3} \mathrm{O}_{12}$.

A tensão total do filme de $\mathrm{Si}_{3} \mathrm{~N}_{4}$, medida na temperatura ambiente, que foi depositado na amostra a uma temperatura de processo de $720^{\circ} \mathrm{C}$ (filme estequiométrico, Si/N) foi de 0,75 .

A tensão térmica, $\sigma_{t h}$, que depende da diferença dos coeficientes de expansão térmica linear do filme e do substrato, é calculada pela equação abaixo [122, 123]:

$$
\sigma_{t h}=\left(\alpha_{f}-\alpha_{S}\right) \cdot \Delta T \cdot \frac{E_{f}}{1-v_{f}}
$$

onde:

$\alpha_{f}$ e $\alpha_{S}$ são os coeficientes de expansão linear térmica do filme de $\mathrm{Si}_{3} \mathrm{~N}_{4}$ e do substrato de $\mathrm{Bi}_{4} \mathrm{Ge}_{3} \mathrm{O}_{12}$, respectivamente, $E_{f}$ é o módulo de Young ou de elasticidade do filme; $v_{f}$ é a razão de Poisson do filme e $\Delta T$ é a variação de temperatura. 
Para calcular a tensão intrínseca é usada a equação de tensão total, que é a soma das duas componentes principais, isto é, $\sigma_{t h}$ mais tensão intrínseca $\left(\sigma_{i}\right)$, conforme a equação abaixo:

$$
\sigma_{t}=\sigma_{i}+\sigma_{t h}
$$

onde

$\sigma_{i}$ é a tensão intrínseca, $\sigma_{t}$ é a tensão total e $\sigma_{t h}$ é a tensão térmica.

A tensão intrínseca do filme de $\mathrm{Si}_{3} \mathrm{~N}_{4}$ é analisada por Espectroscopia de infravermelho (IV) [124]. Observou-se que o número de onda correspondente à vibração da ligação característica Si-N é função da temperatura de deposição. É necessário um estudo dessa função para caracterizar o filme e dar sequência ao processo de medição de estresse total da amostra. Tal estudo será objeto de comentários na seção 4.2.7 do capítulo de resultados e discussões.

\subsection{Simulação auxiliando iterativamente o processo de fabricação de dispositivos em óptica integrada}

Nessa seção é apresentada a proposta de método pelo qual a simulação do modulador eletroóptico baseado em guia de onda do tipo canal auxiliaria iterativamente o processo de fabricação desse modulador.

A proposta do processo iterativo prevê que, a partir dos resultados das simulações sejam definidos os parâmetros de fabricação do filme, da trincheira e dos eletrodos. Após a fabricação desses elementos, o componente deve ser caracterizado para que sejam medidos os parâmetros reais do filme e do substrato. Esses valores devem então ser realimentados nas simulações para refinar o projeto do componente.

Resumidamente, o método proposto consiste em:

1. Simular numericamente um projeto de um modulador eletro-óptico baseado em guia de onda do tipo canal, em um substrato de BGO, usando a técnica ISS no programa COMSOL;

2. Fabricar o modulador eletro-óptico baseado em guia de onda do tipo canal com os parâmetros fornecidos pela simulação. Em primeiro lugar, é necessário realizar a 
deposição do filme fino sobre o substrato. A seguir são feitos os processos de litografia óptica e corrosão por plasma para obter as trincheiras dos guias. Depois disso, devem ser depositados os eletrodos metálicos sobre o filme e por último, devem ser realizados os processos de litografia óptica e corrosão do metal para a formação das linhas dos eletrodos;

3. Caracterizar o modulador eletro-óptico baseado em guia de onda do tipo canal em OI fabricado através de: medida de estresse do substrato (antes e depois da deposição do filme indutor de tensão mecânica), medida da espessura do filme e dos eletrodos através de perfilômetro, verificação da existência de modos guiados por acoplamento direto de luz nas regiões dos guias na borda do substrato, medição do tamanho do modo por projeção do campo próximo em anteparo, medição da tensão de meia onda; (objetivo específicos 6 e 7)

4. Realimentar com os parâmetros fornecidos pelo processo de fabricação a simulação no programa COMSOL;

5. Comparar os resultados da simulação com os resultados da fabricação do modulador eletro-óptico;

6. Caso os resultados do processo de fabricação não correspondam como os resultados simulados, voltar para o passo 2 desse método e refazer os passos seguintes;

Refazendo os passos desse método, é possível realizar o refinamento das simulações numéricas e dos processos de fabricação do componente de forma iterativa, até chegar a um resultado desejado.

O método visa auxiliar iterativamente o processo de fabricação, eliminando o desperdício de materiais e tempo de processo, assim como refinando iterativamente a simulação, tornando-a mais próxima da realidade.

Não foi possível realizar todos os passos desta proposta durante a execução deste trabalho, tendo-se atingido até a etapa 2. Como é apresentado no capítulo que trata dos trabalhos futuros, pretende-se dar continuidade às atividades iniciadas neste trabalho, e almejando concluir o processo iterativo aqui proposto.

No próximo, capítulo em que são apresentados os resultados simulados e experimentais, são também discutidos alguns aspectos desse método iterativo. 


\section{RESULTADOS E DISCUSSÕES}

A autora usou o programa Comsol Multiphysics ${ }^{\circledR}$ (disponível comercialmente) do laboratório da Divisão de Física Aplicada (EFA) da Subdivisão de Eletromagnetismo Aplicado (EFA-E) do IEAv/DCTA para simular numericamente um projeto de modulador eletro-óptico baseado em guia de onda do tipo canal, construído em substrato de BGO, utilizando-se a técnica ISS. Essas simulações são baseadas no MEF que acoplam fenômenos físicos (ver a seção 3.5.1 do capítulo 3) e são apresentadas na seção 4.1 deste capítulo.

A lâmina de $\mathrm{BGO}$ com faces superiores e inferiores rugosas, que nesse caso é o $\mathrm{Bi}_{12} \mathrm{GeO}_{20}$, com dimensões de $20 \mathrm{~mm}$ X $100 \mathrm{~mm}$ X $1 \mathrm{~mm}$ foi cortada em pedaços de $20 \mathrm{~mm}$ X $25 \mathrm{~mm}$ no Laboratório da EFO-O da EFO do IEAv/DCTA. Foi projetado e confeccionado um suporte como o qual pretendia-se prender os substratos de BGO para serem polidos (efeito de borda e quina) nas áreas desejadas. No entanto, como desejava-se construir moduladores com $V_{\pi}$ menor, foi decidido fazer novas compras de lâminas de BGO com comprimento maior, nas medidas de $30 \mathrm{~mm}$ X $50 \mathrm{~mm}$ X $1 \mathrm{~mm}$. Logo o suporte não serviria para essas lâminase não foi usado. Os resultados dos guias de onda do tipo canal em OI fabricados sobre essa lâmina são apresentados seção 4.2.2 deste capítulo.

A sala de processos e os equipamentos do LSI/EPUSP foram utilizados com o auxílio dos pesquisadores daquele laboratório para realizar a deposição do filme de $\mathrm{Si}_{3} \mathrm{~N}_{4}$ sobre o substrato de BGO. Os resultados dos processos de fabricação dos moduladores eletro-ópticos baseados em guias de onda do tipo canal são apresentados na seção 4.2 deste capítulo.

A máquina de corte automática modelo Disco DAD322, a máquina atende ao Laboratório de Sensores e Atuadores da Engenharia Mecatrônica e de Sistemas Mecânicos da Escola Politécnica da Universidade de São Paulo (PMR/EPUSP) foi apresentada o processo de corte dos componentes na seção 3.7 do capítulo 3 e os resultados de testes dos cortes do substrato de BGO (amostra danificada) são apresentados na seção 4.2.6 deste capítulo.

\subsection{Resultados das simulações numéricas e discussões}

Nas simulações numéricas foram implementadas as equações no programa COMSOL e foram obtidos como resultados gráficos: os perfis de deformações mecânicas, os modos de 
propagação ópticos, as equipotenciais elétricas e o campo elétrico, que são apresentados nas seções 4.1.1.1 e 4.1.1.2 deste capítulo.

\subsubsection{Primeiro grupo: rotações dos eixos do elipsoide de índice do substrato de $\mathrm{Bi}_{12} \mathrm{GeO}_{12}$ e as condições de contorno do problema}

A princípio pensou-se em depositar uma camada de $\mathrm{SiO}_{2}$ como filme indutor de tensão mecânica sobre os substratos BGO. Foi realizada uma simulação no COMSOL, definindo uma espessura de $500 \mathrm{~nm}$ para o filme de $\mathrm{SiO}_{2}$. O resultado dessa simulação indicava que inicialmente esta estrutura parecia promissora para a fabricação do componente desejado caso a temperatura de deposição do filme estivesse entre $900^{\circ} \mathrm{C}$ e $1000^{\circ} \mathrm{C}$. Os resultados dessas simulações são apresentados na seção 4.1.1.1 e 4.1.1.2 deste capítulo.

O primeiro grupo está dividido em dois subgrupos. Estes subgrupos estão classificados em dois tipos de rotação do elipsoide de índices dos materiais estudados. Em cada subgrupo são definidas as condições de contorno e são realizadas as análises dos efeitos elasto-óptico [56] e eletro-óptico [44, 45, 56], bem como a análise modal [58].

\subsubsection{Primeiro subgrupo do primeiro grupo: modulador eletro-óptico baseado em guias de onda do tipo canal em $\mathrm{OI}$ com filme indutor de $\mathrm{SiO}_{2}$}

Nas simulações realizadas no primeiro e no segundo subgrupo desse grupo considerou-se a deposição de um filme indutor de $\mathrm{SiO}_{2}$ sobre o substrato de $\mathrm{Bi}_{12} \mathrm{GeO}_{20}$. Considerou-se também que o substrato foi aquecido a $1000^{\circ} \mathrm{C}$ no primeiro subgrupo e, no segundo, foram consideradas as temperaturas de $900^{\circ} \mathrm{C}$ e $1000{ }^{\circ} \mathrm{C}$ durante a deposição desse filme. Esses dois estudos foram realizados no intuito de validar os resultados obtidos pelo programa COMSOL e foram comparados com os resultados do trabalho [45, 61, 62]. 
Foram consideradas as seguintes condições de contorno:

a) A Figura 34 ilustra o corte do substrato de $\mathrm{Bi}_{12} \mathrm{GeO}_{20}$;

b) As espessuras do filme de $\mathrm{SiO}_{2}(t)$ foram de $0,2 \mu \mathrm{m}$ a $1,5 \mu \mathrm{m}$, passos de $0,1 \mu \mathrm{m}$;

c) As larguras utilizadas do canal $(G)$ foram de 3 a $14 \mu \mathrm{m}$ passos de $1 \mu \mathrm{m}$;

d) As espessuras dos eletrodos metálicos foram de $1 \mu \mathrm{m}$ e $1,5 \mu \mathrm{m}$;

e) A temperatura do forno de deposição do filme de $\mathrm{SiO}_{2}$ foi de $1000^{\circ} \mathrm{C}$;

f) Foram inseridas as equações 3.9, 3.10, 3.11 e 3.12 que representam o efeito elastoóptico, as equações 3.25, 3.26 e 3.27 que representam o efeito eletro-óptico e a fórmula de dispersão do substrato e do filme no programa Comsol.

Figura 34- Modulador eletro-óptico em $\mathrm{Bi}_{12} \mathrm{GeO}_{20}$ com camada de filme indutor de tensão mecânica de $\mathrm{SiO}_{2}$ e dois eletrodos metálicos
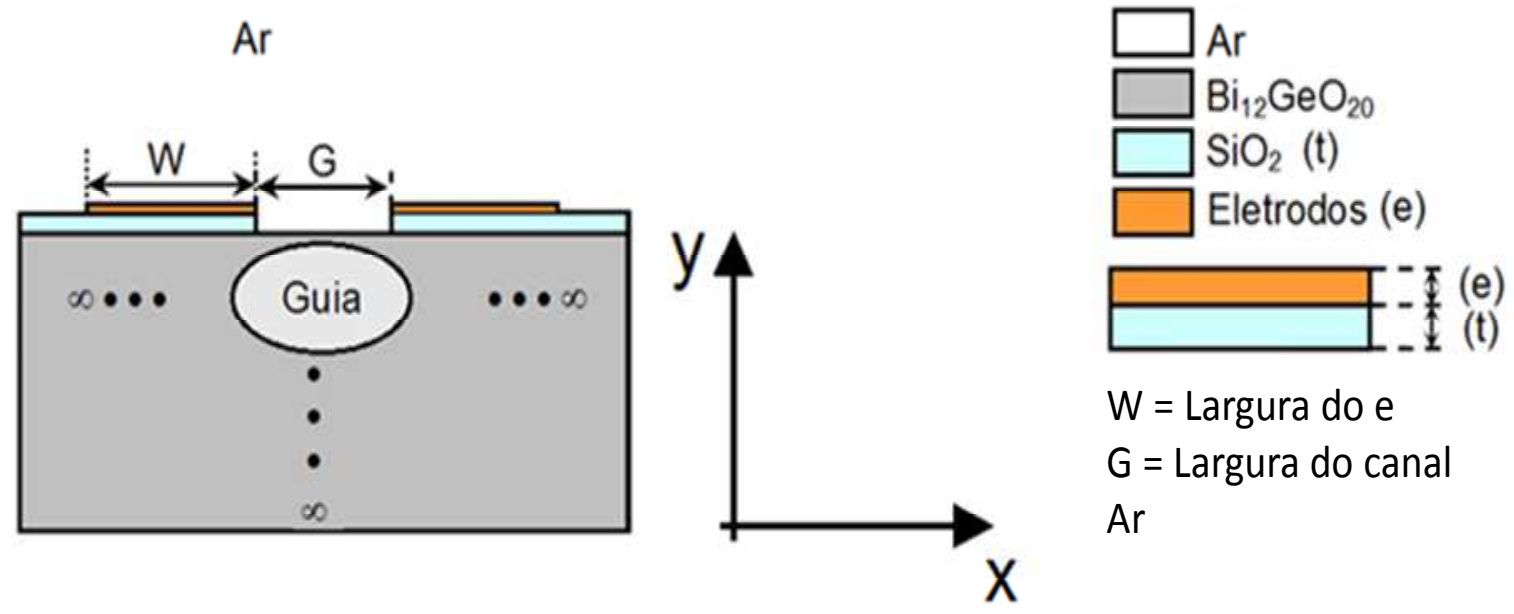

$\mathrm{W}=$ Largura do e

$\mathrm{G}=$ Largura do canal

$\mathrm{Ar}$

Fonte: [108]

A Figura 35 (a-c) mostram os perfis de deformação $S_{1}, S_{2}$ e $S_{6}$ na região induzida do guia óptico (trincheira de $5 \mu \mathrm{m}$ e espessura de filme de $1 \mu \mathrm{m}$ ). 
Figura 35- Perfis de deformação induzida na região do guia óptico do tipo canal. (a) Deformação $S_{1}$. (b) Deformação $S_{2}$. (c) Deformação $S_{6}$

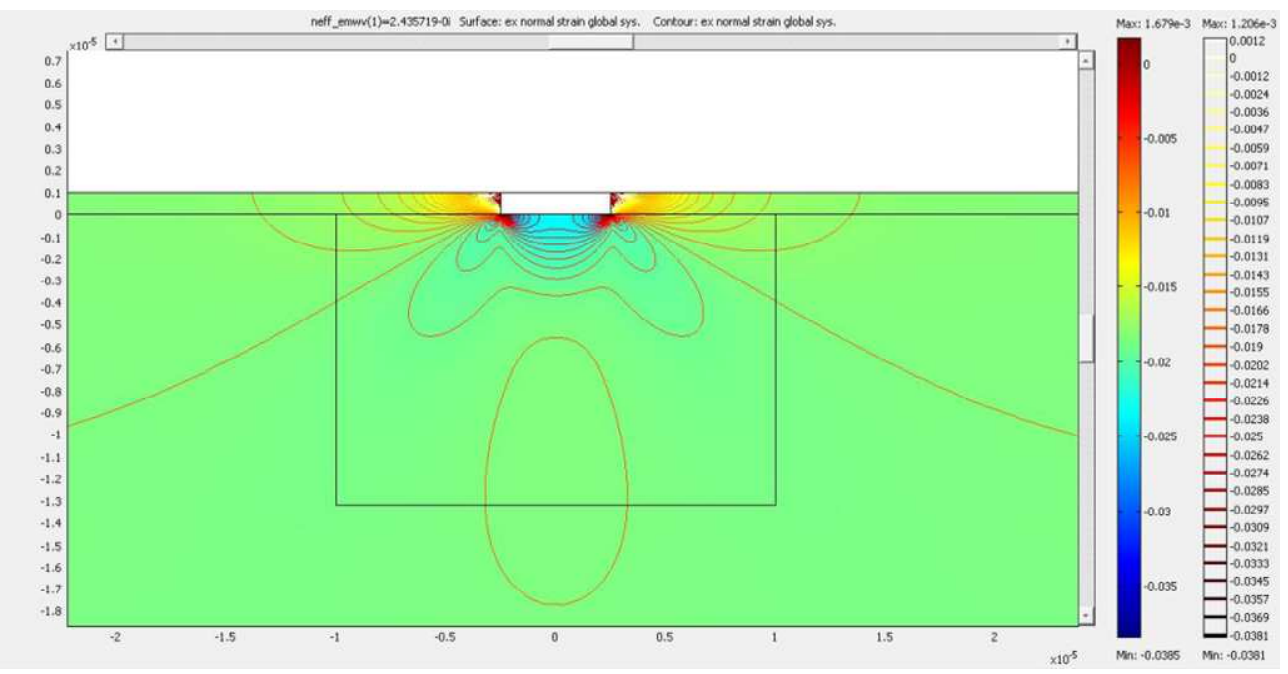

(a)

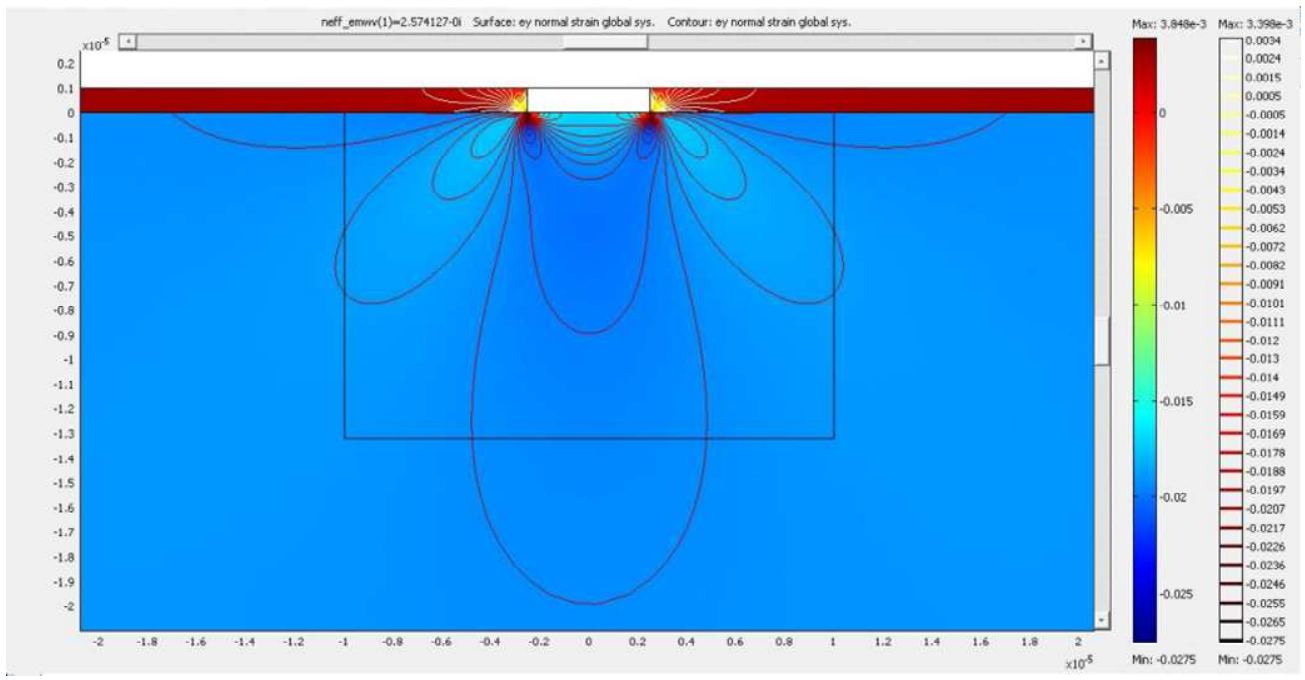

(b)

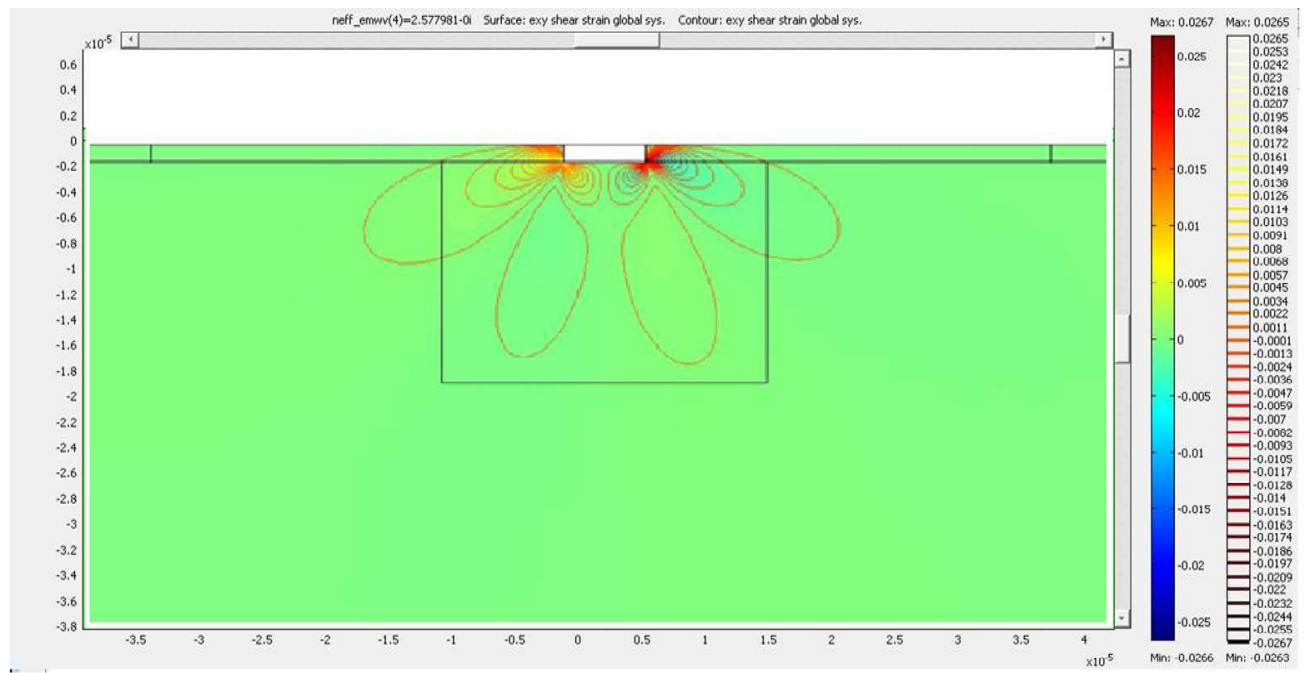

(c)

Fonte: [108] 
A análise quase-estática permite obtenção do perfil de potencial elétrico e, em seguida, a modulação da distribuição de campo elétrico. A Figura 36 mostra as isolinhas de potencial elétrico e os vetores locais representam o campo elétrico da onda de modulação.

Figura 36- Isolinhas de potencial elétrica e campo elétrico (vetores locais) da onda TEM. Vista da região da trincheira (gap)

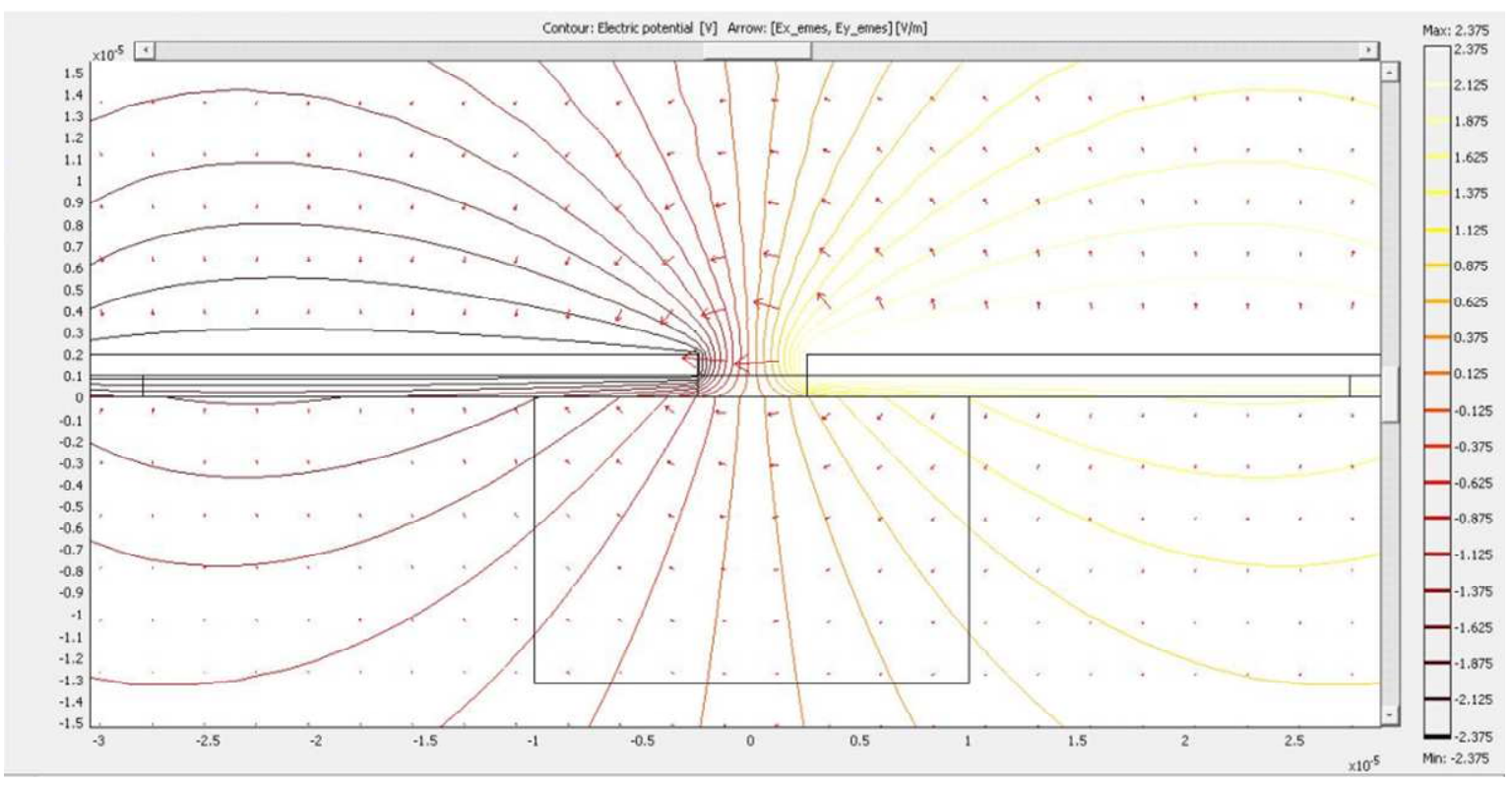

Fonte: [108]

A Figura $37(a-b)$ ilustra os perfis de monomodos dos campos ópticos modais típicos, $E^{x}$ e $E^{y}$. Os guias são obtidos pela técnica ISS com birrefringência aproximadamente de $10^{-4}$ com o campo aplicado para as configurações geométricas analisadas.

A Figura 38 mostra os índices efetivos ( $\underline{\text { neff })}$ dos modos $E^{x}$ guiados pela técnica ISS em função da largura da trincheira para diferentes espessuras do filme de $\mathrm{SiO}_{2}$. Os resultados desses índices são obtidos sem o campo aplicado, pois é necessário saber, qual das trincheiras obterá o modo desejado que case com a fibra óptica trabalhada. Quando a largura da trincheira aumenta, diminui o neff em função da espessura $(t)$ do filme de $\mathrm{SiO}_{2}$, contudo os valores de $t$ são muito pequenos. Além disso, os resultados neff são maiores quando $t$ aumenta.

Foram considerados eletrodos do tipo CPS (microlinhas acopladas) depositados desde o inicio do filme de $\mathrm{SiO}_{2}$ até o final do mesmo, portanto, as principais características do modulador de fase foram detalhadas na seção 2.6. 
Figura 37- Perfil do campo óptico modal. (a) $\operatorname{modo} E^{x}$. (b) $\operatorname{modo} E^{y}$

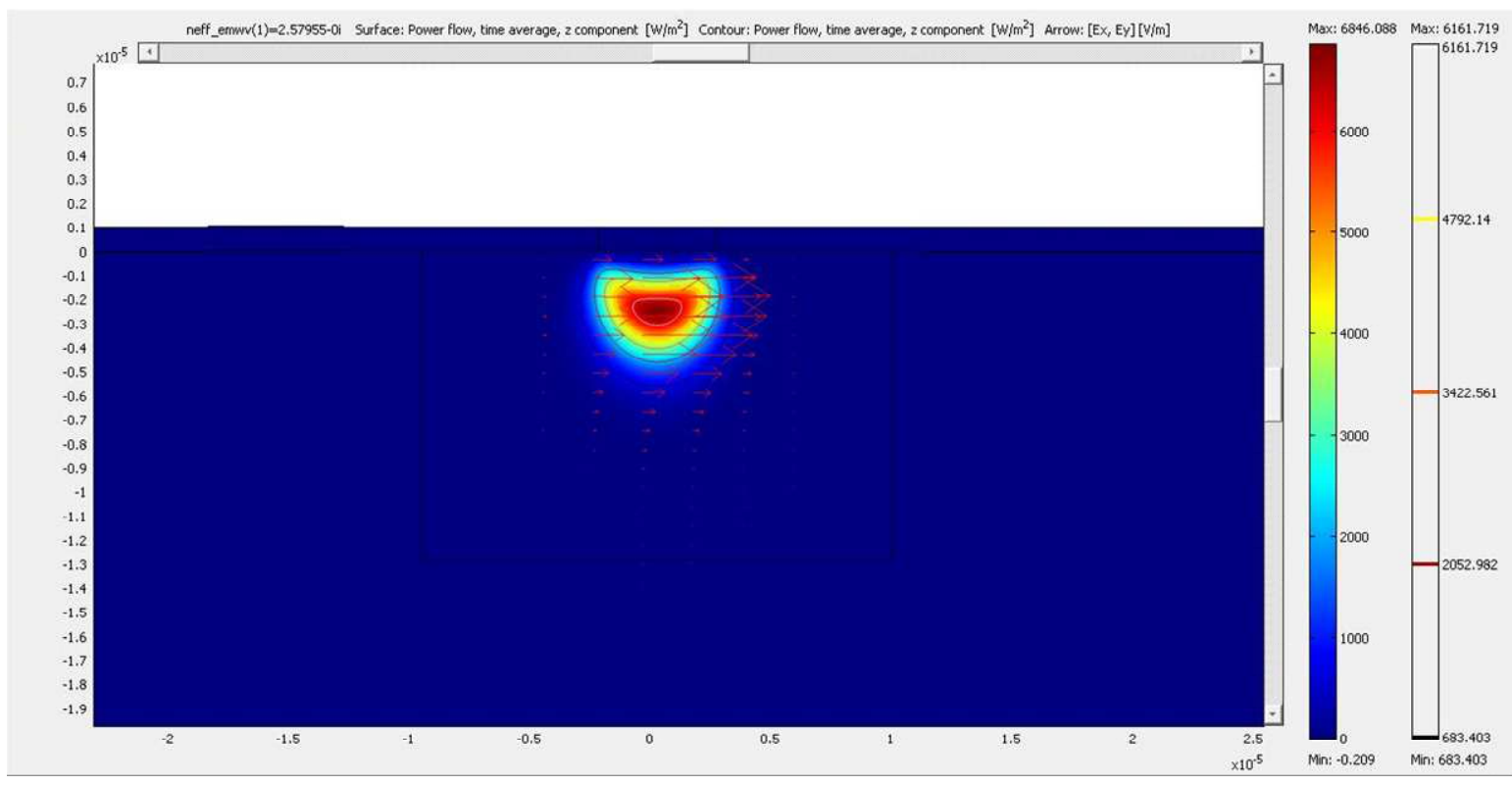

(a)

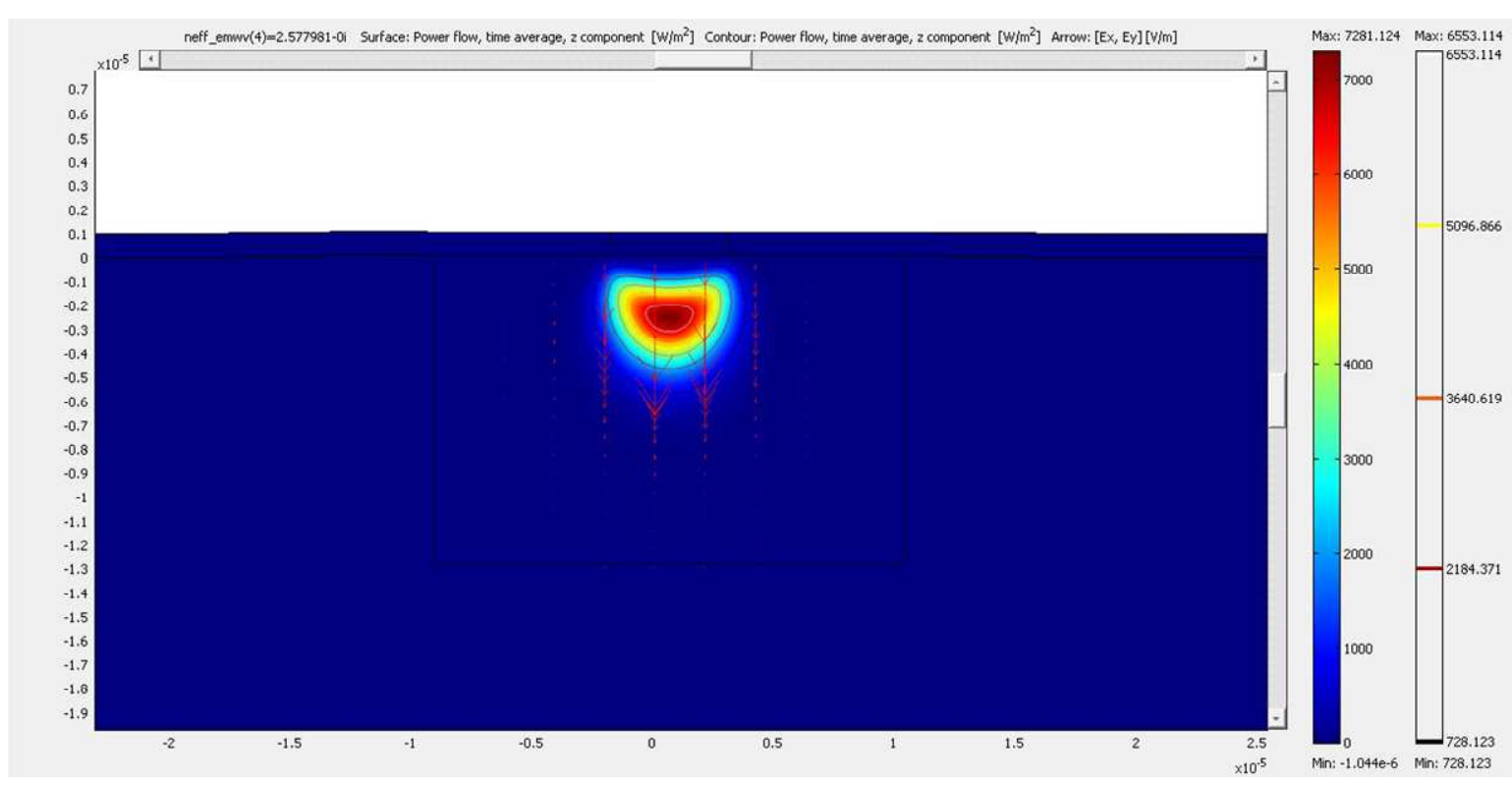

(b)

Fonte: [108] 
Figura 38- $\boldsymbol{n}_{\text {eff }}$ dos modos fundamentais ópticos guiados em função da largura do canal (trincheira), $G$, pela espessura do filme de $\mathrm{SiO}_{2}, t$, (passo a passo de $0,1 \mu \mathrm{m}$ )

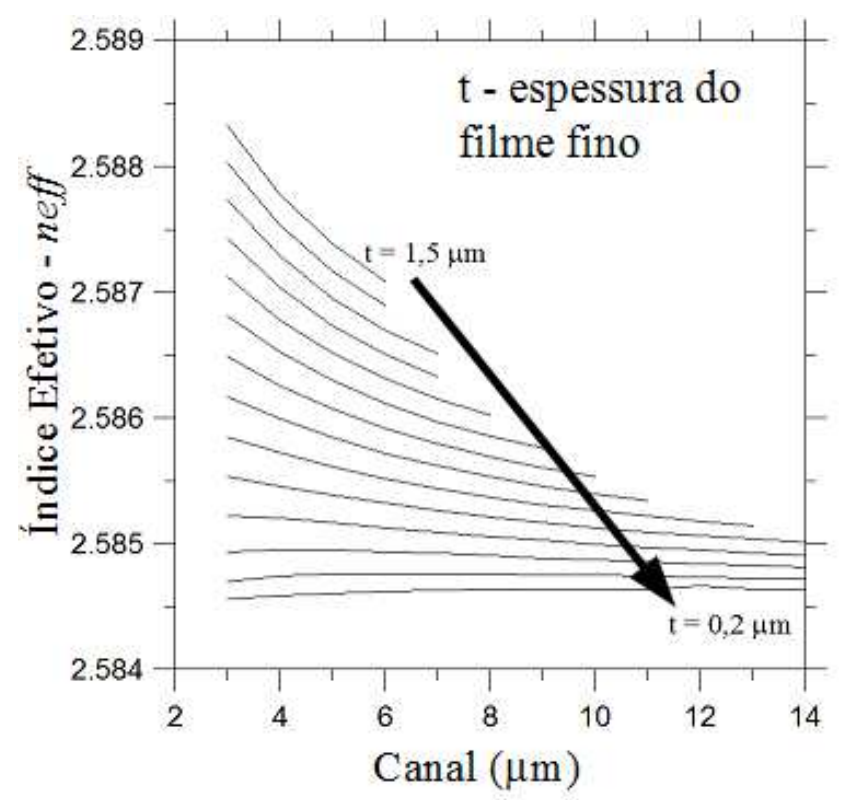

Fonte: [108]

A Figura 39 mostra a impedância característica $\left(Z_{c}\right)$ e Neff da onda elétrica modulante em função da largura do canal, considerando-se eletrodos e filme com espessura de $1 \mu \mathrm{m}$. A medida que a largura do canal, $G$, aumenta tanto a $Z_{c}$ e o $N$ eff atingem valores elevados. Para $G=9 \mu \mathrm{m}, Z_{c} \cong 49 \Omega$ e $N e f f \cong 3,2459$, resultando em uma impedância aproximadamente correspondente à da fonte externa de modulação, mas a largura de banda é pequena, porque Neff torna-se diferente de neff [79-82]. Se esse modulador for usado em telecomunicações, o valor de $Z_{c}$ é muito importante para transmissão de dados. Se ele for usado como componente de um sensor, o valor de $Z_{c}$ não é importante para transmissão de energia, pois nesse caso, o componente tem que exibir um valor de $V \pi$ baixo.

A Figura 40 mostra a $Z_{c}$ e o $N e f f$ (para onda elétrica-TEM) em função da espessura do filme de $\mathrm{SiO}_{2}, t$, para uma espessura de eletrodos, $e$, de $1 \mu \mathrm{m}$ e uma largura do canal, $G$, de $5 \mu \mathrm{m}$ [79-82].

A Figura 41 mostra a $Z_{c}$ e o Neff da onda elétrica-TEM para $G=5 \mu \mathrm{m}$ e $t=1 \mu \mathrm{m}$ em função da espessura dos eletrodos, $t$. De uma série de avaliações realizadas, o melhor conjunto de parâmetros geométricos encontrados foi: $G=5 \mu \mathrm{m}, t=1,5 \mu \mathrm{m}$ e $e=1 \mu \mathrm{m}$, resultando-se em $Z_{c}=48 \Omega$ e $N e f f=2,8192$ permitindo chegar a uma largura de banda de aproximadamente $57,6 \mathrm{GHz}$ [79-82]. O valor de $Z_{c}$ é satisfatório, se o componente for utilizado em 
telecomunicações, entretanto esse mesmo componente pode ser usado como compoente integrante de um sensor.

Figura 39- $Z_{c}$ e Neff da onda elétrica em função da largura do canal, $G$, e do filme de $\mathrm{SiO}_{2}$

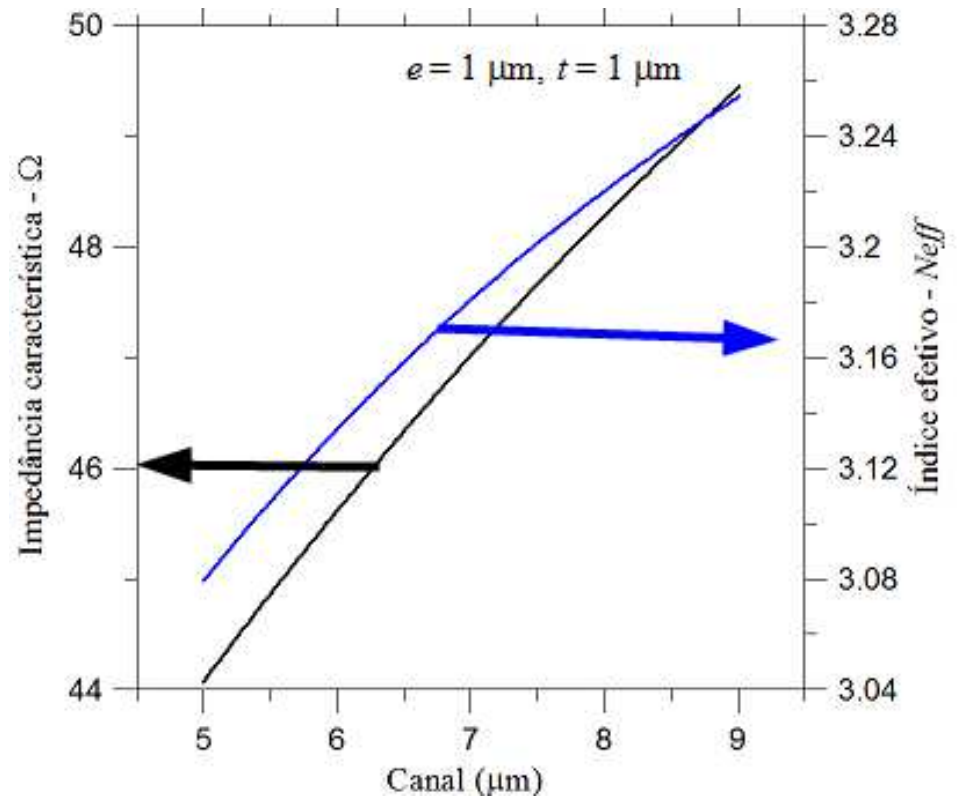

Fonte: [108]

Figura 40- $Z_{c}$ e Neff da onda elétrica em função da espessura do eletrodo, com $G=5 \mu \mathrm{m}$ e $t=1 \mu \mathrm{m}$

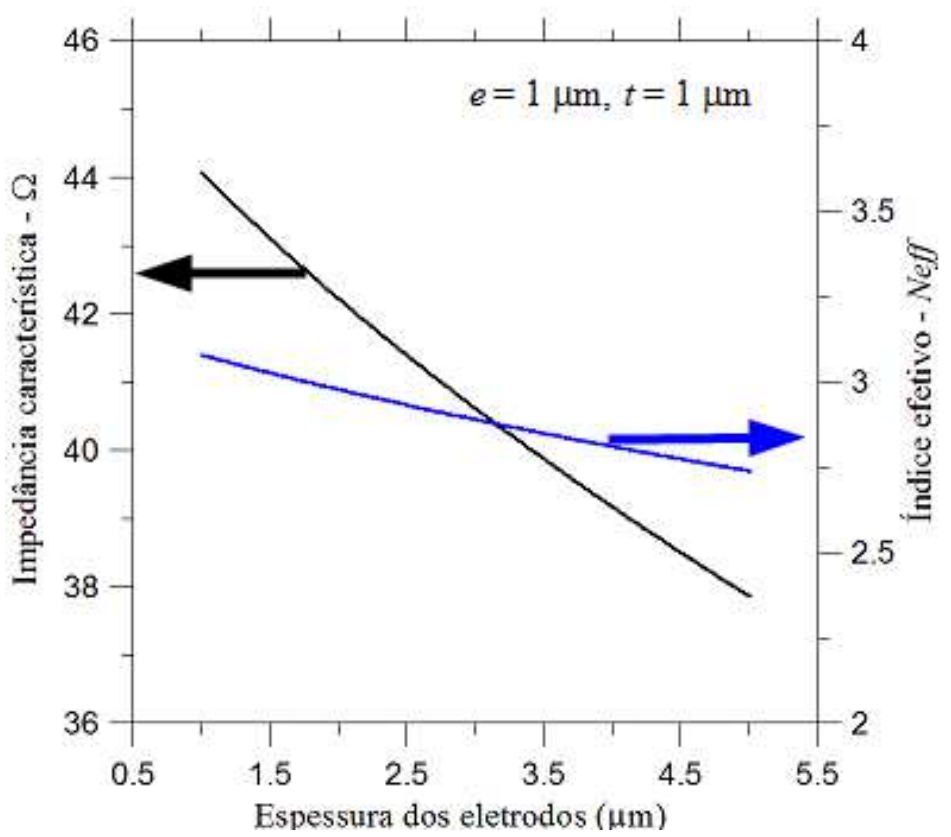

Fonte: [108] 
Figura 41- $Z_{c}$ e Neff da onda elétrica em função da espessura do filme fino $\mathrm{SiO}_{2}$ para $G=5 \mu \mathrm{m}$ e $e=$ $1 \mu \mathrm{m}$

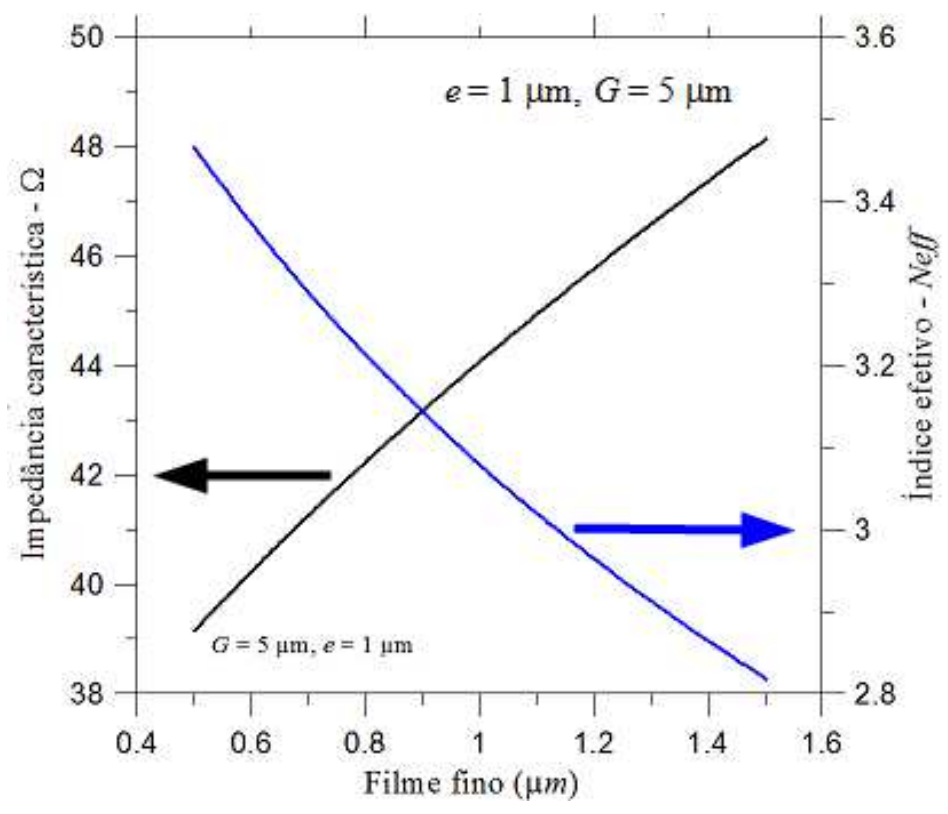

Fonte: [108]

A integral de sobreposição $(\Gamma)$ indica o fator espacial de acoplamento entre o campo óptico elétrico e o campo óptico. O perfil de modulação do campo elétrico foi também avaliado em função desse parâmetro [79-82]. Para guias ópticos (com eletrodos do tipo CPS) de $e=1 \mu \mathrm{m}$ e $t=1,5 \mu \mathrm{m}$, os valores do fator da integral de sobreposição correspondentes a $G=5 \mu \mathrm{m}, 7$ $\mu \mathrm{m}$ e $8 \mu \mathrm{m}$ são de $14,53 \%, 17,66 \%$ e $20,21 \%$, respectivamente.

A partir da análise modal é possível avaliar a variação do neff $x$ e neffy quando uma modulação externa é aplicada. Constatou-se que o efeito eletro-óptico causa a $\Delta n e f f x$ aproximadamente $2,99 \times 10^{-4}$, e esse valor é praticamente insencivel a alterações dos parâmetros $e$ do modulador e $\Delta V$ da simulação. No entanto, neffy é sensível a mudanças de outros parâmetros do modulador e a diferentes valores de $\Delta V$. Para o modo $E^{y}, \Delta$ neffy varia de 2,97 $10^{-4}$ até 2,67 x $10^{-4}$ quando $\mathrm{G}$ varia de $5 \mu \mathrm{m}$ a $9 \mu \mathrm{m}$. Considerando $\Delta V$ igual a $1 V, 5 V$ e $20 V$ obtem-se a $\Delta$ neffy assumindo os valores de $2,94 \times 10^{-4}, 2,97 \times 10^{-4}$ e $3,1 \times 10^{-4}$, respectivamente, como mostra a Figura 42.

Os resultados obtidos pela simulação foram baseados nos trabalhos $[58,62,68]$, que não estão relatados nesta tese. Aqueles trabalhos concederam confiança na utilização do programa $\mathrm{COMSOL}^{\circledR}$ para dar continuidade a este trabalho. 
Figura 42- $\Delta V$ e $\Delta$ neffy em função da largura do canal $e=1 \mu \mathrm{m}$ e $t=1 \mu \mathrm{m}$

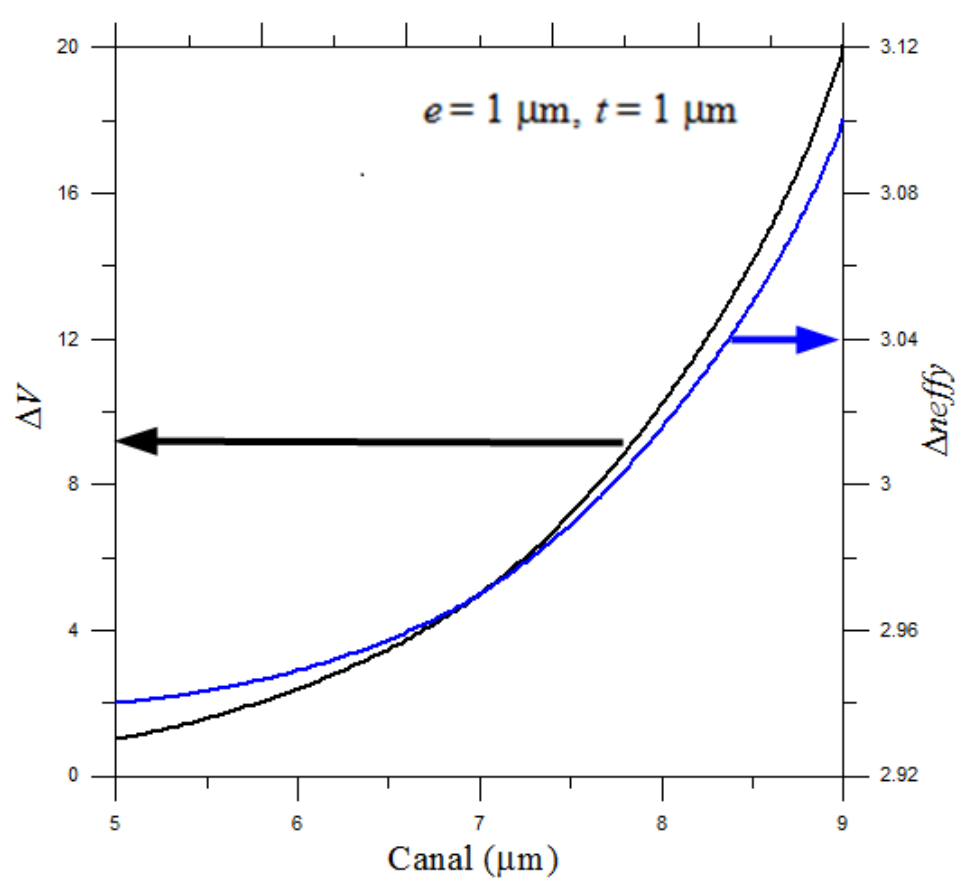

Fonte: [108]

\subsubsection{O segundo subgrupo do primeiro grupo: modulador eletro-óptico baseado em} guias de onda do tipo canal em OI na orientação ( $\overline{1} 10$ ) e propagação em $z^{\prime}$

Foram consideradas as seguintes condições de contorno:

a) A Figura 43 ilustra o corte do substrato de $\mathrm{Bi}_{12} \mathrm{GeO}_{20}$;

b) Foram consideradas as mesmas medidas (as espessuras do filme e dos eletrodos e a largura do canal) do primeiro subgrupo do primeiro grupo;

c) As temperaturas utilizadas no forno de deposição do filme foram de $1000^{\circ} \mathrm{C}$ e $900^{\circ} \mathrm{C}$;

d) Foram inseridas as equações 3.19, 3.20 e 3.21 que representam o efeito elasto-óptico, as equações 3.25, 3.26 e 3.27 que representam o efeito eletro-óptico e a fórmula de dispersão do substrato e do filme no programa Comsol. 
Figura 43- Modulador eletro-óptico em $\mathrm{Bi}_{12} \mathrm{GeO}_{20} \mathrm{com}$ filme indutor de tensão mecânica de $\mathrm{SiO}_{2}$ e dois eletrodos metálicos

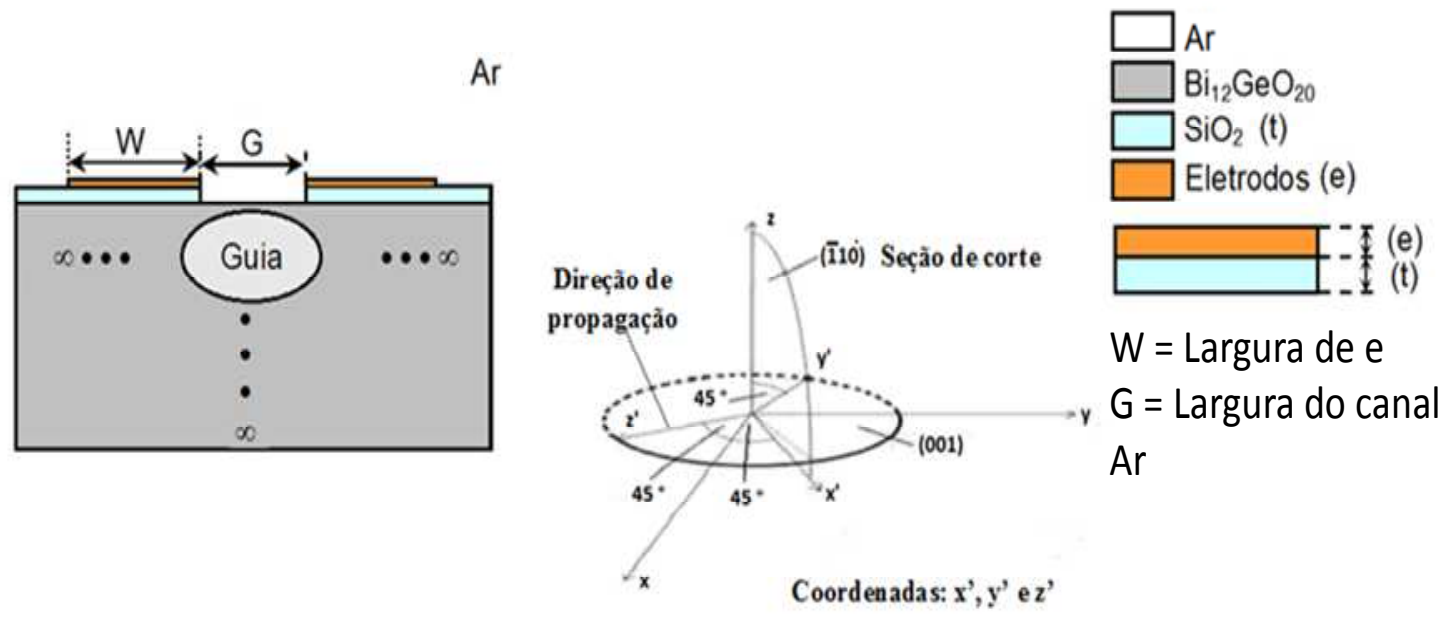

Fonte: [109].

Os perfis de deformação $S_{1}, S_{2}$ e $S_{6}$, de isolinhas do potencial elétrico e das representações do vetor de um campo elétrico local são semelhantes aos resultados obtidos para o primeiro subgrupo do primeiro grupo, apresentados nas Figuras 35 (a-c) e na Figura 36 [109].

A Figura 44 (a-b) mostra os perfis dos modos $E^{x}$ e $E^{y}$. Os guias são obtidos pela técnica ISS com birrefringência de aproximadamente $10^{-3}$ para a configuração de geometria analisada. Essa birrefringência apareceu após aplicar a tensão mecânica, no entanto ela é considerada elevada, o que indica que esta configuração não é adequada para a construção do componente desejado.

A Figura 45 (a-b) ilustra os neff dos modos $E^{x}$ do guia de onda óptico pela técnica ISS em função da largura do canal para diferentes espessuras do filme de $\mathrm{SiO}_{2}$. Quando a largura do canal aumenta, o índice efetivo, neff diminui para os filmes espessos de $\mathrm{SiO}_{2}(t)$, mas para filmes estreitos (finos), neff é aproximadamente constante. Além disso, o aumento da espessura de $t$ resulta em valores mais altos de neff, para ambas as temperaturas de deposição $\left(900^{\circ} \mathrm{C}\right.$ e $\left.1000^{\circ} \mathrm{C}\right)$. 
Figura 44- Perfil do campo modal óptico. (a) Modo $E^{x}$. (b) Modo $E^{y}$

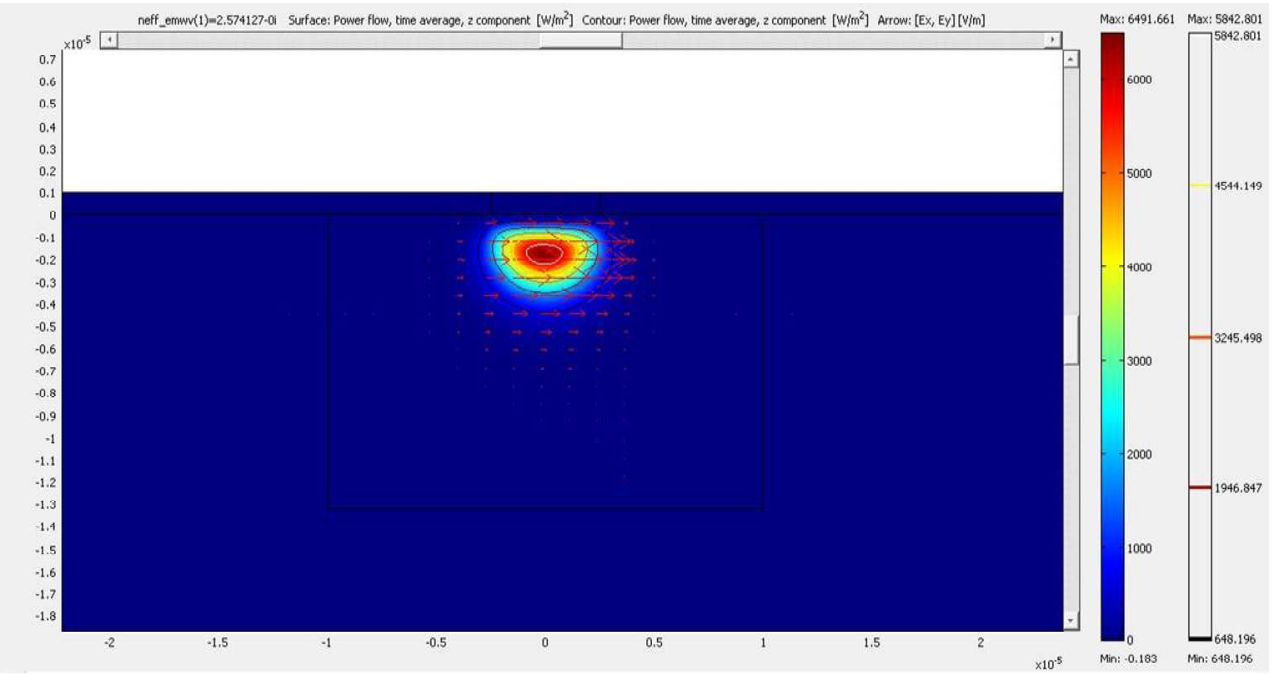

(a)

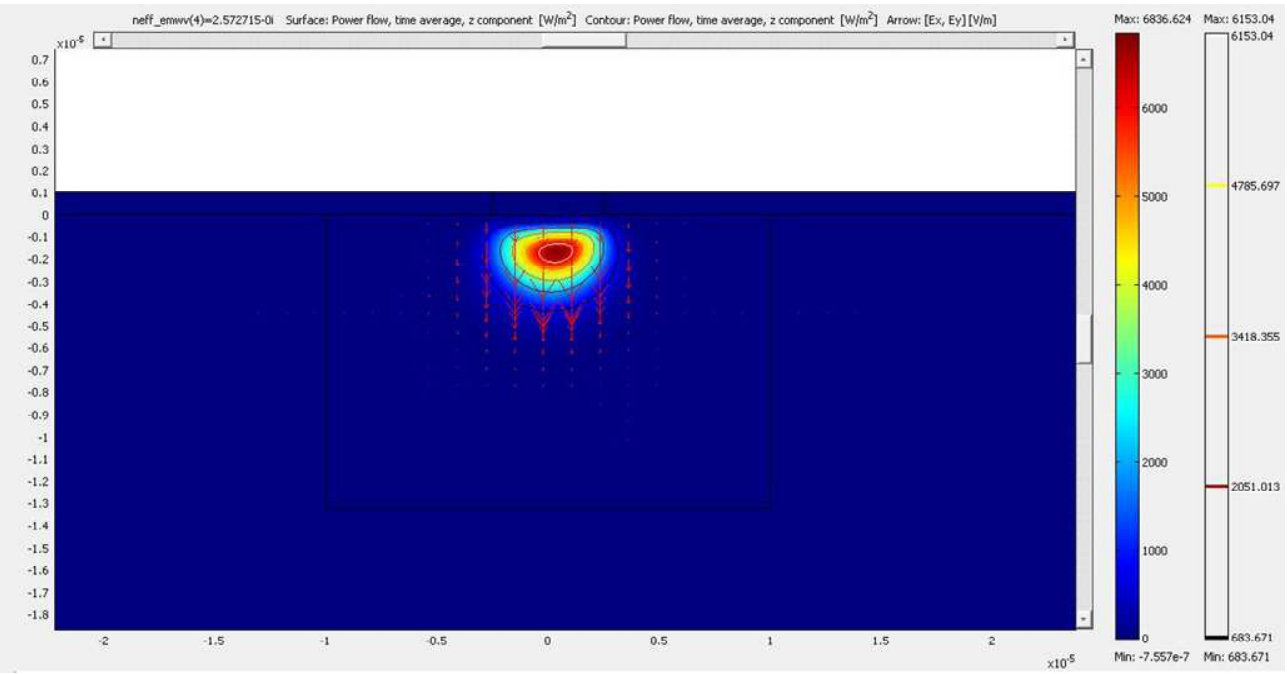

(b)

Fonte: [109] 
Figura 45- neff do monomodo guiado em função largura do canal, $G$, e da espessura do filme de $\mathrm{SiO}_{2}, t$, (passo a passo de $0,1 \mu \mathrm{m}$ ). (a) Temperatura de $900^{\circ} \mathrm{C}$. (b) Temperatura de ${ }_{1000^{\circ} \mathrm{C}}$

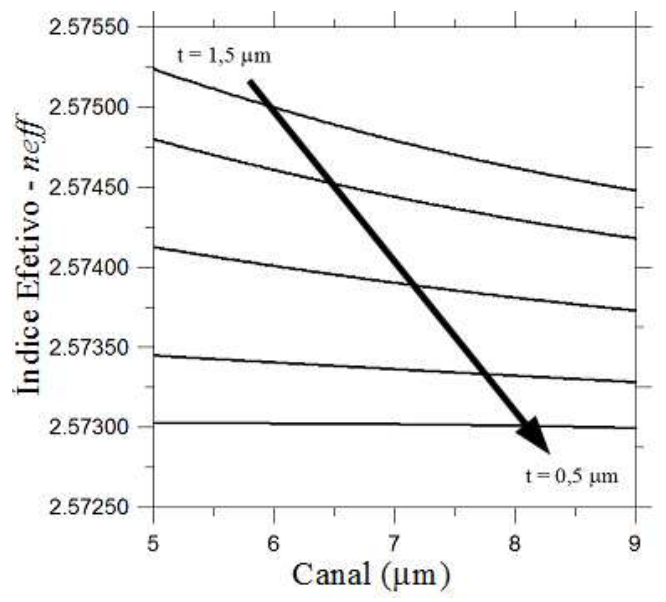

(a) Temperatura de $900^{\circ} \mathrm{C}$.

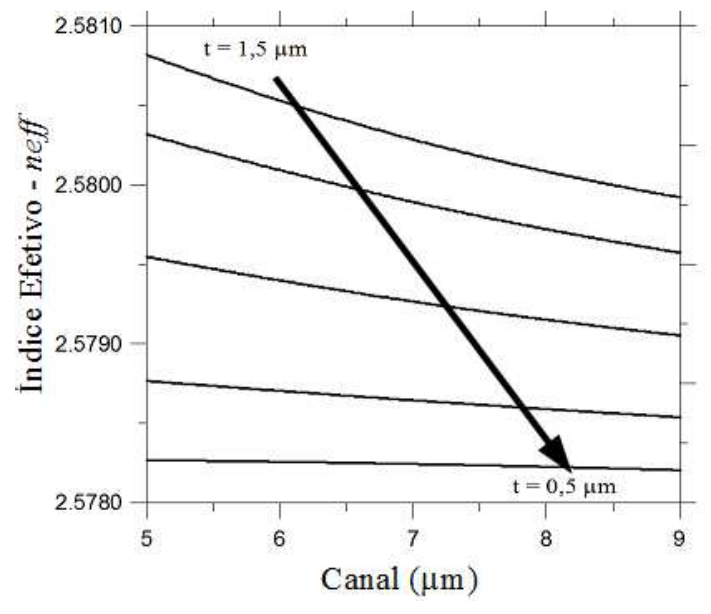

(b) Temperatura de $1000^{\circ} \mathrm{C}$.

Fonte: [109].

A Figura 46 (a) mostra $Z_{c}$ e Neff da onda elétrica modulante em função da largura do canal. Foram utilizadas as mesmas espessuras dos eletrodos e do filme do trabalho anterior. Os resultados obtidos para $Z_{c}$ e do Neff aumentaram em relação aos anteriores. Para $G=9 \mu \mathrm{m}$, a $Z_{c}$ é aproximadamente de $51 \Omega$ e o $N$ eff é aproximadamente de 3,22 , resultando em $Z_{c}$ ligeiramente maior do que a da fonte externa de modulação, mas a largura de banda é menor do que a do caso anterior, porque Neff é muito diferetente do neff.

A Figura 46 (b) apresenta $Z_{c}$ e Neff da onda modulante (onda elétrica-TEM) em função das espesssuras dos eletrodos, $e$, para as espessuras do filme de $\mathrm{SiO}_{2}, t, 1 \mu \mathrm{m}$ e largura do canal, $G$, de $5 \mu \mathrm{m}$. A $Z_{c}$ e Neff da onda elétrica-TEM também foi avaliado na função da espessura do filme de $\mathrm{SiO}_{2}$.

Os resultados apresentados na Figura 46 (c) foram obtidos para os seguintes valores de parâmetros: $G=5 \mu \mathrm{m}, t=1,5 \mu \mathrm{m}$ e $e=1 \mu \mathrm{m}$, resultando em $Z_{c}=48,134 \Omega$, Neff $=2,819$, e $n e f f=2,575784$. A largura de banda, neste caso, é aproximadamente de 57,6 GHz.

Foi analisada a sobreposição do perfil do campo elétrico de modulação com o campo óptico através do parâmetro $\Gamma_{\text {sob }}$. Para os eletrodos do tipo CPS com $e=1 \mu \mathrm{m}$ e t $=1,5 \mu \mathrm{m}$, os valores das integrais de sobreposição correspondentes a $G=5 \mu \mathrm{m}, 7 \mu \mathrm{m}$ e $9 \mu \mathrm{m}$ são de $14,53 \%, 17,66 \%$ e $20,21 \%$ respectivamente. 
Quando a modulação externa é aplicada, a partir da análise modal é possível analisar a variação de neffx e neffy. Nesta análise foi observado que o efeito eletro-óptico causa $\Delta n e f f x$ de aproximadamente $2,9910^{-4}$, sendo este valor quase insencível aos parâmetros $e$ e $\Delta V$ do modulador. No entanto, neffy é sensível a mudanças nos parâmetros da geometria do modulador para diferentes valores de $\Delta V$.

Na primeira simulação foi usada uma orientação $x y$ e propagação em $z$, uma orientação mais simples do elipsoide de índice do efeito elasto-óptico no cristal de BGO. No entanto, quando é aplicado o efeito eletro-óptico no componente, o modelamento do elipsoide de índice perturbado por desse efeito fica muito complexo para ser resolvido. Então, decidiu-se mudar de orientação do plano de corte de $x z$ com propagação em $z$ para a orientação do plano de corte ( 110$)$ e propagação em z’ (conforme mostrado na Figura 43), uma orientação mais complicada do cristal de BGO, mas que facilita o modelamento do efeito eletro-óptico, entretanto, a sua solução também é complicada.

A segunda simulação apresenta um aumento significativo da birrefringência (stress birrefrigence) em comparação com o resultado da primeira simulação. O valor do perfil do campo óptico modal da primeira simulação $(n x=2,57955$ e $n y=2,577981)$ é maior do que o valor do perfil do campo óptico modal da segunda simulação $(n x=2,574127$ e $n y=$ $2,572715)$.

Se esse modulador for usado em telecomunicações, o valor de $Z_{c}$ é muito importante para transmissão de dados. Se ele for usado como componente de um sensor, o valor de $Z_{c}$ não é importante para transmissão de energia, pois nesse caso, o componente tem que exibir um valor de $V \pi$ baixo.

A partir das simulações, os pesquisadores do grupo LSO/PEA/EPUSP em reunião com os pesquisadores do LSI/EPUSP decidiram não fabricar esse componente, como foi relatado na seção 3.2 do capítulo 3, porque o processo de deposição do filme indutor de $\mathrm{SiO}_{2}$ necessário para obter uma espessura de $500 \mathrm{~nm}$ é muito demorado. Ao invés disso, optou-se por utilizar o material de $\mathrm{Si}_{3} \mathrm{~N}_{4}$ como filme indutor de tensão mecânica.

Na seção abaixo são apresentados os resultados das simulações de moduladores, usando dois tipos de substratos $\left(\mathrm{Bi}_{4} \mathrm{Ge}_{3} \mathrm{O}_{12}\right.$ e $\left.\mathrm{Bi}_{12} \mathrm{GeO}_{20}\right)$ e o filme de $\mathrm{Si}_{3} \mathrm{~N}_{4}$. 
Figura 46- (a) $Z_{c}$ e Neff da onda elétrica em função da espessura do filme de $\mathrm{SiO}_{2}$. As espessuras dos eletrodos e do filme são de $1 \mu \mathrm{m}$. (b) $Z_{c}$ e $N$ eff da onda elétrica em função da espessura dos eletrodos, com $G=5 \mu \mathrm{m}$ e $t=1 \mu \mathrm{m}$. (c) $Z_{c}$ e $N$ eff da onda elétrica em função da espessura do filme de $\mathrm{SiO}_{2}, \operatorname{com} G=5 \mu \mathrm{m}$ e $e=1 \mu \mathrm{m}$

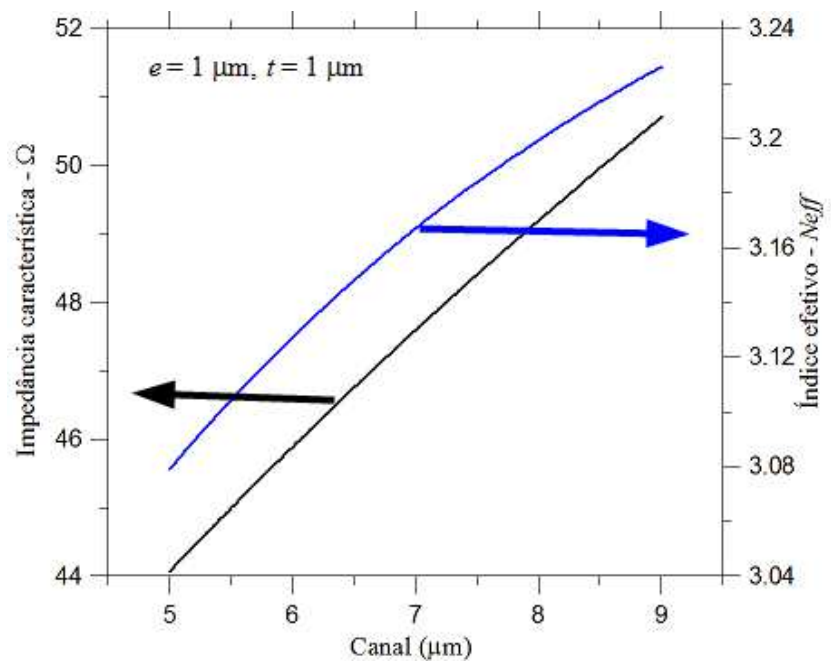

(a)

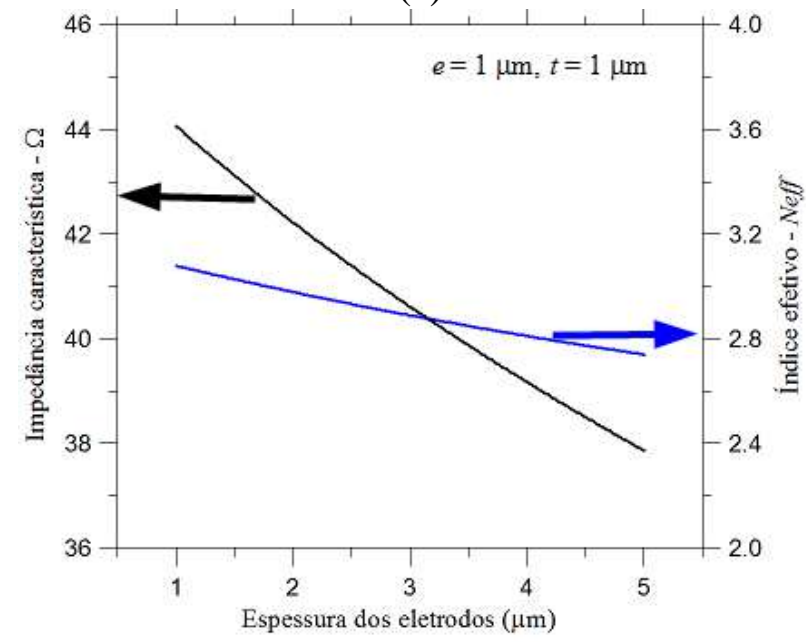

(b)

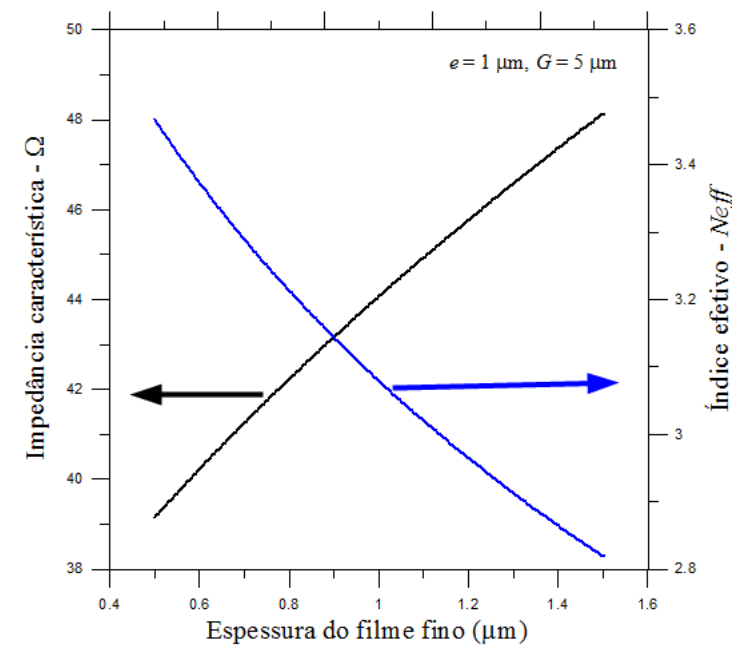

(c)

Fonte: [109]. 


\subsubsection{Segundo grupo: usando a segunda orientação do cristal dos $\mathrm{BGOs}\left(\mathrm{Bi}_{12} \mathrm{GeO}_{20} \mathrm{E}\right.$ $\left.\mathrm{Bi}_{4} \mathrm{Ge}_{3} \mathrm{O}_{12}\right)$ e condições de contorno}

Foram realizadas simulações de moduladores eletro-ópticos em substrato de $\mathrm{Bi}_{12} \mathrm{GeO}_{20}$ (projeto proposto pela autora), usando o filme de $\mathrm{Si}_{3} \mathrm{~N}_{4}$ (sugestão dos pesquisadores do LSI/EPUSP). Esses resultados estão apresentados na seção 4.1.2.1 deste capítulo.

Após a realização das simulações anteriores, houve a necessidade de trocas de substratos, porque o substrato que estava implementado naquelas simulações apresentava atividade óptica. Em vista disso, o mesmo foi trocado pelo substrato de $\mathrm{Bi}_{4} \mathrm{Ge}_{3} \mathrm{O}_{12}$, pois esse não apresenta atividade óptica. Foram realizadas novas simulações de moduladores eletro-ópticos em $\mathrm{Bi}_{4} \mathrm{Ge}_{3} \mathrm{O}_{12}$, usando a técnica ISS. Os resultados dessas simulações são apresentados num segundo grupo, que está dividido em dois subgrupos. Estes subgrupos estão classificados em dois tipos de $\mathrm{BGO}\left(\mathrm{Bi}_{12} \mathrm{GeO}_{20}\right.$ e $\left.\mathrm{Bi}_{4} \mathrm{Ge}_{3} \mathrm{O}_{12}\right)$ usando o $\mathrm{Si}_{3} \mathrm{~N}_{4}$, como filme fino indutor de tensão mecânica.

A partir deste grupo iníciam-se as simulações que fazem parte do método de auxilio interativo ao processo de fabricação de moduladores eletro-ópticos baseados em guias de onda do tipo canal em substratos de BGOs. Nessas simulações são utilizadas os seguintes comprimentos de ondas : $0,633 \mu \mathrm{m} ; 0,950 \mu \mathrm{m} ; 1,310 \mu \mathrm{m}$ e $1,55 \mu \mathrm{m}$.

\subsubsection{Primeiro subgrupo do segundo grupo}

Foram consideradas as seguintes condições de contorno:

a) A Figura 47 ilustra o corte do substrato de $\mathrm{Bi}_{12} \mathrm{GeO}_{20}$;

b) As espessuras do filme de $\mathrm{Si}_{3} \mathrm{~N}_{4}(t)$ foram de $500 \mathrm{~nm}$;

c) As larguras do canal $(G)$ foram de 1 a $10 \mu \mathrm{m}$, passos de $1 \mu \mathrm{m}$;

d) As espessuras dos eletrodos metálicos foram de $500 \mathrm{~nm}$;

e) A temperatura do forno de deposição foi de $750^{\circ} \mathrm{C}$.

f) Foram inseridas as equações 3.19, 3.20 e 3.21 que representam o efeito elasto-óptico, as equações $3.25,3.26$ e 3.27 que representam o efeito eletro-óptico e a fórmula de dispersão do substrato e do filme no programa Comsol. 
Figura 47- Modulador eletro-óptico em $\mathrm{Bi}_{12} \mathrm{GeO}_{20}$ com uma camada de filme indutor de tensão mecânica de $\mathrm{Si}_{3} \mathrm{~N}_{4}$ e dois eletrodos metálicos

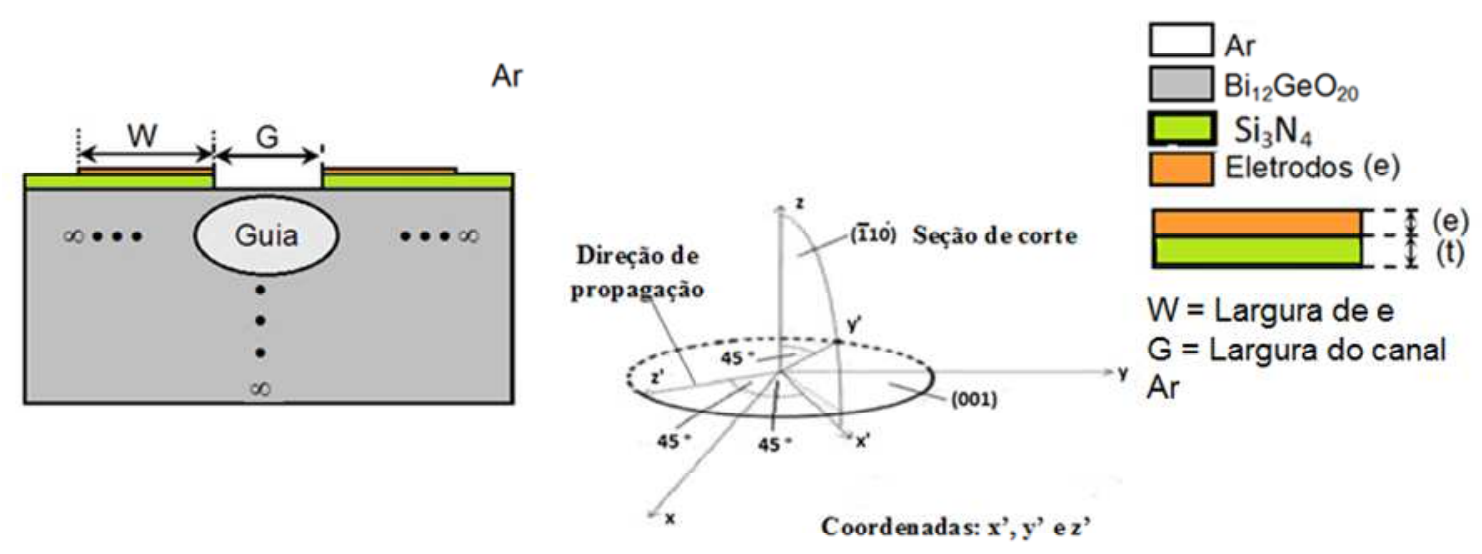

Fonte: Autora

Os perfis de deformação $S_{1}, S_{2}$ e $S_{6}$, de isolinhas do potencial elétrico e das representações do vetor de um campo elétrico local são semelhantes aos resultados obtidos no primeiro grupo do primeiro subgrupo apresentados nas Figuras 35 (a-c) e na Figura 36 [136].

As Figuras 48 (a-b) mostram os perfis dos modos $E^{x}$ e $E^{y}$. Esses modos são obtidos pela técnica ISS com birrefringência de aproximadamente $10^{-3}$ para a configuração de geometria analisada, considerando $\lambda=0,633 \mu \mathrm{m}$, porque as caracterizações do componente serão realizadas no espectro visível. Nessa simulação, foi trocado o filme indutor de tensão mecânica de $\mathrm{SiO}_{2}$ para $\mathrm{Si}_{3} \mathrm{~N}_{4}$, o que provocou o aparecimento de uma birrefringência elevada.

A Figura 49 mostra os neff em função da largura do canal, G. Quando a largura do canal é estreita, o neff é alto, entretanto para canais de largura maiores, o índice efetivo é baixo.

O estudo envolvendo esse substrato foi suspenso, porque o mesmo possui atividade óptica. Nas pesquisas realizadas pelo grupo LSO/PEA/EPUSP, interessa usar substratos que não apresentem atividade óptica, pois essa propriedade prejudica as aplicações da técnica WLI estudada pelo grupo (ver a introdução do trabalho). Como o substrato de $\mathrm{Bi}_{4} \mathrm{Ge}_{3} \mathrm{O}_{12}$ não apresenta esse efeito passou-se utilizá-lo nas simulações seguintes. 
Figura 48- Perfil do campo óptico modal. (a) Modo $E^{x}$. (b) Modo $E^{y}$

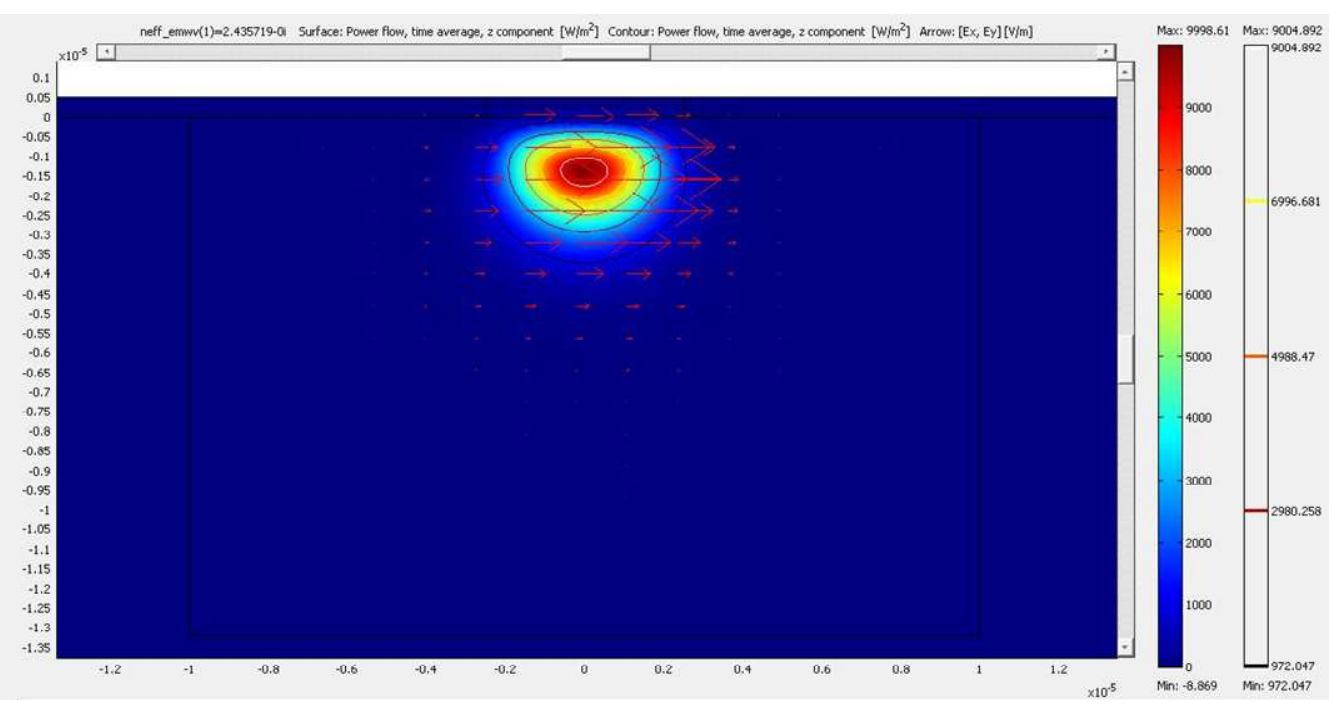

(a)

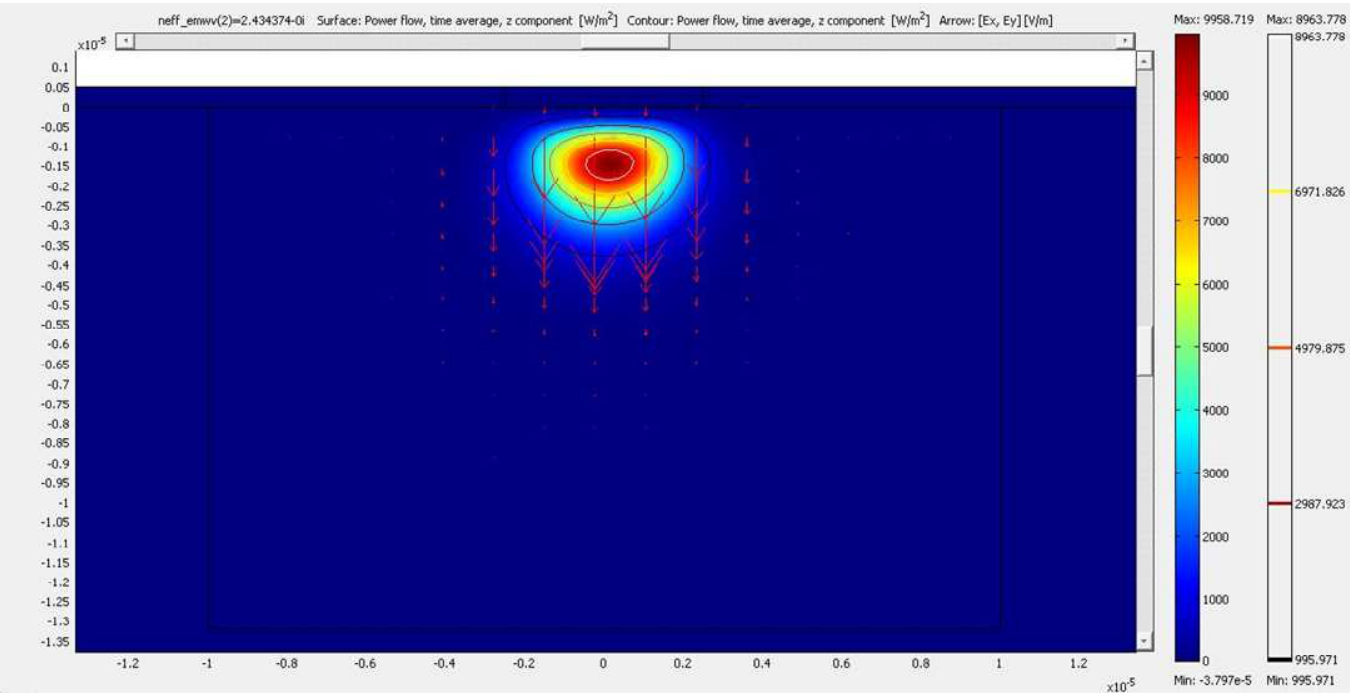

(b)

Fonte: Autora 
Figura 49- neffxe neffy em função da variação da largura do canal, $G$

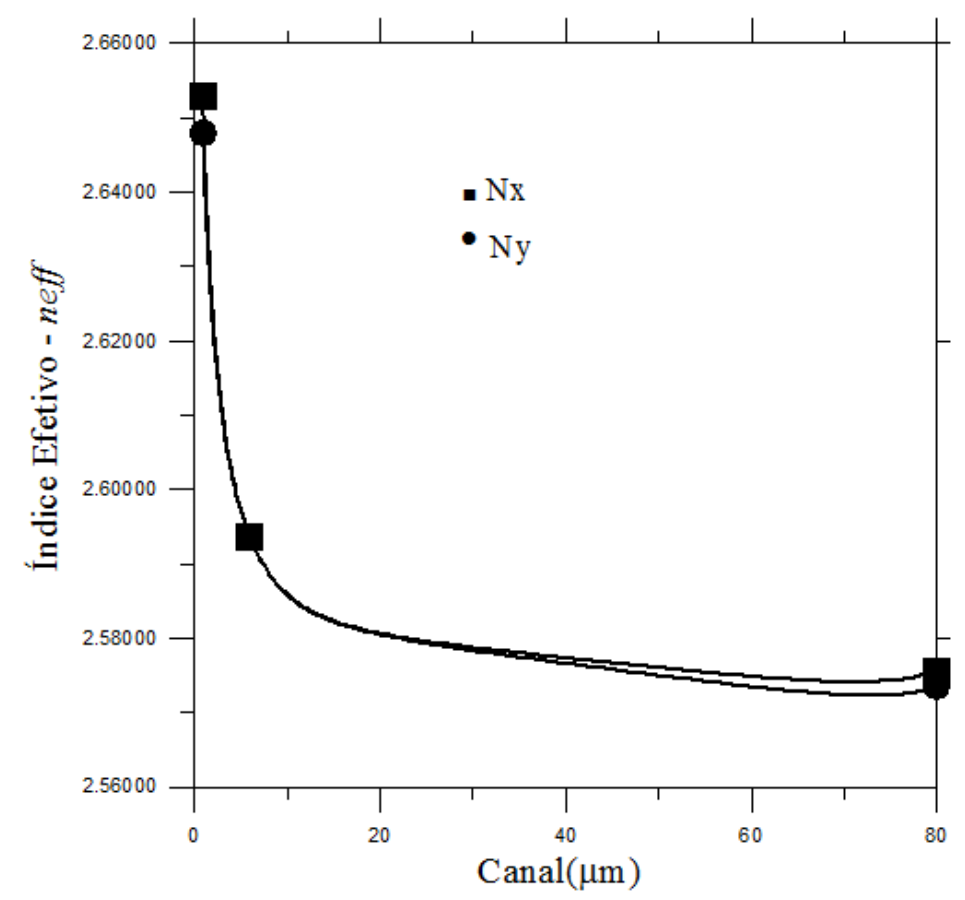

Fonte: Autora.

\subsubsection{Segundo subgrupo do segundo grupo}

Foram consideradas as seguintes condições de contorno:

a) A Figura 50 ilustra o corte do substrato de $\mathrm{Bi} 4 \mathrm{Ge}_{3} \mathrm{O}_{12}$;

b) A espessura do filme fino de $\mathrm{Si}_{3} \mathrm{~N}_{4}(t)$ utilizada foi de $500 \mathrm{~nm}$.

c) As larguras dos canais $(G)$ utilizadas foram de 1 a $10 \mu \mathrm{m}$, passos de $1 \mu \mathrm{m}$;

d) A espessura dos eletrodos metálicos utilizada foi de $500 \mathrm{~nm}$;

e) A temperatura do forno de deposição foi de $750^{\circ} \mathrm{C}$,

f) Foram inseridas as equações 3.19, 3.20 e 3.21 que representam o efeito elasto-óptico, as equações 3.25, 3.26 e 3.27 que representam o efeito eletro-óptico e a fórmula de dispersão do substrato e do filme no programa Comsol.

As Figuras 51 (a-c) mostram os perfis de deformação $S_{1}, S_{2}$ e $S_{6}$ na região induzida do guia óptico. 
O resultado do perfil de deformação $S_{1}$ obtido nessa simulação apresentou diferenças dos resultados apresentados nas simulações anteriores [108, 109] porque essa simulação foi a primeira realizada com o novo substrato. Nota-se que os valores das deformações são significativamente maiores do que no caso do substrato anterior, que indica que podem-se utilizar filmes mais finos para obter guias neste caso.

Os perfis de isolinhas do potencial elétrico e das representações do vetor de um campo elétrico local são semelhantes aos resultados apresentados na Figura 36 [108] relativos ao primeiro subgrupo do primeiro grupo de simulações.

As Figuras 52 (a-b) mostram os perfis do campo elétrico dos modos $E^{x}$ e $E^{y}$. Esses modos são obtidos pela técnica ISS com birrefringência de aproximadamente $10^{-4}$ para a configuração de geometria analisada, considerando $\lambda=1,55 \mu \mathrm{m}[126]$.

Os neff, dos modos $E^{x}$ do guia óptico obtido pela técnica ISS em função da largura do canal, G, estão ilustrados nas Figuras 53 (a-c). Quando a largura do canal aumenta, o índice efetivo neff decresce para espessura de filme de $500 \mathrm{~nm}$ com a temperatura de $750^{\circ} \mathrm{C}$.

A Figura 54 mostra a $Z_{c}$ e o $N e f f$ da modulação da onda elétrica em função da largura do canal do guia. Para o canal de $5 \mu \mathrm{m}, Z_{c}$ é aproximadamente de $54 \Omega$, e o Neff é aproximadamente de 2,65, resultando em $Z_{c}$ próxima à da fonte da modulação externa de modulação. A largura de banda é 216,5 GHz, porque Neff torna-se diferente de neff [58]

Figura 50- Modulador eletro-óptico em substrato de $\mathrm{Bi}_{4} \mathrm{Ge}_{3} \mathrm{O}_{12}$ com camada de filme indutor de tensão mecânica de $\mathrm{Si}_{3} \mathrm{~N}_{4}$ e dois eletrodos metálicos
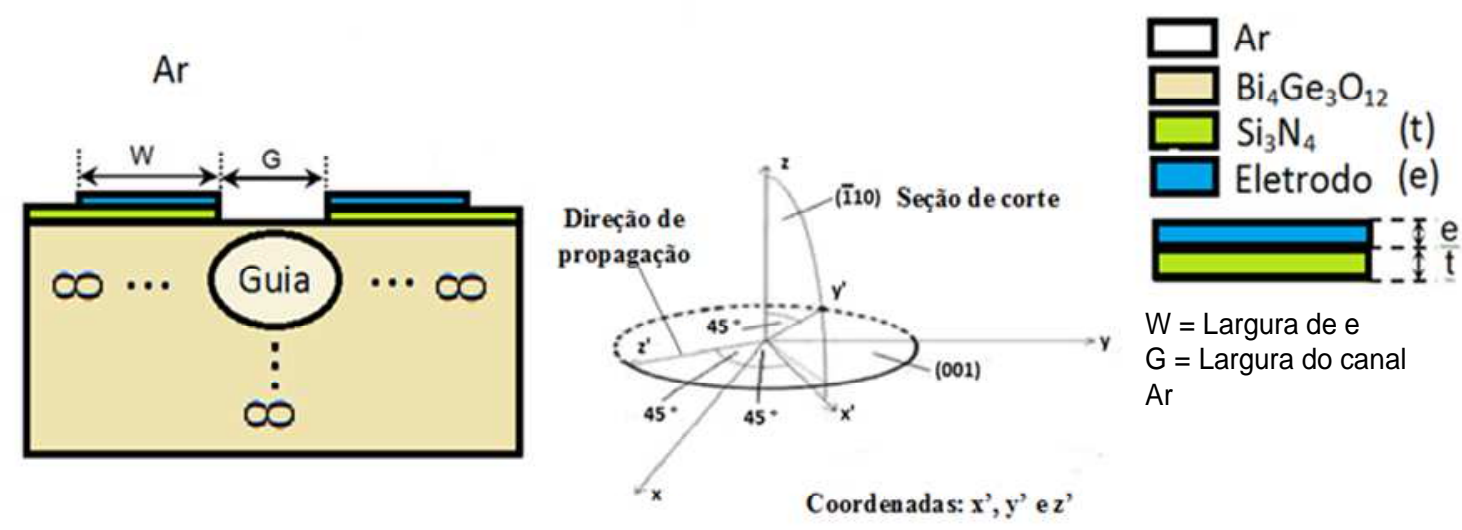

$\mathrm{W}=$ Largura de e

$\mathrm{G}=$ Largura do canal $\mathrm{Ar}$

Fonte: [126]. 
Figura 51-Perfis de deformação induzida na região do guia. (a) Deformação $S_{1}$. (b) Deformação $S_{2}$. (c) Deformação $S_{6}$

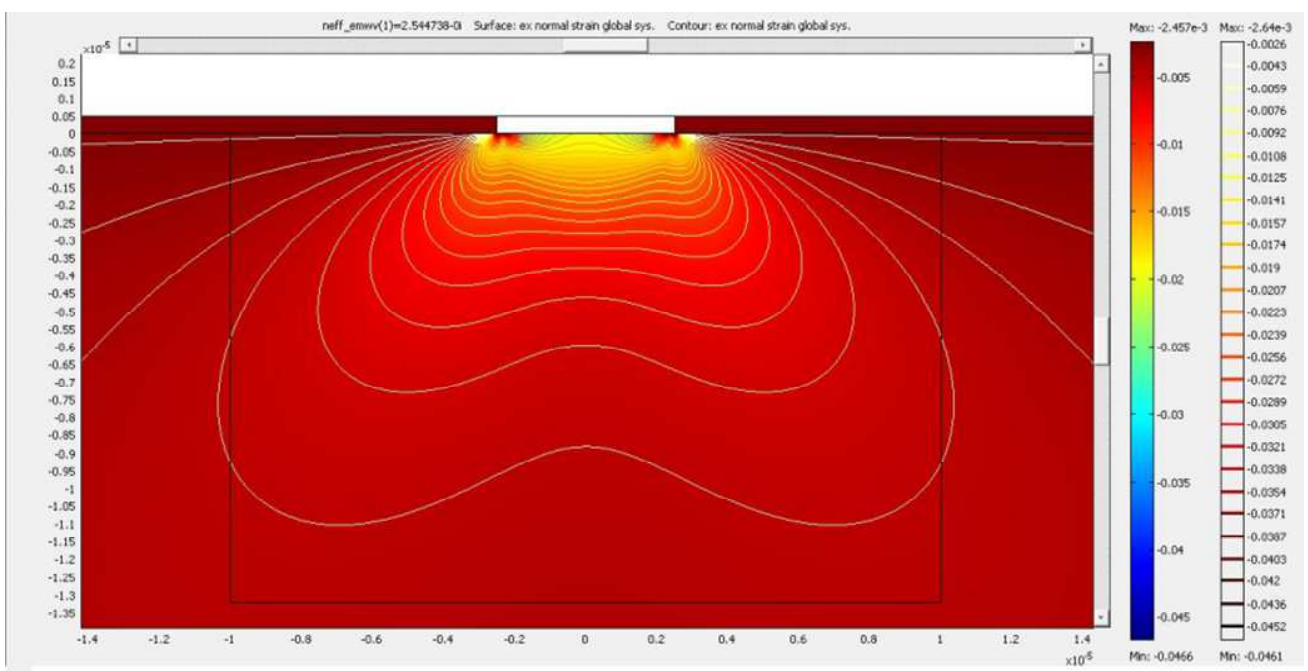

(a)

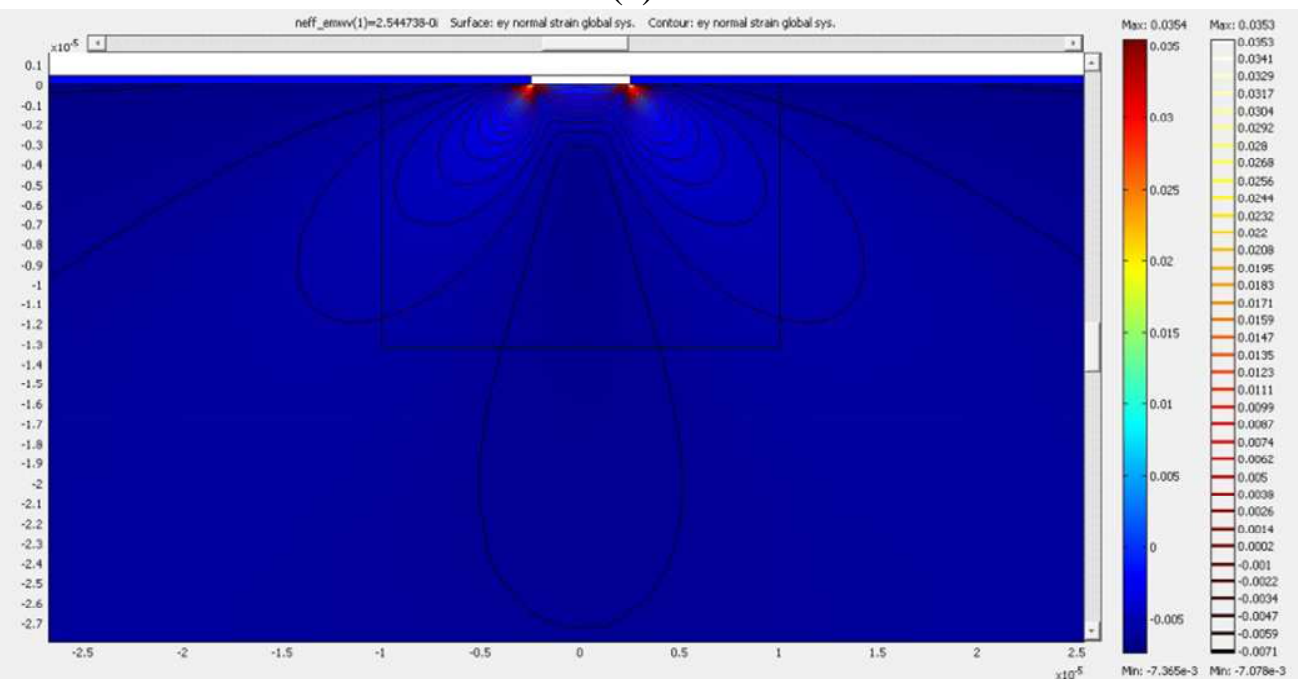

(b)

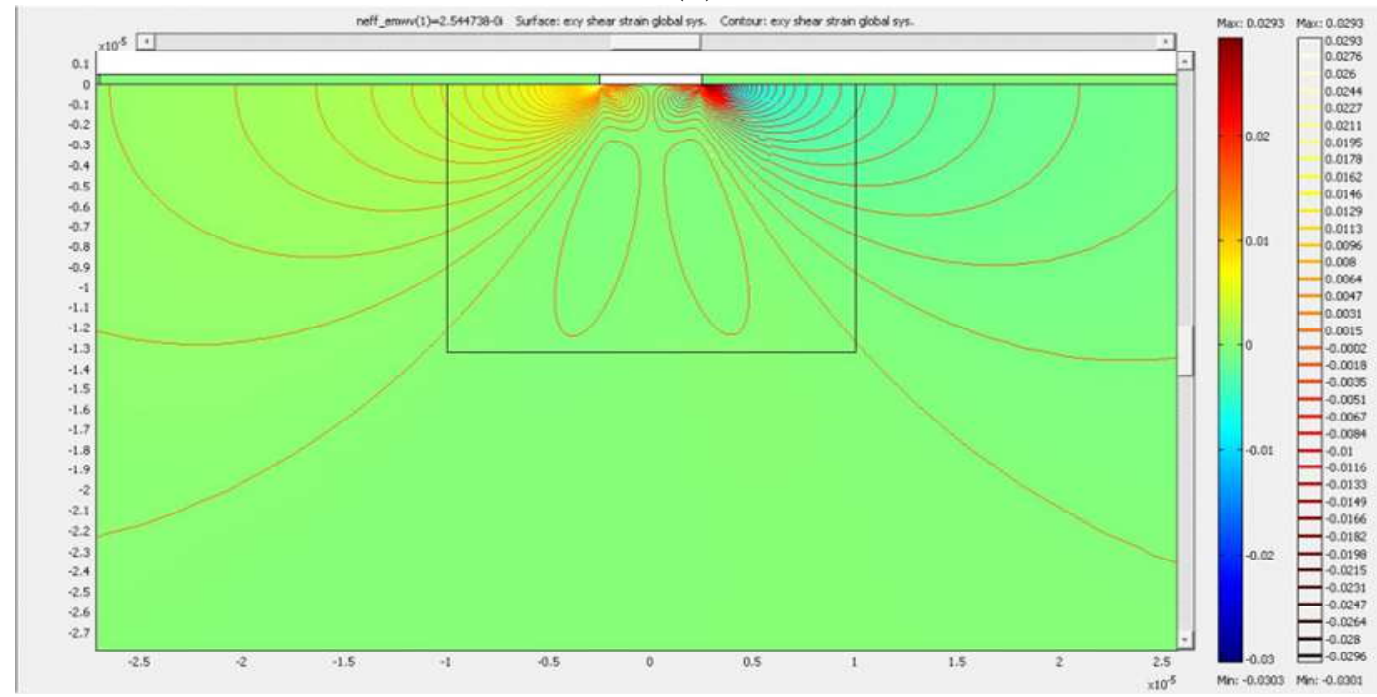

(c)

Fonte: [126]. 
Figura 52- Perfis dos campos ópticos modais com comprimento de onda $\lambda=1,550 \mu m$. (a) Modo $E^{x}$. (b) Modo $E^{y}$

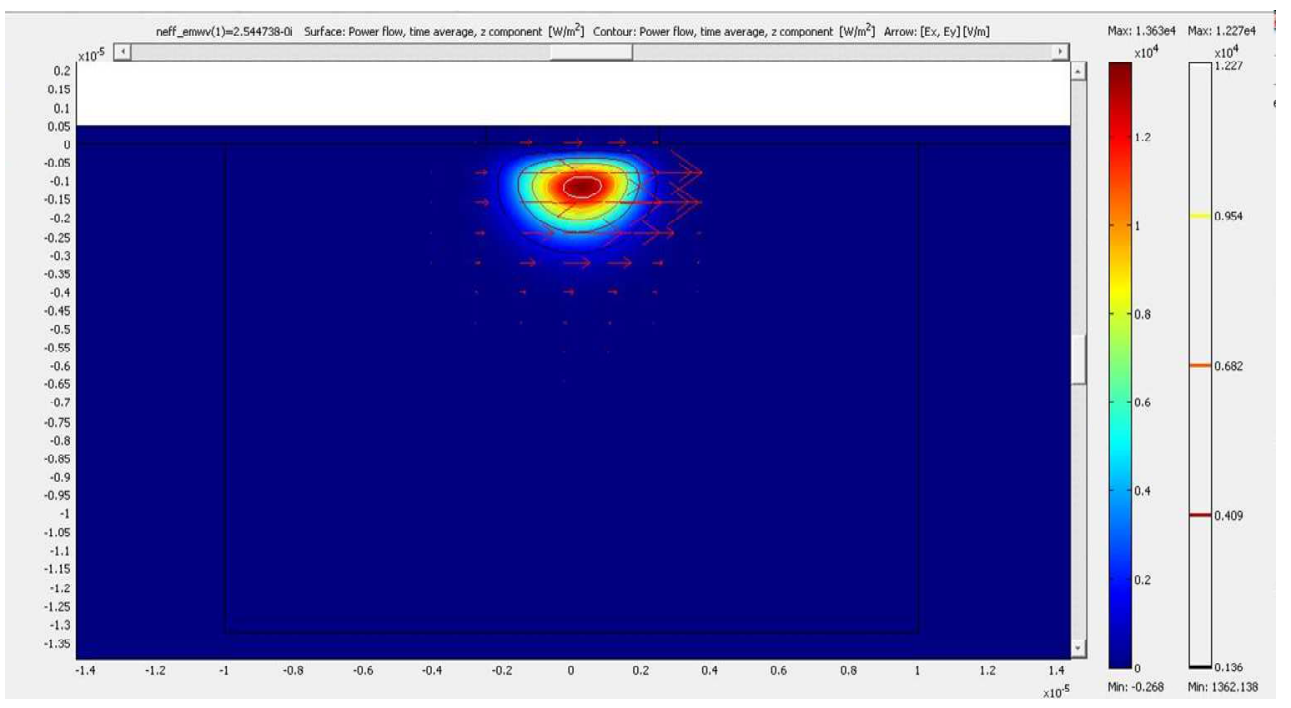

(a)

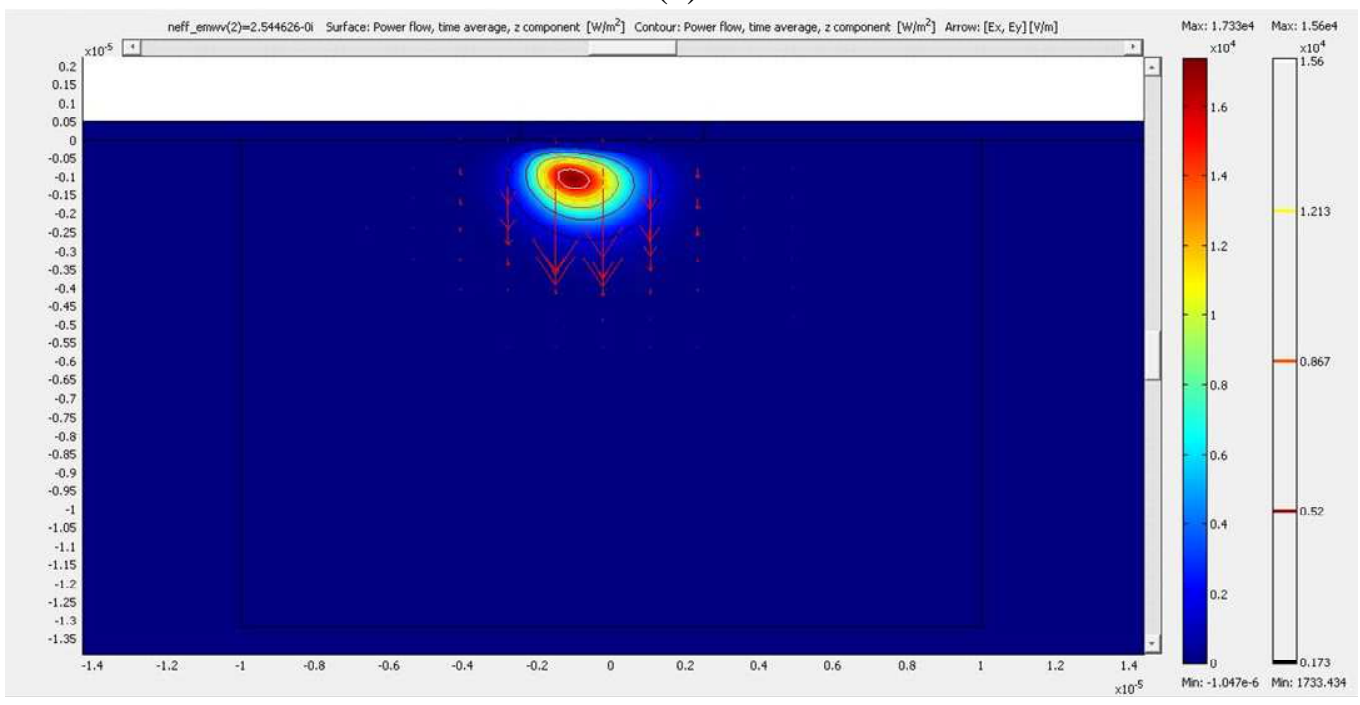

(b)

Fonte: [126]. 
Figura 53- $n$ eff do modo fundamental guiado em função da largura do canal, G. (a) $\lambda=0,633 \mu \mathrm{m}$. (b) $\lambda=0,950 \mu \mathrm{m}$. (c) $\lambda=1,310 \mu \mathrm{m}$. (d) $\lambda=1,55 \mu \mathrm{m}$

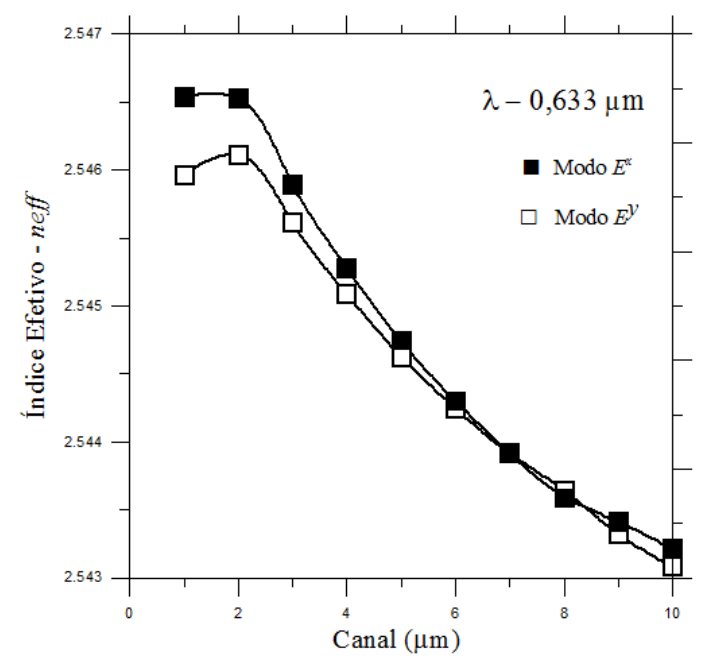

(a)

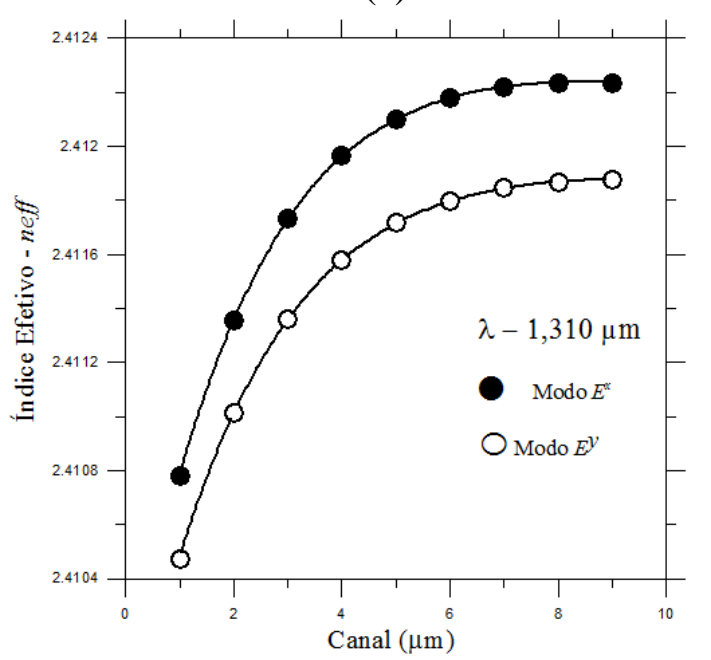

(c)

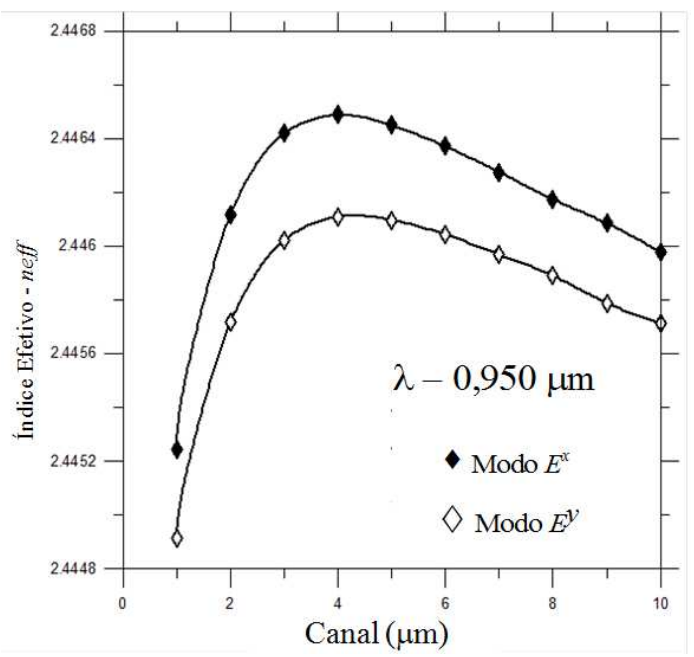

(b)

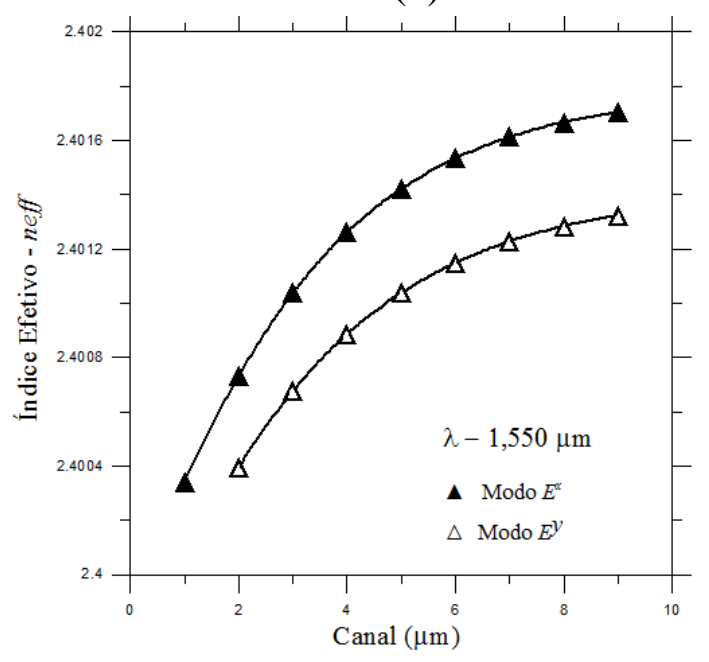

(d)

Fonte: [126] 
Figura 54- Neff e $Z_{c}$ da onda elétrica em função da largura do canal do guia, G, considerando-se espessura dos eletrodos metálicos de $500 \mathrm{~nm}$.

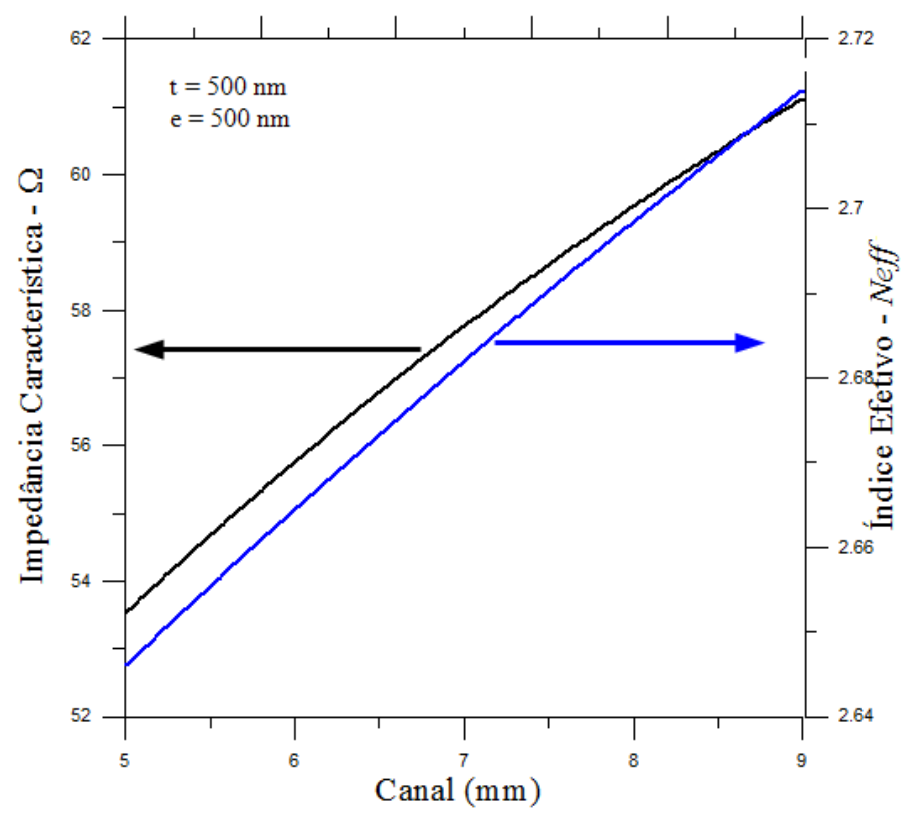

Fonte: Autora.

A Figura 55 mostra os valores da integral de sobreposição, $\Gamma_{\text {sob }}$, em função do comprimento de onda, $\lambda$. Os pesquisadores do LSO pretendem usar o $\lambda$ de $1,55 \mu \mathrm{m}$, então a melhor situação do $\Gamma_{s o b}$ é a do canal de $5 \mu \mathrm{m}$, no qual o valor de $\Gamma_{s o b}$ é mais baixo.

Figura 55- $\Gamma$ em função da variação da largura do canal. $(\bullet) \lambda=0,633 \mu \mathrm{m}$. $(\bullet) \lambda=1,310 \mu \mathrm{m}$. $(\Delta) \lambda=\mathbf{1 , 5 5 0} \mu \mathrm{m}$.

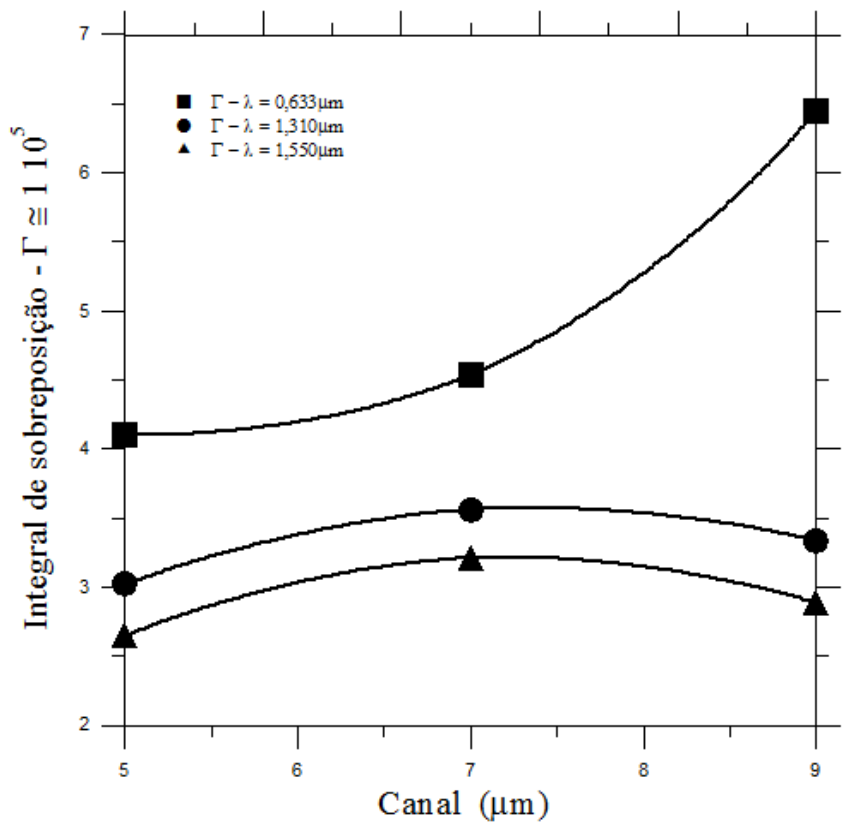

Fonte: [126] 


\subsubsection{Terceiro grupo: simulações de guias de onda óptico do tipo canal para encontrar o melhor grupo de geometria desses guias.}

Com os parâmetros da deposição do filme de $\mathrm{Si}_{3} \mathrm{~N}_{4}$ realizados pelos pesquisadores do CCS/UNICAMP, a autora implementou nas simulações de guias de onda do tipo canal no programa Comsol. Tais parâmetros foram os seguintes: temperatura de $740^{\circ} \mathrm{C}$ e espessura do filme de aproximadamente $500 \mathrm{~nm}$.

Os resultados deste terceiro grupo de simulações está dividido em 3 subgrupos, relacionados às temperaturas de deposição, que foram de: $740^{\circ} \mathrm{C}, 720^{\circ} \mathrm{C}$ e $650^{\circ} \mathrm{C}$. Os processos de fabricação desses guias estão relatados na seção 3.6 do capítulo 3 e seus resultados são aqui apresentados.

A Figura 56 ilustra a orientação da seção de corte do guia de onda do tipo canal em substrato de $\mathrm{Bi}_{4} \mathrm{Ge}_{3} \mathrm{O}_{12}$. Foram inseridas as equações 3.19, 3.20 e 3.21 que representam o efeito elastoóptico no programa Comsol. Nessas simulações foram considerados os seguintes comprimentos de ondas: $0,633 \mu \mathrm{m}, 1,310 \mu \mathrm{m}$ e $1,55 \mu \mathrm{m}$.

Figura 56- Guia de onda do tipo canal em substrato de $\mathrm{Bi}_{4} \mathrm{Ge}_{3} \mathrm{O}_{12}$
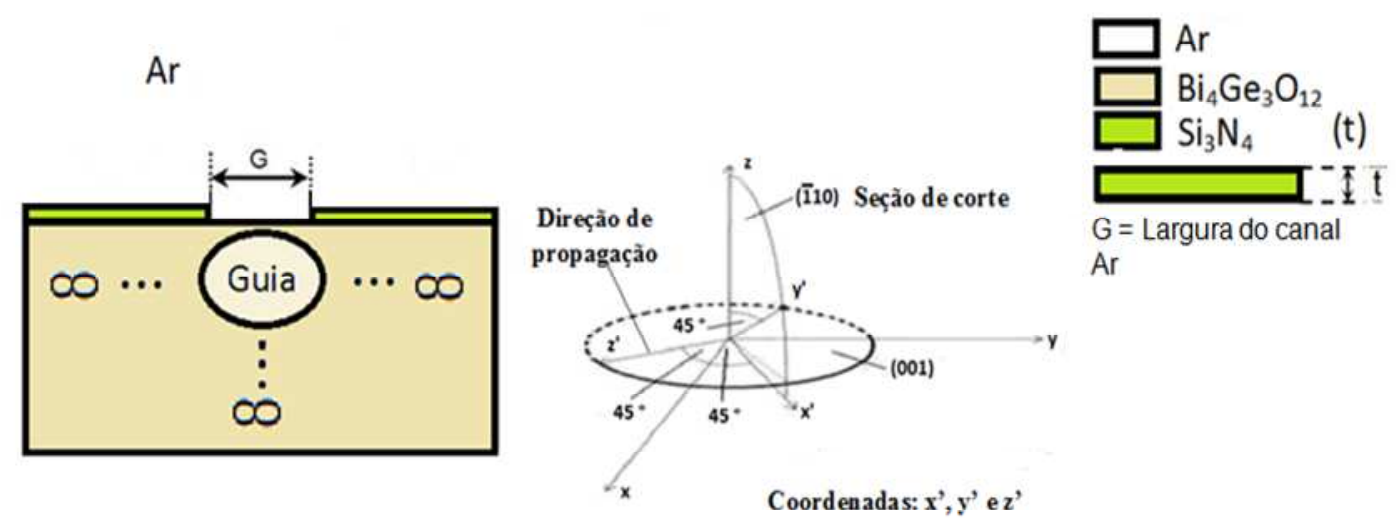

Fonte: Autora. 


\subsubsection{Primeiro subgrupo do terceiro grupo: temperatura de deposição do filme de $\mathrm{Si}_{3} \mathrm{~N}_{4}$}

Foram consideradas as seguintes condições de contorno:

a) A Figura 56 ilustra o corte do substrato de $\mathrm{Bi}_{4} \mathrm{Ge}_{3} \mathrm{O}_{12}$;

b) A espessura do filme de $\mathrm{Si}_{3} \mathrm{~N}_{4}$ utilizada foi de $465 \mathrm{~nm}$ (CCS da UNICAMP);

c) As larguras do canal $(G)$ utilizadas foram de 1 a $10 \mu \mathrm{m}$, passos de $1 \mu \mathrm{m}$;

d) As temperaturas do forno de deposição utilizadas foram de $740^{\circ} \mathrm{C}$ e $720^{\circ} \mathrm{C}$.

Nessas simulações foram inseridas duas temperaturas no processo de deposição do filme de $\mathrm{Si}_{3} \mathrm{~N}_{4}$. A de $720^{\circ} \mathrm{C}$ foi utilizada no laboratório do LSI e a de $740^{\circ} \mathrm{C}$ no laboratório do CCS/UNICAMP.

Os perfis de deformação $S_{1}, S_{2}$ e $S_{6}$, das isolinhas do potencial elétrico e das representações do vetor de um campo elétrico local são semelhantes aos resultados apresentados nas Figuras 51 (a-c) relativas aos resultados do primeiro subgrupo do primeiro grupo das simulações.

As Figuras 57 (a-b) mostram os perfis dos modos $E^{x}$ e $E^{y}$, considerando a temperatura de $740^{\circ} \mathrm{C}$. Os guias são obtidos pela técnica ISS com birrefringência de aproximadamente $10^{-4}$ para a configuração de geometria analisada. As Figuras 58 (a-b) mostram os perfis dos modos $E^{x}$ e $E^{y}$, considerando a temperatura de $720^{\circ} \mathrm{C}$ e para esse guia, o valor da birrefringência é de $10^{-4}$ para essa configuração de geometria.

As Figuras 59 (a-c) mostram os neff dos modos $E^{x}$ e $E^{y}$ do guia de onda óptico pela técnica ISS em função da variação da largura do canal (em $\mu \mathrm{m})$. A Figura 59a mostra a variação do neff para os modos $E^{x}$ e $E^{y}$ no comprimento de onda $0,633 \mu \mathrm{m}$. Do mesmo modo, a Figura $59 \mathrm{~b}$ ilustra a variação do neff para os modos $E^{x}$ e $E^{y}$ no comprimento de onda de $1,310 \mu \mathrm{m}$, a partir do canal de $2 \mu \mathrm{m}$, os modos se espalham ao longo da seção do guia como campos evanescentes. Da mesma forma, a Figura 59c mostra a variação do neff para os modos $E^{x}$ e $E^{y}$ no comprimento de onda de $1,55 \mu \mathrm{m}$, onde os modos $\mathrm{E}^{\mathrm{x}}$ e $\mathrm{E}^{\mathrm{y}}$ espalharam a partir do canal de $3 \mu \mathrm{m}$ e o modo $E^{y}$ no canal de $4 \mu \mathrm{m}$ também espalhou pelo substrato. 
Figura 57- Perfil do campo óptico modal considerando-se temperatura de $740^{\circ} \mathrm{C}$ (no forno de deposição). (a) Modo $E^{x}$. (b) Modo $E^{y}$

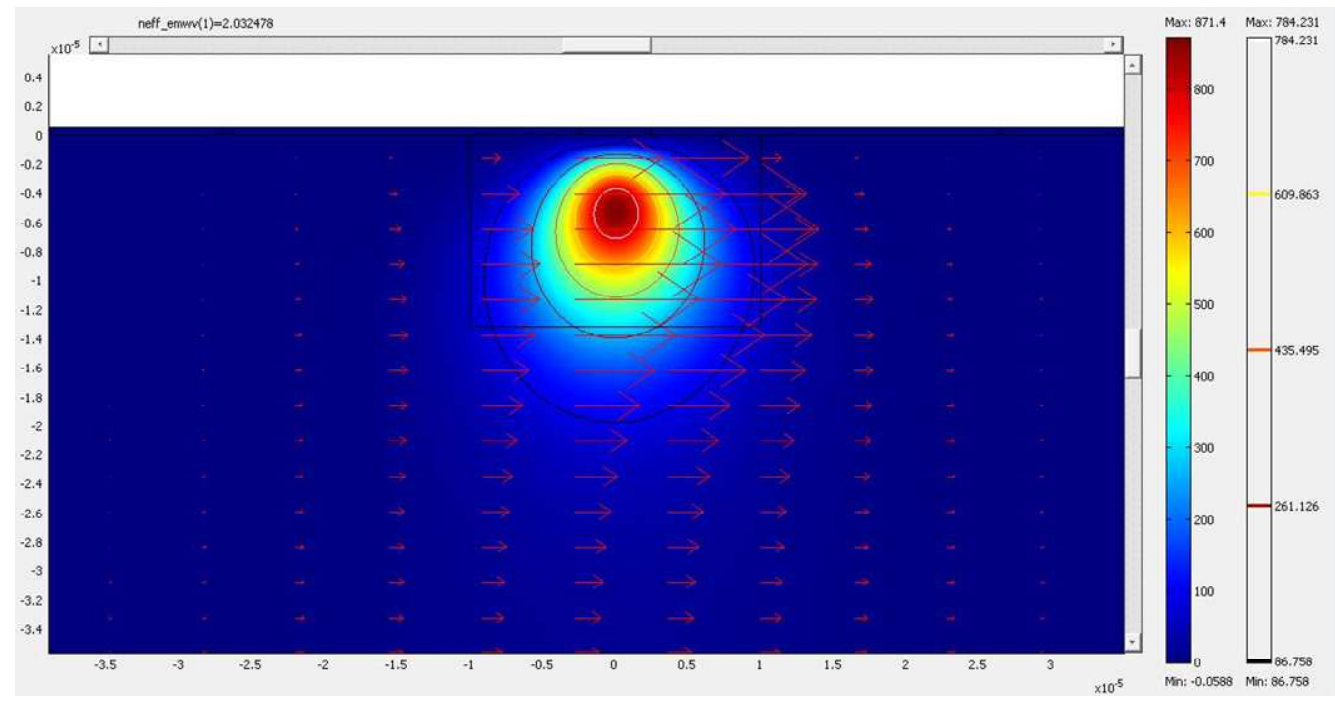

(a)

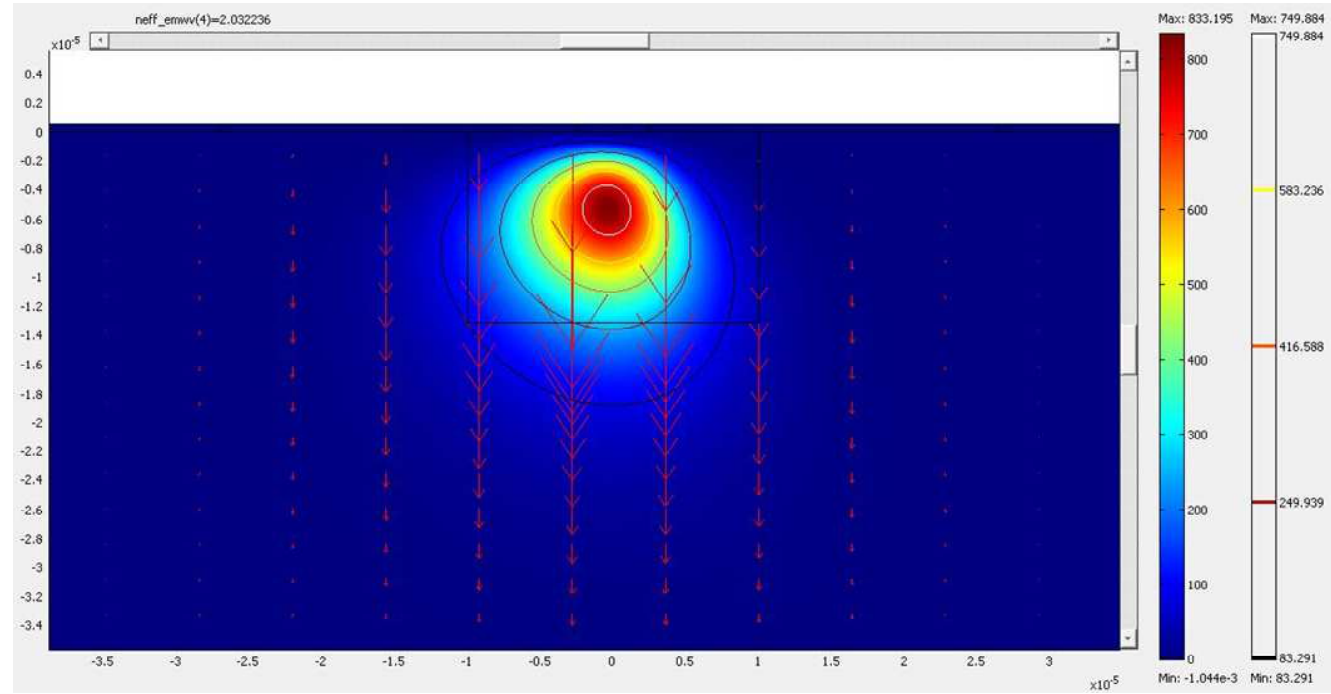

(b)

Fonte: Autora 
Figura 58- Perfil do campo óptico modal considerando-se temperatura de $720^{\circ} \mathrm{C}$ (no forno de deposição). (a) Modo $E^{x}$. (b) Modo $E^{y}$.

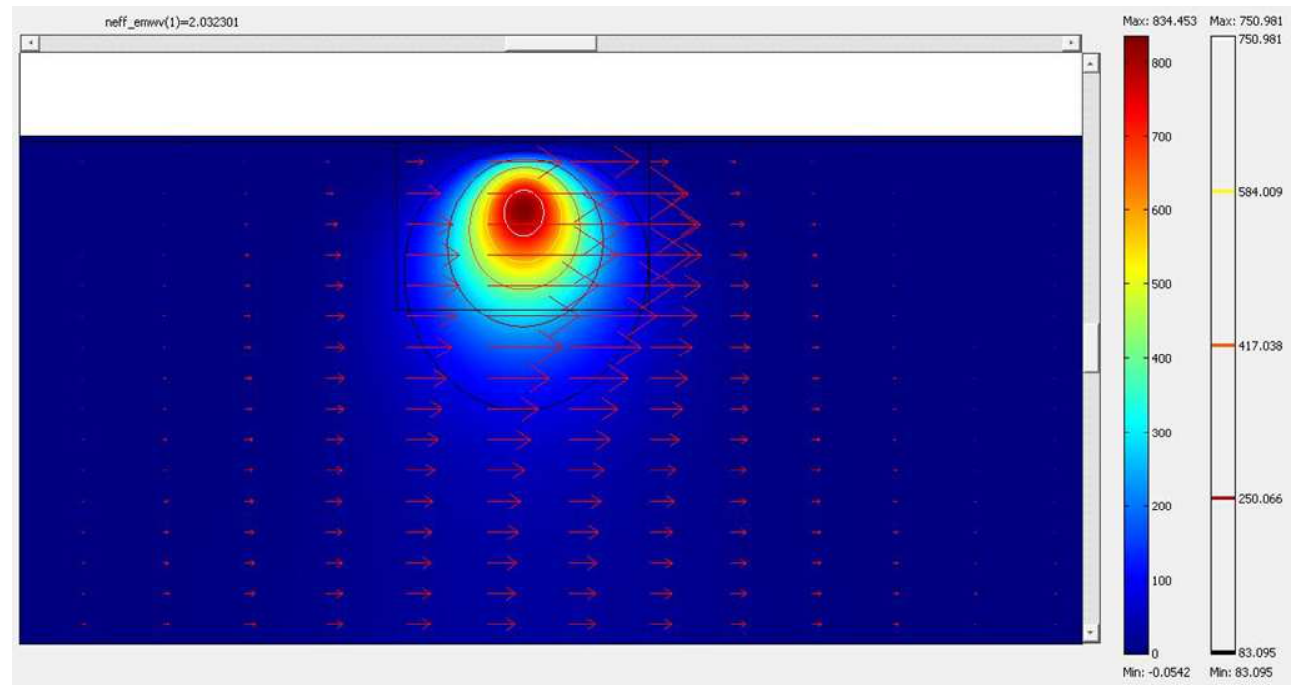

(a)

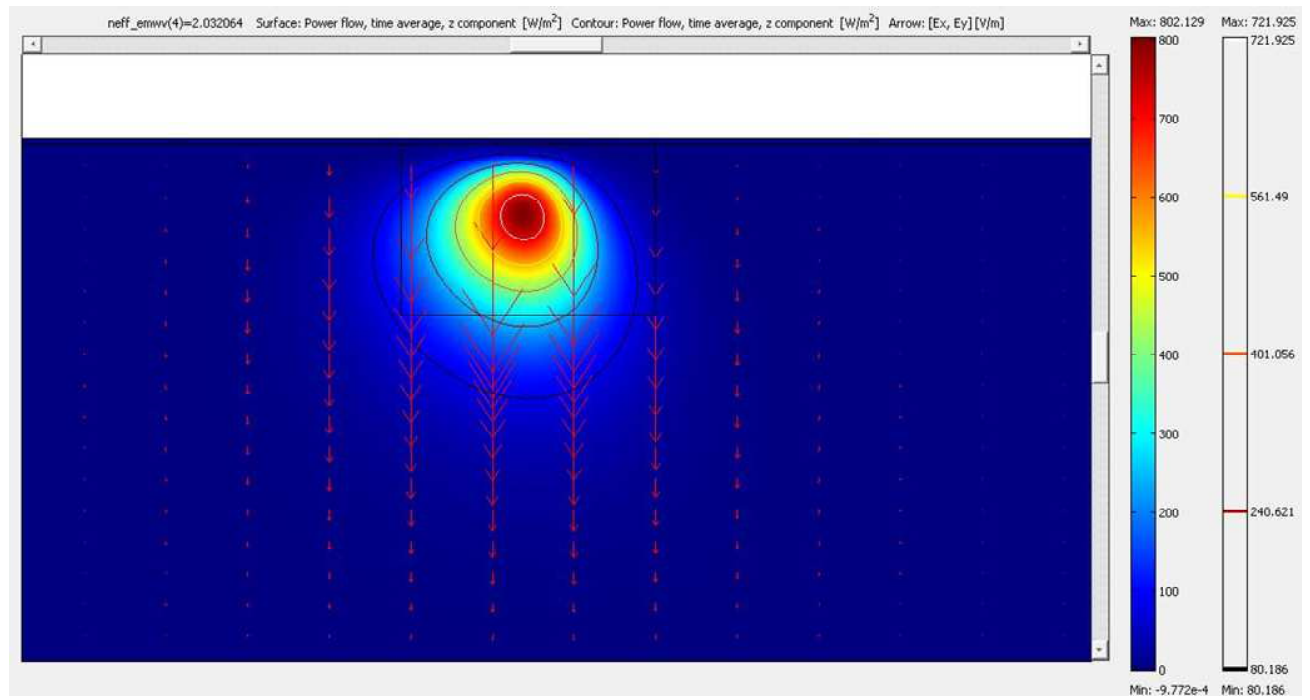

(b)

Fonte: Autora 
Figura 59- $\boldsymbol{n}_{\text {eff }}$ do modo fundamental guiado em função da largura do canal, $G$. (a) $\lambda=0,633 \mu \mathrm{m}$.

(b) $\lambda=1,310 \mu \mathrm{m}$. (c) $\lambda=1,55 \mu \mathrm{m}$

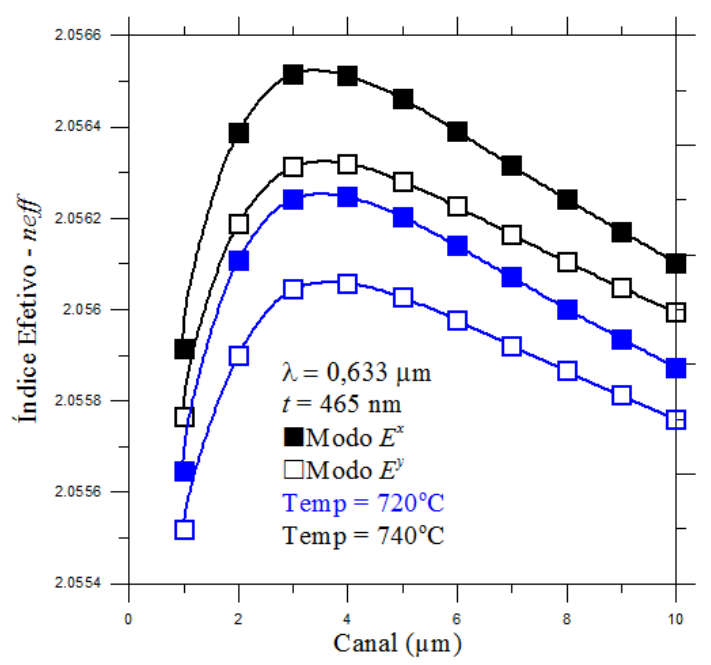

(a)

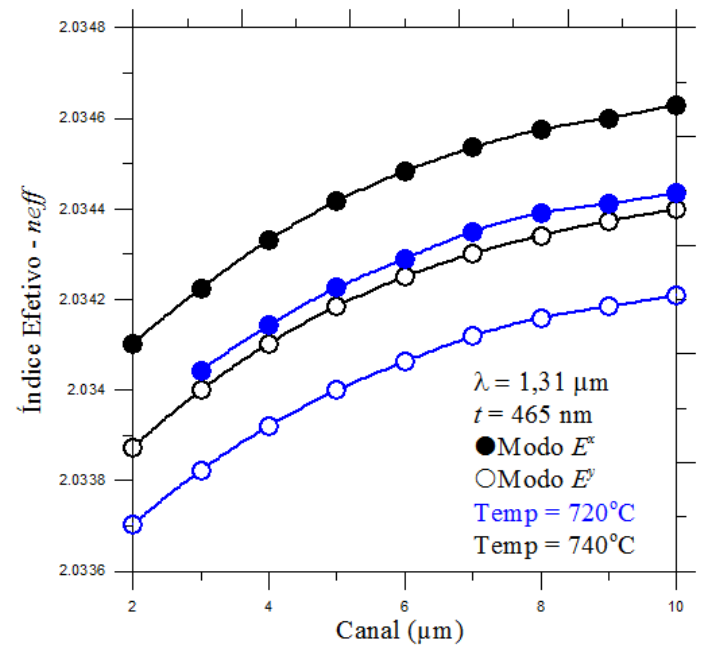

(b)

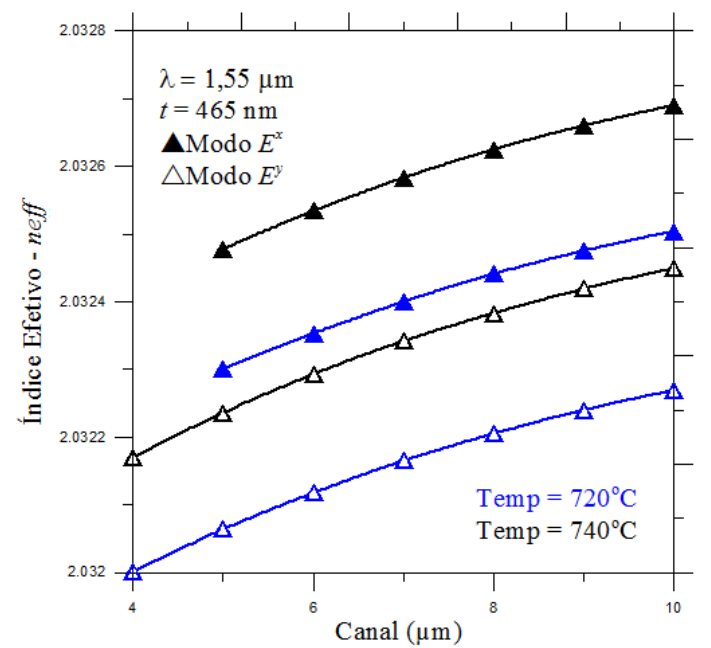

(c)

Fonte: Autora 
Estes resultados não foram comparados com resultados experimentais porque foram observados defeitos (craqueamento e descolamento) no filme depositado, como é apresentado na seção 4.2.3 desse capítulo.

Na próxima seção são apresentadas simulações de guias de ondas ópticos considerando-se a temperatura de $720^{\circ} \mathrm{C}$ no forno de deposição e variando-se a espessura do filme fino de $\mathrm{Si}_{3} \mathrm{~N}_{4}$, conforme os valores indicados no processo de fabricação, como por exemplo, $250 \mathrm{~nm}$, $100 \mathrm{~nm}$ e $90 \mathrm{~nm}$. No entanto, foram também realizados simulações com espessuras de $30 \mathrm{~nm}$ à $30 \mathrm{~nm}$ com passos de $20 \mathrm{~nm}$, consequentemente, é possível observar o modo se propagando no guia.

\subsubsection{Segundo subgrupo do terceiro grupo: temperatura de $720^{\circ} \mathrm{C}$ e variação da espessura do filme $\mathrm{Si}_{3} \mathrm{~N}_{4}$.}

Como a espessura do filme de $\mathrm{Si}_{3} \mathrm{~N}_{4}$ depositado anteriormente foi próxima de $100 \mathrm{~nm}$, foram realizadas várias simulações de guias de onda do tipo canal com valores em torno deste, até a espessura mínima de $30 \mathrm{~nm}$. Os resultados dessas simulações são apresentados a seguir.

Foram consideradas as seguintes condições de contorno:

a) A Figura 56 ilustra o corte do substrato de $\mathrm{Bi}_{4} \mathrm{Ge}_{3} \mathrm{O}_{12}$;

b) As espessuras do filme de $\mathrm{Si}_{3} \mathrm{~N}_{4}$ utilizadas foram: de $250 \mathrm{~nm}$, de $100 \mathrm{~nm}$, de $90 \mathrm{~nm}$, de $70 \mathrm{~nm}$, de $50 \mathrm{~nm}$ e de $30 \mathrm{~nm}$;

c) As larguras do canal $(G)$ utilizadas foram as mesmas da simulação anteriores.

As Figuras $60(\mathrm{a}-\mathrm{b})$ mostram os perfis do campo elétrico dos Modos $E^{x}$ e $E^{y}$. Esses modos são obtidos pela técnica ISS com birrefringência de aproximadamente $10^{-4}$ para a configuração de geometria analisada, considerando $\lambda=1,55 \mu \mathrm{m}$.

A Figura $61(\mathrm{a}-\mathrm{c})$ mostram os neff dos modos $E^{x}$ e $E^{y}$ do guia de onda óptico em função em função da largura do canal e variando-se a espessura do filme de $\mathrm{Si}_{3} \mathrm{~N}_{4}$ e o comprimento de onda. A Figura 61a mostra os neff em função da variação da largura do canal. Os modos $E^{x}$ e $E^{y}$ são apresentados a partir do canal de $3 \mu \mathrm{m}$ porque nas larguras de 1 e $2 \mu \mathrm{m}$, os modos $E^{x}$ e $E^{y}$ são espalhados ao longo da seção do guia, como campos evanescentes. Do mesmo modo, 
são mostrados os neff dos modos $E^{x}$ e $E^{y}$ nas Figuras 61 b e 61c para os comprimentos de onda $1,310 \mu \mathrm{m}$ e $1,55 \mu \mathrm{m}$, respectivamente.

Figura 60- Perfil do campo óptico modal considerando-se $\lambda$ de $1,55 \mu \mathrm{m}$ e temperatura de $720^{\circ} \mathrm{C}$ do forno de deposição. (a) Modo $E^{x}$. (b) Modo $E^{y}$

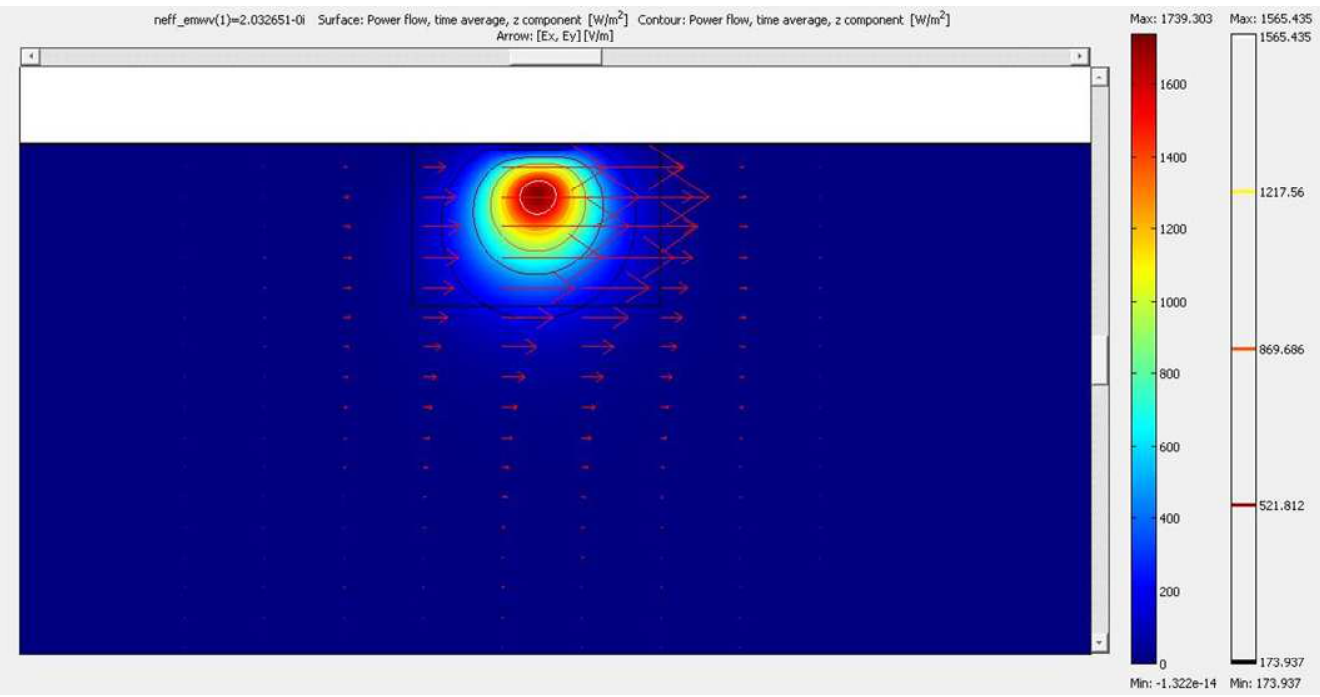

(a)

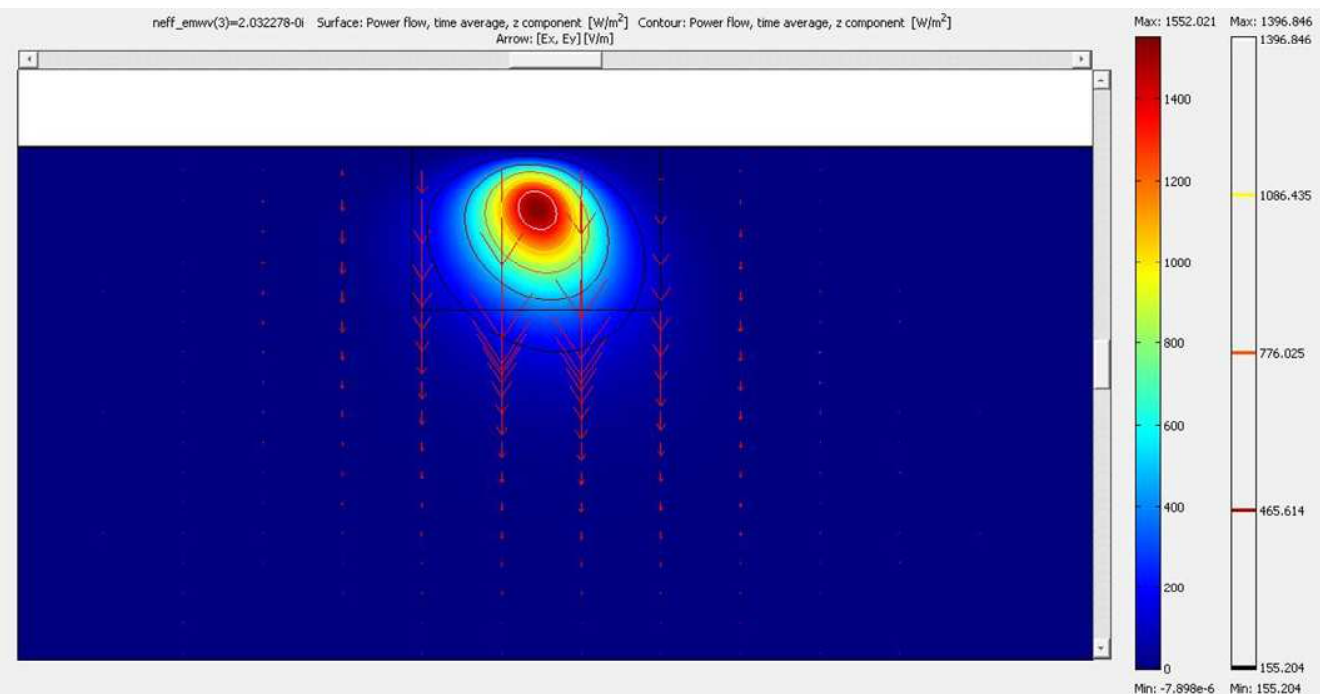

(b)

Fonte: Autora

Dos resultados apresentados acima, não foi possível ser usada a amostra depositada com espessura de $250 \mathrm{~nm}$ de filme de $\mathrm{Si}_{3} \mathrm{~N}_{4}$, porque ocorreu um problema com a tubulação de gás do equipamento e não se conseguiu terminar o processo de deposição do filme, como é relatado na seção 4.2.4 desse capítulo. 
Figura 61- neff em função da variação da largura do canal. (a) $\lambda=0,633 \mu \mathrm{m}$. (b) $\lambda=1,31 \mu \mathrm{m}$. (c) $\lambda=1,55 \mu \mathrm{m}$.

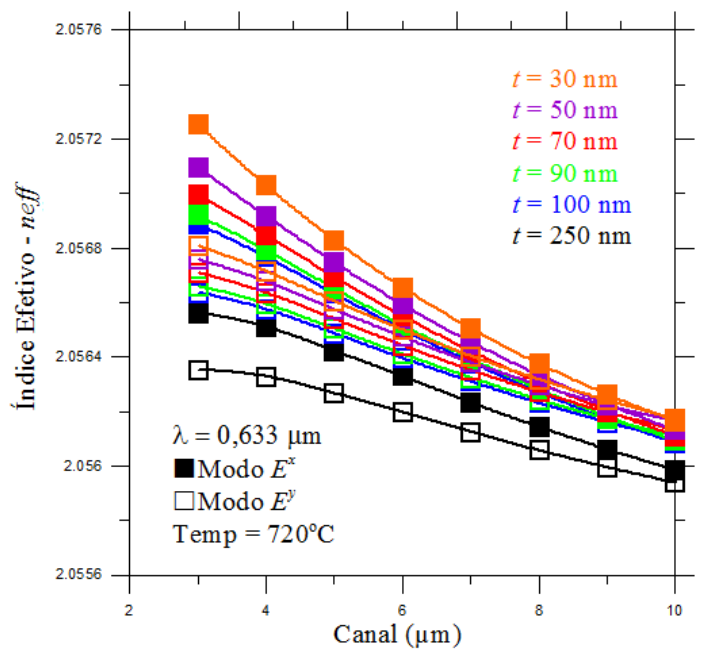

(a)

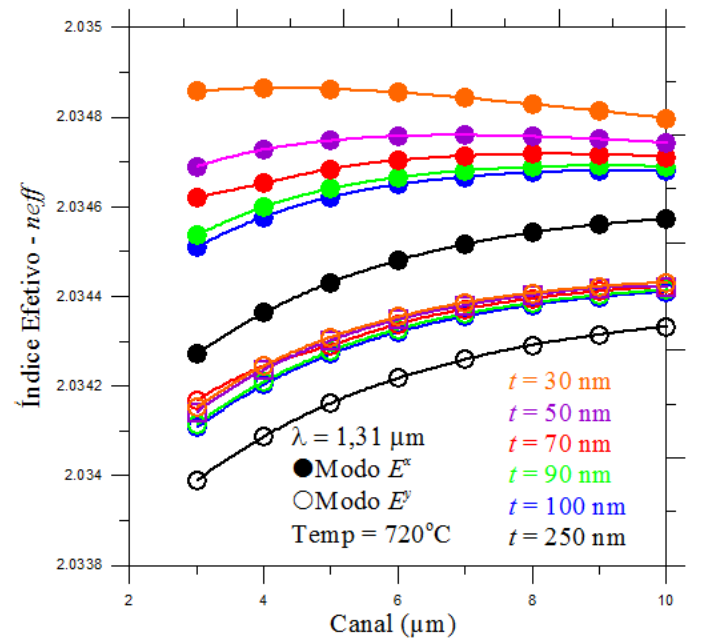

(b)

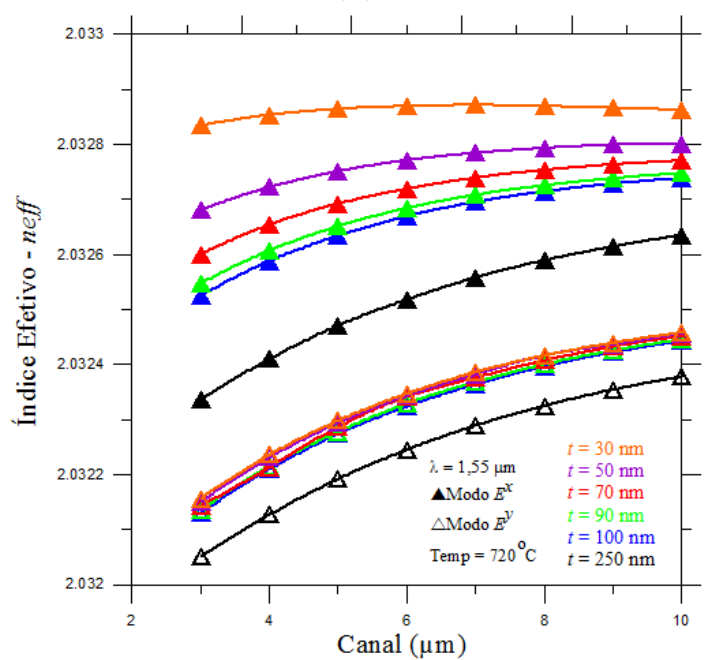

(c) 
Como o filme depositado à temperatura de $720^{\circ} \mathrm{C}$ demonstrou-se muito indutor de tensão mecânica, a ponto de trincar com espessuras da ordem de $250 \mathrm{~nm}$, ventilou-se a hipótese de que caso a temperatura de deposição fosse reduzida também seria observada a redução do estresse induzido, permitindo a fabricação do componente com filmes mais espessos.

Para testar esta hipótese foram realizadas simulações de guias de ondas ópticos considerandose a temperatura de $650^{\circ} \mathrm{C}$ no forno de deposição do filme fino de $\mathrm{Si}_{3} \mathrm{~N}_{4}$, pois esta temperatura foi indicada como sendo a mínima possível para operação do equipamento de deposição. Os resultados dessas simulações são apresentados a seguir.

\subsubsection{Terceiro subgrupo do terceiro grupo: temperatura de $650^{\circ} \mathrm{C}$}

Foram consideradas as seguintes condições de contorno:

a) A Figura 56 ilustra o corte do substrato de $\mathrm{Bi}_{4} \mathrm{Ge}_{3} \mathrm{O}_{12}$;

b) As espessuras do filme de $\mathrm{Si}_{3} \mathrm{~N}_{4}$ utilizadas foram de: $90 \mathrm{~nm}, 70 \mathrm{~nm}, 50 \mathrm{~nm}$ e $30 \mathrm{~nm}$;

c) As larguras do canal $(G)$ utilizadas foram as mesmas da simulação anterior.

As Figuras $62(\mathrm{a}-\mathrm{c})$ ilustram os neff dos modos $E^{x}$ e $E^{y}$ do guia de onda óptico pela técnica ISS em função da variação da largura do canal. Em cada gráfico apresentam-se dois grupos de linhas, um para o modo $E^{x}$ e outro para o modo $E^{y}$. Em cada grupo de linhas a cor de cada uma está relacionada a uma espessura do filme de $\mathrm{Si}_{3} \mathrm{~N}_{4}$. Cada gráfico representa a situação observada para um comprimento de onda. Assim, a Figura 62a é apresentada os neff usando o comprimento de onda de $0,633 \mu \mathrm{m}$. Do mesmo modo, a Figura $62 \mathrm{~b}$ é ilustrada os neff utilizando o comprimento de onda de $1,310 \mu \mathrm{m}$. Da mesma forma, a Figura 62c é mostrada os neff usando o comprimento de onda de $1,55 \mu \mathrm{m}$.

Na próxima seção são apresentadas as simulações de moduladores eletro-ópticos baseados em guias de onda do tipo canal em OI no programa COMSOL. Nessas simulações é usada a espessura de $50 \mathrm{~nm}$ do filme indutor de tensão mecânica, porque nas simulações dos guias apresentada na seção 4.1.32, a espessura de $50 \mathrm{~nm}$ desse filme mostrou-se satisfatória, no sentido que, embora a tensão fosse pequena, ainda assim era forte o suficiente para obter o guia óptico. A escolha pelo menor valor se justifica pelo fato de que quanto menor a espessura mais rápido, seguro e econômico é o processo de deposição. 
Figura 62- neff em função da largura do canal. (a) $\lambda=0,633 \mu \mathrm{m}$. (b) $\lambda=1,31 \mu \mathrm{m}$. (c) $\lambda=1,55 \mu \mathrm{m}$.

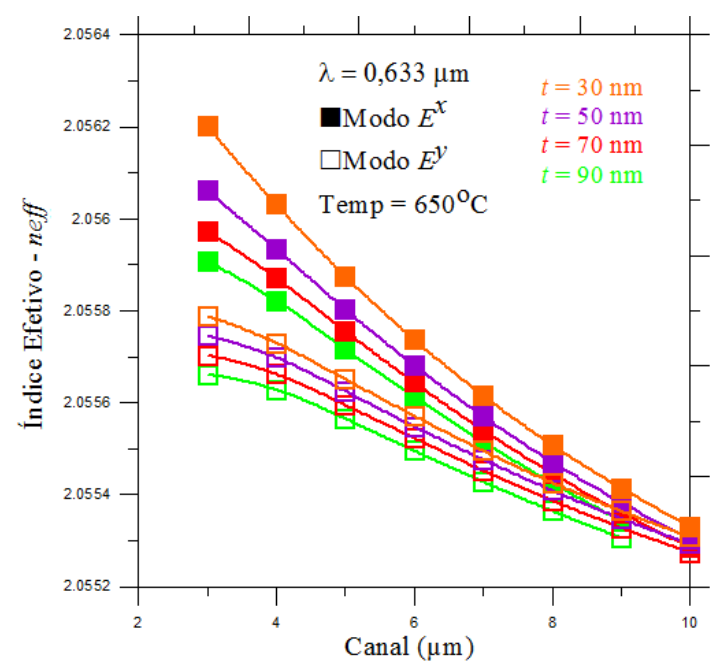

(a)

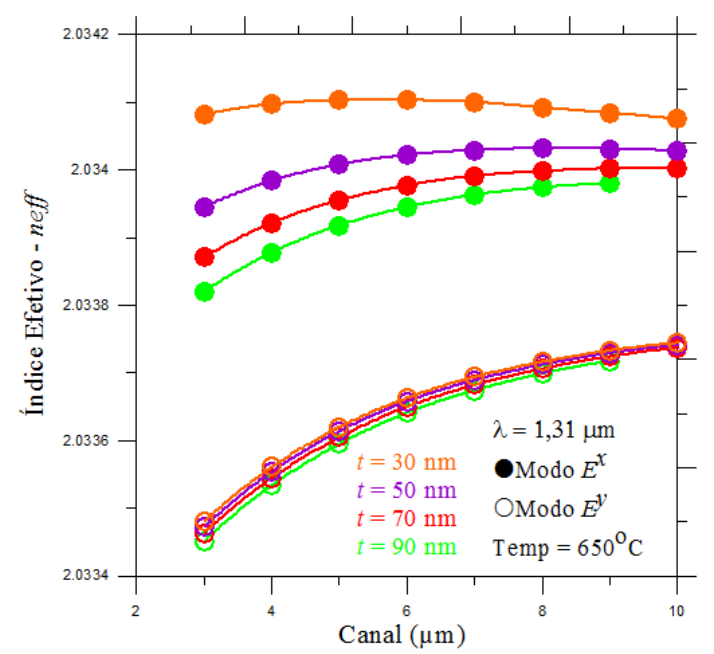

(b)

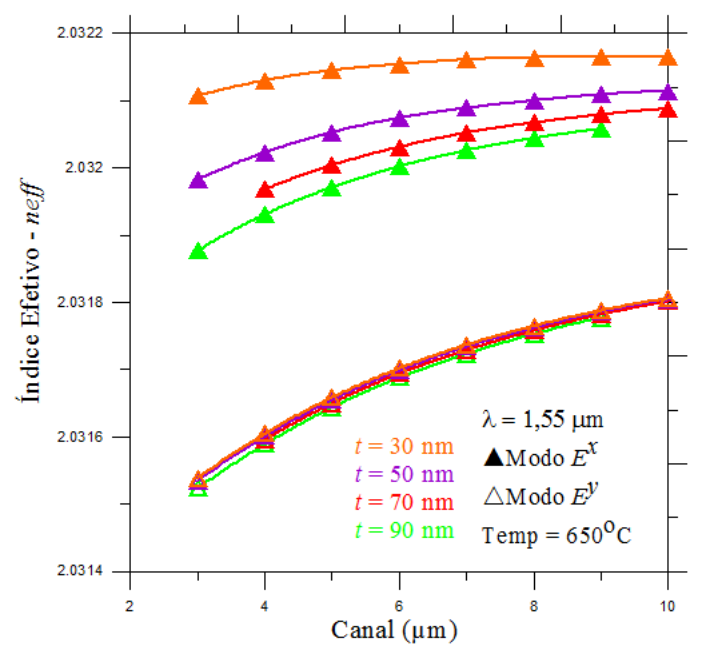

(c)

Fonte: Autora 


\subsubsection{Quarto grupo: moduladores eletro-ópticos baseados em guias de onda do tipo canal}

No caso das simulações de moduladores eletro-ópticos baseados em guias de onda do tipo canal, os eletrodos metálicos foram considerados ideais e não foram implementados os dados do Al nas simulações. Foram consideradas as espessuras de $500 \mathrm{~nm}$ e de $1 \mu \mathrm{m}$ para os eletrodos metálicos em cada projeto de simulação numérica no programa COMSOL e os resultados são apresentados abaixo.

Foram consideradas as seguintes condições de contorno:
a) A Figura 56 ilustra o corte do substrato de $\mathrm{Bi}_{4} \mathrm{Ge}_{3} \mathrm{O}_{12}$;
b) A espessura do filme de $\mathrm{Si}_{3} \mathrm{~N}_{4}(t)$ utilizada foi de $50 \mu \mathrm{m}$;
c) As larguras dos canais $(G)$ utilizadas foram de 1 a $10 \mu \mathrm{m}$, passos de $1 \mu \mathrm{m}$;
d) A temperatura do forno de deposição foi de $720^{\circ} \mathrm{C}$;
e) As espessuras dos eletrodos metálicos utilizadas foram de $500 \mathrm{~nm}$ e $1 \mu \mathrm{m}$;
f) Foram inseridas as equações 3.25, 3.26 e 3.27 que representam o efeito eletro-óptico no programa Comsol.

Os perfis de deformação $S_{1}, S_{2}$ e $S_{6}$, das isolinhas do potencial elétrico e das representações do vetor de um campo elétrico local são semelhantes aos resultados obtidos no primeiro subgrupo do primeiro grupo de simulações apresentados nas Figuras 51 (a-c) e na Figura 36.

Os perfis do campo elétrico dos Modos $E^{x}$ e $E^{y}$ para $\lambda=1,55 \mu$ m estão ilustrados na Figura 61 para espessura de filme $50 \mathrm{~nm}$. Esses modos são obtidos pela técnica ISS com birrefringência de aproximadamente $10^{-4}$ para a configuração de geometria analisada. Foram realizadas simulações com dois tipos de espessuras de eletrodos (500 nm e $1000 \mathrm{~nm}$ ) e foram considerados dois grupos de largura do canal dos eletrodos: $5 \mu \mathrm{m}, 7 \mu \mathrm{m}$ e $9 \mu \mathrm{m}$ denominados de sem deslocamento e $7 \mu \mathrm{m}, 9 \mu \mathrm{m}$ e $11 \mu \mathrm{m}$ denominados de com deslocamento.

As Figuras 63 (a-d) mostram a $Z_{c}$ e o Neff da modulação da onda elétrica em função da largura do canal do guia, considerando-se a espessura do filme de $\mathrm{Si}_{3} \mathrm{~N}_{4}$ de $50 \mathrm{~nm}$ e espessuras dos eletrodos de $500 \mathrm{~nm}$ e $1000 \mathrm{~nm}$. 
Para o canal de $5 \mu \mathrm{m}$, espessuras de eletrodos $500 \mathrm{~nm}$ e sem deslocamento dos eletrodos são apresentados os seguintes valores: $Z_{c} \approx 50 \Omega$ e $N$ eff $\approx 2,81$. A largura de banda é de 184,3 GHz para um componente com comprimento unitário.

Para o canal de $5 \mu \mathrm{m}$, espessuras de eletrodos $500 \mathrm{~nm}$ e com deslocamento dos eletrodos são apresentados os seguintes valores: $Z_{c} \approx 52 \Omega$ e Neff $\approx 2,71$. A largura de banda é de 214,9 $\mathrm{GHz}$, para um componente com comprimento unitário.

Para o canal de $5 \mu \mathrm{m}$, espessuras de eletrodos $1000 \mathrm{~nm}$ e sem deslocamento dos eletrodos são apresentados os seguintes valores de: $Z_{c} \approx 49 \Omega$ e Neff $\approx 2,76$. A largura de banda é de 198,3 $\mathrm{GHz}$, para um componente com comprimento unitário.

Para o canal de $5 \mu \mathrm{m}$, espessuras de eletrodos $1000 \mathrm{~nm}$ e com deslocamento dos eletrodos são apresentados os seguintes valores de: $Z_{c} \approx 54 \Omega$ e $N$ eff $\approx 2,79$. A largura de banda é de 190 $\mathrm{GHz}$, para um componente com comprimento unitário.

As Figuras 64 (a e b) mostram os resultados das simulações para as tensões de meia onda $(V \pi)$ de moduladores eletro-ópticos em óptica integrada na configuração de modulador de fase. A Figura 64a mostra o comportamento do $V \pi$, considerando-se a espessura dos eletrodos $e$ de $500 \mathrm{~nm}$ e a Figura 64b mostra o comportamento do $V \pi$ com espessura dos eletrodos $e$ de $1000 \mathrm{~nm}$ Essas Figuras mostram ainda os resultados obtidos com os eletrodos afastados de $1 \mu \mathrm{m}$ em relação às bordas do canal.

Como a maior dimensão das lâminas de BGO a serem usadas como substrato é de $5 \mathrm{~cm}$, o comprimento do modulador eletro-óptico também terá este valor e pretende-se fabricá-lo em parceria com o LSI. O processo de fabricação desse componente é apresentado na seção 4.2 desse capítulo. Considerando o canal $=5 \mu \mathrm{m}, \mathrm{t}=50 \mathrm{~nm}, \mathrm{e}=500 \mathrm{~nm}-\mathrm{sem}$ o deslocamento dos eletrodos e usando o $\lambda$ de $1,55 \mu \mathrm{m}$, o valor calculado pela equação 2.54 para $V \pi \cdot L$ é de 1,09 (V.m). Então, o valor real do $V \pi$ é de 22 V. Considerando o canal $=5 \mu \mathrm{m}, \mathrm{t}=50 \mathrm{~nm}$, $\mathrm{e}^{\circ}={ }^{\circ} 500 \mathrm{~nm}-$ com o deslocamento dos eletrodos e usando o $\lambda$ de $1,55 \mu \mathrm{m}$, o valor $V \pi$ calculado é de 1,207. Então, o valor real do $V \pi$ é de $24 \mathrm{~V}$. 
Figura 63- Neff e $Z_{c}$ da onda elétrica em função da largura do canal do guia, $G$, no filme de $\mathrm{Si}_{3} \mathrm{~N}_{4}$, considerando-se espessura dos eletrodos metálicos de 500nm. (a) espessura de $\mathbf{t}=50 \mathrm{~nm}$ $e=500 \mathrm{~nm}$. (b) espessura de $t=50 \mathrm{~nm}, e=500 \mathrm{~nm}$ com deslocamento de $1000 \mathrm{~nm}$ entre o eletrodo e o canal de cada lado. (c) espessura de $t=50 \mathrm{~nm} e=1000 \mathrm{~nm}$. (d) espessura de $t=50 \mathrm{~nm}, e=1000 \mathrm{~nm}$ com deslocamento de $1000 \mathrm{~nm}$ entre o eletrodo e o canal de cada lado.

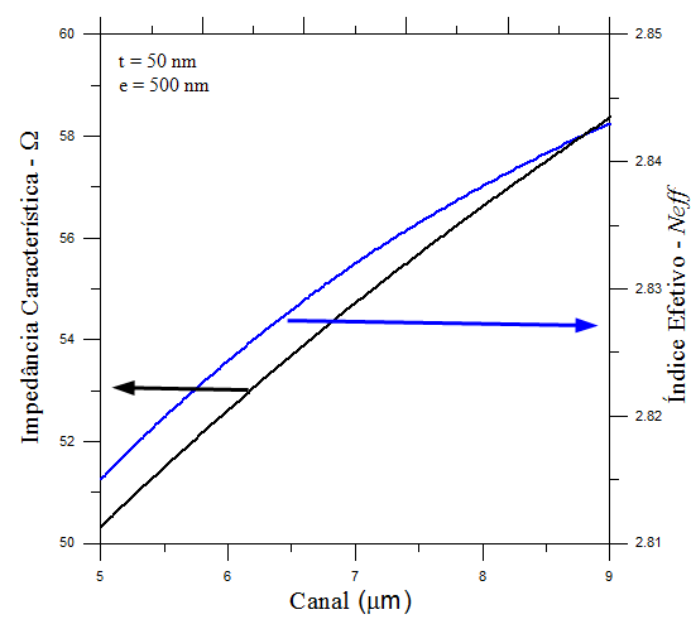

(a)

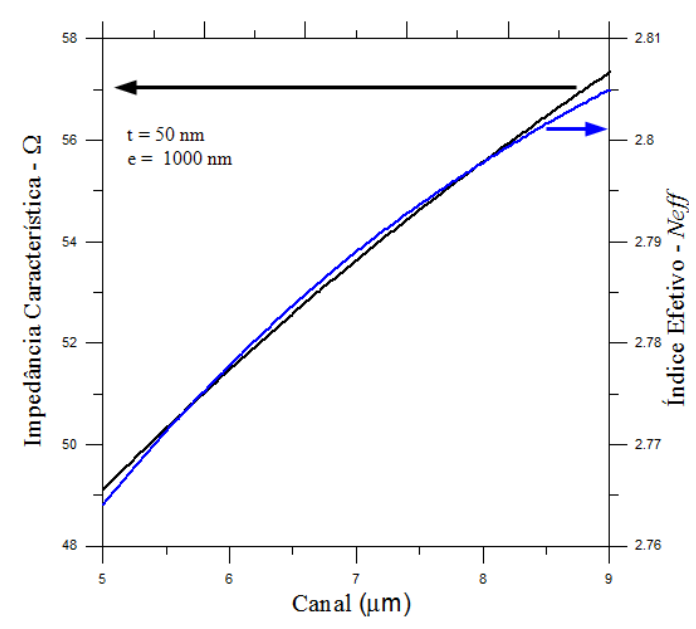

(c)

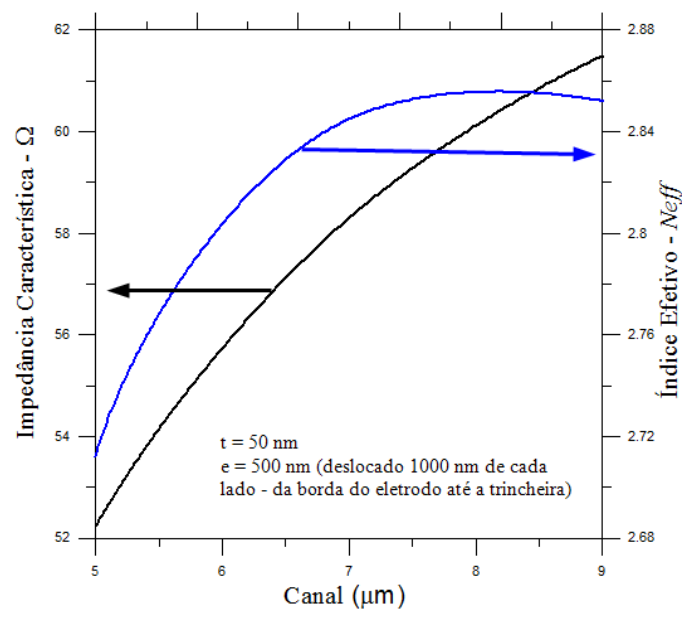

(b)

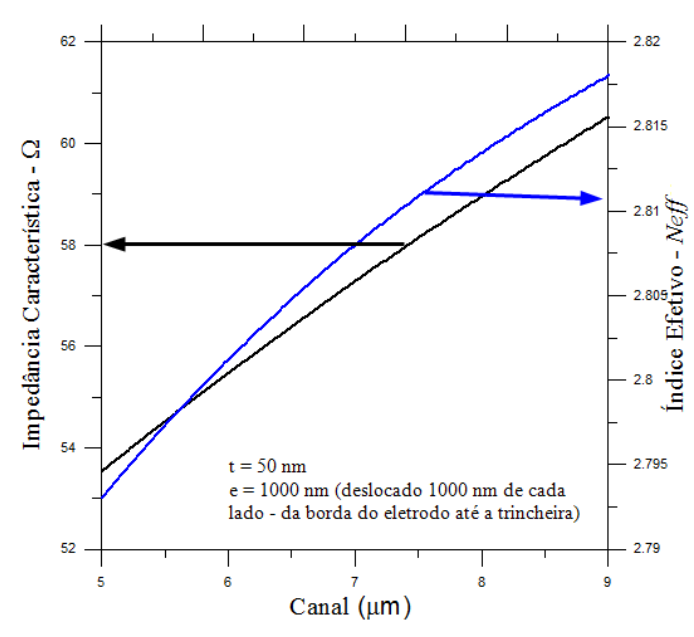

(d)

Fonte: Autora 
Figura 64- $V \pi$ em função da largura do canal. (a) Espessura dos eletrodos de $500 \mathrm{~nm}$. (b) Espessura dos eletrodos de $1000 \mathrm{~nm}$

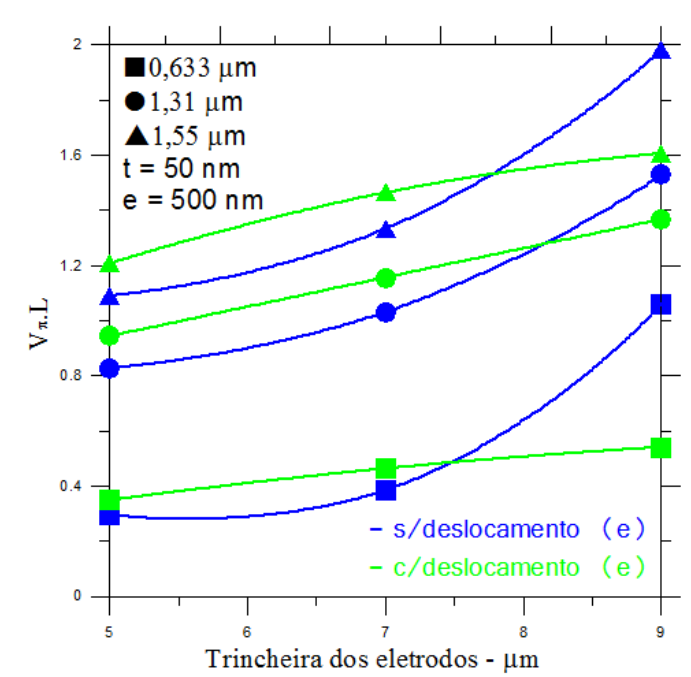

(a)

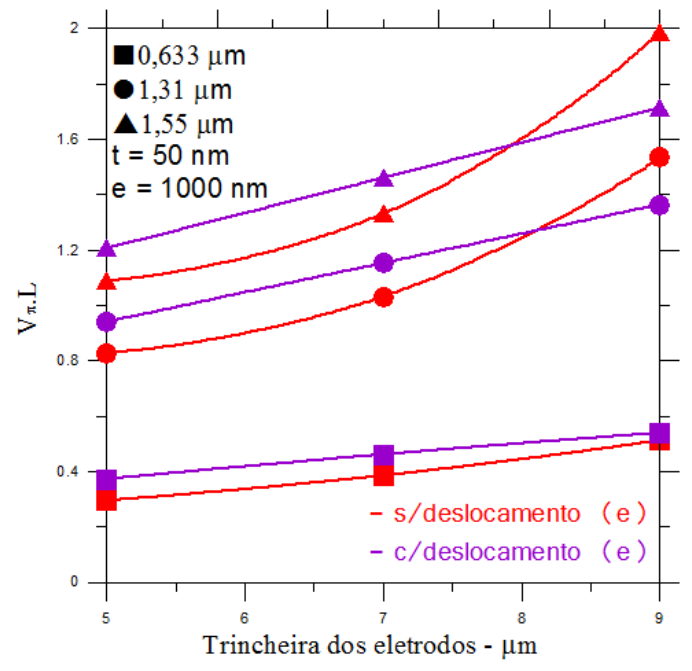

(b)

Fonte: Autora

\subsection{Resultados experimentais e discussões}

Os pesquisadores do grupo LSI/EPUSP iniciaram o processo de fabricação dos guias de ondas do tipo canal, depositando o filme de $\mathrm{Si}_{3} \mathrm{~N}_{4}$ (filme indutor de tensão mecânica) à temperatura de deposição de $800^{\circ} \mathrm{C}$ por LPCVD. As trincheiras foram definidas por fotogravação, usando uma máscara previamente existente no LSI/EPUSP que foi confeccionada originalmente para a fabricação de guias de onda do tipo "rib" [54], na qual as larguras dos canais ou trincheiras (gaps) presentes variam de $1 \mu \mathrm{m}$ a $10 \mu \mathrm{m}$ em passos de $1 \mu \mathrm{m}$. Existe também um canal com largura de $80 \mu \mathrm{m}$ que é usado como uma marca de referência para localização dos outros canais [98] nos processos de litografia óptica e corrosão, como relatado nas seções 3.6.1.3 e 3.6.1.4 do capítulo 3. Esses guias foram obtidos a partir do projeto proposto pela autora. Os resultados da fabricação dos filmes, incluindo as medidas de sua espessura e os parâmetros de corrosão por plasma $\mathrm{SF}_{6}$, são apresentados na seção 4.2.1 deste capítulo. São realizados dois testes: a primeira da máscara existente no LSI/EPUSP e a segunda dos cortes do substrato de BGO e o resultados do cálculo da tensão total dos substratos de $\mathrm{Bi}_{4} \mathrm{Ge}_{3} \mathrm{O}_{12}$ e de $\mathrm{Si}$ (substrato teste).

Os procedimentos descritos nesta seção dividem-se em quatro etapas. 
No primeiro procedimento, a espessura de $500 \mathrm{~nm}$ do filme de $\mathrm{Si}_{3} \mathrm{~N}_{4}$ foi proposta a partir dos resultados das simulações. Esse parâmetro é usado, como referência de espessura no processo de deposição do filme de $\mathrm{Si}_{3} \mathrm{~N}_{4}$ sobre o substrato de $\mathrm{Bi}_{4} \mathrm{Ge}_{3} \mathrm{O}_{12}$ com as faces superior e inferior rugosas. Nessa seção é apresentado o resultado dessa deposição. Após a deposição, são usados os processos de litografia óptica e de corrosão por plasma $\mathrm{SF}_{6}$ para obtenção dos guias de onda do tipo canal, como é apresentado nesse capítulo.

No segundo procedimento, é usada como referência a mesma espessura de $500 \mathrm{~nm}$ do filme de $\mathrm{Si}_{3} \mathrm{~N}_{4}$ no processo de deposição do mesmo sobre o substrato de $\mathrm{Bi}_{4} \mathrm{Ge}_{3} \mathrm{O}_{12}$ com as faces superior e inferior polidas e do substrato Si (substrato teste). Nessa seção é apresentado o seu resultado. Nesse procedimento, foi incluída a compra de uma máscara circular de 3 três polegadas de diâmetro divida em duas partes, uma contendo o padrão para o processo de fotogravação para definição das trincheiras, como mostra a Figura 65, e outra contendo o padrão para os eletrodos com pads, como mostra as Figuras 66.

Foi realizado um teste com uma máscara de placa de quartzo com os padrões em cromo (máscara de padrões de linhas existente no laboratório do LSI/EPUSP) no processo de fabricação de guias de ondas ópticos do tipo canal. O resultado não foi ruim, porém como a mascara era antiga e estava parcialmente danificada, decidiu-se comprar outra máscara do mesmo material, com os padrões ilustrados nas Figuras 65 e 67.

Figura 65- Máscara de padrões dos guias de onda do tipo canal

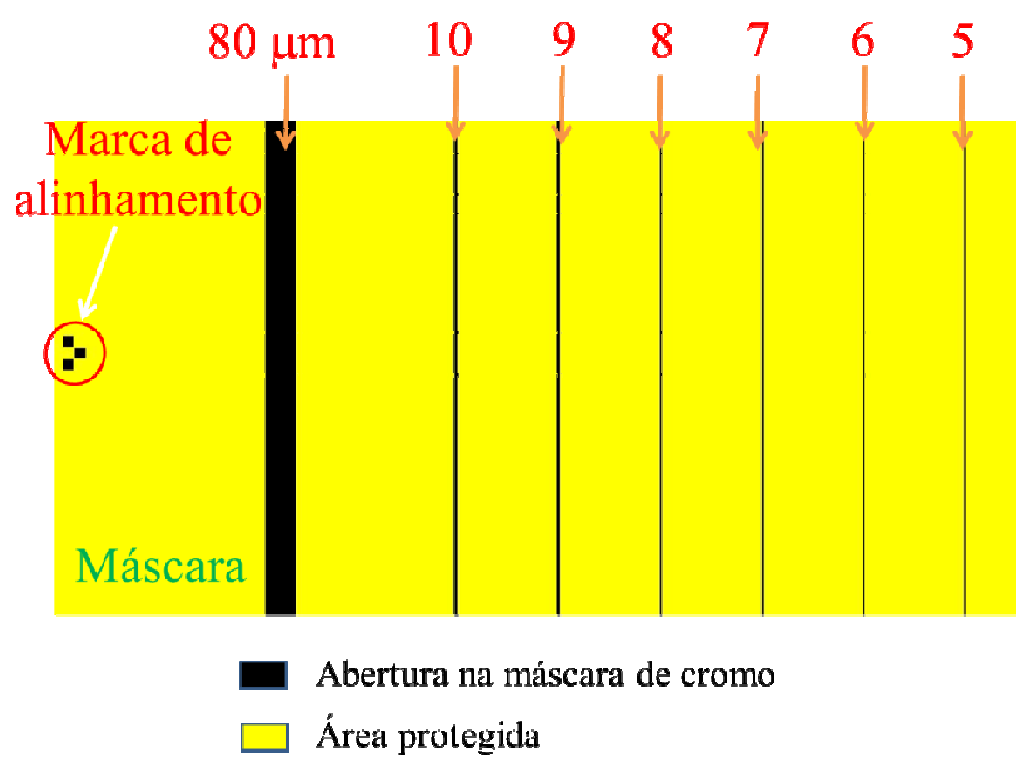

Fonte: Autora 
Figura 66- Máscara de padrões das trincheiras dos eletrodos e os PADs

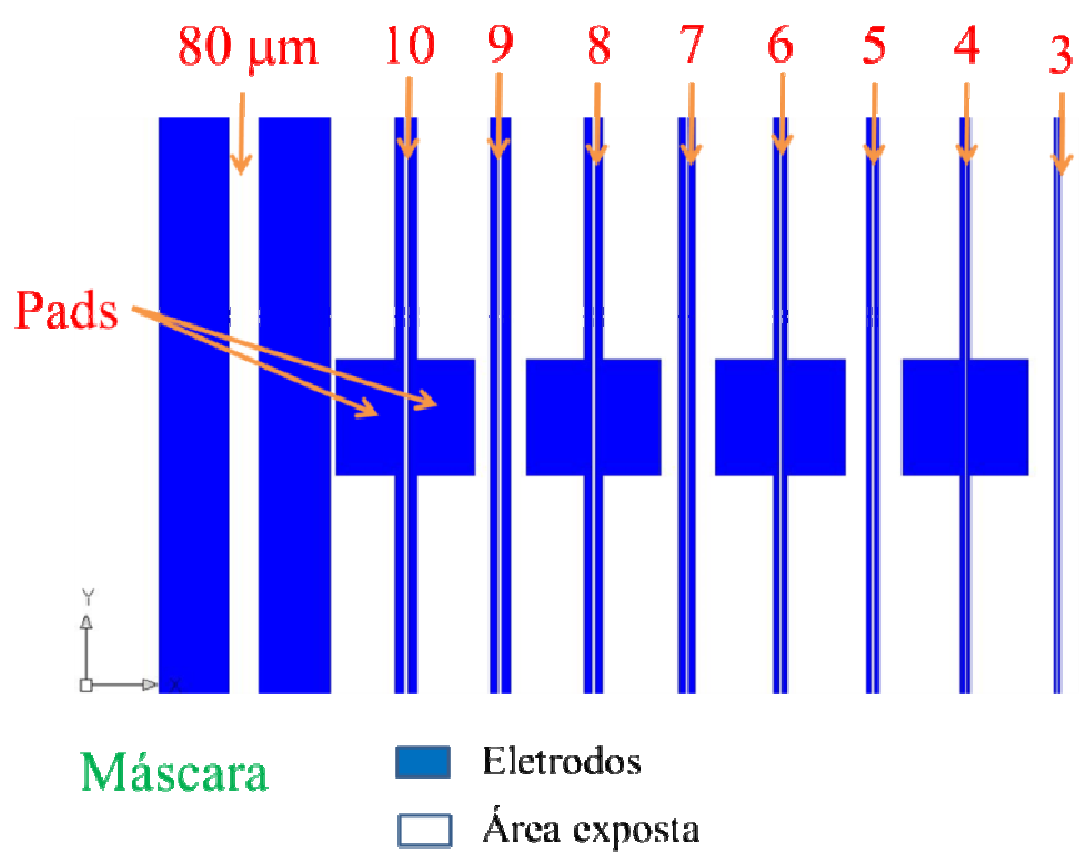

Fonte: Autora

Não foram realizadas medições de Espectroscopia de infravermelho por transformada de Fourier (Fourier transform infrared spectroscopy - FTIR) e de Espectroscopia de Retrodispersão de Rutherford (Rutherford Backscattering Spectroscopy - RBS) para conferir a composição $\mathrm{Si}_{3} \mathrm{~N}_{4}$ que está sendo depositado sobre o substrato de BGO pois estas medição foram realizadas por Zambom [98] em seu trabalho em que foi utilizado o mesmo equipamento e o mesmo processo em condições semelhantes de deposição.

No processo de fabricação de guias de ondas foi incluída uma deposição do filme de $\mathrm{Si}_{3} \mathrm{~N}_{4}$ no laboratório do Centro de Componentes Semicondutores da Universidade de Campinas (CCS/ UNICAMP) porque o equipamento de deposição do LSI/EPUSP estava momentaneamente inoperante.

No terceiro procedimento, é usada como referência a espessura de $250 \mathrm{~nm}$ do filme de $\mathrm{Si}_{3} \mathrm{~N}_{4}$ no processo de deposição sobre uma das faces polidas da amostra de BGO e do substrato teste de Si. Após a deposição dos filmes, são usados os processos de litografia óptica e de corrosão por plasma $\mathrm{SF}_{6}$ para definição das trincheiras. Nesta seção são apresentados os resultados deste processo. 
No quarto procedimento, é usada como referência a espessura de $50 \mathrm{~nm}$ do filme de $\mathrm{Si}_{3} \mathrm{~N}_{4}$ no processo de deposição sobre uma das faces polidas da amostra de BGO e do substrato teste de Si. Após a deposição, são usados os processos de litografia óptica e de corrosão por plasma $\mathrm{SF}_{6}$ para definição das trincheiras, como é apresentado neste capítulo. Neste procedimento é apresentada deposição de um filme de Al. Após a deposição do Al, são usados os processos de litografia óptica e corrosão por via úmida para definição dos eletrodos e pads. Nesta seção são apresentados os resultados deste procedimento.

\subsubsection{Testes realizados com as máscaras existentes no LSI/EPUSP}

Foram realizados os procedimentos de testes das máscaras litográficas ópticas existentes no LSI/EPUSP para as fabricações de guias de onda do tipo rib. Estes testes são muito importantes para definir os parâmetros usados nas fabricações dos guias de ondas propostos neste trabalho.

\subsubsection{Processo de corrosão via úmida}

O procedimento da fabricação de guias de onda, baseado na técnica ISS, inicia-se com a limpeza dos substratos de $\mathrm{Bi}_{4} \mathrm{Ge}_{3} \mathrm{O}_{12}$ conforme descrito na etapa 1 na seção 3.6 do Capítulo 3 . $\mathrm{Na}$ etapa 2, a deposição do filme de $\mathrm{Si}_{3} \mathrm{~N}_{4}$ sobre o substrato de $\mathrm{Bi}_{4} \mathrm{Ge}_{3} \mathrm{O}_{12}$. foi realizada à temperatura de $800^{\circ} \mathrm{C}$. Na etapa 3, realizou-se a deposição do fotorresiste (AZ1518) sobre o filme de $\mathrm{Si}_{3} \mathrm{~N}_{4}$. Na etapa 4, a definição dos guias de onda nos filmes de $\mathrm{Si}_{3} \mathrm{~N}_{4}$ foi realizada pelo procedimento litográfico óptico convencional. Na etapa 5 foi realizado um teste do processo de corrosão úmida, usando a solução para obter trincheiras nas larguras de 1 a $10 \mu \mathrm{m}$ (passos de $1 \mu \mathrm{m}$ ) e de $80 \mu \mathrm{m}$ no substrato de Si (substrato teste). Como o processo de corrosão demonstrou-se muito lento, prolongando o processo de remoção total do filme de $\mathrm{Si}_{3} \mathrm{~N}_{4}$ por mais de 1 hora e 30 minutos, o fotorresiste não suportou e houve seu deslocamento. Com isso, o resultado não ficou como o esperado, conforme ilustra a Figura 67.

Para reduzir o tempo de processamento, foi então decidido realizar o processo de corrosão por plasma $\mathrm{SF}_{6}$ do filme de $\mathrm{Si}_{3} \mathrm{~N}_{4}$ sobre o substrato de $\mathrm{Bi}_{4} \mathrm{Ge}_{3} \mathrm{O}_{12}$. 
Figura 67- Definição dos padrões de linhas para guias de onda ópticos usando a técnica da corrosão por via úmida do filme de $\mathrm{Si}_{3} \mathrm{~N}_{4}$

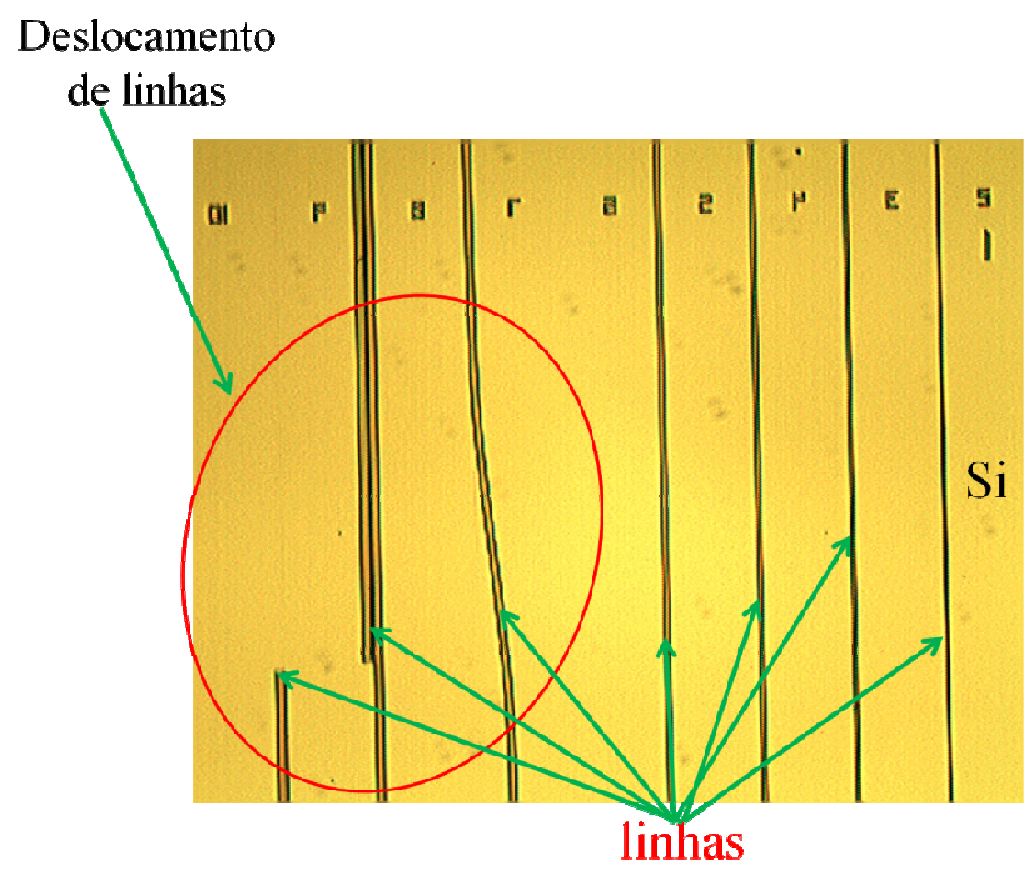

Fonte: Autora

\subsubsection{Processo de corrosão por plasma $\mathrm{FS}_{6}$}

Os parâmetros usados na execução da etapa 5 de corrosão por plasma de $\mathrm{SF}_{6}$ foi apresentados na Tabela 7

A Figura 68 mostra o resultado dos padrões de guias de onda usando a corrosão por plasma de $\mathrm{SF}_{6}$ (g) do filme de $\mathrm{Si}_{3} \mathrm{~N}_{4}$.

Após as realizações dos testes de corrosão via úmida e por plasma de $\mathrm{SF}_{6}$ foi escolhida o procedimento de corrosão por plasma de $\mathrm{SF}_{6}$. A técnica de corrosão por via úmida não demonstrou-se uma boa escolha, pois ocorreu o descolamento de linhas dos guias, como foi mostrado na Figura 67. A técnica de corrosão por plasma de $\mathrm{SF}_{6}$ foi a opção escolhida para a fabricação de guias de onda do tipo linha, como foi mostrado na Figura 68. 
Figura 68- Padrões de guias de onda transferidos

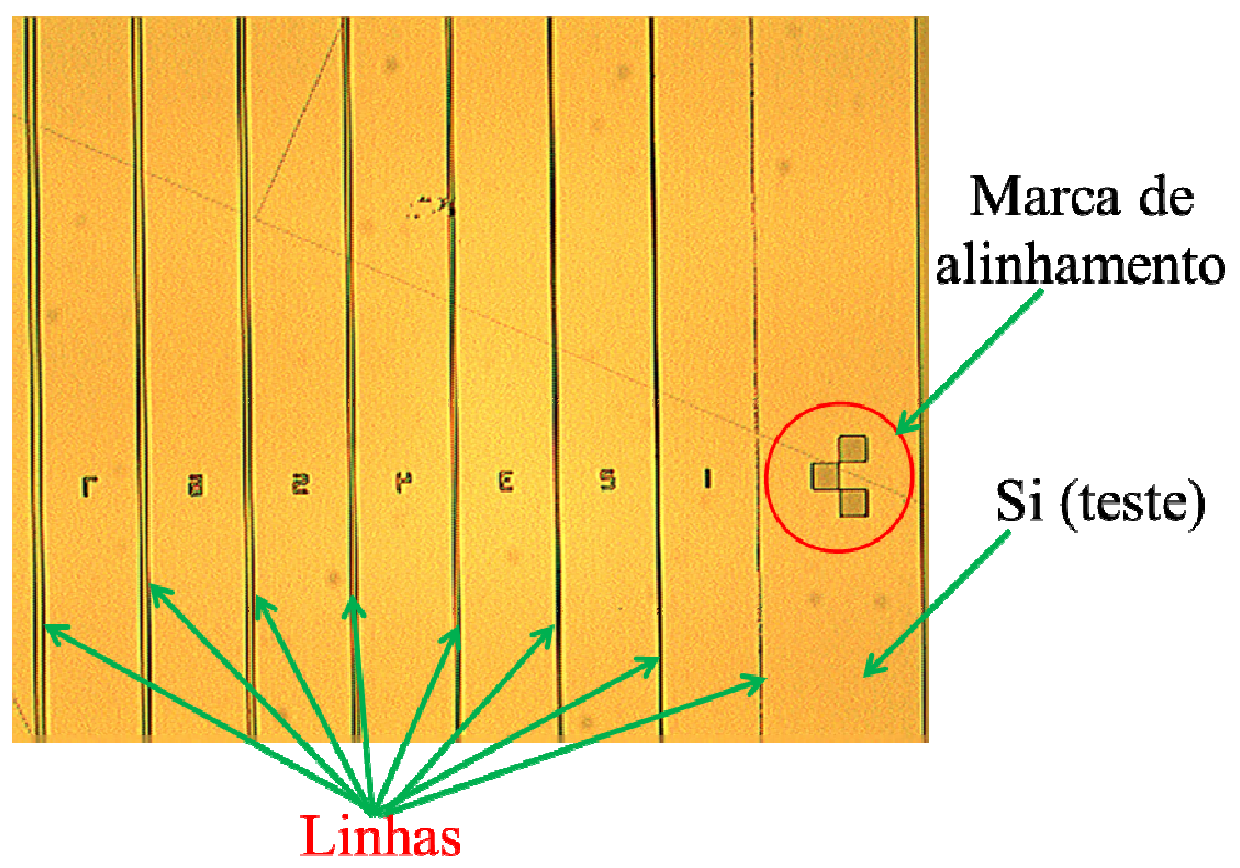

Fonte: Autora

Figura 69- Teste da máscara dos padrões de tricheiras existente no LSI para fabricação de guias de onda do tipo canal

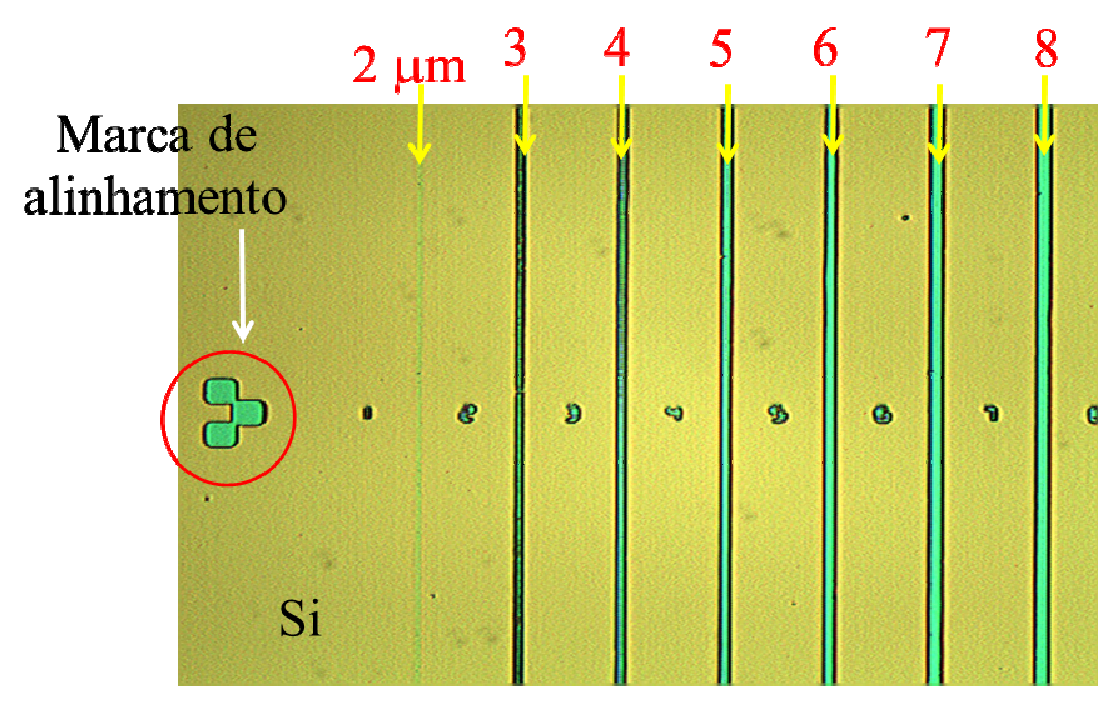

Abertura na máscara do cromo Área protegida

Fonte: Autora 
Utilizou-se, portanto, o substrato de $\mathrm{Bi}_{4} \mathrm{Ge}_{3} \mathrm{O}_{12}$ com faces rugosas (superior e inferior) e seguiram-se as etapas descritas na seção 3.6 no capítulo 3, quais sejam: limpeza dos substratos teste $(\mathrm{Si})$, deposição do filme de $\mathrm{Si}_{3} \mathrm{~N}_{4}$ com espessura aproximadamente de $500 \mathrm{~nm}$ pela técnica LPCVD, transferência de padrões de guias de onda (trincheiras de 1 a $10 \mu \mathrm{m}$ ) usando a máscara litográfica óptica com padrões de trincheiras (máscara existente no LSI) e definição dos guias de onda pelo processo de corrosão por plasma de $\mathrm{SF}_{6}$.

A Figura 69 mostra o resultado do teste da corrosão por plasma $\mathrm{SF}_{6}$ utilizando-se a máscara litográfica óptica dos padrões de trincheiras existente no LSI.A máscara usada no processo descrito acima foi de campo escuro e na revelação para definição das trincheiras, usou-se o PR positivo para obter a imagem reversa, porque era o que estava disponível no laboratório do LSI/EPUSP.

\subsubsection{Procedimento 1: substrato de $\mathrm{Bi}_{4} \mathrm{Ge}_{3} \mathrm{O}_{12}$ rugoso}

A fabricação de guias de onda seguiu as etapas 1 e 2 da seção 3.6 do capítulo 3 . Os filmes de $\mathrm{Si}_{3} \mathrm{~N}_{4}$ obtidos foram depositados sobre o substrato de $\mathrm{Bi}_{4} \mathrm{Ge}_{3} \mathrm{O}_{12}$ em uma das faces rugosas. $\mathrm{A}$ Figura 70 mostra o resultado da deposição do filme de $\mathrm{Si}_{3} \mathrm{~N}_{4}$ sobre os substratos $\mathrm{Bi}_{4} \mathrm{Ge}_{3} \mathrm{O}_{12}$ rugosos.

Figura 70- $\mathrm{O}$ filme de $\mathrm{Si}_{3} \mathrm{~N}_{4}$ depositado por LPCVD sobre o substrato de $\mathrm{Bi}_{4} \mathrm{Ge}_{3} \mathrm{O}_{12}$

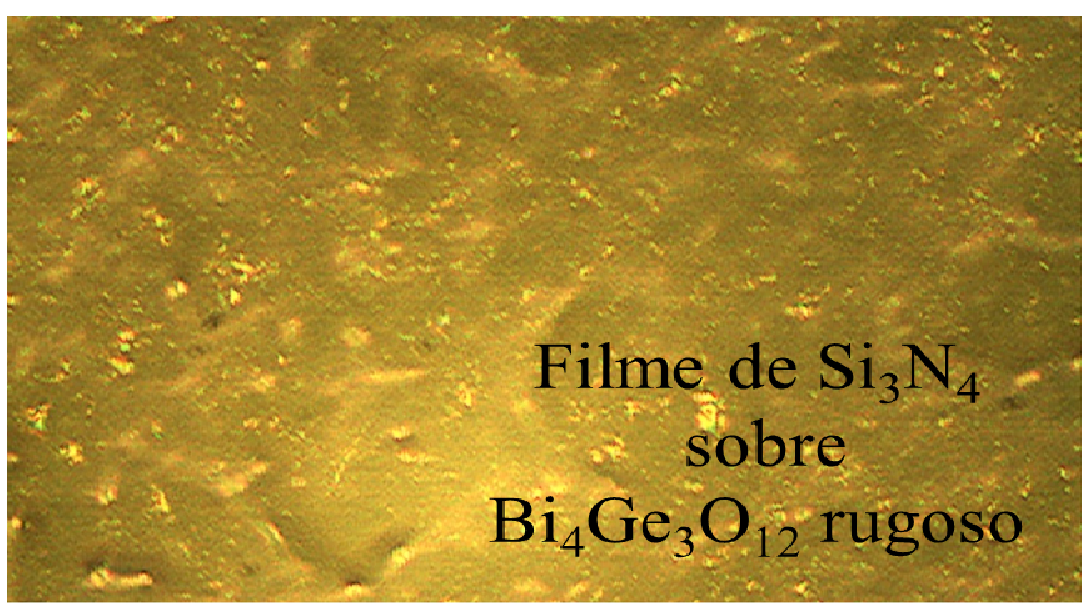

\section{Fonte: Autora}

No procedimento de fabricação de guias de onda foram seguidas as etapas relatadas na seção 3.6 do capítulo 3 e consideram-se parâmetros usados na fabricação de guias de onda do tipo rib. Estes parâmetros são: limpeza dos substratos de $\mathrm{Bi}_{4} \mathrm{Ge}_{3} \mathrm{O}_{12}$, deposição do filme de $\mathrm{Si}_{3} \mathrm{~N}_{4}$ 
com espessura de 500nm, transferência dos padrões da máscara litográfica óptica e definição os guias de onda do tipo canal usando a técnica da corrosão por plasma $\mathrm{SF}_{6}$. Na Figura 71 é ilustrado o resultado dos padrões de guia de onda do tipo canal, de 1 a $10 \mu \mathrm{m}$ e de $80 \mu \mathrm{m}$, e foram obtidos os padrões dos guias de onda do tipo canal usando a técnica de estresse residual induzido termicamente. Este estresse é formado pela diferença do coeficiente de expansão térmica dos materiais envolvidos no estudo.

Figura 71- Trincheiras no filme de $\mathrm{Si}_{3} \mathrm{~N}_{4}$ sobre o substrato de $\mathrm{Bi}_{4} \mathrm{Ge}_{3} \mathrm{O}_{12}$ com face rugosa

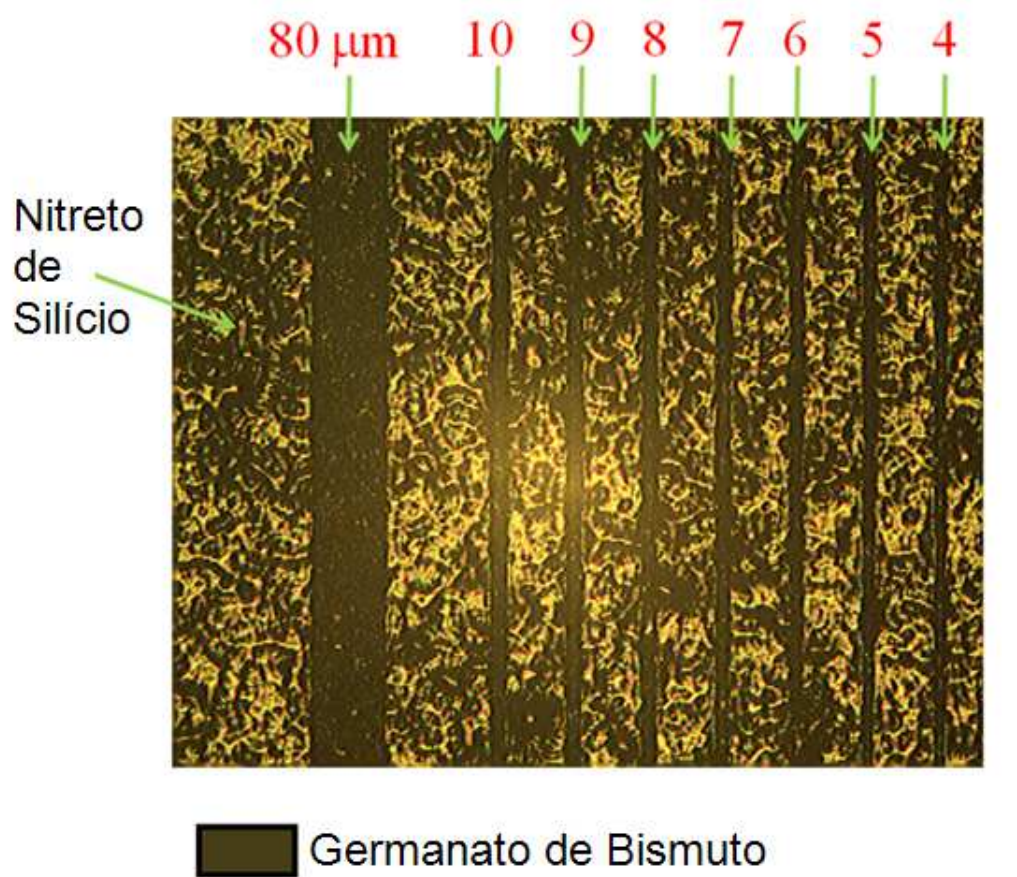

Fonte: Autora

Foi feito no LSI/EPUSP, um teste simples para observar, se havia guiagem da luz sob alguma trincheira. Nesse teste, foi possível, observar a propagação do feixe de laser de HeNe num dos canais, como está ilustrado na Figura 72.

Acredita-se que o espalhamento de luz observado pode ter sido causado pela rugosidade da superfície do substrato. Em vista disso, houve a necessidade de realizar o procedimento de fabricação do guia de onda do tipo canal em substrato de $\mathrm{Bi}_{4} \mathrm{Ge}_{3} \mathrm{O}_{12}$, usando os substratos com superfícies (superior e inferior) polidas. Este segundo procedimento de fabricação é apresentado a seguir. 
Figura 72- Guiamento de feixes de luz no guia de ondas em substrato de $\mathrm{Bi}_{4} \mathrm{Ge}_{3} \mathrm{O}_{12}$ com face rugosa

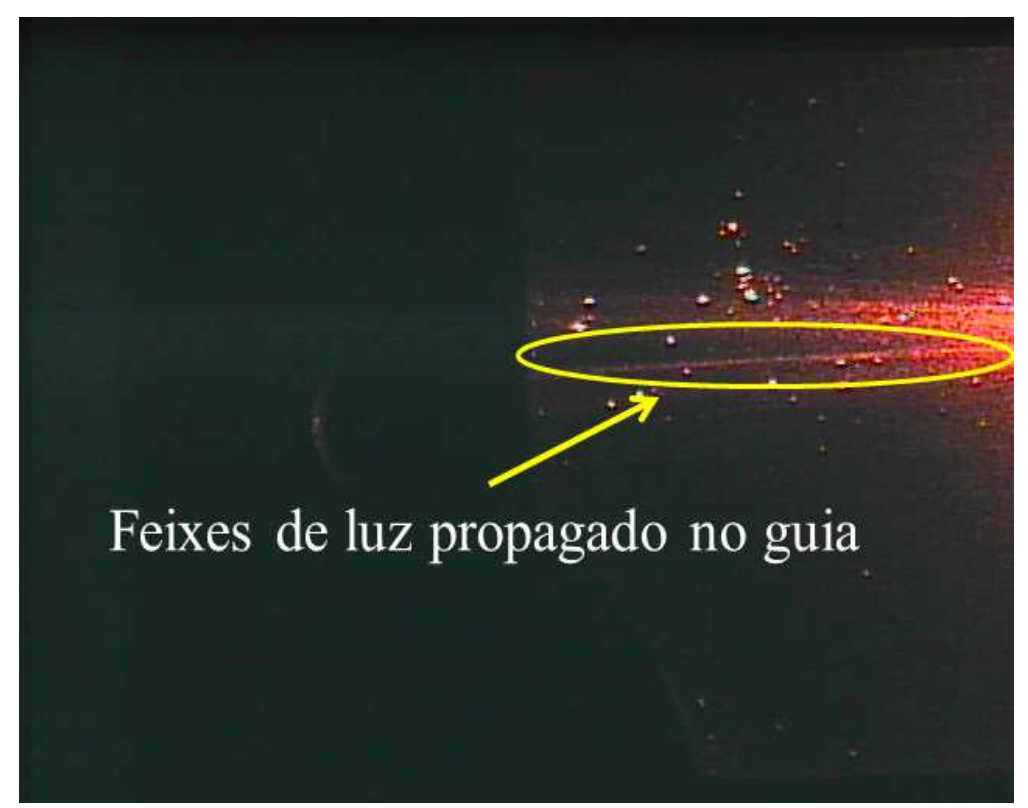

Fonte: Autora

\subsubsection{Procedimento 2: substrato de $\mathrm{Bi}_{4} \mathrm{Ge}_{3} \mathrm{O}_{12}$ polido com espessura aproximadamente de $500 \mathrm{~nm}$ do filme indutor de $\mathrm{Si}_{3} \mathrm{~N}_{4}$}

Foram adquiridas lâminas de substrato de $\mathrm{Bi}_{4} \mathrm{Ge}_{3} \mathrm{O}_{12}$ polidas nas superfícies superior e inferior (polimento óptico de quina e borda), em dimensões de $30 \mathrm{~mm}$ X $50 \mathrm{~mm} \mathrm{X} \mathrm{1,0} \mathrm{mm}$ para dar prosseguimento ao processo de fabricação do modulador eletro-óptico.

Os pesquisadores do grupo LSI/EPUSP realizaram a deposição do filme de $\mathrm{Si}_{3} \mathrm{~N}_{4}$ sobre o substrato de $\mathrm{Bi}_{4} \mathrm{Ge}_{3} \mathrm{O}_{12}$ polido opticamente nas superfícies inferiores e superiores, além das laterais da lâmina. Também foi realizado um projeto de uma máscara de trincheiras e esta foi adquirida para ser usada no processo de litografia óptica e corrosão. Os resultados dessa fabricação são apresentados na seção 4.2.3 desse capítulo.

$\mathrm{Na}$ época em que se pretendia iniciar o segundo procedimento, o equipamento de deposição do laboratório do LSI/EPUSP apresentou-se inoperante por um determinado período e teve de passar por uma manutenção. Identificou-se com infraestrutura alternativa o CCS/UNICAMP, onde deposita-se o filme de $\mathrm{Si}_{3} \mathrm{~N}_{4}$ usando temperatura de deposição menor do que usado no LSI/EPUSP em torno de $720^{\circ} \mathrm{C}$. A solicitação para o uso desta opção foi bem sucedida e no 
CCS/UNICAMP os pesquisadores depositaram o filme de $\mathrm{Si}_{3} \mathrm{~N}_{4}$ no substrato de $\mathrm{Bi}_{4} \mathrm{Ge}_{3} \mathrm{O}_{12}$ usando a temperatura de deposição de $740^{\circ} \mathrm{C}$, com espessura de aproximadamente $500 \mathrm{~nm}$. Nesse caso, os parâmetros de deposição utilizados diferenciaram-se dos utilizados nos processos realizados pelos pesquisadores do LSI/EPUSP. Os parâmetros da deposição do filme de $\mathrm{Si}_{3} \mathrm{~N}_{4}$ realizada pelos pesquisadores do CCS/UNICAMP são apresentados na seção 4.2.3 desse capítulo.

Antes de iniciar o segundo procedimento na fabricação de guias de ondas em substratos polidos de $\mathrm{Bi}_{4} \mathrm{Ge}_{3} \mathrm{O}_{12}$ foi proposto o projeto da nova máscara litográfica de trincheiras, como ilustrado na Figura 65; e a sua aquisição. Neste projeto não foi considerado os padrões de trincheiras, contudo foram considerados os padrões de eletrodos, como ilustra a Figura 66 $[123]$.

Foi usado o photo-resist (PR) positivo (porque era o material que estava disponível no LSI/EPUSP naquele momento) com a máscara de placa de quartzo com padrões em cromo no processo de litografia óptica. Logo não houve a necessidade de realizar a imagem reversa com máscara positiva no processo de litografia óptica.

Neste segundo procedimento foram seguidas as etapas de 1 a 5 da seção 3.6 do Capítulo 3 para a fabricação de guias de onda do tipo canal em substratos polidos nas duas faces (superior e inferior) de $\mathrm{Bi}_{4} \mathrm{Ge}_{3} \mathrm{O}_{12}$. Os substratos polidos foram limpos seguindo os procedimentos da etapa 1 e em seguida, como foi descrito na etapa 2: o filme de $\mathrm{Si}_{3} \mathrm{~N}_{4}$ foi depositado pela técnica de LPCVD sobre o substrato de $\mathrm{Bi}_{4} \mathrm{Ge}_{3} \mathrm{O}_{12}$. Nesta deposição foi obtido um filme com espessura que se aproximou de 500nm, como desejado, mas o resultado não foi satisfatório. Ocorreram vários defeitos no filme depositado, tais como trincas, algumas partes descoladas outras arrancadas e uma parte ficaram cobertas com uma granulação do próprio filme, como é ilustrado na Figura 73.

O equipamento, que realiza o processo de LPCVD do laboratório do LSI, ficou operante após o sua manutenção e foi possível fazer uma deposição do filme de $\mathrm{Si}_{3} \mathrm{~N}_{4}$ com espessura aproximadamente de $500 \mathrm{~nm}$, sobre o substrato de $\mathrm{Bi}_{4} \mathrm{Ge}_{3} \mathrm{O}_{12}$ também foi realizada no LSI/EPUSP. Nesse caso, os parâmetros do processo de deposição foram seguintes: temperatura de deposição $-720^{\circ} \mathrm{C}$, tempo de deposição - 5 horas e 30 min, Pressão - 720 mTorr, fluxos de gás - $322 \mathrm{sccm}$ de $\mathrm{NH}_{3}+60$ sccm de $\mathrm{SiH}_{2} \mathrm{Cl}_{2}$ (ver a seção 3.6 do capítulo 3) e posição das amostras $\left(\mathrm{Bi}_{4} \mathrm{Ge}_{3} \mathrm{O}_{12}\right.$ polido) - horizontal. 
Figura 73- Resultado da deposição do filme de $\mathrm{Si}_{3} \mathrm{~N}_{4}$ com espessura de $465 \mathrm{~nm}$ sobre o $\mathrm{Bi}_{4} \mathrm{Ge}_{3} \mathrm{O}_{12}$. Neste filme apareceram vários tipos de defeitos

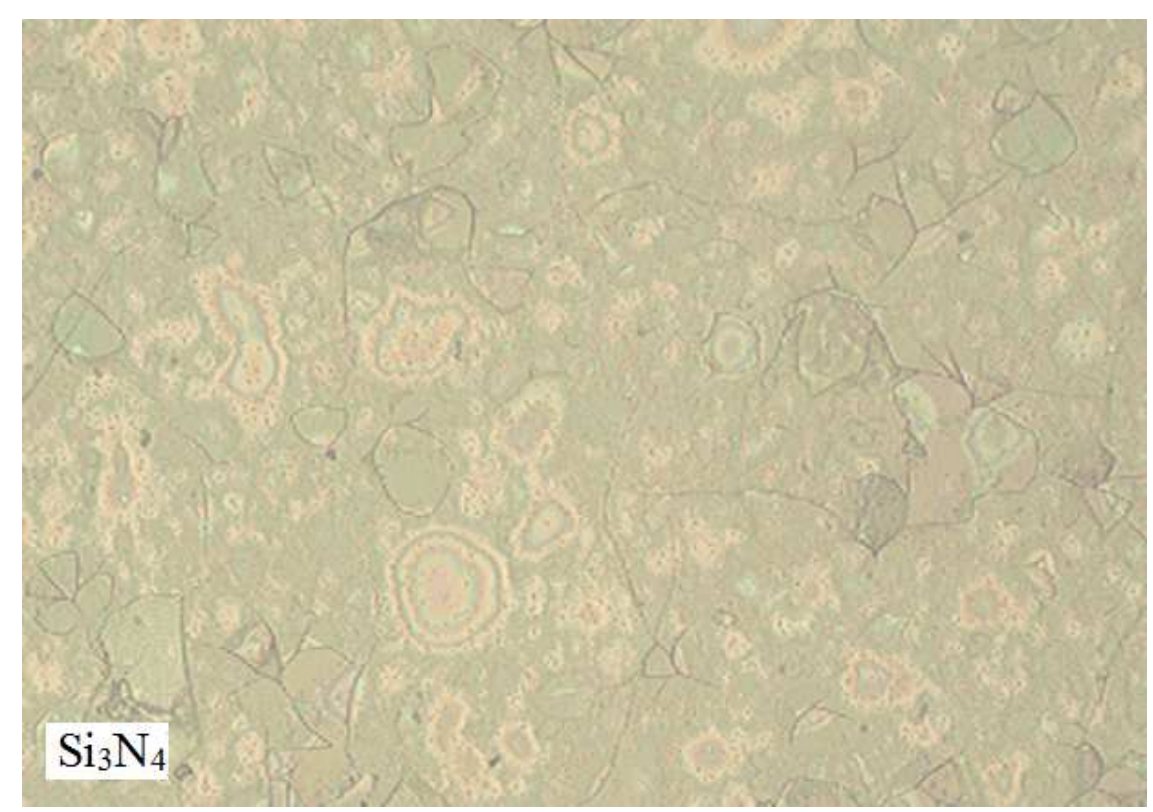

Fonte: Autora

O processo de fabricação de guias de onda do tipo canal teve que ser abortado na segunda etapa (deposição do filme de $\mathrm{Si}_{3} \mathrm{~N}_{4}$ por LPCVD) porque o filme de $\mathrm{Si}_{3} \mathrm{~N}_{4}$ mostrou-se muita indução de tensão mecânica e acarretou a danificação do mesmo.

A espessura de $465 \mathrm{~nm}$ do filme de $\mathrm{Si}_{3} \mathrm{~N}_{4}$ depositado no substrato de $\mathrm{Bi}_{4} \mathrm{Ge}_{3} \mathrm{O}_{12}$ foi realizada no CCS/UNICAMP, mas essa deposição foi realizada nos dois lados da lâmina desse substrato. Nesse caso, os parâmetros do processo de deposição do filme de $\mathrm{Si}_{3} \mathrm{~N}_{4}$ foram os seguintes: temperatura de deposição $-740^{\circ} \mathrm{C}$, tempo de deposição - 2 horas e 15 min, Pressão - 700 mTorr, fluxos de gás - $60 \mathrm{sccm}$ de $\mathrm{NH}_{3}+23 \mathrm{sccm}$ de $\mathrm{SiH}_{2} \mathrm{Cl}_{2}$ ( ver a seção 3.6 do capítulo 3) e a posição das amostras $\left(\mathrm{Bi}_{4} \mathrm{Ge}_{3} \mathrm{O}_{12}\right.$ sem rugosidade e $\left.\mathrm{Si}\right)$ - vertical, deposição dos dois lados.

$\mathrm{O}$ resultado obtido da deposição do filme de $\mathrm{Si}_{3} \mathrm{~N}_{4}$ sobre o substrato polido de $\mathrm{Bi}_{4} \mathrm{Ge}_{3} \mathrm{O}_{12}$ contribuiu com um novo conjunto de parâmetros para interagir com a simulação, tais como a espessura do filme e a temperatura de deposição. 


\subsubsection{Procedimento 3: substrato polido de $\mathrm{Bi}_{4} \mathrm{Ge}_{3} \mathrm{O}_{12}$ com filme fino de $\mathrm{Si}_{3} \mathrm{~N}_{4}$}

Como o resultado da deposição do filme realizado no LSI/EPUSP apresentado anteriormente não saiu como esperado, a autora e os pesquisadores do grupo LSI/EPUSP definiram uma nova espessura de $250 \mathrm{~nm}$ do filme de $\mathrm{Si}_{3} \mathrm{~N}_{4}$ a ser depositada sobre o substrato de $\mathrm{Bi}_{4} \mathrm{Ge}_{3} \mathrm{O}_{12}$ por LPCVD. Enquanto a autora implementava as informações no programa de simulação do projeto de guias de onda, os pesquisadores do grupo LSI/EPUSP realizavam o processo de deposição do filme de $\mathrm{Si}_{3} \mathrm{~N}_{4}$ no substrato de $\mathrm{Bi}_{4} \mathrm{Ge}_{3} \mathrm{O}_{12}$. No processo citado acima ocorreu um problema no sistema de gás durante a deposição do filme, que não permitiu prolongar o processo. Visto que, o filme de $\mathrm{Si}_{3} \mathrm{~N}_{4}$ depositado não ficou muito espesso, pouco menor que $100 \mathrm{~nm}$, mas o suficiente espesso para induzir algum estresse no substrato de $\mathrm{Bi}_{4} \mathrm{Ge}_{3} \mathrm{O}_{12}$ os resultados dessa fabricação são aqui apresentados.

Neste procedimento foram seguidas as etapas da seção 3.6 do Capítulo 3 para a fabricação de guias de onda do tipo canal utilizando a técnica ISS em substrato de $\mathrm{Bi}_{4} \mathrm{Ge}_{3} \mathrm{O}_{12}$ como descrito a seguir:

Após a realização da limpeza dos substratos de $\mathrm{Bi}_{4} \mathrm{Ge}_{3} \mathrm{O}_{12}$ o filme de $\mathrm{Si}_{3} \mathrm{~N}_{4}$ foi depositado utilizando-se como parâmetros: temperatura de $720^{\circ} \mathrm{C}$, tempo de deposição - 50 min, Pressão 500 mTorr, fluxos de gás - $322 \mathrm{sccm}$ de $\mathrm{NH}_{3}+40 \mathrm{sccm}$ de $\mathrm{SiH}_{2} \mathrm{Cl}_{2}$ (conforme a seção 3.6 do capítulo 3) e posição das amostras $\left(\mathrm{Bi}_{4} \mathrm{Ge}_{3} \mathrm{O}_{12}\right.$ sem rugosidade e $\left.\mathrm{Si}\right)$ - horizontal.

$\mathrm{O}$ equipamento foi calibrado para fazer a deposição de filme de $\mathrm{Si}_{3} \mathrm{~N}_{4}$ com espessura de 250nm sobre o substrato de $\mathrm{Bi}_{4} \mathrm{Ge}_{3} \mathrm{O}_{12}$. Durante o processo de deposição, houve um defeito que forçou a parada de injeção do gás, fazendo com que se tivesse que abortar a experiência. Logo, o filme de $\mathrm{Si}_{3} \mathrm{~N}_{4}$ foi obtido com espessura de apenas pouco menos de $100 \mathrm{~nm}$. Foi capturado um conjunto de imagens do substrato de $\mathrm{Bi}_{4} \mathrm{Ge}_{3} \mathrm{O}_{12}$ e a Figura 74 mostra o resultado da deposição do filme de $\mathrm{Si}_{3} \mathrm{~N}_{4}$ por LPCVD [105]. Este apresentou alguns pequenos defeitos, só observáveis por meio de microscópio eletrônico.

Foram realizadas as etapas de fotogravação de trincheiras por litografia óptica usando a nova máscara projetada para este trabalho. Na definição das trincheiras foi usado o processo de corrosão do filme de $\mathrm{Si}_{3} \mathrm{~N}_{4}$ por plasma de $\mathrm{SF}_{6}$. Ao término das etapas de deposição, dos processos de litografia óptica e de corrosão por plasma $\mathrm{FS}_{6}$ foi realizado o procedimento da limpeza e remoção do fotorresiste e eventuais detritos existentes sobre o componente. A 
Figura 75 mostra o resultado final das etapas de fabricação de guias de ondas ópticos do tipo canal obtidos.

Figura 74- Resultado da deposição do filme de $\mathrm{Si}_{3} \mathrm{~N}_{4}$ com espessura menor que $100 \mathrm{~nm}$ sobre o $\mathrm{Bi}_{4} \mathrm{Ge}_{3} \mathrm{O}_{12}$

\section{$\mathrm{Bi}_{4} \mathrm{Ge}_{3} \mathrm{O}_{12}$}

Fonte: Autora

Figura 75- Guias de ondas em substrato de $\mathrm{Bi}_{4} \mathrm{Ge}_{3} \mathrm{O}_{12}$

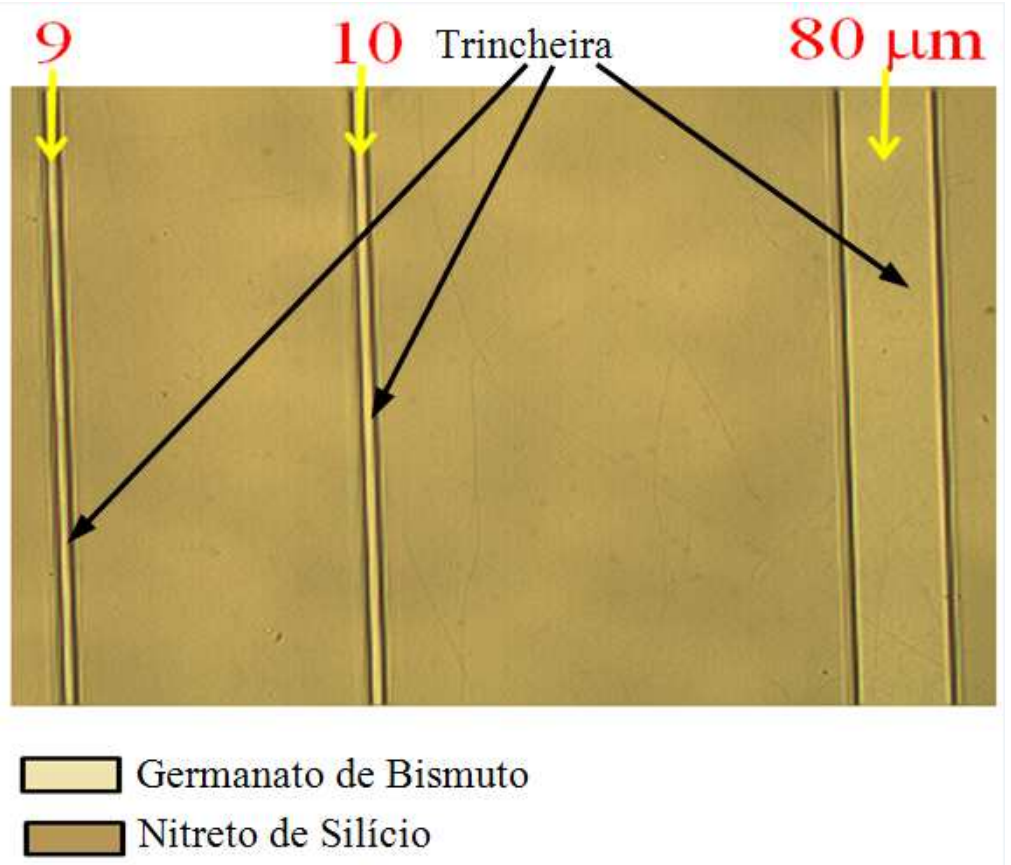

Fonte: Autora 
Utilizando os guias de onda ópticos formados no substrato de $\mathrm{Bi}_{4} \mathrm{Ge}_{3} \mathrm{O}_{12}$ como descrito acima foram realizados novos testes de guiamento de luz no LSI. Nestes testes foram obtidos resultados como o ilustrado na Figura 76. Foi realizado um teste simples de guiamento de um feixe de lazer $(\mathrm{HeNe})$ em um dos guias fabricados. No entanto, a propagação do feixe pelo canal demonstrou espalhamento significativo pelo substrato antes de chegar na saída do guia.

Figura 76- Guiamento de luz em guia de onda formado por ISS em substrato de $\mathrm{Bi}_{4} \mathrm{Ge}_{3} \mathrm{O}_{12}$ com filme de $\mathrm{Si}_{3} \mathrm{~N}_{4}$ de espessura pouco inferior a $100 \mathrm{~nm}$

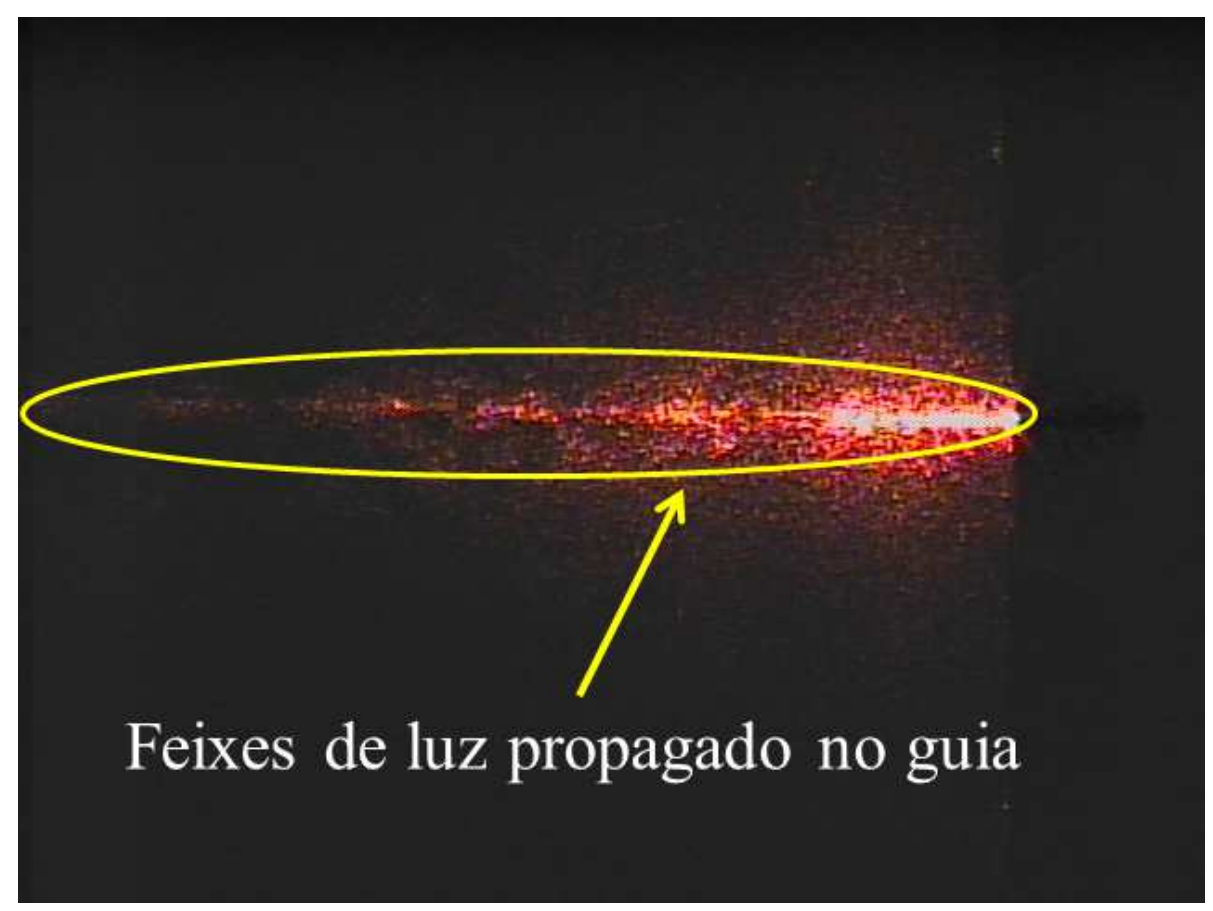

Fonte: Autora

Após o estudo dos procedimentos 1, 2 e 3, finalmente, foram realizadas as simulações com espessuras de filmes variando de 30 a $100 \mathrm{~nm}$, com passo de $10 \mathrm{~nm}$, e foi decido o uso da espessura de $50 \mathrm{~nm}$ para o procedimento 4, apresentado a seguir, que detalha o processo de fabricação do modulador eletro-óptico baseado em guia de onda do tipo canal em substrato de $\mathrm{Bi}_{4} \mathrm{Ge}_{3} \mathrm{O}_{12}$.

\subsubsection{Procedimento 4: fabricação do modulador eletro-óptico}

Nos estudos das simulações de guias de onda do tipo canal realizado no programa COMSOL, percebeu-se que mesmo espessuras muito finas de filmes de $\mathrm{Si}_{3} \mathrm{~N}_{4}$ ainda conseguiam produzir 
estresse suficiente para induzir a formação de guias de onda em substratos de $\mathrm{Bi}_{4} \mathrm{Ge}_{3} \mathrm{O}_{12}$. Buscou-se então determinar por simulação a menor espessura possível para construção dos guias. No entanto, isto não foi possível, pois a medida que se reduz a espessura do filme aumenta a carga computacional necessária ao processo uma vez que para implementar uma malha com resolução suficiente para descrever a região do filme força o aumento do número de nós em todo o espaço de simulação. Ao mesmo tempo, o processo de fabricação enfrenta problemas na obtenção de filmes muito finos, sendo difícil controlar os parâmetros para tornar o processo reprodutível para espessuras abaixo de $50 \mathrm{~nm}$. Em vista do exposto, o valor de $50 \mathrm{~nm}$ de espessura do filme indutor de tensão mecânica de $\mathrm{Si}_{3} \mathrm{~N}_{4}$ foi escolhido pela autora porque essa espessura, apesar de finíssima, ainda consegue modificar o índice de refração do material para o confinamento da luz no guia e é realizável no LSI/EPUSP. Este valor foi repassado aos pesquisadores do LSI/EPUSP, para que fosse utilizado como parâmetro no processo de fabricação dos guias de onda do tipo canal.

No procedimento 4 foram usadas as etapas da seção 3.6 do Capítulo 3 para a fabricação de guias de onda do tipo canal utilizando a técnica ISS em substrato de $\mathrm{Bi}_{4} \mathrm{Ge}_{3} \mathrm{O}_{12}$. Os resultados dessa fabricação são apresentados abaixo.

A limpeza dos substratos de $\mathrm{Bi}_{4} \mathrm{Ge}_{3} \mathrm{O}_{12}$ foi realizada como descrito na seção anterior e o filme de $\mathrm{Si}_{3} \mathrm{~N}_{4}$ foi depositado e utilizando-se a temperatura de $720^{\circ} \mathrm{C}$. Na fotogravação utilizou-se a nova máscara litográfica de padrões dos guias de onda do tipo canal. Na definição de padrões de guias de onda foi usado a técnica de corrosão por plasma $\mathrm{SF}_{6} \mathrm{e}$, logo após, foram realizadas as etapas de 1 ao 4 da seção 3.6 do capítulo 3 para limpeza do restante do fotorresiste positivo AZ1518 dos guias de onda.

O equipamento foi calibrado para fazer a deposição de filme de $\mathrm{Si}_{3} \mathrm{~N}_{4}$ com espessura de $50 \mathrm{~nm}$ sobre o substrato de BGO, tendo sido obtido o valor de 54,9 nm. As Figuras 77 (a e b) mostram partes das imagens do resultado da deposição do filme de $\mathrm{Si}_{3} \mathrm{~N}_{4}$ por LPCVD [75] em uma lâmina de $\mathrm{Bi}_{4} \mathrm{Ge}_{3} \mathrm{O}_{12}$. Os filtros ópticos que são usados no microscópio óptico ajudam a melhorar a qualidade das imagens, porém alteram as cores dos materiais observados nas imagens. No caso da Figura 77, devido à pequena espessura do filme ocorreu um fenômeno de interferência que mudou a cor do filme par uma tonalidade esverdeada. 
Figura 77- Filme de $\mathrm{Si}_{3} \mathrm{~N}_{4}$ depositado por LPCVD exibindo dois tipos de defeitos. (a) Ilha. (b) Trincas.

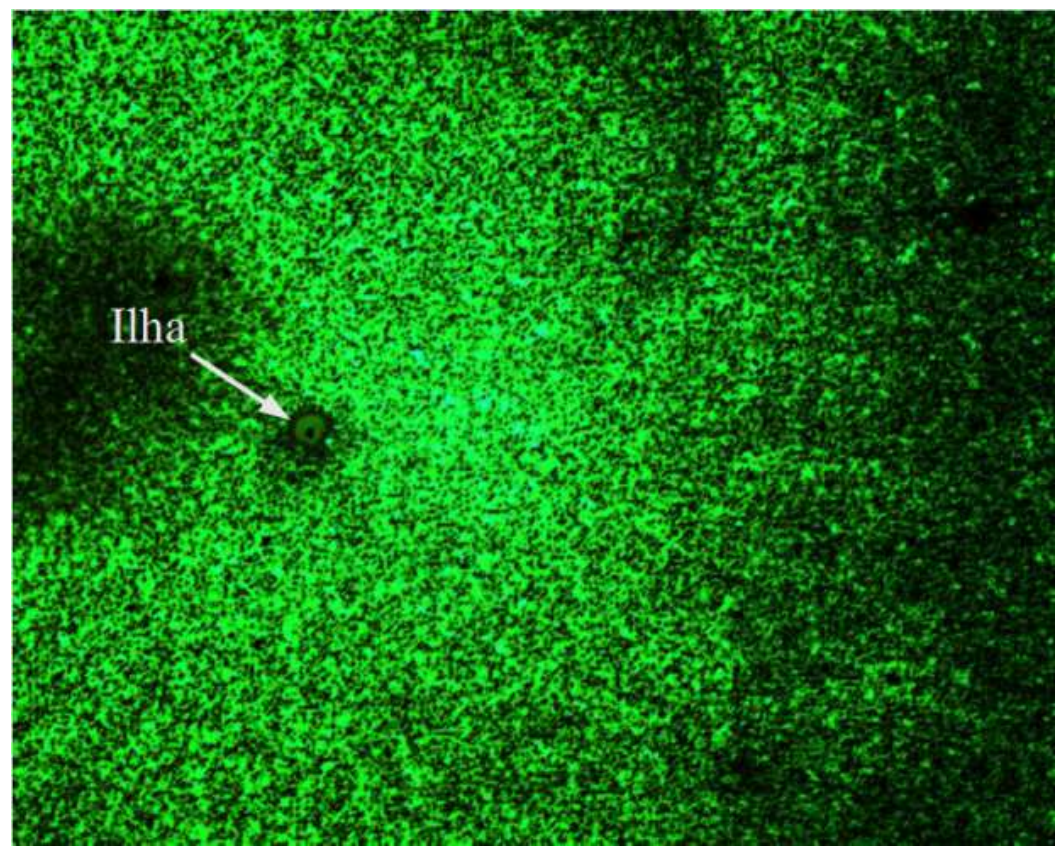

(a)

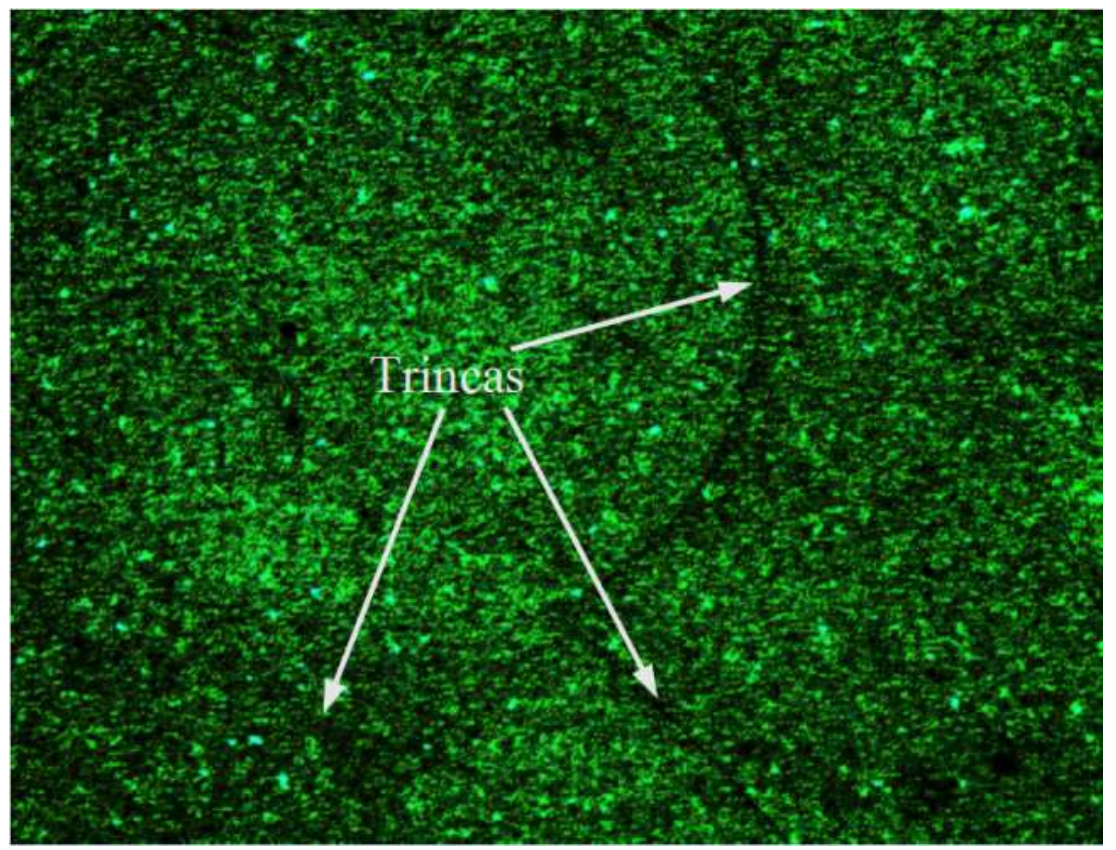

(b)

\section{Fonte: Autora}

Foram realizadas as etapas de fotogravação de trincheiras por litografia óptica usando a nova máscara projetada para este trabalho. As Figuras 78 (a e b) e as Figuras 79 (a e b) mostram os resultados da fotogravação das tricheiras. 
Figura 78- Fotogravação das trincheiras por litografia óptica (a) Detalhe da trincheira de $80 \mu \mathrm{m}$. (b) Trincheiras de $80 \mu \mathrm{m}, 10 \mu \mathrm{m}$ e de $7 \mu \mathrm{m}$.

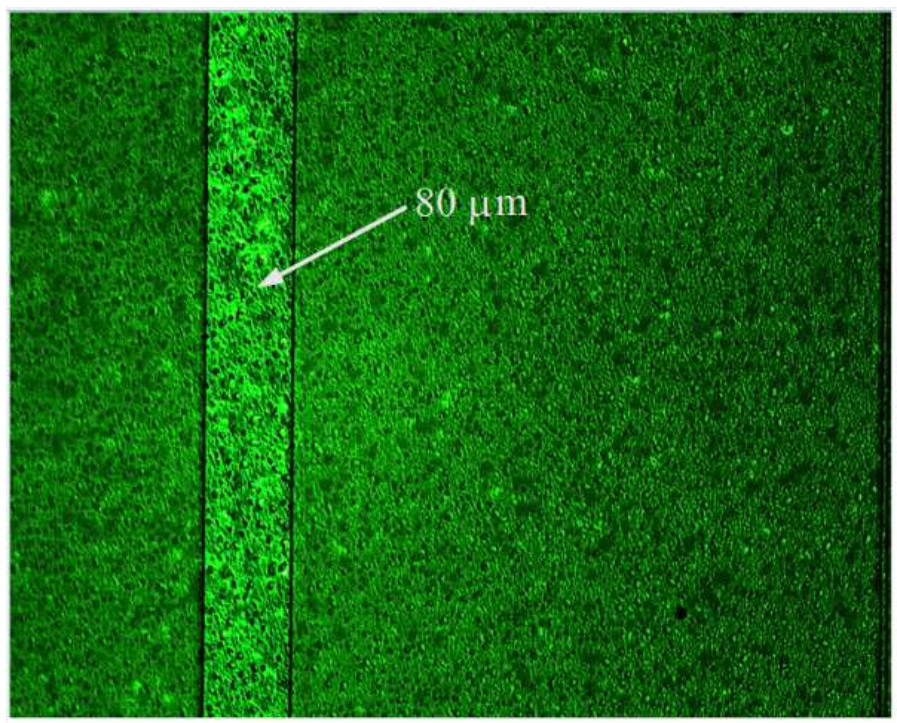

Germanato de Bismuto
Fotorresiste

(a)

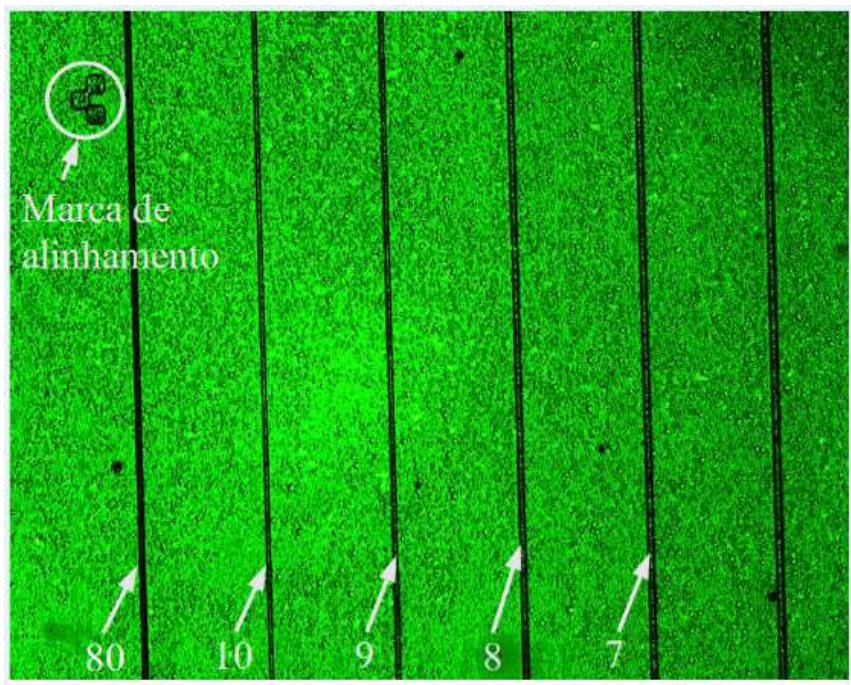

Germanato de Bismuto
Fotorresiste

(b)

Fonte: Autora 
Figura 79- (c) Efeito de borda nas trincheiras de $80 \mu \mathrm{m}$ e de $10 \mu \mathrm{m}$ a $8 \mu \mathrm{m}$ (fotorresiste nas bordas da lâmina). (d) Efeito de borda nas trincheiras de $80 \mu \mathrm{m}$ e de $1 \mu \mathrm{m}$ a $5 \mu \mathrm{m}$ (fotorresiste nas bordas da lâmina)

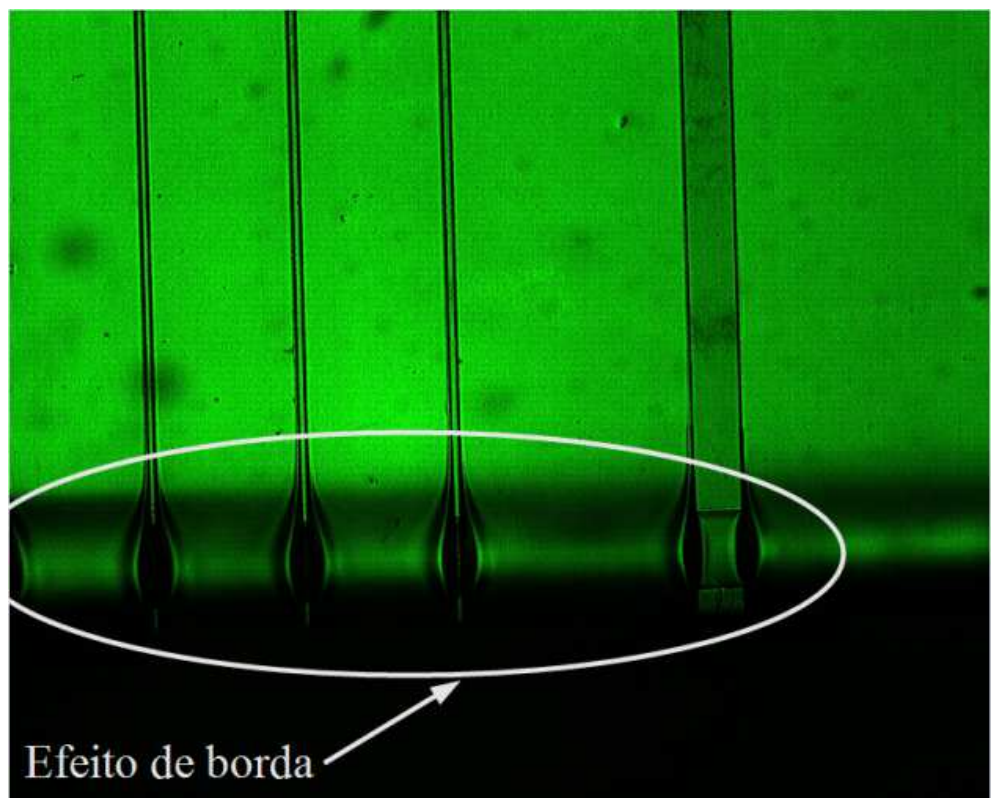

(c)

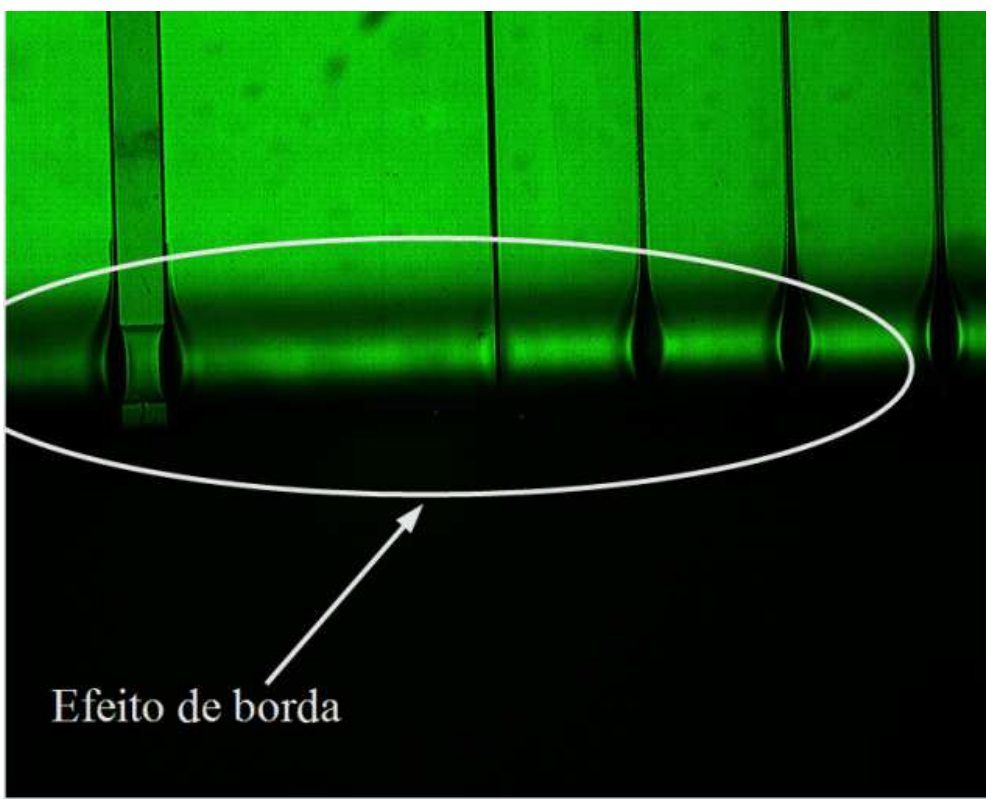

(d)

\section{Fonte: Autora}


Futuramente, pretende-se reduzir viscosidade do fotorresiste aplicado sobre o filme para atenuar o efeito de borda, que também ocorre em amostras circulares. Uma solução para diminuir a viscosidade do fotorresiste é usar um produto tipo Edge Bead Remover-HMDS.

$\mathrm{Na}$ definição das trincheiras foi usado o processo de corrosão do filme de $\mathrm{Si}_{3} \mathrm{~N}_{4}$ por plasma de $\mathrm{SF}_{6}$. As Figuras 80 (a-c) mostram os resultados da definição das trincheiras.

Os pesquisadores do LSI/EPUSP depositaram os eletrodos de Al por meio de uma evaporação térmica convencional (ver a seção 3.3.2 do capítulo 3) com espessuras de $500 \mathrm{~nm}$, espessura essa definida pela autora, e foram definidos pelos processos de litografia óptica, como foi relatado na seção de fabricação do componente (ver a seção 3.6 do capítulo 3).

No microscópio óptico foi observada a definição dos eletrodos e pads do componente, antes de realizar o processo de corrosão via úmida. As imagens observadas no microscópio foram capturadas por uma câmera e um programa de computador. As Figuras 81 (a e b) mostram o resultado da deposição dos eletrodos e pads de Al por meio de uma evaporação térmica convencional com a espessura de $500 \mathrm{~nm}$ antes da corrosão do Al.

As Figuras 82 (a e b) mostram o resultado da deposição dos eletrodos e pads de Al por meio de uma evaporação térmica convencional com a espessura de $500 \mathrm{~nm}$ depois da corrosão via úmida do $\mathrm{Al}$.

Após a realização da corrosão via úmida dos eletrodos e pads de $\mathrm{Al}$ observaram-se trincas no filme de $\mathrm{Si}_{3} \mathrm{~N}_{4}$, como mostra a Figura 81 (b). Supõe-se que o filme de $\mathrm{Si}_{3} \mathrm{~N}_{4}$ já deveria estar craqueado sob os eletrodos e pads e que o agente corrosivo infiltrou-se por essa rachaduras afetando-os também. Como resultado os eletrodos e pads ficaram separados em pedaços ou fragmentados. Desse modo não foi possível fazer os testes de modulação do componente fabricado. A possibilidade de realizar novamente o processo de fabricação desse componente está momentaneamente fora de alcance, pois o equipamento de deposição (LPCVD) no laboratório do LSI/EPUSP está inoperante. Futuramente, é possível que as pesquisas retornem em outro laboratório, como por exemplo, o CCS/UNICAMP. 
Figura 80- Definição das trincheiras dos guias de onda do tipo canal. (a) Trincheiras de 1, 2 e $3 \mu \mathrm{m}$. (b) Imagem da borda do substrato de $\mathrm{Bi}_{4} \mathrm{Ge}_{3} \mathrm{O}_{12}$. (c) Trincheiras de $6 \mu \mathrm{m}$ a $10 \mu \mathrm{m}$ e de $80 \mu \mathbf{m}$

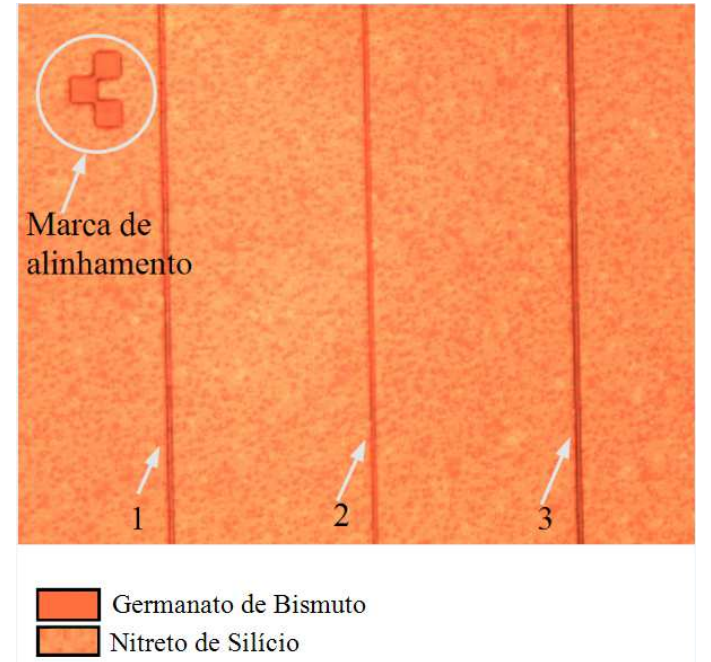

(a)

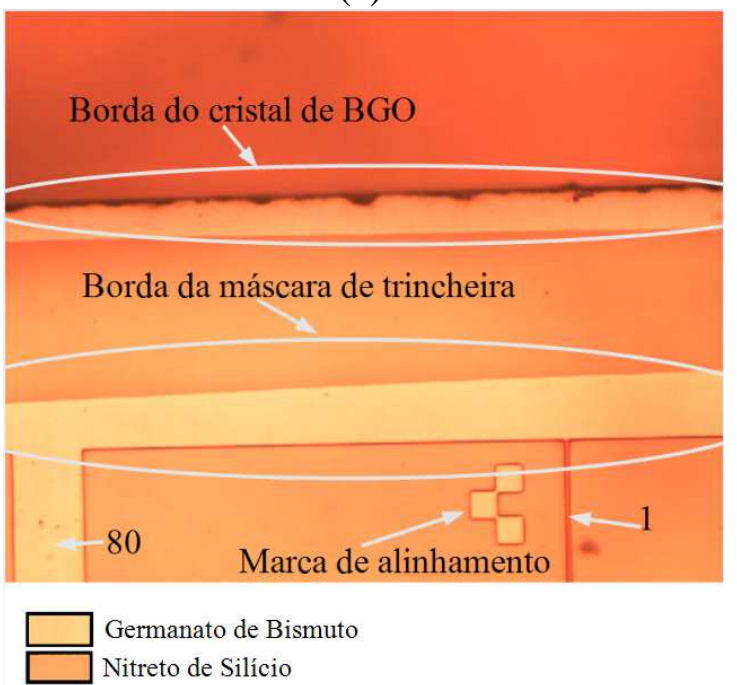

(b)

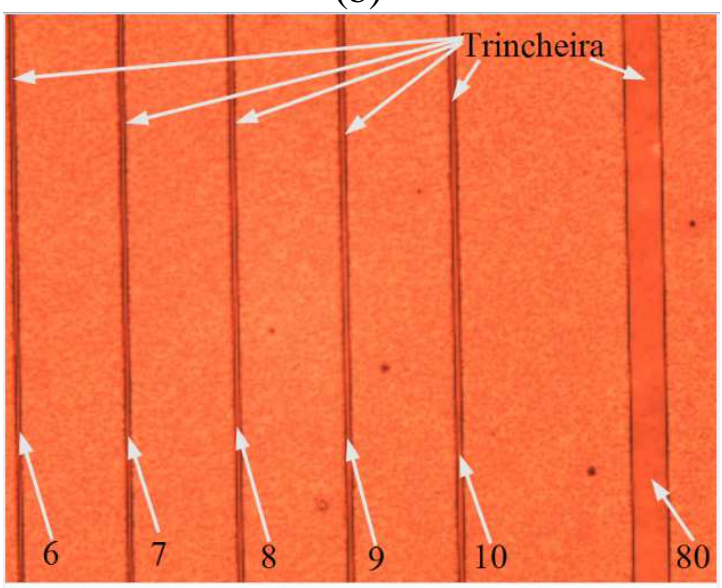

Germanato de Bismuto

Nitreto de Silício

(c) 
Figura 81- Definição dos eletrodos e pads de Al dos moduladores eletro-ópticos, antes da corrosão via úmida deles. (a) Detalhes dos moduladores eletro-ópticos com trincheiras de 8, 9 e $10 \mu \mathrm{m}$. (b) Detalhe do modulador eletro-óptico com trincheira de $80 \mu \mathrm{m}$.

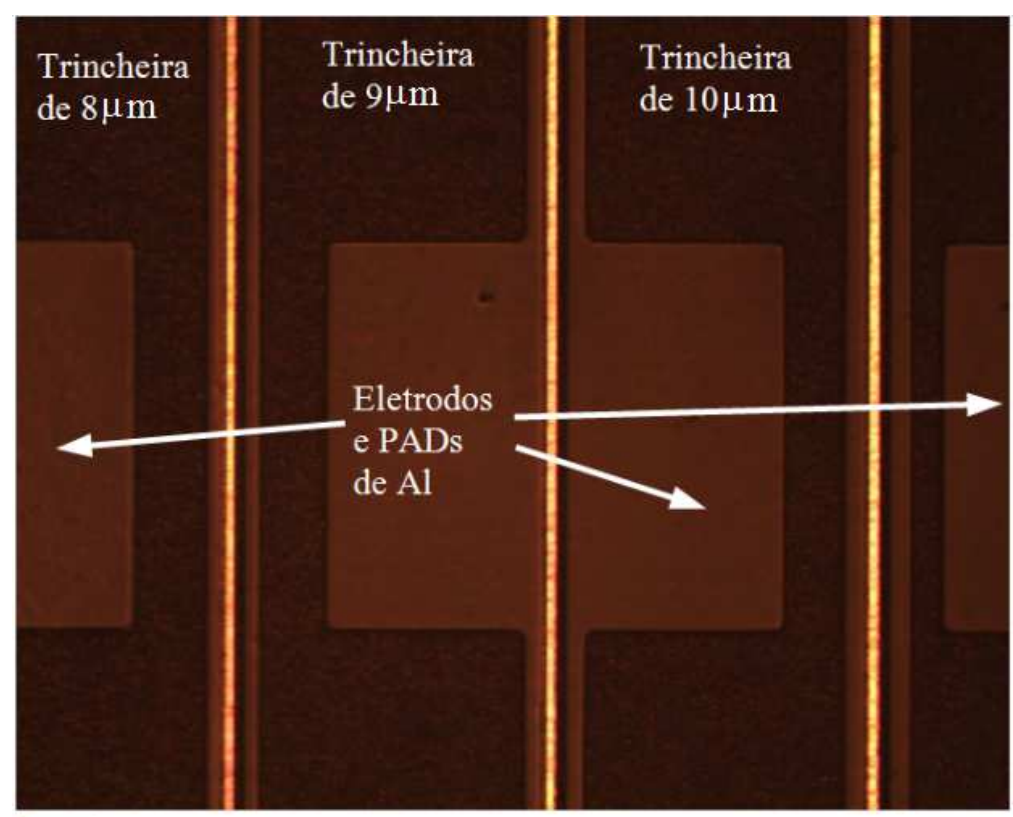

Aluminio

Nitreto de Silicio

Germanato de Bismuto

(a)

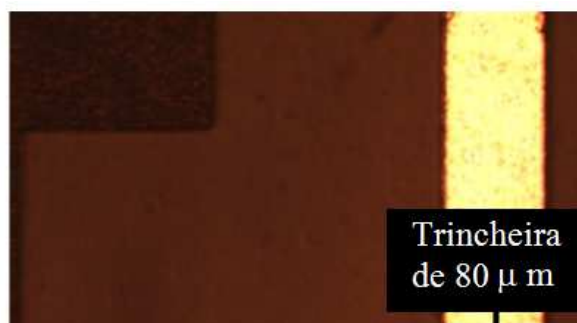

Eletrodos e

PADs de $\mathrm{Al}$

Eletrodos e

$\mathrm{PADs}$ de $\mathrm{Al}$

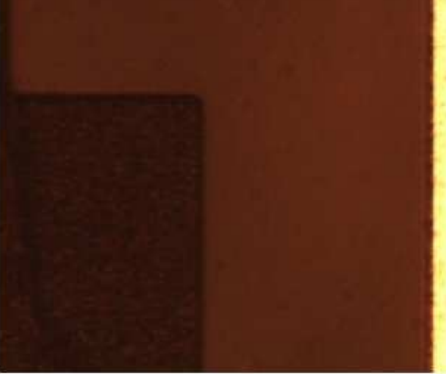

Alumínio

Nitreto de Silício

Germanato de Bismuto

(b)

Fonte: Autora 
Figura 82- Definição dos eletrodos e pads de Al dos moduladores eletro-ópticos, depois da corrosão via úmida deles. (a) Detalhes dos moduladores eletro-ópticos com trincheiras de 8, 9 e $10 \mu \mathrm{m}$. (b) Detalhe do modulador eletro-óptico com trincheira de $80 \mu \mathrm{m}$.

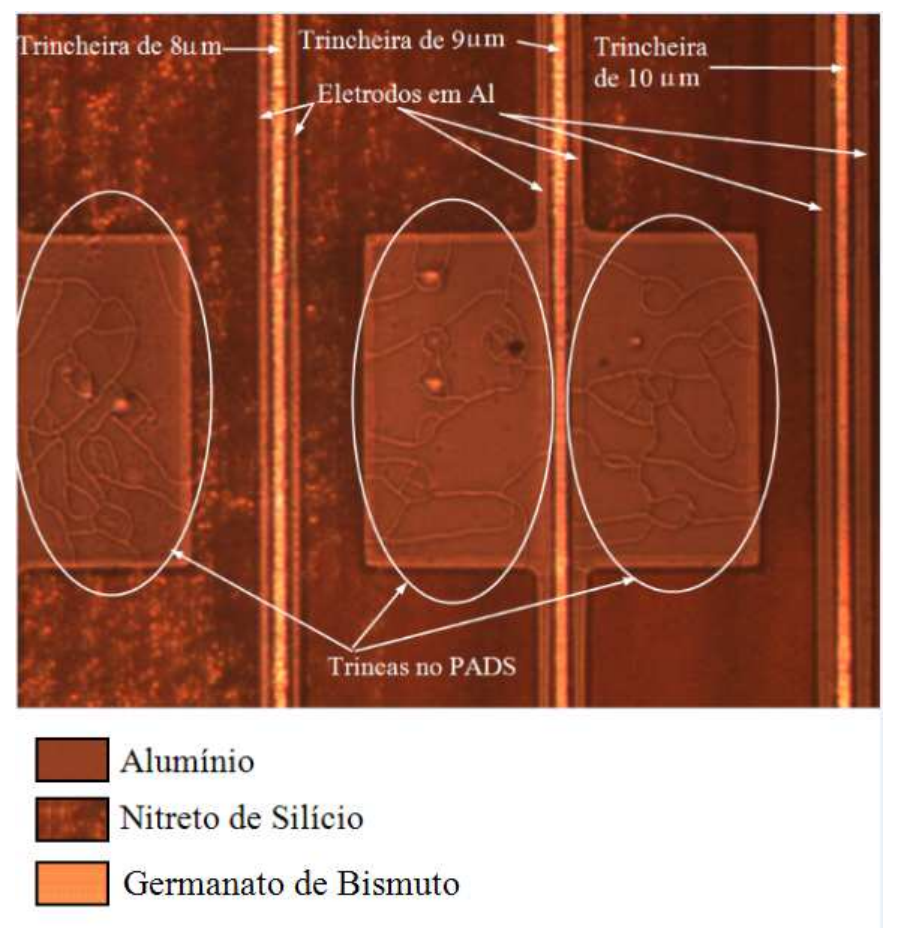

(a)

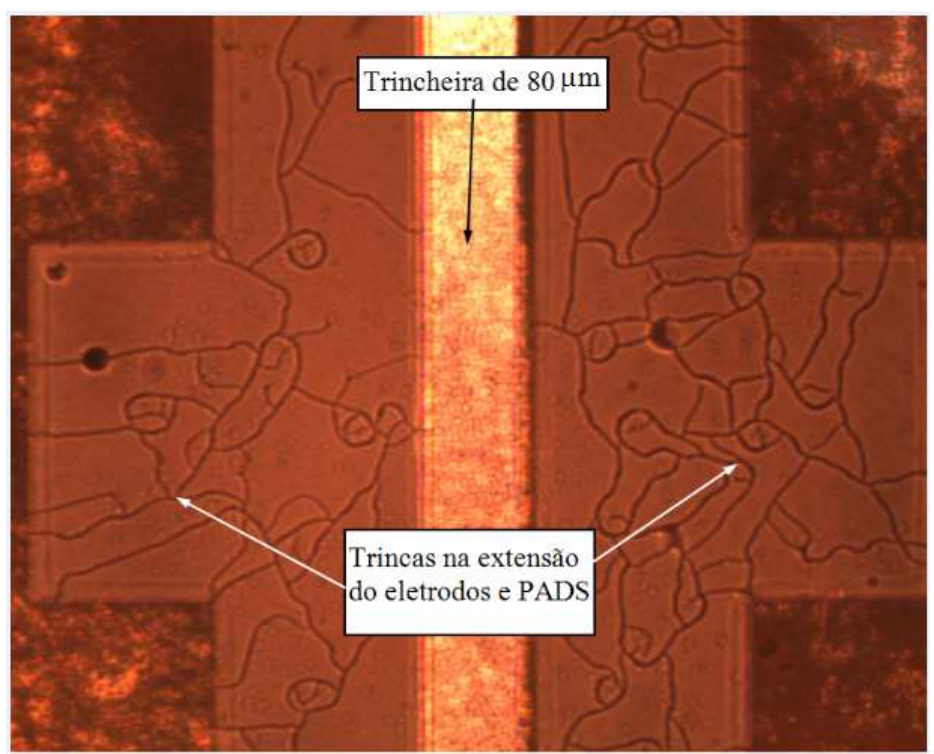

Alumínio

Nitreto de Silício

Germanato de Bismuto

(b)

\section{Fonte: Autora}




\subsubsection{Testes dos cortes do substrato de BGO}

Para dar continuidade ao processo de fabricação dos moduladores eletro-ópticos é necessário cortar o substrato a fim de remover as regiões das bordas em que o fotorresiste não ficou com espessura uniforme, o que prejudicou a definição dos guias nessas regiões. Após a remoção dessas regiões é necessário realizar os polimentos de face e borda no substrato a fim de que seja possível o acoplamento de luz adequado nos guias de onda.

Em vista dessa necessidade, alguns testes de corte foram realizados em amostras de $\mathrm{Bi}_{4} \mathrm{Ge}_{3} \mathrm{O}_{12}$ (amostras danificadas por erros no processo de deposição do filme fino) pelos pesquisadores do PMR/EPUSP, usando uma máquina de corte automática (ver a seção 3.7 do capítulo 3) para cortar os moduladores eletro-ópticos em substrato de $\mathrm{Bi}_{4} \mathrm{Ge}_{3} \mathrm{O}_{12}$. As Figuras 83 ( $\mathrm{a}$ e b) e as Figuras 84 ( $\mathrm{a}$ e b) mostram resultados desses testes em que o substrato foi cortado nos sentidos da largura e do comprimento da lâmina.

Depois dos testes de corte da lâmina de $\mathrm{Bi}_{4} \mathrm{Ge}_{3} \mathrm{O}_{12}$ realizados como descrito acima, foram realizados novos testes de corte em uma outra lâmina de $\mathrm{Bi}_{4} \mathrm{Ge}_{3} \mathrm{O}_{12}$ (lâmina danificada, em que o filme de $\mathrm{Si}_{3} \mathrm{~N}_{4}$ está descolando). No entanto, nessa lâmina estão definidas as trincheiras pelo processo de litografia óptica e corrosão. A Figura 84 (a e b), as Figuras 85 (c e d) e a Figrua 86 mostra os novos resultados dos testes de corte da lâmina de $\mathrm{Bi}_{4} \mathrm{Ge}_{3} \mathrm{O}_{12}$. Nesse caso, os cortes foram realizados sobre a trincheira de $80 \mu \mathrm{m}$ que foi usada como referência para separar cada modulador eletro-óptico da lâmina.

Foram realizados alguns testes de corte no substrato de BGO danificado e a partir de seus resultados foi selecionado um grupo de parâmetros de corte, o qual já foi apresentado na tabela 5 da seção 3.7 deste trabalho. 
Figura 83- Lâmina de $\mathrm{Bi}_{4} \mathrm{Ge}_{3} \mathrm{O}_{12}$ (lâmina de teste). (a) Corte realizado com rotação de $30000^{\circ} \mathrm{RPM}$, avanço de $3^{\circ} \mathrm{mm} / \mathrm{min}$., profundidade de corte passante de $1,10 \mathrm{~mm}$. (b) Corte realizado com rotação de $45000 \mathrm{RPM}$, avanço de $0.5 \mathrm{~mm} / \mathrm{min}$, profundidade de corte de passante $1,10^{\circ} \mathrm{mm}$.

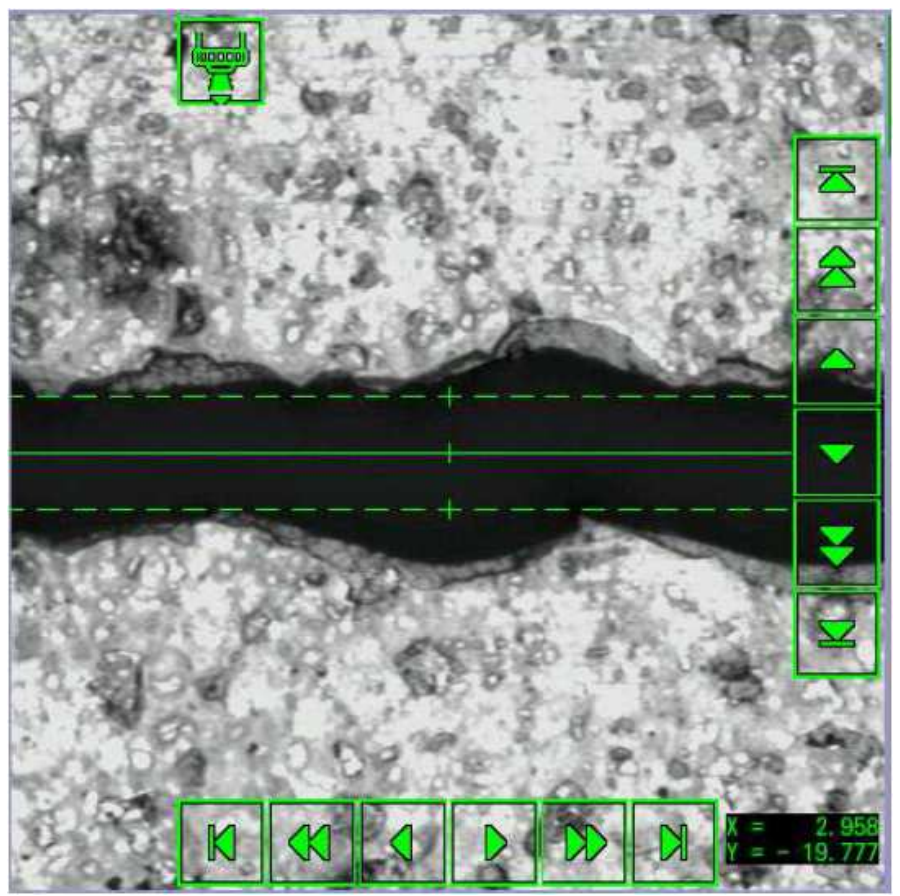

(a)

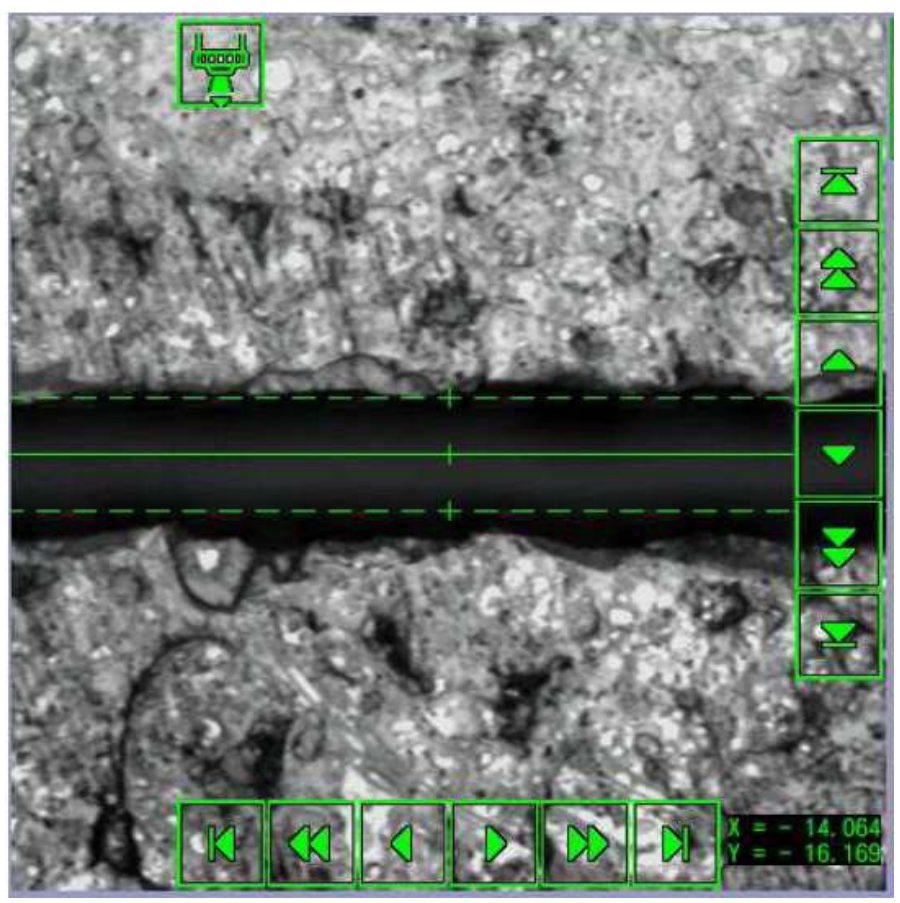

(b) 
Figura 84- (a) Corte realizado com rotação de 45000 RPM, avanço de $0.05 \mathrm{~mm} / \mathrm{min}$, profundidade de corte de passante $1,10 \mathrm{~mm}$. (b) Corte realizado com rotação de $45000 \mathrm{RPM}$, avanço de 0.05 $\mathrm{mm} / \mathrm{min}$, profundidade de corte em vários passos, $-\mathrm{n}=1,2,3,4,5$ e 6 cortes com incrementos de profundidade $1^{\circ} \mathrm{mm} / \mathrm{n}$

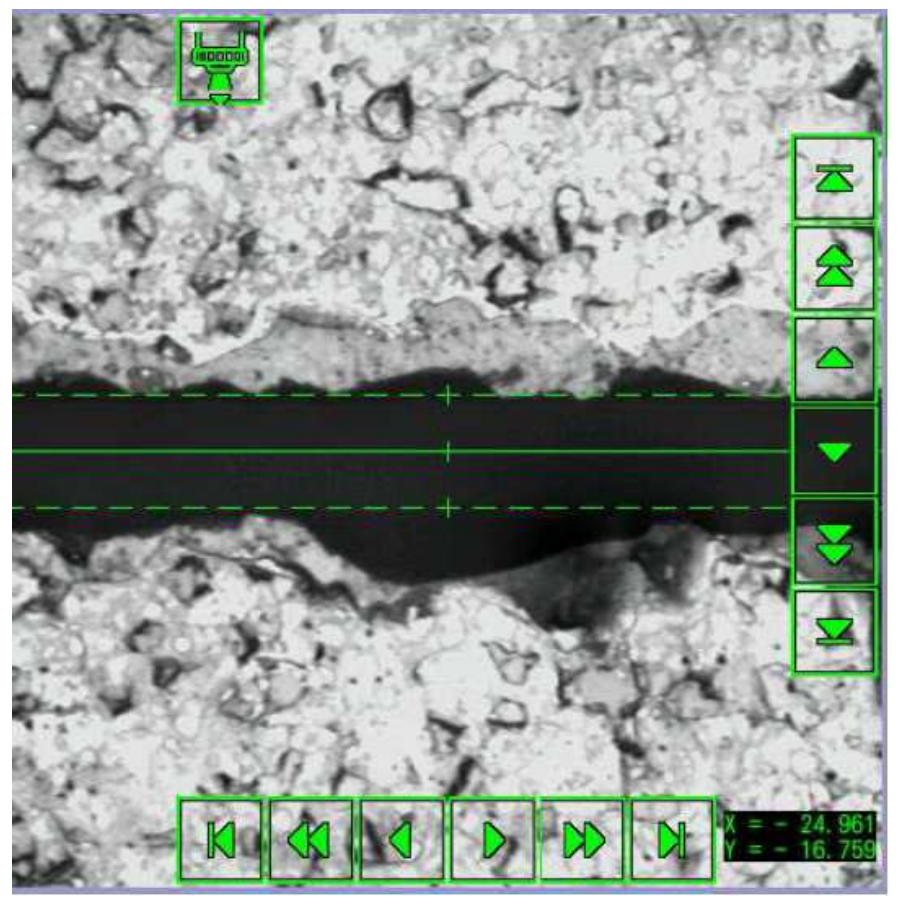

(a)

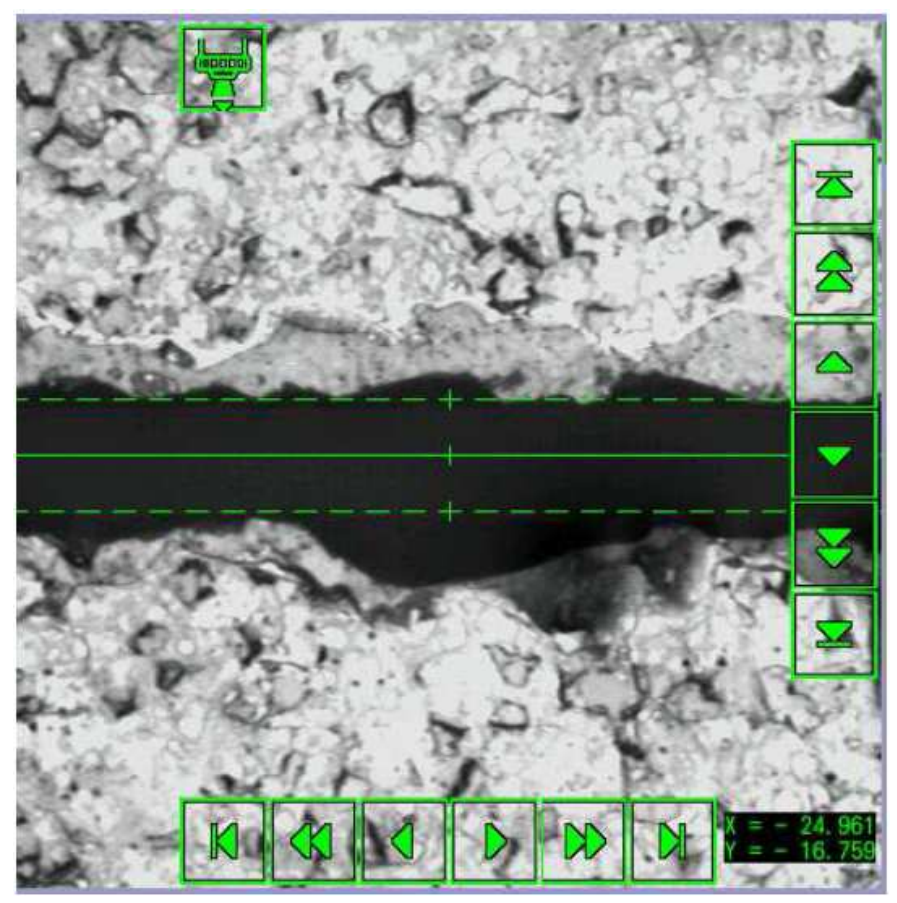

(b) 
Figura 85- Segundo teste de corte para separação dos moduladores eletro-ópticos da lâmina de $\mathrm{Bi}_{4} \mathrm{Ge}_{3} \mathrm{O}_{12}$. (a) Imagem da trincheira de $80 \mu \mathrm{m}$. (b) Imagem da cobertura removida durante o processo de corte pelo refrigerante do spindle (água).

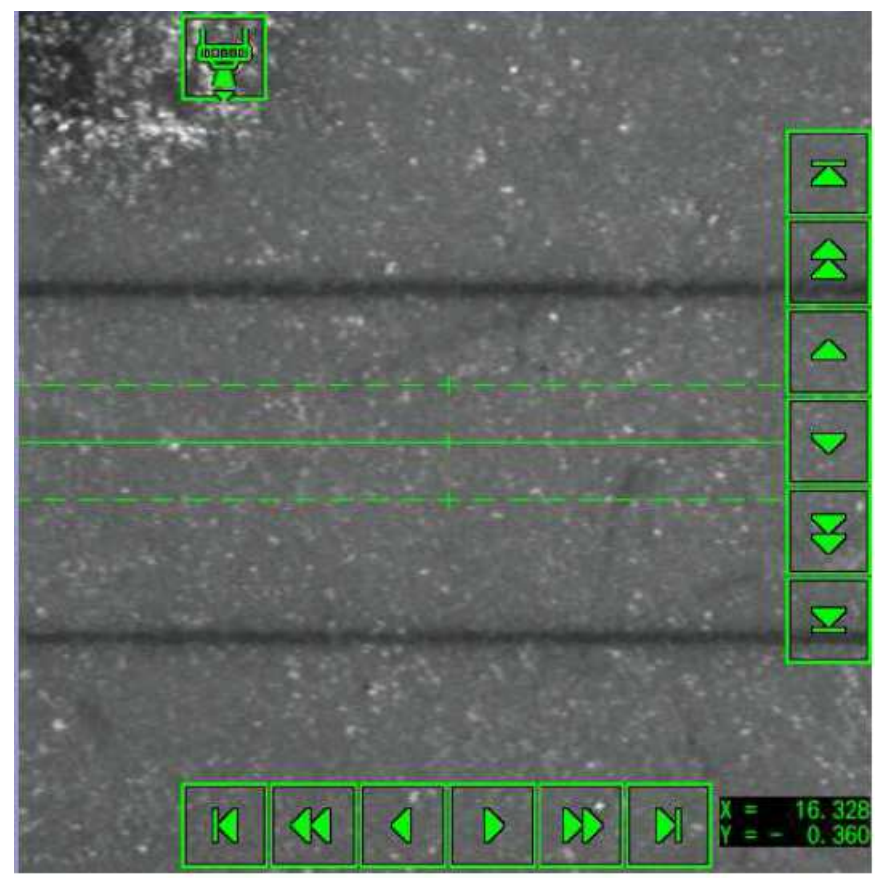

(a)

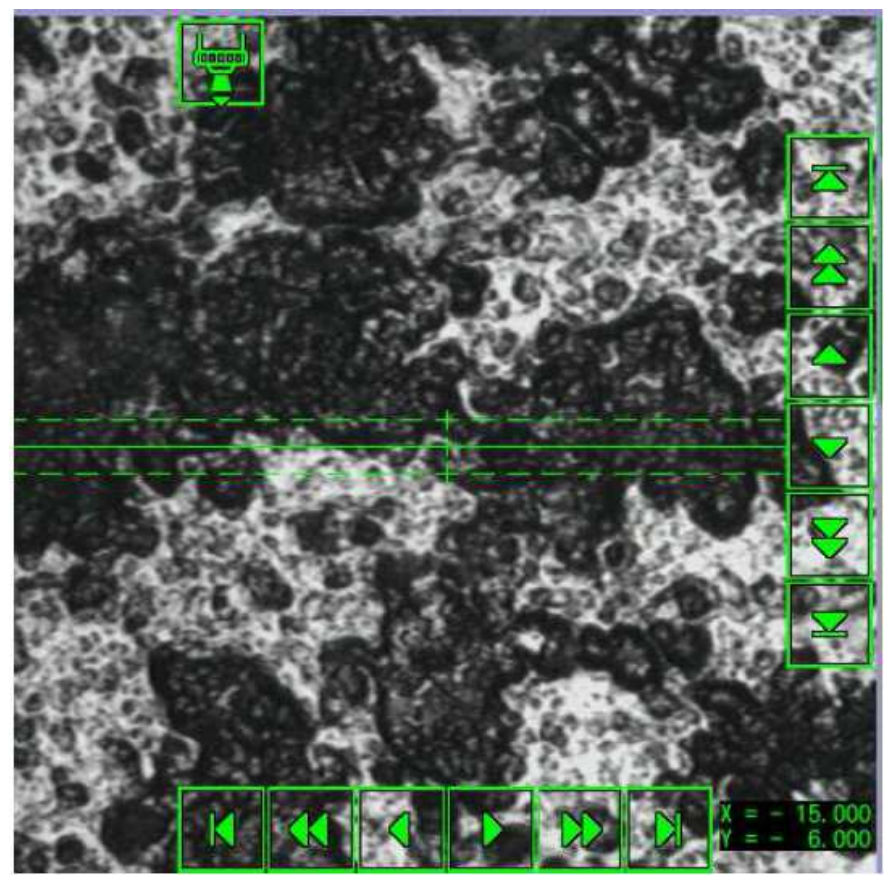

(b)

Fonte: Autora 
Figura 86- (a) Corte realizado com rotação de $45000^{\circ} \mathrm{RPM}$, avanço de $2 \mathrm{~mm} / \mathrm{min}$, Vazão frontal (bucal) de 1L/min, Vazão chuveiro (lateral) de $0,5^{\circ} \mathrm{L} / \mathrm{min}$, Disco com espessura de $80 \mu \mathrm{m}$, tamanho de diamante $12 \mu \mathrm{m}$. (b) corte a "seco": Rotação de 45000,00 RPM, avanço de $2 \mathrm{~mm} / \mathrm{min}$, Vazão frontal (bucal) de $2 \mathrm{~L} / \mathrm{min}$, Vazão chuveiro (lateral) de 0,02L/min, Disco com espessura de 80 $\mu \mathrm{m}$, tamanho de diamante $12 \mu \mathrm{m}$.

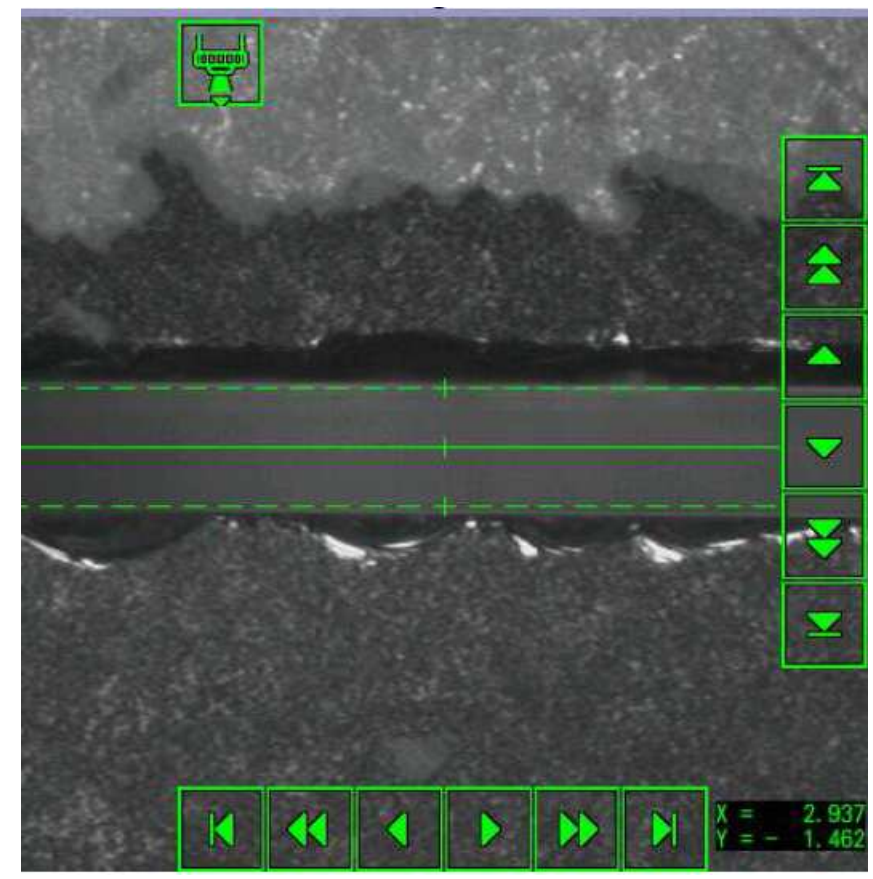

(a)

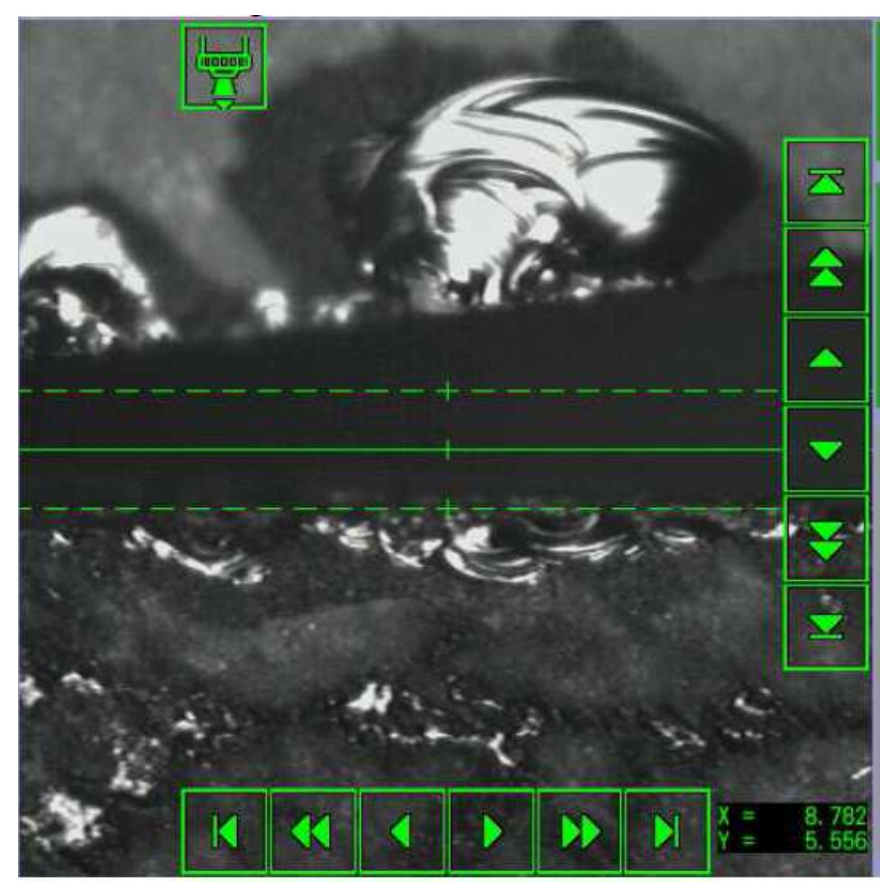

(b) 
Figura 87- Corte a "seco": Rotação de 45000 RPM, avanço de $0,2 \mathrm{~mm} / \mathrm{min}$, Vazão frontal (bucal) de $0,02^{\circ} \mathrm{L} / \mathrm{min}$, Vazão chuveiro (lateral) de $0,5 \mathrm{~L} / \mathrm{min}$, Disco com espessura de $40 \mu \mathrm{m}$, tamanho de diamante $4 \mu \mathrm{m}$.

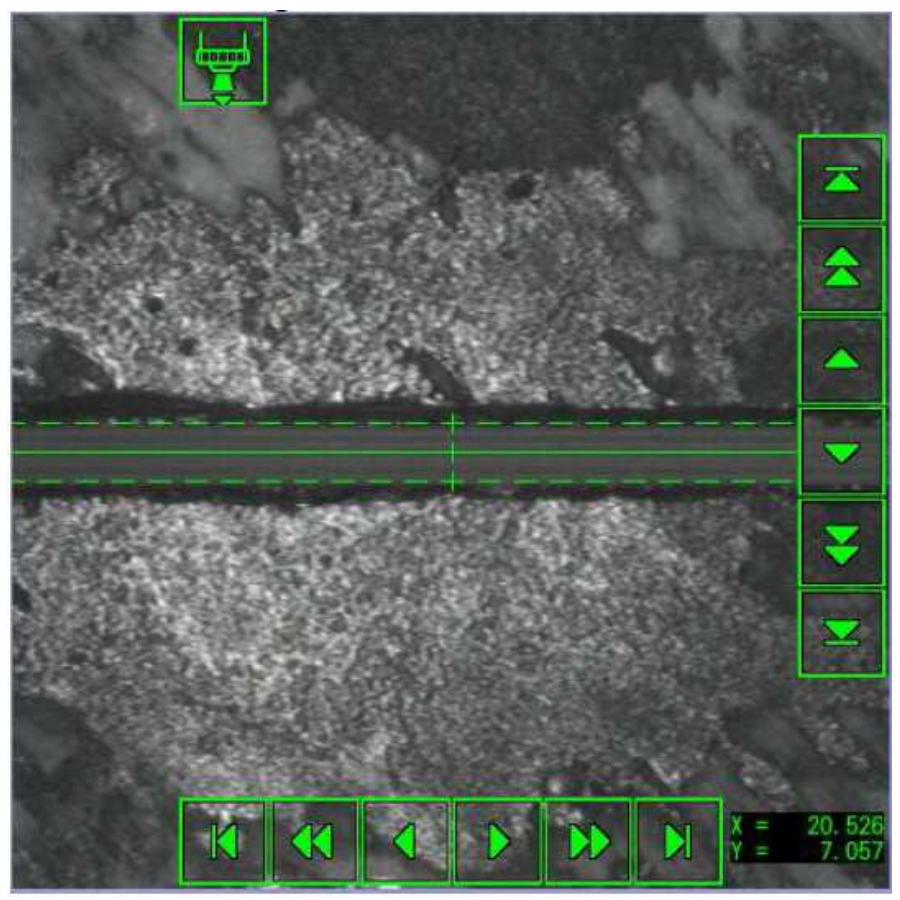

Fonte: Autora

\subsubsection{Resultados do cálculo da tensão total a partir de medições feitas por stress meter}

$\mathrm{O}$ cálculo da tensão total das lâminas de $\mathrm{Bi}_{4} \mathrm{Ge}_{3} \mathrm{O}_{12}$ e de $\mathrm{Si}$ foi realizado a partir de resultados de medições realizadas com equipamento Stress Meter (modelo FLX - 2410), que extrai o raio da curvatura da superfície das lâminas, neste caso dos substratos de $\mathrm{Bi}_{4} \mathrm{Ge}_{3} \mathrm{O}_{12}$ e de $\mathrm{Si}$, antes e depois da deposição do filme de $\mathrm{Si}_{3} \mathrm{~N}_{4}$. Os resultados dessas medidas são apresentados nessa seção.

Foram realizadas duas medidas na mesma lâmina de $\mathrm{Si}$, seguindo o procedimento exposto na seção 3.9 do capítulo 3, tendo sido obtidos os seguintes resultados: Medida 1: Inicial = $+^{\circ} 1,32^{\circ} \mathrm{km}$ (lâmina plana), Final $=-126,04 \mathrm{~m}$. Neste caso a tensão medida é de $-617,0 \mathrm{MPa}$ (estresse compressivo). Medida 2: Inicial $=+1,30 \mathrm{~km}$ (lâmina plana), Final $=-124,97 \mathrm{~m}$, Neste caso a tensão medida é de - 623,0 MPa (estresse compressivo). O valor médio da tensão mecânica do filme de $\mathrm{Si}_{3} \mathrm{~N}_{4}$ no Si é de mais ou menos $620 \mathrm{MPa}$ (estresse compressivo). 
Não foi possível medir a tensão mecânica do filme de $\mathrm{Si}_{3} \mathrm{~N}_{4}$ no $\mathrm{Bi}_{4} \mathrm{Ge}_{3} \mathrm{O}_{12}$, porque a superfície da lâmina de $\mathrm{Bi}_{4} \mathrm{Ge}_{3} \mathrm{O}_{12}$ apresentava muitas ondulações, isto é, a superfície da lâmina de $\mathrm{Bi}_{4} \mathrm{Ge}_{3} \mathrm{O}_{12}$ não apresentava um raio de curvatura predominante, o que impossibilitou realizar a medida da tensão mecânica do filme de $\mathrm{Si}_{3} \mathrm{~N}_{4}$ sobre ele. 


\section{CONCLUSÕES}

$\mathrm{Na}$ introdução foi relatado um panorama geral das linhas de pesquisas realizadas pelo grupo LSO/PEA/EPUSP e em qual parte dessas linhas esse trabalho se encaixa. A autora apresentou o estudo de simulações de moduladores eletro-ópticos baseados em guias de ondas do tipo canal em OI, o processo de fabricação desses moduladores pela técnica ISS e as simulações auxiliando interativamente os processos de fabricação de moduladores eletro-óptico baseados em guias de onda do tipo canal em OI, usando substratos de $\mathrm{Bi}_{4} \mathrm{Ge}_{3} \mathrm{O}_{12}$.

As modelagens dos efeitos elasto-óptico e eletro-óptico foram realizados, nas quais a modelagem do efeito elasto-óptico representa a formação do guia de onda do tipo canal; e a modelagem do efeito eletro-óptico representa o modulador eletro-óptico. Essas modelagens foram implementadas em um programa comercial (COMSOL MULTIPHYSICS ${ }^{\circledR}$ versão 3.2.b) de simulação numérica baseada em MEF, capaz de resolver problemas de propagação de ondas TEM.

Os resultados simulados pelo programa COMSOL MULTIPHYSICS ${ }^{\circledR}$ foram comparados com resultados apresentados pelos trabalhos de Koshiba [93], Saito [45] e Franco [58]. Os resultados obtidos de tais comparações comprovaram sua aplicabilidade e encorajaram o seu emprego na análise de guias de onda ópticos integrados para aplicação como moduladores eletro-ópticos.

O substrato de BGO foi considerado como cristal isotrópico (material macroscópico) nas simulações numéricas de moduladores eletro-óptico baseados em guias de onda do tipo canal em OI, realizadas neste trabalho.

O escopo deste trabalho não ficou restrito, somente, às simulações de guias de onda do tipo canal em OI em substrato de retículo cúbico, como $\mathrm{BGO}\left(\mathrm{Bi}_{12} \mathrm{GeO}_{20}\right.$ e $\left.\mathrm{Bi}_{4} \mathrm{Ge}_{3} \mathrm{O}_{12}\right)$, para aplicação de moduladores eletro-ópticos, mas também estendeu-se à fabricação desses componentes.

$\mathrm{Na}$ fabricação guias de onda do tipo canal foi realizada deposição do filme de $\mathrm{Si}_{3} \mathrm{~N}_{4}$ (filme indutor de tensão mecânica) sobre o substrato de $\mathrm{Bi}_{4} \mathrm{Ge}_{3} \mathrm{O}_{12}$ pela técnica LPCVD e, depois, foram realizados os processos de litografia óptica e de corrosão por plasma de $\mathrm{SF}_{6}$ para 
obtenção de tricheiras no filme e definição dos guias de onda do tipo canal. A fabricação e os testes de guiamento de luz dos guias foram realizados no LSI/EPUSP.

Não foi possível realizar a análise de modos guiados dos guias e dos moduladores eletroópticos fabricados neste trabalho porque tanto a camada do filme de Al quanto a camada do filme de $\mathrm{Si}_{3} \mathrm{~N}_{4}$ ficaram danificadas (trincadas), o que tornou impossível fazer os testes de guiamento de luz e a modulação dessa luz.

Foi realizada a deposição de $\mathrm{Al}$ sobre filme de $\mathrm{Si}_{3} \mathrm{~N}_{4}$ por meio de evaporação térmica convencional e utilizados os processos de litografia óptica e corrosão por plasma para definição e obtenção dos eletrodos metálicos.

Os auxílios interativos entre a simulação numérica e o processo de fabricação de moduladores eletro-ópticos baseados em guias de onda do tipo canal foram alcançados, pois nessas simulações foram consideradas diferentes geometrias e os dados obtidos foram utilizados no processo de fabricação do componente. Esse processo de auxílio interativo, como descrito no capítulo 3 desta tese, foi efetivamente realizado. 


\section{TRABALHOS FUTUROS}

Não foi possível neste trabalho realizar o cálculo de estresse dos substratos de $\mathrm{Bi}_{4} \mathrm{Ge}_{3} \mathrm{O}_{12}$ a partir das medidas por Stress Meter porque a superfície desse substrato não apresenta uniformidade. Uma solução possível é realizar um procedimento de recozimento (annealing) para relaxar a estrutura cristalina do substrato e, possivelmente, reduzir sua ondulação. Caso este procedimento seja bem sucedido poder-se-á depois realizar a medida de estresse nos substratos por Stress Meter.

O processo de auxílio interativo entre as simulações e os processos de fabricação poderá, então ser mais completo, porque poderá ser incluído nas simulações o cálculo de estresse da superfície dos substratos (antes e depois do filme indutor de tensão mecânica depositado) no programa COMSOL. Os resultados numéricos poderão ser comparados com os resultados medidos pelo Stress Meter conforme descrito na seção 3.9 do capítulo 3.

Depois de realizar tal estudo, será necessário repetir as simulações numéricas do projeto, envolvendo os moduladores eletro-ópticos baseados em guias de onda do tipo canal em OI.

O substrato de $\mathrm{BGO}$, que foi considerado como material isotrópico na etapa de simulações mecânicas, deverá ser considerado como cristal anisotrópico nas próximas simulações numéricas de moduladores eletro-ópticos baseados em guias de onda do tipo canal em OI, aperfeiçoando o estudo do efeito de deformação mecânica no cristal de BGO.

Com o domínio das técnicas de modelagem dos efeitos elasto-óptico e eletro-óptico, das simulações e do processo de fabricação de moduladores eletro-ópticos baseados em guias de onda do tipo canal em Oi, será possível realizar o mesmo procedimento relatado acima, utilizando outros substratos cristalinos, como por exemplo, o Silicato de Bismuto $\left(\mathrm{Bi}_{4} \mathrm{Si}_{3} \mathrm{O}_{12}\right)$ e fazer a caracterização das propriedades físicas dos componentes.

O modulador eletro-óptico fabricado pelos pesquisadores LSI/EPUSP será testado e em um futuro próximo, poderá ser utilizado na substituição do modulador em uso no trabalho desenvolvido pela equipe do LSO/PEA-USP, que apresenta várias restrições em termos de performance, disponibilidade e preço. 


\section{REFERÊNCIAS}

[1] PINHEIRO, L.C.S. Interferômetros recuperadores de baixa tensão de meia onda para sistemas interferométricos de luz branca utilizando moduladores eletro-ópticos. 2011. 124 p. Tese (Doutorado) - Escola Politécnica da Universidade de São Paulo. 2011.

[2] UDD, E. Fiber optic sensors: an introduction for engineers and scientists. New York: John Wiley \& Sons, 1991.

[3] KEISER, G. Optical fiber communications. $2^{\text {nd }}$ ed. New York: McGraw-Hill, 1991.

[4] JACKSON, D.A. AND JONES J.D.C. Fibre optic sensors. Optica Acta, v. 33, p. 1469-1503, 1986.

[5] UDD, E. An review of fiber-optic sensors. Rev. Sci. Instrum. 66, 1995, 4015 p.

[6] PINHEIRO, L.C.S. Transformador óptico por interferometria de luz branca para medição de altas tensões. 2006. 62 p. Dissertação (Mestrado) - Escola Politécnica da Universidade de São Paulo, São Paulo, 2006.

[7] LIMA, D. K. Transformadores para instrumentos ópticos: aspectos da viabilidade do seu uso pelas empresas do setor elétrico brasileiro. 2009. 123 p. Dissertação (Mestrado) - Escola Politécnica da Universidade de São Paulo, 2009.

[8] MARTINS, W.W.M. Sensores Ópticos de Tensão Baseados no Efeito Eletroóptico em Cristais de Niobato de Lítio. Dissertação (Mestrado). Universidade Estadual Paulista (UNESP). 2006.

[9] SANTOS, J. C. Estudo e desenvolvimento de moduladores eletro e magnetoópticos e suas aplicações como transformadores de tensão e corrente (tp e tc ópticos) em sistemas elétricos de potência. 1993. 103 p. Dissertação (Mestrado) Escola Politécnica, Universidade de São Paulo, São Paulo, 1993.

[10] SANTOS, J.C. New optical pockels techniques for direct measurement of high voltage. 1997. 163 p. Tese (Doutorado) - Department of Electrical Engineering of University of Tokio, Japão, 1997.

[11] SANTOS, J. C. Contribuições para o desenvolvimento de transformadores de potencial a fibras ópticas (TPs ópticos) aplicáveis em sistemas elétricos de potência. 2009. 151 p. Tese (Livre Docência) Texto de sistematização crítica de parte da obra do candidato, apresentado à Escola Politécnica da Universidade de São Paulo para obtenção do título de Livre Docente, São Paulo, 2009. 
[12] DOU, Y., ZHANG, H. E YAO, M., Generation of Flat Optical-Frequency Comb Using Cascaded Intensity and Phase Modulators, IEEE Photonics Technology Letters, vol. 24, n⿳⺈ 9, p. 727-729, 2012.

[13] YARIV, A.; YEH, P. Photonics: Optical electronics in modern communications, 6 ed., Oxford Series in Electrical and Computer Engineering, 2006.

[14] KITANO, C. Aplicação da abordagem de domínio espectral para análise de moduladores eletro-ópticos integrados. 2001. 390 p. Tese. (Doutorado), Instituto Tecnológico de Aeronáutica, 2001.

[15] SASKI, T., et al., Merged vector gratings recorded in a photocrosslinkable polymer liquid crystal film for polarimetry, Journal of Applied Physics 115, 023110-1-023110-5, 2014.

[16] ZHANG, X., et al., Wide optical spectrum range, subvolt, compact modulator based on an electro-optic polymer refilled silicon slot photonic crystal waveguide, Optic Letters, vol. 38, Issue 22, p. 4031-4034, 2013.

[17] PEATROSS, J.; WARE, M. Physics of light and optics. Local: Brigham Young University, 2012.

[18] BORN, M.; WOLF, E. Principles of Optics: Electromagnetic theory of propagation interference and diffraction of light. Oxford: Pergamon Press. 1989.

[19] FRANÇON, M. Optical interferometry. New York: Academic Press, 1966. ISBN 0-1226.6350-0.

[20] Chen, S.; PAlMER, A. W.; GRATtAn, K. T. V.; MEgGiT, B. T., Digital signal-processing techniques for electronically scanned optical-fiber whitelight interferometry, v.31, n. 28, p. 6003-6010, 1992.

[21] SANTOS, J.C. Estudo e Desenvolvimento de Moduladores Eletro e Magnetoópticos e suas Aplicações como Transformadores de Medição (TP e TC Ópticos) em Sistemas Elétricos de Potência. Dissertação (Mestrado) apresentada à EPUSP para obtenção do título de Mestre em Engenharia, 1993.

[22] SANTOS, J. C. et al. A New electro-optical method for recovering white light interferometric signals. In: International microwave and optoeletronics conference. 1999, Rio de Janeiro. v. 1, 1999. 144 p.

[23] SANTOS, J. C. et al. Optical high voltage measurement transformer using white light interferometry. In: IEEE/PES T\&D Latin America. 2002. São Paulo. Proceedings of IEEE/PES T\&D Latin America. 2002. 
[24] SANTOS, J. C. et al. Improved optical sensor for high voltage measurement using white light interferometry. In: SBMO/IEEE MTT-S International microwave and optoelectronics conference, IMOC'2003. 2003. Foz do Iguaçu. Proceedings SBMO/IEEE MTT-S IMOC 2003. v. 1, p. 615-620, 2003.

[25] RIBEIRO, B. A., WERNECK, M.M. E NETO, J.L., Otimização da demodulação de sinais de um transformador de potencial óptico usando um filtro óptico sintonizável, Anais do XIX Congresso Brasileiro de Automática, CBA, p. 13861391ISBN: 978-85 p. 8001-069-5, 2012.

[26] PEREIRA, F.C., Demodulação de sinais interferométricos de saída de sensor eletro-óptico de tensões elevadas utilizando processador digital de sinais, Dissertação (Mestrado), Faculdade de Engenharia - UNESP, Campus Ilha Solteira, 2013.

[27] LIMA. R.A., Sensor Eletro-Óptico de Tensões Elevadas e sua Viabilidade para Implementação de TP Óptico, Dissertação (Mestrado), Faculdade de Engenharia - UNESP, Campus Ilha Solteira, 2013.

[28] RUBINI, JR J. Sensor eletroóptico para a medida de altas tensões. In: XII Encontro latino americano de iniciação científica e VIII Encontro latino americano de pós-graduação: Universidade do Vale do Paraíba, 2008.

[29] SANTOS, J.C.; ALMEIDA J.C.J.; PINHEIRO, L.C.S. WLI high voltage optical fiber sensor systems with compensation for optical power fluctuations. In: European Workshop on Optical Fibre Sensors - EWOFS. Italy. 2007.

[30] SANTOS, J. C.; HIDAKA, K. Optical high voltage measurement technique using pockels device. Japanese Journal of Applied Physics, Tokyo, Japan. v. 36-1. n. 4A. 1997.2398 p.

[31] SANTOS, J. C.; DE ALMEIDA, J. C. J.; DA SILVA, L. P. C. WLI high voltage optical fiber sensor systems with compensation for optical power fluctuations. In: Third european workshop on optical fibre sensors -EWOFS 2007. 2007. Napoles. Proceedings Third European Workshop on Optical fibre Sensors. Bellingham, Washington, USA. SPIE-The International Society of Photo-Optical Instrumentation Engineers, v. 6619. 2007. 661928-4p.

[32] SANTOS, J. C.; DE ALMEIDA, J. C. J.; DA SILVA, L. P. C. White light interferometry high voltage optical fiber sensor systems with compensation for optical power fluctuations. In: Yasin Moh. (Org.). Optical Fibers/Book 1. Rijeka, Croatia: Intech Open Access Publisher. v. 1. 2012, p 491. 
[33] SANTOS, J.C.; ALMEIDA, J.C.J.; SILVA, L.P.C. White light sensing systems for high voltage measuring using electro-optical modulators as sensor and recovery interferometers. Fiber Optic Sensors. In Tech. 2012. 518 p.

[34] ALMEIDA, J. C. J., Nova técnica de processamento de sinais do domínio do tempo de giroscópios interferométricos de sagnac a fibra óptica, Tese (Doutorado) apresentada à FEEC, Universidade de Estadual de Campinas, 2001.

[35] GONÇALVES, L. C. D. et al. Integrated optical structures obtained by the photoelastic effect. In: XXV encontro nacional de física da matéria condensada, 2002, Caxambú, MG. Annals of Optics XXV ENFMC. v. 4; 2002.

[36] GONÇALVES, L. C. D. and SANTOS, J. C., Stress fields in anisotropic media due to applied delta forces: Application to stress waveguides. In: XXV encontro nacional de física da matéria condensada, 2002, Caxambú. Resumos XXV ENFMC. pp. 315; 2002.

[37] HUNSPERGER, R.G, Integrated optics - Theory and Technology. Springer. 6 ed., 2009.

[38] HAMMANI, K., ETTABIB, M.A., BOGRIS, A., KAPSALI, A. Optical properties of silicon germanium waveguides at telecommunication wavelengths. Optics Express. v. 21, n. 14, 2013.

[39] KICHIGIN, W.I., et al., Characterization of the phase structure of proton exchanged channel waveguides in $\mathrm{Z} \mathrm{CUT} \mathrm{LiNbO}_{3}$ using wet etching technique, Materials Chemistry an Physics, 142, 2013, p. 491-495.

[40] SANTOS, V.B., GOMES, A.S.L., PETROV, D. E SUNDHEIMER, M.L., Fabricação e caracterização de guias de onda em Niobato de Lítio $\left(\mathrm{LiNbO}_{3}\right)$, Congresso Brasileiro de Engenharia e Ciência dos Materiais, 2002, p. 10201026.

[41] YAVUZCETIN, O., et al. Fabrication and characterization of single mode annealed proton exchanged waveguides in-x-cut lithium niobate, Optical Materials, 36, 2013, p.372-375.

[42] BAIG, S., JIANG, G., SUN, Q., WANG, M.R., Fabrication of single-mode channel poliymer waveguides using vacuum assisted microfluidic soft lithography, J. Europ. Opt. Soc. Rap. Public. 8, 2013, p.13076.

[43] JORDAN, E. et.al, Development of $\mathbf{T I}^{+} / \mathrm{Na}^{+}$íon-exchanged single-mode waveguides on silicate glass for visible-blue wavelengths applications, Ceramics International, 41, 2015, p.7996-8001. 
[44] EKNOYAN, O., et. al, Strain induced optical waveguides in lithium niobate, lithium tantalate, and barium titanate, Appl. Phys. Lett. 60 (4), 1992, p. 407409.

[45] SAITOH, K., KOSHIBA, M., TSUJI, Y., Stress Analysis Method for Elastically Anisotropic Material Based Optical Waveguides and Its Application to StrainInduced Optical Waveguides, Journal of lightwave technology, vol. 17, $\mathrm{n}^{\mathrm{o}} 2$, 1999.

[46] PÉRON, O. et al. Erbium doped fluoride glass-ceramics waveguides fabricated by PVD, Journal of Non-Crystalline Solids. 354. 2008. 3586 p.

[47] GILL, D.M., et. al. Thin film channel waveguides fabricated in metalorganic chemical vapor deposition grown $\mathrm{BaTiO}_{3}$ on MgO. Applied Physics Letters. 69. 1996. $2968 \mathrm{p}$.

[48] GONÇALVES, L. C. D. et al. Mechanical properties of silicon oxide films deposited by pecvd-teos for application in MEMS structures and sensors. In: SBMICRO'2002 - 17TH symposium on microelectronics technology and devices, 2002, Porto Alegre - Technology and Devices SBMICRO 2002. Pennington, NJ, USA: The Electrochemical Society - Electronics Division, v. 20028. $2002.123 \mathrm{p}$.

[49] GONÇAlVES, L. C. D.; VIANA, C. E.; SANTOS, J. C.; MORIMOTO, N. I. Correlation between mechanical and electrical properties of silicon oxide deposited by PECVD-TEOS at low temperature. Surface and Coatings Technology. v. 180. n. 181. 2004. 275 p.

[50] PICHON, L., Thin film transistors fabricated by in situ doped unhydrogenated polysilicon films obtained by solid phase crystallization Semicond. Sci. Technol. 16. $2001.918 \mathrm{p}$.

[51] VIANA, C.E.; SILVA, A.N.R.; MORIMOTO, Argon Influence in the PETEOS Silicon Oxide Deposition Process, N.I. International Conference on Microelectronics and Packaging. Curitiba. PR. 1998. 481 p.

[52] EKNOYAN O; TAYLOR H.F.; MARX J.M.; TANG Z.; NEURGAONKAR R.R. Guidewave electrooptic devices utilizing static strain induced effects in ferroelectrics. Ferroelectrics 205. 1998. 147 p.

[53] LINES, ME E GLASS A.M., Principles and Applications of Ferroelectrics and Related Materials, Oxford Classic Texts in the Physical Sciences, 2001. 
[54] GONÇALVES, L.C.D. Dispositivos ópticos obtidos por efeito de tensão estática induzida. Relatório. 2003.

[55] PISSOLATO FILHO, J. EE754 ondas guiadas. Faculdade de Engenharia Elétrica e de Computação da UNICAMP.

[56] YARIV A.; YEH P. Optical Waves in Crystals. 1st ed. Wiley \& Sons. Inc. New York. 1984.

[57] ZILIO, S. C. Óptica Moderna - fundamentos e aplicações. Fotônica. IFSC: USP.

[58] FRANCO, M.A.R. Análise de guias de ondas ópticos e de micro-ondas pelo método dos elementos finitos, 170 p. Tese. (Doutorado) - Escola Politécnica da Universidade de São Paulo. 1999.

[59] RATNAJEEVAN, S.; HOLE, H. Computer-aided analysis and design of electromagnetic devices. New York: Elsevier Science, 1989.

[60] GOELL, J. E. A circular-harmonic computer analysis of retangular dielectric waveguides. The bell system technical journal. 1969. $2160 \mathrm{p}$.

[61] KOSHIBA, M., et al. Simple scalar finite element approach to optical rib waveguides. Optoelectronics, IEE proceedings-J. v.139, n.2, 1992, p. 166-171.

[62] KOSHIBA, M.; HAYATA, K.; SUZUKI, M. Approximate scalar finite element analysis of anisotropic optical waveguides. Electronics Letters. v. 18, n. 10, 1982, p. 411- 413 .

[63] MABAYA, N.; LAGASSE, P.E.; VANDENBULCKE, P. Finite Element analysis of optical waveguides. IEEE Transactions on Microwave Theory and Techniques. v. MTT-29, 1981, p. 600-605.

[64] BhagaVantaM, S., Crystal Symmetry and Physical Properties, Academic Press, New York, 1966.

[65] COOK, W.R., JR. JAFFE, H., Electro-optic Coefficients, Landolt-Bornstein, New Series, K, - H, Hellwege, Ed., Vol. 11, Springer-Verlag, 1979, p. 552-651.

[66] TAMIR, T. Integrated optics. Topics in Applied Physics vol. 7. Springer-Verlag. Berlin. Heidelberg New York. 1979.

[67] NYE, J.F. Physical properties of crystals: Their representation by tensors and matrices Clarendon Press. Oxford. 1957.

[68] KITANO, C Análise do interferômetro Mach-Zehnder com controle acústicoóptico. Xxx p. Dissertação (Mestrado) - Instituto Tecnológico da Aeronáutica-ITA. São José dos Campos, 1993. 
[69] SCHNEIDER, V. M. Modulador de fase eletroóptica em guia canal. Xxx p. Dissertação (Mestrado) - Instituto Tecnológico da Aeronáutica-ITA. São José dos Campos. São Paulo. Brasil. 1993.

[70] RIBEIRO, J. A. J. Moduladores eletroópticos integrados empregando cristais de Niobato de Lítio. 296 p. Tese (Doutorado) - Instituto Tecnológico da Aeronáutica-ITA. São José dos Campos, 1998.

[71] MACHADO, A.A. et. al. Simulação e análise experimental de receptores ópticos em 2,5 GB/s com AFDEs. Anais do XIV Simpósio Brasileiro de Telecomunicações. vol. 1. 1996. 301 p.

[72] De ALMEIDA, V.R. Aplicação de dispositivo multifuncional a óptica integrada em interferômetro de sagna a fibra óptica birrefringente. Xxx p. Tese de mestrado: ITA-SJC. 1998.

[73] LASKOSKIE, C.; HUNG, H.; El-WAilly, T.; CHANG., C.L. Ti-LiNbO Waveguide Serrodyne Modulator with Ultrahigh sideband suppression for fiber optic gyroscopes. Journal of Lightwave Technology vol. 7. 1989. 600 p.

[74] MONTEIRO, E.C., et. AL, Fabricação de Guias de Onda Óptica em Substrato de $\mathrm{LiNbO}_{3}$ Através da Técnica de Difusão de Ti, Anais do Encita 95, 1995, p. 155-157.

[75] SIARKOWSKI, A. L. Implementação de sensores ópticos integrados para aplicação em análises químicas e ambientais. 103 p. Tese (Doutorado) - Escola Politécnica da Universidade de São Paulo. Engenharia Elétrica. São Paulo. 2007.

[76] TONEY, J. E., et al., Quase-phase-matched eletro-óptic modulators for highspeed signal processing, SPIE, Proceedings, vol. 8647, Integrated Optics: Devices, Materials, and Technologies, 86470H, 2013.

[77] KIM, J.W, PARK, S.H., CHU, W.S., OH, M.C., Integrated-optic polarization controllers incorporating polymer waveguide birrefringence modulators, Optics Express, vol. 20, Issue 11, 2012, p. 12443-12448.

[78] CHMIELAK B., et al. Pockels effect based fully integrated, strained silicon electro-optic modulator, Optics Express. Vol. 19, issu 18, 2011, p. 17212-17219.

[79] ZHANG, X.; MIYOSHI, T. Optimum design of coplanar waveguide for $\mathrm{LiNbO}_{3}$ optical modulator. IEEE transactions on microwave theory and techniques. vol. MTT-43. n ${ }^{\circ} 3.1995 .523 \mathrm{p}$.

[80] NISHIHARA, H.; HARUNA M.; SUHARA, T. Optical integrated Circuits, $1^{\underline{a}}$ ed. McGraw-Hill. 1989. 109 p. 
[81] CHUNG, H.; CHANG, W.S.C.; ADLER, E.L. Modeling and optimization of traveling-wave $\mathrm{LiNbO}_{3}$ interferometric modulators. IEEE Journal of Quantum Electronics. vol. 27. $\mathrm{n}^{\mathrm{o}}$ 3. 1991. 608 p.

[82] HUI, K.W.; CHIANG, K.S.; WU, B.; ZHANG, Z.H. Electrode optimization for high-speed tranveling-wave integrated optic modulators. Journal of Lightwave Technology. vol. 16. $\mathrm{n}^{\mathrm{o}}$ 2. 1998. $232 \mathrm{p}$.

[83] COLlin, R. E. Engenharia de micro-ondas. Ed. Guanabara dois S.A. Rio de Janeiro. Brasil. 1979. Capítulo 23.

[84] CARDOSO J. R. Introdução ao método dos elementos finitos. 1995.

[85] MARCATILI, E. A. J., Dielectric rectangular waveguide and directional coupler for integrated optics, Bell Syst. Tech. J., 1969, 48, pp. 2071-2102.

[86] BBV-Software (http://www.bbv-software.com).

[87] COMSOL MULTIPHYSICS ${ }^{\circledR}$ (www.comsol.com).

[88] Beam Propagation Methods (BPM) in optical simulation software.

[89] ARLETT, P. L.; BAHRANI, A. K.; ZIENKIENKIEWCZ, O. C. Applications of finite elements to the solution of Helmholtz's equation. Proc. IEE. v. 115, n 12, p. $1762,1968$.

[90] SILVESTER, P. P. Finite-element solution of homogeneous waveguides problems. Alta frequenza. vol.38. 1969. $313 \mathrm{p}$.

[91] SILVESTER, P. P. A general high-order finite-element waveguide analysis program. IEEE transactions on microwave theory techniques. vol. MTT-17. $\mathrm{n}^{\circ} 4$. 1969. 204 p.

[92] FRANCO, M.A.R.; PASSARO, A.; CARDOSO, J.R.; MACHADO, J.M. Finite element analysis of anisotropic optical waveguide with arbitrary. Index Profile. IEEE Transactions on Magnetics. vol. 35. $\mathrm{n}^{\mathrm{o}}$ 3. 1999. 1546 p.

[93] KOSHIBA, M.; KUMAGAMI, H.; SUZUKI, M. Finite-elment solution of planar arbitrarily anisotropic diffused optical waveguides. Journal of Lightware technology. vol LT-3. n⿳⺈, 4985.773 p.

[94] HAYATA, K.; KOSHIBA, M.; SUZUKI, M. Analysis of partially metal-clad and dielectric overlay-loaded diffused optical waveguide. Electronics and communications in Japan. vol. 67-C. $\mathrm{n}^{\mathrm{0}} 5.1984 .108$ p.

[95] KITANO, C. Aplicação da abordagem de domínio espectral para análise de moduladores eletro-ópticos integrados. 2001. 390 p. Tese. (Doutorado), Instituto Tecnológico de Aeronáutica, 2001. 
[96] WEISS, R.S.; GAYLORD, T.K. Lithium Niobate: Summary of Physical Properties and Crystal Structure. Applied Physics A 32. 1985. 191 p.

[97] TATSCH P.J. Deposição de filmes finos. V Oficina de Microeletrônica. CCS: UNICAMP.

[98] ZAMBOM, L.S. Deposição de Nitreto de Silício por LPCVD. São Paulo. 1994. 110 p. Dissertação (Mestrado) - Escola Politécnica, Universidade de São Paulo.

[99] CHU, T.L.; LEE, C.H.; GRUBER, G.A. Preparation and properties of amorphous silicon nitride films. Journal of the Electrochemical Society. v. 114. $\mathrm{n}^{\mathrm{o}}$ 7. 1967. p. 717-722.

[100] BULLA, D. A. P. Desenvolvimento e caracterização de filmes finos de óxido de silício e nitreto de silício para a fabricação de guias e sensores ópticos. São Paulo. 95 p. Tese (Doutorado) - Escola Politécnica da Universidade de São Paulo. Departamento de Engenharia Eletrônica. 1999.

[101] BULLA, D.A.P. et al. Design and frabrication of $\mathrm{SiO}_{2} / \mathrm{Si}_{3} \mathbf{N}_{4} \mathrm{CVD}$ optical waveguides. 99 Proceedings of 1999 SBMO/IEEE International Microwave and Optoelectronic Conference. Rio de Janeiro. 1999.

[102] BULLA, D. A. P.; MORIMOTO, N.I. Deposition of Thick TEOS PECVD Silicon Oxide Layer for Integrates Optical Waveguide Applications. Thin Solid Films. vol. 334. 1998. 60 p.

[103] SIARKOWSKI, A.L.; ZAMBOM, L.S.; FRANZIN, R.M. Etapas de processo III. Apostila do curso.

[104] WEBER, M. J. Handbook of optical materials. The CRC press laser and optical science and Technology series. 2003.

[105] Handbook of optics: devices, measurements e properties. 2 ed vol. II. Optical society of America. Bass M.Editor in chief. 1995.

[106] WILLIAMS, P.A., et al. Optical, thermo-optic, electro-optic, and photoelastic properties of bismuth germinate $\left(\mathbf{B i}_{\mathbf{4}} \mathbf{G e}_{3} \mathbf{O}_{12}\right)$. Applied optics. vol. 35. n ${ }^{\circ} 19$. 1996. $3562 \mathrm{p}$

[107] MEYERS, M. A.; CHAWLA, K.K. Mechanical behavior of materials. University Press Cambridge 2009.

[108] SATO, S. S. et al. Modeling residual thermal stress-induced integrated optical $\mathrm{Bi}_{12} \mathrm{GeO}_{20}$ substrate for electro-optic modulation application. IMOC 2009 International microwave and optoelectronics conference. Pará, Belém. 2009. 669 p. 
[109] SATO, S. S. et al. Residual thermal stress-induced integrated optical waveguides on $\mathrm{Bi}_{12} \mathbf{G e O}_{20}$ substrate. EWOFS (Fourth European Workshop on Optical Fibre Sensors) - 2010 na cidade de Porto em Portugal. vol. 7653. 2010. 76532R-1 p.

[110] http://www.wolfram.com

[111] MACEDO, Z. S., MARTINEZ, A. L. E HERNANDES, A. C. Characterization of $\mathrm{Bi}_{4} \mathrm{Ge}_{3} \mathrm{O}_{12}$ single crystal by impedance spectroscopy. Materials Research. vol. 6. $\mathrm{n}^{\mathrm{o}} 4.2003 .577 \mathrm{p}$.

[112] KERN, W. The evolution of silicon wafer cleaning technology. Journal of Electrochemical Society. v.137. n.6. 1990. 1887 p.

[113] KERN, W.; PUOTINEM, D.A. Cleaning solutions based on hydrogen peroxide for use in silicon semiconductor technology. RCA Review. v.31. 1970. 187 p.

[114] WOLF, S.; TAUBER, R.N. Silicon processing for the VLSI era. vol.1. Process Technology. Lattice Press. 1986.

[115] BORGES, B.V. et al, Design analysis of silicon-based integrated-optic machzehnder pressure sensors. Fiber and Integrated Optics Journal. vol. 20. nº 4. 2001. $385 \mathrm{p}$

[116] SIARKOWSKI, A. L.; BULLA, D.A.P; MORIMOTO, N.I. Implementation of an optical pressure sensor and experimental results. SBMicro 2002 - XVII Symposium on Microelectronics Technology and Devices. 2002. The Electrochemical Society Proc. v. 8. 2002. 196 p.

[117] SIARKOWSKI, A. L.; BULLA, D.A.P; MORIMOTO, N.I. Mach-Zehnder interferometer simulation results for integrated optical pressure sensor. Proc. of the XVI SBMicro International Conference on Microeletronics and Packaging. Brazil. 2001. 233 p.

[118] SIARKOWSKI, A. L. Implementação de um sensor óptico integrado de pressão baseado no interferômetro Mach-Zehnder (IMZ). São Paulo, Xxx p. Dissertação (Mestrado) - Escola Politécnica, Universidade de São Paulo. 2001.

[119] TAMURA, M. AND SUNAMI, H. Generation of dislocations induced by chemical vapor desposited $\mathrm{Si}_{3} \mathbf{N}_{4}$ films on silicon. Japanese Journal of Applied Physics. v. 11. no 8. 1972.1097 p.

[120] HASHIMOTO, A.; KAMIJOH, T.; TAKANO, H.; AND SAKUTA, M. Stressinduced spectral changes in Raman spectra of n-Ga-As encapsulated with $\mathrm{Si}_{3} \mathbf{N}_{4}$ films. Jounal of the Electrochemical. v. 134. $\mathrm{n}^{\mathrm{o}} 1.1987 .153 \mathrm{p}$. 
[121] TENCOR INSTRUMENTS. FLX-2410 Manual. California. 1993.

[122] NOSKOV, A.G., et al. Correlation between stress and structure in chemically vapour desposited silicon nitride films. Thin Solid Films. v. 162. 1988. 129 p.

[123] IRENE, E.A. Residual stress in silicon nitride films. Journal of Electronic Materials. v. $5 \mathrm{n}^{-}$3. 1976.287 p.

[124] HU, S.M. Properties of amorphous silicon nitride films. Journal of the Electrochemical Society. v. 113. $\mathrm{n}^{-}$7. 1966.693 p.

[125] www.compugraphics-photomasks.com/

[126] SATO, S. S.; CAETANO, R.E; FRANCO M. A. R.; SANTOS J. C.; Simulation of electro-optic modulator based on optical waveguide formed by residual thermal stress-induced on $\mathrm{Bi}_{4} \mathrm{Ge}_{3} \mathrm{O}_{12}$ substrate by $\mathrm{Si}_{3} \mathrm{~N}_{4}$ thin film. Journal of Microwave. Optoelectronics and Electromagnetic Applications. vol.12. n ${ }^{\mathrm{o}} 1.2013$. 


\section{ANEXO A}

\section{Seção de corte no plano $(\overline{1} 10)$ e propagação paralela ao eixo $z$}

Partindo da equação 2.31, considerando a seção de análise no plano ( $\overline{1} 10$ ) paralelo ao campo de deformação aplicado, o novo sistema de coordenadas $x^{\prime}, y^{\prime}$ e $z^{\prime}$ é obtido como:

$$
\frac{x^{\prime 2}}{n_{x}^{\prime 2}}+\frac{y^{\prime 2}}{n_{y}^{\prime 2}}+\frac{z^{\prime 2}}{n_{z}^{\prime 2}}=1
$$

Usando as transformações: primeira rotação do ângulo $\alpha \alpha$ e segunda rotação ângulo $\beta \beta$ nos eixos de coordenadas $x, y$ e $z$, conforme a Figura 84, a matriz de transformação é dada por:

$$
\begin{gathered}
a_{i j}=\left(\begin{array}{ccc}
\cos \alpha \alpha \cos \beta \beta & \cos \alpha \alpha \sin \beta \beta & \sin \alpha \alpha \\
-\sin \beta \beta & \cos \beta \beta & 0 \\
-\sin \alpha \alpha \cos \beta \beta & -\sin \beta \beta \sin \alpha \alpha & \cos \alpha \alpha
\end{array}\right) \\
\left(\begin{array}{l}
x \\
y \\
z
\end{array}\right)=\left(\begin{array}{ccc}
\cos \alpha \alpha \cos \beta \beta & \cos \alpha \alpha \sin \beta \beta & \sin \alpha \alpha \\
-\sin \beta \beta & \cos \beta \beta & 0 \\
-\sin \alpha \alpha \cos \beta \beta & -\sin \beta \beta \sin \alpha \alpha & \cos \alpha \alpha
\end{array}\right)\left(\begin{array}{l}
x^{\prime} \\
y^{\prime} \\
z^{\prime}
\end{array}\right)
\end{gathered}
$$

ou a matriz de transformação dos novos eixos de coordenadas podem ser representada como:

$$
\begin{gathered}
x=x^{\prime} \cos \alpha \alpha \cos \beta \beta+y^{\prime} \cos \alpha \alpha \sin \beta \beta+z^{\prime} x^{\prime} \sin \alpha \alpha \\
y=-x^{\prime} \sin \beta \beta+y^{\prime} \cos \beta \beta \\
z=-x^{\prime} \sin \alpha \alpha \cos \beta \beta-y^{\prime} \sin \alpha \alpha \sin \beta \beta+z^{\prime} x^{\prime} \cos \alpha \alpha
\end{gathered}
$$


Figura 88- Rotação dos ângulos $\alpha \alpha$ e $\beta \beta$ nos eixos de coordenadas $x, y$ e $z$

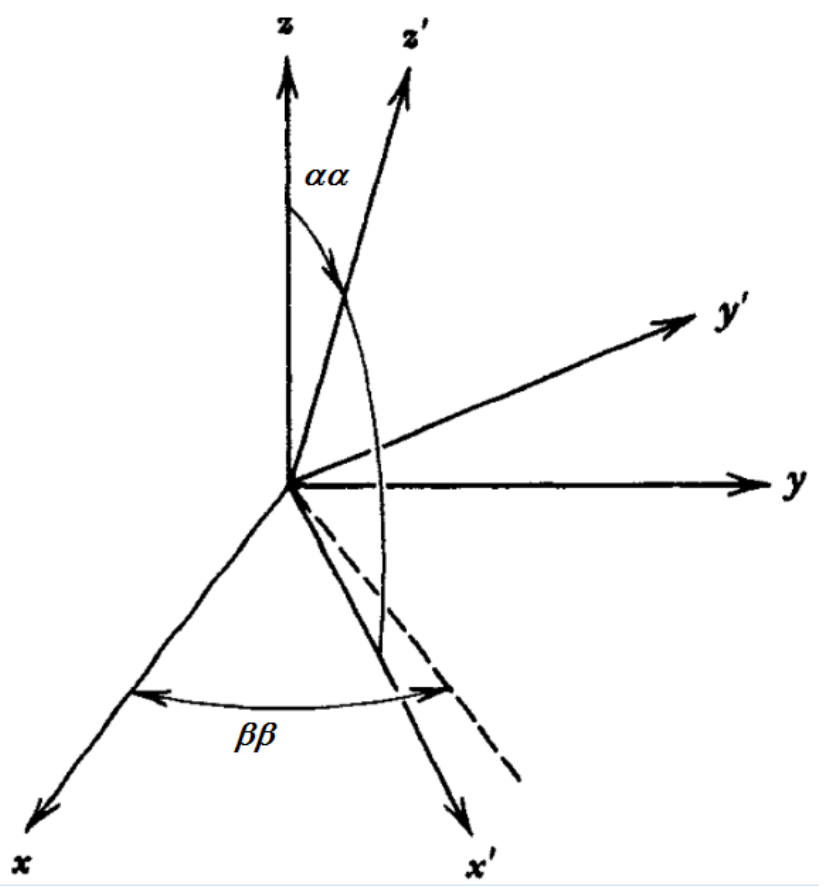

Fonte: [56].

O cálculo da rotação dos eixos do elipsoide de índices foi realizado no programa mathematica [110], porque essa rotação foi considerada muito complexa para ser feita manualmente, por isso optou-se em realizá-la usando um programa de simulação analítica. O programa mathematica obteve o seguinte resultado:

$$
\begin{aligned}
& \frac{z^{\prime 2} \cos ^{2} \alpha \alpha}{n^{2}}+p_{12} S_{1} z^{\prime 2} \cos ^{2} \alpha \alpha+p_{21} S_{2} z^{\prime 2} \cos ^{2} \alpha \alpha+p_{11} S_{3} z^{\prime 2} \cos ^{2} \alpha \alpha \\
& +2 p_{44} S_{4} y^{\prime} z^{\prime} \cos \alpha \alpha \cos \beta \beta+2 p_{44} S_{5} x^{\prime} z^{\prime} \cos ^{2} \alpha \alpha \cos \beta \beta+\frac{y^{\prime 2} \cos ^{2} \beta \beta}{n^{2}} \\
& +p_{21} S_{1} y^{\prime 2} \cos ^{2} \beta \beta+p_{11} S_{2} y^{\prime 2} \cos ^{2} \beta \beta+p_{12} S_{3} y^{\prime 2} \cos ^{2} \beta \beta \\
& +2 p_{44} S_{6} x^{\prime} y^{\prime} \cos \alpha \alpha \cos ^{2} \beta \beta+\frac{x^{\prime 2} \cos ^{2} \alpha \alpha \cos ^{2} \beta \beta}{n^{2}}
\end{aligned}
$$


$+p_{11} S_{1} x^{\prime 2} \cos ^{2} \alpha \alpha \cos ^{2} \beta \beta+p_{12} p_{21} S_{2} S_{3} x^{\prime 2} \cos ^{2} \alpha \alpha \cos ^{2} \beta \beta$

$+2 p_{44} S_{5} z^{\prime 2} \cos \alpha \alpha \sin \alpha \alpha+2 p_{44} S_{6} y^{\prime} z^{\prime} \cos \beta \beta \sin \alpha \alpha$

$+2 p_{11} S_{1} x^{\prime} z^{\prime} \cos \alpha \alpha \cos \beta \beta \sin \alpha \alpha-2 p_{12} S_{1} x^{\prime} z^{\prime} \cos \alpha \alpha \cos \beta \beta \sin \alpha \alpha$

$-2 p_{21} S_{2} x^{\prime} z^{\prime} \cos \alpha \alpha \cos \beta \beta \sin \alpha \alpha-2 p_{11} S_{3} x^{\prime} z^{\prime} \cos \alpha \alpha \cos \beta \beta \sin \alpha \alpha$

$+2 p_{12} p_{21} S_{2} S_{3} x^{\prime} z^{\prime} \cos \alpha \cos \beta \sin \alpha-2 p_{44} S_{4} x^{\prime} y^{\prime} \cos ^{2} \beta \sin \alpha$

$-2 p_{44} S_{5} x^{\prime 2} \cos \alpha \cos ^{2} \beta \sin \alpha+\frac{z^{\prime 2} \sin ^{2} \alpha}{n^{2}}+p_{11} S_{1} z^{2} \sin ^{2} \alpha$

$+p_{12} p_{21} S_{2} S_{3} z^{\prime 2} \sin ^{2} \alpha \alpha-2 p_{44} S_{5} x^{\prime} z^{\prime} \cos \beta \beta \sin ^{2} \alpha \alpha$

$+\frac{x^{\prime 2} \cos ^{2} \beta \beta \sin ^{2} \alpha \alpha}{n^{2}}+p_{12} S_{1} x^{\prime 2} \cos ^{2} \beta \beta \sin ^{2} \alpha \alpha$

(AN4)

$+p_{21} S_{2} x^{\prime 2} \cos ^{2} \beta \beta \sin ^{2} \alpha \alpha+p_{11} S_{3} x^{\prime 2} \cos ^{2} \beta \beta \sin ^{2} \alpha \alpha$

$-2 p_{44} S_{4} x^{\prime} z^{\prime} \cos \alpha \alpha \sin \beta \beta+2 p_{44} S_{5} y^{\prime} z^{\prime} \cos ^{2} \alpha \alpha \sin \beta \beta$

$-\frac{2 x^{\prime} y^{\prime} \cos \beta \beta \sin \beta \beta}{n^{2}}-2 p_{21} S_{1} x^{\prime} y^{\prime} \cos \beta \beta \sin \beta \beta$

$-2 p_{11} S_{2} x^{\prime} y^{\prime} \cos \beta \beta \sin \beta \beta-2 p_{12} S_{3} x^{\prime} y^{\prime} \cos \beta \beta \sin \beta \beta$

$-2 p_{44} S_{6} x^{\prime 2} \cos \alpha \alpha \cos \beta \beta \sin \beta \beta+2 p_{44} S_{6} y^{\prime 2} \cos \alpha \alpha \cos \beta \beta \sin \beta \beta$

$+\frac{2 x^{\prime} y^{\prime} \cos ^{2} \alpha \alpha \cos \beta \beta \sin \beta \beta}{n^{2}}$

$+2 p_{11} S_{1} x^{\prime} y^{\prime} \cos ^{2} \alpha \alpha \cos \beta \beta \sin \beta \beta+2 p_{12} p_{21} S_{2} S_{3} x^{\prime} y^{\prime} \cos ^{2} \alpha \alpha \cos \beta \beta \sin \beta \beta$ $-2 p_{44} S_{6} x^{\prime} z^{\prime} \sin \alpha \alpha \sin \beta \beta+2 p_{11} S_{1} y^{\prime} z^{\prime} \cos \alpha \alpha \sin \alpha \alpha \sin \beta \beta$ $-2 p_{12} S_{1} y^{\prime} z^{\prime} \cos \alpha \alpha \sin \alpha \alpha \sin \beta \beta-2 p_{21} S_{2} y^{\prime} z^{\prime} \cos \alpha \alpha \sin \alpha \alpha \sin \beta \beta$ $-2 p_{11} S_{3} y^{\prime} z^{\prime} \cos \alpha \alpha \sin \alpha \alpha \sin \beta \beta+2 p_{12} p_{21} S_{2} S_{3} y^{\prime} z^{\prime} \cos \alpha \alpha \sin \alpha \alpha \sin \beta \beta$ $+2 p_{44} S_{4} y^{\prime 2} \cos \beta \beta \sin \alpha \alpha \sin \beta \beta-4 p_{44} S_{5} x^{\prime} y^{\prime} \cos \alpha \alpha \cos \beta \beta \sin \alpha \alpha \sin \beta \beta$ $-2 p_{44} S_{5} y^{\prime} z^{\prime} \sin ^{2} \alpha \alpha \sin \beta \beta+\frac{2 x^{\prime} y^{\prime} \cos \beta \beta \sin ^{2} \alpha \alpha \sin \beta \beta}{n^{2}}$

$+2 p_{12} S_{1} x^{\prime} y^{\prime} \cos \beta \beta \sin ^{2} \beta \beta \sin \beta \beta+2 p_{21} S_{2} x^{\prime} y^{\prime} \cos \beta \beta \sin ^{2} \alpha \alpha \sin \beta \beta$

$+2 p_{11} S_{3} x^{\prime} y^{\prime} \cos \beta \beta \sin ^{2} \alpha \alpha \sin \beta \beta+\frac{x^{\prime 2} \sin ^{2} \beta \beta}{n^{2}}+p_{21} S_{1} x^{\prime 2} \sin ^{2} \beta \beta$

$+p_{11} S_{2} x^{\prime 2} \sin ^{2} \beta \beta+p_{12} S_{3} x^{\prime 2} \sin ^{2} \beta \beta-2 p_{44} S_{6} x^{\prime} y^{\prime} \cos \alpha \alpha \sin ^{2} \beta \beta$

$+\frac{y^{\prime 2} \cos ^{2} \alpha \alpha \sin ^{2} \beta \beta}{n^{2}}+p_{11} S_{1} y^{\prime 2} \cos ^{2} \alpha \alpha \sin ^{2} \beta \beta$

$+p_{12} p_{21} S_{2} S_{3} y^{\prime 2} \cos ^{2} \alpha \alpha \sin ^{2} \beta \beta+2 p_{44} S_{4} x^{\prime} y^{\prime} \sin \alpha \sin ^{2} \beta$

$-2 p_{44} S_{5} y^{\prime 2} \cos \alpha \sin \alpha \sin ^{2} \beta+\frac{y^{\prime 2} \sin ^{2} \alpha \sin ^{2} \beta}{n^{2}}$

$+p_{12} S_{1} y^{\prime 2} \sin ^{2} \alpha \sin ^{2} \beta+p_{21} S_{2} y^{\prime 2} \sin ^{2} \alpha \sin ^{2} \beta+p_{11} S_{3} y^{\prime 2} \sin ^{2} \alpha \sin ^{2} \beta$ 
Organizando a nova equação do elipsoide de índice pode ser reescrita como:

$$
\begin{aligned}
& \frac{x^{\prime 2} \cos ^{2} \alpha \alpha \cos ^{2} \beta \beta}{n^{2}}+p_{11} S_{1} x^{\prime 2} \cos ^{2} \alpha \alpha \cos ^{2} \beta \beta \\
& +p_{12} p_{21} S_{2} S_{3} x^{\prime 2} \cos ^{2} \alpha \alpha \cos ^{2} \beta \beta-2 p_{44} S_{5} x^{\prime 2} \cos \alpha \alpha \cos ^{2} \beta \beta \sin \alpha \alpha \\
& +\frac{x^{\prime 2} \cos ^{2} \beta \beta \sin ^{2} \alpha \alpha}{n^{2}}+p_{12} S_{1} x^{\prime 2} \cos ^{2} \beta \beta \sin ^{2} \alpha \alpha \\
& +p_{21} S_{2} x^{\prime 2} \cos ^{2} \beta \beta \sin ^{2} \alpha \alpha+p_{11} S_{3} x^{\prime 2} \cos ^{2} \beta \beta \sin ^{2} \alpha \alpha \\
& -2 p_{44} S_{6} x^{\prime 2} \cos \alpha \alpha \cos \beta \beta \sin \beta \beta+\frac{x^{\prime 2} \sin ^{2} \beta \beta}{n^{2}} \\
& +p_{21} S_{1} x^{\prime 2} \sin ^{2} \beta \beta+p_{11} S_{2} x^{\prime 2} \sin ^{2} \beta \beta+p_{12} S_{3} x^{\prime 2} \sin ^{2} \beta \beta \\
& +\frac{y^{\prime 2} \cos ^{2} \beta \beta}{n^{2}}+p_{21} S_{1} y^{\prime 2} \cos ^{2} \beta \beta+p_{11} S_{2} y^{\prime 2} \cos ^{2} \beta \beta+p_{12} S_{3} y^{\prime 2} \cos ^{2} \beta \beta \\
& +2 p_{44} S_{6} y^{\prime 2} \cos \alpha \alpha \cos \beta \beta \sin \beta \beta+2 p_{44} S_{4} y^{\prime 2} \cos \beta \beta \sin \alpha \alpha \sin \beta \beta \\
& +\frac{y^{\prime 2} \cos ^{2} \alpha \alpha \sin ^{2} \beta \beta}{n^{2}}+p_{11} S_{1} y^{\prime 2} \cos ^{2} \alpha \alpha \sin ^{2} \beta \beta \\
& +p_{12} p_{21} S_{2} S_{3} y^{\prime 2} \cos ^{2} \alpha \alpha \sin ^{2} \beta \beta-2 p_{44} S_{5} y^{\prime 2} \cos \alpha \alpha \sin \alpha \alpha \sin ^{2} \beta \beta \\
& +\frac{y^{\prime 2} \sin ^{2} \alpha \alpha \sin ^{2} \beta \beta}{n^{2}}+p_{12} S_{1} y^{\prime 2} \sin ^{2} \alpha \alpha \sin ^{2} \beta \beta+p_{21} S_{2} y^{\prime 2} \sin ^{2} \alpha \alpha \sin ^{2} \beta \beta \\
& +p_{11} S_{3} y^{\prime 2} \sin ^{2} \alpha \alpha \sin ^{2} \beta \beta \\
& \frac{z^{\prime 2} \cos ^{2} \alpha \alpha}{n^{2}}+p_{12} S_{1} z^{2} \cos ^{2} \alpha \alpha+p_{21} S_{2} z^{2} \cos ^{2} \alpha \alpha+p_{11} S_{3} z^{\prime 2} \cos ^{2} \alpha \alpha \\
& +2 p_{44} S_{5} z^{\prime 2} \cos \alpha \alpha \sin \alpha \alpha+\frac{z^{\prime 2} \sin ^{2} \alpha \alpha}{n^{2}}+p_{11} S_{1} z^{\prime 2} \sin ^{2} \alpha \alpha \\
& +p_{12} p_{21} S_{2} S_{3} z^{2} \sin ^{2} \alpha \alpha \\
& +2 p_{44} S_{6} x^{\prime} y^{\prime} \cos \alpha \alpha \cos ^{2} \beta \beta-2 p_{44} S_{4} x^{\prime} y^{\prime} \cos ^{2} \beta \beta \sin \alpha \alpha \\
& -\frac{2 x^{\prime} y^{\prime} \cos \beta \beta \sin \beta \beta}{n^{2}}-2 p_{21} S_{1} x^{\prime} y^{\prime} \cos \beta \beta \sin \beta \beta \\
& -2 p_{11} S_{2} x^{\prime} y^{\prime} \cos \beta \beta \sin \beta \beta-2 p_{12} S_{3} x^{\prime} y^{\prime} \cos \beta \beta \sin \beta \beta \\
& +\frac{2 x^{\prime} y^{\prime} \cos ^{2} \alpha \alpha \cos \beta \beta \sin \beta \beta}{n^{2}}+2 p_{11} S_{1} x^{\prime} y^{\prime} \cos ^{2} \alpha \alpha \cos \beta \beta \sin \beta \beta \\
& +2 p_{12} p_{21} S_{2} S_{3} x^{\prime} y^{\prime} \cos ^{2} \alpha \cos \beta \sin \beta \\
& -4 p_{44} S_{5} x^{\prime} y^{\prime} \cos \alpha \cos \beta \sin \alpha \sin \beta+\frac{2 x^{\prime} y^{\prime} \cos \beta \sin ^{2} \alpha \sin \beta}{n^{2}} \\
& +2 p_{12} S_{1} x^{\prime} y^{\prime} \cos \beta \sin ^{2} \beta \sin \beta+2 p_{21} S_{2} x^{\prime} y^{\prime} \cos \beta \sin ^{2} \alpha \sin \beta \\
& +2 p_{11} S_{3} x^{\prime} y^{\prime} \cos \beta \sin ^{2} \alpha \sin \beta-2 p_{44} S_{6} x^{\prime} y^{\prime} \cos \alpha \sin ^{2} \beta \\
& +2 p_{44} S_{4} x^{\prime} y^{\prime} \sin \alpha \sin ^{2} \beta
\end{aligned}
$$


$+2 p_{44} S_{5} x^{\prime} z^{\prime} \cos ^{2} \alpha \alpha \cos \beta \beta+2 p_{11} S_{1} x^{\prime} z^{\prime} \cos \alpha \alpha \cos \beta \beta \sin \alpha \alpha$

$-2 p_{12} S_{1} x^{\prime} z^{\prime} \cos \alpha \alpha \cos \beta \beta \sin \alpha \alpha-2 p_{21} S_{2} x^{\prime} z^{\prime} \cos \alpha \alpha \cos \beta \beta \sin \alpha \alpha$

$-2 p_{11} S_{3} x^{\prime} z^{\prime} \cos \alpha \alpha \cos \beta \beta \sin \alpha \alpha+2 p_{12} p_{21} S_{2} S_{3} x^{\prime} z^{\prime} \cos \alpha \alpha \cos \beta \beta \sin \alpha \alpha$

$-2 p_{44} S_{5} x^{\prime} z^{\prime} \cos \beta \beta \sin ^{2} \alpha \alpha-2 p_{44} S_{4} x^{\prime} z^{\prime} \cos \alpha \alpha \sin \beta \beta$

$-2 p_{44} S_{6} x^{\prime} z^{\prime} \sin \alpha \alpha \sin \beta \beta-2 p_{44} S_{5} y^{\prime} z^{\prime} \sin ^{2} \alpha \alpha \sin \beta \beta$

$+2 p_{44} S_{4} y^{\prime} z^{\prime} \cos \alpha \alpha \cos \beta \beta+2 p_{44} S_{6} y^{\prime} z^{\prime} \cos \beta \beta \sin \alpha \alpha$

$+2 p_{44} S_{5} y^{\prime} z^{\prime} \cos ^{2} \alpha \alpha \sin \beta \beta+2 p_{11} S_{1} y^{\prime} z^{\prime} \cos \alpha \alpha \sin \alpha \alpha \sin \beta \beta$

$-2 p_{12} S_{1} y^{\prime} z^{\prime} \cos \alpha \alpha \sin \alpha \alpha \sin \beta \beta-2 p_{21} S_{2} y^{\prime} z^{\prime} \cos \alpha \alpha \sin \alpha \alpha \sin \beta \beta$

$-2 p_{11} S_{3} y^{\prime} z^{\prime} \cos \alpha \alpha \sin \alpha \alpha \sin \beta \beta+2 p_{12} p_{21} S_{2} S_{3} y^{\prime} z^{\prime} \cos \alpha \alpha \sin \alpha \alpha \sin \beta \beta$

A nova equação do elipsoide de índice pode ser reescrita como:

Para o eixo $x$, é obtida por:

$$
\begin{aligned}
x^{\prime 2} \rightarrow & \frac{x^{\prime 2} \cos ^{2} \alpha \alpha \cos ^{2} \beta \beta}{n^{2}}+\frac{x^{\prime 2} \cos ^{2} \beta \beta \sin ^{2} \alpha \alpha}{n^{2}}+\frac{x^{\prime 2} \sin ^{2} \beta \beta}{n^{2}} \\
& +p_{11} S_{1} x^{\prime 2} \cos ^{2} \alpha \alpha \cos ^{2} \beta \beta+p_{12} p_{21} S_{2} S_{3} x^{\prime 2} \cos ^{2} \alpha \alpha \cos ^{2} \beta \beta \\
& -2 p_{44} S_{5} x^{\prime 2} \cos \alpha \alpha \cos ^{2} \beta \beta \sin \alpha \alpha+p_{12} S_{1} x^{\prime 2} \cos ^{2} \beta \beta \sin ^{2} \alpha \alpha \\
& +p_{21} S_{2} x^{\prime 2} \cos ^{2} \beta \beta \sin ^{2} \alpha \alpha+p_{11} S_{3} x^{\prime 2} \cos ^{2} \beta \beta \sin ^{2} \alpha \alpha \\
& -2 p_{44} S_{6} x^{\prime 2} \cos \alpha \alpha \cos \beta \beta \sin \beta \beta+p_{21} S_{1} x^{\prime 2} \sin ^{2} \beta \beta \\
& +p_{11} S_{2} x^{\prime 2} \sin ^{2} \beta \beta+p_{12} S_{3} x^{\prime 2} \sin ^{2} \beta \beta .
\end{aligned}
$$

Fazendo as junções dos $\cos ^{2} \beta \beta \cos ^{2} \alpha \alpha, \sin ^{2} \beta \beta$ e $\cos ^{2} \beta \beta \sin ^{2} \alpha \alpha$ e é sabido que $\sin \alpha \alpha$. $\cos \alpha \alpha$ $=\sin 2 \alpha \alpha / 2$ e $\sin ^{2} \alpha \alpha+\cos ^{2} \alpha \alpha=1$, a equação AN7 pode ser reescrita como:

$$
\begin{aligned}
& {\left[\frac{\cos ^{2} \beta \beta\left(\cos ^{2} \alpha \alpha+\sin ^{2} \alpha \alpha\right)}{n^{2}}+\frac{\sin ^{2} \beta \beta}{n^{2}}\right]} \\
& +\cos ^{2} \beta \beta\left(+p_{11} S_{1} \cos ^{2} \alpha \alpha+p_{12} S_{1} \sin ^{2} \alpha \alpha\right)+p_{21} S_{1} \sin ^{2} \beta \beta \\
& +p_{21} S_{2} \cos ^{2} \beta \beta \sin ^{2} \alpha \alpha+p_{11} S_{2} \sin ^{2} \beta \beta \\
& +p_{11} S_{3} \cos ^{2} \beta \beta \sin ^{2} \alpha \alpha+p_{12} S_{3} \sin ^{2} \beta \beta \\
& +p_{12} p_{21} S_{2} S_{3} \cos ^{2} \alpha \alpha \cos ^{2} \beta \beta-2 p_{44} S_{5} \cos \alpha \alpha \cos ^{2} \beta \beta \sin \alpha \alpha \\
& -2 p_{44} S_{6} \cos \alpha \alpha \cos \beta \beta \sin \beta \beta
\end{aligned}
$$


O novo eixo $x^{, 2}$ pode ser reescrito como:

$$
\begin{aligned}
x^{\prime 2} \rightarrow & \frac{1}{n^{2}}+\cos ^{2} \beta \beta\left(p_{11} S_{1} \cos ^{2} \alpha \alpha+p_{12} S_{1} \sin ^{2} \alpha \alpha\right) \\
& +\left(p_{21} S_{1}+p_{12} S_{3}+p_{11} S_{2}\right) \sin ^{2} \beta \beta+\left(p_{11} S_{3}+p_{21} S_{2}\right) \cos ^{2} \beta \beta \sin ^{2} \alpha \alpha \\
& +p_{12} p_{21} S_{2} S_{3} \cos ^{2} \alpha \alpha \cos ^{2} \beta \beta-2 p_{44} S_{5} \cos \alpha \alpha \cos ^{2} \beta \beta \sin \alpha \alpha \\
& -2 p_{44} S_{6} \cos \alpha \alpha \cos \beta \beta \sin \beta \beta
\end{aligned}
$$

Para o eixo $y^{, 2}$ é obtida por:

$$
\begin{aligned}
y^{\prime 2} \rightarrow & +\frac{y^{\prime 2} \cos ^{2} \beta \beta}{n^{2}}+\frac{y^{\prime 2} \cos ^{2} \alpha \alpha \sin ^{2} \beta \beta}{n^{2}}+\frac{y^{\prime 2} \sin ^{2} \alpha \alpha \sin ^{2} \beta \beta}{n^{2}} \\
& +p_{21} S_{1} y^{\prime 2} \cos ^{2} \beta \beta+p_{11} S_{1} y^{\prime 2} \cos ^{2} \alpha \alpha \sin ^{2} \beta \beta \\
& +p_{12} S_{1} y^{\prime 2} \sin ^{2} \alpha \alpha \sin ^{2} \beta \beta+p_{11} S_{2} y^{\prime 2} \cos ^{2} \beta \beta \\
& +p_{21} S_{2} y^{\prime 2} \sin ^{2} \alpha \alpha \sin ^{2} \beta \beta+p_{12} S_{3} y^{\prime 2} \cos ^{2} \beta \beta \\
& +p_{11} S_{3} y^{\prime 2} \sin ^{2} \alpha \alpha \sin ^{2} \beta \beta+p_{12} p_{21} S_{2} S_{3} y^{\prime 2} \cos ^{2} \alpha \alpha \sin ^{2} \beta \beta \\
& +2 p_{44} S_{4} y^{\prime 2} \cos \beta \beta \sin \alpha \alpha \sin \beta \beta-2 p_{44} S_{5} y^{\prime 2} \cos \alpha \alpha \sin \alpha \alpha \sin ^{2} \beta \beta \\
& +2 p_{44} S_{6} y^{\prime 2} \cos \alpha \cos \beta \beta \sin \beta \beta
\end{aligned}
$$

Fazendo as mesmas considerações aplicadas para o eixo $x^{, 2}$, a equação AN10 é reescrita como:

$$
\begin{aligned}
& \frac{1}{n^{2}}\left[\sin ^{2} \beta \beta\left(\cos ^{2} \alpha \alpha+\sin ^{2} \alpha \alpha\right)+\cos ^{2} \beta \beta\right] \\
& +\sin ^{2} \beta \beta\left(p_{11} S_{1} \cos ^{2} \alpha \alpha+p_{12} S_{1} \sin ^{2} \alpha \alpha\right)+p_{21} S_{1} \cos ^{2} \beta \beta \\
& +p_{11} S_{2} \cos ^{2} \beta \beta+p_{21} S_{2} \sin ^{2} \alpha \alpha \sin ^{2} \beta \beta \\
& +p_{12} S_{3} \cos ^{2} \beta \beta+p_{11} S_{3} \sin ^{2} \alpha \alpha \sin ^{2} \beta \beta \\
& +p_{12} p_{21} S_{2} S_{3} \cos ^{2} \alpha \alpha \sin ^{2} \beta \beta+p_{44} S_{4} \sin \alpha \beta \sin 2 \beta \beta \\
& -p_{44} S_{5} \sin 2 \alpha \alpha \sin ^{2} \beta \beta+p_{44} S_{6} \cos \alpha \alpha \sin 2 \beta \beta
\end{aligned}
$$


O novo eixo $y^{, 2}$ pode ser reescrito como:

$$
\begin{aligned}
y^{\prime 2} \rightarrow & \frac{1}{n^{2}}+\sin ^{2} \beta \beta\left(p_{11} S_{1} \cos ^{2} \alpha \alpha+p_{12} S_{1} \sin ^{2} \alpha \alpha\right) \\
& +\left(p_{21} S_{1}+p_{11} S_{2}+p_{12} S_{3}\right) \cos ^{2} \beta \beta \\
& +\left(p_{21} S_{2}+p_{11} S_{3}\right) \sin ^{2} \alpha \alpha \sin ^{2} \beta \beta \\
& +\left(p_{44} S_{4} \sin \alpha \alpha+p_{44} S_{6} \cos \alpha \alpha\right) \sin 2 \beta \beta \\
& +\left(p_{12} p_{21} S_{2} S_{3} \cos ^{2} \alpha \alpha-p_{44} S_{5} \sin 2 \alpha \alpha\right) \sin ^{2} \beta \beta
\end{aligned}
$$

Para o eixo $z^{, 2}$ é obtida por:

$$
\begin{aligned}
z^{\prime 2} & \rightarrow \frac{1}{n^{2}}\left(\cos ^{2} \alpha \alpha+\sin ^{2} \alpha \alpha\right)+p_{12} S_{1} \cos ^{2} \alpha \alpha \\
& +p_{11} S_{1} \sin ^{2} \alpha \alpha+p_{21} S_{2} \cos ^{2} \alpha \alpha+p_{11} S_{3} \cos ^{2} \alpha \alpha \\
& +p_{12} p_{21} S_{2} S_{3} \sin ^{2} \alpha \alpha+2 p_{44} S_{5} \cos \alpha \sin \alpha \alpha
\end{aligned}
$$

O novo eixo $z^{, 2}$ pode ser reescrito como:

$$
\begin{aligned}
z^{\prime 2} \rightarrow & \frac{1}{n^{2}}+\left(p_{12} S_{1}+p_{21} S_{2}+p_{11} S_{3}\right) \cos ^{2} \alpha \alpha \\
& +\left(p_{11} S_{1}+p_{12} p_{21} S_{2} S_{3}\right) \sin ^{2} \alpha \alpha+p_{44} S_{5} \sin 2 \alpha \alpha
\end{aligned}
$$

Para os termos cruzados $x^{\prime} y^{\prime}$ podem ser reescritos como:

$$
\begin{aligned}
x^{\prime} y^{\prime} \rightarrow & +\frac{\cos ^{2} \sin 2 \beta \beta}{n^{2}}+\frac{\sin ^{2} \alpha \alpha \sin 2 \beta \beta}{n^{2}}-\frac{2 \cos \beta \beta \sin \beta \beta}{n^{2}} \\
& +2 p_{12} S_{1} \cos \beta \beta \sin ^{2} \alpha \alpha \sin \beta \beta+2 p_{11} S_{1} \cos ^{2} \alpha \alpha \cos \beta \beta \sin \beta \beta \\
& -2 p_{21} S_{1} \cos \beta \beta \sin \beta \beta+2 p_{21} S_{2} \cos \beta \beta \sin ^{2} \alpha \alpha \sin \beta \beta \\
& -2 p_{11} S_{2} \cos \beta \beta \sin \beta \beta+2 p_{11} S_{3} \cos \beta \beta \sin ^{2} \alpha \alpha \sin \beta \beta \\
& -2 p_{12} S_{3} \cos \beta \beta \sin \beta \beta+2 p_{12} p_{21} S_{2} S_{3} \cos ^{2} \alpha \alpha \cos \beta \beta \sin \beta \beta \\
& +2 p_{44} S_{4} \sin \alpha \alpha \sin ^{2} \beta \beta-2 p_{44} S_{4} \cos ^{2} \beta \beta \sin \alpha \alpha \\
& -4 p_{44} S_{5} \sin \alpha \alpha \cos \alpha \alpha \sin \beta \beta \cos \beta \beta \\
& +2 p_{44} S_{6} \cos \alpha \alpha \cos ^{2} \beta \beta-2 p_{44} S_{6} \cos \alpha \alpha \sin ^{2} \beta \beta
\end{aligned}
$$


Re-ordenando a equação AN15, ela pode ser reescrita como:

$$
\begin{aligned}
x^{\prime} y^{\prime} \rightarrow & \frac{1}{n^{2}}[\sin 2 \beta \beta-2 \cos \beta \beta \sin \beta \beta] \\
& +\sin 2 \beta \beta\left[+\left(p_{12} S_{1} \sin ^{2} \alpha \alpha+p_{11} S_{1} \cos ^{2} \alpha \alpha\right)-\left(p_{21} S_{1}+p_{21} S_{2} \sin ^{2} \alpha \alpha\right)\right. \\
& \left.-\left(p_{11} S_{2}+p_{11} S_{3} \sin ^{2} \alpha \alpha\right)-\left(p_{12} S_{3}+p_{12} p_{21} S_{2} S_{3} \cos ^{2} \alpha \alpha\right)-p_{44} S_{5} \sin 2 \alpha \alpha\right] \\
& +2 p_{44} S_{4} \sin \alpha \alpha\left(\sin ^{2} \beta \beta-\cos ^{2} \beta \beta\right)+2 p_{44} S_{6} \cos \alpha \alpha \cos ^{2} \beta \beta \\
& -2 p_{44} S_{6} \cos \alpha \alpha \sin ^{2} \beta \beta
\end{aligned}
$$

Para os termos cruzados $x^{\prime} z^{\prime}$ podem ser reescritos como:

$$
\begin{aligned}
x^{\prime} z^{\prime} \rightarrow & \frac{1}{n^{2}}[\sin 2 \beta \beta-2 \cos \beta \beta \sin \beta \beta]+\left(p_{12} S_{1} \sin ^{2} \alpha \alpha+p_{11} S_{1} \cos ^{2} \alpha \alpha\right) \sin 2 \beta \beta \\
& -\left(p_{21} S_{1}+p_{21} S_{2} \sin ^{2} \alpha \alpha\right) \sin 2 \beta \beta-\left(p_{11} S_{2}+p_{11} S_{3} \sin ^{2} \alpha \alpha\right) \sin 2 \beta \beta \\
& -\left(p_{12} S_{3}+p_{12} p_{21} S_{2} S_{3} \cos ^{2} \alpha \alpha\right) \sin 2 \beta \beta \\
& +2 p_{44} S_{4} \sin \alpha \alpha\left(\sin ^{2} \beta \beta-\cos ^{2} \beta \beta\right) \\
& -p_{44} S_{5} \sin 2 \alpha \alpha \sin 2 \beta \beta+2 p_{44} S_{6} \cos \alpha \alpha \cos ^{2} \beta \beta \\
& -2 p_{44} S_{6} \cos \alpha \alpha \sin ^{2} \beta \beta
\end{aligned}
$$

Re-ordenando a equação AN17, ela pode ser reescrita como:

$$
\begin{aligned}
x^{\prime} z^{\prime} \rightarrow & \left(p_{11} S_{1}-p_{12} S_{1}\right) \cos \beta \beta \sin 2 \alpha \alpha \\
& -\left(p_{21} S_{2}+p_{11} S_{3}\right) \cos \beta \beta \sin 2 \alpha \alpha \\
& +p_{12} p_{21} S_{2} S_{3} \cos \beta \beta \sin 2 \alpha \alpha-2 p_{44} S_{4} \cos \alpha \alpha \sin \beta \beta \\
& +\left(2 p_{44} S_{5} \cos ^{2} \alpha \alpha-2 p_{44} S_{5} \sin ^{2} \alpha \alpha\right) \cos \beta \beta \\
& -\left(2 p_{44} S_{5} \sin ^{2} \alpha-2 p_{44} S_{6} x^{\prime} z^{\prime} \sin \alpha\right) \sin \beta
\end{aligned}
$$

Para os termos cruzados y'z' podem ser reescritos como:

$$
\begin{aligned}
y^{\prime} z^{\prime} \rightarrow & 2 p_{11} S_{1} \cos \alpha \alpha \sin \alpha \alpha \sin \beta \beta-2 p_{12} S_{1} \cos \alpha \alpha \sin \alpha \alpha \sin \beta \beta \\
& -2 p_{21} S_{2} \cos \alpha \alpha \sin \alpha \alpha \sin \beta \beta-2 p_{11} S_{3} \cos \alpha \alpha \sin \alpha \alpha \sin \beta \beta \\
& +2 p_{12} p_{21} S_{2} S_{3} \cos \alpha \alpha \sin \alpha \alpha \sin \beta \beta+2 p_{44} S_{4} \cos \alpha \alpha \cos \beta \beta \\
& +2 p_{44} S_{5} \cos ^{2} \alpha \alpha \sin \beta \beta+2 p_{44} S_{6} \cos \beta \beta \sin \alpha \alpha
\end{aligned}
$$


Re-ordenando a equação AN19, ela pode ser reescrita como:

$$
\begin{aligned}
y^{\prime} z^{\prime} \rightarrow & \left(p_{11} S_{1}-p_{12} S_{1}\right) \sin 2 \alpha \alpha \sin \beta \beta \\
& -\left(p_{21} S_{2}-p_{11} S_{3}\right) \sin 2 \alpha \alpha \sin \beta \beta \\
& +p_{12} p_{21} S_{2} S_{3} \sin 2 \alpha \alpha \sin \beta \beta+2 p_{44} S_{4} \cos \alpha \alpha \cos \beta \beta \\
& +2 p_{44} S_{5} \cos ^{2} \alpha \alpha \sin \beta \beta+2 p_{44} S_{6} \cos \beta \beta \sin \alpha \alpha
\end{aligned}
$$

Foram consideradas $\alpha \alpha=\beta \beta=45^{\circ}$ nos termos cruzados da equação acima.

Além da rotação em torno do eixo $z$, foi observado que o elipsoide de índice sofre variações nos comprimentos de seus eixos principais em relação ao novo sistema de eixos principais, portanto, $x^{\prime}, y^{\prime}$ e $z$ ' do elipsoide de índice podem ser representados por:

$$
A_{A 1} x^{2}+A_{A 2} y^{\prime 2}+A_{A 3} z^{\prime 2}=1
$$

onde $A_{A l}=1 /\left(\chi \chi_{1}\right)^{1 / 2} \equiv 1 / n_{1},{ }^{2}, A_{A 2}=1 /\left(\chi \chi_{2}\right)^{1 / 2} \equiv 1 / n_{2}{ }^{, 2} \mathrm{e} A_{A 3}=1 /\left(\chi \chi_{3}\right)^{1 / 2} \equiv 1 / n_{3},{ }^{2}$; e os $n_{1}{ }^{2}, n_{2}{ }^{2}$ e $n_{3}{ }^{2}$ são os novos índices de refração. A determinação dos autovalores $\chi \chi_{1}=\chi \chi_{2}=\chi \chi_{3}$ pode ser calculada pela determinante abaixo:

$$
\operatorname{det}\left[\begin{array}{ccc}
a_{11}-\chi \chi_{1} & a_{12} & a_{13} \\
a_{12} & a_{22}-\chi \chi_{2} & a_{23} \\
a_{13} & a_{23} & a_{33}-\chi \chi_{3}
\end{array}\right]=0
$$

Que resulta em:

$$
\left[\left(a_{11}-\chi \chi_{1}\right)\left(a_{22}-\chi \chi_{2}\right)\left(a_{33}-\chi \chi_{3}\right)\right]
$$

Substituindo as equações AN9, AN12 e AN15 na equação acima e separando por eixos, temos:

$$
\begin{aligned}
x^{\prime 2} \rightarrow & \left\{\left[\frac{1}{n^{2}}+\cos ^{2} \beta \beta\left(p_{11} S_{1} \cos ^{2} \alpha \alpha+p_{12} S_{1} \sin ^{2} \alpha \alpha\right)\right.\right. \\
& +\left(p_{21} S_{1}+p_{12} S_{3}+p_{11} S_{2}\right) \sin ^{2} \beta \beta+\left(p_{11} S_{3}+p_{21} S_{2}\right) \cos ^{2} \beta \beta \sin ^{2} \alpha \alpha \\
& +p_{12} p_{21} S_{2} S_{3} \cos ^{2} \alpha \alpha \cos ^{2} \beta \beta-2 p_{44} S_{5} \cos \alpha \alpha \cos ^{2} \beta \beta \sin \alpha \alpha \\
& \left.\left.-2 p_{44} S_{6} \cos \alpha \alpha \cos \beta \beta \sin \beta \beta\right]-\chi_{1}\right\}=0
\end{aligned}
$$




$$
\begin{aligned}
y^{\prime 2} \rightarrow & \left\{\left[\frac{1}{n^{2}}+\sin ^{2} \beta \beta\left(p_{11} S_{1} \cos ^{2} \alpha \alpha+p_{12} S_{1} \sin ^{2} \alpha \alpha\right)\right.\right. \\
& +\left(p_{21} S_{1}+p_{11} S_{2}+p_{12} S_{3}\right) \cos ^{2} \beta \beta \\
& +\left(p_{21} S_{2}+p_{11} S_{3}\right) \sin ^{2} \alpha \alpha \sin ^{2} \beta \beta \\
& +\left(p_{44} S_{4} \sin \alpha \alpha+p_{44} S_{6} \cos \alpha \alpha\right) \sin 2 \beta \beta \\
& \left.\left.+\left(p_{12} p_{21} S_{2} S_{3} \cos ^{2} \alpha \alpha-p_{44} S_{5} \sin 2 \alpha \alpha\right) \sin ^{2} \beta \beta\right]-\chi_{2}\right\}=0 \\
z^{\prime 2} \rightarrow & \left\{\left[\frac{1}{n^{2}}+\left(p_{12} S_{1}+p_{21} S_{2}+p_{11} S_{3}\right) \cos ^{2} \alpha \alpha\right.\right. \\
& \left.\left.+\left(p_{11} S_{1}+p_{12} p_{21} S_{2} S_{3}\right) \sin ^{2} \alpha \alpha+p_{44} S_{5} \sin 2 \alpha \alpha\right]\right\}-\chi_{3}=0
\end{aligned}
$$

Resolvendo o autovalores para o eixo $x^{2}$, temos:

$$
\begin{aligned}
& \frac{1}{n^{2}}+\cos ^{2} \beta \beta\left(p_{11} S_{1} \cos ^{2} \alpha \alpha+p_{12} S_{1} \sin ^{2} \alpha \alpha\right) \\
& +\left(p_{21} S_{1}+p_{12} S_{3}+p_{11} S_{2}\right) \sin ^{2} \beta \beta+\left(p_{11} S_{3}+p_{21} S_{2}\right) \cos ^{2} \beta \beta \sin ^{2} \alpha \alpha \\
& +p_{12} p_{21} S_{2} S_{3} \cos ^{2} \alpha \alpha \cos ^{2} \beta \beta-2 p_{44} S_{5} \cos \alpha \alpha \cos ^{2} \beta \beta \sin \alpha \alpha \\
& -2 p_{44} S_{6} \cos \alpha \alpha \cos \beta \beta \sin \beta \beta-\chi \chi_{1} \cong 0 \\
\chi \chi_{1} \cong & \frac{1}{n^{2}}+\cos ^{2} \beta \beta\left(p_{11} S_{1} \cos ^{2} \alpha \alpha+p_{12} S_{1} \sin ^{2} \alpha \alpha\right) \\
& +\left(p_{21} S_{1}+p_{12} S_{3}+p_{11} S_{2}\right) \sin ^{2} \beta \beta+\left(p_{11} S_{3}+p_{21} S_{2}\right) \cos ^{2} \beta \beta \sin ^{2} \alpha \alpha \\
& +p_{12} p_{21} S_{2} S_{3} \cos ^{2} \alpha \alpha \cos ^{2} \beta \beta-2 p_{44} S_{5} \cos \alpha \alpha \cos ^{2} \beta \beta \sin \alpha \alpha \\
& -2 p_{44} S_{6} \cos \alpha \alpha \cos \beta \beta \sin \beta \beta
\end{aligned}
$$

Resolvendo o autovalores para o eixo $y^{, 2}$, temos:

$$
\begin{aligned}
& \frac{1}{n^{2}}+\sin ^{2} \beta \beta\left(p_{11} S_{1} \cos ^{2} \alpha \alpha+p_{12} S_{1} \sin ^{2} \alpha \alpha\right) \\
& +\left(p_{21} S_{1}+p_{11} S_{2}+p_{12} S_{3}\right) \cos ^{2} \beta \beta \\
& +\left(p_{21} S_{2}+p_{11} S_{3}\right) \sin ^{2} \alpha \alpha \sin ^{2} \beta \beta \\
& +\left(p_{44} S_{4} \sin \alpha \alpha+p_{44} S_{6} \cos \alpha \alpha\right) \sin 2 \beta \beta \\
& +\left(p_{12} p_{21} S_{2} S_{3} \cos ^{2} \alpha \alpha-p_{44} S_{5} \sin 2 \alpha \alpha\right) \sin ^{2} \beta \beta-\chi \chi_{2} \cong 0
\end{aligned}
$$




$$
\begin{aligned}
\chi \chi_{2} \cong & \frac{1}{n^{2}}+\sin ^{2} \beta \beta\left(p_{11} S_{1} \cos ^{2} \alpha \alpha+p_{12} S_{1} \sin ^{2} \alpha \alpha\right) \\
& +\left(p_{21} S_{1}+p_{11} S_{2}+p_{12} S_{3}\right) \cos ^{2} \beta \beta \\
& +\left(p_{21} S_{2}+p_{11} S_{3}\right) \sin ^{2} \alpha \alpha \sin ^{2} \beta \beta \\
& +\left(p_{44} S_{4} \sin \alpha \alpha+p_{44} S_{6} \cos \alpha \alpha\right) \sin 2 \beta \beta \\
& +\left(p_{12} p_{21} S_{2} S_{3} \cos ^{2} \alpha \alpha-p_{44} S_{5} \sin 2 \alpha \alpha\right) \sin ^{2} \beta \beta
\end{aligned}
$$

Resolvendo o autovalores para o eixo $z^{, 2}$, temos:

$$
\begin{aligned}
& \frac{1}{n^{2}}+\left(p_{12} S_{1}+p_{21} S_{2}+p_{11} S_{3}\right) \cos ^{2} \alpha \alpha \\
& +\left(p_{11} S_{1}+p_{12} p_{21} S_{2} S_{3}\right) \sin ^{2} \alpha \alpha+p_{44} S_{5} \sin 2 \alpha \alpha-\chi \chi_{3} \cong 0 \\
& \chi \chi_{3} \cong \frac{1}{n^{2}}+\left(p_{12} S_{1}+p_{21} S_{2}+p_{11} S_{3}\right) \cos ^{2} \alpha \alpha \\
& +\left(p_{11} S_{1}+p_{12} p_{21} S_{2} S_{3}\right) \sin ^{2} \alpha \alpha+p_{44} S_{5} \sin 2 \alpha \alpha
\end{aligned}
$$

Aplicando à expansão binomial (série de Taylor) nas equações abaixo, é possível calcular os comprimentos dos novos eixos.

$$
\begin{aligned}
& \left(1+r_{A N}\right)^{-\frac{1}{2}}=1-\frac{1}{2} r_{A N}+\frac{3}{8} r_{A N}{ }^{2}-\frac{15}{48} r_{A N}{ }^{3}+\cdots \quad \text { para }\left|r_{A N}\right|<1 \\
& \left(1-r_{A N}\right)^{-\frac{1}{2}}=1+\frac{1}{2} r_{A N}-\frac{3}{8} r_{A N}^{2}+\frac{15}{48} r_{A N}{ }^{3}-\cdots \quad \text { para }\left|r_{A N}\right|<1
\end{aligned}
$$

Para $x^{, 2}$, temos:

$$
\begin{aligned}
\frac{1}{n_{x}^{\prime 2}}= & \frac{1}{n^{2}}+\cos ^{2} \beta \beta\left(p_{11} S_{1} \cos ^{2} \alpha \alpha+p_{12} S_{1} \sin ^{2} \alpha \alpha\right) \\
& +\left(p_{21} S_{1}+p_{12} S_{3}+p_{11} S_{2}\right) \sin ^{2} \beta \beta+\left(p_{11} S_{3}+p_{21} S_{2}\right) \cos ^{2} \beta \beta \sin ^{2} \alpha \alpha \\
& +p_{12} p_{21} S_{2} S_{3} \cos ^{2} \alpha \alpha \cos ^{2} \beta \beta-2 p_{44} S_{5} \cos \alpha \alpha \cos ^{2} \beta \beta \sin \alpha \alpha \\
& -2 p_{44} S_{6} \cos \alpha \alpha \cos \beta \beta \sin \beta \beta
\end{aligned}
$$


onde:

$$
\begin{aligned}
B_{B 1} & =\cos ^{2} \beta \beta\left(p_{11} S_{1} \cos ^{2} \alpha \alpha+p_{12} S_{1} \sin ^{2} \alpha \alpha\right) \\
& +\left(p_{21} S_{1}+p_{12} S_{3}+p_{11} S_{2}\right) \sin ^{2} \beta \beta+\left(p_{11} S_{3}+p_{21} S_{2}\right) \cos ^{2} \beta \beta \sin ^{2} \alpha \alpha \\
& +p_{12} p_{21} S_{2} S_{3} \cos ^{2} \alpha \alpha \cos ^{2} \beta \beta-2 p_{44} S_{5} \cos \alpha \alpha \cos ^{2} \beta \beta \sin \alpha \alpha \\
& -2 p_{44} S_{6} \cos \alpha \alpha \cos \beta \beta \sin \beta \beta
\end{aligned}
$$

Aplicando o mmc na equação abaixo:

$$
\begin{aligned}
& \frac{1}{n_{x}^{\prime 2}}=\frac{1}{n^{2}}+B_{B 1} \\
& \frac{1}{n_{x}^{\prime 2}}=\frac{1+n^{2} B_{B 1}}{n^{2}}
\end{aligned}
$$

Invertendo a equação:

$$
n_{x}^{\prime 2}=\frac{n^{2}}{1+n^{2} B_{B 1}}
$$

Tirando raiz quadrada nos dois lados da equação:

$$
\begin{gathered}
\sqrt{n_{x}^{\prime 2}}=\sqrt{\frac{n^{2}}{1+n^{2} B_{B 1}}} \\
n_{x}^{\prime}=\frac{n}{\sqrt{1+n^{2} B_{B 1}}} \\
n_{x}^{\prime}=n\left(1+n^{2} B_{B 1}\right)^{-\frac{1}{2}} \\
n_{x}^{\prime}=n\left\{1+n^{2}\left[\cos ^{2} \beta \beta\left(p_{11} S_{1} \cos ^{2} \alpha \alpha+p_{12} S_{1} \sin ^{2} \alpha \alpha\right)\right.\right. \\
+\left(p_{21} S_{1}+p_{12} S_{3}+p_{11} S_{2}\right) \sin ^{2} \beta \beta+\left(p_{11} S_{3}+p_{21} S_{2}\right) \cos ^{2} \beta \beta \sin ^{2} \alpha \alpha \\
+p_{12} p_{21} S_{2} S_{3} \cos ^{2} \alpha \alpha \cos ^{2} \beta \beta-2 p_{44} S_{5} \cos \alpha \alpha \cos ^{2} \beta \beta \sin \alpha \alpha \\
\left.\left.-2 p_{44} S_{6} \cos \alpha \alpha \cos \beta \beta \sin ^{2} \beta \beta\right]\right\}^{-\frac{1}{2}}
\end{gathered}
$$


Aplicando a série de Taylor e truncando no primeiro termo na equação acima, resulta em:

$$
\begin{aligned}
n_{x}^{\prime}=n\left[1+C_{c}\right]^{-\frac{1}{2}} & {\left[1+C_{c}\right]^{-\frac{1}{2}}=1-\frac{1}{2} C_{c}+\frac{3}{8} C_{c}^{2} } \\
C_{c}= & n^{2}\left[\cos ^{2} \beta \beta\left(p_{11} S_{1} \cos ^{2} \alpha \alpha+p_{12} S_{1} \sin ^{2} \alpha \alpha\right)\right. \\
& +\left(p_{21} S_{1}+p_{12} S_{3}+p_{11} S_{2}\right) \sin ^{2} \beta \beta+\left(p_{11} S_{3}+p_{21} S_{2}\right) \cos ^{2} \beta \beta \sin ^{2} \alpha \alpha \\
& +p_{12} p_{21} S_{2} S_{3} \cos ^{2} \alpha \alpha \cos ^{2} \beta \beta-2 p_{44} S_{5} \cos \alpha \alpha \cos ^{2} \beta \beta \sin \alpha \alpha \\
& \left.-2 p_{44} S_{6} \cos \alpha \alpha \cos \beta \beta \sin \beta \beta\right] \\
n_{x}^{\prime}=n\left[1-\frac{1}{2} C_{c}\right]^{-\frac{1}{2}} & \\
n_{x}^{\prime}= & \left\{1-\frac{1}{2} n^{2}\left[\cos ^{2} \beta \beta\left(p_{11} S_{1} \cos ^{2} \alpha \alpha+p_{12} S_{1} \sin ^{2} \alpha \alpha\right)\right.\right. \\
& +\left(p_{21} S_{1}+p_{12} S_{3}+p_{11} S_{2}\right) \sin ^{2} \beta \beta+\left(p_{11} S_{3}+p_{21} S_{2}\right) \cos ^{2} \beta \beta \sin ^{2} \alpha \alpha \\
& +p_{12} p_{21} S_{2} S_{3} \cos ^{2} \alpha \alpha \cos ^{2} \beta \beta-2 p_{44} S_{5} \cos \alpha \alpha \cos ^{2} \beta \beta \sin \alpha \alpha \\
& \left.\left.-2 p_{44} S_{6} \cos \alpha \alpha \cos \beta \beta \sin ^{2} \beta \beta\right]\right\}^{-\frac{1}{2}}
\end{aligned}
$$

Finalmente é obtida a expressão de $n^{\prime}$ :

$$
\begin{aligned}
n_{x}^{\prime}= & \left\{n-\frac{1}{2} n^{3}\left[\cos ^{2} \beta \beta\left(p_{11} S_{1} \cos ^{2} \alpha \alpha+p_{12} S_{1} \sin ^{2} \alpha \alpha\right)\right.\right. \\
& -\frac{1}{2} n^{3}\left(p_{21} S_{1}+p_{12} S_{3}+p_{11} S_{2}\right) \sin ^{2} \beta \beta-\frac{1}{2} n^{3}\left(p_{11} S_{3}+p_{21} S_{2}\right) \cos ^{2} \beta \beta \sin ^{2} \alpha \alpha \\
& -\frac{1}{2} n^{3} p_{12} p_{21} S_{2} S_{3} \cos ^{2} \alpha \alpha \cos ^{2} \beta \beta+\frac{1}{2} n^{3} 2 p_{44} S_{5} \cos \alpha \alpha \cos ^{2} \beta \beta \sin \alpha \alpha \\
& \left.\left.+\frac{1}{2} n^{3} 2 p_{44} S_{6} \cos \alpha \cos \beta \sin \beta\right]\right\}^{-\frac{1}{2}}
\end{aligned}
$$


Para $y^{\prime 2}$, temos:

$$
\begin{aligned}
\frac{1}{n_{y}^{\prime 2}}= & \frac{1}{n^{2}}+\sin ^{2} \beta \beta\left(p_{11} S_{1} \cos ^{2} \alpha \alpha+p_{12} S_{1} \sin ^{2} \alpha \alpha\right) \\
& +\left(p_{21} S_{1}+p_{11} S_{2}+p_{12} S_{3}\right) \cos ^{2} \beta \beta \\
& +\left(p_{21} S_{2}+p_{11} S_{3}\right) \sin ^{2} \alpha \alpha \sin ^{2} \beta \beta \\
& +\left(p_{44} S_{4} \sin \alpha \alpha+p_{44} S_{6} \cos \alpha \alpha\right) \sin 2 \beta \beta \\
& +\left(p_{12} p_{21} S_{2} S_{3} \cos ^{2} \alpha \alpha-p_{44} S_{5} \sin 2 \alpha \alpha\right) \sin ^{2} \beta \beta
\end{aligned}
$$

onde:

$$
\begin{aligned}
D_{D 1} & =\sin ^{2} \beta \beta\left(p_{11} S_{1} \cos ^{2} \alpha \alpha+p_{12} S_{1} \sin ^{2} \alpha \alpha\right) \\
& +\left(p_{21} S_{1}+p_{11} S_{2}+p_{12} S_{3}\right) \cos ^{2} \beta \beta \\
& +\left(p_{21} S_{2}+p_{11} S_{3}\right) \sin ^{2} \alpha \alpha \sin ^{2} \beta \beta \\
& +\left(p_{44} S_{4} \sin \alpha \alpha+p_{44} S_{6} \cos \alpha \alpha\right) \sin 2 \beta \beta \\
& +\left(p_{12} p_{21} S_{2} S_{3} \cos ^{2} \alpha \alpha-p_{44} S_{5} \sin 2 \alpha \alpha\right) \sin ^{2} \beta \beta
\end{aligned}
$$

Aplicando o mmc na equação acima:

$$
\begin{aligned}
& \frac{1}{n_{y}^{\prime 2}}=\frac{1}{n^{2}}+D_{D 1} \\
& \frac{1}{n_{y}^{\prime 2}}=\frac{1+n^{2} D_{D 1}}{n^{2}}
\end{aligned}
$$

Invertendo a equação:

$$
n_{y}^{\prime 2}=\frac{n^{2}}{1+n^{2} D_{D 1}}
$$

Tirando raiz quadrada nos dois lados da equação:

$$
\sqrt{n_{y}^{\prime 2}}=\sqrt{\frac{n^{2}}{1+n^{2} D_{D 1}}}
$$




$$
\begin{gathered}
n_{y}^{\prime}=\frac{n}{\sqrt{1+n^{2} D_{D 1}}} \\
n_{y}^{\prime}=n\left(1+n^{2} D_{D 1}\right)^{-\frac{1}{2}} \\
n_{y}^{\prime}=n\left\{1+n^{2}\left[\sin ^{2} \beta \beta\left(p_{11} S_{1} \cos ^{2} \alpha \alpha+p_{12} S_{1} \sin ^{2} \alpha \alpha\right)\right.\right. \\
+\left(p_{21} S_{1}+p_{11} S_{2}+p_{12} S_{3}\right) \cos ^{2} \beta \beta \\
+\left(p_{21} S_{2}+p_{11} S_{3}\right) \sin ^{2} \alpha \alpha \sin ^{2} \beta \beta \\
+\left(p_{44} S_{4} \sin \alpha \alpha+p_{44} S_{6} \cos \alpha \alpha\right) \sin 2 \beta \beta \\
\left.\left.+\left(p_{12} p_{21} S_{2} S_{3} \cos ^{2} \alpha \alpha-p_{44} S_{5} \sin 2 \alpha \alpha\right) \sin ^{2} \beta \beta\right]\right\}^{-\frac{1}{2}}
\end{gathered}
$$

Aplicando a série de Taylor e truncando no primeiro termo na equação acima, resulta em:

$$
\begin{gathered}
n_{y}^{\prime}=n\left[1+E_{E 1}\right]^{-\frac{1}{2}} \\
{\left[1+E_{E 1}\right]^{-\frac{1}{2}}=1-\frac{1}{2} E_{E 1}+\frac{3}{8} E_{E 1}^{2}}
\end{gathered}
$$

onde:

$$
\begin{aligned}
E_{E 1}= & n^{2}\left[\sin ^{2} \beta \beta\left(p_{11} S_{1} \cos ^{2} \alpha \alpha+p_{12} S_{1} \sin ^{2} \alpha \alpha\right)\right. \\
& +\left(p_{21} S_{1}+p_{11} S_{2}+p_{12} S_{3}\right) \cos ^{2} \beta \beta \\
& +\left(p_{21} S_{2}+p_{11} S_{3}\right) \sin ^{2} \alpha \alpha \sin ^{2} \beta \beta \\
& +\left(p_{44} S_{4} \sin \alpha \alpha+p_{44} S_{6} \cos \alpha \alpha\right) \sin 2 \beta \beta \\
& \left.+\left(p_{12} p_{21} S_{2} S_{3} \cos ^{2} \alpha \alpha-p_{44} S_{5} \sin 2 \alpha \alpha\right) \sin ^{2} \beta \beta\right] \\
& n_{y}^{\prime}=n\left[1-\frac{1}{2} E_{E 1}\right]^{-\frac{1}{2}}
\end{aligned}
$$




$$
\begin{aligned}
n_{y}^{\prime}= & n\left\{1-\frac{1}{2} n^{2}\left[\sin ^{2} \beta \beta\left(p_{11} S_{1} \cos ^{2} \alpha \alpha+p_{12} S_{1} \sin ^{2} \alpha \alpha\right)\right.\right. \\
& +\left(p_{21} S_{1}+p_{11} S_{2}+p_{12} S_{3}\right) \cos ^{2} \beta \beta \\
& +\left(p_{21} S_{2}+p_{11} S_{3}\right) \sin ^{2} \alpha \alpha \sin ^{2} \beta \beta \\
& +\left(p_{44} S_{4} \sin \alpha \alpha+p_{44} S_{6} \cos \alpha \alpha\right) \sin 2 \beta \beta \\
& \left.\left.+\left(p_{12} p_{21} S_{2} S_{3} \cos ^{2} \alpha \alpha-p_{44} S_{5} \sin 2 \alpha \alpha\right) \sin ^{2} \beta \beta\right]\right\}^{-\frac{1}{2}}
\end{aligned}
$$

Finalmente é obtida a expressão de $n_{y}^{\prime}$ :

$$
\begin{aligned}
& n_{y}^{\prime}=\left\{n-\frac{1}{2} n^{3}\left[\sin ^{2} \beta \beta\left(p_{11} S_{1} \cos ^{2} \alpha \alpha+p_{12} S_{1} \sin ^{2} \alpha \alpha\right)\right.\right. \\
&-\frac{1}{2} n^{3}\left(p_{21} S_{1}+p_{11} S_{2}+p_{12} S_{3}\right) \cos ^{2} \beta \beta \\
&-\frac{1}{2} n^{3}\left(p_{21} S_{2}+p_{11} S_{3}\right) \sin ^{2} \alpha \alpha \sin ^{2} \beta \beta \\
&-\frac{1}{2} n^{3}\left(p_{44} S_{4} \sin \alpha \alpha+p_{44} S_{6} \cos \alpha \alpha\right) \sin 2 \beta \beta \\
&\left.\left.-\frac{1}{2} n^{3}\left(p_{12} p_{21} S_{2} S_{3} \cos ^{2} \alpha \alpha-p_{44} S_{5} \sin 2 \alpha \alpha\right) \sin ^{2} \beta \beta\right]\right\}^{-\frac{1}{2}}
\end{aligned}
$$

Para $z^{, 2}$, temos:

$$
\begin{aligned}
\frac{1}{n_{z}^{\prime 2}}= & \frac{1}{n^{2}}+\left(p_{12} S_{1}+p_{21} S_{2}+p_{11} S_{3}\right) \cos ^{2} \alpha \alpha \\
& +\left(p_{11} S_{1}+p_{12} p_{21} S_{2} S_{3}\right) \sin ^{2} \alpha \alpha+p_{44} S_{5} \sin 2 \alpha \alpha
\end{aligned}
$$

onde:

$$
\begin{aligned}
F_{F 1}= & \left(p_{12} S_{1}+p_{21} S_{2}+p_{11} S_{3}\right) \cos ^{2} \alpha \alpha \\
& +\left(p_{11} S_{1}+p_{12} p_{21} S_{2} S_{3}\right) \sin ^{2} \alpha \alpha+p_{44} S_{5} \sin 2 \alpha \alpha
\end{aligned}
$$


Aplicando o mmc na equação acima:

$$
\begin{aligned}
& \frac{1}{n_{z}^{\prime 2}}=\frac{1}{n^{2}}+F_{F 1} \\
& \frac{1}{n_{z}^{\prime 2}}=\frac{1+n^{2} F_{F 1}}{n^{2}}
\end{aligned}
$$

Invertendo a equação:

$$
n_{z}^{\prime 2}=\frac{n^{2}}{1+n^{2} F_{F 1}}
$$

Tirando raiz quadrada nos dois lados da equação:

$$
\begin{gathered}
\sqrt{n_{z}^{\prime 2}}=\sqrt{\frac{n^{2}}{1+n^{2} F_{F 1}}} \\
n_{z}^{\prime}=\frac{n}{\sqrt{1+n^{2} F_{F 1}}} \\
n_{z}^{\prime}=n\left(1+n^{2} F_{F 1}\right)^{-\frac{1}{2}} \\
n_{z}^{\prime}=n\left\{1+n^{2}\left[\left(p_{12} S_{1}+p_{21} S_{2}+p_{11} S_{3}\right) \cos ^{2} \alpha \alpha\right.\right. \\
\left.\left.+\left(p_{11} S_{1}+p_{12} p_{21} S_{2} S_{3}\right) \sin ^{2} \alpha \alpha+p_{44} S_{5} \sin 2 \alpha \alpha\right]\right\}^{-\frac{1}{2}}
\end{gathered}
$$

Aplicando a série de Taylor e truncando no primeiro termo na equação acima, resulta em:

$$
\begin{gathered}
n_{z}^{\prime}=n\left[1+G_{G 1}\right]^{-\frac{1}{2}} \\
{\left[1+G_{G 1}\right]^{-\frac{1}{2}}=1-\frac{1}{2} G_{G 1}+\frac{3}{8} G_{G 1}^{2}}
\end{gathered}
$$

onde: 


$$
\begin{aligned}
& G_{G 1}= n^{2}\left[\left(p_{12} S_{1}+p_{21} S_{2}+p_{11} S_{3}\right) \cos ^{2} \alpha \alpha\right. \\
&\left.+\left(p_{11} S_{1}+p_{12} p_{21} S_{2} S_{3}\right) \sin ^{2} \alpha \alpha+p_{44} S_{5} \sin 2 \alpha \alpha\right] \\
& n_{z}^{\prime}=n\left[1-\frac{1}{2} G_{G 1}\right]^{-\frac{1}{2}} \\
& n_{z}^{\prime}=n\left\{1-\frac{1}{2} n^{2}\left[\left(p_{12} S_{1}+p_{21} S_{2}+p_{11} S_{3}\right) \cos ^{2} \alpha \alpha\right.\right. \\
&\left.\left.+\left(p_{11} S_{1}+p_{12} p_{21} S_{2} S_{3}\right) \sin ^{2} \alpha \alpha+p_{44} S_{5} \sin 2 \alpha \alpha\right]\right\}^{-\frac{1}{2}}
\end{aligned}
$$

Finalmente é obtida a expressão de $n_{z}^{\prime}$ :

$$
\begin{aligned}
n_{z}^{\prime}= & \left\{n-\frac{1}{2} n^{3}\left[\left(p_{12} S_{1}+p_{21} S_{2}+p_{11} S_{3}\right) \cos ^{2} \alpha \alpha\right.\right. \\
& \left.\left.-\frac{1}{2} n^{3}\left(p_{11} S_{1}+p_{12} p_{21} S_{2} S_{3}\right) \sin ^{2} \alpha \alpha-\frac{1}{2} n^{3} p_{44} S_{5} \sin 2 \alpha \alpha\right]\right\}^{-\frac{1}{2}}
\end{aligned}
$$




\section{ANEXO B}

Partindo da equação 3.24 e aplicando a rotação nos eixos do elipsoide de índice do substrato de $\mathrm{Bi}_{4} \mathrm{Ge}_{3} \mathrm{O}_{12}$ :

$$
\begin{aligned}
& \frac{x^{\prime 2}}{n_{x}^{\prime 2}}+\frac{y^{\prime 2} \cos ^{2} \varphi}{n_{y}^{\prime 2}}-\frac{2 y^{\prime} z^{\prime} \sin \varphi \cos \varphi}{n_{y}^{\prime 2}}+\frac{z^{\prime} \sin ^{2} \varphi}{n_{z}^{\prime 2}}+\frac{y^{\prime 2} \sin ^{2} \varphi}{n_{z}^{\prime 2}} \\
& +\frac{2 y^{\prime} z^{\prime} \sin \varphi \cos \varphi}{n_{z}^{\prime 2}}+2 r_{41} E_{x} y^{\prime 2} \cos \varphi \sin \varphi+\frac{z^{\prime} \cos ^{2} \varphi}{n_{z}^{\prime 2}} \\
& +2 r_{41} E_{x} y^{\prime} z^{\prime} \cos ^{2} \varphi-2 r_{41} E_{x} y^{\prime} z^{\prime} \sin ^{2} \varphi-2 r_{41} E_{x} z^{\prime 2} \cos \varphi \sin \varphi=1 .
\end{aligned}
$$

Separando a equação acima por eixos, que pode ser representada como:

$$
\begin{gathered}
x^{\prime 2}\left(\frac{1}{n_{x}^{\prime 2}}\right) \\
y^{\prime 2}\left(\frac{\cos ^{2} \varphi}{n_{y}^{\prime 2}}+\frac{\sin ^{2} \varphi}{n_{z}^{\prime 2}}+2 r_{41} E_{x} y^{\prime 2} \cos \varphi \sin \varphi\right) \\
z^{\prime}\left(\frac{\sin ^{2} \varphi}{n_{z}^{\prime 2}}+\frac{z^{\prime} \cos ^{2} \varphi}{n_{z}^{\prime 2}}-2 r_{41} E_{x} z^{\prime 2} \cos \varphi \sin \varphi\right) \\
y^{\prime} z^{\prime}\left[\frac{2 \sin \varphi \cos \varphi}{n_{z}^{\prime 2}}-\frac{2 \sin \varphi \cos \varphi}{n_{y}^{\prime 2}}+2 r_{41} E_{x}\left(\cos ^{2} \varphi-\sin ^{2} \varphi\right)\right]
\end{gathered}
$$

Resolvendo o termo cruzado, temos:

$$
\frac{\sin 2 \varphi}{n_{z}^{\prime 2}}-\frac{\sin 2 \varphi}{n_{y}^{\prime 2}}+2 r_{41} E_{x} \cos 2 \varphi=0
$$

Dividindo por cosseno $2 \varphi$, temos:

$$
\begin{gathered}
\frac{\tan 2 \varphi}{n_{z}^{\prime 2}}-\frac{\tan 2 \varphi}{n_{y}^{\prime 2}}+2 r_{41} E_{x}=0 \\
(-1) \tan 2 \varphi\left(\frac{1}{n_{z}^{\prime 2}}-\frac{1}{n_{y}^{\prime 2}}\right)=-2 r_{41} E_{x}(-1)
\end{gathered}
$$




$$
\tan 2 \varphi=\frac{2 r_{41} E_{x}}{\frac{1}{n_{y}^{\prime 2}}-\frac{1}{n_{z}^{\prime 2}}}
$$

Supondo que $\underline{n}_{\underline{y}} \approx n_{\underline{Z}}^{\prime}, \log$ a $\tan 2 \varphi \rightarrow \infty$, portanto $\varphi=\pi / 4$ [56]. Os novos eixos do elipsoide de índice podem ser reescrita como:

$$
\frac{1}{n_{x}^{\prime 2}} \cong \frac{1}{n_{x}^{\prime 2}}
$$

No caso do eixo $y^{\prime 2}$, temos:

$$
\frac{1}{n_{y}^{\prime 2}} \cong \frac{1}{n_{y}^{\prime 2}}+2 r_{41} E_{x} \sin \varphi \cos \varphi
$$

onde

$\varphi=\pi / 4$, então, $\sin \varphi=\sqrt{2} / 2$ e $\cos \varphi=\sqrt{2} / 2$ [56], portando a equação pode ser reescrita como:

$$
\frac{1}{n_{y}^{\prime 2}} \cong \frac{1}{n_{y}^{\prime 2}}+r_{41} E_{x}
$$

O caso $z^{, 2}$ foi resolvido comoo caso do eixo $y^{, 2}$, então, temos:

$$
\begin{gathered}
\frac{1}{n_{z}^{\prime \prime 2}} \cong \frac{1}{n_{z}^{\prime 2}}-2 r_{41} E_{x} \sin \varphi \cos \varphi \\
\frac{1}{n_{z}^{\prime \prime 2}} \cong \frac{1}{n_{z}^{\prime 2}}-E_{x} r_{41}
\end{gathered}
$$

Aplicando a expansão binomial nos termos acima, temos:

No caso $n_{x}{ }^{, 2}$ :

$$
\begin{gathered}
\frac{1}{n_{x}^{\prime 2}} \cong \frac{1}{n_{x}^{\prime 2}} \\
n_{x}^{\prime \prime 2} \cong n_{x}^{\prime 2} \\
n_{x}^{\prime \prime} \cong n_{x}^{\prime}
\end{gathered}
$$


No caso $n_{y}{ }^{, 2}$ :

$$
\begin{gathered}
\frac{1}{n_{y}^{\prime \prime 2}} \cong \frac{1}{n_{y}^{\prime 2}}+r_{41} E_{x} \\
n_{y}^{\prime \prime 2} \cong \frac{n_{y}^{\prime 2}}{1+E_{x} r_{41} n_{y}^{\prime 2}} \\
n_{y}^{\prime \prime} \cong \frac{n_{y}^{\prime}}{\sqrt{1+E_{x} r_{41} n_{y}^{\prime 2}}} \\
n_{y}^{\prime \prime} \cong n_{y}^{\prime}\left(1+E_{x} r_{41} n_{y}^{\prime 2}\right)^{-\frac{1}{2}}
\end{gathered}
$$

onde

$$
H_{H 1}=E_{x} r_{41} n_{y}{ }^{2} \text { e aplicando a expansão de Taylor em } n_{y}{ }^{\prime \prime} \text {, temos: }
$$

$$
n_{y}^{\prime \prime} \cong n_{y}^{\prime}\left(1+H_{H 1}\right)^{-\frac{1}{2}}
$$

Truncando a série no segundo termo, a equação pode ser representada como:

$$
\begin{aligned}
& n_{y}^{\prime \prime} \cong n_{y}^{\prime}\left(1-\frac{1}{2} H_{H 1}\right) \\
& n_{y}^{\prime \prime} \cong n_{y}^{\prime}-\frac{1}{2} E_{x} r_{41} n_{y}^{\prime 3}
\end{aligned}
$$

No caso $n_{z}, 2$ :

$$
\begin{aligned}
& \frac{1}{n_{z}^{\prime \prime 2}} \cong \frac{1}{n_{z}^{\prime 2}}-r_{41} E_{x} \\
& \frac{1}{n_{z}^{\prime \prime 2}} \cong \frac{1-E_{x} r_{41} n_{z}^{\prime 2}}{n_{z}^{\prime 2}} \\
& n_{z}^{\prime \prime 2} \cong \frac{n_{z}^{\prime 2}}{1-E_{x} r_{41} n_{z}^{\prime 2}}
\end{aligned}
$$




$$
\begin{gathered}
n_{z}^{\prime \prime} \cong \frac{n_{z}^{\prime}}{\sqrt{1-E_{x} r_{41} n_{z}^{\prime 2}}} \\
n_{z}^{\prime \prime} \cong n_{z}^{\prime}\left(1+E_{x} r_{41} n_{z}^{\prime 2}\right)^{-\frac{1}{2}}
\end{gathered}
$$

onde

$H_{H 2}=E_{x} r_{41} n_{z}{ }^{2}$ e aplicando a expansão de Taylor em $n_{z}{ }^{\prime}$, temos:

$$
n_{z}^{\prime \prime} \cong n_{z}^{\prime}\left(1+H_{H 2}\right)^{-\frac{1}{2}}
$$

Truncando a série no segundo termo, a equação pode ser representada como:

$$
\begin{aligned}
& n_{z}^{\prime \prime} \cong n_{z}^{\prime}\left(1-\frac{1}{2} H_{H 2}\right) \\
& n_{z}^{\prime \prime} \cong n_{z}^{\prime}-\frac{1}{2} E_{x} r_{41} n_{z}^{\prime 3}
\end{aligned}
$$




\section{ANEXO C}

\section{Início de um projeto de modulador eletro-óptico baseado em guia de onda do tipo canal}

Nesse trabalho usou-se a seguinte sequência para executar as simulações de moduladores eletro-ópticos baseados em guias de onda do tipo canal em substratos de BGOs, usando a técnica ISS.

Ao iniciar o programa, aparecerá uma tela similar à Figura 89. Nessa tela são definidos os modos de aplicações físicas e as dimensões espaciais da estrutura do projeto proposto.

Figura 89- Tela inicial do Comsol Multiphysics 3.2b.

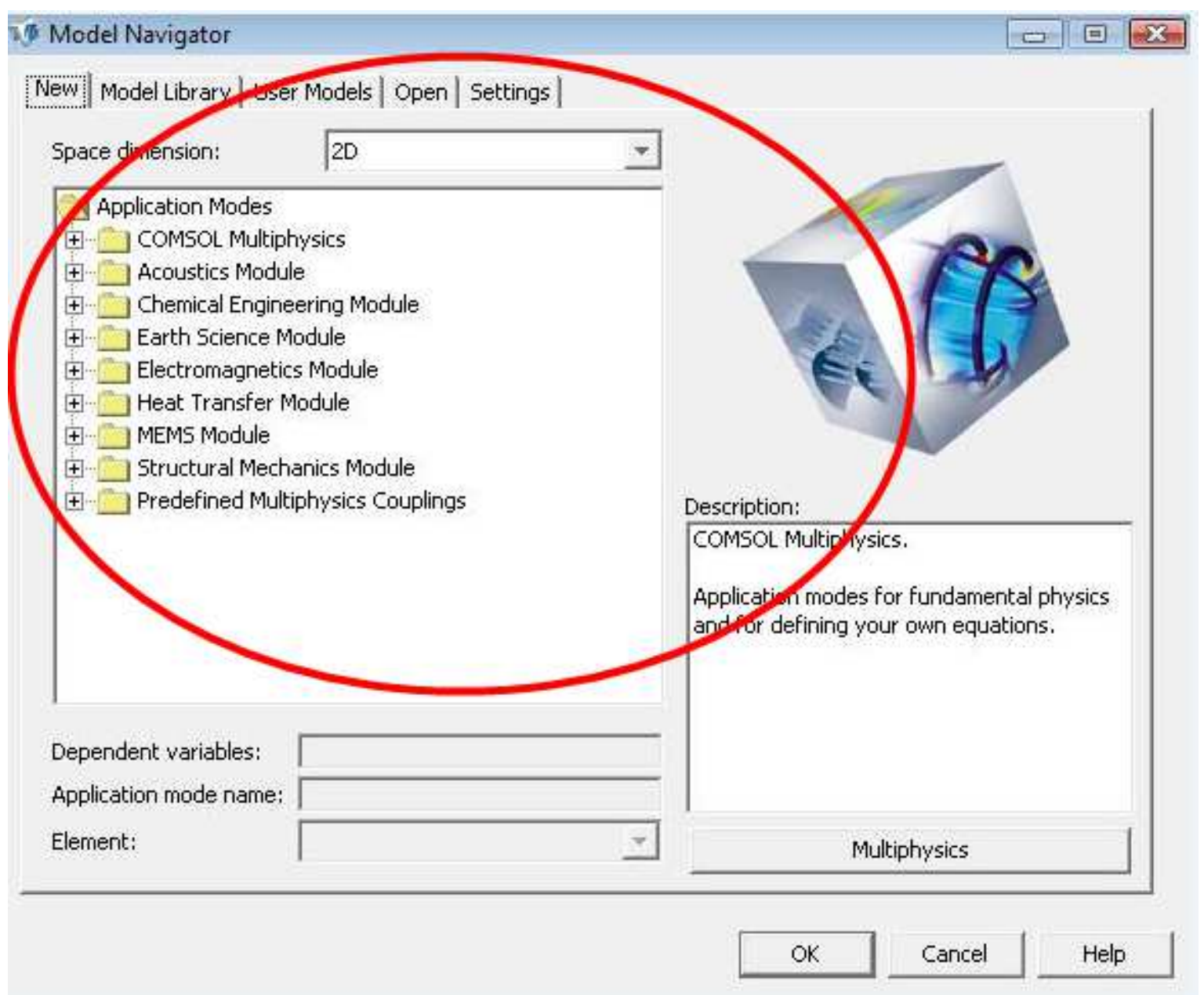

Fonte: Autora

Nesse trabalho é mantida a dimensão 2D para o projeto. A Figura 89 mostra a janela do modelo de navegação (model navigator) do programa, onde estão selecionados e adicionados os modos. 
O próximo passo é selecionar o Modo estrutural mecânico - plane strain, como ilustra a Figura 90.

Figura 90- Escolha do Modo Estrutural Mecânico.

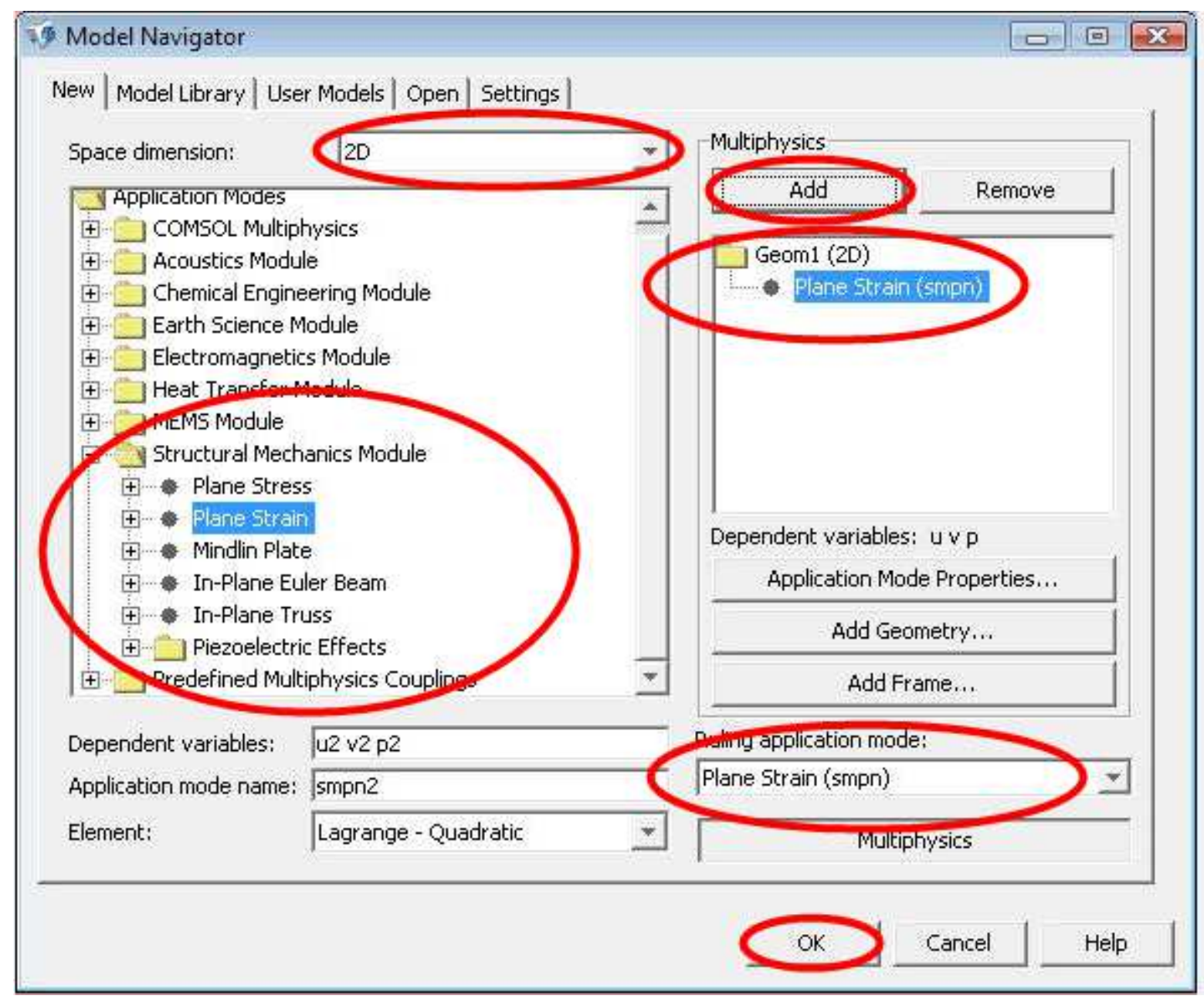

Fonte: Autora

O segundo passo é selecionar o Modo eletromagnetismo - ondas perpendiculares - ondas de modo híbrido, como ilustra a Figura 91. 
Figura 91- Escolha do Modo Eletromagnetismo - ondas perpendiculares - ondas de modo híbrido

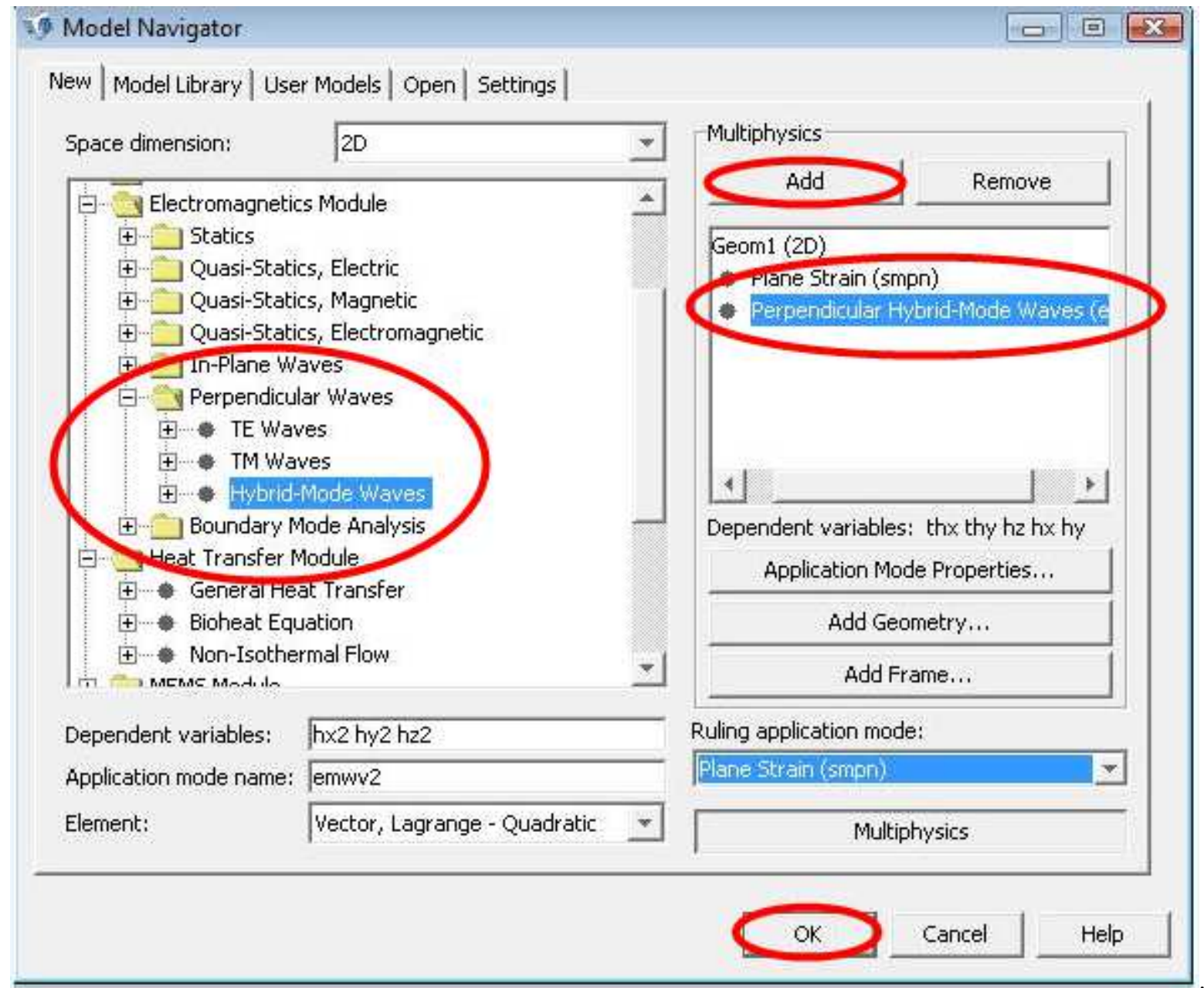

Fonte: Autora

O terceiro passo é selecionar o Modo de Sistema Microeletromecânico (MEMS) microfluídico - eletrostático, como ilustra a Figura 92. 
Figura 92- Escolha do Modo MEMS (microelectromechanical systems - sistema microeletromecânico) - microfluídico - eletrostático.

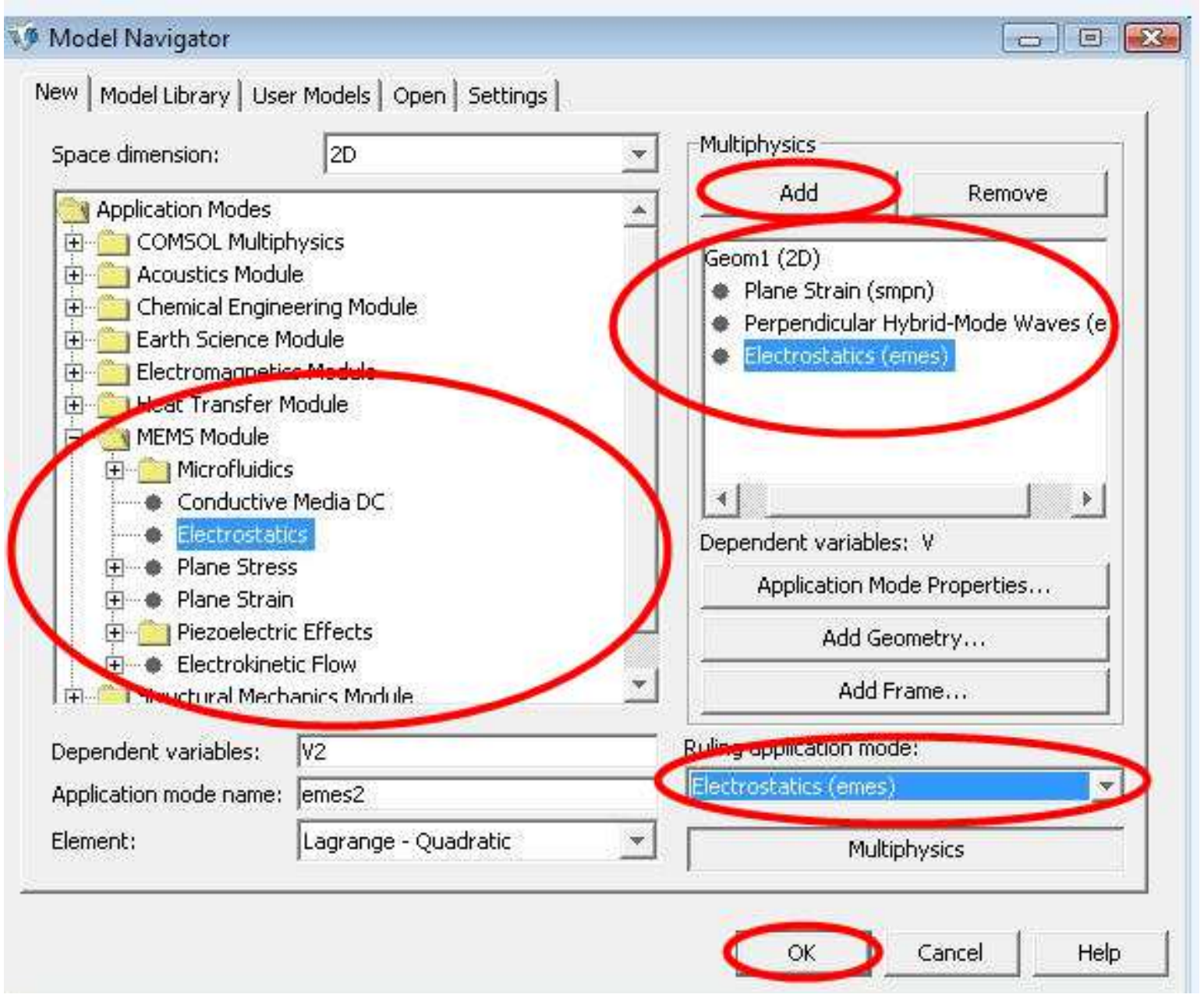

\section{Fonte: Autora}

No Comsol Multiphysics 3.2b é possível desenhar diversas formas geométricas, tais como, quadrados, retângulos, triângulos, círculos, elipses, etc. Nesse trabalho foram usados apenas retângulos. 
No próximo passo são definidos o Axis e o Grid para adequar a tela de exibição ao tamanho da estrutura desejada, através da utilização do botão de Options $\rightarrow$ Axis/Grid Settings, como mostra a Figura 93. Alguns valores devem ser inseridos, conforme abaixo, para melhor resolução do projeto (unidades em metros):

Axis

$x-y$ limits

x min: $-6.737371 \mathrm{e}-4$;

$x$ min: $6.737371 \mathrm{e}-4$;

y min: $-3.30525 \mathrm{e}-4$;

y $\min : 3.30025 \mathrm{e}-4$.

\section{Grid}

X spacing: 1e-5;

Y spacing: 2e-6.

Figura 93- Definição das grades (grid) e das dimensões do projeto de modulador baseado em guia de onda do tipo canal.

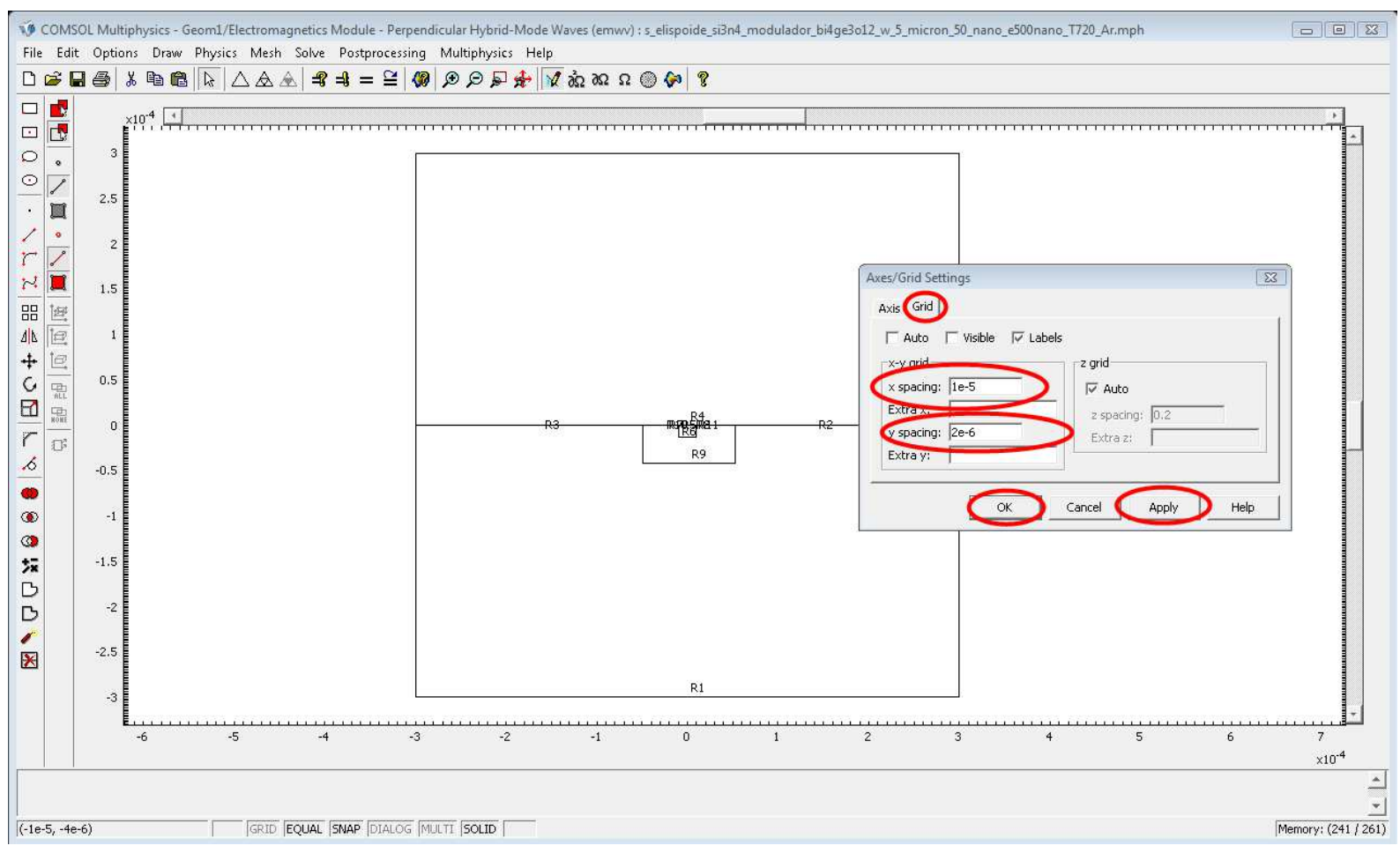

Fonte: Autora

Definida as dimensões, a estrutura do projeto pode ser construída. É possível desenhar o modulador eletro-óptico baseado em guia de onda do tipo canal utilizando as ferramentas de desenho do programa e, nesse trabalho, foram usados retângulos para limitar a área desejada, facilitando o processamento computacional e também obtendo resultados mais próximos à realidade. As dimensões dos retângulos estão descritas a seguir: 
R1 - size - width: 6.0e-4, heigh: 3.0e-4, position - base: corner, x:-3.0e-4, y:-3.005e-4, R2 - size - width: 2.975e-4, heigh: 5.0e-8, position - base: corner, x: 2.5e-6, y:-5.0e-7, R3 - size - width: 2.975e-4, heigh: 5.0e-8, position - base: corner, x: -2.5e-6, y:-5.0e-7, R4 - size - width: 6.0e-4, heigh: 3.0e-4, position - base: corner, x: -3.0e-4, y: -4,5e-7, R5 - size - width: 5.0e-6, heigh: 5.0e-8, position - base: corner, x: -2.5e-6, y: -5.0e-7, R6 - size - width: 2.0e-5, heigh: 1.32e-5, position - base: center, x: 0, y: -7.1e-6, R7 - size - width: 2.55e-5, heigh: 5.0e-8, position - base: corner, x: -2.8e-5, y: -5.0e-7, R8 - size - width: 5.0e-6, heigh: 5.0e-8, position - base: corner, x: -2.5e-6, y: -5.0e-7, R9 - size - width: 1.02e-4, heigh: 4.2e-5, position - base: center, x: 2.01e-6, y:-2.15e-5, R10 - size - width: 3.0e-5, heigh: 5.0e-7, position - base: corner, x: -3.25e-7, y:-4.5e-7, R11 - size - width: 3.0e-5, heigh: 5.0e-7, position - base: corner, x: 3.25e-7, y: -4.5e-7.

Nas definições acima R1 à R11 são representações dos retângulos de um modulador baseado em guia de onda do tipo canal, x e y são as coordenadas cartesianas e as dimensões desses retângulos estão em metros. A Figura 94, a seguir, ilustra a representação de todos os retângulos descritos acima, e os dois retângulos R1 e R4 foram desenhados com dimensões bem grandes, para forçar a definição da área total da figura no tamanho adequadamente grande para não interferir no resultado da propagação dos modos. Isto é feito porque nessa versão do COMSOL não há um comando para especificar a área total da simulação, ela se adapta aos elementos gráficos colocados. 
Figura 94- Geometria de um projeto de modulador baseado em guia de onda do tipo canal.

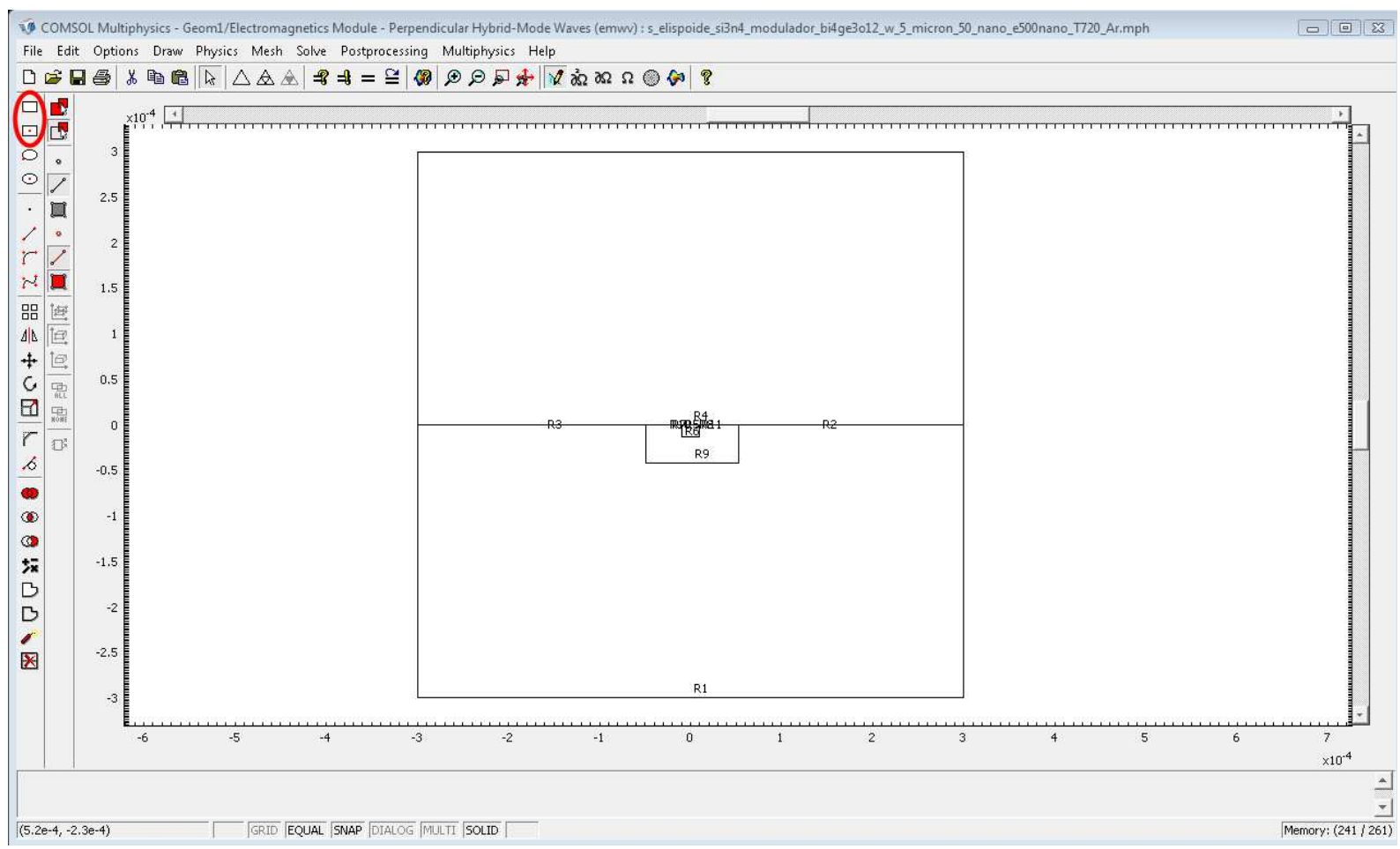

Fonte: Autora

O quarto passo é definir as constantes físicas dos materiais. A partir do menu Options $\rightarrow$ Constants são inseridas esses valores, quais sejam, epsr (constante dielétrica relativa), Tensão_esq (volt), Tensão_dir (volt), alfa e beta (ângulos da equação do índice de refração), alpha (coeficiente de expansão térmica), $\mathrm{E}_{\mathrm{s}}$ (módulo de Young), nu (razão de Poisson), T1 (temperatura ambiente de trabalho), T0 (temperatura de deposição do filme), Lamb (comprimento de onda), rho (densidade), N (índice de refração). A Figura 95 ilustra como é definida cada constante. 
Figura 95- Definição das constantes do substrato de BGO e do filme de $\mathrm{Si}_{3} \mathbf{N}_{4}$.

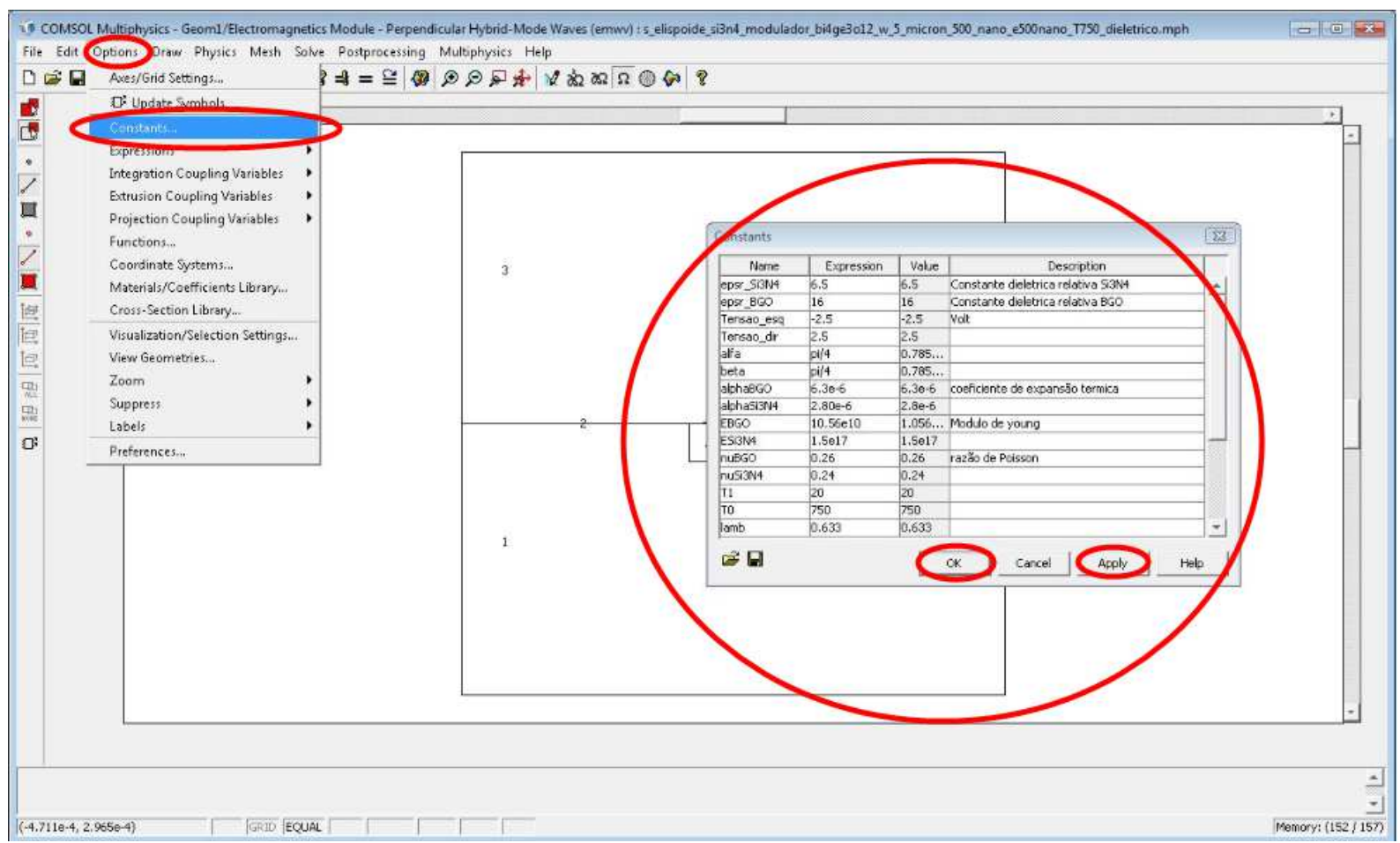

Fonte: Autora

No quinto passo são inseridas as equações do efeito elasto-óptico, do efeito eletro-óptico e as fórmulas de dispersão do índice de refração do substrato e do filme, apresentadas nas seções anteriores deste capítulo. A partir do menu Options $\rightarrow$ Expressions $\rightarrow$ Subdomain Expressions, por exemplo, são selecionados os retângulos que forma um grupo preenchido pelo material do BGO e são iniciadas as implementações das equações 3,2 , 3,4 3.9, 3.10, 3.11, 3.12, 3.25, 3.26 e 3.27, apresentadas nas seções 3.4.1, 3.4.2.2.2 e 3.4.3 deste trabalho. Nesse caso, em Name é colocado o valor $\mathrm{Nx} 0$ e em Expression nBGO (Fórmula de dispersão). A Figura 96 ilustra as equações inseridas no programa. 
Figura 96- Inserção no COMSOL das equações dos efeitos elasto-óptico e eletro-óptico e da fórmula de dispersão do índice de refração do substrato de $\mathrm{BGO}$, do filme de $\mathrm{Si}_{3} \mathrm{~N}_{4}$.

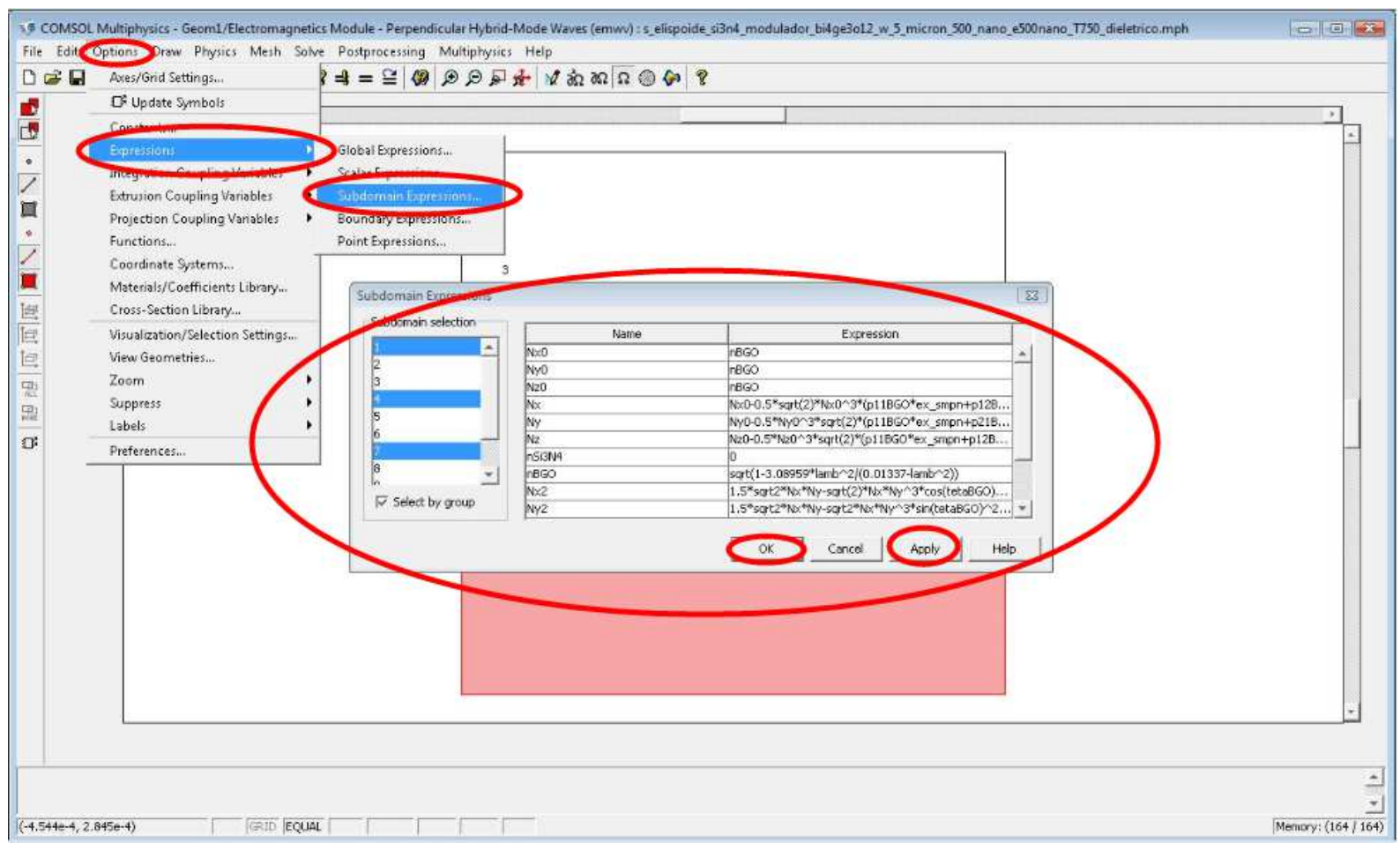

\section{Fonte: Autora}

O sexto passo consiste nas definições da física das condições de contorno do modulador eletro-óptico baseado em guia de onda do tipo canal, que estão divididas em: subdomínio, fronteira e pontos; cada uma dessas divisões está subdividida em três partes: primeiro são definidas as condições para a deformação plana, em seguida são definidas condições para ondas de modo híbrido e por último são definidas as condições eletrostáticas.

A partir do menu Physics $\rightarrow$ Subdomain Settings são definidas as condições para os três modos citados acima. As Figuras 97 (a e b) e as Figuras 98 (a e b) ilustram os passos das definições da física das condições de contorno do subdomínio para a deformação plana. 
Figura 97- Definições das condições de contorno do subdomínio para a deformação plana. (a) Inicialização da definição, (b) Definição das condições para o substrato,

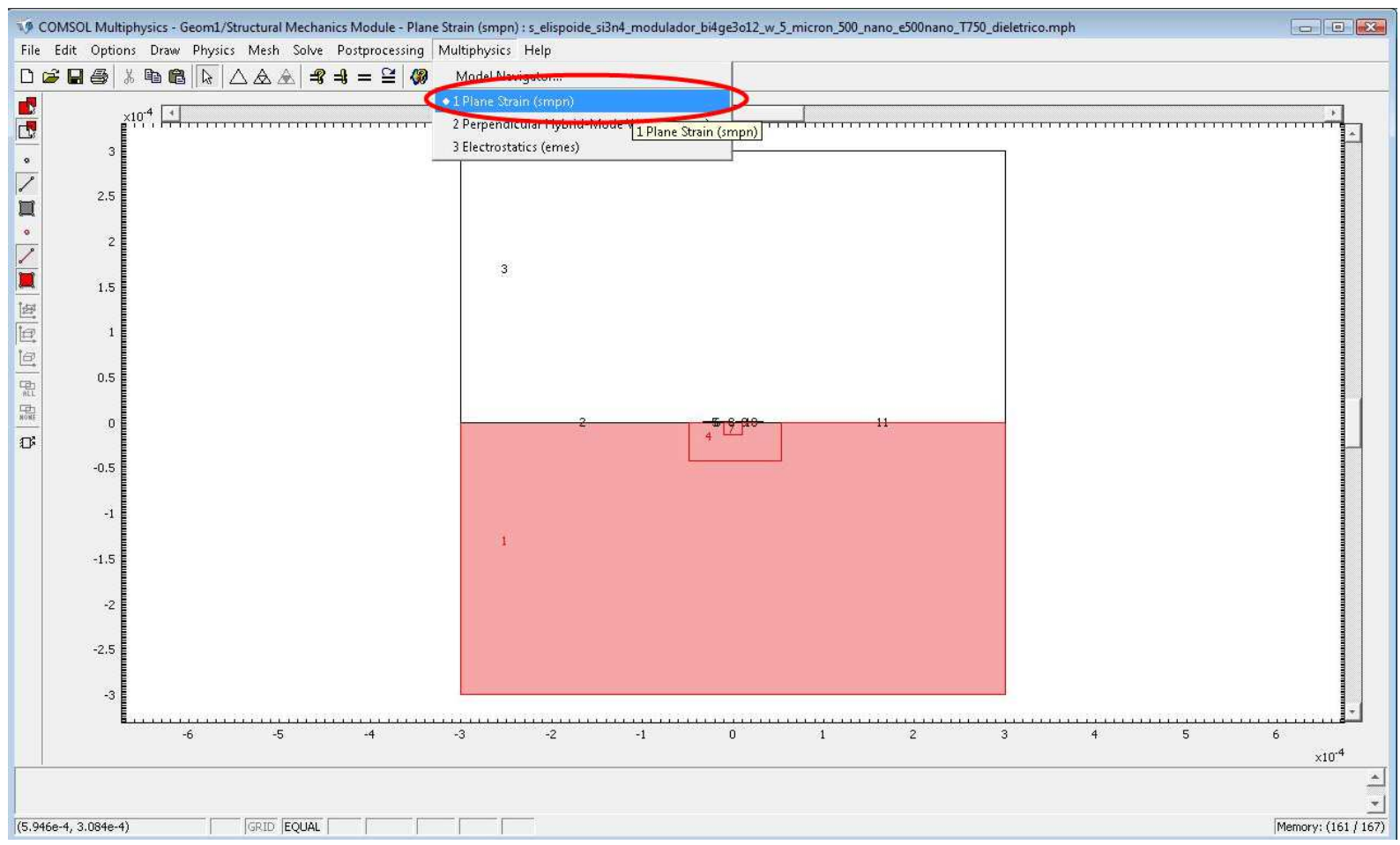

(a)

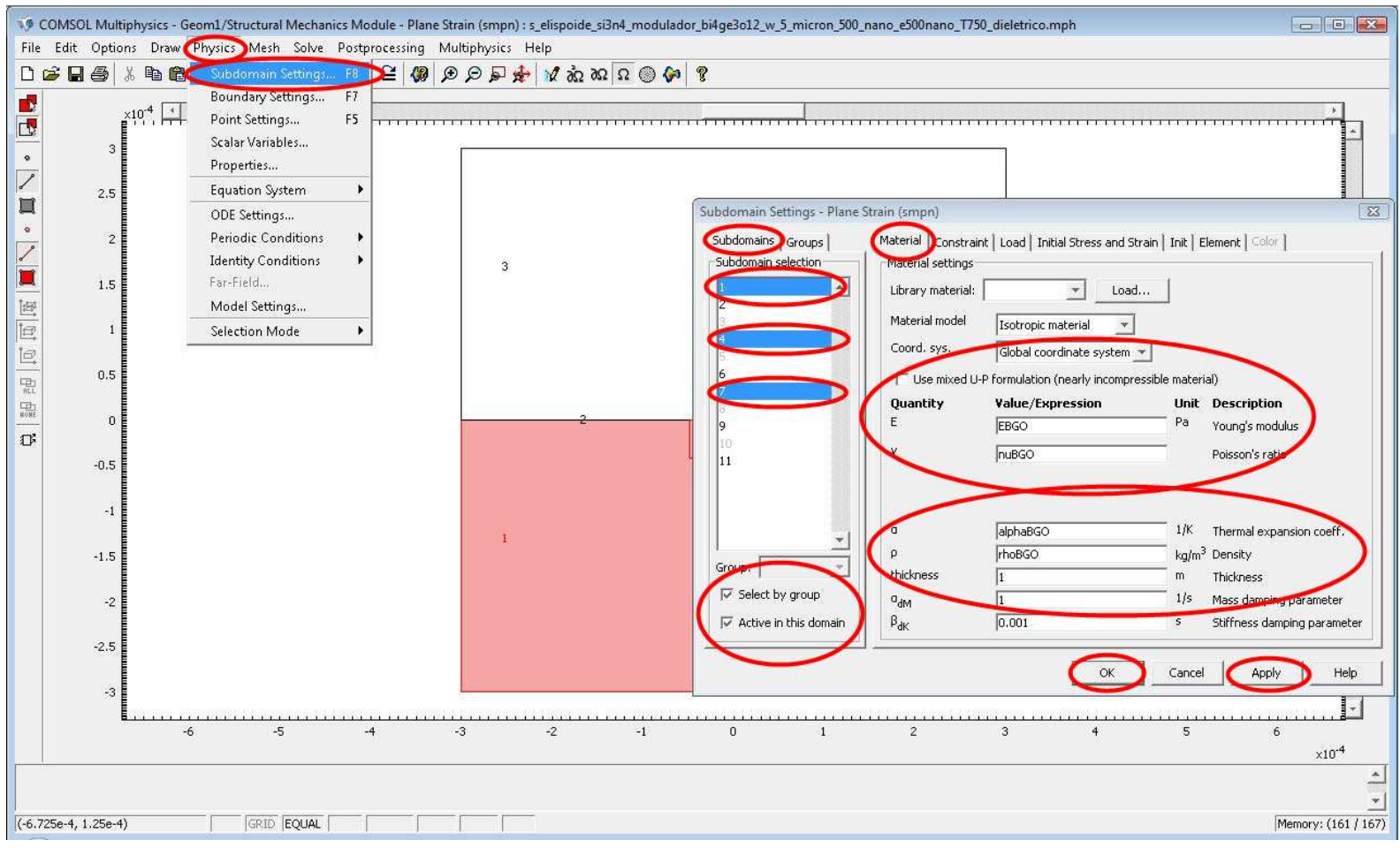

(b)

Fonte: Autora 
Figura 98- (a) Definição das condições para o filme e (b) Definição das condições para o ar.

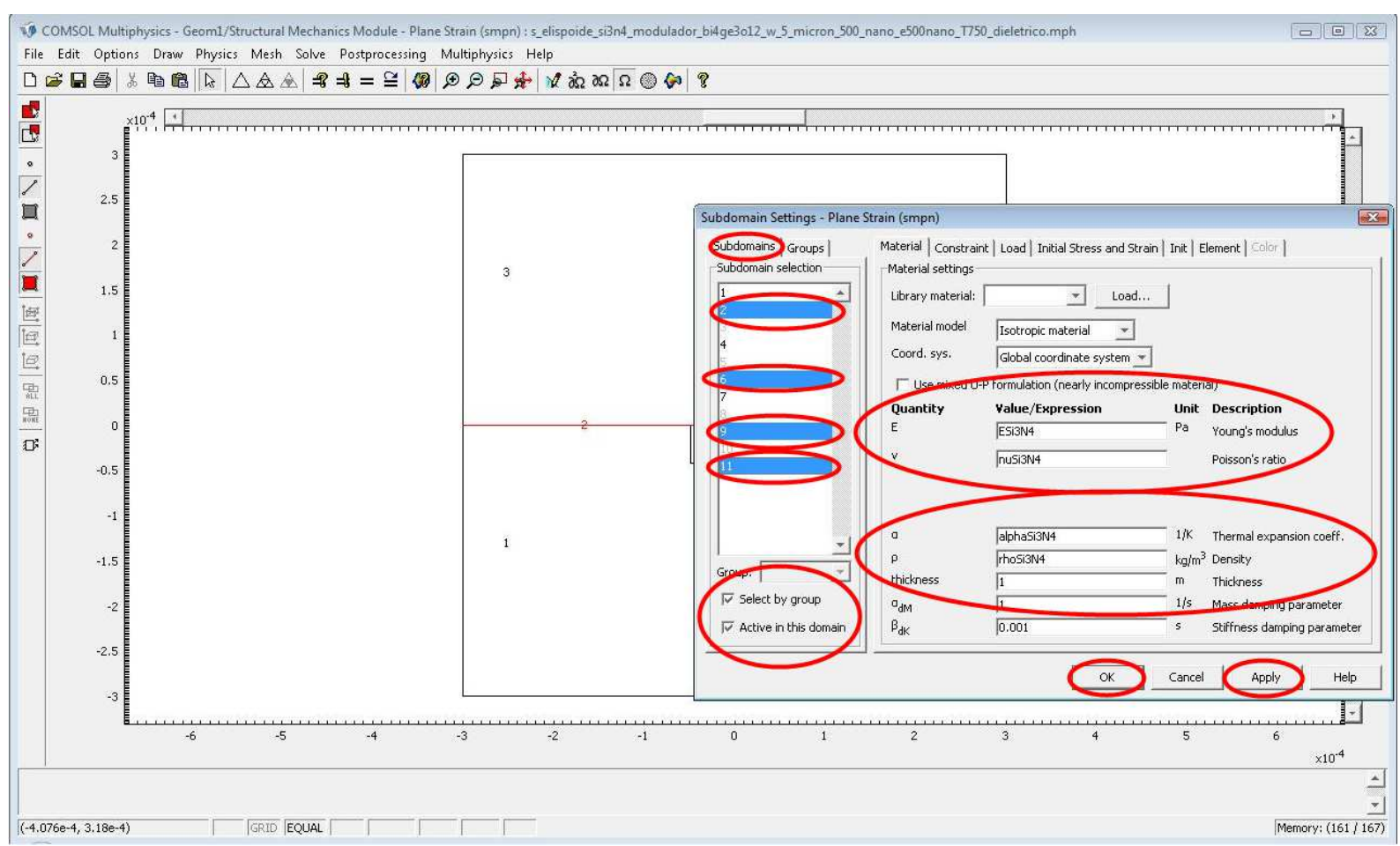

(a)

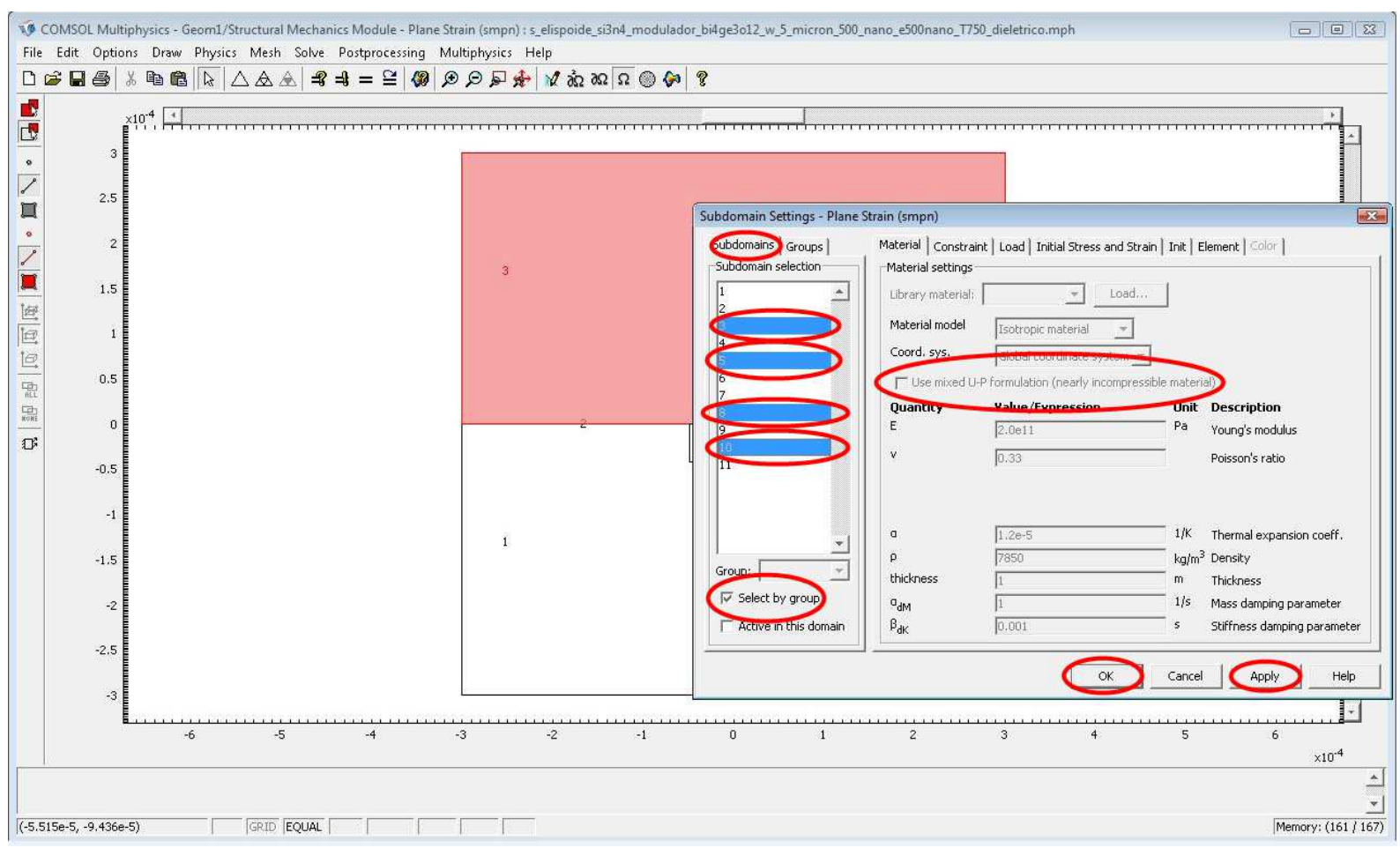

(b)

Fonte: Autora 
As Figuras 99 (a e b) e as Figuras 100 (a e b) ilustram os passos das definições da física das condições de contorno do subdomínio para ondas de modo híbrido.

Figura 99- Definições das condições de contorno do subdomínio para ondas de modo híbrido. (a) Inicialização da definição, (b) Definição das condições para o substrato

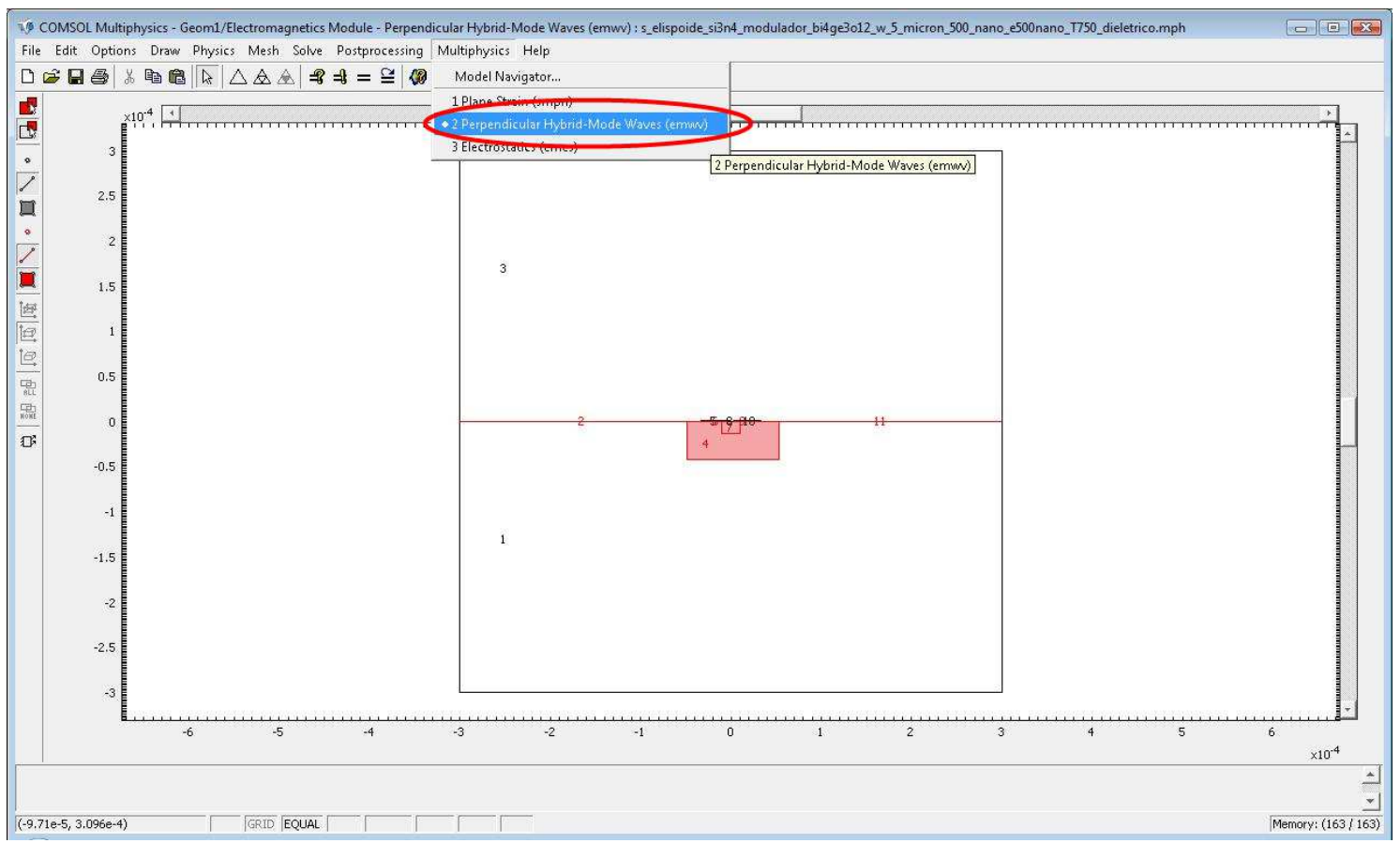

(a)

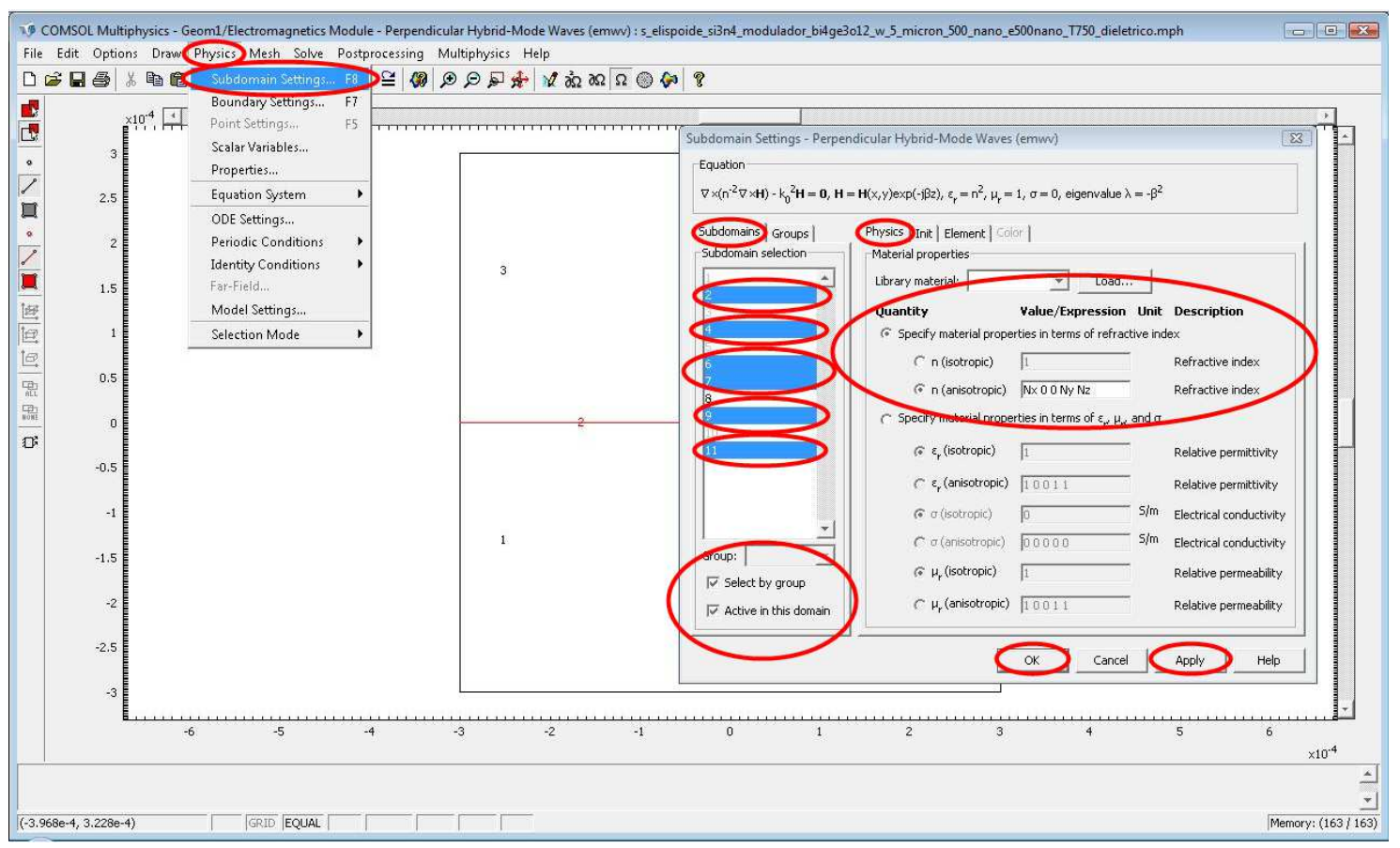

(b)

Fonte: Autora 
Figura 100- (a) Definição das condições para o filme e (b) Definição das condições para o ar.

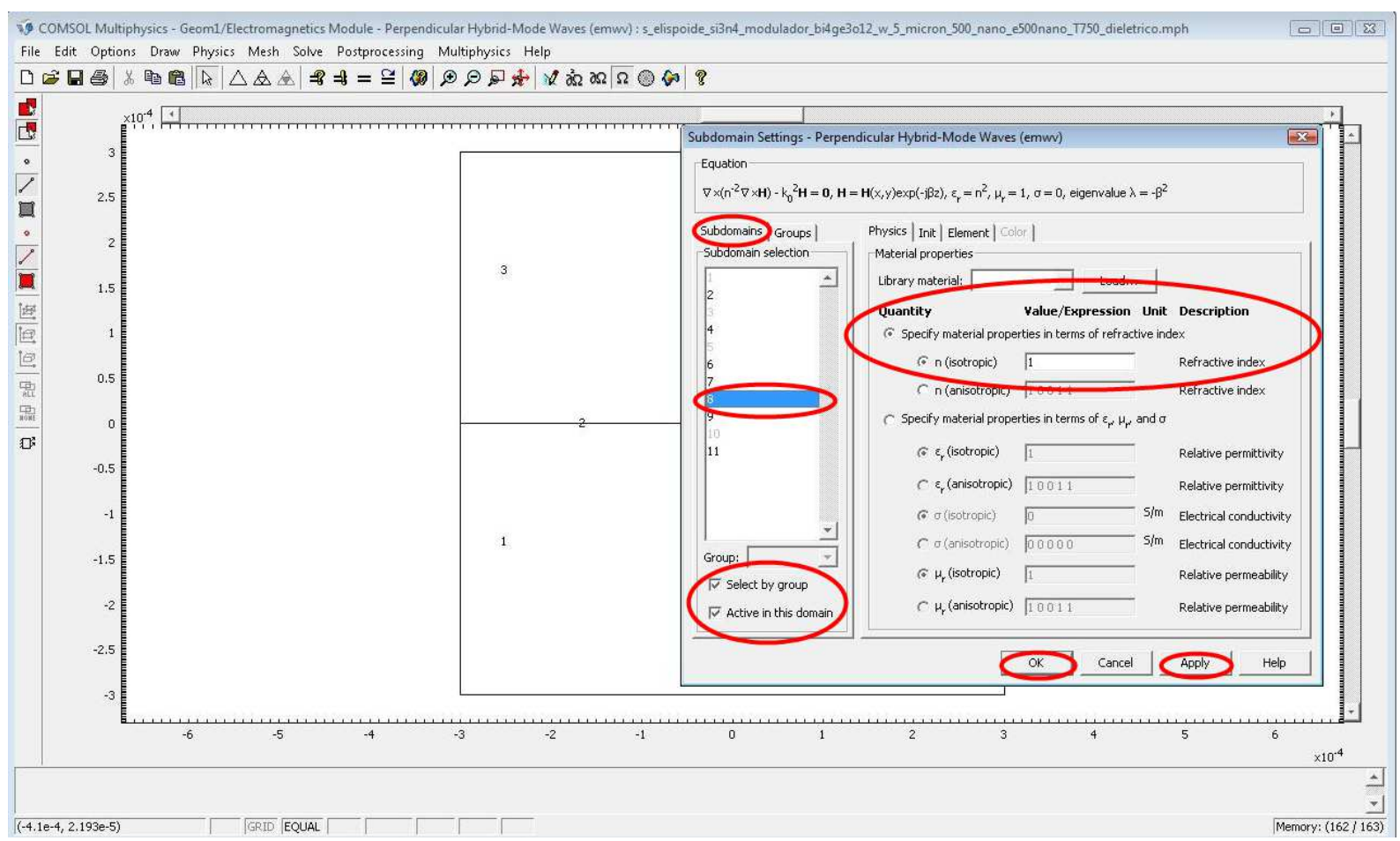

(a)

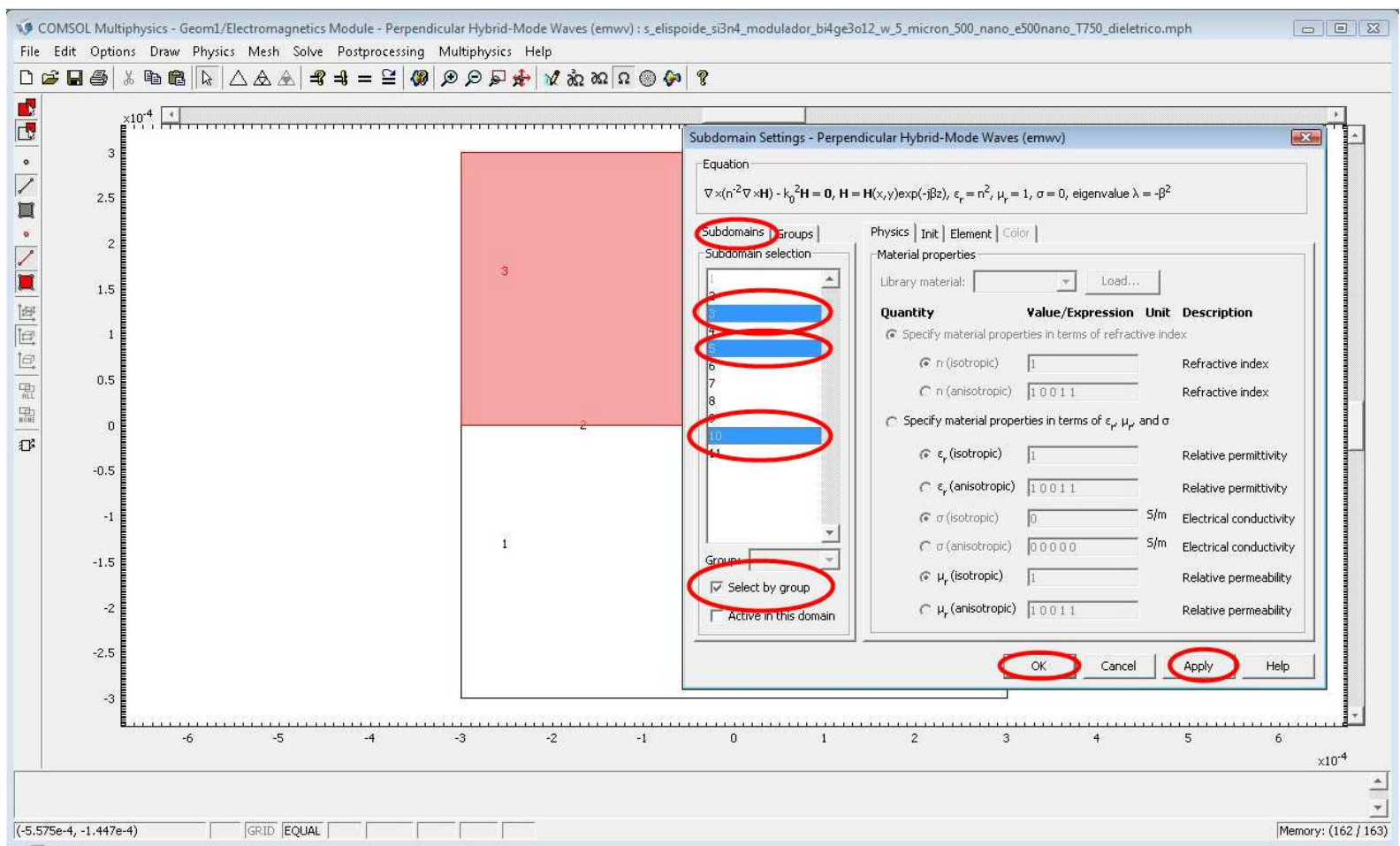

(b) 
A Figura 101 (a e b) e as Figuras 102 (a e b) ilustram os passos das definições da física das condições de contorno do subdomínio para eletrostática.

Figura 101- Definições das condições de contorno do subdomínio para eletrostática. (a) Inicialização da definição, (b) Definição das condições para o substrato.

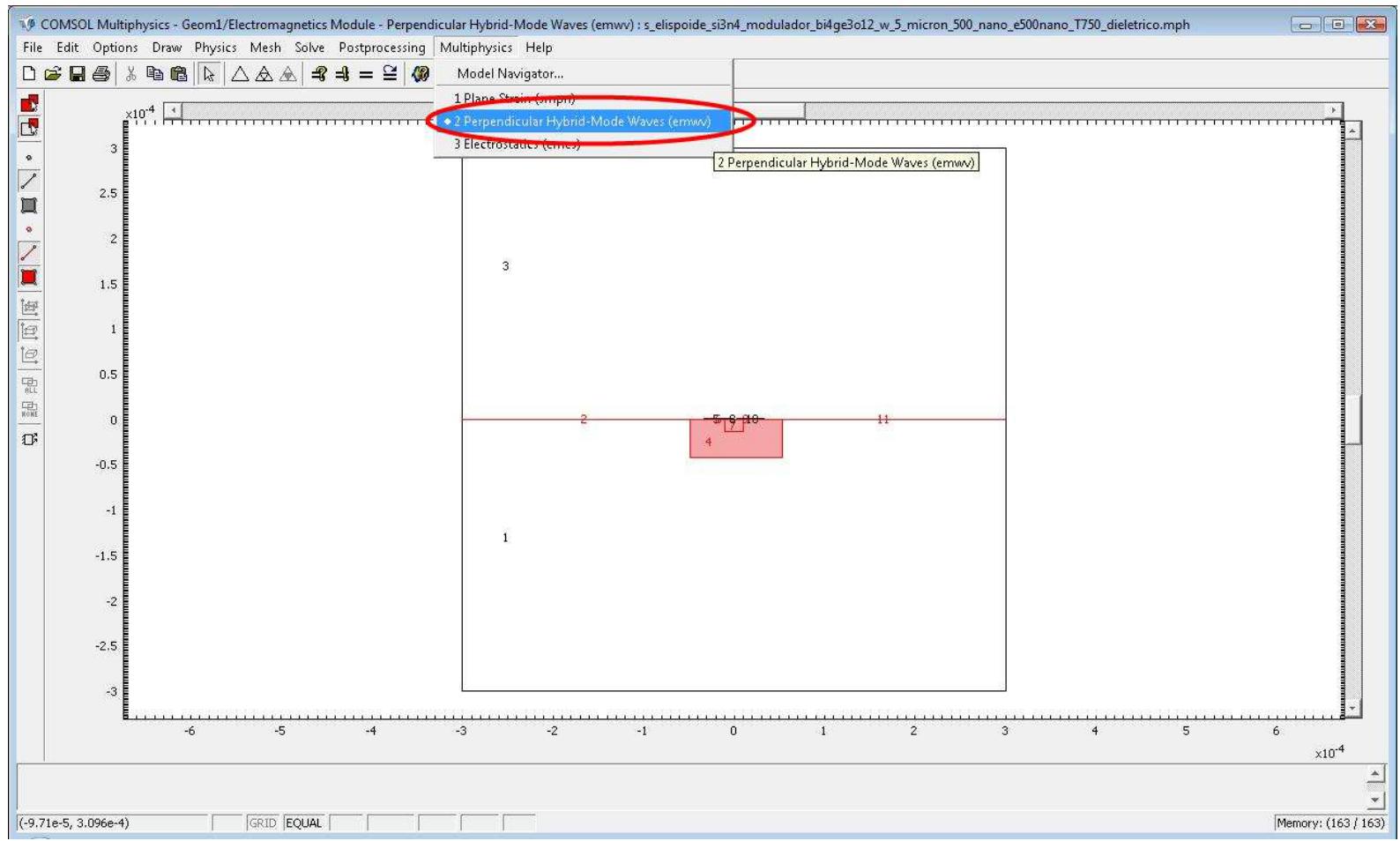

(a)

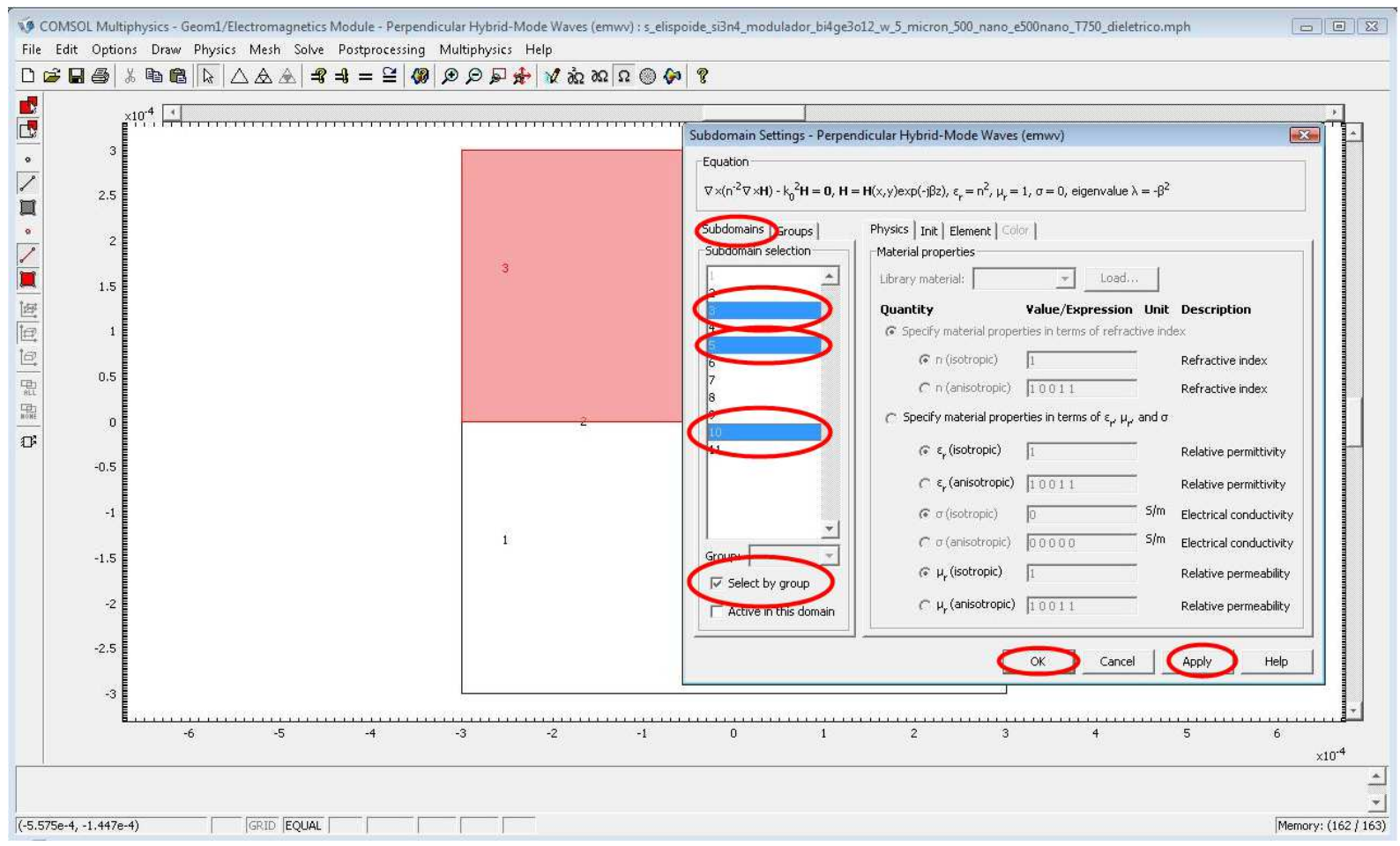

(b)

Fonte: Autora 
Figura 102- (a) Definição das condições para o filme e (b) Definição das condições para o ar

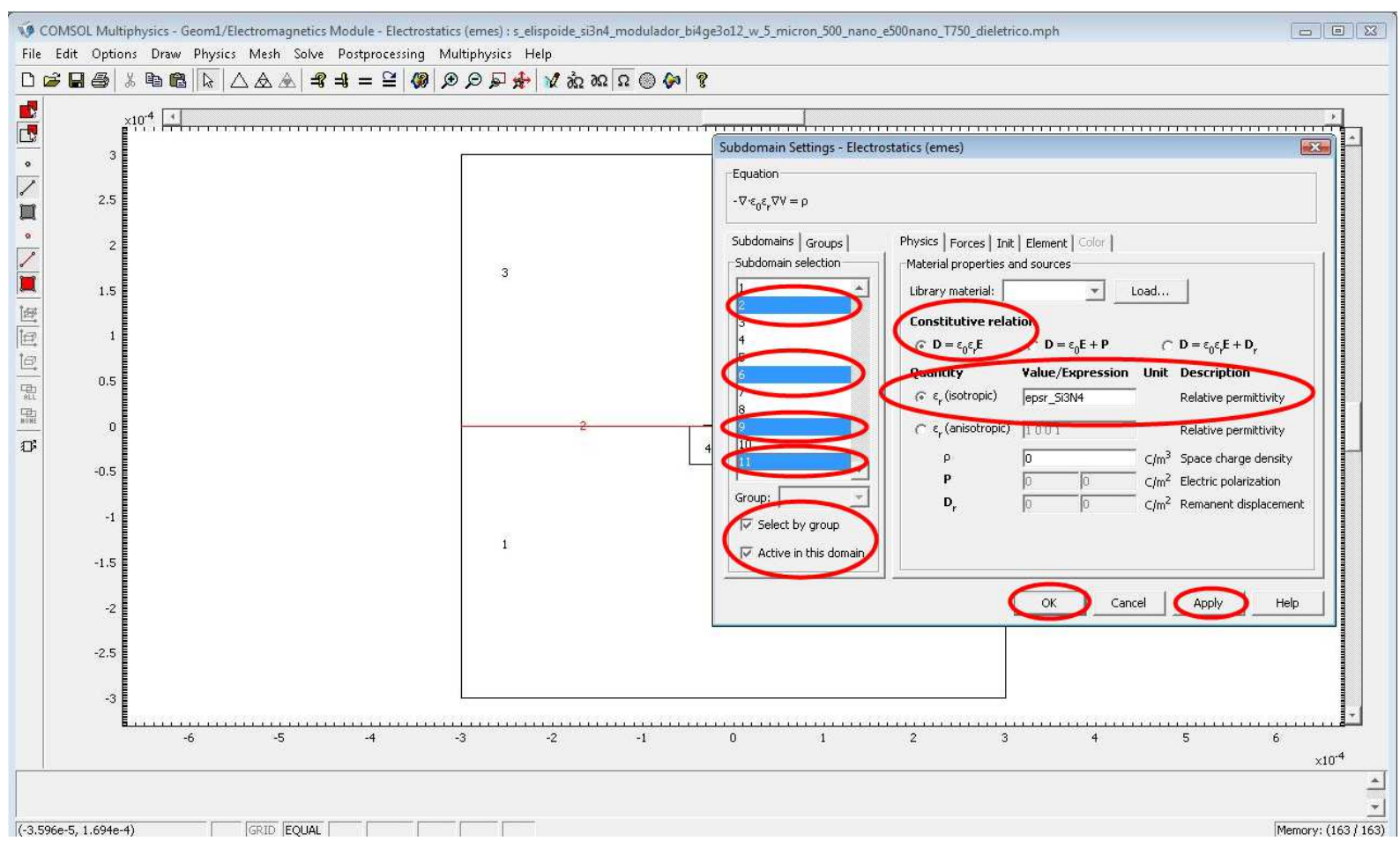

(a)

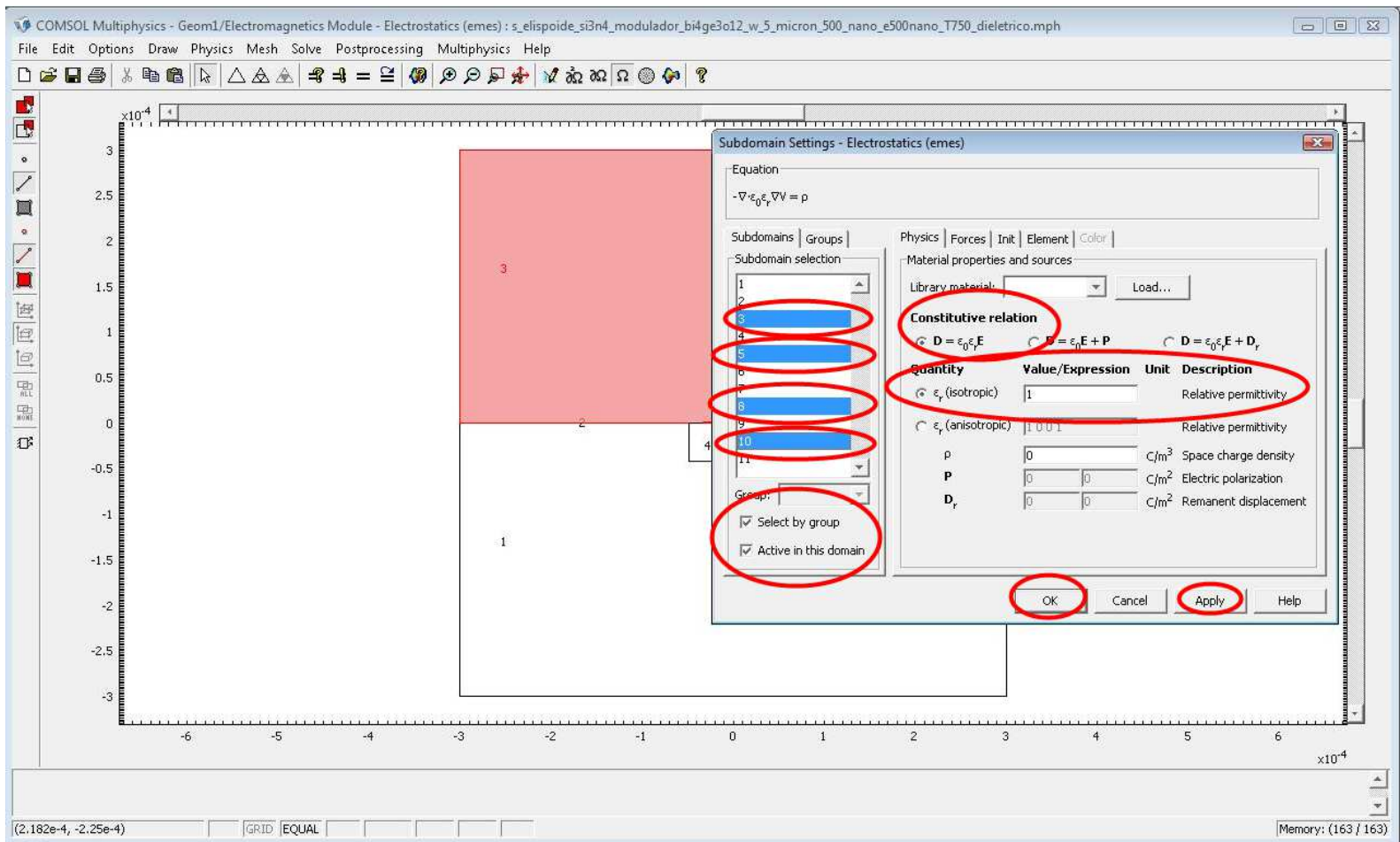

(b)

Fonte: Autora 
A partir do menu Physics $\rightarrow$ Boundary Settings são definidas as condições de fronteira para os três modos citados acima. As Figuras 103 (a e b) e as Figuras 104 ilustram os passos das definições da física das condições de contorno da fronteira para deformação plana.

Figura 103- Definiçõos das condições de contorno da fronteira para deformação plana. (a) Inicialização da definição, (b) Definição das condições para o substrato,

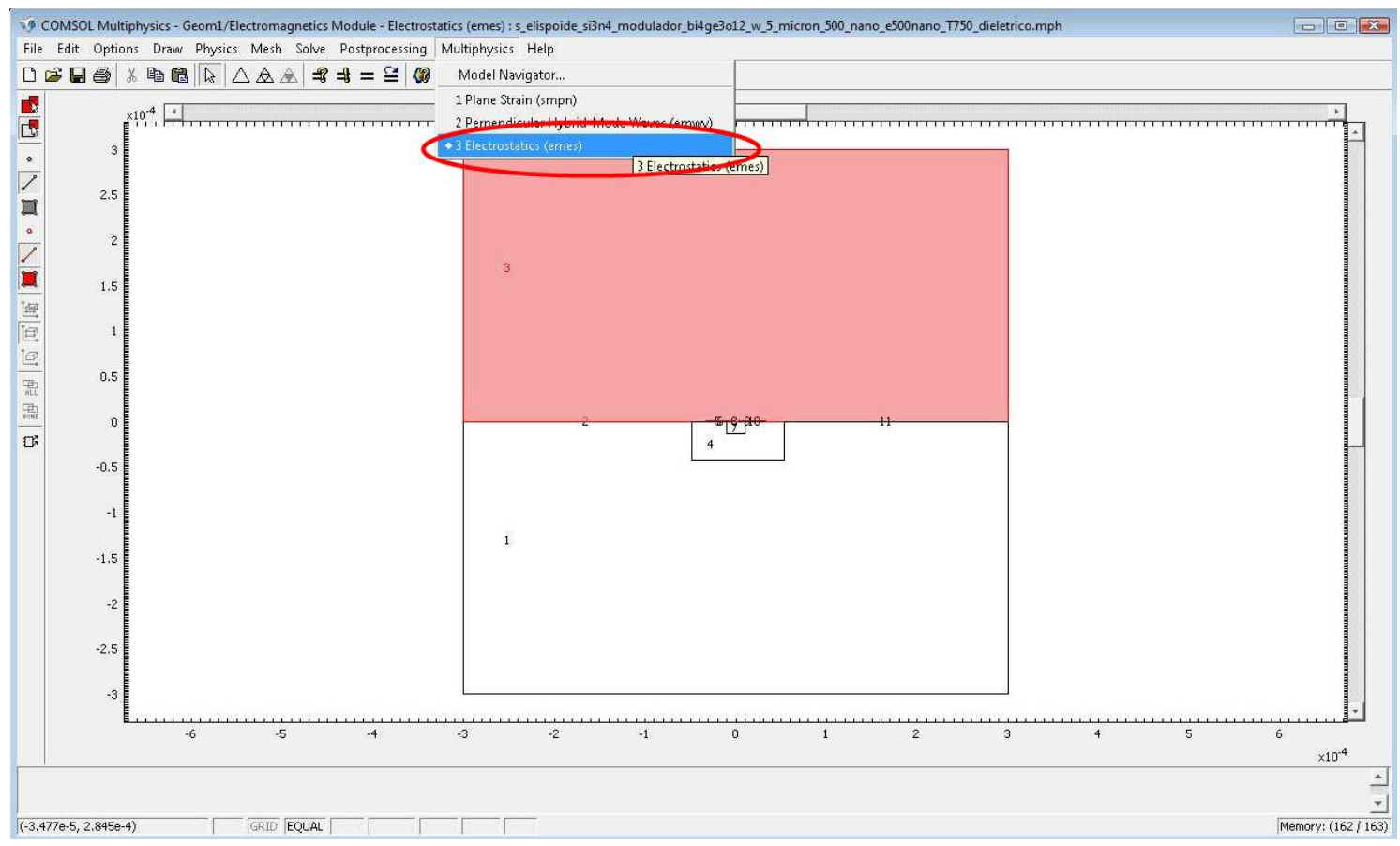

(a)

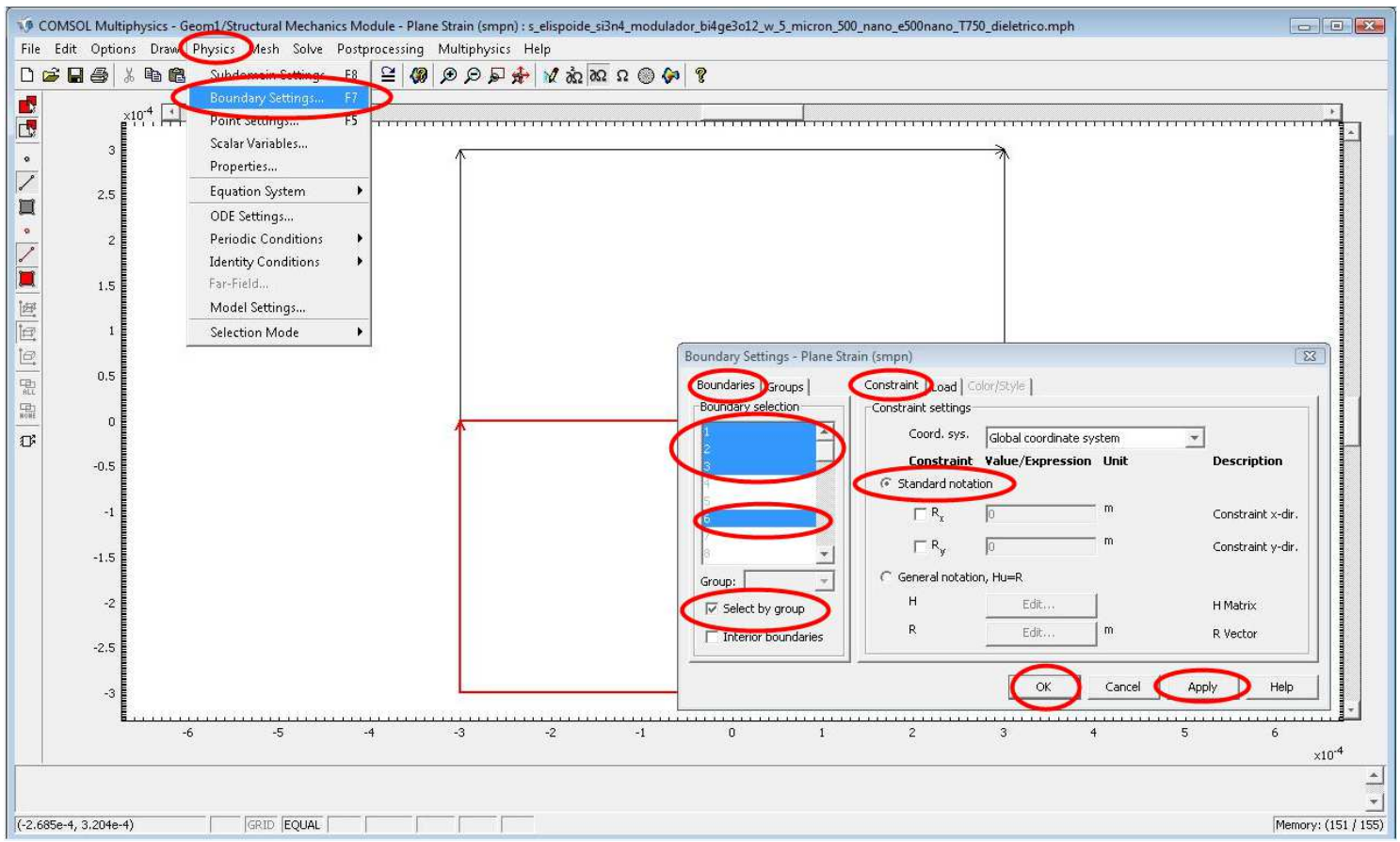

(b)

Fonte: Autora 
Figura 104- Definição das condições para o filme e o ar.

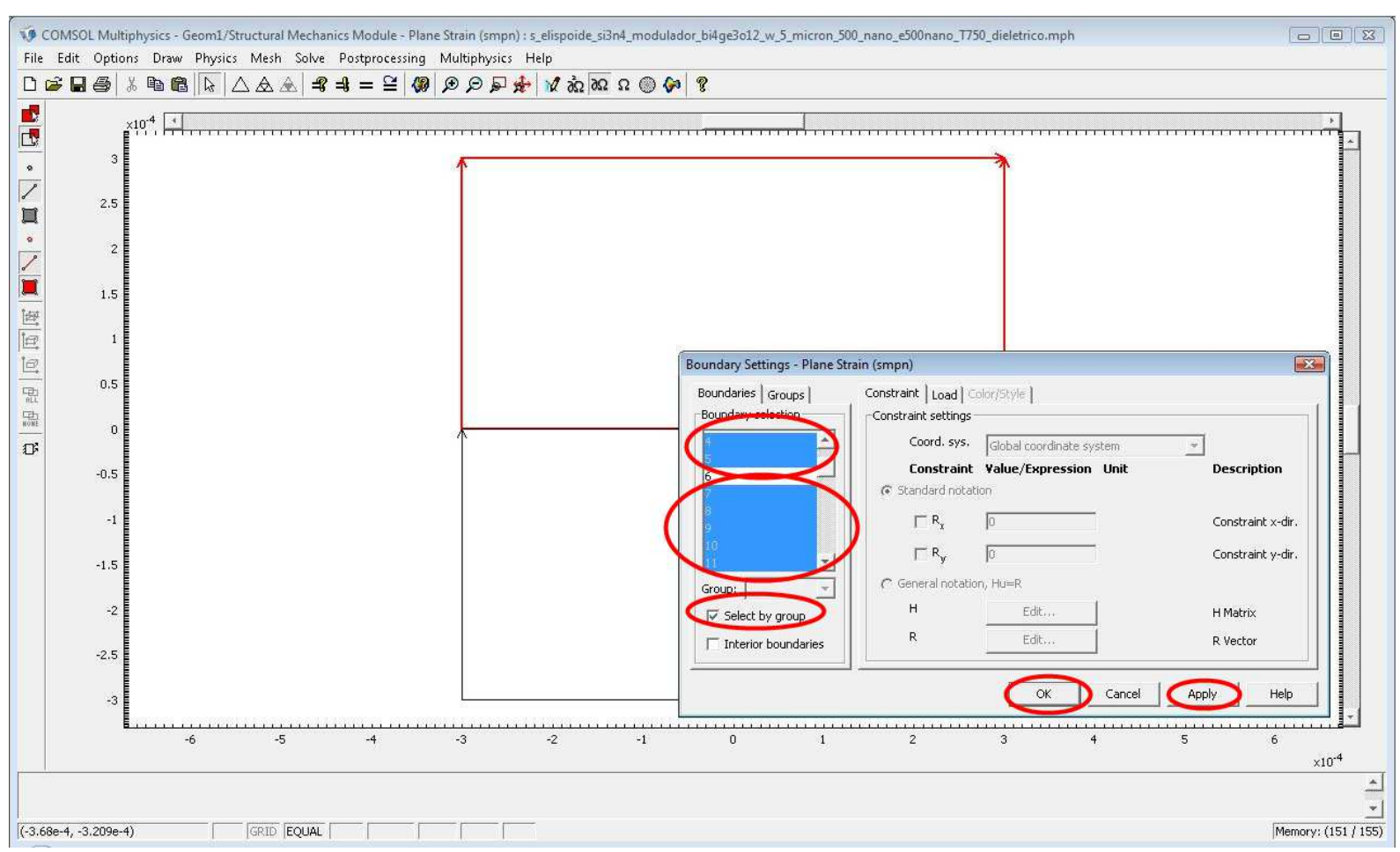

\section{Fonte: Autora}

As Figuras 105 (a e b) e a Figura 106 ilustram os passos das definições da física das condições de contorno da fronteira para ondas de modo híbrido.

A aplicação da física das condições de contorno da fronteira para eletrostática é mais detalhada, pois nela são definidas as condições que envolvem o problema estudado, neste caso, cada seta representa um tipo de condição a ser definida. A Figura 107, as Figuras 108 (a e b) e as Figuras 109 (a e b) ilustram os passos das definições das condições desse contorno. 
Figura 105- Definições das condições de contorno da fronteira para ondas de modo híbrido. (a) Inicialização da definição, (b) Definição das condições no substrato e no filme como condutor magnético perfeito.

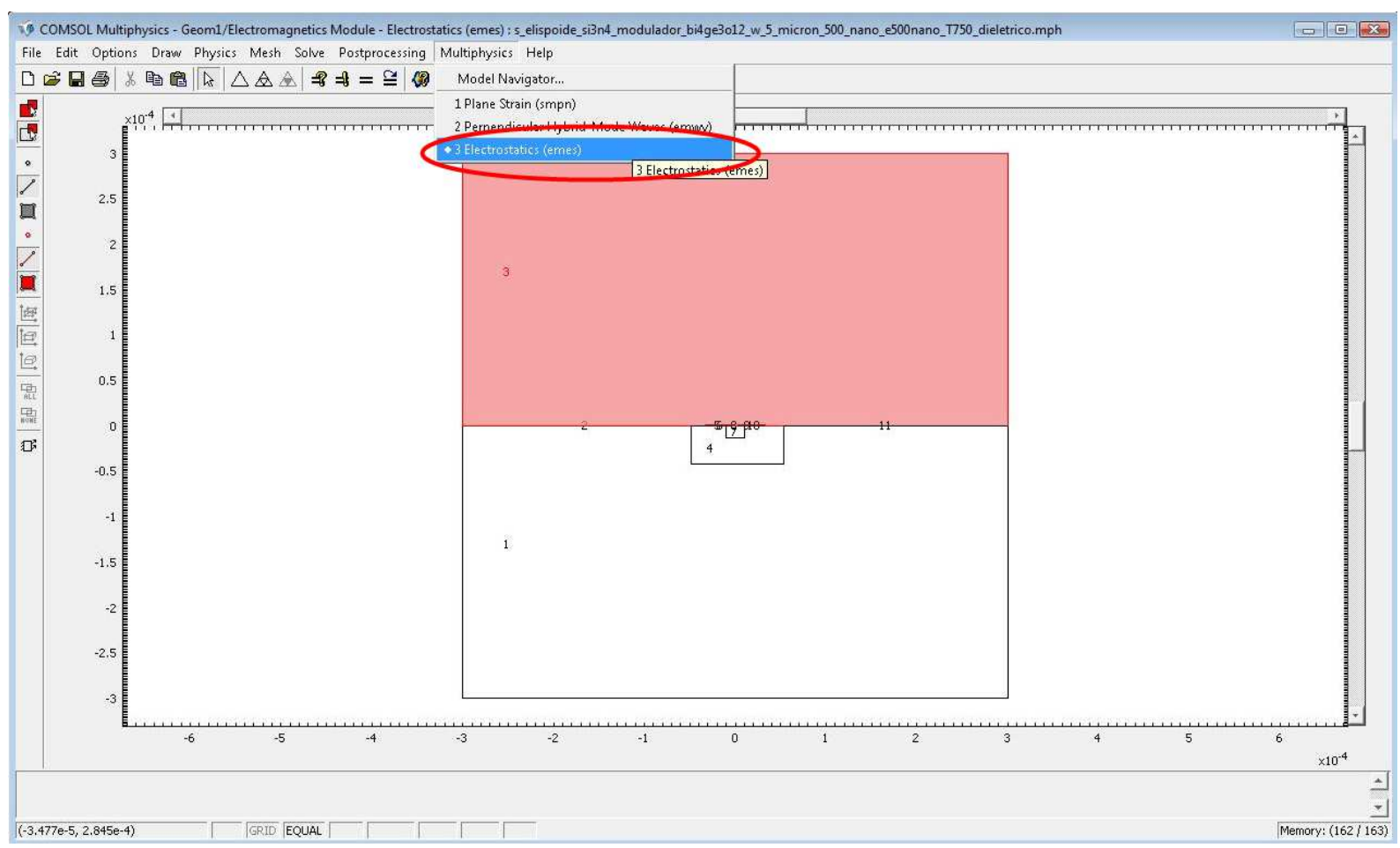

(a)

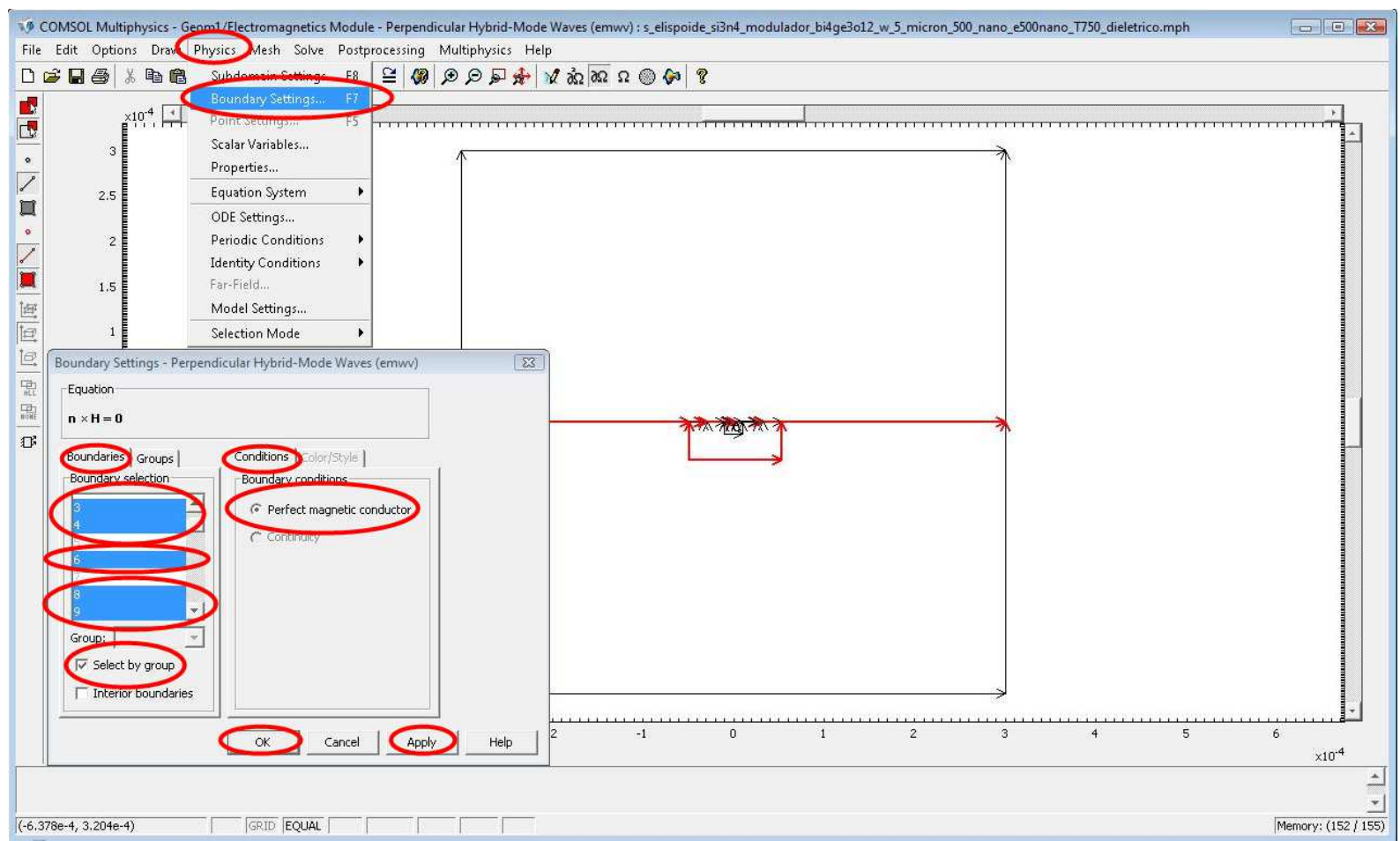

(b) 
Figura 106- Definição das condições como continuidade para os eletrodos e as fronteiras externas do problema.

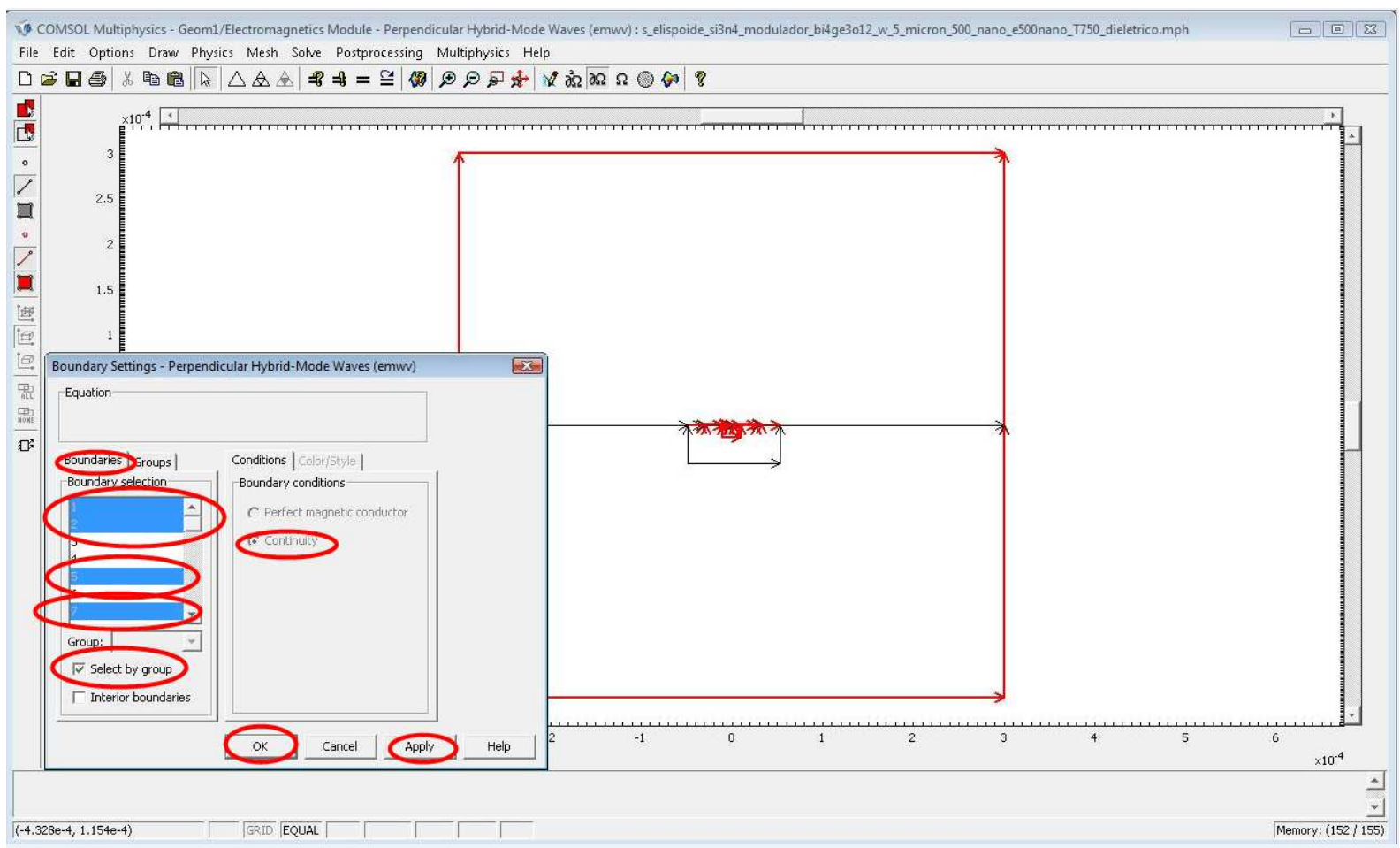

Fonte: Autora

Figura 107- Definições das condições de contorno da fronteira para eletrostática. Inicialização da definição

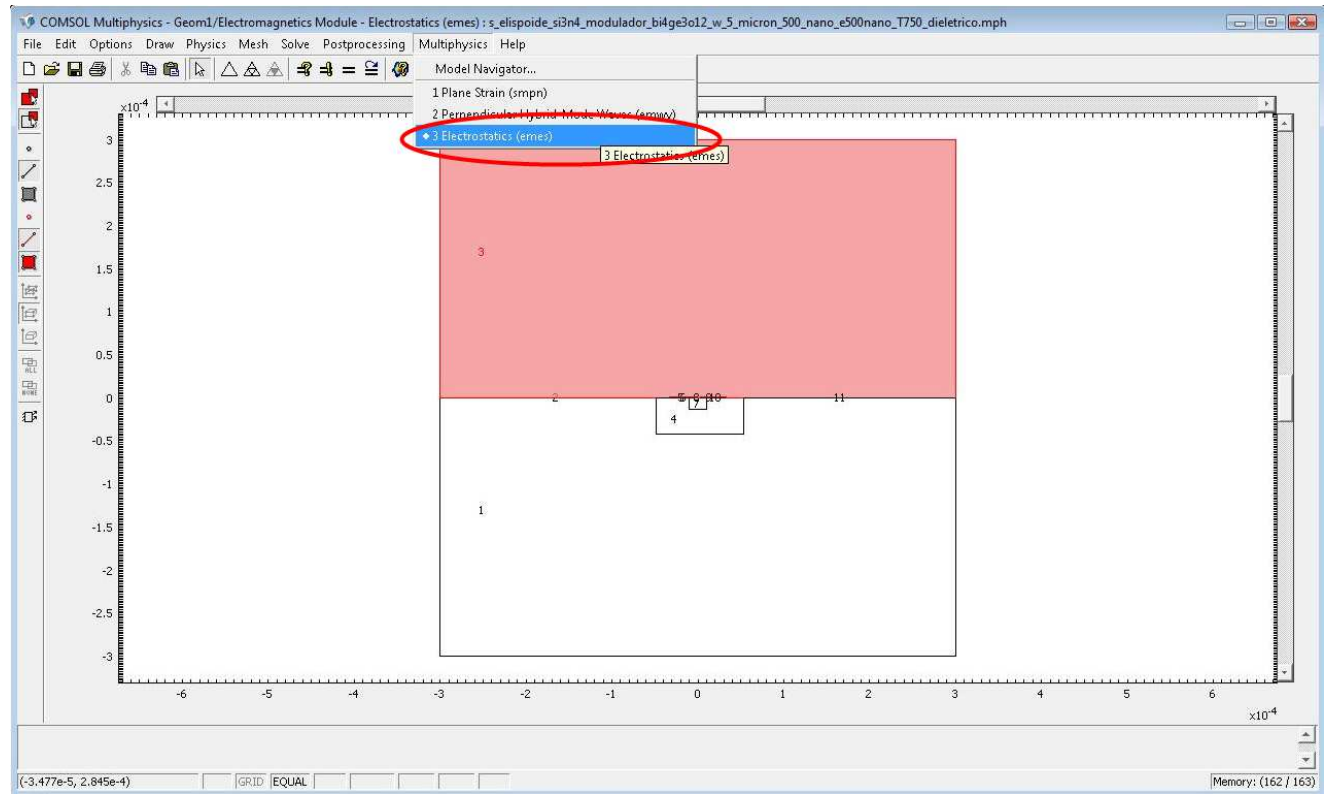

Fonte: Autora 
Figura 108 (a) Definição das condições como continuidade para o filme, (b) Definição das condições como potencial flutuante para as fronteiras externas do problema.

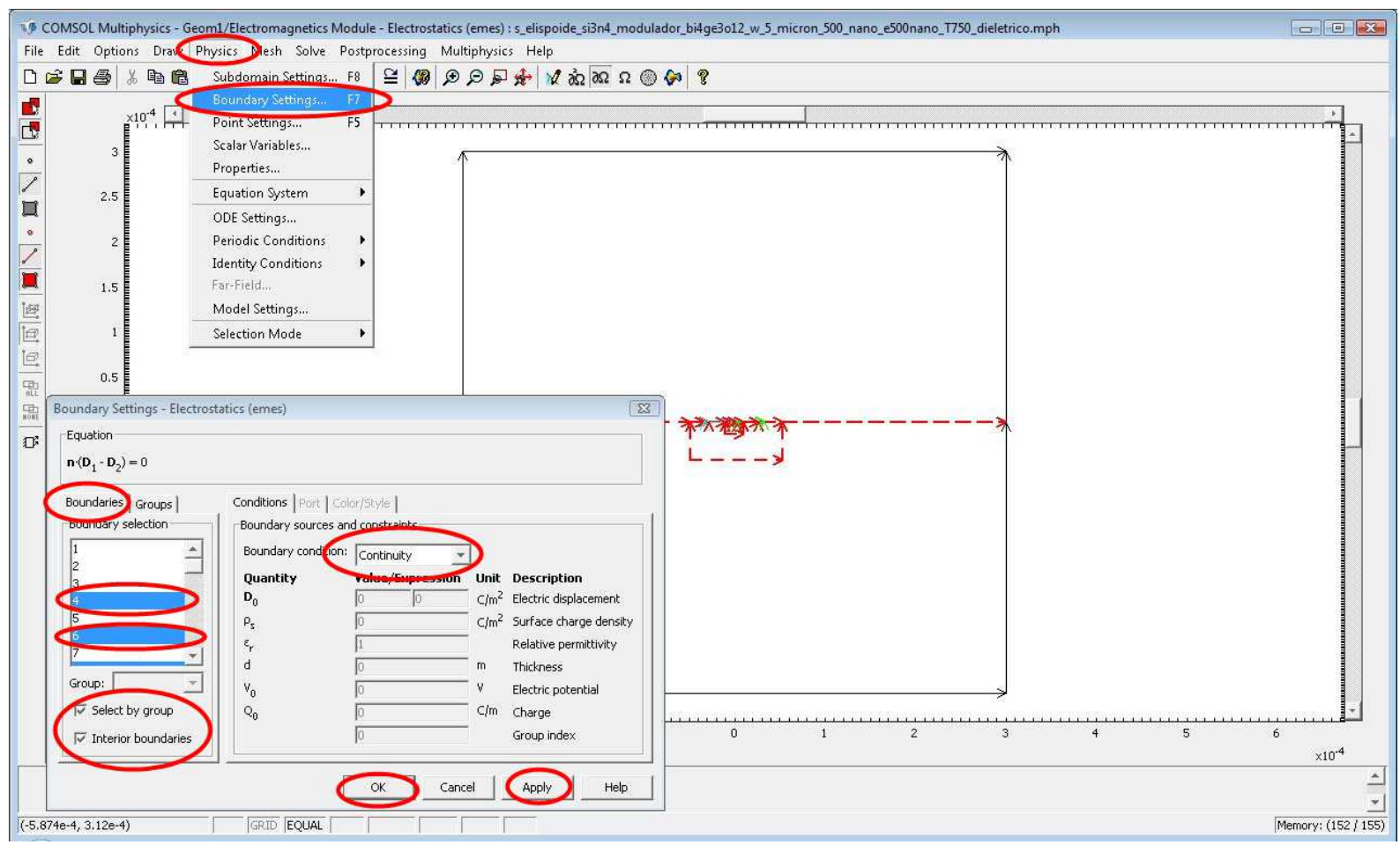

(a)

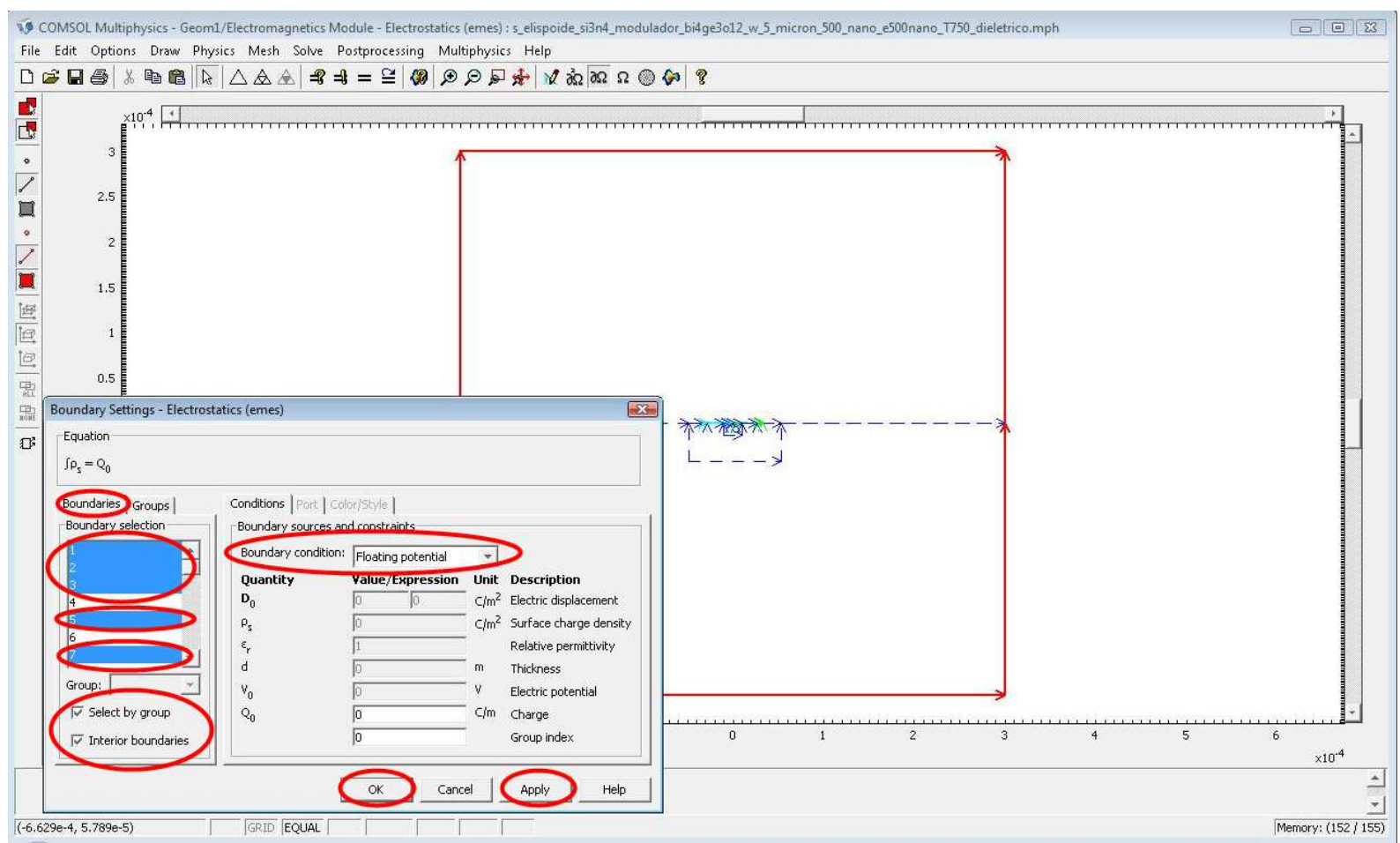

(b)

Fonte: Autora 
Figura 109- (a) Definição das condições como potencial elétrico, nesse caso, tensão do eletrodo esquerdo. (b) Definição das condições como potencial elétrico, nesse caso, tensão do eletrodo direito.

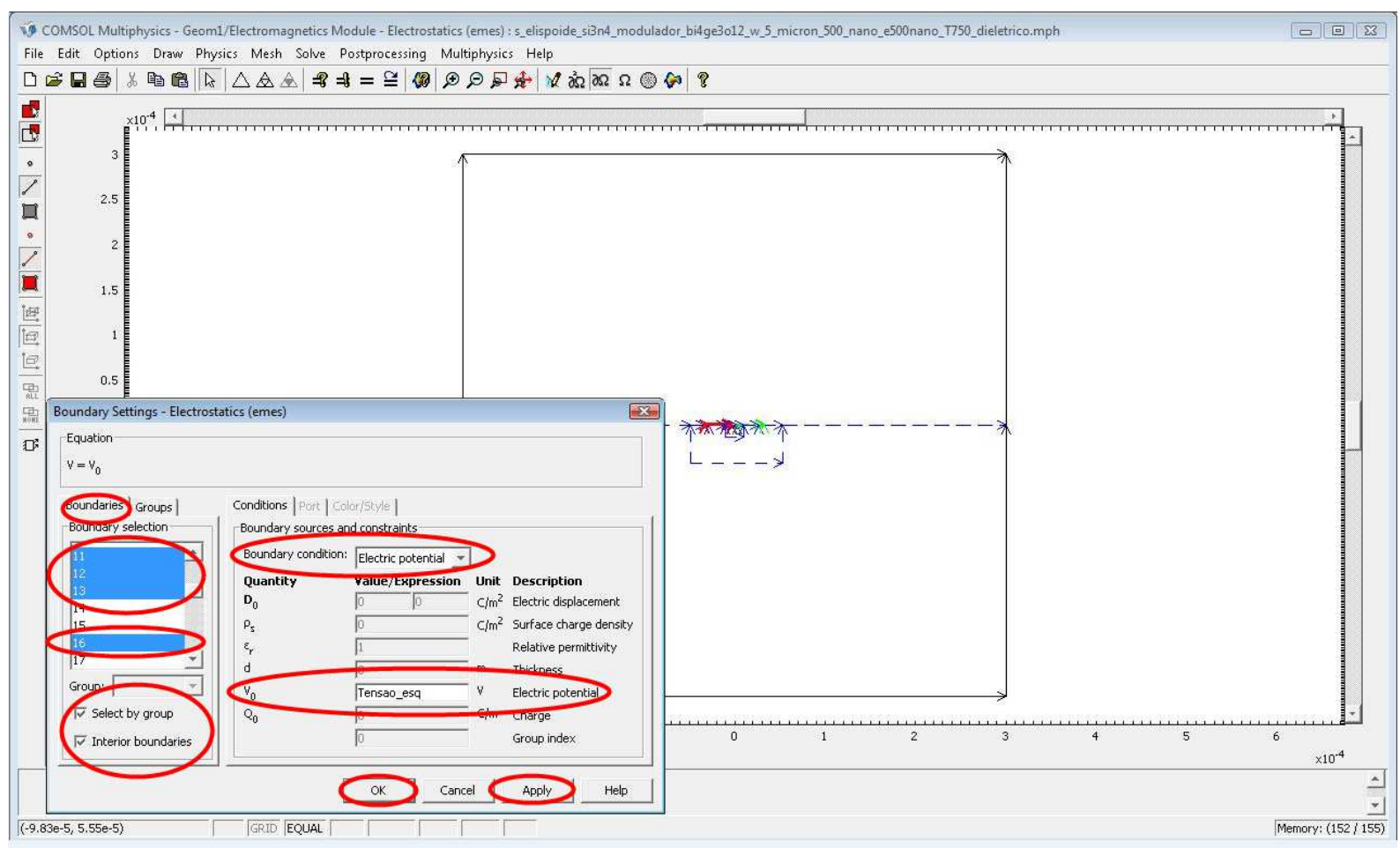

(a)

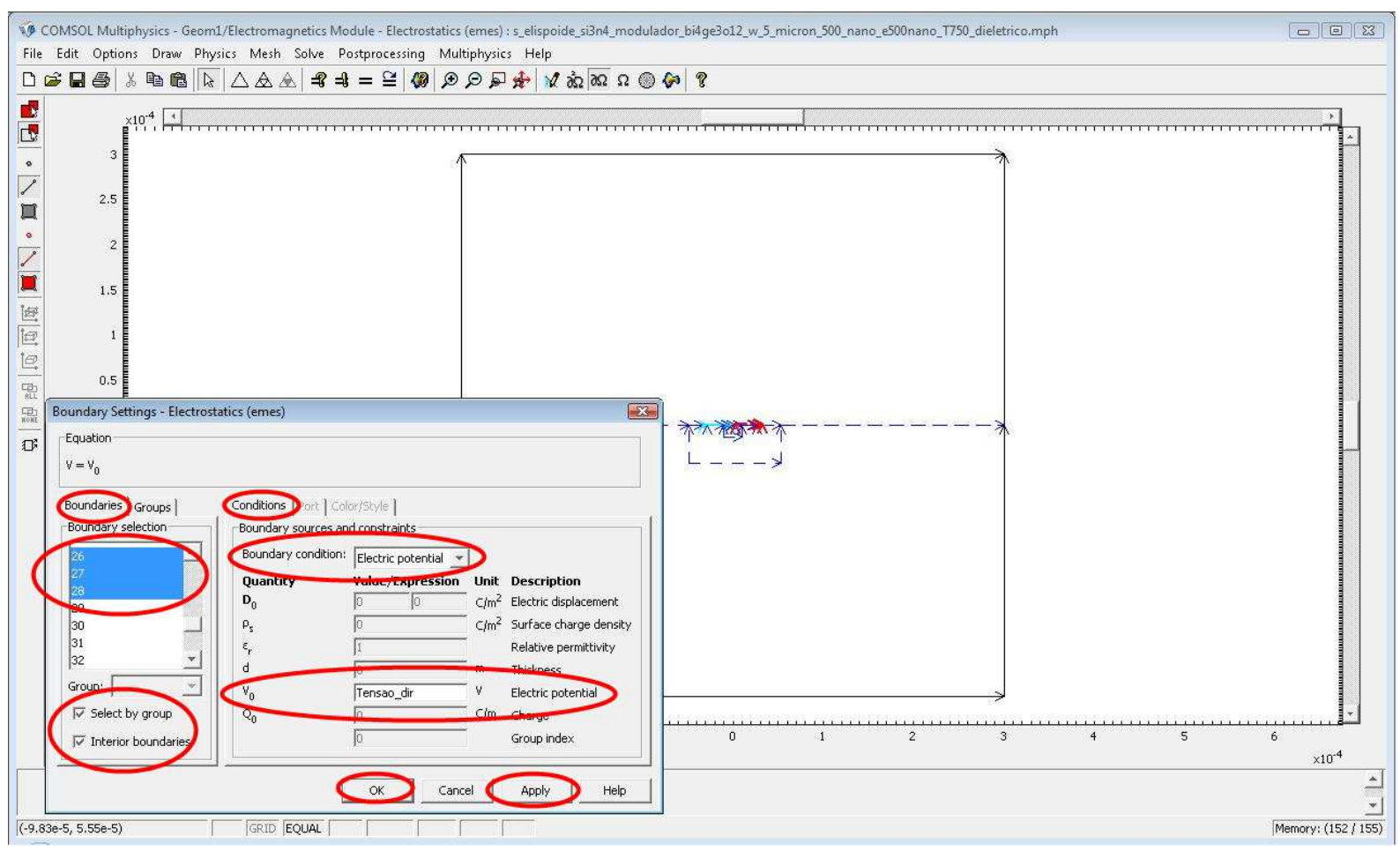

(b)

Fonte: Autora 
A partir do menu Physics $\rightarrow$ Point Settings é inserido em lamb0_emwv, o valor da unidade de comprimento de onda da luz que se deseja simular, nesse caso micrometros, ou seja, lamb*1e6, m, Free space wavelength. A Figura 110 ilustra passo a passo as definições da física dos pontos do modulador proposto.

Figura 110- Definições das condições de contorno dos pontos do modulador proposto.

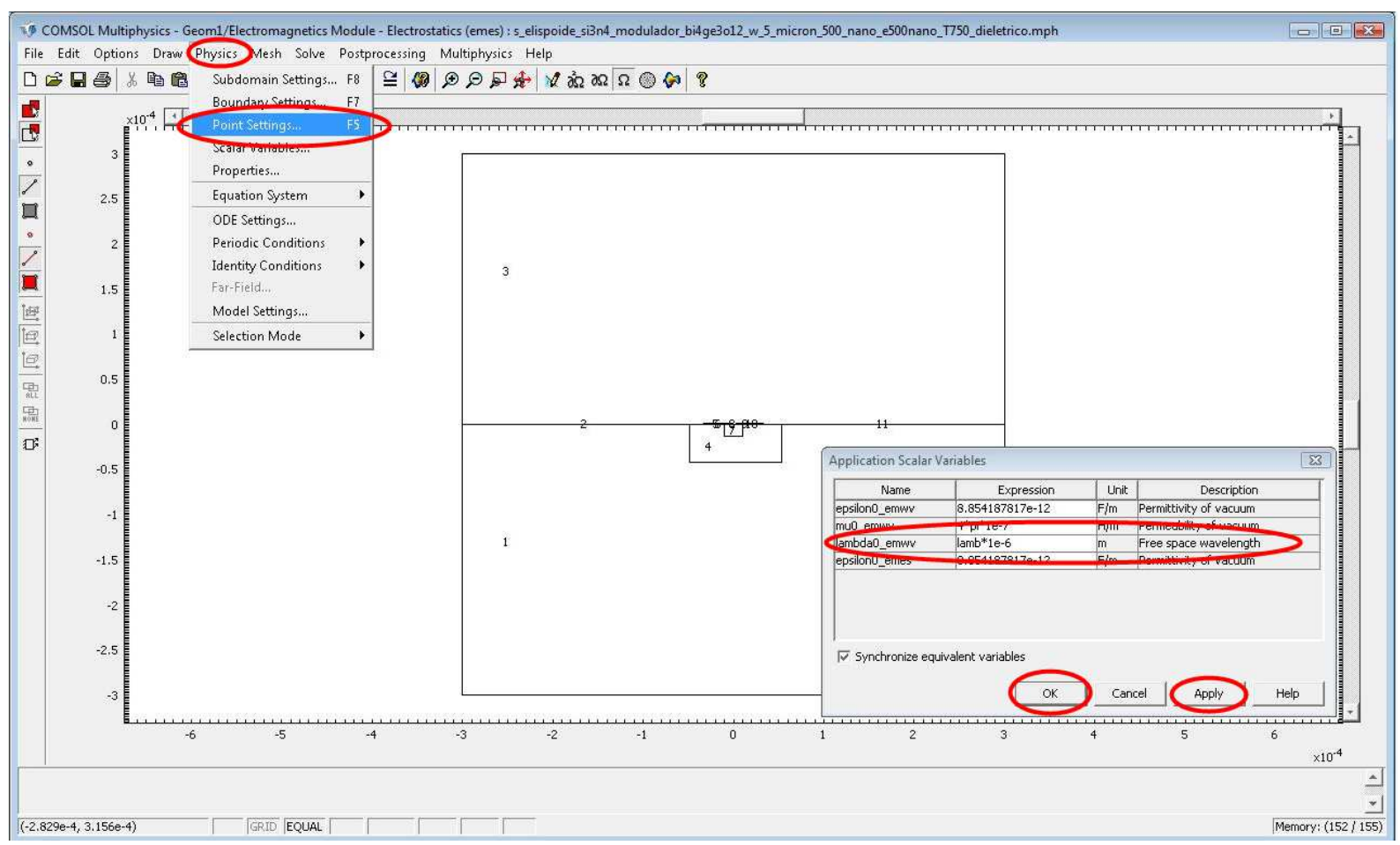

Fonte: Autora

O sétimo passo é definir a malha para o projeto do modulador. A definição de uma malha pode ser inicializada através de um click no botão da barra de menu do programa, que inicializará uma malha de triângulos aleatória. Caso se deseje, pode-se realizar uma definição mais criteriosa, ou seja, uma malha mais fina nas regiões escolhidas. A partir do menu Mesh $\rightarrow$ Mesh Parameters são definidos os pontos nodais Global, Subdomain e Boundary para o projeto do modulador baseado em guia do tipo canal. As Figuras 111 (a e b), as Figuras 112 (a e b), as Figuras 113 (a e b), as Figuras 114 (a e b), a Figura 115 ilustram os passos da definição dessa malha. 
Figura 111- Definição da malha de triângulos para o projeto do modulador. (a) Definição dos pontos nodais Global. (b) Definição dos pontos nodais no Subdomain para o subdomínio 1 e 4.

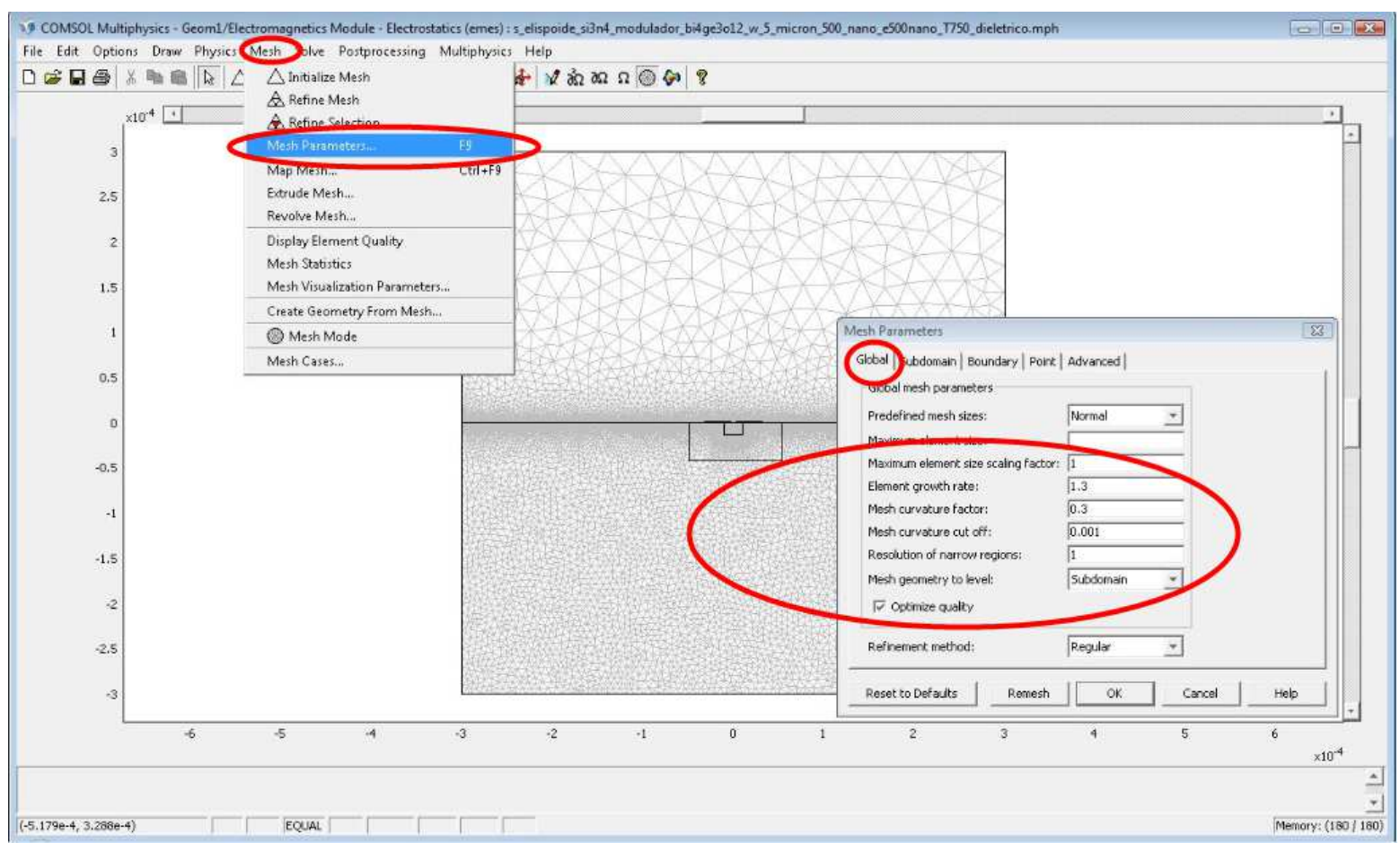

(a)

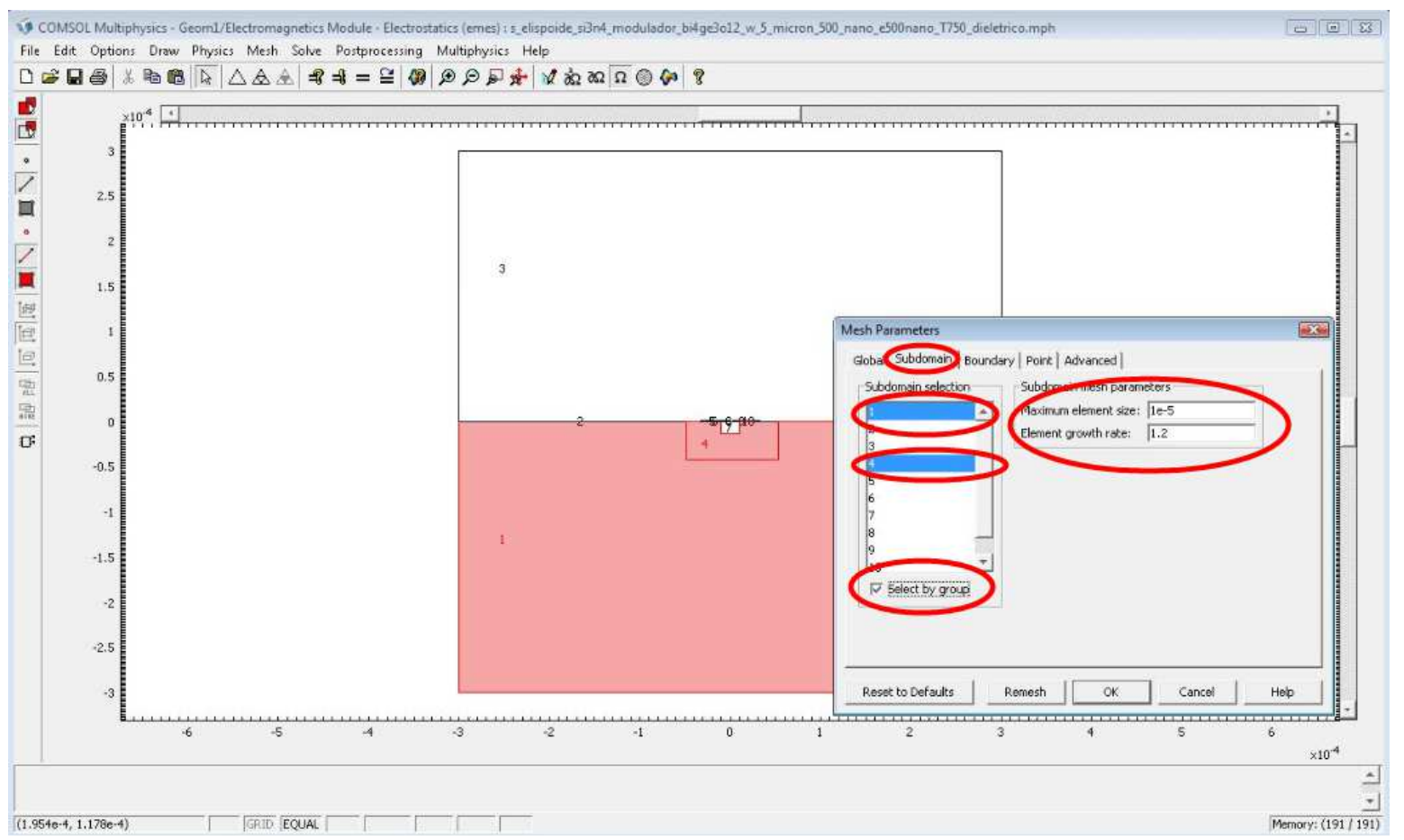

(b)

Fonte: Autora 
Figura 112- (a) Definição dos pontos nodais no Subdomain para o subdomínio 2, 4 e 11. (b) Definição dos pontos nodais no Subdomain para o subdomínio 3.

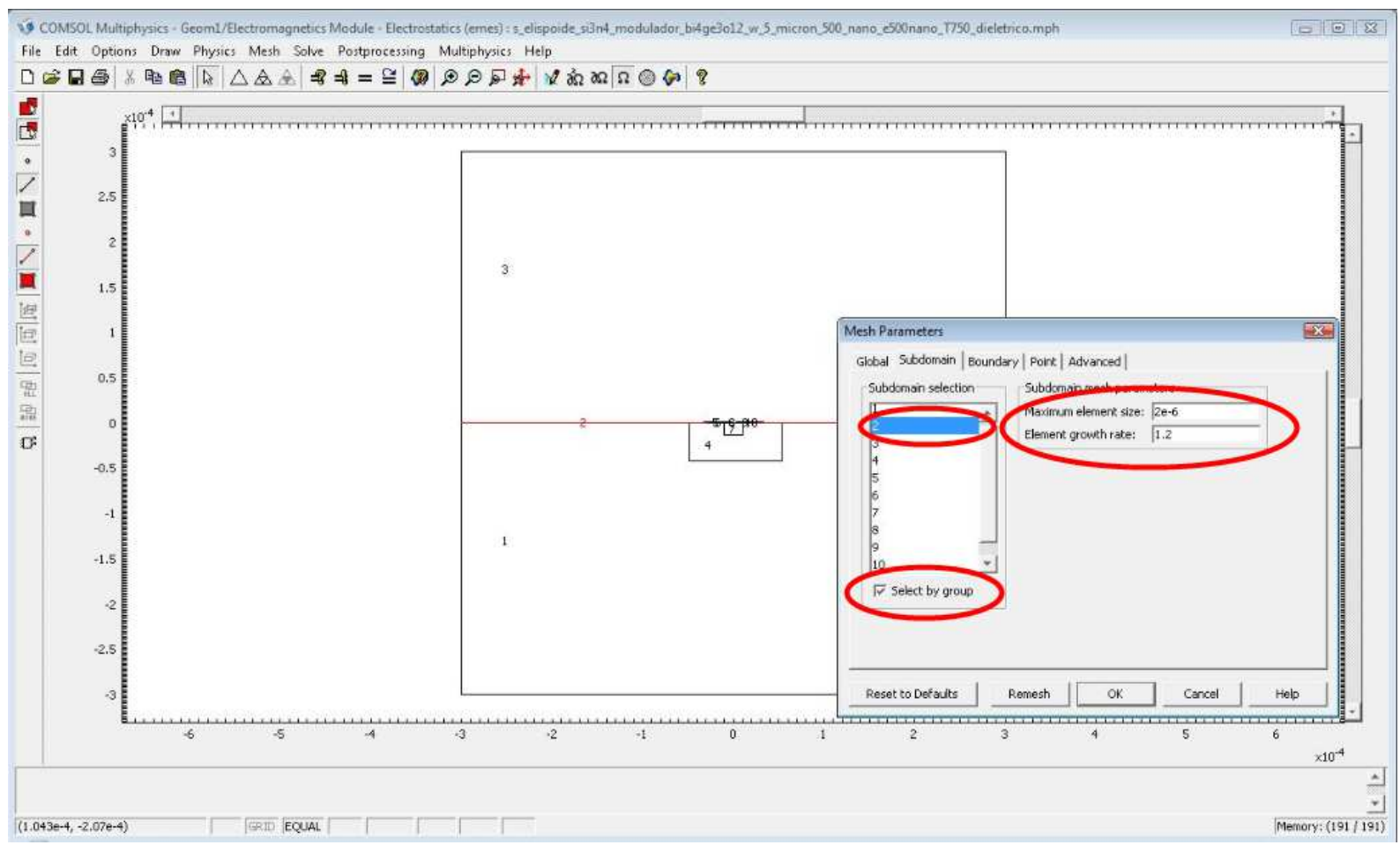

(a)

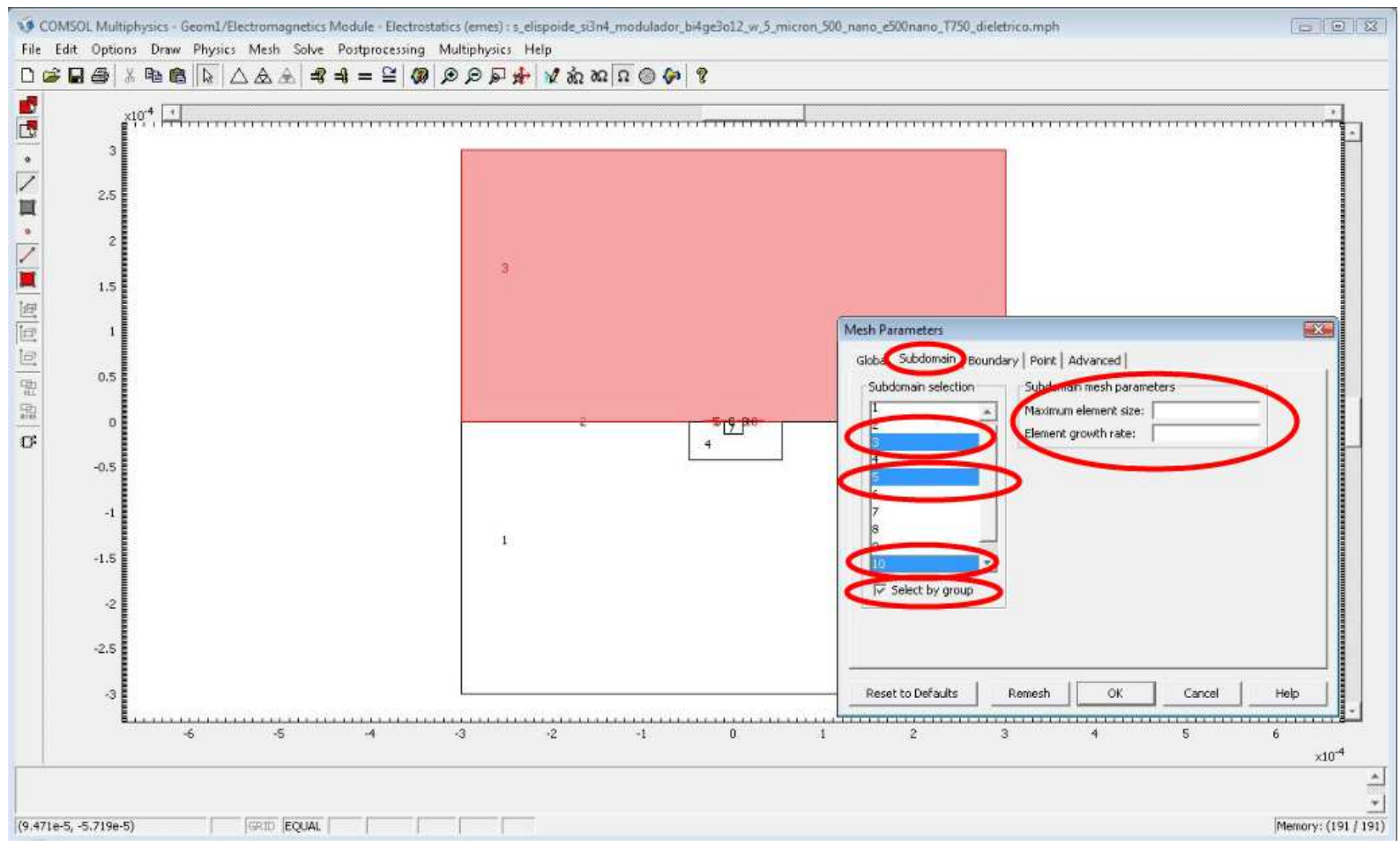

(b)

Fonte:Autora 
Figura 113- (a) Definição dos pontos nodais no Subdomain para o subdomínio 6 e 9. (b) Definição dos pontos nodais no Subdomain para o subdomínio 7.

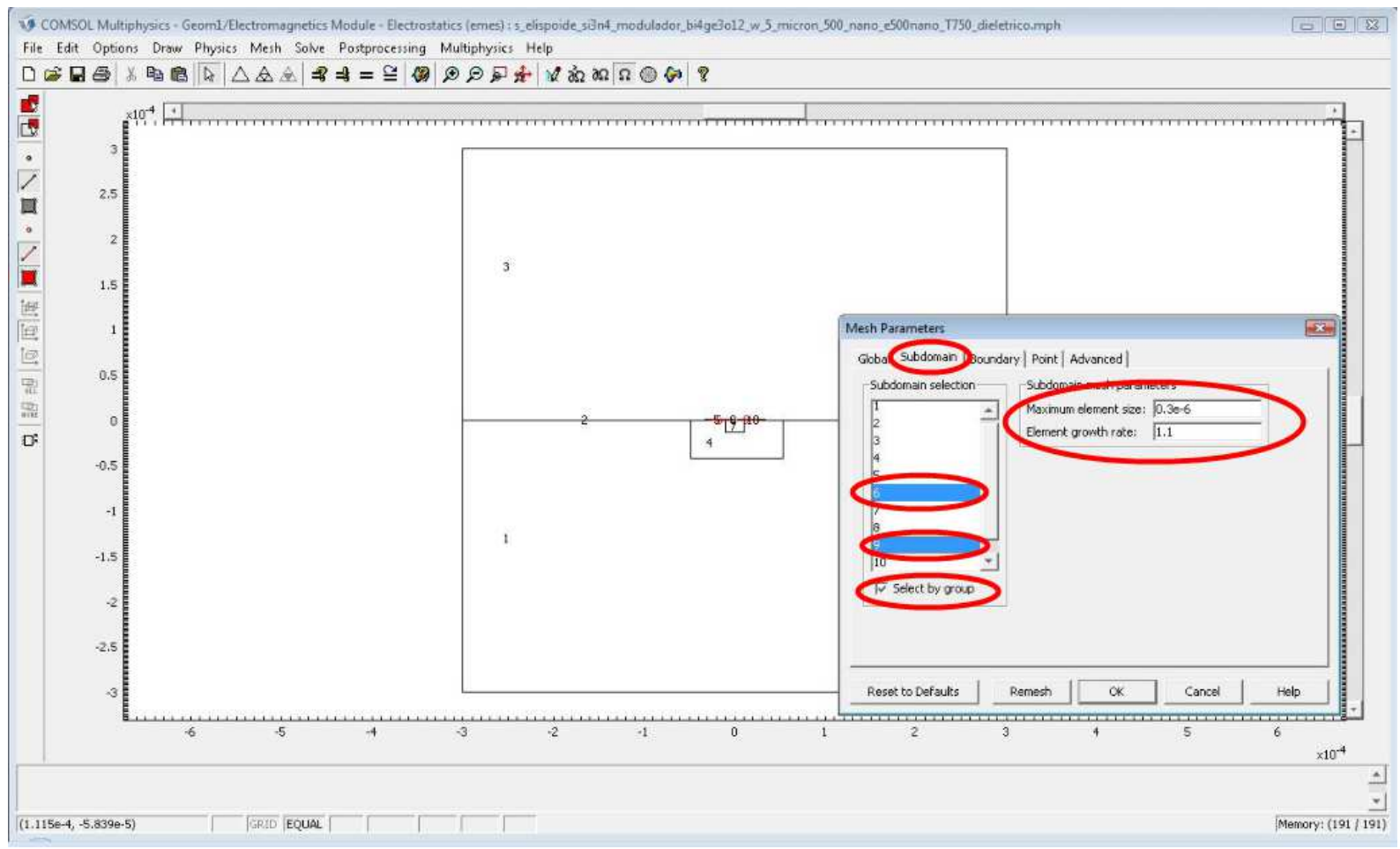

(a)

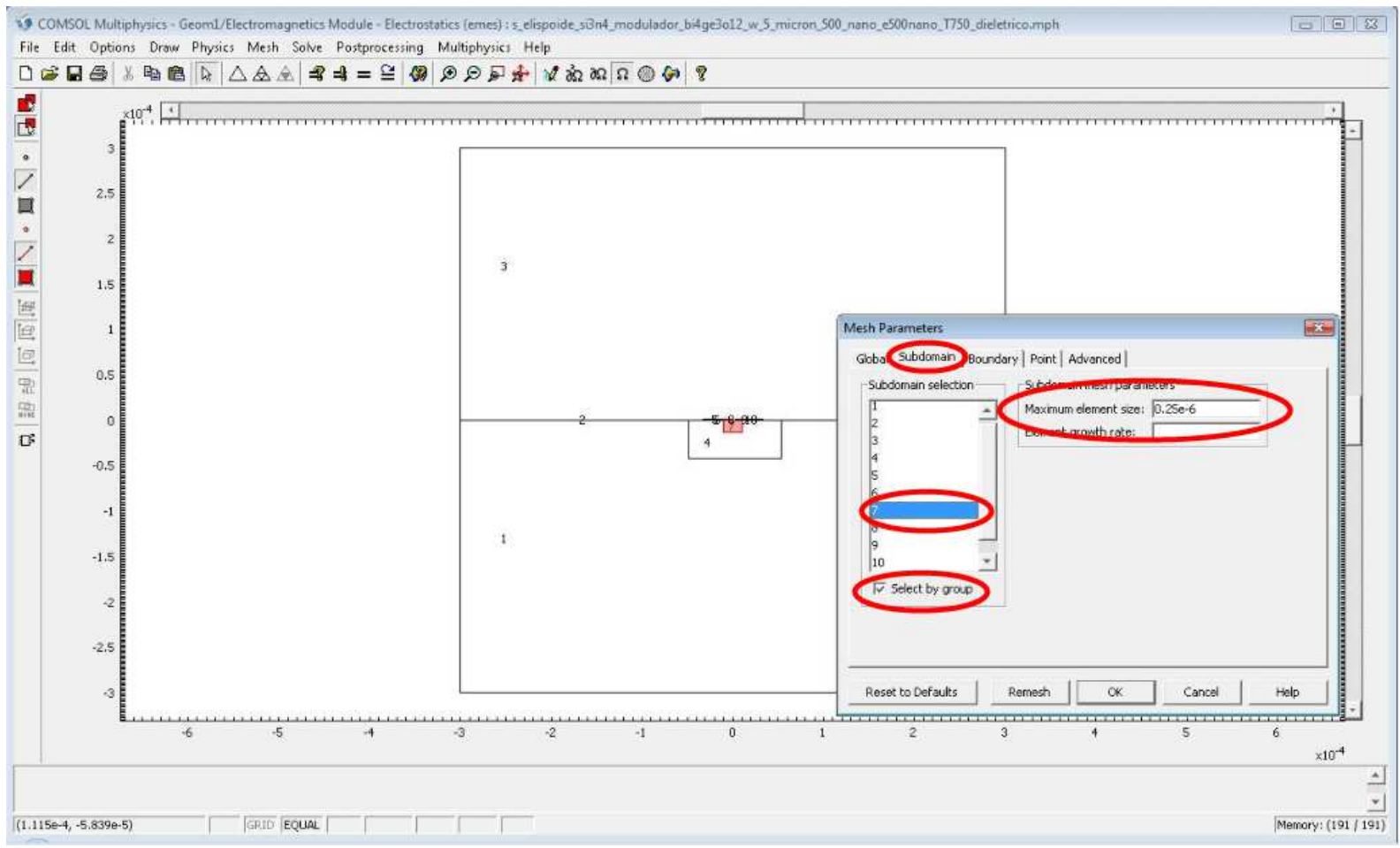

(b)

Fonte: Autora 
Figura 114- (a) Definição dos pontos nodais no Subdomain para o subdomínio 8. (b) Definição dos pontos nodais no Subdomain para o subdomínio 3, 5 e 10.

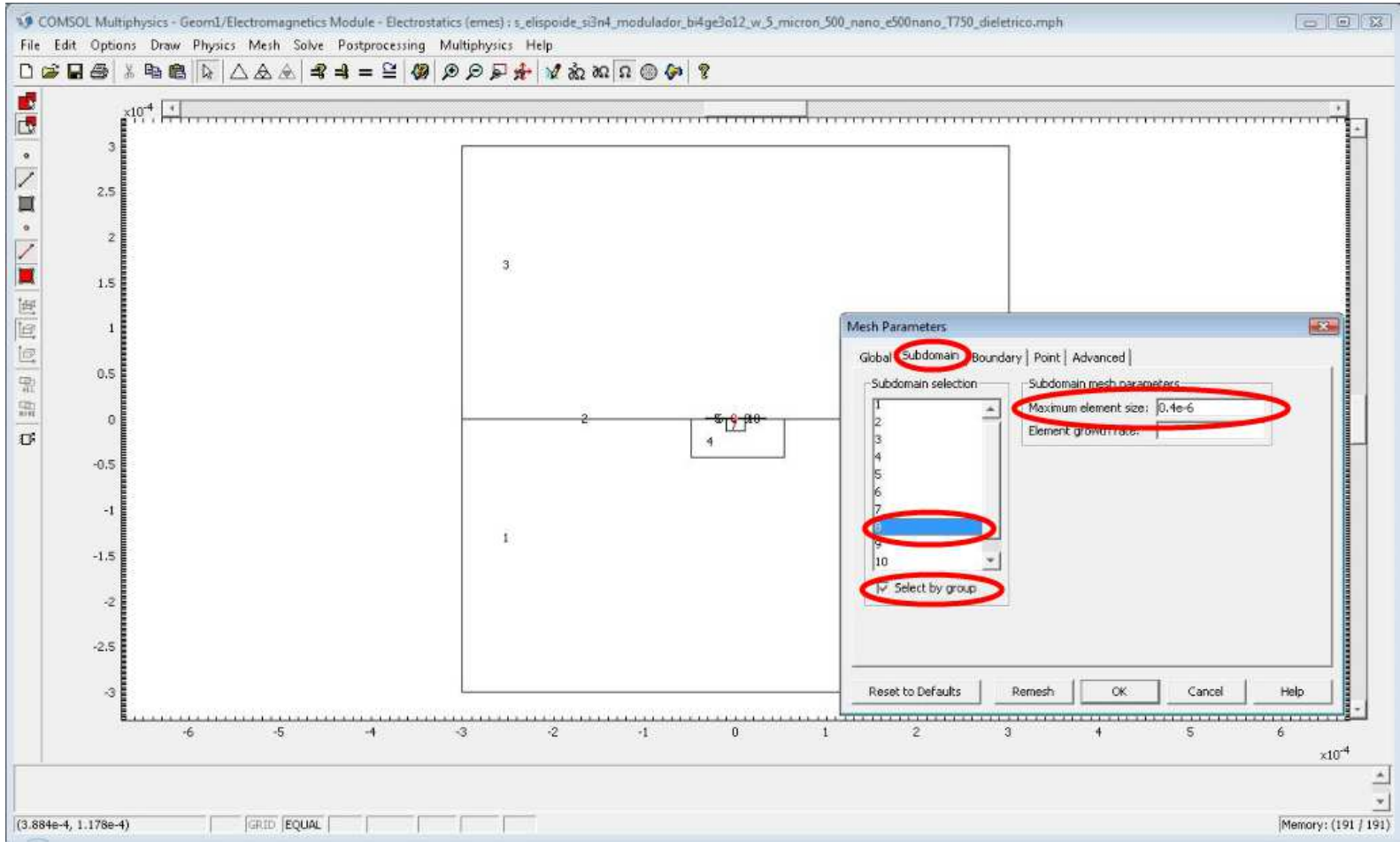

(a)

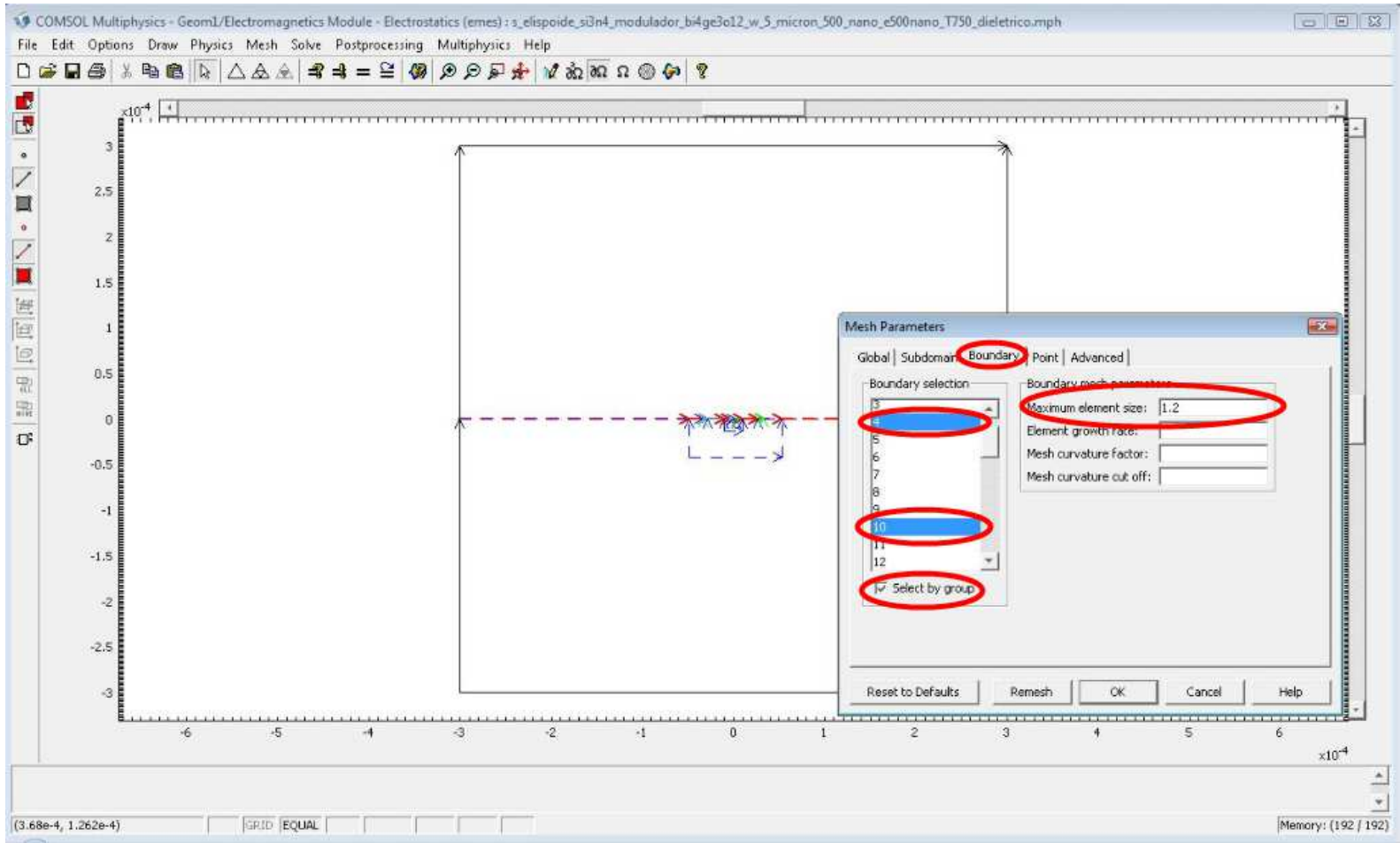

(b)

Fonte: Autora 
Figura 115Malha definida para o projeto do modulador.

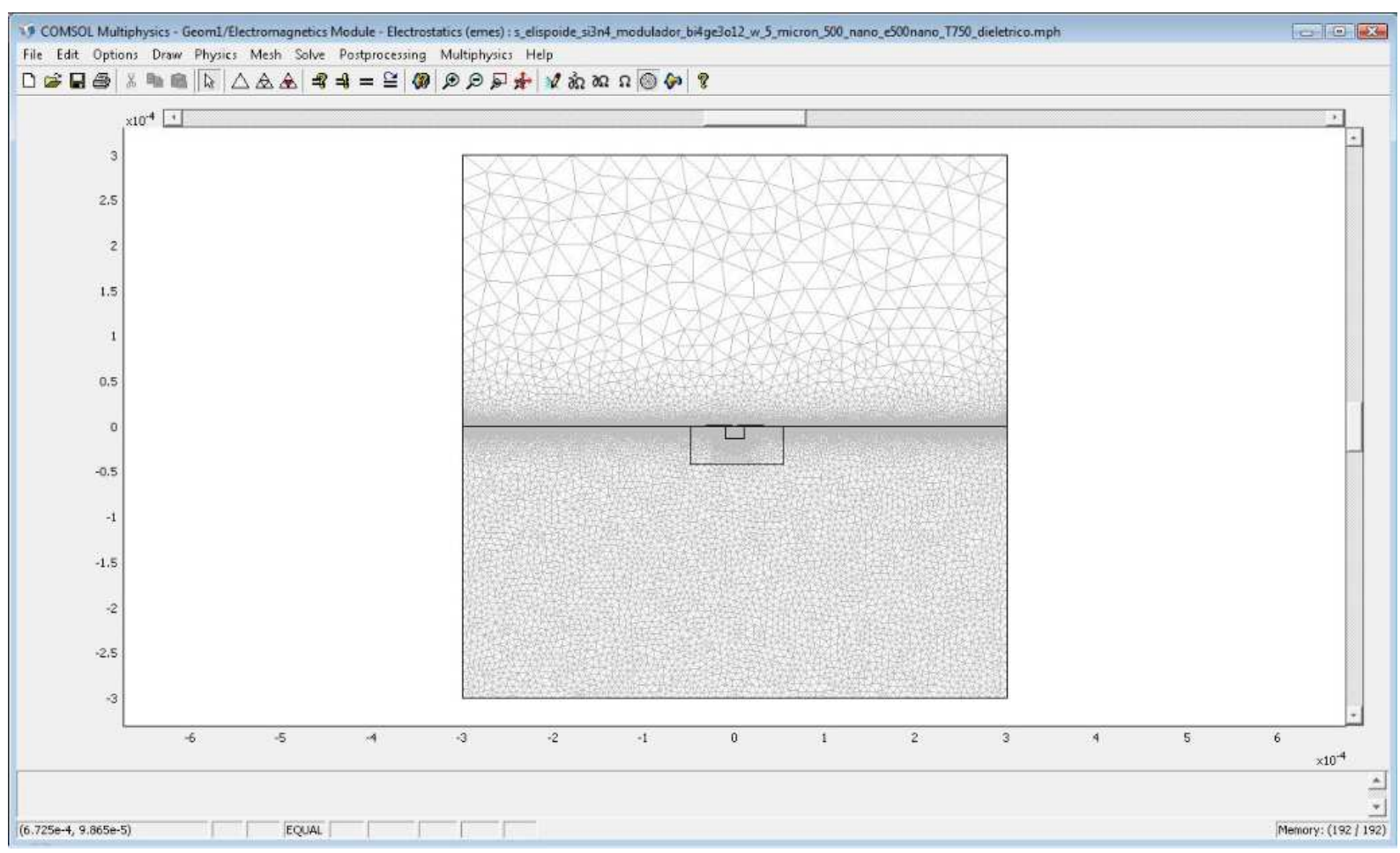

Fonte: Autora

O oitavo passo é iniciar a simulação do projeto do modulador. A partir do menu Multiphysics $\rightarrow$ Model Navigator é definida a inicialização da simulação do Modo Estrutural Mecânico $\rightarrow$ Plane Strain, como ilustra a Figura 116.

O nono passo é a definição do Solver do projeto do modulador. A partir do menu Solver $\rightarrow$ Solver Parameters é definida a análise: Static linear e no menu Solver é definida a análise: Stationary linear, como ilustra a Figura 117.

O décimo passo é a continuação da definição do Solver desse projeto. A partir do menu Solver $\rightarrow$ Solver Manager são definidos: Initial Value, Solver For e Output, como ilustram as Figuras 118 (a e b) e a Figura 119. 
Figura 116- Definição da simulação do Plane Strain.

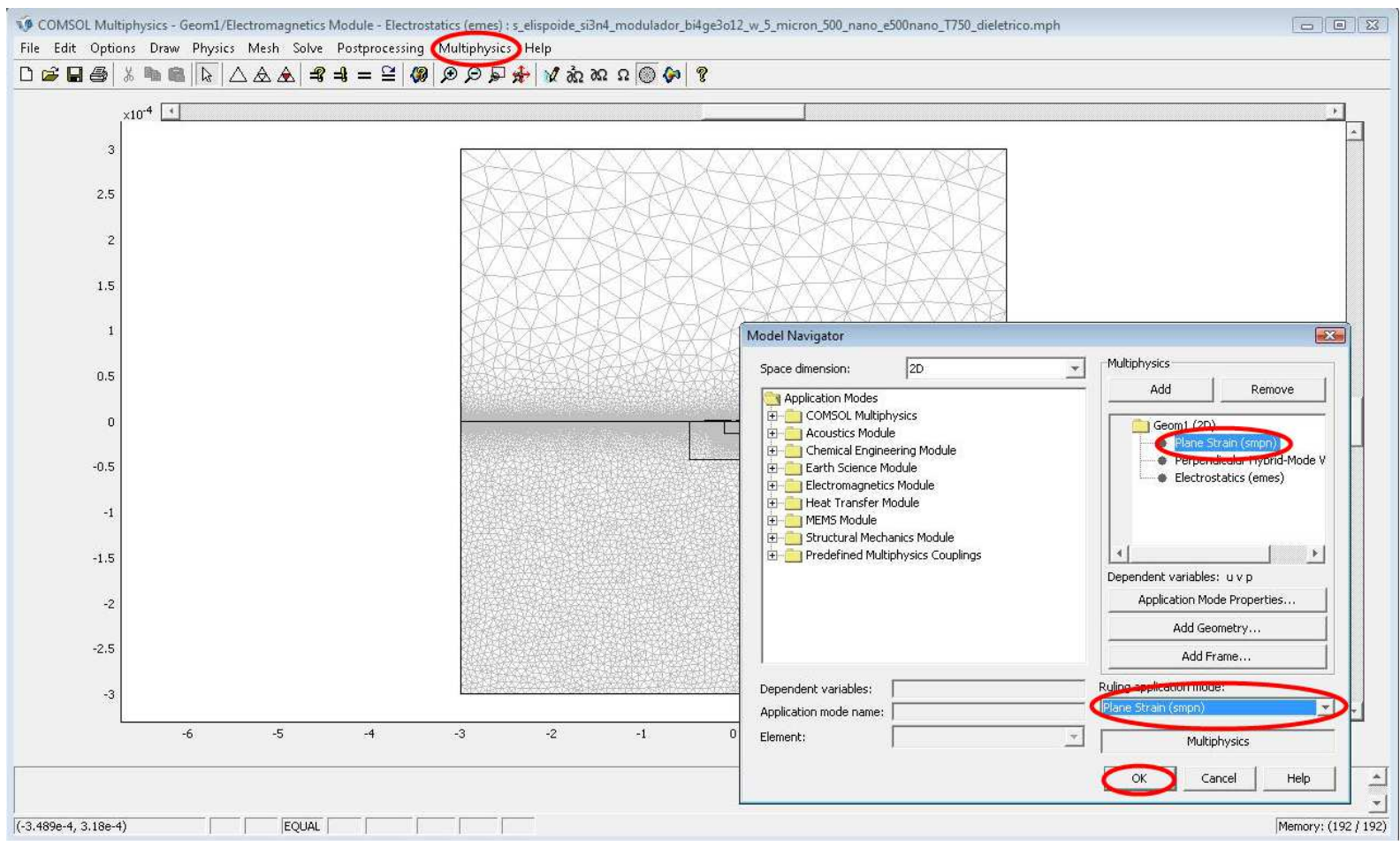

Fonte: Autora

Figura 117- Definição do Solver Parameters.

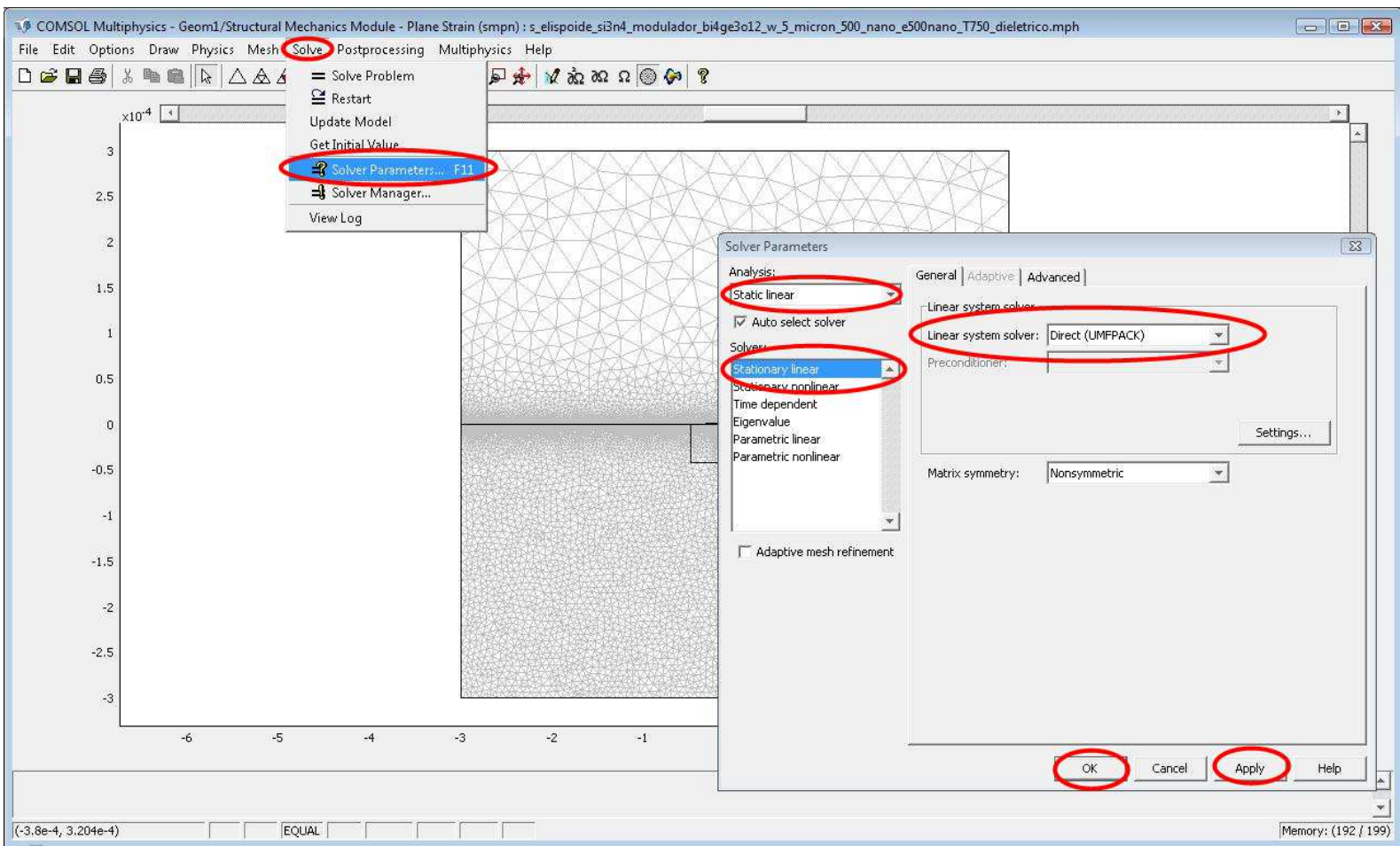

Fonte: Autora 
Figura 118- Definição do Solver Manager para o modo estrutural mecânico. (a) Definição do valor inicial. (b) Definição para entrada da solução.

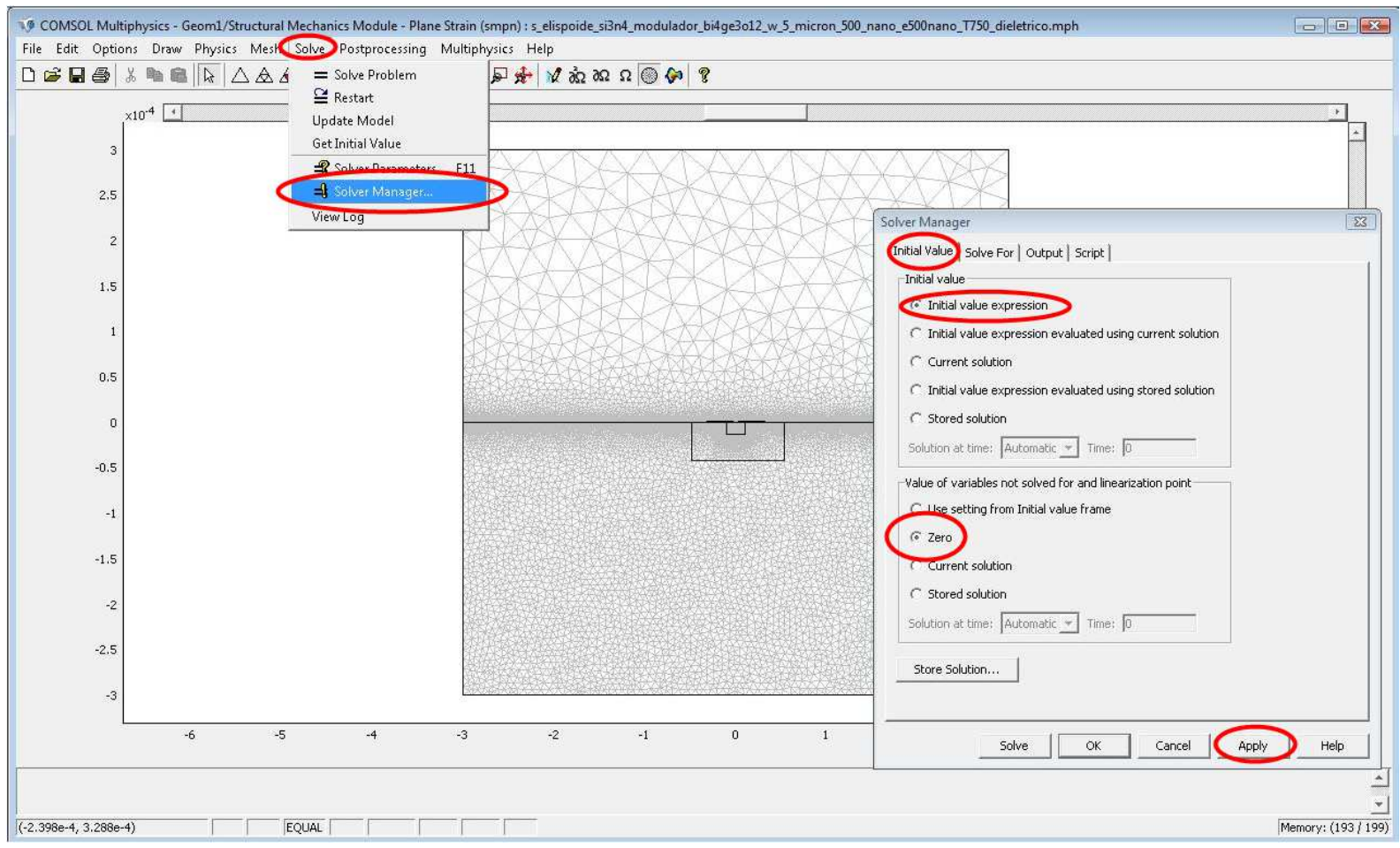

(a)

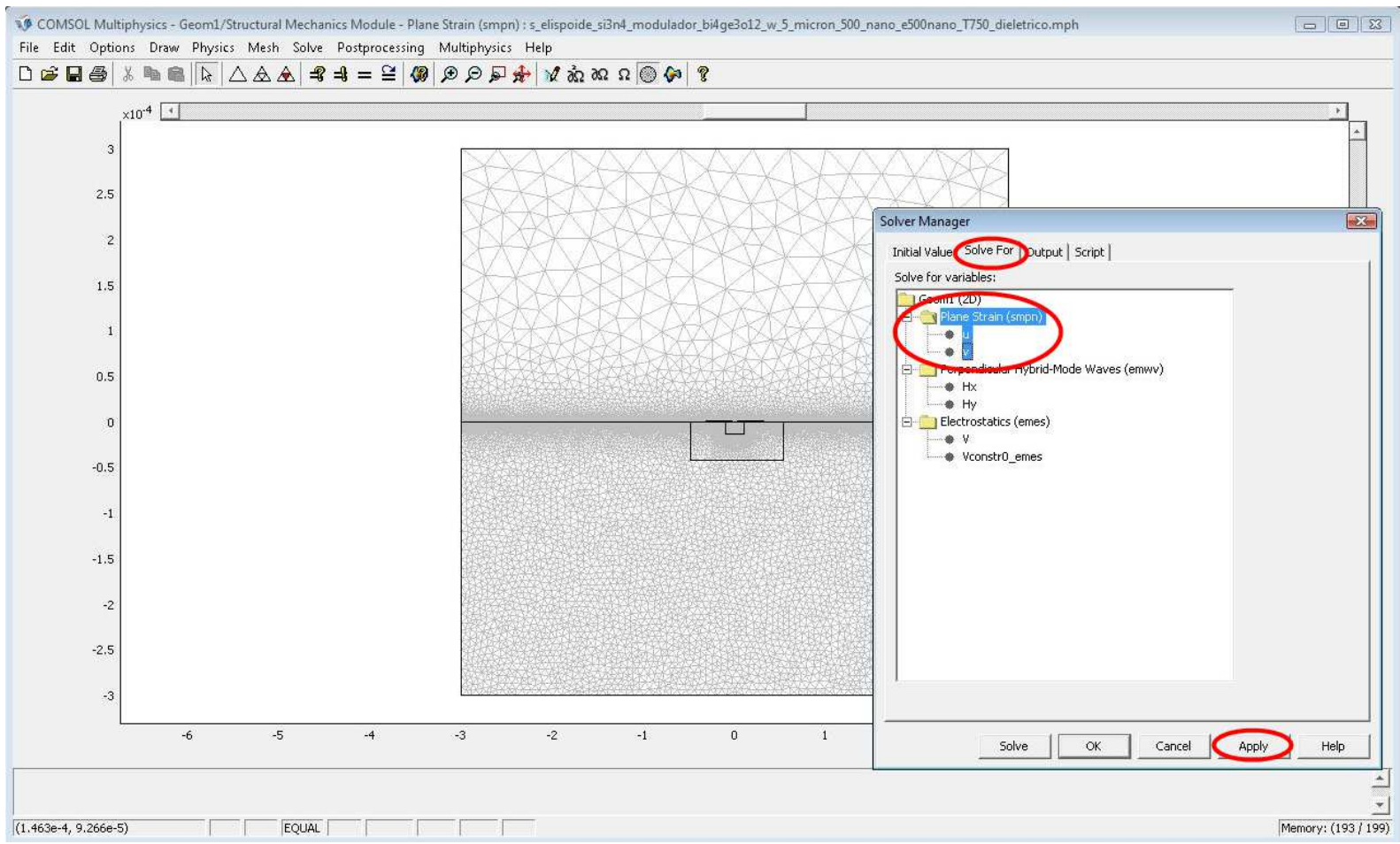

(b)

Fonte: Autora 
Figura 119- Definição para saída da solução.

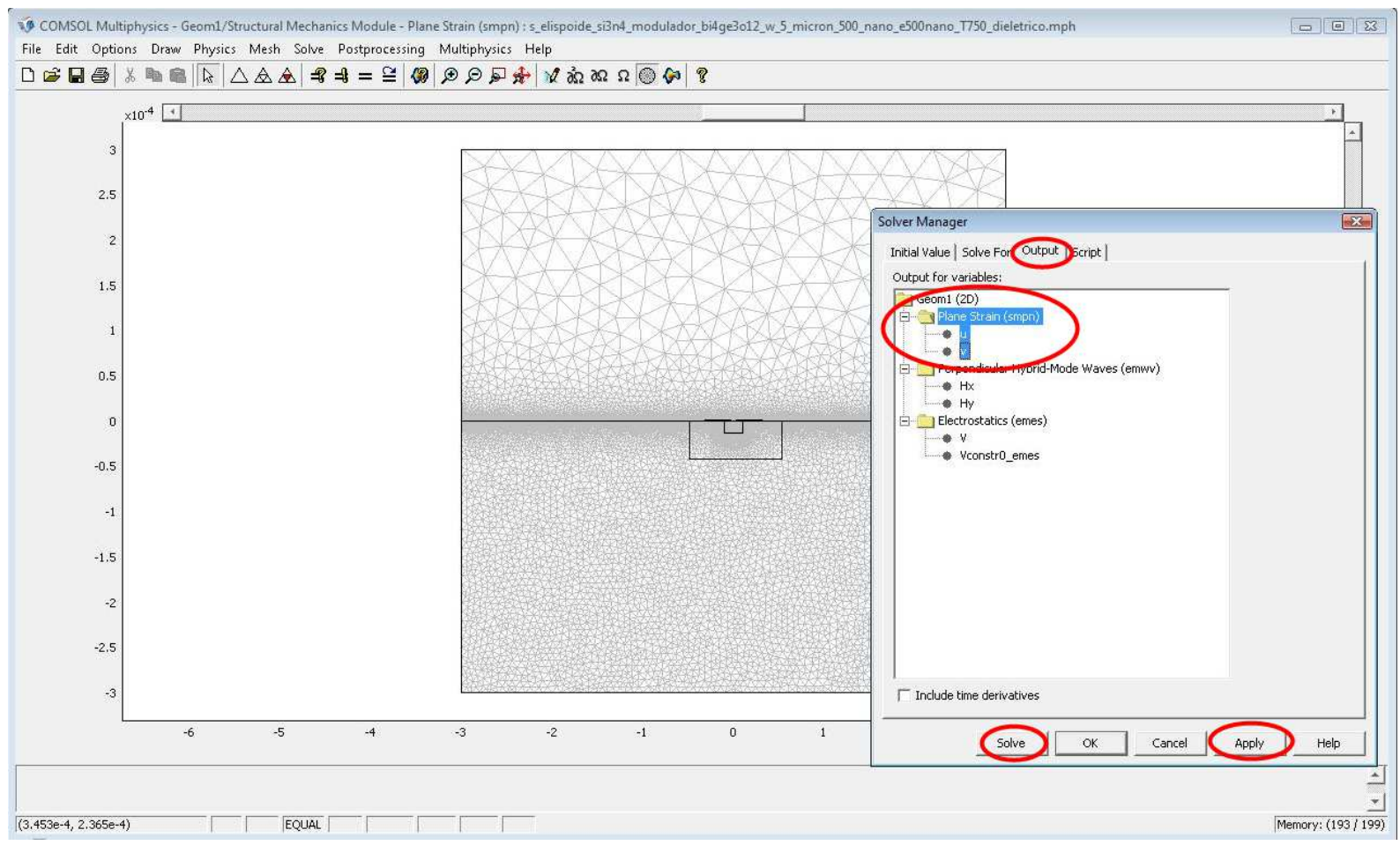

Fonte: Autora

O décimo primeiro passo é iniciar a simulação do projeto do modulador. A partir do menu Multiphysics $\rightarrow$ Model Navigator é definida a inicialização da simulação do Modo de Sistema Microeletromecânico (MEMS) $\rightarrow$ Eletrostatics.

O décimo segundo passo é a definição do Solver do projeto do modulador. A partir do menu Solver $\rightarrow$ Solver Parameters são definidos: a análise: Static linear e Solver: Stationary linear, como ilustram as Figuras 120(a e b) e a Figura 121.

O décimo terceiro passo é a continuação da definição do Solver desse projeto. A partir do menu Solver $\rightarrow$ Solver Manager são definidos: Initial Value, Solver For e Output, como ilustra a Figura 122. 
Figura 120- Definição do Solver Manager para o modo eletrostático. (a) Definição do valor inicial. (b) Definição para entrada da solução.

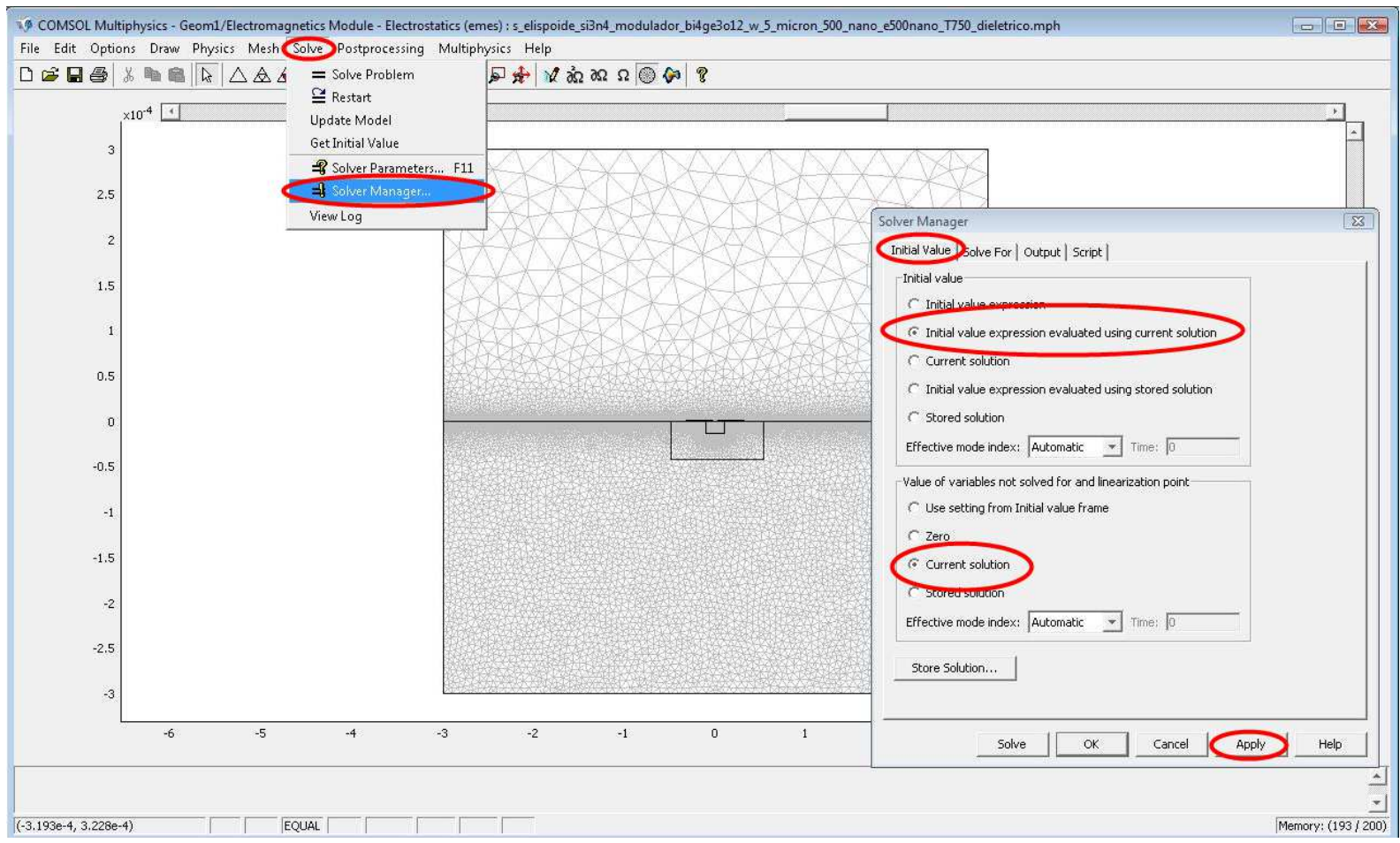

(a)

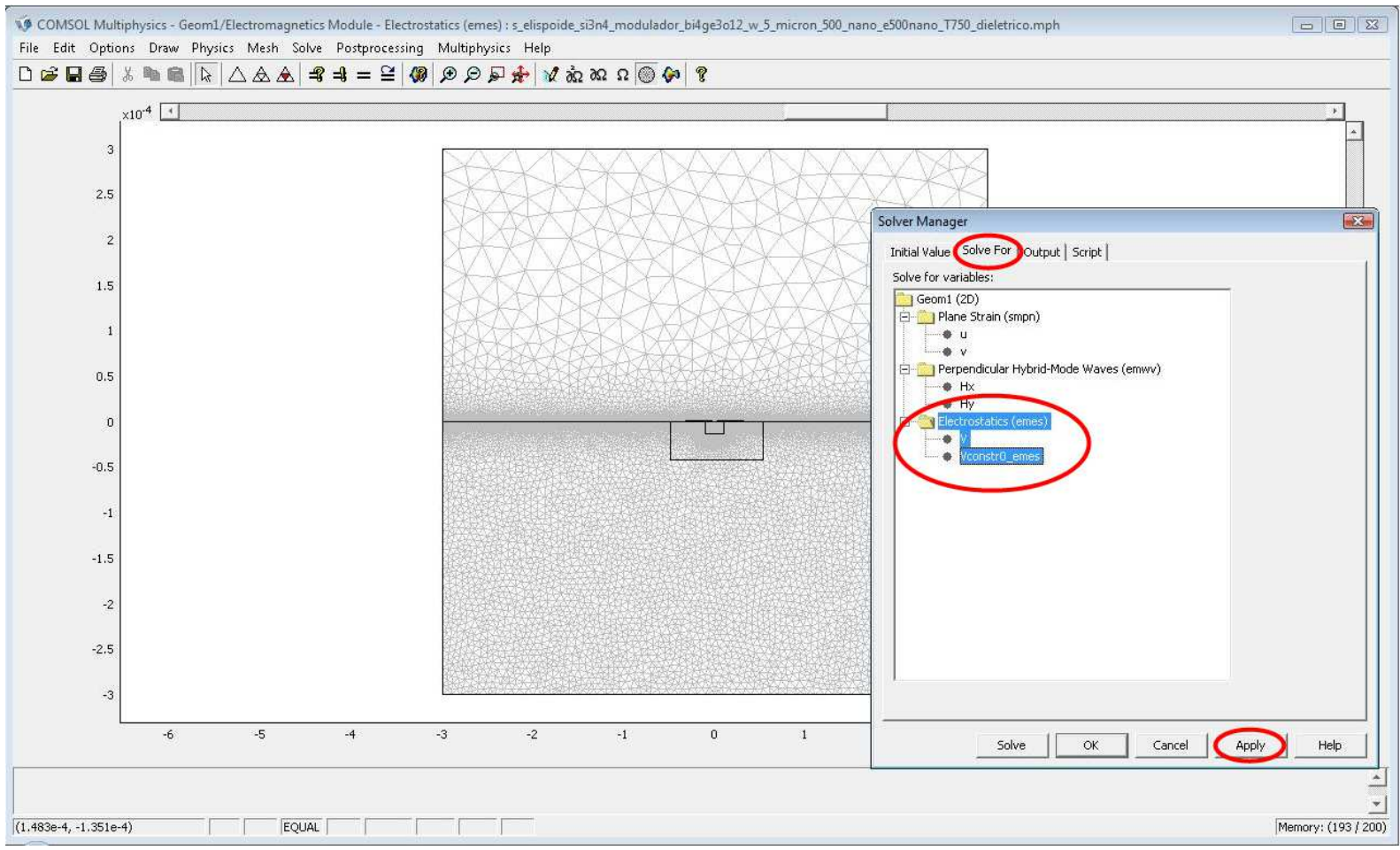

(b)

\section{Fonte: Autoa}


Figura 121- Definição para saída da solução.

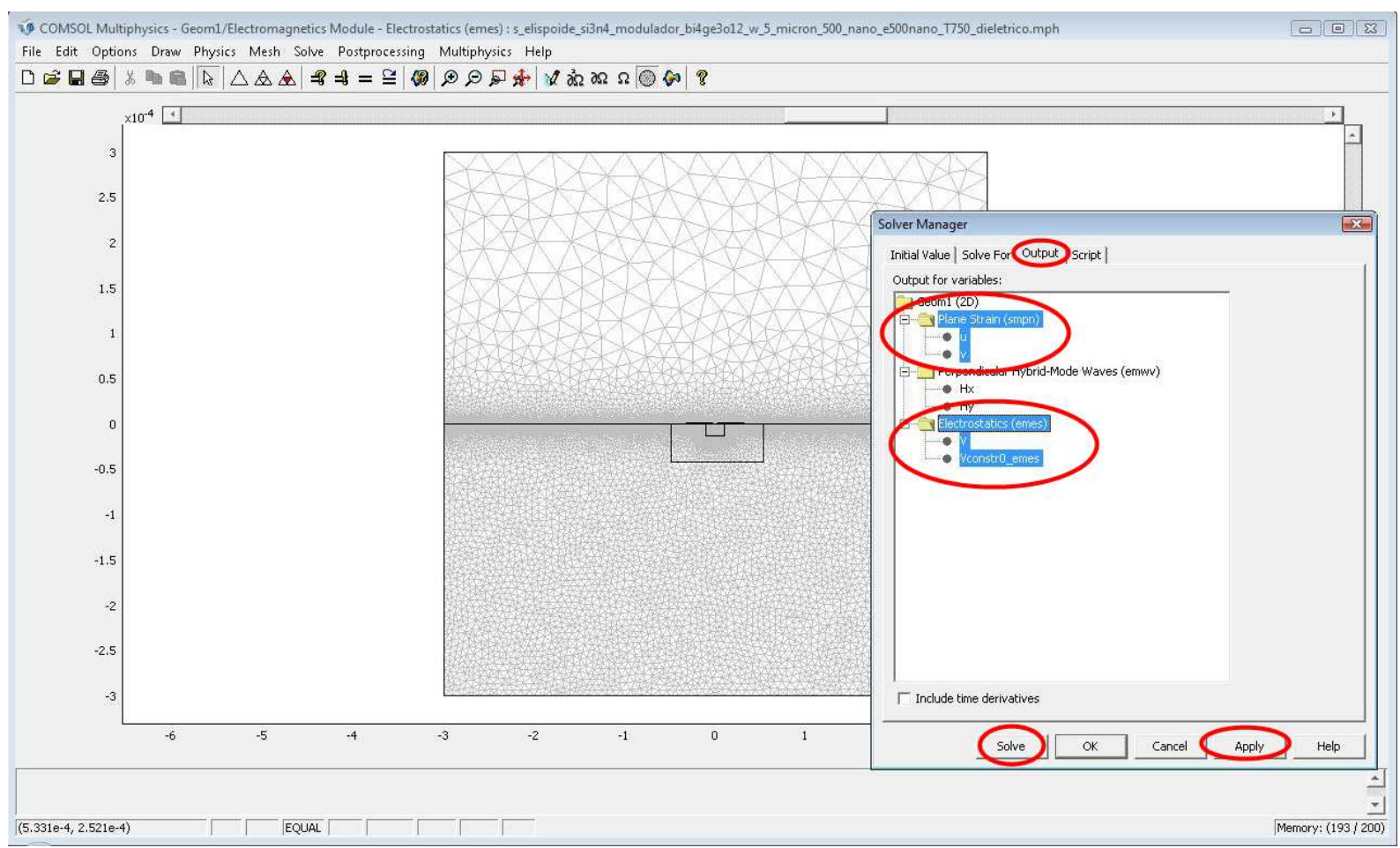

Fonte: Autora

O décimo quarto passo é iniciar a simulação do projeto do modulador. A partir do menu Multiphysics $\rightarrow$ Model Navigator é definida a inicialização da simulação do Modo eletromagnetismo $\rightarrow$ Perpendicular Hybrid-Mode Wave.

O décimo quinto passo é a definição do Solver do projeto do modulador. A partir do menu Solver $\rightarrow$ Solver Parameters são definidas as análises: Static linear e Eigenvalue, como ilustra a Figura 105. 
Figura 122- Definição do Solver Parameters para os autovalores .

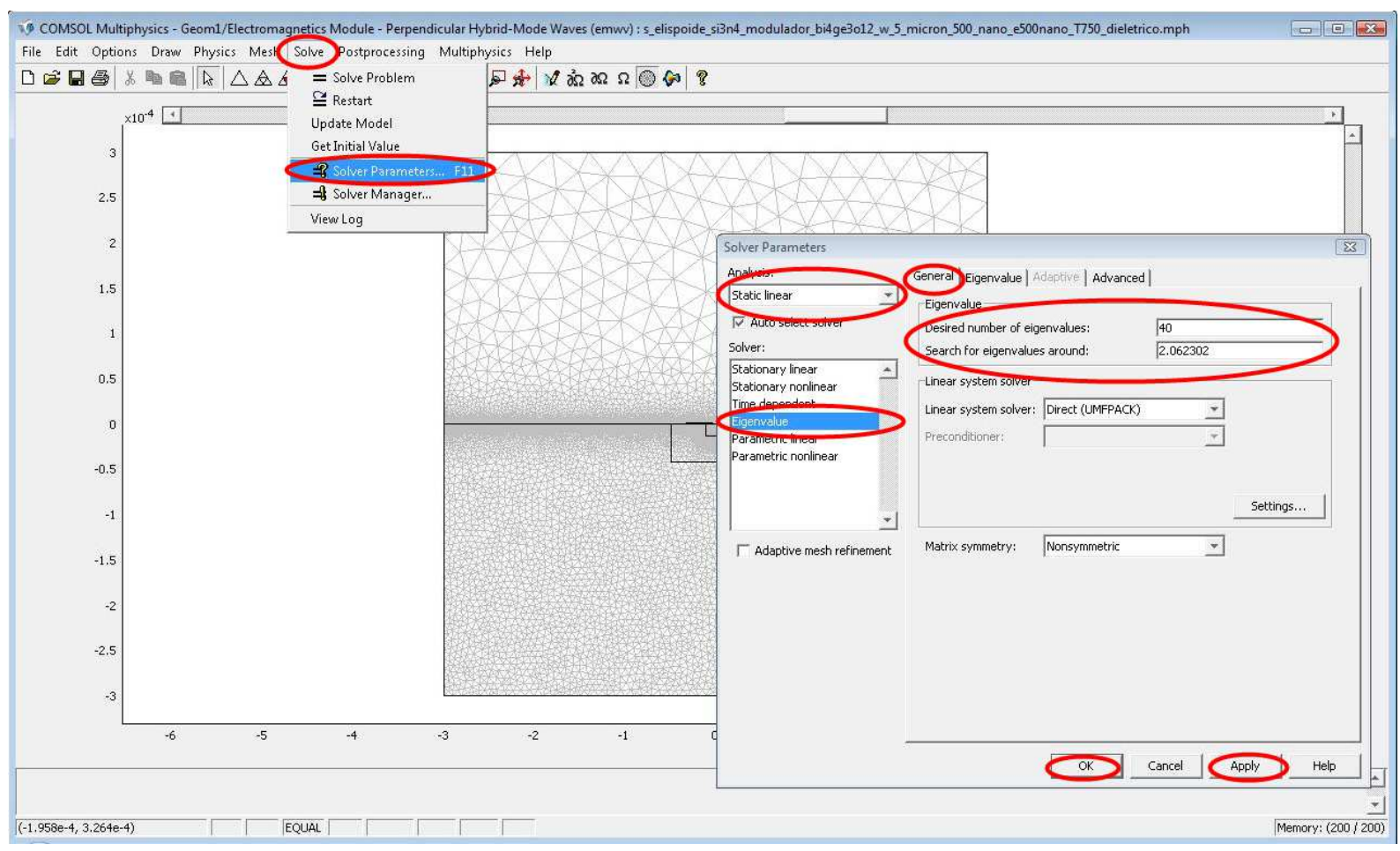

\section{Fonte: Autora}

O décimo sexto passo é a continuação da definição do Solver desse projeto. A partir do menu Solver $\rightarrow$ Solver Manager são definidos: Initial Value, Solver For e Output. As Figuras 123 (a e b) ilustram as definições do Initial Value e a outra solução é ilustrada na Figura 1124. 
Figura 123- Definição do Solver Manager. (a) Definição para entrada da solução. (b) Definição para saída da solução.

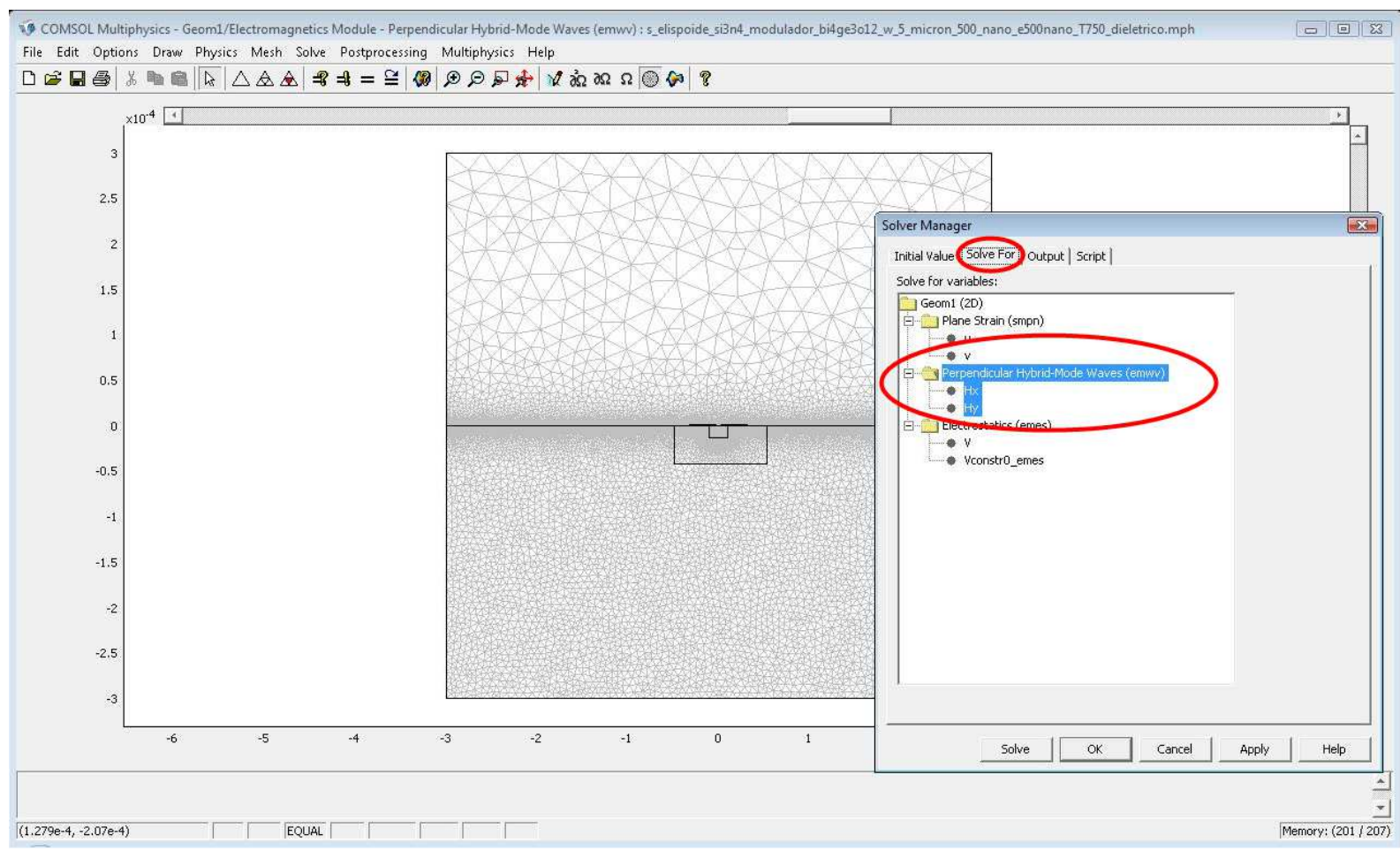

(a)

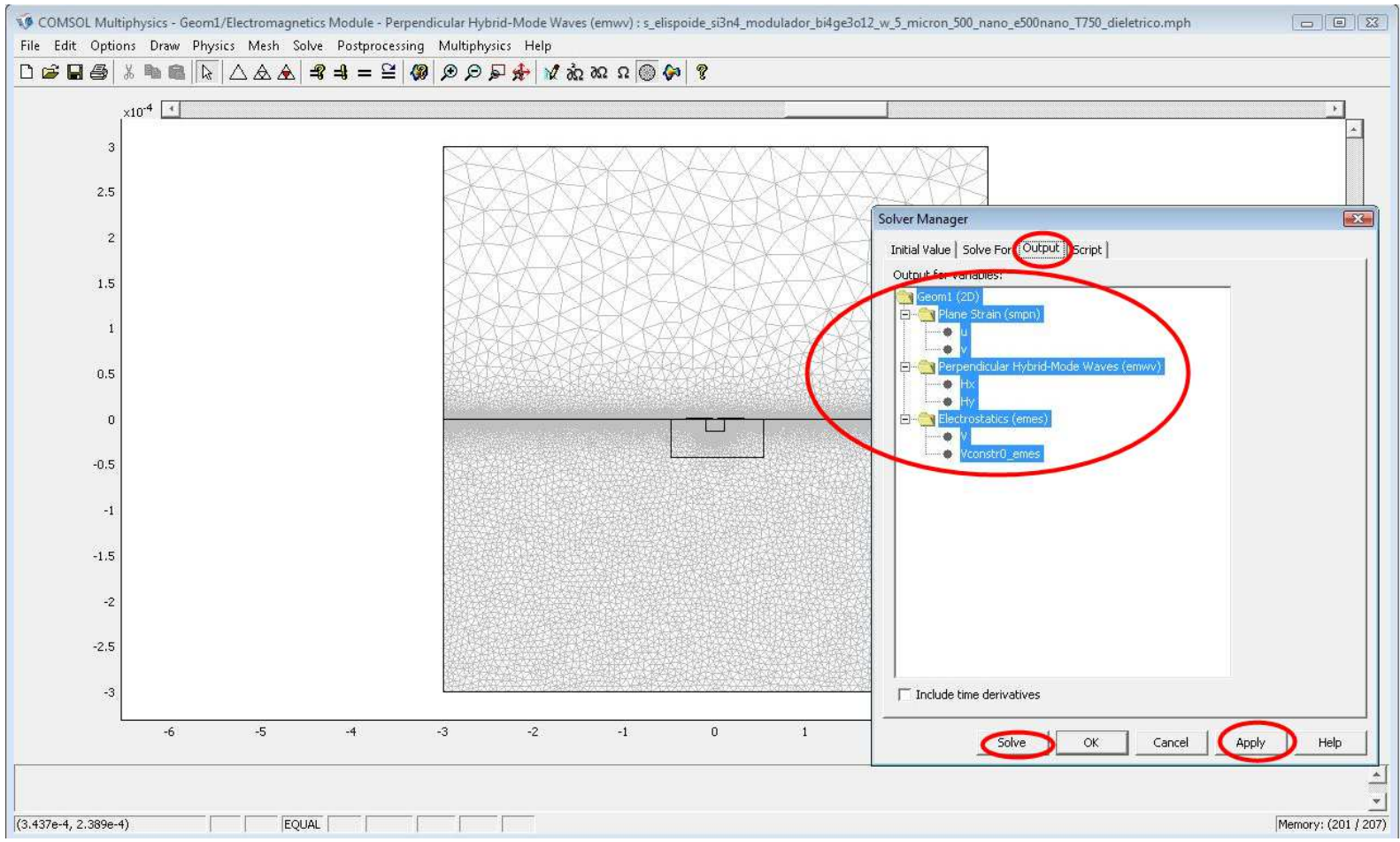

(b)

Fonte: Autora 
O último passo é a obtenção dos modos propagados. A partir do menu Postprocessing $\rightarrow$ Plot Parameters são definidos: General, Surface, Contour, Boundary e Arrow. As definições do General são: Plot type (Surface, Contour, Boundary, Arrow and Geometry edges), Solution to use $\rightarrow$ Effective mode index (procurar os modos $\mathrm{E}^{\mathrm{x}}$ e $\mathrm{E}^{\mathrm{y}}$. As definições do Surface são: Surface plot, Surface data, predefined quantities $\rightarrow$ Power flow, time average e $z$ component. As definições do Contour são: Contour plot, Contour data, Predefined quantities $\rightarrow$ Power flow, time average, z component e Expression $\rightarrow$ Pozav_emwv, Contour levels $\rightarrow$ Levels $\rightarrow$ Number of level (5). As definições do Arrow são: Arrow plot, Subdomain Data, x component: Ex, y component: Ey, Arrow positioning e Number of points, $x$ points: 250, y points: 150. A Figura 124 ilustra a definição do Arrow para obter os Modos, como por exemplo, o Modo $\mathrm{E}^{\mathrm{x}}$.

Figura 124- Modo $\mathbf{E}^{\mathrm{x}}$.

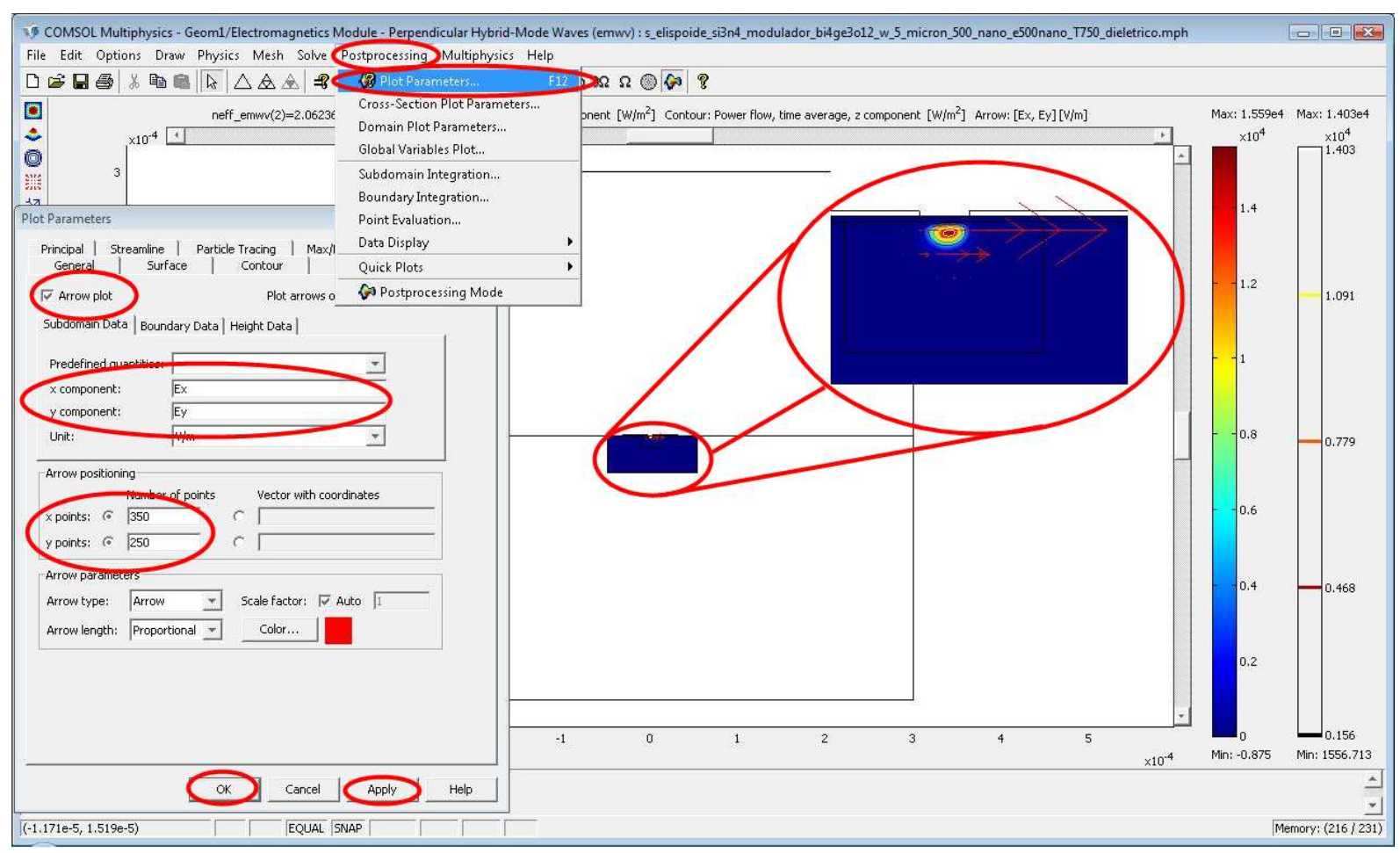

Fonte: Autora

A partir do menu Postprocessing $\rightarrow$ Plot Parameters também são definidas as linhas do potencial elétrico para o Modo $\mathrm{E}^{\mathrm{x}}$. A Figura 125 ilustra essa definição com o item Arrow desabilitado. 
Figura 125- Definição das linhas do Potencial Elétrico

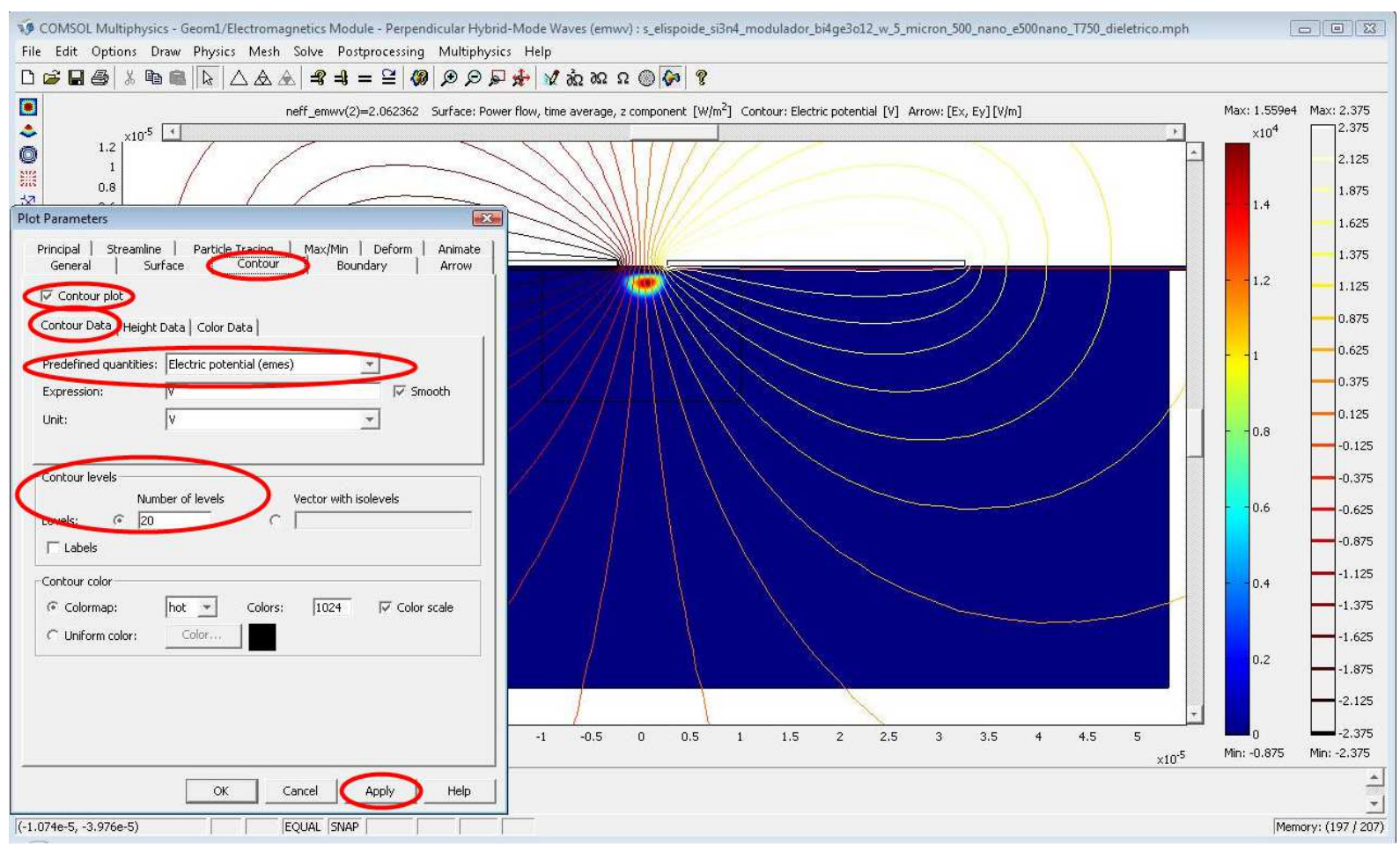

Fonte: Autora

A partir do menu Postprocessing $\rightarrow$ Plot Parameters também são definidas os vetores locais do campo elétrico para o Modo $\mathrm{E}^{\mathrm{x}}$. A Figura 126 ilustra essa definição. 
Figura 126- Definição das representações do vetor de um Campo Elétrico Local

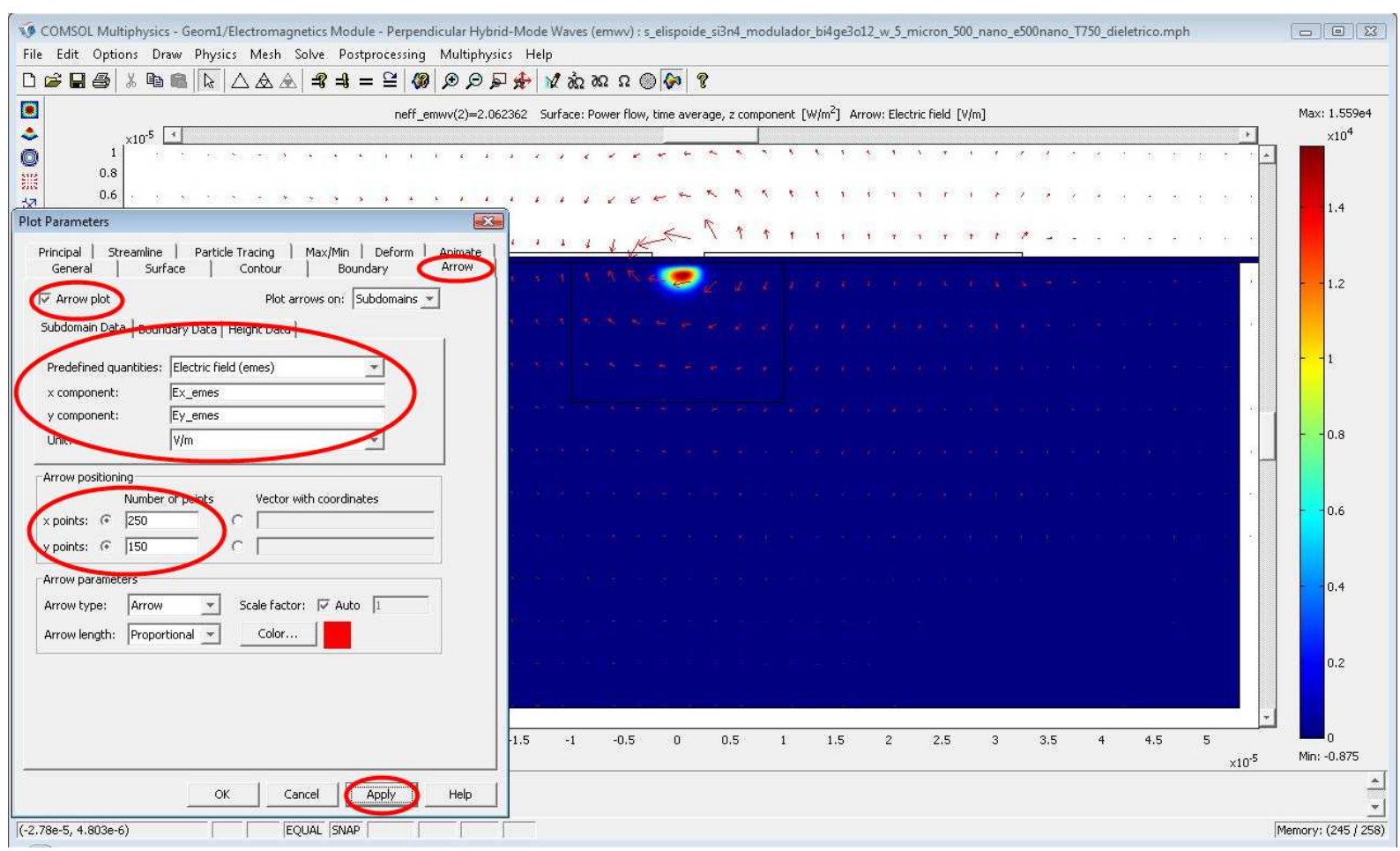

Fonte: Autora 